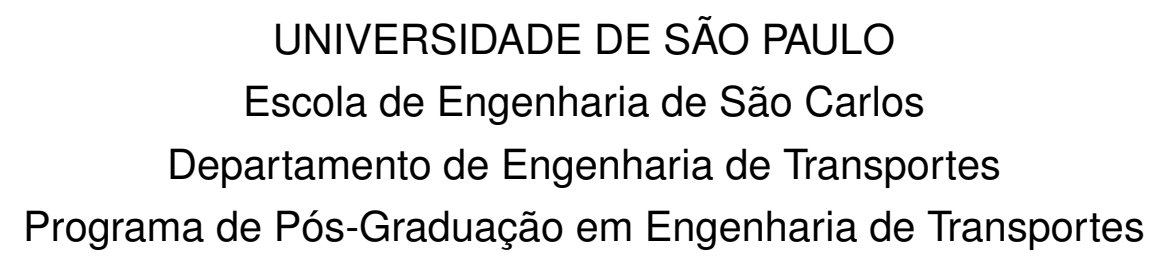

CASSIANO AUGUSTO ISLER

\title{
Avaliação socioeconômica de uma rede ferroviária regional para o transporte de passageiros
}



CASSIANO AUGUSTO ISLER

\section{Avaliação socioeconômica de uma rede ferroviária regional para o transporte de passageiros}

Tese de Doutorado submetida à Escola de Engenharia de São Carlos, da Universidade de São Paulo, como parte dos requisitos para a obtenção do título de Doutor em Ciências, Programa de Pós-Graduação em Engenharia de Transportes. Área de Concentração: Planejamento e Operação de Sistemas de Transportes

Orientador: Prof. Dr. João Alexandre Widmer

São Carlos

2015 
AUTORIZO A REPRODUÇÃO TOTAL OU PARCIAL DESTE TRABALHO, POR QUALQUER MEIO CONVENCIONAL OU ELETRÔNICO, PARA FINS DE ESTUDO E PESQUISA, DESDE QUE CITADA A FONTE.

Isler, Cassiano Augusto

Avaliação socioeconômica de uma rede ferroviária regional para o transporte de passageiros / Cassiano Augusto Isler; orientador João Alexandre Widmer. São Carlos, 2015.

Tese (Doutorado) - Programa de Pós-Graduação em Engenharia de Transportes e Área de Concentração em Planejamento e Operação de Sistemas de Transporte -Escola de Engenharia de São Carlos da Universidade de São Paulo, 2015.

1. Ferrovia. 2. Passageiro. 3. Computação Paralela. 4. Escolha Modal. 5. Análise Sócioeconômica. I. Título. 


\section{FOLHA DE JULGAMENTO}

Candidato: Engenheiro CASSIANO AUGUSTO ISLER.

Título da tese: "Avaliação socioeconômica de uma rede ferroviária regional para o transporte de passageiros"

Data da defesa: 15/05/2015

\section{Comissão Julgadora:}

Resultado:

Prof. Titular João Aleandre Widmer

(Orientador)

(Escola/de Engenharia de São Carlos/EESC)

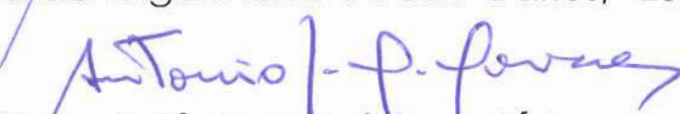

Prof. Titylar Antônio Galvāó Naclério Novaes

(Escolg Politécnica/EP-USP)

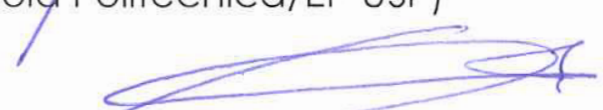

Prof. Dr. Orlando Fontes Lima Júnior

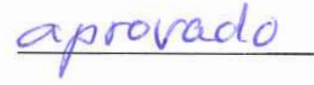

(Universidade Estadual de Campinas/UNICAMP)



AfNOVA Do

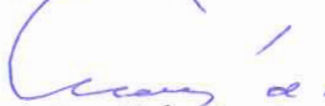

Prof. Dr. Márcio de Almeida D'Agosto

(Universidade Federal do Rio de Janeiro/UFRJ)

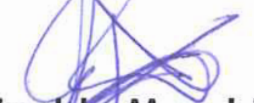

Prof. Dr. Reinaldo Morabito Neto

(Universidade Federal de São Carlos/UFSCar)

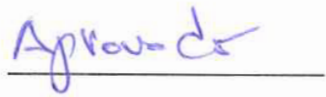

Coordenador do Programa de Pós-Graduação em Engenharia de Transportes:

Prof. Associado Paulo César Lima Segantine

Presidente da Comissão de Pós-Graduação:

Prof. Associado Paulo César Lima Segantine 



\section{Agradecimentos}

Ao Prof. João Alexandre Widmer pelo acompanhamento da minha trajetória acadêmica e pelos valiosos conselhos e orientações em momentos oportunos. Ao Prof. Chris Nash e Prof. Mark Wardman pela recepção na Universidade de Leeds, na realização de um projeto profissional e pessoal, e pelas importantes contribuições para o avanço da pesquisa.

Aos meus pais Sérgio e Isolina pela educação, exemplo e apoio nas decisões, e aos meus irmãos Juliana e Érico pelo convívio e incentivo nos períodos desafiadores.

Aos professores e funcionários do Departamento de Engenharia de Transportes da EESC, pelas sugestões e apoio na concretização deste e de outros trabalhos anteriores. Ao Prof. José Reinaldo A. Setti, pela elaboração do template específico para teses e dissertações do STT em LTEXque profundamente contribuiu para a qualidade da formatação deste texto.

Aos colegas de jornada acadêmica no STT, pelo compartilhamento de experiências e momentos de descontração: Andrea Nicola, Andressa Ng, Antonio Nilson, Artur Piatti, Fernando Piva, Gabriela Morais, Iara Alves, José Elievam Bessa, Mateus Gama e Monique Martins.

Aos amigos que desinteressadamente apoiaram-me em diversos momentos: Aline Perine, Ana Furlan, Cleber Rocco, Elaine Carvalho, Erika e Isabela Uagaia, Glaucia Pereira, Ísis Sartori, Marcelo Haack, Pedro Brandão, Rochele Ribeiro e Tatiane Bianchini.

É impossível relatar todos os envolvidos nesse importante processo, mas estendo meus agradecimentos às pessoas que compartilharam-no de alguma maneira. 



\section{Resumo}

ISLER, C.A. Avaliação socioeconômica de uma rede ferroviária regional para o transporte de passageiros. 299 p. Tese de Doutorado - Escola de Engenharia de São Carlos, Universidade de São Paulo, 2015.

A utilização majoritária da malha ferroviária brasileira para o transporte de cargas e a sua incompatibilidade para desenvolvimento de altas velocidades inviabiliza a oferta de serviços competitivos para o transporte intermunicipal de passageiros. A questão explorada nesta tese é sobre qual tecnologia ferroviária provê melhores resultados socioeconômicos no contexto de uma nova rede para o transporte intermunicipal de passageiros com operação exclusiva de Trens de Alto Desempenho (High Performance Trains - HPTs) ou Trens de Alta Velocidade (High Speed Trains - HSTs), caracterizados por velocidades médias de $150 \mathrm{~km} / \mathrm{h}$ e $300 \mathrm{~km} / \mathrm{h}$ respectivamente. Nesse sentido, a hipótese é que a diferença entre benefícios e custos socioeconômicos da oferta de serviços de HSTs resultam em valores positivos e maiores do que aquelas decorrentes da operação de HPTs, mediante parâmetros específicos de avaliação socioeconômica e uma configuração hipotética de rede na Região Sudeste do Brasil. Assim, o objetivo principal da tese é estimar e comparar os custos e benefícios socioeconômicos de uma rede ferroviária pela estimativa dos investimentos para a construção de novos traçados ferroviários, estimativa do número de viagens intermunicipais na Região Sudeste em um horizonte de planejamento estratégico e a propensão à escolha modal, estabelecimento de uma formulação de Análise Custo-Benefício (Cost Benefit Analysis - CBA) e aplicação dos modelos em cenários considerando a operação exclusiva de HPTs ou de HSTs. A resolução do problema de otimização de traçados ferroviários, com uma abordagem de computação paralela aplicada a um Algoritmo Genético, indica que os investimentos em infraestrutura variam majoritariamente em função da topografia, os custos de desapropriações são proporcionalmente pequenos e as restrições geométricas dos traçados não influenciam significativamente nesses resultados. 
Após a projeção do número de viagens intermunicipais por modelos analíticos, os dados coletados em uma pesquisa de preferência declarada são utilizados para modelagem da propensão à escolha modal. Finalmente, uma proposta de formulação para o cálculo dos principais itens de custos e benefícios de uma avaliação socioeconômica para o transporte ferroviário de passageiros viabiliza a análise de cenários em função de produtividade da construção da infraestrutura, variabilidade dos investimentos estimados e capacidade de atração de demanda reprimida. Os resultados dos cenários indicam que a diferença entre os benefícios estritamente econômicos (receita operacional e valor residual dos investimentos em infraestrutura) e os custos de construção e operacionais são negativos para qualquer tarifa ferroviária, apesar dos resultados para a rede de HSTs serem maiores do que para a de HPTs. Considerando os aspectos sociais, os benefícios totais da operação ferroviária sobrepõem-se aos seus custos em situações tarifárias específicas, novamente com resultados maiores para uma rede de HSTs, cuja tendência também é observada quando apenas os benefícios sociais são relacionados com custos totais através de uma Razão Benefício-Custo (Benefit-Cost Ratio - BCR). Portanto, segundo as premissas desta tese, há indícios que o investimento em uma infraestrutura ferroviária aparentemente não é uma decisão promissora em termos de viabilidade socioeconômica, apesar da operação de HSTs ser mais conveniente do que HPTs nos condições analisadas.

Palavras-chave: Ferrovia; Passageiro; Computação Paralela; Escolha Modal; Análise Sócioeconômica. 


\section{Abstract}

ISLER, C.A. Socioeconomic assessment of a regional railway network for passenger transport. 299 p. Ph.D. Thesis - São Carlos School of Engineering, University of São Paulo, 2015.

The major use of the Brazilian railway network for freight transport and its incompatibility with high speed trains does not enable running competitive services of intercity passenger transport. The research question of this thesis is which rolling stock technology provides better socioeconomic results on a new intercity passenger network with exclusive operation of High Performance Trains (HPTs) or High Speed Trains (HSTs) with average speeds of $150 \mathrm{~km} / \mathrm{h}$ and $300 \mathrm{~km} / \mathrm{h}$ respectively. The hypothesis is that the difference between the socioeconomic benefits and costs of operating HSTs results in positive values and greater than those from the operation of HPTs given specific socioeconomic parameters and a hypothetical network in the Southeastern region of Brazil. The main goal of this research is to estimate and compare the major socioeconomic costs and benefits of a hypothetical railway network by first estimating the required investments of new alignments. Furthermore, the number of trips among cities in the Southeastern Region over a strategic planning horizon and the mode choice are estimated and a Cost-Benefit Analysis formulation is provided to be applied to scenarios of exclusive operation of HPTs or HSTs. The solution of the railway alignment optimization problem with a parallel computing approach applied to a Genetic Algorithm shows that the infrastructure investments vary mainly due to the topography, whereas the expropriation costs are proportionally small and the railway geometric constraints do not significantly affect the results. The number of trips by transport mode over a planning horizon is expanded analytically and the collected data of a stated preference survey is applied to a mode choice modeling approach. Finally, a formulation for the major items of costs and benefits of a socioeconomic assessment for a rail passenger transport project is proposed and it is applied to specific scenarios where the effects of the infrastructure building productivity, variability of the estimated investments, 
and the ability to attract new passengers are analyzed. The results from these scenarios show that the difference between the operating income and the net residual value of investments in infrastructure, construction and operating costs are negative for any rail fare, despite the results for the network of HSTs being higher than for HPTs. Furthermore, the overall benefits of the railway operation outweigh the costs in specific pricing policies with better results for a network operating HSTs. This trend is also noticed when only the social benefits are compared to the total costs by a Benefit-Cost Ratio (BCR). Therefore, there is evidence that the investment in railway infrastructure for passenger transport apparently is not a promising decision in terms of socioeconomic feasibility under the assumptions of this thesis, despite the operation of HSTs being more attractive than HPTs under the specified conditions.

Keywords: Railway; Passenger; Parallel Computing; Mode Choice; Socioeconomic Analysis. 


\section{Lista de ilustrações}

Figura 1.1 Evolução do transporte ferroviário de cargas e passageiros no Brasil no século $\mathrm{XX} \ldots \ldots \ldots \ldots$. . . . . . . . . . . . . . . . . . . . .

Figura 1.2 Proposta de hierarquia para redes ferroviárias brasileiras para o transporte de passageiros ......................... 31

Figura 1.3 Fluxograma do procedimento proposto para avaliação socioeconômica de uma rede ferroviária para o transporte de passageiros na Região Sudeste . 34

Figura 2.1 Componentes dos custos de construção de elementos lineares de infraestrutura 39

Figura 2.2 Exemplo de comparação de traçados . . . . . . . . . . . . . . . . . 40

Figura 2.3 Alinhamento non-backtracking e backtracking . . . . . . . . . . . . . 43

Figura 2.4 Representação dos limites de um traçado ferroviário . . . . . . . . . . . . . 44

Figura 2.5 Representação de um alinhamento tridimensional . . . . . . . . . . . . . 44

Figura 2.6 Representação dos planos perpendiculares ao alinhamento entre a origem e o destino de um traçado . . . . . . . . . . . . . . . . . . . . . . 47

Figura 2.7 Traçado com excessivas curvas circulares . . . . . . . . . . . . . . . . . 48

Figura 2.8 Exemplo de descontinuidade entre curvas circulares horizontais sucessivas . 48

Figura 2.9 Elementos das curvas circulares horizontais do traçado . . . . . . . . . . . 49

Figura 2.10 Sucessão de PVs na seção longitudinal . . . . . . . . . . . . . . . . . . 49

Figura 2.11 Exemplo de coincidência dos PIs na projeção horizontal e da seção longitudinal em um alinhamento . . . . . . . . . . . . . . . . . 5 50

Figura 2.12 Sucessão de pontos de interseção verticais e exemplo de descontinuidade na seção longitudinal . . . . . . . . . . . . . . . . . . . 5 50

Figura 2.13 Definição de estações na projeção horizontal da ferrovia . . . . . . . . . . . 51

Figura 2.14 Definição de estações na seção longitudinal da ferrovia . . . . . . . . . . . 51

Figura 2.15 Rasters de elevação do terreno e de uso do solo da Região Sudeste do Brasil 52

Figura 2.16 Exemplo de avaliação de uso do solo . . . . . . . . . . . . . . . . . . . 53 
Figura 2.17 Seções transversais de corte e aterro e exemplo de seção transversal com áreas de bota-fora e empréstimo . . . . . . . . . . . . . . 53

Figura 2.18 Exemplos de operadores de mutação . . . . . . . . . . . . . . . 55

Figura 2.19 Exemplos de operadores de cruzamento . . . . . . . . . . . . 56

Figura 2.20 Página de acesso ao ambiente Nuvem USP e exemplo de lista de máquinas virtuais . . . . . . . . . . . . . . . . . . . . . 59 59

Figura 2.21 Topologias possíveis de redes estabelecidas no JPPF _ . . . . . . . . . 60

Figura 2.22 Fluxograma de processamento de dados utilizando o JPPF . . . . . . . . . 61

Figura 2.23 Interface do usuário representando a conexão entre nodes e server no Administration Tool do JPPF . . . . . . . . . . . . . . . . . . . 62

Figura 2.24 Topologia da rede de máquinas virtuais no Administration Tool do JPPF . . 62

Figura 2.25 Gráfico do tempo de processamento durante execução do $G A$ em paralelo no Administration Tool do JPPF . . . . . . . . . . . . . . . . . . . . 63

Figura 2.26 Exemplo de representação das medidas de desempenho durante a execução do GA em paralelo no Administration Tool do JPPF . . . . . . . . . . . 63

Figura 2.27 Fluxograma do $G A$ adaptado ao $J P P F \quad \ldots \ldots$. . . . . . . . . . . . . 65

Figura 2.28 Modelo teórico de representação das forças atuantes no trem em uma curva circular horizontal . . . . . . . . . . . . . . . . . 67

Figura 2.29 Gráficos de desempenho do $G A$ em paralelo de alinhamentos para operação de HPT entre Rio de Janeiro e Juiz de Fora . . . . . . . . . . . . . . . . 70

Figura 2.30 Gráficos de desempenho do $G A$ em paralelo de alinhamentos para operação de $H S T$ entre Rio de Janeiro e Juiz de Fora . . . . . . . . . . . . . . 72

Figura 2.31 Gráficos de desempenho do $G A$ em paralelo de alinhamentos para operação de HPT entre Campinas e Poços de Caldas . . . . . . . . . . . . . . 76

Figura 2.32 Gráficos de desempenho do GA em paralelo de alinhamentos para operação de HST entre Campinas e Poços de Caldas . . . . . . . . . . . . . 78

Figura 2.33 Gráficos de desempenho do GA em paralelo de alinhamentos para operação de HPT entre Ribeirão Preto e Araraquara . . . . . . . . . . . . . . . . .

Figura 2.34 Gráficos de desempenho do GA em paralelo de alinhamentos para operação de $H S T$ entre Ribeirão Preto e Araraquara . . . . . . . . . . . . . . . . . . 83

Figura 2.35 Custos médios por quilômetro para construção de novos alinhamentos ferroviários de $H S T$. . . . . . . . . . . . . . . . . . . .

Figura 2.36 Representação do traçado de mínimo custo para operação de $H P T$ entre Rio de Janeiro e Juiz de Fora

Figura 2.37 Representação do traçado de mínimo custo para operação de $H S T$ entre Rio de Janeiro e Juiz de Fora

Figura 2.38 Representação do traçado de mínimo custo para operação de $H P T$ entre Campinas e Poços de Caldas 
Figura 2.39 Representação do traçado de mínimo custo para operação de $H S T$ entre Campinas e Poços de Caldas . . . . . . . . . . . . . . . . . . . . . 91

Figura 2.40 Representação do traçado de mínimo custo para operação de HPT entre Araraquara e Ribeirão Preto . . . . . . . . . . . . . . . . . . . . . . . . . . . . 92

Figura 2.41 Representação do traçado de mínimo custo para operação de HST entre Araraquara e Ribeirão Preto . . . . . . . . . . . . . . . . . . . . . . . . . . . . 93

Figura 3.1 Fluxograma do método de modelagem quatro etapas . . . . . . . . . . . . 96

Figura 3.2 Alocação dos carregamentos decorrentes das projeções do PNLT para 2015 . 109

Figura 3.3 Exemplo de alocação de tráfego para estimativa de matriz OD pelo método "Tudo-ou-Nada"no TRANSCAD . . . . . . . . . . . . . . . . . . . 111

Figura 3.4 Linhas de Desejo dos dados observados para calibração do modelo gravitacional para o Modo Avião . . . . . . . . . . . . . . . . . . . . . . . . . . . 117

Figura 3.5 Estimativa de crescimento da população brasileira . . . . . . . . . . . . . . 121

Figura 3.6 Estimativa de crescimento da renda média per capita brasileira . . . . . . . 121

Figura 3.7 Alocação dos fluxos anuais estimados para o número de viagens pelo modo Ônibus . . . . . . . . . . . . . . . . . . . . . 123

Figura 3.8 Alocação dos fluxos anuais estimados para o número de viagens pelo modo Automóvel . . . . . . . . . . . . . . . . . . . . . 125

Figura 3.9 Linhas de Desejo dos fluxos anuais estimados para o Modo Avião . . . . . . 127

Figura 3.10 Escolha da cidade de origem de onde o participante respondeu a pesquisa . . 138

Figura 3.11 Escolha de um destino para onde o participante já tenha viajado . . . . . . . 138

Figura 3.12 Escolha do modo da viagem realizada pelo participante . . . . . . . . . . . 139

Figura 3.13 Escolha do motivo da viagem realizada pelo participante . . . . . . . . . . 139

Figura 3.14 Obtenção de informações a respeito da viagem realizada . . . . . . . . . . . . 140

Figura 3.15 Caracterização dos modos de transporte considerados na pesquisa . . . . . . 140

Figura 3.16 Cenário de escolha modal mediante diferentes níveis de atributos . . . . . . 141

Figura 3.17 Obtenção de informações socioeconômicas . . . . . . . . . . . . . . . . . . 142

Figura 3.18 Distribuição da escolha dos modos de transporte na pesquisa online . . . . . 143

Figura 3.19 Número de respostas entre pares Origem-Destino . . . . . . . . . . . . . . 144

Figura 3.20 Modos de transporte utilizados nas viagens realizadas pelos participantes . . 144

Figura 3.21 Histograma dos tempos de acesso nas viagens realizadas . . . . . . . . . . 145

Figura 3.22 Histograma dos tempos de egresso dispendidos nas viagens realizadas . . . 145

Figura 3.23 Histograma dos tempos de acesso estimados para os modos de transporte não utilizados nas viagens realizadas . . . . . . . . . . . . . . . . . 146

Figura 3.24 Histograma dos tempos de egresso estimados para os modos de transporte não utilizados nas viagens realizadas . . . . . . . . . . . . . . . . . 147

Figura 3.25 Distribuição dos valores observados dos atributos socioeconômicos . . . . . 148

Figura 3.26 Opinião dos respondentes a respeito do realismo dos níveis dos atributos de caracterização das viagens pelo modo Automóvel . . . . . . . . . . . . . . 148 
Figura 3.27 Opinião dos respondentes a respeito do realismo dos níveis dos atributos de caracterização das viagens pelo modo Ônibus . . . . . . . . . . . . . . 149

Figura 3.28 Opinião dos respondentes a respeito do realismo dos níveis dos atributos de caracterização das viagens pelo modo Avião

Figura 3.29 Opinião dos respondentes a respeito do realismo dos níveis dos atributos de caracterização das viagens pelo modo Trem $(H P T)$.

Figura 3.30 Opinião dos respondentes a respeito do realismo dos níveis dos atributos de caracterização das viagens pelo modo Trem $(H S T)$. . . . . . . . . . . . . . 149

Figura 3.31 Exemplo de arquivo de um MNL no Biogeme . . . . . . . . . . . . . . . 160

Figura 3.32 Gráfico da verossimilhança dos modelos estimados para o motivo trabalho e lazer . . . . . . . . . . . . . . . . . . . 170

Figura 3.33 Gráfico de acertos dos modelos estimados em relação às respostas da pesquisa para o motivo trabalho $W \ldots \ldots$. . . . . . . . . . . . 172

Figura 3.34 Gráfico de acertos dos modelos estimados em relação às respostas da pesquisa para o motivo lazer $L$

Figura 4.1 Extensão dos sistemas ferroviários que operam trens com velocidade maior que $200 \mathrm{~km} / \mathrm{h}$ no mundo . . . . . . . . . . . . . . . . . . . . . 177

Figura 4.2 Relação entre os elementos de uma Análise Custo-Benefício . . . . . . . . 180

Figura 4.3 Estimativa do excedente do consumidor considerando demanda inelástica - 192

Figura 4.4 Rule of Half para estimativa do excedente do consumidor considerando demanda elástica . . . . . . . . . . . . . . . . . . . . . . . 193

Figura 4.5 Modelo teórico para estimativa do excedente do consumidor . . . . . . . . . 195

Figura 4.6 Aproximação numérica do Rule of Half para estimativa do excedente do consumidor .......................... 196

Figura 5.1 Proposta de rede ferroviária hipotética conectando os principais centros urbanos da Região Sudeste . . . . . . . . . . . . . . . . . . . . . . . . . . 214

Figura 5.2 Segregação dos serviços da rede hipotética em eixos ferroviários para avaliação socioeconômica . . . . . . . . . . . . . . . . . . 215

Figura 5.3 Rede ferroviária estimada para o transporte de passageiros por $H P T$ sobre a projeção de declividade do terreno . . . . . . . . . . . . . . . . . . . 22

Figura 5.4 Rede ferroviária estimada para o transporte de passageiros por HPT sobre a projeção de uso do solo . . . . . . . . . . . . . . . . . . . . . . . . . 221

Figura 5.5 Rede ferroviária estimada para o transporte de passageiros por $H S T$ sobre a projeção de declividade do terreno . . . . . . . . . . . . . . . . 222

Figura 5.6 Rede ferroviária estimada para o transporte de passageiros por HST sobre a projeção de uso do solo . . . . . . . . . . . . . . . . . . . . . . . . 222

Figura 5.7 Representação esquemática para estimativa dos tempos de viagem entre uma origem e um destino pelos diferentes modos de transporte . . . . . . . . . . 227 
Figura 5.8 Valor Presente Líquido Econômico $(E N P V)$ em função da tarifa ferroviária média para a rede de $H P T$. . . . . . . . . . . . . . . . . . . 231

Figura 5.9 Valor Presente Líquido Econômico $(E N P V)$ em função da tarifa ferroviária média para a rede de $H S T$. . . . . . . . . . . . . . . . . . . . 232

Figura 5.10 Valor Presente Líquido Total $(T N P V)$ em função da tarifa ferroviária média para a rede de $H P T$. . . . . . . . . . . . . . . . . . . 235

Figura 5.11 Valor Presente Líquido Total $(T N P V)$ em função da tarifa ferroviária média para a rede de $H S T$. . . . . . . . . . . . . . . . . 236

Figura 5.12 Razão Benefício Custo $(B C R)$ em função da tarifa ferroviária média para a rede de $H P T$. . . . . . . . . . . . . . . . . . . . . . . . . . . . . . . . . . 238

Figura 5.13 Razão Benefício Custo $(B C R)$ em função da tarifa ferroviária média para a rede de $H S T$. . . . . . . . . . . . . . . . . . . . . . . . . . . . . . . . . . 239

Figura 5.14 Proporções de custos e benefícios da operação de HPT no cenário Conservador242

Figura 5.15 Proporções de custos e benefícios da operação de HPT no cenário Intermediário . . . . . . . . . . . . . . . . . . . . . . . 243

Figura 5.16 Proporções de custos e benefícios da operação de HPT no cenário Otimista . 244

Figura 5.17 Proporções de custos e benefícios da operação de HST no cenário Conservador246

Figura 5.18 Proporções de custos e benefícios da operação de HST no cenário Intermediário . . . . . . . . . . . . . . . . . . . . . . . . 247

Figura 5.19 Proporções de custos e benefícios da operação de $H S T$ no cenário Otimista . 248

Figura 5.20 Valor Presente Líquido Econômico ( $E N P V)$ mediante a variação do valor residual dos investimentos em infraestrutura para o cenário Intermediário . . 250

Figura 5.21 Razão Benefício-Custo $(B C R)$ mediante a variação do valor residual dos investimentos em infraestrutura para o cenário Intermediário . . . . . . . . 251

Figura 5.22 Valor Presente Líquido Econômico (ENPV) mediante a variação da taxa mínima de atratividade para o cenário Intermediário . . . . . . . . . . . . 252

Figura 5.23 Razão Benefício-Custo $(B C R)$ mediante a variação da taxa mínima de atratividade para o cenário Intermediário . . . . . . . . . . . . . 253

Figura A.1 Representação esquemática da seção transversal dos traçados ferroviários . 276 



\section{Lista de tabelas}

Tabela 2.1 Custos totais de alinhamentos para operação de HPT entre Rio de Janeiro e Juiz de Fora . . . . . . . . . . . . . . . . . . . . . . . . . . . . . . . 69

Tabela 2.2 Tempo de processamento para obtenção das soluções de alinhamentos para operação de HPT entre Rio de Janeiro e Juiz de Fora ～. . . . . . . . . . . 69

Tabela 2.3 Comprimentos dos alinhamentos para operação de HPT entre Rio de Janeiro e Juiz de Fora . . . . . . . . . . . . . . . . . . . . . . . . . . . 6 69

Tabela 2.4 Custos médios de alinhamentos para operação de HPT entre Rio de Janeiro e Juiz de Fora

Tabela 2.5 Custos totais de alinhamentos para operação de $H S T$ entre Rio de Janeiro e Juiz de Fora . . . . . . . . . . . . . . . . . . . . . . . . 71

Tabela 2.6 Tempo de processamento para obtenção das soluções de alinhamentos para operação de HST entre Rio de Janeiro e Juiz de Fora . . . . . . . . . . . . . 71

Tabela 2.7 Comprimentos dos alinhamentos para operação de HST entre Rio de Janeiro e Juiz de Fora

Tabela 2.8 Custos médios de alinhamentos para operação de HST entre Rio de Janeiro e Juiz de Fora . . . . . . . . . . . . . . . . . . . . . . . . . . . .

Tabela 2.9 Custos totais de alinhamentos para operação de HPT entre Campinas e Poços de Caldas . . . . . . . . . . . . . . . . . . . . . 75

Tabela 2.10 Tempo de processamento para obtenção das soluções de alinhamentos para operação de HPT entre Campinas e Poços de Caldas . . . . . . . . . . . . 75

Tabela 2.11 Comprimentos dos alinhamentos para operação de HPT entre Campinas e Poços de Caldas . . . . . . . . . . . . . . . . . . . 75

Tabela 2.12 Custos médios de alinhamentos para operação de HPT entre Campinas e Poços de Caldas . . . . . . . . . . . . . . . . . . . . 75

Tabela 2.13 Custos totais de alinhamentos para operação de HST entre Campinas e Poços de Caldas 
Tabela 2.14 Tempo de processamento para obtenção das soluções de alinhamentos para operação de HST entre Campinas e Poços de Caldas . . . . . . . . . . . 77

Tabela 2.15 Comprimentos dos alinhamentos para operação de HST entre Campinas e Poços de Caldas . . . . . . . . . . . . . . . . . . . . . . . 77

Tabela 2.16 Custos médios de alinhamentos para operação de HST entre Campinas e Poços de Caldas . . . . . . . . . . . . . . . . . . . . . . 77

Tabela 2.17 Custos totais de alinhamentos para operação de HPT entre Ribeirão Preto e Araraquara . . . . . . . . . . . . . . . . . . 80

Tabela 2.18 Tempo de processamento para obtenção das soluções de alinhamentos para operação de HPT entre Ribeirão Preto e Araraquara . . . . . . . . . . . . . 80

Tabela 2.19 Comprimentos dos alinhamentos para operação de HPT entre Ribeirão Preto e Araraquara . . . . . . . . . . . . . . . . . . . . . . 88 80

Tabela 2.20 Custos médios de alinhamentos para operação de HPT entre Ribeirão Preto e Araraquara . . . . . . . . . . . . . . . . . . . . . . . 80

Tabela 2.21 Custos totais de alinhamentos para operação de HST entre Ribeirão Preto e Araraquara . . . . . . . . . . . . . . . . . . . .

Tabela 2.22 Tempo de processamento para obtenção das soluções de alinhamentos para operação de $H S T$ entre Ribeirão Preto e Araraquara . . . . . . . . . . . . .

Tabela 2.23 Comprimentos dos alinhamentos para operação de HST entre Ribeirão Preto e Araraquara . . . . . . . . . . . . . . . . . . . . . . . .

Tabela 2.24 Custos médios de alinhamentos para operação de HST entre Ribeirão Preto e Araraquara . . . . . . . . . . . . . . . . . . . . . . 82

Tabela 2.25 Resultados relativos aos traçados de menor custo . . . . . . . . . . . . 85

Tabela 3.1 Fatores de regionalidade para o modelo gravitacional do modo Ônibus . . . 103

Tabela 3.2 Estimativa dos parâmetros do modelo gravitacional para o modo Ônibus em viagens entre capitais $($ Grupo A) . . . . . . . . . . . . . . 105

Tabela 3.3 Estimativa dos parâmetros do modelo gravitacional para o modo Ônibus em viagens interestaduais excluindo-se as capitais (Grupo B) . . . . . . . . 106

Tabela 3.4 Estimativa dos parâmetros do modelo gravitacional para o modo Ônibus em viagens intermunicipais $($ Grupo $\mathrm{C}) \ldots \ldots$. . . . . . . . . . 107

Tabela 3.5 Estimativa dos parâmetros do modelo gravitacional para o modo Automóvel em viagens entre capitais (Grupo A)

Tabela 3.6 Estimativa dos parâmetros do modelo gravitacional para o modo Automóvel em viagens interestaduais excluindo-se as capitais (Grupo B) . . . . . . . 113

Tabela 3.7 Estimativa dos parâmetros do modelo gravitacional para o modo Automóvel em viagens intermunicipais $($ Grupo $\mathrm{C})$. . . . . . . . . . . . 115

Tabela 3.8 Estimativa dos parâmetros do modelo gravitacional para o modo Avião . . 118

Tabela 3.9 Atributos considerados nas pesquisa de preferência declarada . . . . . . . . 130

Tabela 3.10 Níveis de velocidade média para definição dos tempos de viagem . . . . . . 131 
Tabela 3.11 Formulação para cálculo dos níveis de custo dos modos de transporte em função da distância média de viagem . . . . . . . . . . . . . . . . . 131

Tabela 3.12 Aeroportos com maior movimentação de passageiros em voos domésticos na Região Sudeste no ano de 2011 . . . . . . . . . . . . . . . . . . . . 132

Tabela 3.13 Cidades de origem, destino, distâncias rodoviárias aproximadas e distâncias estabelecidas para definição dos níveis dos atributos . . . . . . . . . . . . 133

Tabela 3.14 Exemplo de bloco para um cenário de $H S T$ com AIR de $400 \mathrm{~km}$. . . . . . . 135

Tabela 3.15 Número de repostas obtidas na pesquisa de preferência declarada . . . . . . 142

Tabela 3.16 Número de respostas das amostras para calibração e validação dos modelos de escolha discreta relativos à pesquisa de preferência declarada . . . . . . . 161

Tabela 3.17 Medidas de desempenho para estimativa dos parâmetros do Modelo A . . . 162

Tabela 3.18 Medidas de desempenho para estimativa dos parâmetros do Modelo B . . . 163

Tabela 3.19 Testes de razão de verossimilhança entre o Modelo A e o Modelo B . . . . . 163

Tabela 3.20 Medidas de desempenho para estimativa dos parâmetros do Modelo C . . . 164

Tabela 3.21 Medidas de desempenho para estimativa dos parâmetros do Modelo D . . 165

Tabela 3.22 Intervalos das classes de atributos socioeconômicos para inserção nos modelos de escolha modal . . . . . . . . . . . . . . . . . . . 166

Tabela 3.23 Medidas de desempenho para estimativa dos parâmetros do Modelo E . . . 167

Tabela 3.24 Medidas de desempenho para estimativa dos parâmetros do Modelo F . . 170

Tabela 3.25 Diferenças percentuais de verossimilhanças entre modelos pelo motivo $W \quad$. 171

Tabela 3.26 Diferenças percentuais de verossimilhanças entre modelos pelo motivo $L$. . 171

Tabela 3.27 Resumo das estatísticas $\rho^{2}$ e $\bar{\rho}^{2}$ da calibração dos modelos de escolha modal 172

Tabela 3.28 Porcentagem de acertos das Árvores de Decisão na modelagem da pesquisa de preferência declarada . . . . . . . . . . . . . . . . . . . . . 174

Tabela 4.1 Investimentos estimados e realizados para construção de novos alinhamentos ferroviários para Trens de Alta Velocidade em países europeus . . . . . 184

Tabela 4.2 Alternativas para estimativa do tempo médio de viagem por motivo trabalho 201

Tabela 4.3 Alternativas para estimativa do tempo médio de viagem por motivo lazer . . 202

Tabela 5.1 Resumo dos investimentos necessários à implantação de um rede ferroviária hipotética para operação de HPT . . . . . . . . . . . . . . . . . . . 218

Tabela 5.2 Resumo dos investimentos necessários à implantação de um rede ferroviária hipotética para operação de $H S T$. . . . . . . . . . . . . . . . . . . . . . . 218

Tabela 5.3 Estimativa de tempo necessário para construção da rede ferroviária em cada cenário mediante a tecnologia ferroviária . . . . . . . . . . . . . . . . . . 224

Tabela 5.4 Regressão dos tempos de acesso e egresso segundo a pesquisa de preferência declarada e as características das cidades . . . . . . . . . . . . . . . 228

Tabela 5.5 Tempo médio de bloco pelo modo Aéreo (minutos) - Fonte: ANAC (2014b) 229

Tabela 5.6 Definição dos parâmetros dos cenários para avaliação socioeconômica . . . 230 
Tabela B.1 Siglas e respectivos municípios sob influencia das estações consideradas na análise socioeconômica . . . . . . . . . . . . . . . . . 277

Tabela B.2 Projeções do número de viagens pelo modo Ônibus $(2015$ - 2032) . . . . 278

Tabela B.3 Projeções do número de viagens pelo modo Ônibus $(2033$ - 2050) . . . . . 279

Tabela B.4 Projeções do número de viagens pelo modo Automóvel $(2015$ - 2032) . . 280

Tabela B.5 Projeções do número de viagens pelo modo Automóvel $(2033$ - 2050) . . 281

Tabela B.6 Projeções do número de viagens pelo modo Avião $(2015$ - 2032) . . . . . 282

Tabela B.7 Projeções do número de viagens pelo modo Avião $(2033$ - 2050) . . . . . . 283

Tabela C.1 Modelo A $(W) \ldots \ldots \ldots \ldots \ldots$. . . . . . . . . . . . . . . . . . . . . . .

Tabela C.2 Modelo A $(L) \ldots \ldots \ldots \ldots \ldots \ldots$

Tabela C.3 Modelo B $(W) \ldots \ldots \ldots \ldots \ldots \ldots \ldots$

Tabela C.4 Modelo B $(L) \ldots \ldots \ldots \ldots \ldots \ldots$

Tabela C.5 Modelo C $(W) \ldots \ldots \ldots \ldots \ldots \ldots$. . . . . . . . . . . . . . . . . . . . . . . .

Tabela C.6 Modelo C $(L) \quad \ldots \ldots \ldots \ldots$. . . . . . . . . . . . . . 287

Tabela C.7 Modelo D $(W) \ldots \ldots \ldots \ldots \ldots$. . . . . . . . . . . . . . . . . . . . . . .

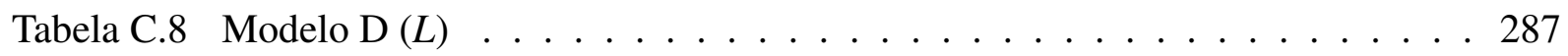

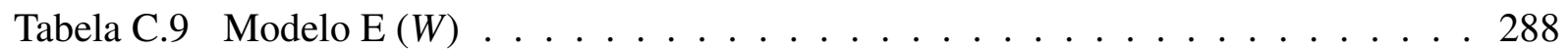

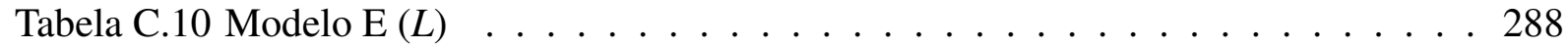

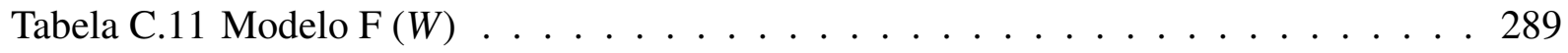

Tabela C.12 Modelo F $(L) \quad \ldots \ldots \ldots$. . . . . . . . . . . . . 290

Tabela E.1 Resultados da análise socioeconômica da rede ferroviária para operação de HPTs no Cenário Conservador . . . . . . . . . . . . . . . . . . . . . 294

Tabela E.2 Resultados da análise socioeconômica da rede ferroviária para operação de HPTs no Cenário Intermediário . . . . . . . . . . . . . . . . . . 295

Tabela E.3 Resultados da análise socioeconômica da rede ferroviária para operação de HPTs no Cenário Otimista . . . . . . . . . . . . . . . . . . . 296

Tabela E.4 Resultados da análise socioeconômica da rede ferroviária para operação de HSTs no Cenário Conservador . . . . . . . . . . . . . . . . . . . 297

Tabela E.5 Resultados da análise socioeconômica da rede ferroviária para operação de HSTs no Cenário Intermediário . . . . . . . . . . . . . . . . . 298

Tabela E.6 Resultados da análise socioeconômica da rede ferroviária para operação de HSTs no Cenário Otimista . . . . . . . . . . . . . . . . . . . . . . . 299 


\section{Lista de Siglas}

$A G E$ Idade

AIR Modo Aéreo

ASC Constante Específica da Alternativa

ABCR Associação Brasileira de Concessionárias de Rodovias

AD Árvore de Decisão

ANAC Agência Nacional de Aviação Civil

ANP Agência Nacional de Petróleo

ANTT Agência Nacional de Transportes Terrestres

ARTESP Agência Reguladora de Transporte do Estado de São Paulo

$B C R \quad$ Razão Benefício-Custo

BUS Modo Ônibus

$C A D$ Desenho assistido por Computador

CAR Modo Automóvel

$C B A$ Análise Custo-Benefício

CC Custo Total de Construção de um Novo Traçado

CNH Carteira Nacional de Habilitação

CPTM Companhia Paulista de Trens Metropolitanos 
$D B \quad$ Banco de Dados

$D R I V_{L I C}$ Carteira de Habilitação

DER Departamento de Estradas de Rodagem

EMP Empregabilidade

ENPV Valor Presente Líquido Econômico

EWC Custo de Terraplenagem

FA Tarifa de Viagem

FR Frequência de Serviços

GA Algoritmo Genético

GIS Sistema de Informações Geográficas

HPT Trem de Alto Desempenho

HST Trem de Alta Velocidade

IaaS Infraestrutura como um Serviço

IC $C^{C}$ Valor Presente Líquido dos Investimentos para Construção da Infraestrutura

$I C^{M} \quad$ Valor Presente Líquido das Despesas de Manutenção da Infraestrutura

IID Independente e Igualmente Distribuído

INC Renda Média per Capita

IRR Taxa Interna de Retorno

IBGE Instituto Brasileiro de Geografia e Estatística

IDH Índice de Desenvolvimento Humano

JPPF Java Parallel Programming Framework

LR Razão de Verossimilhança

LUC Custo de Desapropriações

MARR Taxa Mínima de Atratividade

MCA Análise Multicritério

OD Origem-Destino 
PaaS Plataforma como um Serviço

PE Custo de Combustível

PI Ponto de Interseção

PIB Produto Interno Bruto

PV Ponto de Interseção Vertical

$R S C^{A}$ Valor Presente Líquido dos Investimentos em Aquisição do Material Rodante

$R S C^{M}$ Valor Presente Líquido das Despesas de Manutenção do Material Rodante

$R S C^{O}$ Valor Presente Líquido das Despesas de Operação do Material Rodante

SaaS Software como um Serviço

TAR Valor Presente Líquido pela Redução de Acidentes

TBC Custo de Túneis e Viadutos

TCSTS Valor Presente Líquido do Excedente do Consumidor pelo Tempo de Viagem

TCSUC Valor Presente Líquido do Excedente do Consumidor pela Tarifação

TER Valor Presente Líquido pela Redução de Externalidades

TINA Transport Infrastrucutre Needs Assessment

TNPV Valor Residual Total

TO Custo de Pedágio

TRC Custo da Superestrutura

$T R V \quad$ Valor Presente Líquido do Valor Residual da Infraestrutura

TR Valor Presente Líquido da Receita Total

TT Tempo de Viagem

$V M \quad$ Máquina Virtual

VDMA Volume Diário Médio Anual 



\section{Sumário}

1 Introdução 29

1.1 Escopo e problema de tese . . . . . . . . . . . . . 33

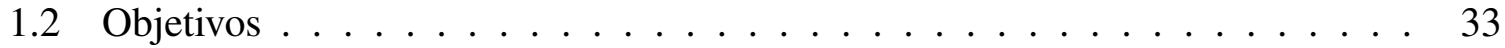

1.3 Contribuições da pesquisa . . . . . . . . . . . . . 35

1.4 Estrutura da Tese . . . . . . . . . . . . . . . . . 35

2 Estimativa de Custos de Traçados Ferroviários $\quad 37$

2.1 Algoritmo Genético para o Problema de Definição de Traçados Ferroviários 42

2.2 Algoritmo Genético e Programação Paralela . . . . . . . . . . . . . . 58

2.3 Análise de Desempenho . . . . . . . . . . . . . . . . . . 64

2.3.1 Definição de Parâmetros . . . . . . . . . . . . . . . . 66

2.3.2 Resultados da Análise de Desempenho . . . . . . . . . . . . . 68

3 Estimativa de Demanda $\quad 95$

3.1 Distribuição de viagens . . . . . . . . . . . . . . . . 96

3.1.1 Método do Fator de Crescimento . . . . . . . . . . . . . . . . . 97

3.1 .2 Modelo Gravitacional . . . . . . . . . . . . . . . . . . . . . 98

3.1 .3 Maximização da Entropia . . . . . . . . . . . . . . . . . . . 99

3.1.4 Modelos Econométricos de Regressão Linear . . . . . . . . . . . . . 100

3.1.5 Estimativa de Viagens no Ano Base . . . . . . . . . . . . . . . 101

3.1.6 Projeção das Viagens Estimadas . . . . . . . . . . . . . . . . . . . 119 
3.2 Escolha Modal . . . . . . . . . . . . . . . . . . . . . . . . . 128

3.2.1 Pesquisa de Preferência Declarada . . . . . . . . . . . . . . 128

3.2.2 Análise dos Dados Coletados na Pesquisa . . . . . . . . . . . 143

3.2.3 Modelagem de Escolha Modal . . . . . . . . . . . . . . . . 151

3.2.4 Estimativa dos modelos . . . . . . . . . . . . . . . 159

3.2.5 Considerações sobre a Modelagem de Escolha Modal . . . . . . . . 170

4 Análise Socioeconômica de Projetos Ferroviários 175

4.1 Análise Custo-Benefício de Projetos de Transporte Ferroviário . . . . . . . 176

4.2 Formulação para Análise Custo-Benefício de Projetos Ferroviários . . . . . 178

4.2.1 Recomendações do Banco Mundial . . . . . . . . . . . . . . . . . . 179

4.2.2 Recomendações do WebTAG . . . . . . . . . . . . . . . 181

4.2.3 Parâmetros de Entrada . . . . . . . . . . . . . . . . . . . . . 182

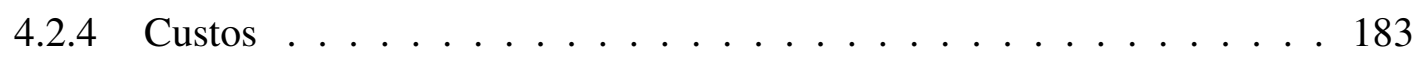

4.2 .5 Benefícios . . . . . . . . . . . . . . . . . 189

4.2.6 Medidas de Desempenho . . . . . . . . . . . . . . . 210

5 Cenários para o Transporte Ferroviário Regional de Passageiros 213

5.1 Definição de Traçados e Estimativa de Investimentos . . . . . . . . . . . 216

5.2 Estimativa de Número de Passageiros e Divisão Modal . . . . . . . . . . . . . 224

5.3 Definição dos Tempos de Viagem e Tarifas . . . . . . . . . . . . . 226

5.4 Análise Socioeconômica de Cenários . . . . . . . . . . . . . . . . . . 229

5.5 Considerações sobre a Análise Socioeconômica . . . . . . . . . . . . . 249

6 Considerações Finais e Recomendações 255

6.1 Recomendações para Pesquisas Futuras . . . . . . . . . . . . . . . 258

$\begin{array}{ll}\text { Referências } & 261\end{array}$

$\begin{array}{ll}\text { Apêndices } & 273\end{array}$ 
APÊNDICE B Projeções do Número de Viagens

APÊNDICE C Resultados dos Modelos de Escolha Modal 285

APÊNDICE D Parâmetros para Análise Custo-Benefício 291

APÊNDICE E Resultados dos Cenários de Análise Socioeconômica 293 

Capítulo

\section{Introdução}

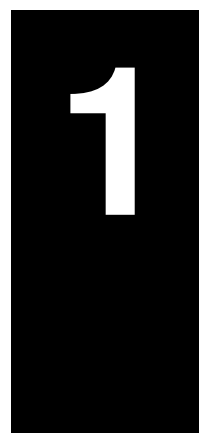

O contexto de construção e operação das ferrovias difere historicamente entre países. Na Europa Ocidental, a infraestrutura para operação do modo ferroviário foi implantada para conexão de cidades que se formaram durante os séculos anteriores ao surgimento desse meio de transporte. Atualmente, verifica-se que a densa malha ferroviária do continente é utilizada majoritariamente para o deslocamento de pessoas entre os centros urbanos (UIC, 2011).

Por outro lado, a instalação desse tipo de infraestrutura no continente americano contribuiu principalmente para a expansão das fronteiras e o estabelecimento das cidades. Nesse caso, o sistema ferroviário fora mais suscetível à influencia dos avanços da indústria automobilística a partir da segunda metade do século XX. No caso específico dos Estados Unidos, as ferrovias foram reestruturadas nas últimas décadas daquele século e sua utilização culminou no atual cenário de predominância do transporte de cargas a longas distâncias (UIC, 2011).

Essa tendência norte-americana pode ser observada também no Brasil, onde o transporte ferroviário contribuiu para o desenvolvimento do interior do país, sobretudo no âmbito do transporte de passageiros na primeira metade do século XX (SCHOPPA, 2004), com utilização majoritária para o transporte de cargas a partir de meados da década de 1960, conforme a Figura 1.1.

Entretanto, ao contrário dos EUA, no caso brasileiro não houve uma política consistente de utilização da malha ferroviária durante o século XX, cuja reestruturação deu-se tardiamente ao final da década de 1990 pelas concessões do transporte de cargas à iniciativa privada. 


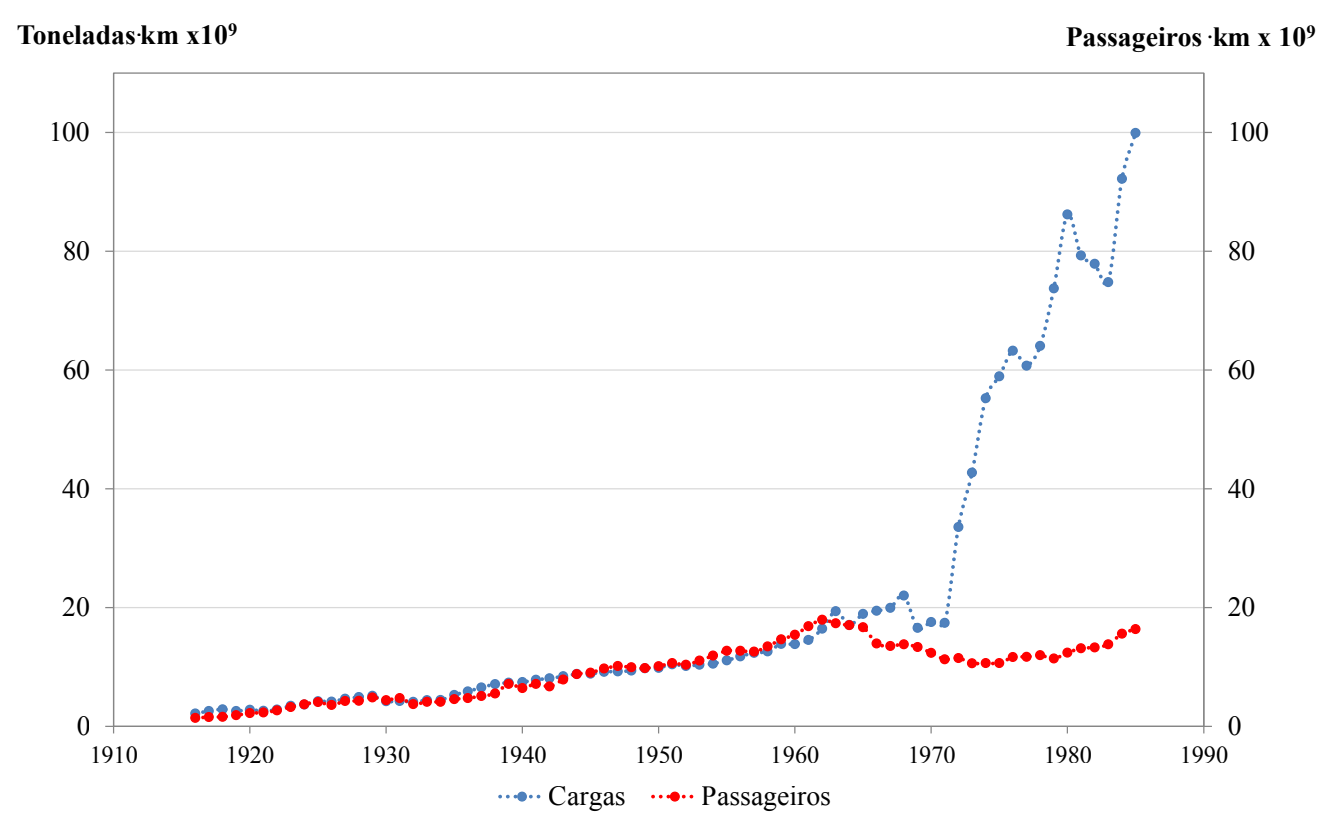

Figura 1.1 - Evolução do transporte ferroviário de cargas e passageiros no Brasil no século XX Fonte: IBGE (1990)

Relegados a alguns trechos da malha ferroviária, os serviços de transporte de passageiros permaneceram em operação apenas nas localidades em que se mostraram indispensáveis - como nas áreas urbanas das principais capitais brasileiras, por exemplo, nas regiões metropolitanas do Rio de Janeiro e de São Paulo - ou para viagens a longa distância em situações particulares como entre Belo Horizonte (MG) e Vitória (ES) ou Parauapebas (PA) e São Luís (MA).

Porém, ainda que em operação, esses serviços mostram-se ineficientes em relação aos tempos de viagens dos outros modos de transporte, particularmente devido ao compartilhamento das vias com trens de carga que impõem restrições de velocidades aos de passageiros.

Nesse contexto, é considerado impróprio planejar a reativação do transporte ferroviário intermunicipal de passageiros no Brasil tendo como referência as experiências norte-americana e europeia, dadas as discrepâncias históricas e respectivas políticas de planejamento.

No ano de 2010 o Governo Federal do Brasil apresentou uma proposta de projeto de Trem de Alta Velocidade (High Speed Train - HST) para conexão das cidades de Campinas, São Paulo e Rio de Janeiro com veículos caracterizados por velocidade média de $300 \mathrm{~km} / \mathrm{h}$ (TAV, 2014). Entretanto, até 2015, o projeto não apresenta perspectivas de implantação em um futuro 
próximo sobretudo pelas dúvidas que suscita a respeito da demanda que possa utilizar o sistema.

Concomitantemente, o Governo do Estado de São Paulo, sob representação da Companhia Paulista de Trens Metropolitanos (CPTM), apresentou propostas de conexões da Região Metropolitana de São Paulo às cidades de Campinas, Sorocaba, São José dos Campos e Santos (CPTM, 2014a) através de trens caracterizados por velocidade média de $150 \mathrm{~km} / \mathrm{h}$.

Apesar dessas propostas, não existe uma terminologia adequada e comum às esferas governamentais para denominação dos diferentes tipos de serviços que são prestados ou que eventualmente serão ofertados aos usuários. Portanto, com intuito de padronizar uma terminologia para esta tese, foi feita uma adaptação da classificação de Wang et al. (2012) para hierarquização das ferrovias para o transporte de passageiros no Brasil conforme a Figura 1.2.

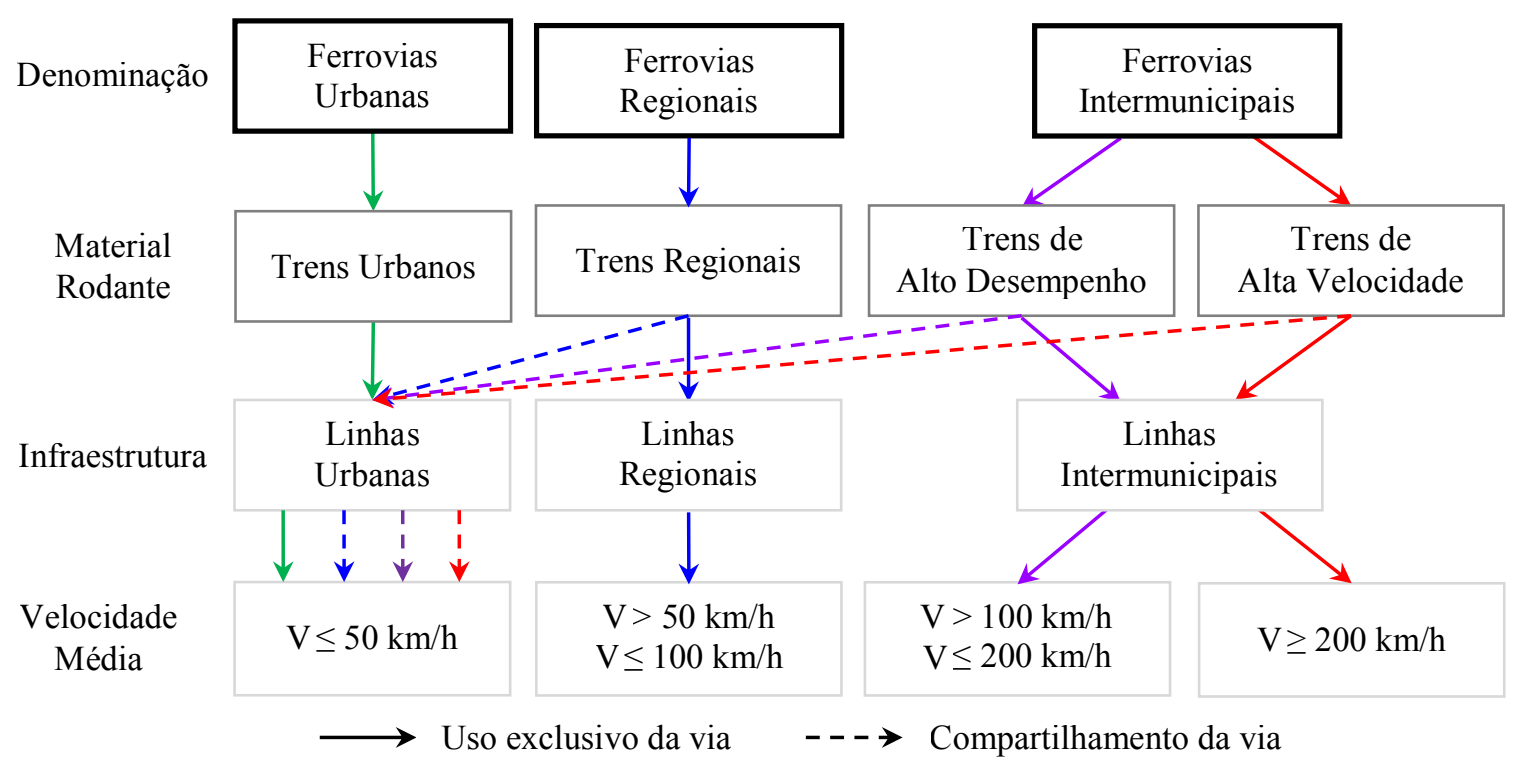

Figura 1.2 - Proposta de hierarquia para redes ferroviárias brasileiras para o transporte de passageiros - Fonte: adaptado de Wang et al. (2012)

No escopo das ferrovias intermunicipais enquadram-se os Trens de Alto Desempenho (High Performance Train - HPT), que englobam as propostas da CPTM para conexão das cidades do interior do Estado de São Paulo à capital (CPTM, 2014b).

Nessa mesma categoria de ferrovias, os HSTs podem operar nas linhas intermunicipais com o objetivo de redução dos tempos de viagem como, por exemplo, a proposta de conexão entre as Regiões Metropolitanas de São Paulo, do Rio de Janeiro e à cidade de Campinas (TAV, 2014). 
Os serviços de HSTs em geral mostram-se viáveis quando conectam regiões de grandes concentrações populacionais e distâncias de aproximadamente $600 \mathrm{~km}$ entre si, tornando o modo competitivo com o transporte aéreo (LACERDA, 2008). Em conexões com distâncias maiores que 300 km os HSTs são mais competitivos que os aviões devido à maior facilidade de embarque e desembarque, porém, em percursos acima de $800 \mathrm{~km}$, o modo ferroviário atrai menores fluxos pelo aumento dos tempos de viagem quando comparado aos aviões (GLEAVE, 2004).

A captura da demanda pelos HSTs não depende apenas dos tempos de viagem em relação aos outros modos, mas também das tarifas praticadas e condições de conforto dos passageiros, indicando que a operação dessa tecnologia e a dos HPTs apresentam distinções significativas quanto ao padrão de serviço ofertado ao usuário (GIVONI, 2006).

Mediante o interesse das esferas governamentais a respeito da implantação de novos serviços ferroviários para o transporte de passageiros no Brasil (sobretudo na Região Sudeste), as discussões sobre o tema permeiam as estimativas de investimentos necessários à construção de novos traçados ou a possibilidade de utilização das vias existentes.

Pesquisas anteriores corroboram o fato de que a infraestrutura ferroviária existente na Região Sudeste inviabiliza a oferta de serviços ferroviários competitivos para o transporte de passageiros, principalmente pela incompatibilidade da geometria e dos níveis de manutenção requeridos para operação de trens com maiores velocidades (BATISTA, 2006; ISLER, 2010).

Isler e Widmer (2012) mostram que essa infraestrutura ferroviária brasileira foi concebida com padrão geométrico de raios de curvas circulares horizontais que restringem a velocidade média dos trens, sobretudo para aqueles que transportam cargas com centro de gravidade elevado (como no caso de contêineres empilhados, ou double-stack).

Assim, é pertinente considerar uma investigação sobre alternativas de implantação de uma infraestrutura ferroviária para o transporte de passageiros baseada em concepções geométricas que permitam a redução dos tempos de viagem e que sejam atraentes para os investidores no âmbito econômico-financeiro e para os usuários do ponto de vista econômico e social. 


\subsection{Escopo e problema de tese}

A Região Sudeste do Brasil se destaca em relação às demais regiões nos aspectos econômicos e em termos de padrões de viagens entre cidades (IBGE, 2010), com população maior do que 85 milhões de habitantes e Produto Interno Bruto (PIB) acima de dois trilhões de reais no ano de 2010 (equivalentes a aproximadamente $44 \%$ e $49 \%$ do total nacional, respectivamente).

Nesse sentido, o escopo da pesquisa apresentada nesta tese delimita-se à investigação de possibilidades de oferta de serviços ferroviários para o transporte de passageiros no âmbito regional dos estados de Espírito Santo, Minas Gerais, Rio de Janeiro e São Paulo.

Nesta tese são avaliadas alternativas de implantação de serviços ferroviários para o transporte de passageiros de longa distância (acima de 100 km) na Região Sudeste do Brasil. A investigação abrange a proposta de novos serviços em Linhas Intermunicipais com operação de HPTs de velocidade média de $150 \mathrm{~km} / \mathrm{h}$ ou de $H S T s$ caracterizados por velocidade média de $300 \mathrm{~km} / \mathrm{h}$.

Sob essas definições, o problema da pesquisa de doutorado é a ausência de comparações da viabilidade socioeconômica da operação de HPTs e HSTs no âmbito do transporte de passageiros na Região Sudeste do Brasil. Assim, a pergunta de tese sobre esse problema é: "Qual tipo de serviço oferecido pela operação de HPTs ou de HSTs provê melhores resultados socioeconômicos no contexto de uma rede ferroviária para o transporte intermunicipal de passageiros?"

Como resposta a essa pergunta propõe-se a seguinte hipótese: "Dada uma configuração específica de conexões ferroviárias intermunicipais na Região Sudeste do Brasil, a diferença entre os benefícios e custos socioeconômicos da oferta de serviços de HSTs resultam em valores positivos e maiores do que a diferença resultante da oferta de serviços de HPTs, mediante as particularidades dessas tecnologias e parâmetros específicos de avaliação socioeconômica."

\subsection{Objetivos}

O objetivo principal da tese é estimar os custos e benefícios socioeconômicos de uma rede ferroviária hipotética para o transporte intermunicipal de passageiros na Região Sudeste do Brasil com operação de HPTs, e compará-los com os resultados de uma avaliação socioeconômica 
sob as mesmas condições de rede com operação de HSTs. Assim, para atingir esse objetivo precípuo da pesquisa são estabelecidos os objetivos secundários a seguir.

a. Estimar os valores econômicos dos investimentos necessários para a construção de novos traçados ferroviários, mediante diferentes restrições geométricas segundo as especificidades das tecnologias ferroviárias contempladas nesta tese;

b. Estimar o número de viagens intermunicipais na Região Sudeste em um horizonte de planejamento estratégico e a propensão à escolha modal na eventualidade da oferta de serviços ferroviários para o transporte de passageiros;

c. Estabelecer uma formulação de Análise Custo-Benefício (Cost-Benefit Analysis) de projetos ferroviários para o transporte de passageiros contemplando os investimentos, as despesas operacionais, e os benefícios econômicos e sociais decorrentes da sua construção e operação;

d. Aplicar os modelos propostos e a formulação de $C B A$ em cenários de uma rede ferroviária hipotética na Região Sudeste do Brasil considerando a operação exclusiva de HPTs ou de HSTs.

O fluxograma da Figura 1.3 relaciona os objetivos secundários da pesquisa, sintetizando o procedimento proposto para atingir o objetivo principal de avaliação socioeconômica de diferentes tecnologias ferroviárias para o transporte de passageiros na Região Sudeste do Brasil.

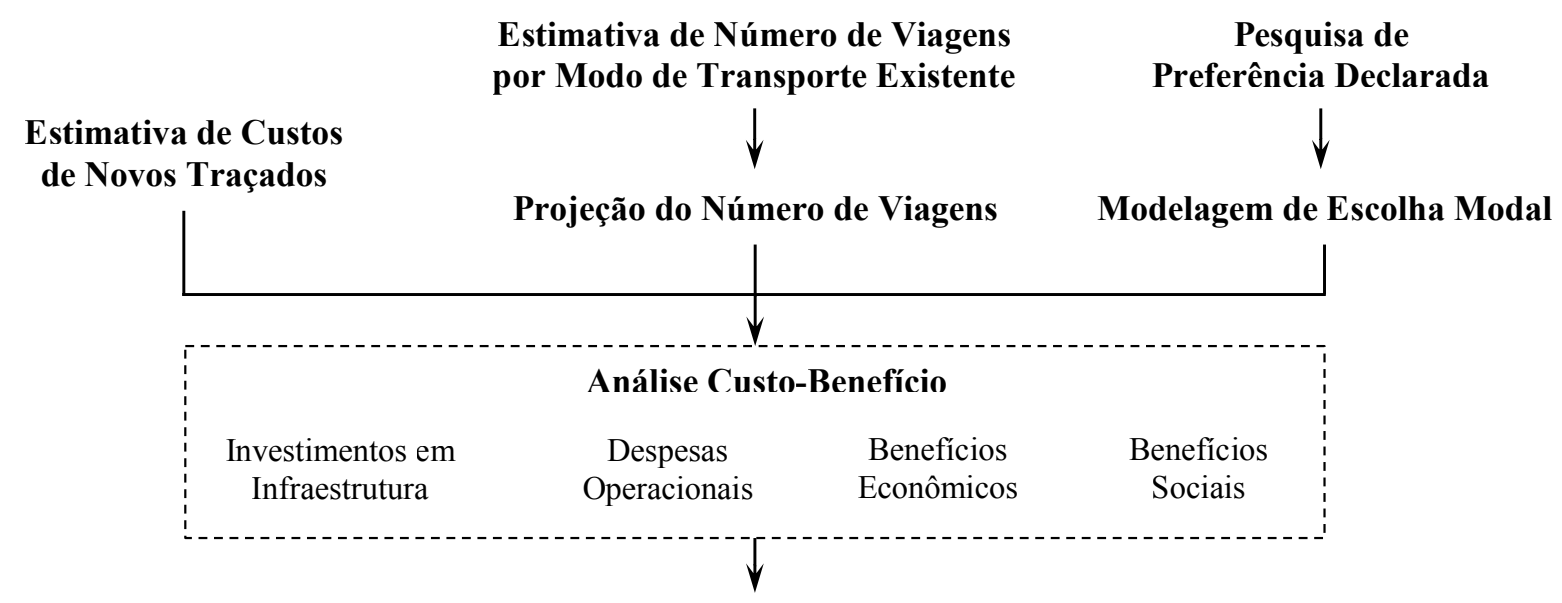

Aplicação em Rede Ferroviária Hipotética na Região Sudeste

Figura 1.3 - Fluxograma do procedimento proposto para avaliação socioeconômica de uma rede ferroviária para o transporte de passageiros na Região Sudeste 


\subsection{Contribuições da pesquisa}

O Brasil apresenta inexpressiva operação de trens intermunicipais de passageiros de longa distância e não possui uma estratégia consolidada e comum às diferentes esferas governamentais para oferta de serviços competitivos dessa natureza. Assim, a principal contribuição desta pesquisa é a comparação da operação HPTs e HSTs do ponto de vista socioeconômico, de modo a cooperar com decisões sobre a escolha de uma alternativa condizente às necessidades de melhoria das condições dos deslocamentos da população na Região Sudeste do Brasil.

Do ponto de vista da modelagem, constata-se que os atuais estudos para oferta de serviços ferroviários no Brasil carecem de um procedimento explícito de avaliação socioeconômica seja para a operação de HPTs ou de HSTs.

Assim, a proposta de formulação de análise socioeconômica contida nesta tese exige a estimativa dos investimentos para construção de novos traçados com os padrões requeridos pelas tecnologias de $H P T$ e $H S T$. Entretanto, dadas as particularidades topográficas do território brasileiro, a utilização de um valor médio por quilômetro para definição dos investimentos nesse tipo de infraestrutura não é realista, sendo portanto justificável a proposta de um método mais acurado para tal propósito conforme descrito nesta tese.

Diferentemente de muitos países europeus em que a malha ferroviária de trens convencionais está consolidada e existe uma propensão à expansão dos $H S T s$, a carência desses serviços no Brasil dificulta a estimativa da divisão modal no caso da oferta de transporte ferroviário de passageiros. Portanto, a execução de uma pesquisa de preferência declarada contribui para a mitigação das incertezas a respeito da caracterização dos padrões de viagens e permite a comparação da escolha de diferentes tipos de serviços dessa natureza.

\subsection{Estrutura da Tese}

Esta tese está estruturada em 6 capítulos, com a descrição da revisão da literatura naqueles pertinentes a cada um dos itens abordados na pesquisa. Após esta Introdução o Capítulo 2 contém o método para estimativa dos investimentos para a construção de traçados ferroviários adequados ao transporte de passageiros respeitando-se as restrições dos HPTs e HSTs. 
No Capítulo 3 são descritos os procedimentos considerados para estimativa do número de viagens intermunicipais na Região Sudeste do Brasil pelos modos de transporte atualmente disponíveis e para projeção dessas viagens em um horizonte de planejamento estratégico. Ainda naquele capítulo é apresentado o método para estimativa da propensão à escolha modal mediante a modelagem das respostas de uma pesquisa de preferência declarada.

No Capítulo 4 os métodos usuais de análise de projetos de transporte são descritos, sendo apresentada uma proposta de formulação explícita para avaliação socioeconômica agregando os itens descritos nos capítulos anteriores, as despesas operacionais e de manutenção, e os benefícios sociais de economia de tempo e redução de acidentes e externalidades.

No Capítulo 5 são apresentados os cenários de aplicação das abordagens dos capítulos anteriores para avaliação da hipótese de tese e, finalmente, no Capítulo 6 são indicadas as considerações finais a respeito dos resultados obtidos e propostas de pesquisas futuras sobre o tema. 


\section{Capítulo}

\section{Estimativa de Custos de Traçados Ferroviários}

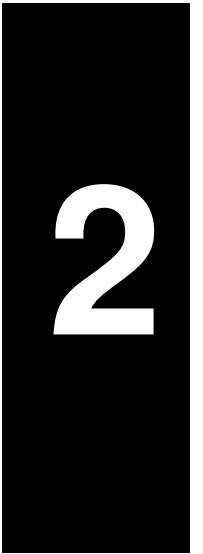

Segundo Kim, Jha e Son (2005), o problema de definição de traçados rodoferroviários envolve a escolha do alinhamento de menor custo que conecta duas localidades e é formalizado pela seguinte proposição: "Dada a localização de dois pontos e a possibilidade de alteração da configuração do terreno na região em que estão contidos, determinar o alinhamento constituído por trechos em tangente conectados por curvas horizontais que minimiza o valor de uma função objetivo específica segundo as restrições geométricas e operacionais do modo de transporte".

Esse problema tem sido extensamente explorado na literatura científica. Ao estabelecer uma ferramenta de planejamento para definição de traçados rodoviários entre áreas urbanas utilizando um Algoritmo Genético (Genetic Algorithm - GA), Kang, Jha e Schonfeld (2012) apresentam uma abrangente revisão sobre as principais abordagens propostas para resolução do problema considerando as características horizontais e verticais dos alinhamentos separada ou simultaneamente. Além de distinguir cada método de solução, os autores apresentam uma análise das principais deficiências de alguns desses métodos.

Existem algumas distinções entre abordagens para otimização de traçados rodoviários e ferroviários, entretanto estas diferenças mostram-se mais significativas na definição da função objetivo do problema, sendo que os métodos de solução geralmente são generalizados para ambos os modos, com algumas alterações no cálculo dos parâmetros geométricos dos traçados.

Parker (1977) e Trietsch (1987) propõem modelos de redes que utilizam uma abordagem de 
otimização em dois estágios, os quais podem ser considerados uma combinação de modelos em duas dimensões (horizontal e vertical).

No cotexto da programação dinâmica, a otimização tridimensional de alinhamentos (horizontal e vertical simultaneamente) consiste na definição dos estágios como planos igualmente espaçados entre o ponto inicial e final do traçado, os quais são perpendiculares ao segmento que conecta essas localidades. Hogan (1973) e Nicholson, Elms e Williman (1976) são exemplos de aplicação dessa abordagem e sua precisão varia conforme o nível de tolerância estabelecido nas malhas perpendiculares ao traçado.

Um modelo de traçado tridimensional suavizado foi desenvolvido por Chew, Goh e Fwa (1989) como extensão de um modelo contínuo para otimização de alinhamentos verticais proposto em Goh, Chew e Fwa (1988). No problema de cálculo variacional um conjunto de funções cúbicas contínuas são utilizadas para interpolação do traçado. Nesse contexto, a função objetivo envolve a resolução de integrais matemáticas, cuja solução proposta pelos autores é uma integração numérica associada a um "Algoritmo de Quase-Newton em Descida".

Com base em Jong e Schonfeld (2003), Kang, Jha e Schonfeld (2012) argumentam que o $G A$ tem se mostrado como a estratégia de solução mais eficiente na resolução do problema de otimização simultânea de alinhamentos horizontais e verticais de rodovias, uma vez que nesse método a região factível é intensamente explorada evitando-se soluções ótimas locais.

No aspecto econômico, segundo OECD (1973) e Chew, Goh e Fwa (1989), a distribuição dos valores econômicos dos itens necessários à construção de elementos lineares de infraestrutura (rodovias e ferrovias) é categorizada conforme indicado na Figura 2.1. Nessa representação, $75 \%$ dos custos correspondem a apenas três itens específicos: terraplenagem, implantação da superestrutura, e construção de pontes, viadutos e túneis.

Schonfeld et al. (2007) classificam esses valores quanto aos custos de construção e despesas operacionais incidentes sobre o operador e o usuário. Ao operador do sistema cabem os custos de implantação da via (trilhos, dormentes e demais elementos), construção das estações, desapropriações, terraplenagem e as despesas operacionais dos veículos. Por outro lado, os usuários arcam com as despesas de acesso, egresso e tarifa da viagem. 


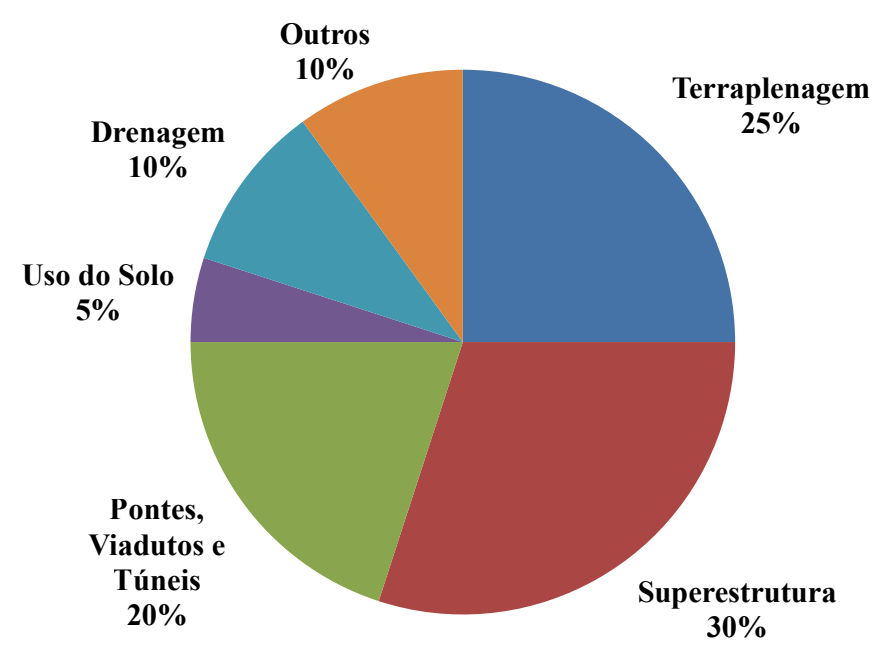

Figura 2.1 - Componentes dos custos de construção de elementos lineares de infraestrutura Fonte: adaptado de Jha et al. (2006)

Um importante aspecto vinculado à aquisição e desapropriação de terrenos foi contemplado em Jha e Schonfeld (2000), pela associação de um modelo de otimização de traçados rodoviários à um Sistema de Informações Geográficas (Geographic Information System - GIS) . No artigo os autores contemplam os investimentos totais e despesas atribuídos ao operador e aos usuários, vinculando um GIS aos valores monetários de aquisição de propriedades e aos impactos ambientais das áreas investigadas na solução de um problema real.

Jha, McCall e Schonfeld (2001) apresentam um aprimoramento da pesquisa anterior pela associação de um GA e um GIS a um modelo de visualização computacional, de modo que os aspectos não contemplados pelo algoritmo pudessem ser investigados pela intervenção do planejador. Esse modelo permite um maior detalhamento do traçado e a avaliação das interferências da via em relação aos possíveis obstáculos nas suas adjacências.

Jha (2003) propõe um sistema de suporte à decisão que considera não apenas a minimização de custos econômicos, mas também as interferências das novas vias no meio ambiente e nas aglomerações urbanas. A proposta do autor é comparar um conjunto de alinhamentos provenientes do $G A$ com um traçado de referência em função dos seus comprimentos e áreas de interseção (ver Figura 2.2), permitindo que os tomadores de decisão avaliem as consequências de implantação de um traçado em termos de impactos ambientais e sociais. 


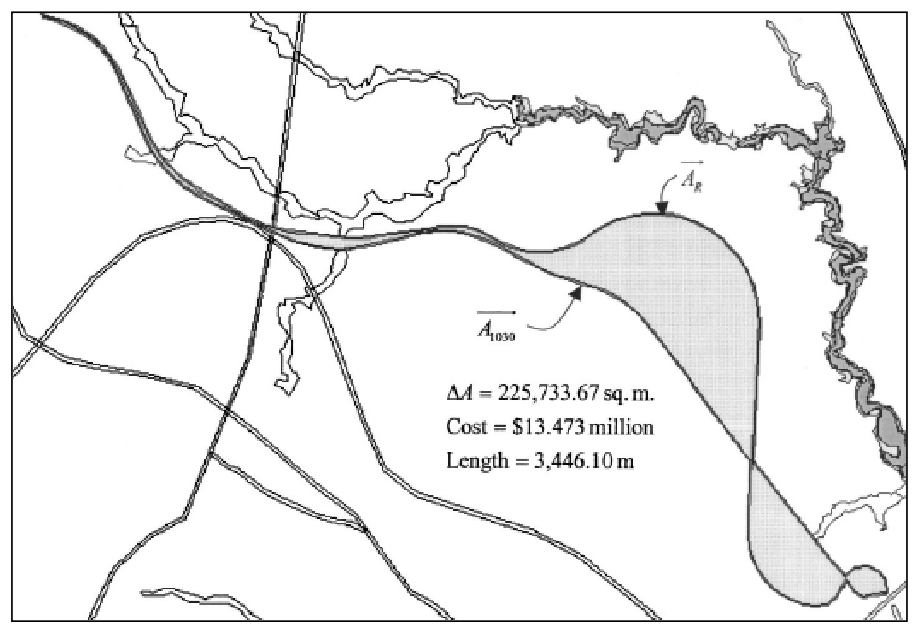

Figura 2.2 - Exemplo de comparação de traçados - Fonte: Jha (2003)

Kim et al. (2004) apresentam uma metodologia que contempla os custos requeridos para a construção das interseções com um sistema rodoviário existente. Os autores consideram as principais características geométricas de interseções rodoviárias, incluindo um procedimento de busca local da geometria que minimiza o custo total estimado, incluindo os itens associados à desapropriação, terraplenagem e pavimentação.

Um compêndio das pesquisas apresentadas anteriormente pode ser identificado em Jha et al. (2006), cujas contribuições são interpretadas como o trabalho mais significativo sobre o tema, contendo uma abrangente revisão de literatura, além de instruções detalhadas sobre o cálculo dos parâmetros geométricos horizontais e verticais de alinhamentos rodoviários, bem como a vinculação do GA a Sistemas de Informações Geográficas.

No âmbito ferroviário, Jha, Schonfeld e Samanta (2007) apresentam uma extensão dos procedimentos associados à definição de alinhamentos rodoviários de mínimo custo. Os autores formalizam os elementos do GA baseado em Jha et al. (2006), bem como os operadores de cruzamento e mutação associados ao método. Na função objetivo do modelo são considerados os custos incidentes sobre o operador do sistema (implantação da via, construção das estações, desapropriações, terraplenagem e despesas operacionais) e os custos incorridos aos usuários (tempo de acesso às estações, tempo de viagem e tempo de egresso).

Na mesma temática ferroviária, Samanta e Jha (2011) apresentam uma modelagem de localização de estações que integra despesas dos usuários aos custos de construção dos traçados. 
Os autores apresentam um algoritmo para escolha das estações e também utilizam um GA para estimativa dos custos dos alinhamentos entre as instalações.

Além do conjunto de pesquisas apresentados por esses autores, existem outras propostas metodológicas para resolução do problema de definição de alinhamentos rodoferroviários, bem como a abrangência de diferentes funções objetivo aplicadas ao problema.

Dado o alinhamento horizontal de uma rodovia, Lee e Cheng (2001) apresentam uma modelagem matemática que determina a configuração ótima das rampas e curvas verticais com vistas à minimização dos custos de terraplenagem e maximização da velocidade de tráfego. Um algoritmo em três níveis é proposto para resolução do problema: no primeiro nível é realizada uma busca em vizinhança para identificação dos pontos de mudança de declividade da via; no segundo nível os intervalos das declividades dos trechos previamente definidos são calculados com base no desempenho dos veículos; e no terceiro nível a configuração da seção longitudinal é estabelecida pela resolução de um modelo de programação linear inteira.

Ainda sobre a determinação da configuração ótima da seção longitudinal de alinhamentos rodoviários, Goktepe, Lav e Altun (2009) apresentam um método que considera as propriedades do solo com o intuito de minimizar os custos de terraplenagem. Um GA é aplicado à resolução do problema, que contempla o cálculo dos volumes de corte e aterro nas seções entre estacas sucessivas do alinhamento.

Tunalioğlu e Soycan (2011) apresentam uma modelagem distinta para o problema de traçados rodoferroviários. Os autores propõem um algoritmo que estabelece as estacas sucessivas na via e ajusta o traçado a uma função polinomial sob restrições de geometria previamente estabelecidas. Apesar da redução do tempo de processamento computacional, o método não é eficiente em regiões com grandes dimensões a serem exploradas.

Huang, Chen e Dzeng (2011) apresentam um procedimento expedito para definição de traçados rodoferroviários baseado em uma ferramenta de desenho assistida por computador (Computer Aided Design - CAD) . A ferramenta computacional permite considerar os obstáculos existentes entre duas localidades e executa os cálculos dos parâmetros geométricos em tempo real, de modo que a atenção do planejador permanece nos aspectos de compatibilidade da via 
com os elementos em seu entorno e de conformidade com as restrições geométricas.

Koc e Palikowska (2001) apresentam uma abordagem alternativa para o problema de definição de traçados em terrenos com obstáculos. Os autores propõem um $G A$ para ajuste dos pontos de uma curva circular horizontal representada por uma função polinomial, em que os genes dos indivíduos do algoritmo representam os pontos adjacentes na curva e a função objetivo contempla as interações entre os trens e a via em relação às oscilações laterais dos veículos.

Na mesma tendência de aplicação de $G A$ à resolução do problema otimização de traçados, Avdagic, Smajevic e Boskovic (2008) apresentam um método cuja função aptidão dos indivíduos a ser minimizada é dada pela soma da relação entre a declividade e a distância entre estações sucessivas de um alinhamento.

Apesar da existência de diferentes abordagens para resolução do problema de otimização de traçados rodoferroviários, a aplicação de um $G A$ tem se mostrado como a mais promissora em termos de qualidade dos resultados e desempenho computacional. Nesse caso, é preponderante que a função objetivo seja adequadamente definida para que essa técnica de resolução de problemas de análise combinatória apresente resultados satisfatórios.

\subsection{Algoritmo Genético para o Problema de Definição de Traçados Ferroviários}

Um modelo de otimização de traçados ferroviários deve contemplar várias propriedades (JHA et al., 2006): considerar os itens de custos mais expressivos na função objetivo, como terraplenagem e obras de arte; respeitar as principais restrições do problema, sobretudo quanto à geometria da via; resultar em um alinhamento realista; identificar traçados em qualquer direção da região de estudo; otimizar o alinhamento sobre as projeções horizontal e vertical simultaneamente; e identificar soluções com a menor variabilidade possível.

Além disso, os autores citam propriedades como eficiência em termos de tempo de processamento, baixo armazenamento de dados, identificação de soluções em uma região factível contínua, desvio de regiões de alto custo de desapropriação, e compatibilidade com um SIG. 
A ênfase em alguns desses itens pode negligenciar a importância de outros e resultar em soluções inadequadas ao problema proposto. Apesar dos avanços no desenvolvimento dos modelos de otimização de traçados, existem ainda dificuldades práticas na obtenção de alinhamentos de mínimo custo pela análise simultânea da geometria horizontal e vertical.

Conforme descrito na seção anterior, a aplicação de heurísticas tem se consolidado como estratégia de solução para o problema, pela disponibilidade atual de equipamentos computacionais para o processamento de grande quantidade de dados.

Na sequência deste capítulo um $G A$ é descrito com base no procedimento detalhado por Jha et al. (2006), cuja implementação foi realizada para estimativa dos custos de novas infraestruturas ferroviárias como um dos objetivos desta tese.

Existem duas abordagens principais consideradas por Jha et al. (2006) para definição de um novo alinhamento: non-backtracking e backtracking (Figura 2.3). Na primeira, a progressão do alinhamento é sempre na direção do ponto de origem $(S)$ para o ponto de destino $(E)$, de modo que o traçado é interceptado por apenas um segmento de reta perpendicular à $\overline{S E}$. Na segunda abordagem esse segmento perpendicular pode interceptar o alinhamento ferroviário em mais de um ponto, resultando em maior complexidade na definição do traçado em contrapartida de um maior realismo da solução fornecida pelo $G A$.

Nesta tese foi implementado um modelo backtracking para proposta de novos alinhamentos ferroviários tridimensionais. Para isso, os pontos de alteração da orientação dos trechos em tangente (Pontos de Interseção - PIs) são definidos sob a forma de pares de coordenadas $(x, y)$ relativos a suas respectivas longitude e latitude.

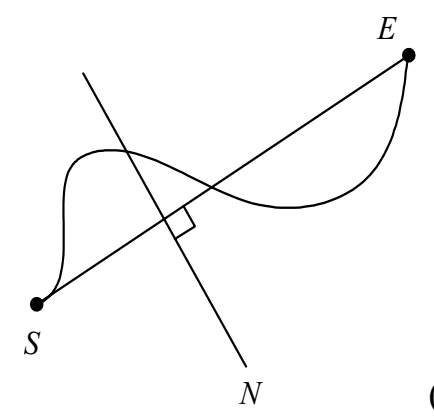

(a)

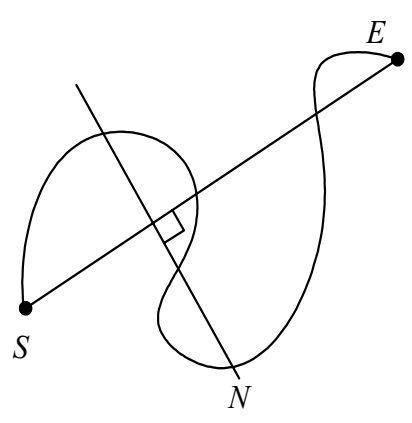

(b)

Alinhamento backtracking

Alinhamento non-backtracking

Figura 2.3 - Alinhamento non-backtracking (a) e backtracking (b) - Fonte: Jha et al. (2006) 
Seja $\left(x_{0}, y_{0}\right)$ o par de coordenadas do ponto extremo inferior esquerdo da região de estudo para possível implantação de um traçado ferroviário, e $\left(x_{\max }, y_{\max }\right)$ as coordenadas do ponto superior direito dessa região conforme ilustrado na Figura 2.4. Considere ainda um alinhamento ferroviário com $n$ PIs representados por $P\left(x_{P_{i}}, y_{P_{i}}\right)$ para o $i$-ésimo ponto, tal que $P_{0}=S$ e $P_{n+1}=E$, resultando na representação tridimensional de um traçado como da Figura 2.5.

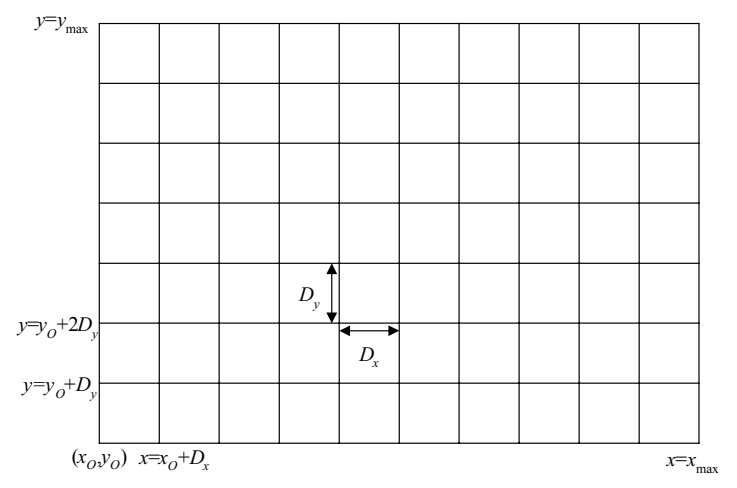

Figura 2.4 - Representação dos limites de um traçado ferroviário - Fonte: Jha et al. (2006)

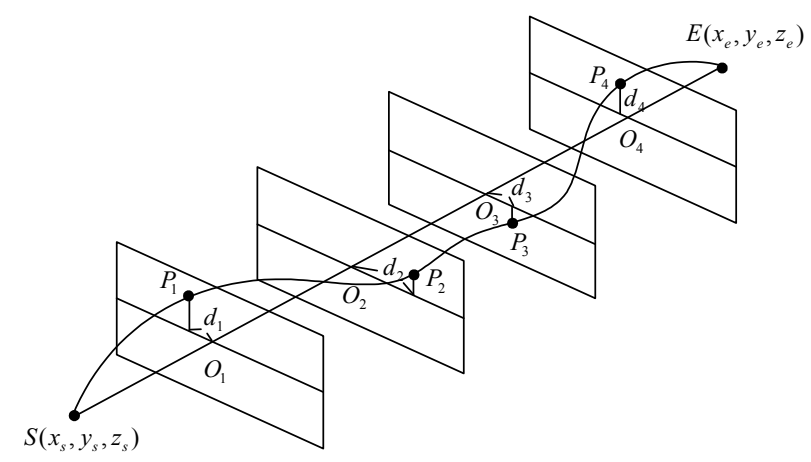

Figura 2.5 - Representação de um alinhamento tridimensional - Fonte: Jha et al. (2006)

Jha et al. (2006) formalizam um modelo matemático para o problema de otimização de traçados em que o alinhamento é caracterizado como uma função contínua diferenciável nos PIs. Nesse caso, as restrições dos raios mínimos das curvas horizontais e verticais, e declividades mínimas e máximas, são estabelecidas como relações entre essas derivadas nesses pontos.

Entretanto, existem dificuldades na definição de um traçado apropriado sob essa perspectiva, sobretudo pela representação adequada do relevo como uma superfície contínua e sua compatibilização com a função representativa do traçado. Assim, a resolução desse problema pelos métodos mencionados no início deste capítulo, como alternativas à modelagem mate- 
mática, considera a função objetivo da Equação (2.1) e restrições entre a Equação (2.2) e a Equação (2.5) com vistas à minimização do custo total de construção da via.

$$
\text { Minimizar } C C=T R C+L U C+E W C+T B C
$$

sujeito a

$$
\begin{gathered}
x_{0} \leq x_{P_{i}} \leq x_{\max } \quad \forall \quad i=1, \cdots, n \\
y_{0} \leq y_{P_{i}} \leq y_{\max } \quad \forall \quad i=1, \cdots, n \\
L_{v_{i}} \geq L_{m_{i}} \quad \forall \quad i=1, \cdots, n \\
\left|g_{i}\right| \leq G_{\max } \quad \forall \quad i=0, \cdots, n
\end{gathered}
$$

onde $C C=$ custo total de construção de um traçado ; TRC = custo da superestrutura (trilhos, dormentes etc.) ; $L U C=$ custo de desapropriações ; $E W C=$ custo de terraplenagem ; $T B C=$ custo para implantação de túneis e viadutos ; $L_{v_{i}}=$ comprimento da curva vertical no $i$-ésimo ponto de interseção vertical (PV); $L_{m_{i}}=$ comprimento mínimo da curva vertical no $i$-ésimo PV; $\left|g_{i}\right|=\left|z_{r}(i)-z_{r}(i+1)\right|=$ declividade da via entre o $i$-ésimo e $(i+1)$-ésimo PV; $G_{\text {max }}=$ declividade máxima estabelecida para a via.

Nas restrições, o domínio das variáveis está condicionado à delimitação da área de estudo, aos limites de declividade da via (definidos a priori como dados de entrada do modelo) e aos comprimentos mínimos das curvas verticais.

As etapas do $G A$ são representadas no pseudocódigo a seguir com base nos procedimentos descritos em Jha et al. (2006). Na sequência desta seção os passos do GA são apresentados sumariamente, sem o detalhamento da formulação matemática e algoritmos auxiliares.

Inicialmente as coordenadas dos pontos inicial $(S)$ e final $(E)$ do alinhamento são definidos e os valores indicados no Apêndice A são atribuídos aos respectivos parâmetros do método de solução, incluindo o número de indivíduos $n_{p}$ (equivalente ao número de alternativas de traçados avaliados), o número de gerações $N$ (iterações) que define o critério de parada do $G A$, e os valores unitários para estimativa da função aptidão dos indivíduos da população. 
Na sequência, o algoritmo procede à inicialização dos indivíduos, ou seja, à criação dos vetores que definem os traçados. Nesse processo, as coordenadas dos PIs de cada indivíduo são definidas aleatoriamente entre as cinco possibilidades descritas a seguir.

\section{Inicialização de parâmetros \\ Criação de indivíduos \\ Escolha das coordenadas dos PIs no alinhamento horizontal \\ Para cada indivíduo executar a $S U B$-ROTINA \\ Verificar adequação do traçado (eliminação de curvas circulares horizontais) \\ Definir os raios das curvas circulares horizontais \\ Definir os atributos das curvas circulares horizontais \\ Definir a posição e altitude dos Pontos de Interseção Verticais (PVs) \\ Calcular o comprimento das curvas parabólicas verticais \\ Definir os atributos das curvas parabólicas verticais \\ Caracterizar os pontos em estações sucessivas \\ Calcular o custo total do alinhamento (aptidão do indivíduo) \\ Ordenar a população em função da aptidão \\ Identificar indivíduo de menor valor de aptidão \\ Calcular a probabilidade acumulada de alteração e exclusão de um indivíduo Enquanto NÚMERO DE GERAÇÕES $\neq \mathbf{N}$}

Calcular o número de operadores de cruzamento e mutação $\left(N_{\text {operadores }}\right)$

Escolher aleatoriamente os operadores a serem executados $(1 \leq O P E R A D O R \leq 8)$

Se $1 \leq O P E R A D O R \leq 4$

Executar operador de CRUZAMENTO

Executar SUB-ROTINA

Se $5 \leq O P E R A D O R \leq 8$ então MUTAÇÃO

Executar Operador de MUTAÇÃO

Executar SUB-ROTINA

Ordenar população em função do custo total do alinhamento (aptidão)

Identificar indivíduo com menor valor de aptidão

Verificar se a menor aptidão é do mesmo indivíduo da iteração anterior

Se o indivíduo de menor aptidão permanece inalterado então $\mathrm{N}=\mathrm{N}+1$

Se o indivíduo de menor aptidão é alterado então $\mathrm{N}=0$

\section{Fim Enquanto}

Impressão de resultados (traçado de menor custo, tempo de processamento, atributos do traçado de mínimo custo e arquivo vetorial georreferenciado)

1. Pontos de Interseção Equidistantes no Alinhamento $\overline{S E}$ : as coordenadas $\left(x_{i}, y_{i}\right)$ são estabelecidas nas interseções de planos verticais equidistantes na reta $\overline{S E}$, conforme ilustrado na Figura 2.6. As coordenadas verticais $\left(z_{n}\right)$ desses pontos são definidas nessa mesma proporção em relação à diferença de altitude entre os pontos $S\left(z_{S}\right)$ e $E\left(z_{E}\right)$. 


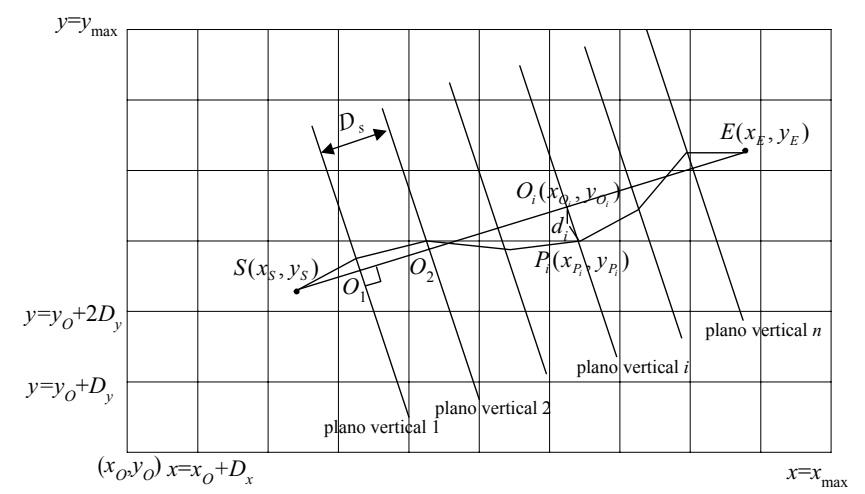

Figura 2.6 - Representação dos planos perpendiculares ao alinhamento entre a origem e o destino de um traçado - Fonte: Jha et al. (2006)

2. Pontos de Interseção sobre os Planos Perpendiculares Equidistantes no Alinhamento $\overline{S E}$ e Elevações Definidas Aleatoriamente: as coordenadas $\left(x_{n}, y_{n}\right)$ são estabelecidas aleatoriamente sobre os planos de corte verticais equidistantes na reta $\overline{S E}$, e as coordenadas verticais $\left(z_{n}\right)$ são definidas aleatoriamente em um intervalo restrito às declividades máxima e mínima preestabelecidas.

3. Pontos de Interseção sobre os Planos Perpendiculares Equidistantes no Alinhamento $\overline{S E}$ e Elevações Definidas Próximas do Perfil do Terreno: as coordenadas $\left(x_{n}, y_{n}\right)$ são estabelecidas aleatoriamente sobre os planos de corte verticais equidistantes na reta $\overline{S E}$, e as respectivas coordenadas verticais $\left(z_{n}\right)$ são definidas como as mais próximas do perfil do terreno com base em um arquivo raster de elevação.

4. Pontos de Interseção Escolhidos Aleatoriamente sobre a Região de Estudo e Elevações Escolhidas Aleatoriamente: as coordenadas $\left(x_{n}, y_{n}\right)$ são escolhidas aleatoriamente no intervalo da região factível de estudo do traçado, delimitado pelas coordenadas $\left(x_{0}, y_{0}\right)$ e $\left(x_{\max }, y_{\max }\right)$. As coordenadas verticais $\left(z_{n}\right)$ desses pontos são definidas aleatoriamente em um intervalo restrito às declividades máxima e mínima preestabelecidas.

5. Pontos de Interseção Escolhidos Aleatoriamente sobre a Região de Estudo e Elevações Definidas Próximas do Perfil do Terreno: as coordenadas $\left(x_{n}, y_{n}\right)$ são escolhidas aleatoriamente no intervalo da região factível de estudo do traçado, e as respectivas coordenadas verticais $\left(z_{n}\right)$ são estabelecidas como as mais próximas do perfil do terreno com base em um arquivo raster de elevação. 
Após a atribuição de valores às coordenadas dos PIs, o algoritmo executa uma SUB-ROTINA de caracterização de cada traçado com base nesses valores. O primeiro procedimento é a verificação do excesso de curvas circulares horizontais em um traçado conforme exemplificado na Figura 2.7. Para solucionar esse eventual problema, uma correção é executada de modo que curvas circulares são transformadas em tangentes pela reconfiguração da posição dos PIs.

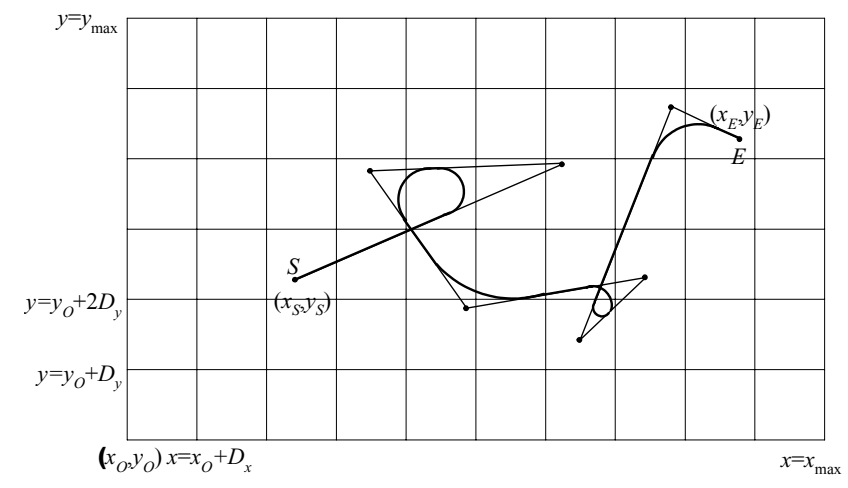

Figura 2.7 - Traçado com excessivas curvas circulares - Fonte: Jha et al. (2006)

Em seguida, procede-se à definição dos raios das curvas circulares horizontais mediante um valor de raio mínimo limitado pela tecnologia ferroviária que deve ser operada na infraestrutura, sob a restrição de que os comprimentos das seções em tangente entre curvas sucessivas seja sempre maior ou igual a zero para evitar a sobreposição de curvas (ou descontinuidade do traçado) como na Figura 2.8.

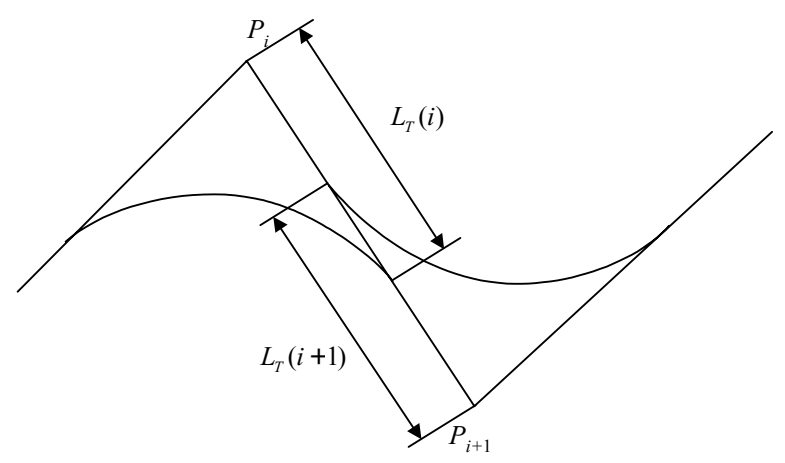

Figura 2.8 - Exemplo de descontinuidade entre curvas circulares horizontais sucessivas Fonte: Jha et al. (2006)

No próximo passo da SUB-ROTINA, o GA calcula os atributos indicados na Figura 2.9 para cada curva circular horizontal, sendo excluídas as transições entre tangentes e curvas circulares, 
uma vez que esse nível de detalhamento não condiz com a proposta de estimativa dos custos no nível de anteprojeto como considerado nesta tese.

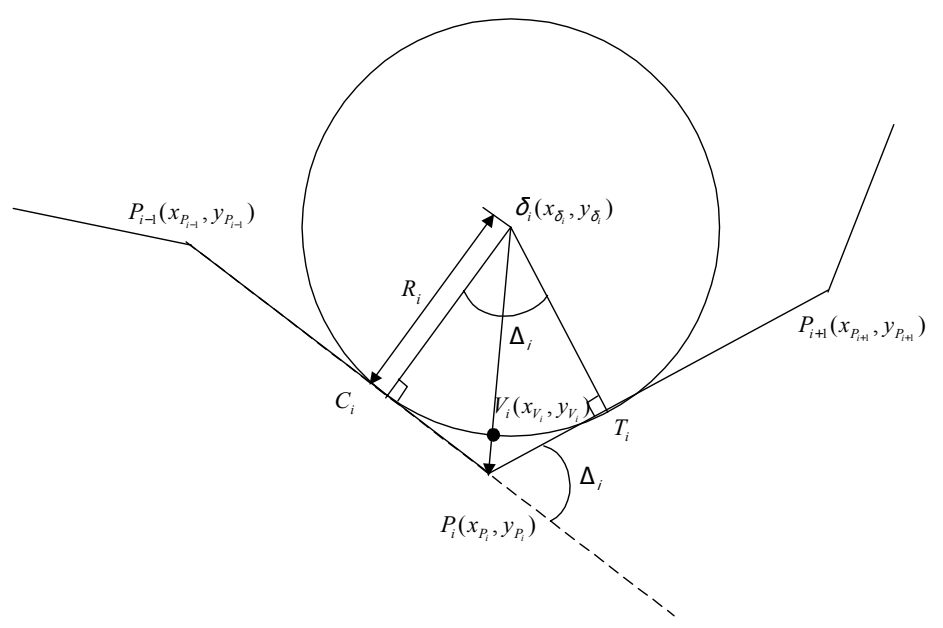

Figura 2.9 - Elementos das curvas circulares horizontais do traçado - Fonte: Jha et al. (2006)

Ainda na SUB-ROTINA, as posições dos pontos de interseção das curvas verticais (PVs) são definidas onde há alteração da declividade na seção longitudinal da ferrovia (Figura 2.10).

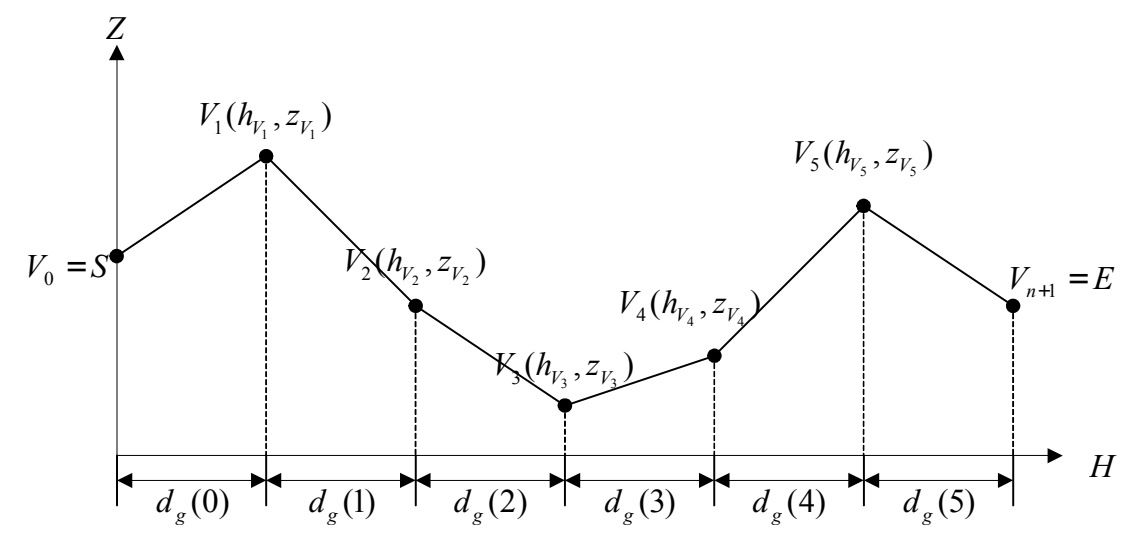

Figura 2.10 - Sucessão de PVs na seção longitudinal - Fonte: Jha et al. (2006)

É importante ressaltar que o número de PVs (e, portanto, o número de curvas verticais) é equivalente ao de PIs definidos a priori, de modo que a posição daqueles coincide com a desses (Figura 2.11). Assim, existem três possibilidades de elementos geométricos na posição de um ponto de interseção:i) uma curva circular horizontal $\left(R_{\min } \leq R_{i}<\infty\right)$ e uma curva vertical $\left(z_{v_{i}-1} \neq z_{v_{i}} \neq z_{v_{i}+1}\right)$, perfazendo uma seção de curva mista; ii) uma curva horizontal 
$\left(R_{\min } \leq R_{i}<\infty\right)$ em trecho plano, em aclive ou declive $\left(z_{v_{i}-1}=z_{v_{i}}=z_{v_{i}+1}\right)$; iii) e um trecho tangente $\left(R_{i} \approx \infty\right)$ em uma curva vertical $\left(z_{v_{i}-1} \neq z_{v_{i}} \neq z_{v_{i}+1}\right)$.

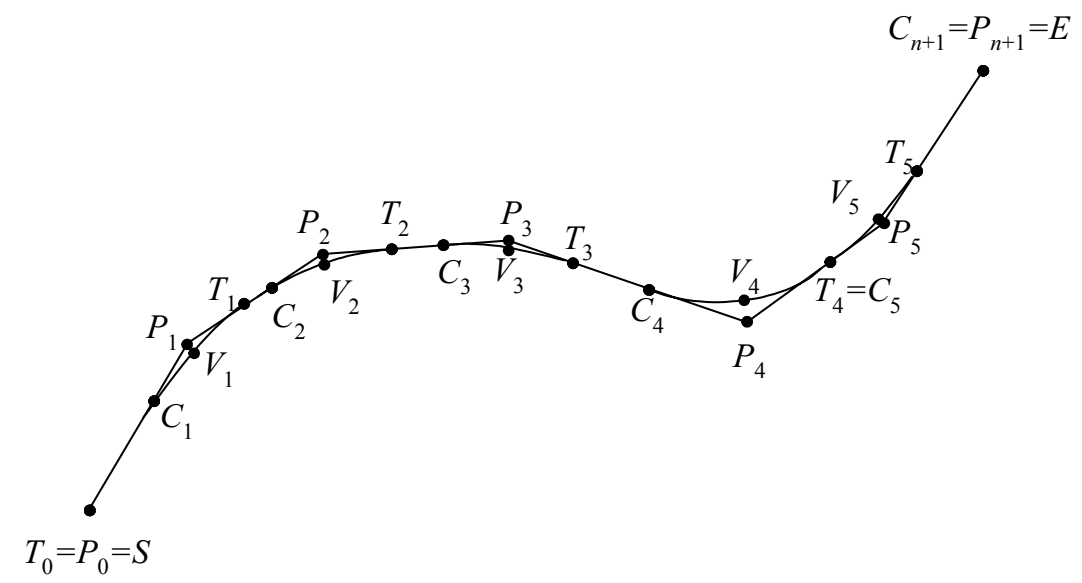

Figura 2.11 - Exemplo de coincidência dos PIs na projeção horizontal $(P)$ e da seção longitudinal $(V)$ em um alinhamento - Fonte: Jha et al. (2006)

A partir da definição das altitudes dos PIs $\left(z_{n}\right)$ segundo uma das cinco regras apresentadas anteriormente (ou após a execução de um operador de mutação ou cruzamento), a altitude ( $h_{V_{n}}$ ) nos pontos de interseção das curvas parabólicas verticais (PVs) é estabelecida com base em um algoritmo auxiliar para verificação da eventual violação de restrições de declividade.

Uma vez definidas as altitudes desses pontos de interseção verticais, as declividades da ferrovia são calculadas nas seções entre curvas parabólicas sucessivas. A partir disso, os comprimentos dessas curvas $\left(L_{v}\right)$ são calculados de modo a evitar a descontinuidade dos traçados em relação à seção longitudinal conforme ilustrado na Figura 2.12.

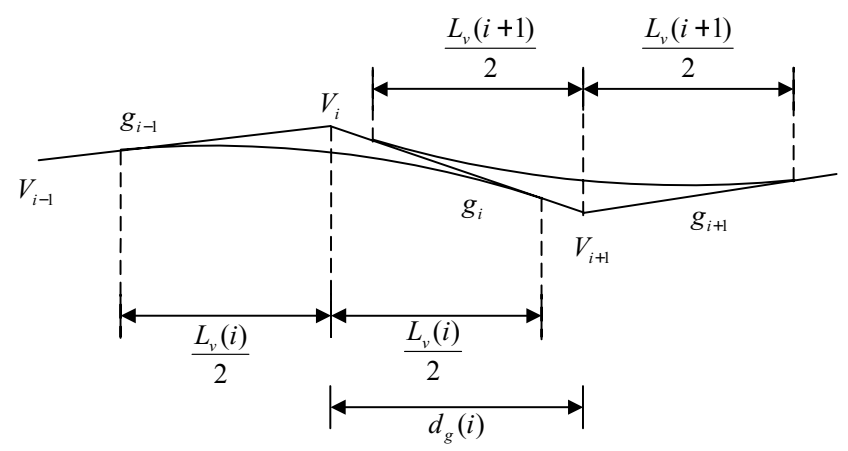

Figura 2.12 - Sucessão de pontos de interseção verticais e exemplo de descontinuidade na seção longitudinal - Fonte: Jha et al. (2006) 
No caso da definição de alinhamentos rodoviários, Jha et al. (2006) tratam do comprimento mínimo de curvas verticais mediante restrições de visibilidade. Entretanto, na SUB-ROTINA do GA para alinhamentos ferroviários essa restrição é desconsiderada devido às características operacionais do modo de transporte.

Após caracterização dos pontos de interseção das curvas horizontais e verticais, e os pontos de transição entre as seções em tangente e essas curvas $\left(C_{i}\right.$ e $T_{i}$ na Figura 2.13, e $C_{i}^{V}$ e $T_{i}^{V}$ na Figura 2.14), o próximo passo da SUB-ROTINA é executar o estaqueamento de cada traçado, ou seja, identificar a posição e altitude de estacas separadas por uma distância preestabelecida.

A Figura 2.13 (esq.) representa graficamente a posição de uma estação $\left(S_{i}\right)$ em um trecho em tangente e a Figura 2.13 (dir.) ilustra esse ponto em uma curva circular da projeção horizontal. Analogamente, a estação é representada na seção longitudinal à esquerda da Figura 2.14 em um trecho em tangente e à direita em uma curva vertical parabólica.
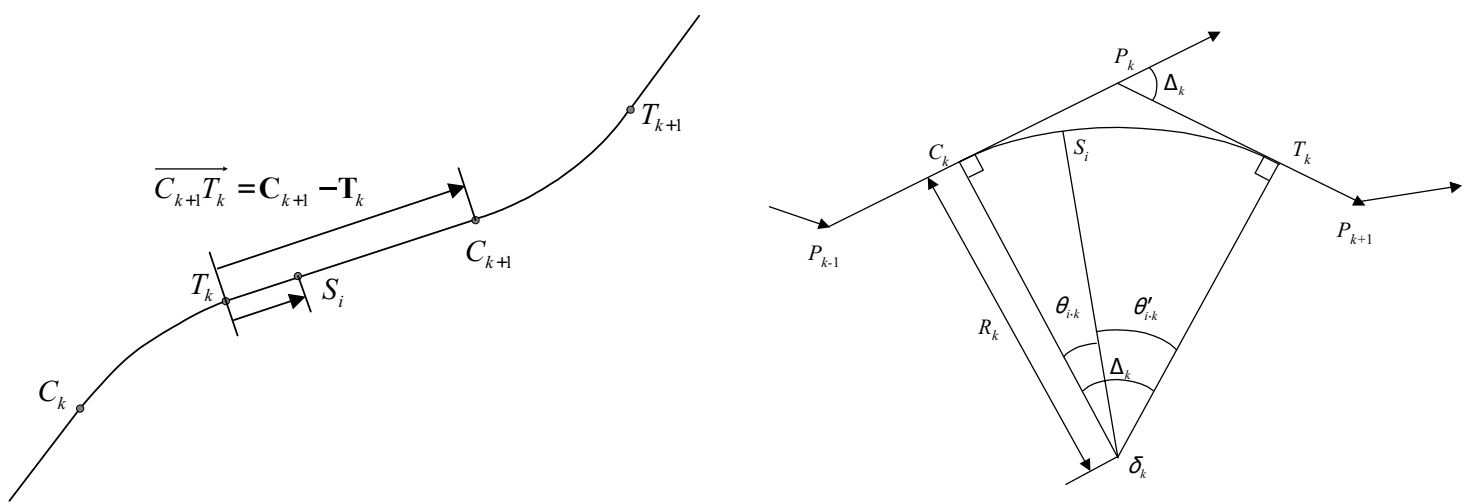

Figura 2.13 - Definição de estações na projeção horizontal da ferrovia - Fonte: Jha et al. (2006)
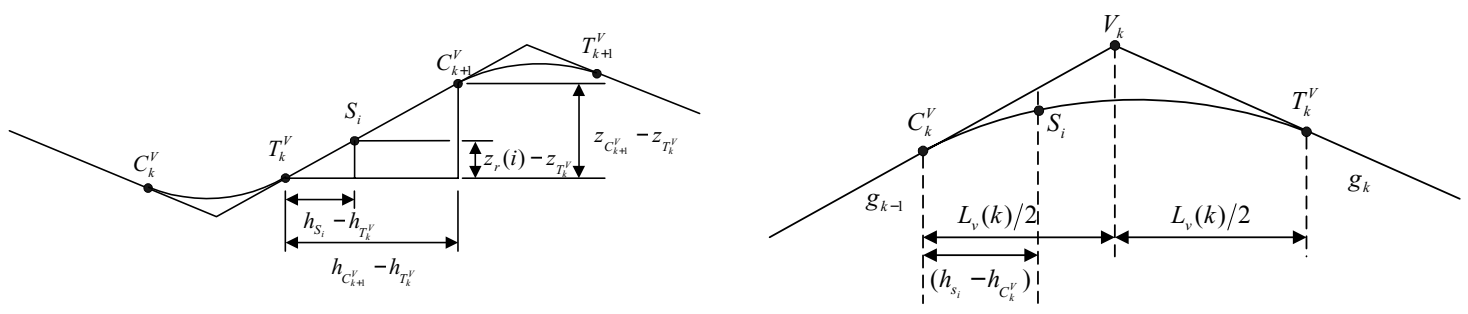

Figura 2.14 - Definição de estações na seção longitudinal da ferrovia - Fonte: Jha et al. (2006)

A distância entre estacas $\left(S_{i}\right)$ é definida em função das dimensões do pixel dos aquivos rasters de configuração do terreno (Figura 2.15, esq.) disponibilizados pela U.S. Geological Survey (USGS, 2014) através da interface online EarthExplorer (USGS, 2014). Esses arquivos contêm 
valores numéricos sobre a topografia do Brasil com pixels representados por quadrículas de 90 metros (i.e. $D_{x}=D_{y}=90$ metros na Figura 2.4).

Para estimativa de custos de desapropriação foram obtidos arquivos do tipo raster de uso e cobertura do solo providos pelo Instituto Brasileiro de Geografia e Estatística (IBGE, 2014a), cuja classificação foi generalizada para áreas urbanas e rurais (Figura 2.15, dir.).
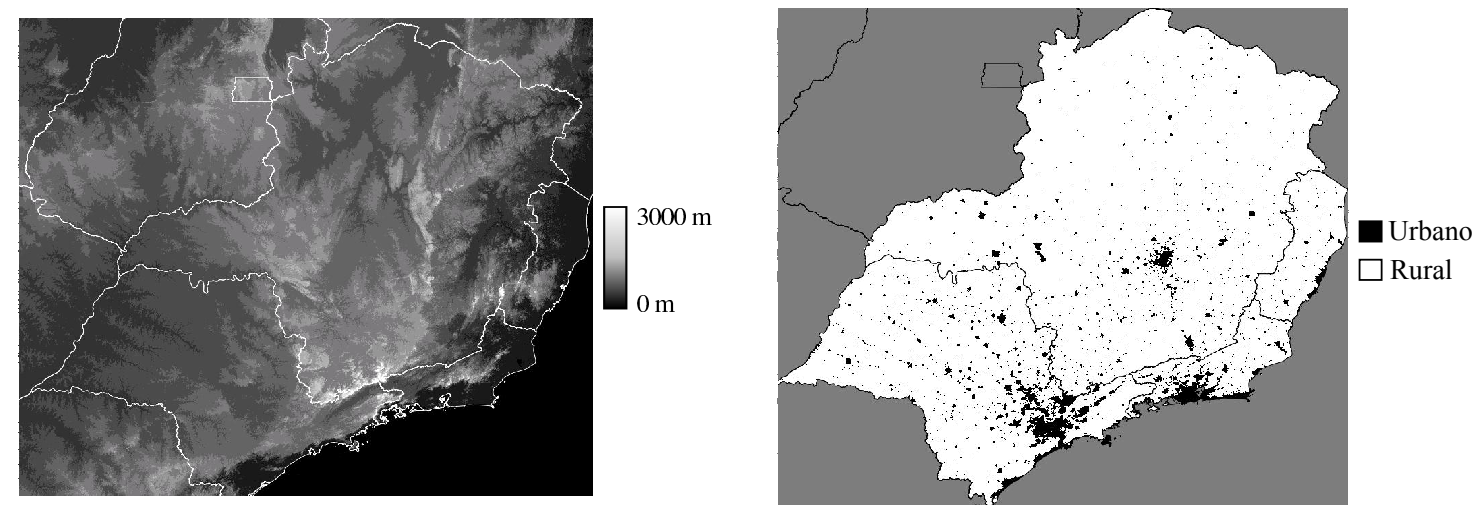

Figura 2.15 - Rasters de elevação do terreno (NASA, 2014) e de uso do solo (IBGE, 2014a) da Região Sudeste do Brasil

Uma vez que os rasters são georreferenciados, a elevação do terreno na posição das estacas e o uso do solo em que estão localizadas são facilmente identificados e convertidos em valores numéricos para cálculo da função aptidão dos indivíduos da população do $G A$.

Nesse sentido, o primeiro item de custo da Equação 2.1 (TRC) diz respeito ao custo total para implantação dos elementos lineares da via (trilhos, dormentes, eletrificação quando existente etc.), que é calculado com base no comprimento total do alinhamento (considerando os trechos sucessivos em tangente e curvas circulares horizontais) e um custo médio por quilômetro indicado no Apêndice A.

O segundo item $(L U C)$ está associado aos valores de desapropriações na faixa de domínio da via a ser implantada. Para isso, define-se a priori uma distância entre o eixo da ferrovia e as bordas limítrofes da faixa de domínio e calcula-se a área de desapropriação (Figura 2.16), multiplicando esse valor por um custo médio (Apêndice A) em função do tipo de uso do solo.

O terceiro item equivale à estimativa dos valores econômicos de terraplenagem $(E W C)$. Para isso, após a obtenção das elevações nas estações do traçado com base no perfil longitudinal do terreno e da ferrovia, procede-se ao cálculo das áreas de corte e aterro nas seções transversais e 


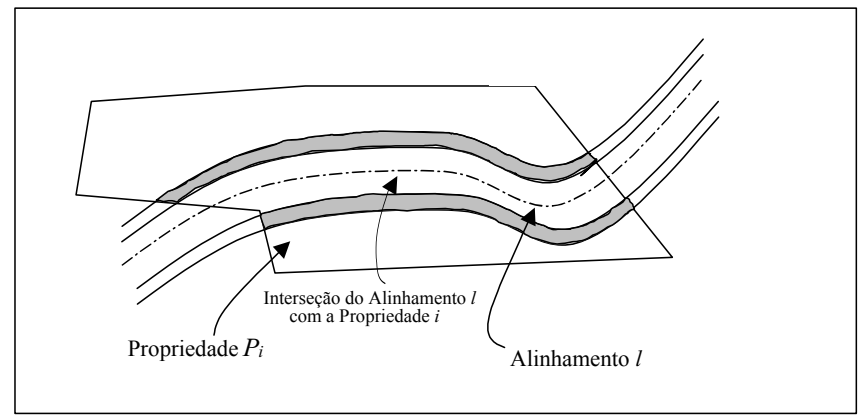

Figura 2.16 - Exemplo de avaliação de uso do solo - Fonte: Jha et al. (2006)

do volume de movimentação de terra entre estações sucessivas do alinhamento.

A Figura 2.17 (a) representa as seções transversais finais pretendidas para a ferrovia nos casos de corte e aterro, enquanto a Figura $2.17(b)$ representa a seção longitudinal entre duas estações genéricas para o cálculo das áreas de bota-fora (corte) e empréstimo (aterro) em função das altitudes do terreno e da ferrovia obtidas nos procedimentos descritos anteriormente.

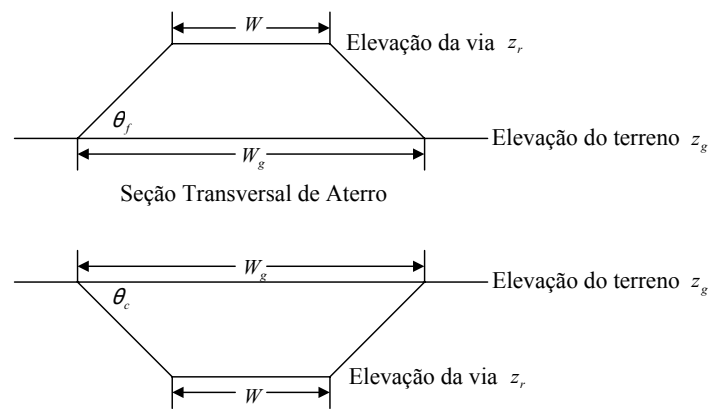

Seção Transversal de Corte

(a) Seções de corte e aterro

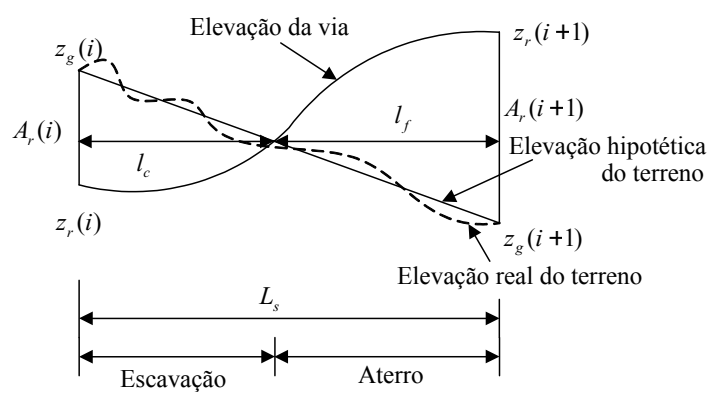

(b) Áreas de bota-fora e empréstimo

Figura 2.17 - Seções transversais de corte e aterro $(a)$ e exemplo de seção transversal com áreas de bota-fora e empréstimo $(b)$ - Fonte: Jha et al. (2006)

Finalmente, o quarto item da função aptidão dos indivíduos do $G A$ é a estimativa dos valores monetários de implantação de túneis, pontes e viadutos ao longo da via (TBUC). Essas estruturas são consideradas nas seções em que a execução de terraplenagem é proibitiva por motivos técnicos (e.g. alturas máximas de talude).

Uma ponte ou viaduto é definido quando a diferença entre a elevação do terreno e de uma estação do alinhamento é negativa e o valor absoluto desse cálculo é maior que um limite caracterizado no Apêndice A. Nesse caso, o custo de movimentação de terra é substituído pelo custo total de construção da estrutura, dado pela multiplicação da extensão do trecho, a largura da sua plataforma e um custo médio de construção por metro quadrado indicado naquele apêndice. 
Por outro lado, um túnel é estabelecido quando a diferença entre as altitudes é positiva e maior do que um valor limite para taludes de corte em termos construtivos. Nesse caso, o custo de terraplenagem é substituído por um custo de implantação de túneis, dado pela multiplicação da área da seção transversal padrão pelo seu comprimento, e um custo unitário (em $\mathrm{R} \$ / \mathrm{km}) \mathrm{ne}$ construção dessa infraestrutura conforme definido no Apêndice A.

Ao finalizar a SUB-ROTINA de caracterização dos traçados, o algoritmo principal é retomado, os indivíduos são ordenados em ordem crescente dos custos totais calculados (aptidão) e prossegue-se às iterações de cruzamento e mutação para identificação de alternativas de configurações dos PIs e PVs (e seus respectivos atributos) que resultem em menores custos.

Para isso, primeiramente calcula-se a probabilidade acumulada de participação de um indivíduo em um dos operadores de cruzamento e/ou mutação em função do valor de sua aptidão segundo a Equação 2.6.

$$
p_{k}=\frac{q \cdot(1-q)^{k-1}}{1-(1-q)^{n_{p}}}
$$

em que $p_{k}=$ probabilidade de escolha do $k$-ésimo indivíduo da lista ordenada em função da aptidão; $n_{p}=$ tamanho da população; e $q$ = parâmetro de troca definido pelo usuário, $q \in(0,1)$.

O coeficiente $q$ pode ser interpretado como um indicador do nível de seleção dos indivíduos pois valores elevados desse parâmetro resultam em menor variabilidade da população (i.e. uma menor quantidade de indivíduos tem maior probabilidade de seleção) enquanto valores pequenos resultam em maior exploração da região factível de solução do problema sob penalidade de maior tempo de processamento computacional.

Considerando a Equação 2.6, a probabilidade de escolha de indivíduos para aplicação dos operadores é maior para aqueles que encontram-se no topo da lista ordenada em relação à aptidão, ou seja, os traçados de menor valor de custo.

Definido o vetor de probabilidades de seleção dos indivíduos em função do tamanho da população e do parâmetro $q$ (Apêndice A), procede-se à definição do número de operadores de cruzamento ou mutação $\left(N_{\text {operadores }}\right)$ a serem executados na geração corrente do $G A$. A recomendação de Jha et al. (2006) é que sejam executadas alterações entre $30 \%$ e $50 \%$ dos indivíduos da população (i.e. $0,3 \cdot n_{p} \leq N_{\text {operadores }} \leq 0,5 \cdot n_{p}$ ). 
Assim, os operadores de cruzamento ou mutação são escolhidos aleatoriamente com distribuição de probabilidade uniforme, os quais são definidos em oito tipos distintos (quatro para os de cruzamento e quatro para os de mutação) conforme descritos na sequência. Se a escolha aleatória resultar em um número inteiro entre um e quatro, então o operador executado é de cruzamento. Se não, se o valor sorteado for entre cinco e oito, uma mutação é executada.

1. UNIFORM MUTATION: substituição do PI de um traçado selecionado por outro cujas coordenadas são escolhidas aleatoriamente na região de estudo (Figura 2.18,a);

2. STRAIGHT MUTATION: escolha aleatória de dois PIs de um indivíduo existente e definição de uma seção em tangente entre eles (Figura 2.18, $b$ );

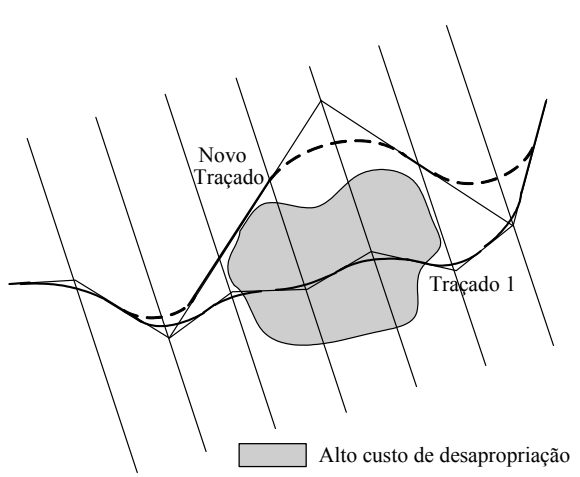

(a) UNIFORM MUTATION

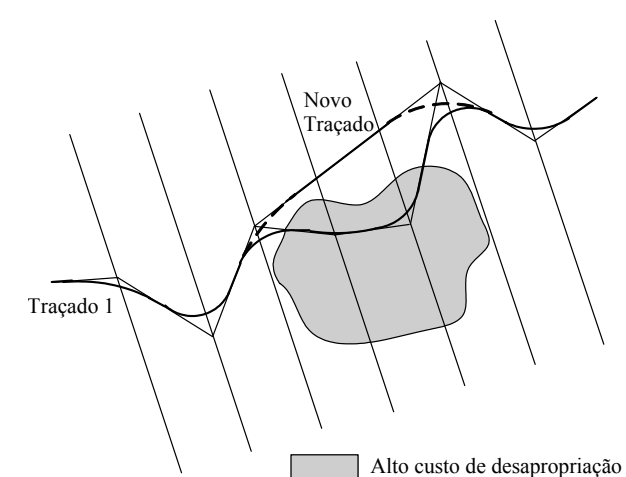

(b) STRAIGHT MUTATION

Figura 2.18 - Exemplos de operadores de mutação - Fonte: Jha et al. (2006)

3. NON-UNIFORM MUTATION: escolha aleatória de um PI e definição de uma nova coordenada segundo uma função parametrizada pela geração corrente do $G A$ (página 103 de JHA et al., 2006);

4. WHOLE NON-UNIFORM MUTATION: análogo ao NON-UNIFORM MUTATION porém com alteração das coordenadas de todos os PIs de um indivíduo selecionado aleatoriamente.

5. SIMPLE CROSSOVER: dois indivíduos (traçados) são escolhidos aleatoriamente na população e o gene (ponto de interseção) de um deles é trocado com o gene do outro, resultando em dois novos traçados conforme representado na Figura 2.19 (a); 
6. TWO-POINT CROSSOVER: análogo ao SIMPLE CROSSOVER, diferindo apenas pela troca de pares de genes entre indivíduos (Figura 2.19, b);

7. ARITHMETIC CROSSOVER: um terceiro traçado resulta da interpolação entre dois indivíduos escolhidos aleatoriamente, através de uma ponderação conforme ilustrado na Figura $2.19(c)$;

8. HEURISTIC CROSSOVER: um terceiro indivíduo resulta da extrapolação aleatória de dois traçados (Figura 2.19, d);

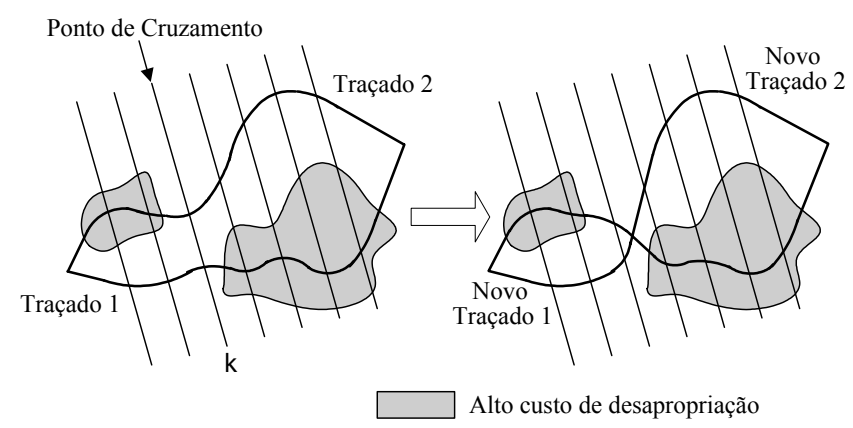

(a) SIMPLE CROSSOVER

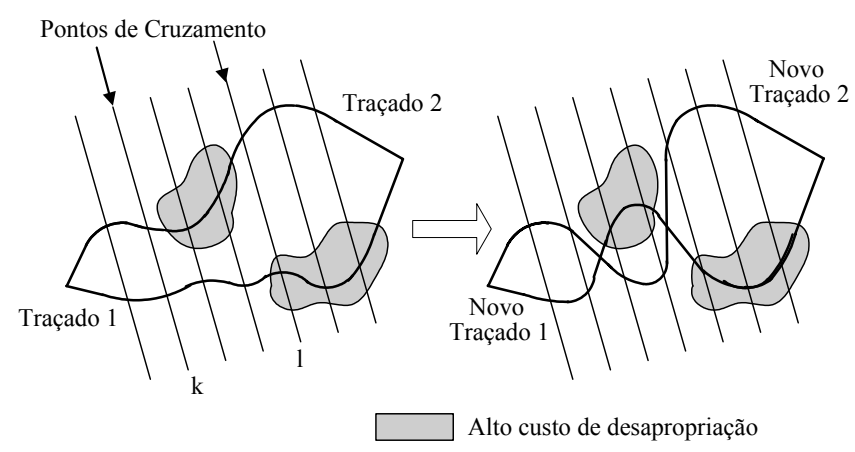

(b) TWO-POINT CROSSOVER

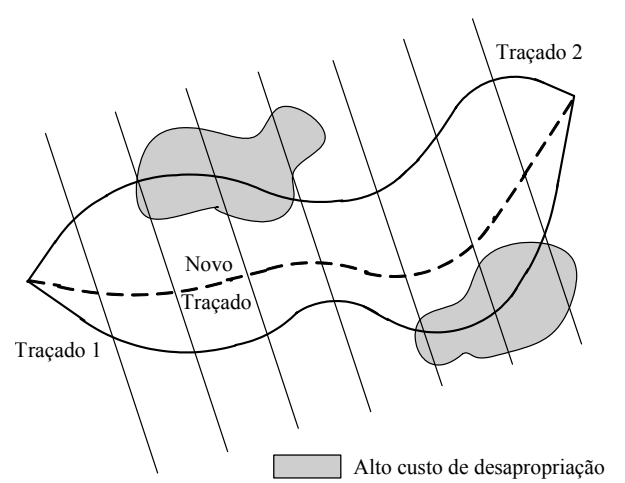

(c) ARITHMETIC CROSSOVER

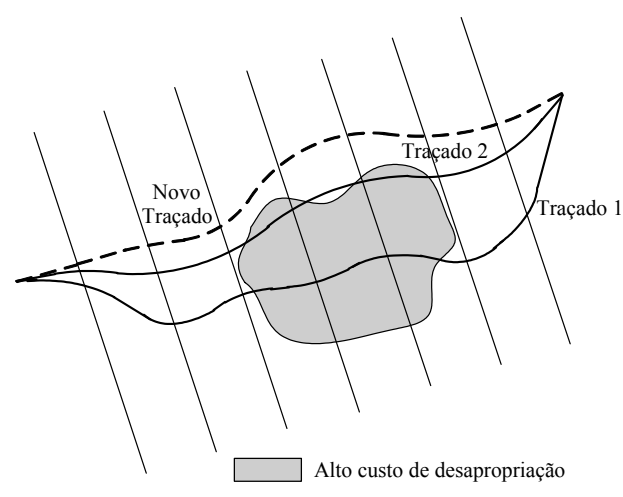

(d) HEURISTIC CROSSOVER

Figura 2.19 - Exemplos de operadores de cruzamento - Fonte: Jha et al. (2006) 
Para cada operador de cruzamento ou mutação executado, os novos indivíduos produzidos são submetidos à SUB-ROTINA idêntica à caracterização da população inicial. Ao final desse processo em cada geração do $G A$, a Equação 2.6 é utilizada para cálculo da probabilidade de exclusão de um indivíduo considerando-se a ordenação da lista de traçados em ordem decrescente do valor das respectivas funções aptidão.

Os indivíduos escolhidos são substituídos pelos novos traçados resultantes dos operadores, mesmo que os valores da aptidão daqueles sejam menores que dos indivíduos antigos. Essa regra pode eventualmente incorrer na exclusão de traçados de boa qualidade, porém foi estabelecida para promover a variabilidade da população em detrimento da manutenção de indivíduos de melhor qualidade por um número excessivo de gerações, sob o risco de estagnação do $G A$ em soluções ótimas locais.

Após ordenação da nova população, o indivíduo de menor valor de custo total é identificado e selecionado como aquele que reproduz o melhor traçado entre a origem e o destino definidos. Em seguida, um critério de parada preestabelecido é verificado e, caso não seja satisfeito, uma nova iteração de operadores é executada.

Por outro lado, caso o critério de parada seja satisfeito, o $G A$ é encerrado e os resultados de custo total, características do traçado escolhido e os tempos de processamento são impressos em arquivo de texto, seguido da criação de um arquivo vetorial georreferenciado do tipo shapefile (extensão ".shp").

Apesar de os modelos descritos neste capítulo serem ferramentas úteis para resolução do problema de otimização de traçados, na literatura encontrada a aplicação do $G A$ restringe-se à exploração de áreas com pequena extensão quando consideradas as características topográficas e ocupação do solo. Isso decorre do fato de que a resolução desses problemas envolve o processamento de grande quantidade de dados e acesso recorrente aos arquivos que contém informações sobre as características do terreno durante a execução do algoritmo.

Uma alternativa para contornar a questão é a aplicação da abordagem de programação paralela, que consiste na atribuição de tarefas a múltiplas máquinas simultaneamente e viabiliza a redução dos tempos de processamento computacional. A literatura mostra que o tema tem sido 
abordado em pesquisas para resolução de problemas de otimização combinatória, implementados sob diferentes heurísticas e meta-heurísticas como Variable Neighborhood Search e Bee Colony Algorithm (GUPTA; DEEP, 2009 e CRAINIC; DAVIDOVIĆ; RAMLJAK, 2012).

No âmbito da estimativa de custos de traçados rodoviários, algumas publicações fazem referência à aplicação de computação paralela demonstrando a sua eficiência na resolução do problema (CHEN; GUO; LV, 2011 e KAZEMI; SHAFAHI, 2013) , não tendo sido identificada nenhuma pesquisa anterior sobre a implementação de $G A$ à modelos de alinhamentos ferroviários como descrito nas seções subsequentes deste capítulo.

\subsection{Algoritmo Genético e Programação Paralela}

Existem três fatores que justificam a implementação do $G A$ utilizando a abordagem de programação paralela. Primeiramente, há uma grande quantidade de dados a serem processados a cada geração (iteração) do algoritmo durante a execução dos operadores de cruzamento e mutação. Em segundo lugar, os arquivos rasters que caracterizam a topografia do terreno e o uso do solo são consultados recorrentemente nesses iterações, requerendo vasta capacidade de acesso à memória de um computador. Finalmente, o armazenamento de dados sobre os atributos dos traçados exigem uma ampla disponibilidade de memória computacional.

A utilização de computação paralela é definida por duas interfaces: uma infraestrutura computacional física constituída de equipamentos conectados entre si, ou máquinas virtuais (Virtual Machines - VMs) hospedadas em processadores acessados remotamente; e uma plataforma (framework) ou software que permite a comunicação entre essas máquinas em uma rede.

O armazenamento e processamento de dados pode ser através de um conglomerado de computadores de alto desempenho (data warehouse) interligados em uma rede acessada pela Internet. A oferta recente de serviços com base nessa infraestrutura configura o termo "Computação em Nuvem"(Cloud Computing), cuja troca de informações entre servidores e clientes é permitida a qualquer usuário, em geral, mediante pagamento de tarifas. Uma revisão de literatura extensa sobre o tema, com referências relevantes, pode ser encontrada em Hashem et al. (2015).

Atualmente, existem três modelos de serviços mais comuns: Plataforma como um Serviço 
(PaaS - Platform as a Service), que disponibiliza uma plataforma com recursos para usuários, como um banco de dados ou web service (por exemplo, Jelastic, Google's Apps Engine, Salesforce.com, Force Platform e Microsoft Azure); Software como Serviço (SaaS - Software as a Service), que oferece acesso através da Internet a aplicativos hospedados na nuvem (e.g. Google Docs, Microsoft Share Point Online, Gmail, Salesforce.com e Online Payroll); e Infraestrutura como um Serviço (IaaS - Infrastructure as a Service), que disponibiliza processamento remoto de dados sob demanda dos usuários como Yahoo.com, Flexiscale e Amazon's EC2.

Nesta tese utilizou-se serviços do tipo IaaS para execução do GA. Como exemplificado, existem diferentes provedores que permitem o acesso a máquinas virtuais para processamento de dados e, nessa tendência, a Universidade de São Paulo implantou recentemente uma infraestrutura que disponibiliza vastos recursos computacionais para seus membros ou para usuários externos mediante pagamento pelo uso horário (NUVEMUSP, 2013).

O ambiente em nuvem da Universidade de São Paulo é acessado através de um website pelas credenciais fornecidas aos usuários (Figura 2.20,a). As máquinas virtuais criadas são apresentadas em uma lista (Figura 2.20, b), identificadas por seus respectivos IPs (Internet Protocols) internos à rede. Essas máquinas são acessadas através de um $I P$ estático público que viabiliza a transferência de dados entre usuário e máquinas virtuais.

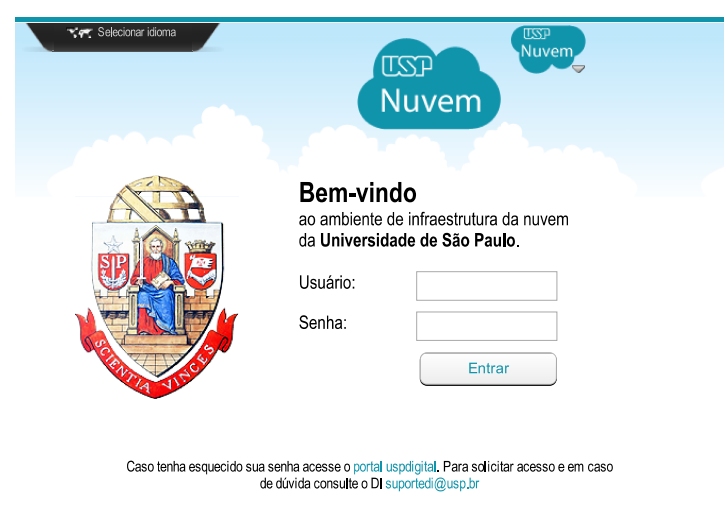

(a) Página de acesso à Nuvem USP

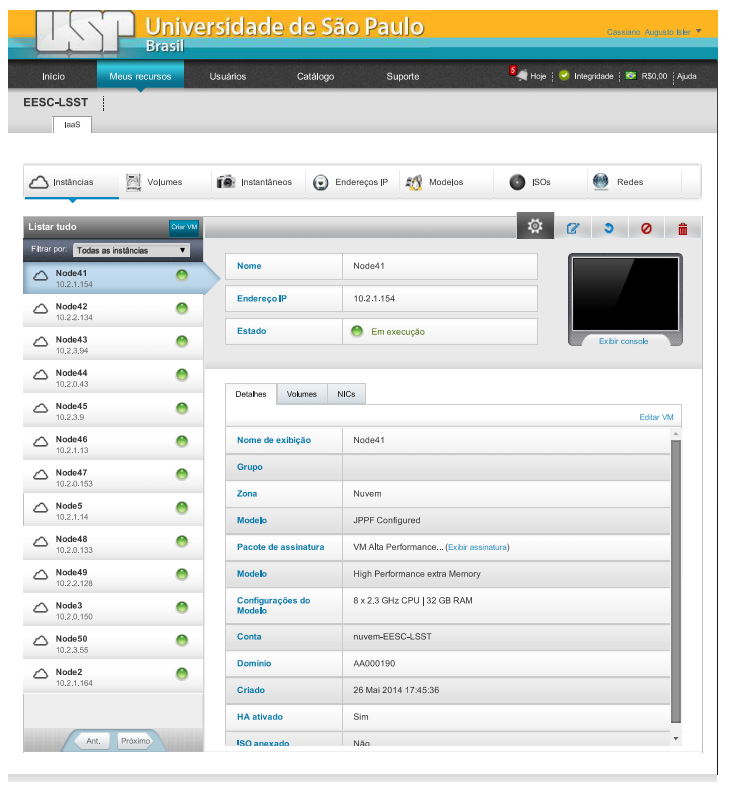

(b) Exemplo de lista de máquinas virtuais

Figura 2.20 - Página de acesso ao ambiente Nuvem USP e exemplo de lista de máquinas virtuais 
Além da infraestrutura computacional, a aplicação da programação paralela requer a utilização de interface específica para tratamento das informações e execução de comandos. O JPPF (Java Parallel Programming Framework; JPPF, 2014) é um framework gratuito (freeware) que permite o desenvolvimento de interfaces computacionais para processamento de dados em paralelo utilizando a linguagem de programação Java (ORACLE, 2012).

Uma vantagem do $J P P F$ é a facilidade de construção da rede de máquinas virtuais interconectadas e por permitir a interação de computadores com sistemas operacionais distintos (Windows, Linux ou Mac), de modo que a sua instalação e execução não requer uma rede de sistemas operacionais homogênea e dedicada exclusivamente ao processamento de dados.

Sob a terminologia do $J P P F$, um ou mais computadores (clients) que contêm um algoritmo principal são conectados a uma ou mais máquinas virtuais denominadas servers, que gerenciam a execução desse código em paralelo. Esses servers, por sua vez, são conectados a múltiplas máquinas virtuais denominadas nodes, que executam partes do algoritmo principal. A menor sequência desse algoritmo principal executada em cada node é denominada task, e um agrupamento de vários tasks é denominado job.

A Figura 2.21 a seguir exemplifica duas topologias de rede para interligação entre clients, servers e nodes no $J P P F$. A criação de diferentes alternativas de configuração da rede dá-se por motivos de confiabilidade das conexões e a quantidade de informações transmitidas na rede.

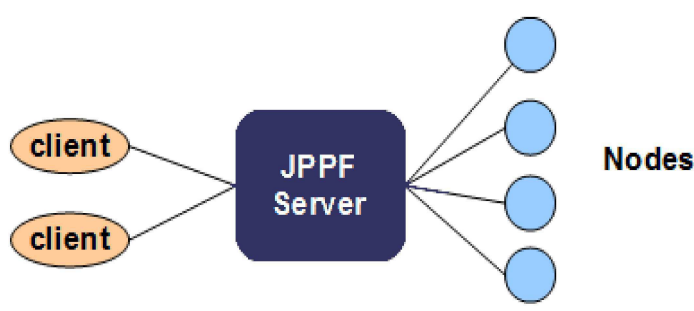

(a) Topologia com um servidor

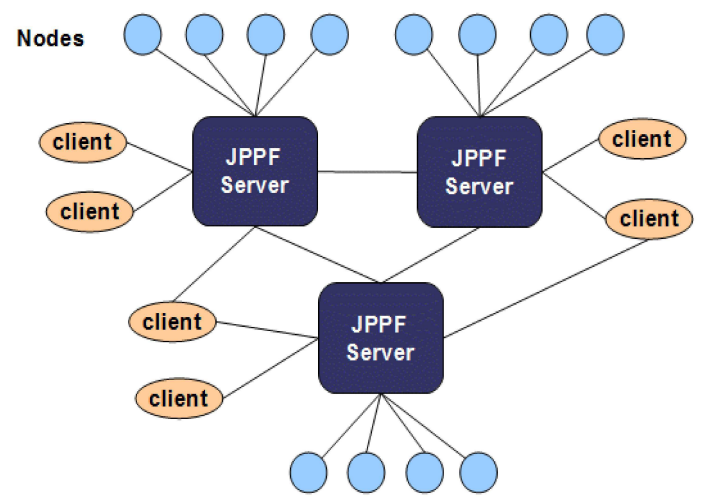

(b) Topologia com múltiplos servidores

Figura 2.21 - Topologias possíveis de redes estabelecidas no JPPF - Fonte: JPPF (2014)

A Figura 2.21 (a) representa a topologia mais simples, onde cada client é conectado a um único server, ao qual estão conectados vários nodes. Em uma arquitetura desse tipo há o risco de 
falha nas conexões, cuja mitigação se dá pela conexão de múltiplos servidores simultaneamente de modo a prover alternativas de conectividade, conforme ilustrado na Figura $2.21(b)$.

Crainic, Davidović e Ramljak (2012) referem-se à primeira topologia como "arquitetura estrela"(star architecture) e à segunda como "rede interconectada"(interconnected network). No $J P P F$ os nodes são providos de um mecanismo que permite conectarem-se automaticamente a um server alternativo no caso de falha daquele a que está conectado.

O fluxograma de execução de um algoritmo no JPPF pode ser verificado na Figura 2.22. Após a criação dos tasks em uma iteração do algoritmo principal no client e agrupamento em um job, esse é enviado ao server que gerencia a atribuição de cada task aos nodes disponíveis, utilizando algoritmos específicos em um processo denominado load balancing. Ao término da execução de todos os tasks, os resultados obtidos são retornados ao server que, por sua vez, gerencia a apresentação desses ao client.

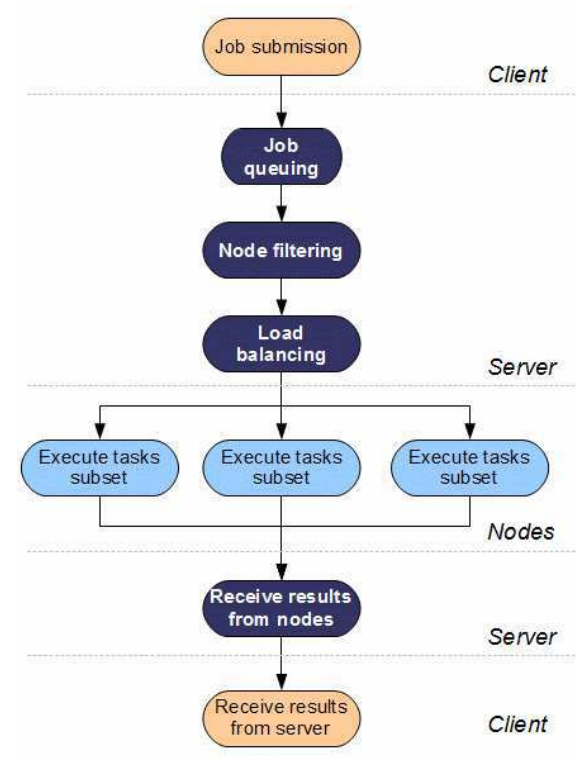

Figura 2.22 - Fluxograma de processamento de dados utilizando o JPPF - Fonte: JPPF (2014)

O JPPF possibilita o controle da rede e verificação do desempenho durante a execução de um job através da interface Administration and Monitoring Tool. A Figura 2.23 representa a janela da interface que permite parar ou reiniciar uma máquina virtual e a Figura 2.24 ilustra a visualização da topologia da rede de máquinas virtuais interconectadas ao server. 


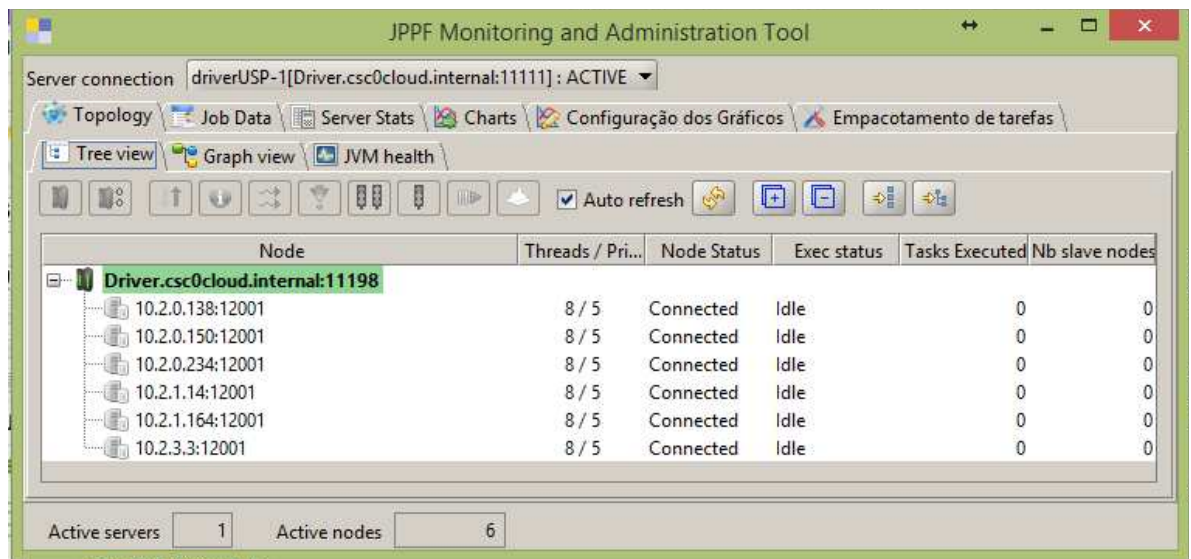

Figura 2.23 - Interface do usuário representando a conexão entre nodes e server no Administration Tool do JPPF

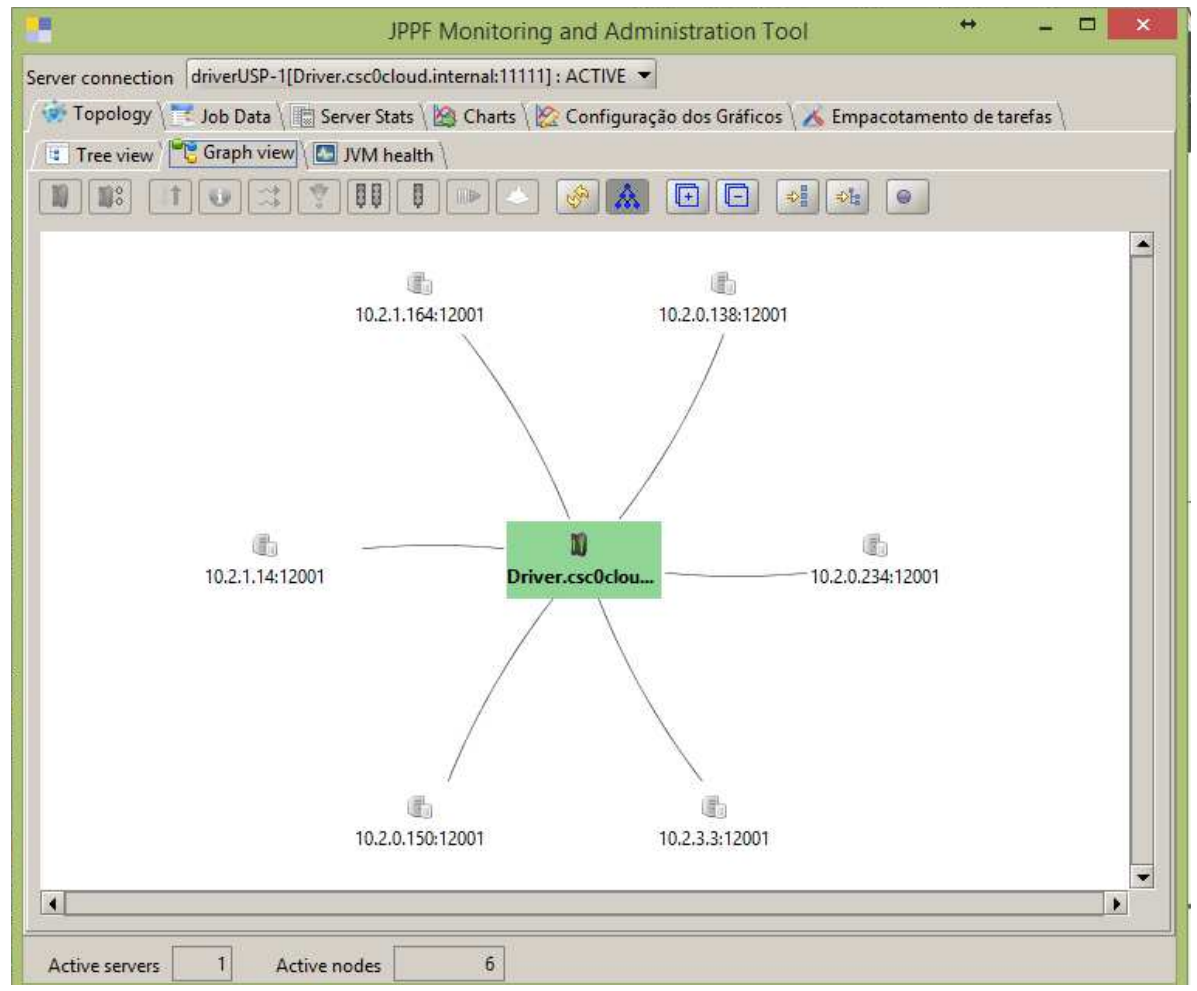

Figura 2.24 - Topologia da rede de máquinas virtuais no Administration Tool do JPPF

Ainda no ambiente do Administration and Monitoring Tool, a Figura 2.25 exemplifica os tempos de execução e transmissão dos jobs, e a Figura 2.26 ilustra as medidas de desempenho reportadas durante a execução de um algoritmo. 


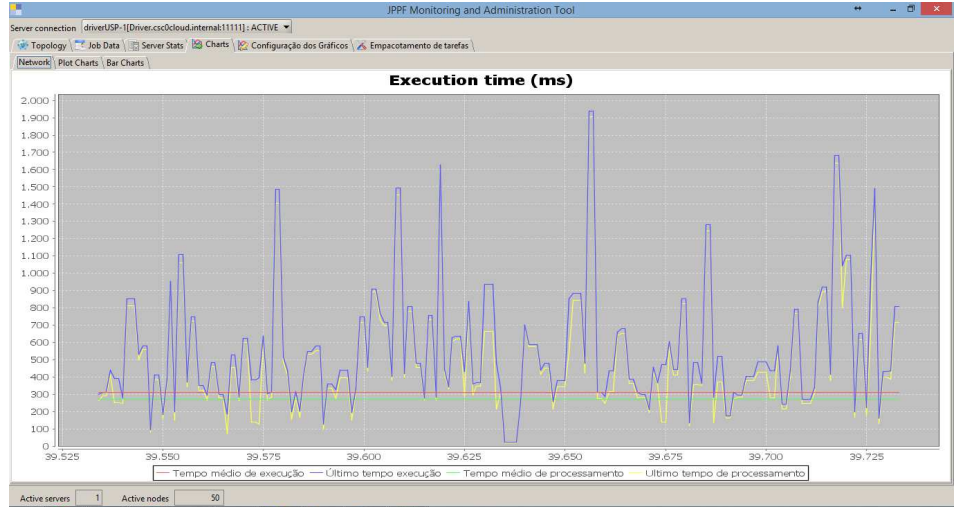

Figura 2.25 - Gráfico do tempo de processamento durante execução do $G A$ em paralelo no Administration Tool do JPPF

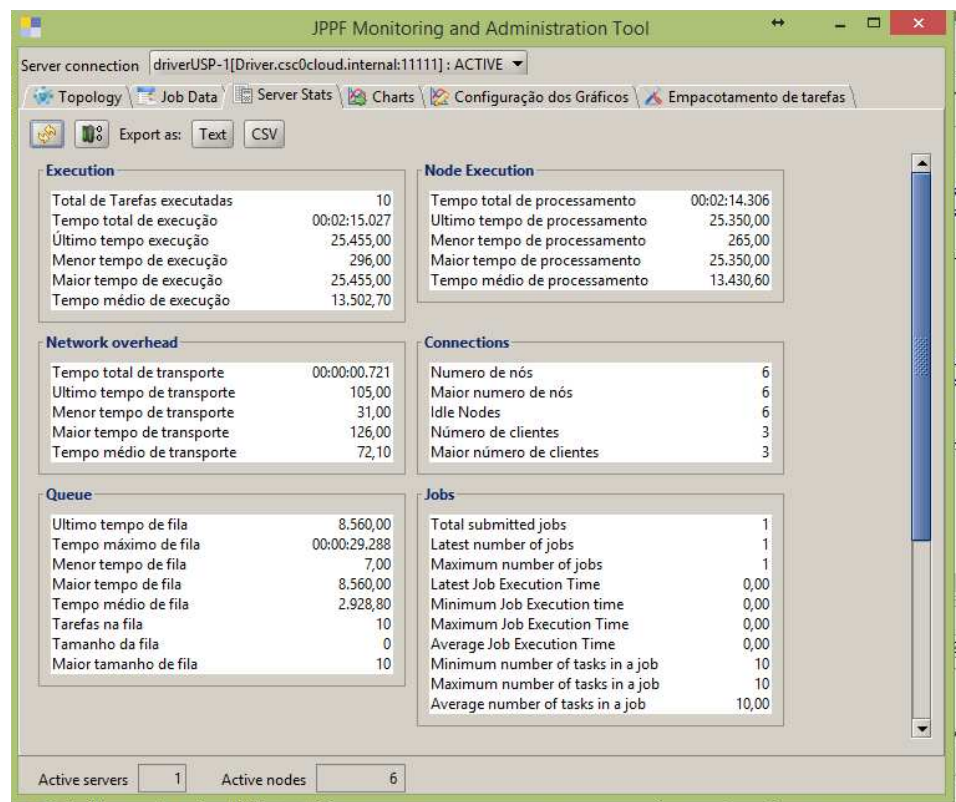

Figura 2.26 - Exemplo de representação das medidas de desempenho durante a execução do GA em paralelo no Administration Tool do JPPF

Uma questão imperativa para o melhor aproveitamento das propriedades do processamento em paralelo é a capacidade de transferência de dados na rede de máquinas virtuais. Em geral, essa transferência está condicionada à qualidade e estabilidade das conexões, as quais invariavelmente sofrem oscilações no tempo.

Mediante testes do $G A$ adaptado à topologia do $J P P F$ verificou-se que a quantidade de dados transferidos entre client, server e nodes em cada geração era uma restrição para a redução dos 
tempos de processamento. Desse modo, optou-se pela implementação de um sistema de banco de dados (Database - DB) utilizando-se o MySQL (MYSQL, 2014).

Durante a execução do $G A$, cada node transfere as características dos indivíduos para um banco de dados instalado no server, que podem ser acessadas tanto das máquinas virtuais onde o tasks foram executados quanto dos clients que os enviaram. Esse processo reduz drasticamente o tempo de transferência de dados na rede pois as informações são armazenadas no $D B$ do server e rapidamente acessadas pelos nodes e clients.

No contexto do GA para definição de novos traçados ferroviários, propõe-se uma topologia de rede do tipo "estrela"como representado na Figura 2.21 (a) tal que os elementos do JPPF associam-se ao GA da seguinte maneira: o algoritmo indicado na página 46 é executado no client; um task é uma SUB-ROTINA que define cada indivíduo quanto à escolha das coordenadas dos PIs, caracterização dos traçados e estimativa da função aptidão.

Conforme ilustrado no fluxograma da Figura 2.27, em cada geração do $G A$ os operadores de cruzamento e mutação são executados no algoritmo principal e os tasks gerados pelo código da SUB-ROTINA são submetidos aos servers sob a forma de um job. Em seguida, esse job é desmembrado novamente nos tasks, os quais são submetidos aos nodes e cujos resultados são enviados ao $D B$ do server e disponibilizados ao client na respectiva iteração.

\subsection{Análise de Desempenho}

Nesta seção são apresentadas análises dos resultados do $G A$ considerando a abordagem de programação paralela através do framework JPPF aplicado a diferentes conexões ferroviárias.

As condições estabelecidas para essa avaliação foram: definição de três diferentes cenários de novos alinhamentos ferroviários entre cidades da Região Sudeste; variação do número de PIs dos traçados entre essas localidades; e número de máquinas virtuais (nodes) disponibilizadas para execução dos operadores de cruzamento e mutação. As medidas de desempenho analisadas para cada cenário são o custo total, o tempo de processamento, a extensão dos traçados obtidos e o custo médio por quilômetro de ferrovia.

Os pares de cidades dos cenários foram definidos em função de uma análise prévia das carate- 


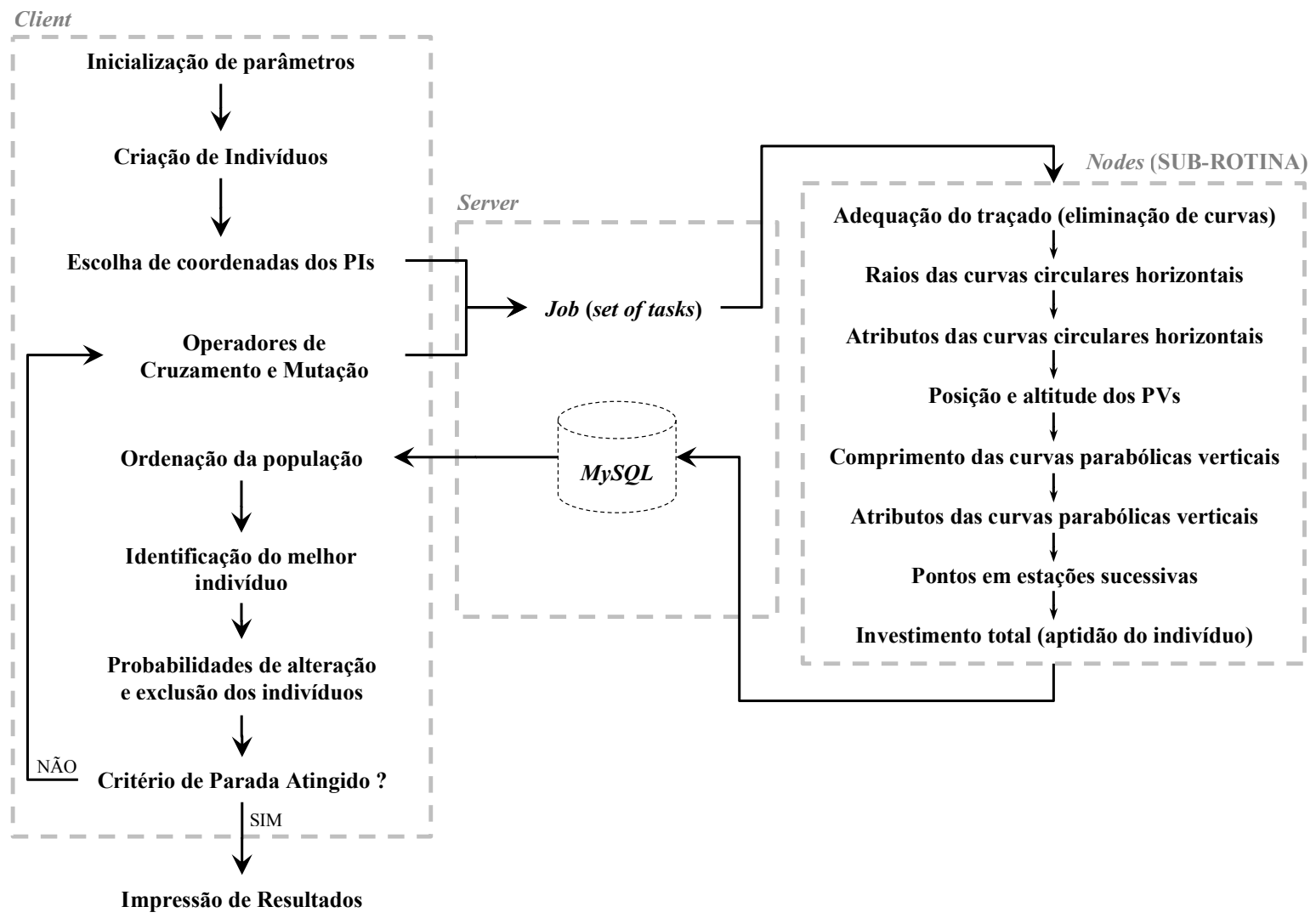

Figura 2.27 - Fluxograma do $G A$ adaptado ao $J P P F$

rísticas topográficas e de uso do solo entre elas. Assim, foram estabelecidas três conexões entre cidades da Região Sudeste cujas características topográficas e de uso do solo fossem distintas entre si de modo a viabilizar a comparação quantitativa e qualitativa dos resultados do $G A$ : Rio de Janeiro e Juiz de Fora; Campinas e Poços de Caldas; e Araraquara e Ribeirão Preto.

Para esses cenários optou-se pela definição de uma densidade de pontos de interseção por quilômetro em detrimento de um valor absoluto de PIs, de modo a viabilizar a comparação do desempenho do $G A$ entre cenários, dada a possível discrepância de desempenho do algoritmo em função da distância entre as cidades.

A variação da quantidade de máquinas virtuais $(V M s)$ mostrou-se pertinente para avaliação da eficácia da aplicação do $G A$ executado em paralelo em relação aos tempos de processamento do algoritmo, bem como uma contribuição a possíveis aplicações futuras dessa estratégia de solução a outros problemas de otimização combinatória.

Para a distância média entre PIs foram estabelecidos seis valores, iguais a $5 \mathrm{~km}, 10 \mathrm{~km}$, $15 \mathrm{~km}, 20 \mathrm{~km}$ e $25 \mathrm{~km}$. Quanto ao número de máquinas virtuais disponíveis foram estabele- 
cidos cinco valores: 1 (equivalente à execução do $G A$ em um único computador incluindo a transmissão de dados na rede de nodes interconectados), 5, 10, 25 e 50.

Assim, uma replicação do $G A$ entre duas localidades equivale a 25 execuções do algoritmo da página 46. Porém, para obtenção de um valor médio das medidas de desempenho propostas optou-se pela execução de cinco replicações de cada cenário, resultando em 125 execuções daquele algoritmo para cada par de cidades. Todas as máquinas virtuais utilizadas nessas replicações possuem configuração idêntica e são denominadas no ambiente em nuvem da USP como "VM Alta Performance com Memória Extra Linux"e possui oito processadores com memória RAM total de 32768 MB e capacidade de armazenamento no disco rígido de 500 GB (i.e. 8 vCPU 32768 MB vRAM e 500 GB de memória).

Dado que as cidades escolhidas para análise do desempenho do $G A$ possuem atualmente uma infraestrutura ferroviária nas regiões urbanas (como consequência do processo histórico de sua criação e desenvolvimento), optou-se pela proposta de definição de novos alinhamentos somente nas áreas rurais que as separam. Na etapa de aplicação da análise socioeconômica desta tese considera-se um custo médio por quilômetro de revitalização e uso da faixa de domínio existente na eventualidade de implantação de uma rede ferroviária futura.

Antes da apresentação dos resultados das replicações dos cenários descritos nesta seção, são esclarecidas a seguir as premissas de caracterização geométrica, de definição dos custos unitários dos traçados, e de parametrização do $G A$.

\subsubsection{Definição de Parâmetros}

A via permanente considerada para definição dos traçados é composta por uma faixa de domínio delimitada por barreiras de proteção e plataforma ferroviária com via dupla para movimentação de trens em dois sentidos opostos. Os parâmetros para caracterização dos traçados em projeção horizontal, longitudinal e transversal são definidos no Apêndice A, que contém uma representação esquemática da seção transversal dessa via permanente padrão.

Para estabelecer os raios mínimos das curvas circulares horizontais considera-se um modelo teórico simplificado de equilíbrio dos veículos ferroviários na seção transversal de uma curva 
circular horizontal conforme ilustrado na Figura 2.28. Nesse caso, $P$ é o peso do veículo, $F_{c}$ é a força centrífuga atuante sobre o veículo, $h$ é diferença de cota entre o trilho interno e o externo, $e$ é a superelevação (ângulo entre o plano horizontal e a superfície da ferrovia) e $B$ é bitola.

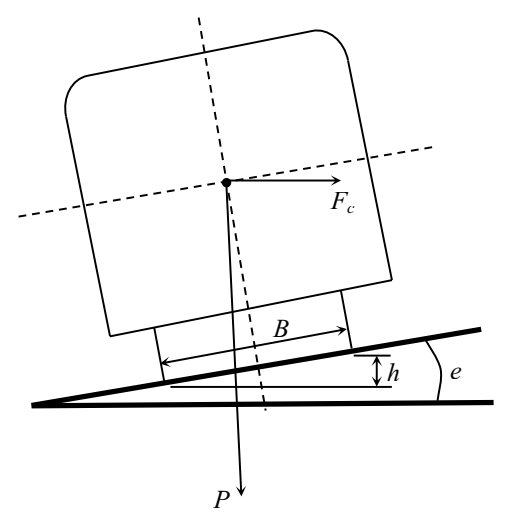

Figura 2.28 - Modelo teórico de representação das forças atuantes no trem em uma curva circular horizontal

De modo a evitar o tombamento do veículo na direção oposta à curva, o equilíbrio entre o peso e a força centrífuga pode ser representado pela Equação 2.7.

$$
\frac{m \cdot V^{2}}{R} \cdot \cos (\alpha)=m \cdot g \cdot \operatorname{sen}(\alpha)
$$

onde $V$ = velocidade do trem; $R=$ raio da curva circular; $g=$ aceleração da gravidade.

Sob a premissa de $\operatorname{sen}(e)=\tan (e)=h / B$ e $\cos (e)=1,0$, o raio da curva circular horizontal pode ser calculado conforme explicitado na Equação 2.8 para $g \simeq 9,81 \mathrm{~m} / \mathrm{s}^{2}$. Nesse caso, o raio mínimo que permite a operação de trens com segurança é calculado quando os veículos trafegam à velocidade máxima de projeto em uma curva com superelevação específica.

$$
R_{\text {min }}=\frac{B \cdot V_{\max }^{2}}{127 \cdot h}
$$

onde $R_{\min }=$ raio mínimo da curva circular (metros); $B=$ bitola (metros) $V_{\max }=$ velocidade máxima do trem $(\mathrm{km} / \mathrm{h}) ; h=$ diferença de cota entre bordas dos trilhos (metros).

AREMA (2003) sugere uma diferença média de altura entre trilhos $(h)$ para compensar os efeitos da aceleração centrífuga em trens de passageiros igual a 6 polegadas ou aproximadamente 0,1524 metros. Logo, para uma bitola $(B)$ de 1,435 metros, o raio mínimo de curvas 
circulares horizontais para operação de HPTs $(150 \mathrm{~km} / \mathrm{h})$ e de HSTs $(300 \mathrm{~km} / \mathrm{h})$ segundo a Equação 2.8 é de aproximadamente 1.668,0 metros e 6.673,0 metros.

Assim, com vistas à manutenção da operação segura dos trens, os raios mínimos das curvas circulares horizontais de projeto considerados nesta tese foram de 2.000 metros e 7.000 metros para HPTs e HSTs, respectivamente.

Em relação aos parâmetros do $G A$, Jha et al. (2006) recomendam o número de indivíduos equivalente a 15 vezes o número de Pontos de Interseção possíveis no traçado ( $n_{p}=15$. PIs). Ainda, com base em análise de resultados em instâncias de teste, os autores indicam como critério de parada um número máximo de 300 iterações sucessivas para que seja atingida uma convergência satisfatória da solução de custo total. Entretanto, pela realização de testes preliminares propõe-se a alteração dessa regra, com parada do $G A$ após 100 gerações sucessivas.

O Apêndice A contém valores numéricos para os parâmetros de caracterização da via permanente de ambas as tecnologias, os parâmetros de execução do $G A$ e os custos unitários dos itens contemplados na composição do custo total dos traçados.

\subsubsection{Resultados da Análise de Desempenho}

Na aplicação do método entre o Rio de Janeiro e Juiz de Fora, os resultados das replicações quanto aos valores de custos totais, tempos de processamento para obtenção das soluções, comprimentos dos alinhamentos e custos médios $(\mathrm{R} \$ / \mathrm{km})$ para traçados compatível com a operação de HPTs são apresentados entre a Tabela 2.1 e a Tabela 2.4 .

Analogamente, são apresentados os resultados para traçados apropriados à operação de HSTs entre a Tabela 2.5 e a Tabela 2.8. A Figura 2.29 e Figura 2.30 resumem os valores apresentados nessas tabelas em relação às respectivas tecnologias ferroviárias. 
Tabela 2.1 - Custos totais de alinhamentos para operação de HPT entre Rio de Janeiro e Juiz de Fora [(Média / Desvio Padrão) $10^{9}$ R \$]

\begin{tabular}{ccccccc}
\hline \multirow{2}{*}{$\begin{array}{l}\text { Distância média } \\
\text { entre PIs }(\mathbf{k m})\end{array}$} & $\begin{array}{l}\text { Número } \\
\text { de PIs }\end{array}$ & \multicolumn{5}{c}{ Número de Máquinas Virtuais Disponíveis } \\
\cline { 3 - 7 } & & $\mathbf{1}$ & $\mathbf{5}$ & $\mathbf{1 0}$ & $\mathbf{2 5}$ & $\mathbf{5 0}$ \\
\hline $\mathbf{5}$ & $\mathbf{1 9}$ & $8,84 / 1,67$ & $9,01 / 0,93$ & $8,66 / 1,03$ & $8,51 / 1,09$ & $8,20 / 1,12$ \\
$\mathbf{1 0}$ & $\mathbf{9}$ & $8,54 / 0,39$ & $9,60 / 1,18$ & $8,51 / 0,79$ & $9,60 / 1,42$ & $9,75 / 1,89$ \\
$\mathbf{1 5}$ & $\mathbf{6}$ & $9,51 / 0,85$ & $9,42 / 0,54$ & $9,16 / 1,01$ & $10,08 / 1,66$ & $9,78 / 1,01$ \\
$\mathbf{2 0}$ & $\mathbf{5}$ & $9,35 / 0,67$ & $10,36 / 0,73$ & $10,28 / 1,23$ & $10,83 / 1,71$ & $10,32 / 1,15$ \\
$\mathbf{2 5}$ & $\mathbf{4}$ & $11,33 / 0,46$ & $11,57 / 0,98$ & $12,07 / 1,89$ & $9,91 / 0,48$ & $10,18 / 0,62$ \\
\hline
\end{tabular}

Tabela 2.2 - Tempo de processamento para obtenção das soluções de alinhamentos para operação de $H P T$ entre Rio de Janeiro e Juiz de Fora [(Média / Desvio Padrão) minutos]

\begin{tabular}{ccccccc}
\hline \multirow{2}{*}{$\begin{array}{l}\text { Distância média } \\
\text { entre PIs }(\mathbf{k m})\end{array}$} & $\begin{array}{l}\text { Número } \\
\text { de PIs }\end{array}$ & \multicolumn{5}{c}{ Número de Máquinas Virtuais Disponíveis } \\
\cline { 3 - 7 } & & $\mathbf{1}$ & $\mathbf{5}$ & $\mathbf{1 0}$ & $\mathbf{2 5}$ & $\mathbf{5 0}$ \\
\hline $\mathbf{5}$ & $\mathbf{1 9}$ & $184 / 70$ & $36 / 24$ & $48 / 28$ & $69 / 22$ & $53 / 21$ \\
$\mathbf{1 0}$ & $\mathbf{9}$ & $168 / 53$ & $37 / 16$ & $35 / 32$ & $28 / 8$ & $33 / 21$ \\
$\mathbf{1 5}$ & $\mathbf{6}$ & $168 / 48$ & $37 / 13$ & $27 / 9$ & $29 / 13$ & $21 / 9$ \\
$\mathbf{2 0}$ & $\mathbf{5}$ & $146 / 65$ & $35 / 22$ & $25 / 16$ & $18 / 11$ & $26 / 21$ \\
$\mathbf{2 5}$ & $\mathbf{4}$ & $114 / 48$ & $32 / 11$ & $13 / 3$ & $17 / 5$ & $14 / 3$ \\
\hline
\end{tabular}

Tabela 2.3 - Comprimentos dos alinhamentos para operação de HPT entre Rio de Janeiro e Juiz de Fora [(Média / Desvio Padrão) km]

\begin{tabular}{ccccccc}
\hline \multirow{2}{*}{$\begin{array}{l}\text { Distância média } \\
\text { entre PIs }(\mathbf{k m})\end{array}$} & $\begin{array}{l}\text { Número } \\
\text { de PIs }\end{array}$ & \multicolumn{5}{c}{ Número de Máquinas Virtuais Disponíveis } \\
\cline { 3 - 7 } & & $\mathbf{1}$ & $\mathbf{5}$ & $\mathbf{1 0}$ & $\mathbf{2 5}$ & $\mathbf{5 0}$ \\
\hline $\mathbf{5}$ & $\mathbf{1 9}$ & $112,4 / 9,0$ & $112,0 / 6,9$ & $114,1 / 7,1$ & $117,7 / 5,7$ & $115,7 / 7,4$ \\
$\mathbf{1 0}$ & $\mathbf{9}$ & $112,5 / 5,2$ & $123,8 / 8,4$ & $112,3 / 7,9$ & $117,8 / 14,4$ & $114,1 / 7,3$ \\
$\mathbf{1 5}$ & $\mathbf{6}$ & $111,3 / 3,7$ & $113,1 / 5$ & $110,0 / 7$ & $111,8 / 7,1$ & $114,5 / 7,7$ \\
$\mathbf{2 0}$ & $\mathbf{5}$ & $113,9 / 3,9$ & $112,7 / 4,7$ & $113,5 / 4,2$ & $113,5 / 3,8$ & $114,2 / 8,1$ \\
$\mathbf{2 5}$ & $\mathbf{4}$ & $116,0 / 4,9$ & $113,8 / 4,3$ & $119,0 / 10,2$ & $113,5 / 4,7$ & $114,3 / 9,2$ \\
\hline
\end{tabular}

Tabela 2.4 - Custos médios de alinhamentos para operação de HPT entre Rio de Janeiro e Juiz de Fora [(Média / Desvio Padrão) $10^{7} \mathrm{R} \$ / \mathrm{km}$ ]

\begin{tabular}{ccccccc}
\hline \multirow{2}{*}{$\begin{array}{l}\text { Distância média } \\
\text { entre PIs }(\mathbf{k m})\end{array}$} & $\begin{array}{l}\text { Número } \\
\text { de PIs }\end{array}$ & \multicolumn{5}{c}{ Número de Máquinas Virtuais Disponíveis } \\
\cline { 3 - 7 } & & $\mathbf{1}$ & $\mathbf{5}$ & $\mathbf{1 0}$ & $\mathbf{2 5}$ & $\mathbf{5 0}$ \\
\hline $\mathbf{5}$ & $\mathbf{1 9}$ & $7,82 / 0,93$ & $8,06 / 0,87$ & $7,58 / 0,57$ & $7,23 / 0,80$ & $7,07 / 0,57$ \\
$\mathbf{1 0}$ & $\mathbf{9}$ & $7,60 / 0,37$ & $7,74 / 0,54$ & $7,58 / 0,53$ & $8,14 / 0,40$ & $8,51 / 1,34$ \\
$\mathbf{1 5}$ & $\mathbf{6}$ & $8,56 / 0,87$ & $8,33 / 0,26$ & $8,31 / 0,45$ & $9,00 / 1,26$ & $8,53 / 0,35$ \\
$\mathbf{2 0}$ & $\mathbf{5}$ & $8,22 / 0,63$ & $9,19 / 0,50$ & $9,04 / 0,82$ & $9,53 / 1,39$ & $9,03 / 0,66$ \\
$\mathbf{2 5}$ & $\mathbf{4}$ & $9,78 / 0,52$ & $10,18 / 0,87$ & $10,10 / 0,95$ & $8,73 / 0,30$ & $8,93 / 0,54$ \\
\hline
\end{tabular}



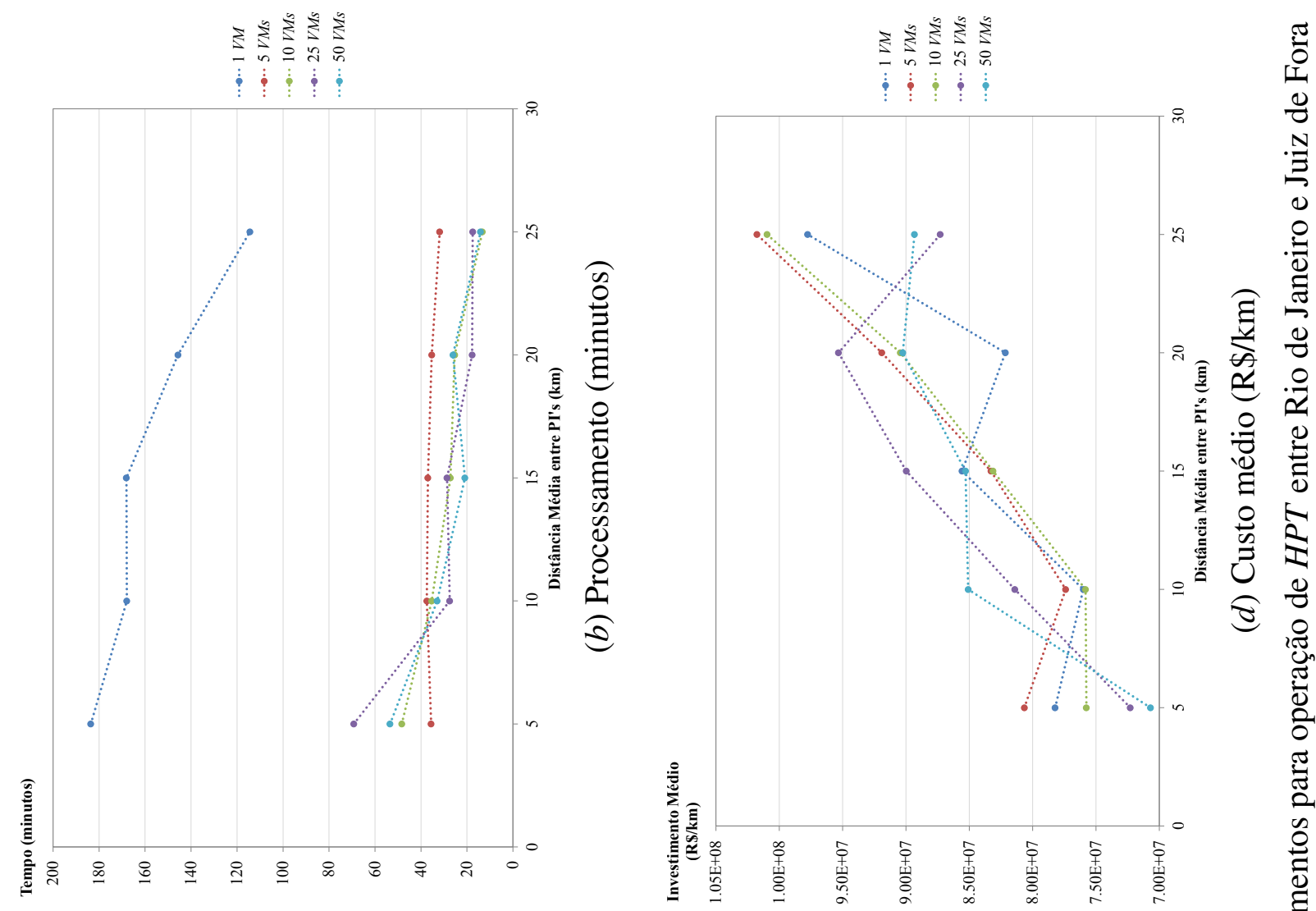

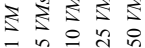

(5)
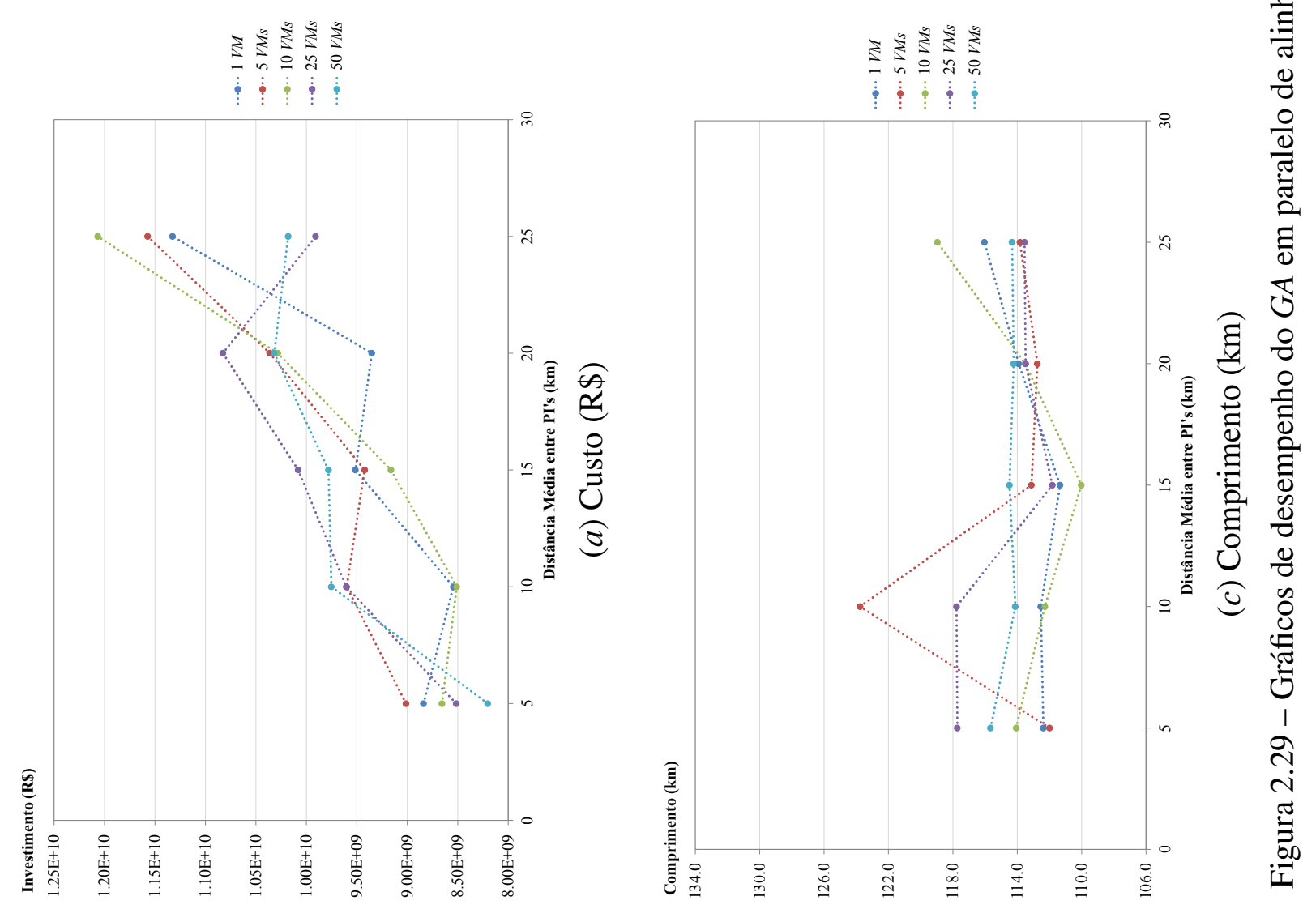
Tabela 2.5 - Custos totais de alinhamentos para operação de HST entre Rio de Janeiro e Juiz de Fora [(Média / Desvio Padrão) $\cdot 10^{9} \mathrm{R} \$$ ]

\begin{tabular}{ccccccc}
\hline \multirow{2}{*}{$\begin{array}{l}\text { Distância média } \\
\text { entre PIs }(\mathbf{k m})\end{array}$} & $\begin{array}{l}\text { Número } \\
\text { de PIs }\end{array}$ & \multicolumn{5}{c}{ Número de Máquinas Virtuais Disponíveis } \\
\cline { 3 - 7 } & & $\mathbf{1}$ & $\mathbf{5}$ & $\mathbf{1 0}$ & $\mathbf{2 5}$ & $\mathbf{5 0}$ \\
\hline $\mathbf{5}$ & $\mathbf{1 9}$ & $8,51 / 0,85$ & $8,88 / 0,76$ & $8,63 / 0,55$ & $8,50 / 1,12$ & $8,69 / 0,73$ \\
$\mathbf{1 0}$ & $\mathbf{9}$ & $9,01 / 1,04$ & $9,75 / 1,30$ & $8,80 / 0,18$ & $9,92 / 0,74$ & $9,75 / 1,25$ \\
$\mathbf{1 5}$ & $\mathbf{6}$ & $10,20 / 1,54$ & $10,61 / 1,01$ & $10,06 / 1,53$ & $10,46 / 0,75$ & $9,84 / 0,94$ \\
$\mathbf{2 0}$ & $\mathbf{5}$ & $10,70 / 1,64$ & $10,49 / 1,94$ & $10,51 / 1,81$ & $11,30 / 1,59$ & $9,42 / 0,52$ \\
$\mathbf{2 5}$ & $\mathbf{4}$ & $10,02 / 1,27$ & $10,51 / 0,94$ & $11,33 / 0,96$ & $11,41 / 1,17$ & $12,05 / 1,18$ \\
\hline
\end{tabular}

Tabela 2.6 - Tempo de processamento para obtenção das soluções de alinhamentos para operação de HST entre Rio de Janeiro e Juiz de Fora [(Média / Desvio Padrão) minutos]

\begin{tabular}{ccccccc}
\hline \multirow{2}{*}{$\begin{array}{l}\text { Distância média } \\
\text { entre PIs }(\mathbf{k m})\end{array}$} & $\begin{array}{l}\text { Número } \\
\text { de PIs }\end{array}$ & \multicolumn{5}{c}{ Número de Máquinas Virtuais Disponíveis } \\
\cline { 3 - 7 } & & $\mathbf{1}$ & $\mathbf{5}$ & $\mathbf{1 0}$ & $\mathbf{2 5}$ & $\mathbf{5 0}$ \\
\hline $\mathbf{5}$ & $\mathbf{1 9}$ & $180 / 101$ & $85 / 42$ & $71 / 46$ & $44 / 30$ & $52 / 22$ \\
$\mathbf{1 0}$ & $\mathbf{9}$ & $144 / 88$ & $39 / 18$ & $30 / 13$ & $21 / 10$ & $34 / 16$ \\
$\mathbf{1 5}$ & $\mathbf{6}$ & $75 / 20$ & $39 / 39$ & $28 / 16$ & $20 / 15$ & $29 / 25$ \\
$\mathbf{2 0}$ & $\mathbf{5}$ & $107 / 56$ & $40 / 17$ & $17 / 5$ & $17 / 9$ & $23 / 7$ \\
$\mathbf{2 5}$ & $\mathbf{4}$ & $132 / 39$ & $32 / 5$ & $18 / 9$ & $16 / 2$ & $15 / 4$ \\
\hline
\end{tabular}

Tabela 2.7 - Comprimentos dos alinhamentos para operação de HST entre Rio de Janeiro e Juiz de Fora [(Média / Desvio Padrão) km]

\begin{tabular}{ccccccc}
\hline \multirow{2}{*}{$\begin{array}{l}\text { Distância média } \\
\text { entre PIs }(\mathbf{k m})\end{array}$} & $\begin{array}{l}\text { Número } \\
\text { de PIs }\end{array}$ & \multicolumn{5}{c}{ Número de Máquinas Virtuais Disponíveis } \\
\cline { 3 - 7 } & & $\mathbf{1}$ & $\mathbf{5}$ & $\mathbf{1 0}$ & $\mathbf{2 5}$ & $\mathbf{5 0}$ \\
\hline $\mathbf{5}$ & $\mathbf{1 9}$ & $113,0 / 3,6$ & $116,9 / 4,3$ & $111,7 / 8,4$ & $107,9 / 2,3$ & $111,3 / 6,9$ \\
$\mathbf{1 0}$ & $\mathbf{9}$ & $113,9 / 6,3$ & $115,7 / 6,0$ & $110,4 / 3,0$ & $113,5 / 2,3$ & $114,7 / 6,9$ \\
$\mathbf{1 5}$ & $\mathbf{6}$ & $114,0 / 6,2$ & $110,5 / 5,1$ & $113,6 / 6,7$ & $110,4 / 8,3$ & $112,8 / 7,5$ \\
$\mathbf{2 0}$ & $\mathbf{5}$ & $117,4 / 10,4$ & $114,6 / 6,5$ & $112,6 / 7,6$ & $117,9 / 8,9$ & $111,4 / 2,7$ \\
$\mathbf{2 5}$ & $\mathbf{4}$ & $111,4 / 3,2$ & $112,1 / 3,3$ & $122,2 / 16,9$ & $117,9 / 2,2$ & $132,0 / 17,4$ \\
\hline
\end{tabular}

Tabela 2.8 - Custos médios de alinhamentos para operação de $H S T$ entre Rio de Janeiro e Juiz de Fora [(Média / Desvio Padrão) $10^{7} \mathrm{R} \$ / \mathrm{km}$ ]

\begin{tabular}{ccccccc}
\hline \multirow{2}{*}{$\begin{array}{l}\text { Distância média } \\
\text { entre PIs }(\mathbf{k m})\end{array}$} & $\begin{array}{l}\text { Número } \\
\text { de PIs }\end{array}$ & \multicolumn{5}{c}{ Número de Máquinas Virtuais Disponíveis } \\
\cline { 3 - 7 } & & $\mathbf{1}$ & $\mathbf{5}$ & $\mathbf{1 0}$ & $\mathbf{2 5}$ & $\mathbf{5 0}$ \\
\hline $\mathbf{5}$ & $\mathbf{1 9}$ & $7,53 / 0,69$ & $7,60 / 0,58$ & $7,76 / 0,86$ & $7,87 / 1,02$ & $7,80 / 0,41$ \\
$\mathbf{1 0}$ & $\mathbf{9}$ & $7,89 / 0,51$ & $8,40 / 0,75$ & $7,97 / 0,33$ & $8,74 / 0,62$ & $8,51 / 1,10$ \\
$\mathbf{1 5}$ & $\mathbf{6}$ & $8,93 / 1,14$ & $9,62 / 0,97$ & $8,84 / 1,08$ & $9,51 / 0,87$ & $8,71 / 0,37$ \\
$\mathbf{2 0}$ & $\mathbf{5}$ & $9,08 / 0,78$ & $9,11 / 1,33$ & $9,28 / 1,01$ & $9,56 / 0,76$ & $8,46 / 0,48$ \\
$\mathbf{2 5}$ & $\mathbf{4}$ & $8,99 / 1,05$ & $9,38 / 0,89$ & $9,37 / 1,08$ & $9,67 / 0,91$ & $9,18 / 0,46$ \\
\hline
\end{tabular}



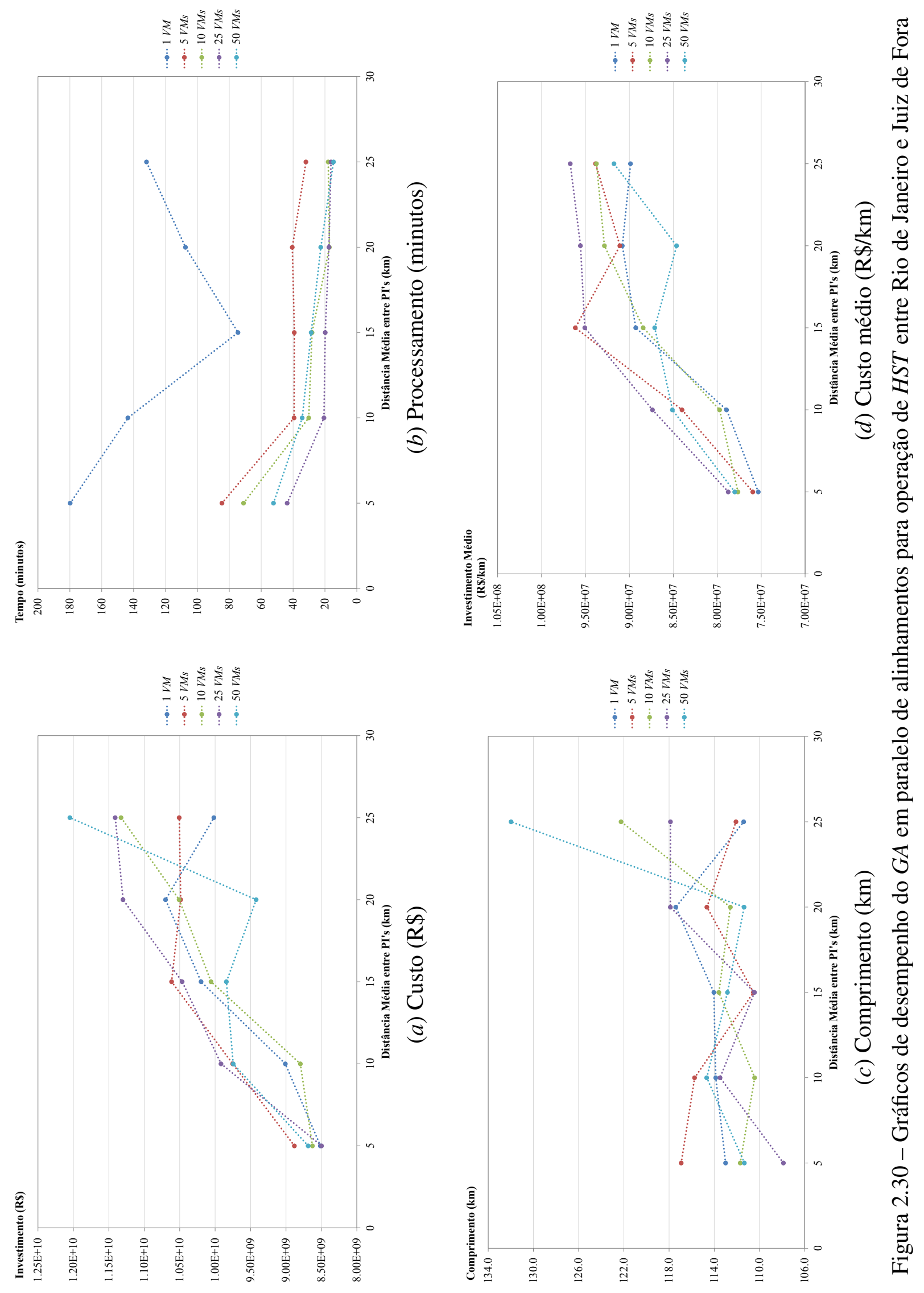
Como pode se observado desses resultados, os custos totais não mudam significativamente com a variação do número de $V M s$, mas aumentam proporcionalmente com a distância média entre PIs, tanto nos traçados para HPTs quanto para HSTs. Entretanto, é importante salientar que os custos variam praticamente no mesmo intervalo para ambas as tecnologias, com custo médio mínimo de $\mathrm{R} \$ 8,20 \cdot 10^{9}$ (desvio padrão de $\mathrm{R} \$ 1,12 \cdot 10^{9}$ ) para HPTs nas replicações com distância média entre PIs de $5 \mathrm{~km}$ (ou 19 PIs) e 50 VMs disponíveis para processamento, e de $\mathrm{R} \$ 8,50 \cdot 10^{9}$ (desvio padrão de $\mathrm{R} \$ 1,12 \cdot 10^{9}$ ) para os $H S T$ s nas replicações com distância média entre PIs de 5 km (ou 19 PIs) e 25 VMs disponíveis para processamento.

No caso dos tempos de processamento, não há uma tendência definida em relação à distância média entre PIs. Entretanto, um importante resultado é a variação acentuada da medida de desempenho quando o número de máquinas virtuais disponibilizadas varia, pois os tempos de processamento reduzem-se drasticamente quando cinco máquinas são utilizadas no lugar de apenas uma $V M$.

No caso de replicações com distância entre PIs igual a 5 km, o tempo médio de processamento é de 184 minutos (desvio de 70 minutos) para traçados de HPTs e 180 minutos (desvio de 101 minutos) para os de HSTs. Ainda com essa densidade de pontos de interseção, quando cinco máquinas virtuais são disponibilizadas, os tempos reduzem-se para valores médios de 36 minutos (desvio padrão de 24 minutos) e 85 minutos (desvio de 42 minutos), respectivamente em relação às tecnologias ferroviárias.

Entretanto, ao se aumentar o número de $V M s$ disponíveis entre 5 e 50, observa-se que esses tempos não reduzem-se na mesma proporção, indicando que a quantidade de processadores disponíveis contribui marginalmente para a redução dos tempos até um limite mínimo.

No âmbito do comprimento médio dos alinhamentos, a distância entre PIs e o número de máquinas virtuais disponibilizadas para processamento nota-se uma variabilidade relativamente pequena entre os resultados obtidos para traçados compatíveis para operação de HPTs e de HSTs. Observa-se uma exceção para a distância de $25 \mathrm{~km}$ entre PIs para HSTs, com valor médio de 132,0 km (desvio de 17,4 km) para as replicações com 50 VMs, em comparação com um comprimento médio mínimo de $107,9 \mathrm{~km}$ (desvio padrão de 2,3 km) para as replicações com 25 VMs e distância de 5 km entre PIs. 
Uma vez que o comprimento médio dos alinhamentos não varia expressivamente e os custos totais aumentam quando a distância média entre PIs aumenta, é de se esperar que o custo médio por quilômetro varie nessa mesma tendência como observado no gráfico inferior direito da Figura 2.29 e da Figura 2.30. Para HPTs, o valor médio mínimo do custo é de R $\$ 7,07 \cdot 10^{7} / \mathrm{km}$ (desvio padrão de $\mathrm{R} \$ 0,57 \cdot 10^{7} / \mathrm{km}$ ) para as replicações de distância média entre PIs de $5 \mathrm{~km}$ com 50 VMs disponíveis, e para HSTs esse valor mínimo é de $\mathrm{R} \$ 7,53 \cdot 10^{7} / \mathrm{km}$ (desvio padrão de $\mathrm{R} \$ 0,69 \cdot 10^{7} / \mathrm{km}$ ) para as replicações de distância média entre PIs de $5 \mathrm{~km}$ com apenas uma máquina virtual para processamento.

Portanto, para o caso específico do custo médio por quilômetro na construção de novos alinhamentos na área rural entre a cidade de Rio de Janeiro e Juiz de Fora, os valores monetários podem ser considerados praticamente equivalentes em relação à tecnologia ferroviária. Isso pode ser justificado pela particular topografia da região como representado nas ilustrações da Figura 2.36 e Figura 2.37. Naquelas figuras, os traçados de menor custo total obtidos nas replicações são muito semelhantes do ponto de vista da projeção horizontal e da implantação de túneis e viadutos.

Nas análises subsequentes de desempenho do $G A$, foram executadas replicações para obtenção de novos traçados ferroviários em um segundo cenário entre as cidades de Campinas e Poços de Caldas, cujo perfil topográfico e de ocupação do solo distingue-se do cenário anterior. Os valores de custos totais, tempo de processamento, comprimento e custo médio de traçados na área rural entre essas cidades são indicados entre a Tabela 2.9 e a Tabela 2.16 e resumidos na Figura 2.31 e Figura 2.32, respectivamente para os traçados para operação de HPTs e HSTs. 
Tabela 2.9 - Custos totais de alinhamentos para operação de HPT entre Campinas e Poços de Caldas [(Média / Desvio Padrão) $\cdot 10^{9} \mathrm{R} \$$ ]

\begin{tabular}{ccccccc}
\hline \multirow{2}{*}{$\begin{array}{l}\text { Distância média } \\
\text { entre PIs }(\mathbf{k m})\end{array}$} & $\begin{array}{l}\text { Número } \\
\text { de PIs }\end{array}$ & \multicolumn{5}{c}{ Número de Máquinas Virtuais Disponíveis } \\
\cline { 3 - 7 } & & $\mathbf{1}$ & $\mathbf{5}$ & $\mathbf{1 0}$ & $\mathbf{2 5}$ & $\mathbf{5 0}$ \\
\hline $\mathbf{5}$ & $\mathbf{2 4}$ & $7,59 / 0,78$ & $7,91 / 2,4$ & $7,22 / 0,67$ & $7,72 / 1,23$ & $8,33 / 2,43$ \\
$\mathbf{1 0}$ & $\mathbf{1 2}$ & $10,37 / 2,41$ & $10,44 / 3,8$ & $9,33 / 2$ & $9,39 / 1,11$ & $10,41 / 1,36$ \\
$\mathbf{1 5}$ & $\mathbf{8}$ & $11,09 / 1,4$ & $10,27 / 0,64$ & $11,66 / 1,94$ & $11,23 / 2$ & $11,58 / 1,67$ \\
$\mathbf{2 0}$ & $\mathbf{6}$ & $12,65 / 1,91$ & $11,55 / 1,39$ & $12,75 / 2,13$ & $11,1 / 2,41$ & $11,01 / 1,01$ \\
$\mathbf{2 5}$ & $\mathbf{5}$ & $13,4 / 1,31$ & $13,95 / 2,68$ & $14,25 / 2,75$ & $13,37 / 1,93$ & $12,87 / 1,98$ \\
\hline
\end{tabular}

Tabela 2.10 - Tempo de processamento para obtenção das soluções de alinhamentos para operação de $H P T$ entre Campinas e Poços de Caldas [(Média / Desvio Padrão) minutos]

\begin{tabular}{ccccccc}
\hline \multirow{2}{*}{$\begin{array}{l}\text { Distância média } \\
\text { entre PIs }(\mathbf{k m})\end{array}$} & $\begin{array}{l}\text { Número } \\
\text { de PIs }\end{array}$ & \multicolumn{5}{c}{ Número de Máquinas Virtuais Disponíveis } \\
\cline { 3 - 7 } & & $\mathbf{1}$ & $\mathbf{5}$ & $\mathbf{1 0}$ & $\mathbf{2 5}$ & $\mathbf{5 0}$ \\
\hline $\mathbf{5}$ & $\mathbf{2 4}$ & $110 / 90$ & $55 / 40$ & $67 / 21$ & $81 / 16$ & $72 / 48$ \\
$\mathbf{1 0}$ & $\mathbf{1 2}$ & $113 / 49$ & $43 / 25$ & $29 / 13$ & $36 / 26$ & $24 / 8$ \\
$\mathbf{1 5}$ & $\mathbf{8}$ & $93 / 51$ & $32 / 17$ & $24 / 8$ & $26 / 14$ & $31 / 18$ \\
$\mathbf{2 0}$ & $\mathbf{6}$ & $74 / 16$ & $48 / 27$ & $22 / 8$ & $22 / 8$ & $21 / 14$ \\
$\mathbf{2 5}$ & $\mathbf{5}$ & $157 / 50$ & $28 / 14$ & $35 / 15$ & $21 / 7$ & $17 / 6$ \\
\hline
\end{tabular}

Tabela 2.11 - Comprimentos dos alinhamentos para operação de HPT entre Campinas e Poços de Caldas [(Média / Desvio Padrão) km]

\begin{tabular}{ccccccc}
\hline \multirow{2}{*}{$\begin{array}{l}\text { Distância média } \\
\text { entre PIs }(\mathbf{k m})\end{array}$} & $\begin{array}{l}\text { Número } \\
\text { de PIs }\end{array}$ & \multicolumn{5}{c}{ Número de Máquinas Virtuais Disponíveis } \\
\cline { 3 - 7 } & & $\mathbf{1}$ & $\mathbf{5}$ & $\mathbf{1 0}$ & $\mathbf{2 5}$ & $\mathbf{5 0}$ \\
\hline $\mathbf{5}$ & $\mathbf{2 4}$ & $140,2 / 4,7$ & $158,0 / 28,4$ & $141,3 / 8,4$ & $150,7 / 12,3$ & $151,3 / 13,0$ \\
$\mathbf{1 0}$ & $\mathbf{1 2}$ & $160,3 / 13,1$ & $164,8 / 27,0$ & $147,7 / 11,9$ & $155,5 / 22,8$ & $151 / 10,7$ \\
$\mathbf{1 5}$ & $\mathbf{8}$ & $151,9 / 7,6$ & $150,7 / 10,6$ & $162,0 / 22,6$ & $153,7 / 12,1$ & $167,4 / 17$ \\
$\mathbf{2 0}$ & $\mathbf{6}$ & $156,4 / 16,7$ & $150,0 / 13,7$ & $164,6 / 22,2$ & $159,1 / 22,1$ & $150,7 / 8,8$ \\
$\mathbf{2 5}$ & $\mathbf{5}$ & $157,1 / 14,1$ & $176,1 / 19,0$ & $171,8 / 18,8$ & $160,3 / 22,5$ & $162,9 / 14,6$ \\
\hline
\end{tabular}

Tabela 2.12 - Custos médios de alinhamentos para operação de HPT entre Campinas e Poços de Caldas [(Média / Desvio Padrão) $\cdot 10^{7} \mathrm{R} \$ / \mathrm{km}$ ]

\begin{tabular}{ccccccc}
\hline \multirow{2}{*}{$\begin{array}{l}\text { Distância média } \\
\text { entre PIs }(\mathbf{k m})\end{array}$} & $\begin{array}{l}\text { Número } \\
\text { de PIs }\end{array}$ & \multicolumn{5}{c}{ Número de Máquinas Virtuais Disponíveis } \\
\cline { 3 - 7 } & & $\mathbf{1}$ & $\mathbf{5}$ & $\mathbf{1 0}$ & $\mathbf{2 5}$ & $\mathbf{5 0}$ \\
\hline $\mathbf{5}$ & $\mathbf{2 4}$ & $5,41 / 0,51$ & $4,94 / 0,71$ & $5,12 / 0,50$ & $5,10 / 0,44$ & $5,45 / 1,19$ \\
$\mathbf{1 0}$ & $\mathbf{1 2}$ & $6,42 / 0,98$ & $6,20 / 1,26$ & $6,35 / 1,51$ & $6,11 / 0,84$ & $6,89 / 0,71$ \\
$\mathbf{1 5}$ & $\mathbf{8}$ & $7,29 / 0,82$ & $6,84 / 0,65$ & $7,27 / 1,22$ & $7,27 / 0,86$ & $6,94 / 1,00$ \\
$\mathbf{2 0}$ & $\mathbf{6}$ & $8,07 / 0,56$ & $7,69 / 0,40$ & $7,75 / 0,76$ & $7,01 / 1,36$ & $7,33 / 0,84$ \\
$\mathbf{2 5}$ & $\mathbf{5}$ & $8,59 / 1,13$ & $7,88 / 0,81$ & $8,22 / 0,86$ & $8,35 / 0,58$ & $7,89 / 0,93$ \\
\hline
\end{tabular}



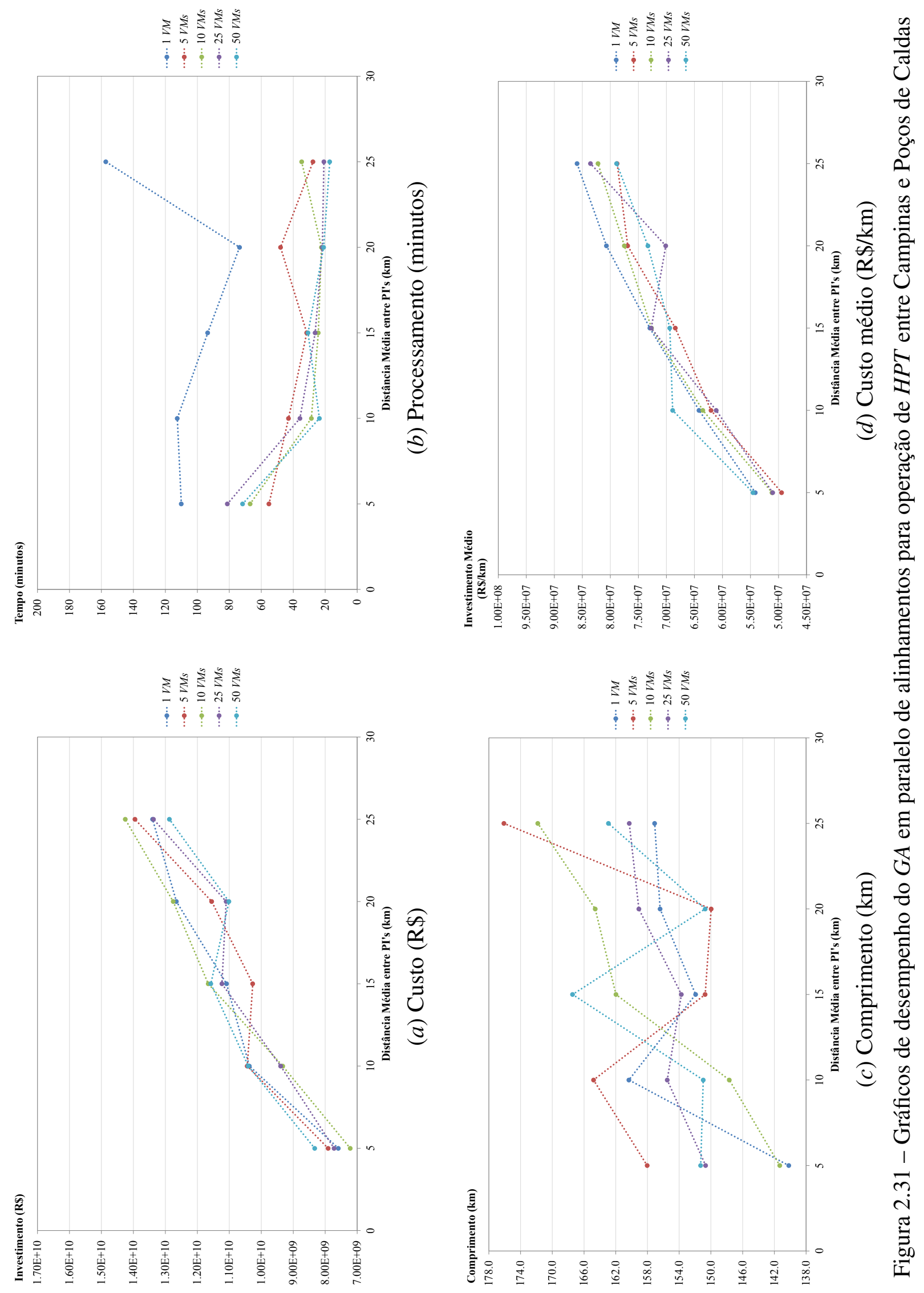
Tabela 2.13 - Custos totais de alinhamentos para operação de HST entre Campinas e Poços de Caldas [(Média / Desvio Padrão) $\cdot 10^{9} \mathrm{R} \$$ ]

\begin{tabular}{ccccccc}
\hline \multirow{2}{*}{$\begin{array}{l}\text { Distância média } \\
\text { entre PIs }(\mathbf{k m})\end{array}$} & $\begin{array}{l}\text { Número } \\
\text { de PIs }\end{array}$ & \multicolumn{5}{c}{ Número de Máquinas Virtuais Disponíveis } \\
\cline { 3 - 7 } & & $\mathbf{1}$ & $\mathbf{5}$ & $\mathbf{1 0}$ & $\mathbf{2 5}$ & $\mathbf{5 0}$ \\
\hline $\mathbf{5}$ & $\mathbf{2 4}$ & $8,16 / 1,61$ & $7,78 / 0,75$ & $8,21 / 1,60$ & $8,54 / 1,14$ & $7,98 / 1,60$ \\
$\mathbf{1 0}$ & $\mathbf{1 2}$ & $10,53 / 2,07$ & $9,54 / 1,03$ & $10,52 / 0,97$ & $9,83 / 1,54$ & $10,31 / 2,10$ \\
$\mathbf{1 5}$ & $\mathbf{8}$ & $10,51 / 0,88$ & $10,92 / 1,36$ & $11,30 / 1,62$ & $11,13 / 2,51$ & $11,62 / 1,95$ \\
$\mathbf{2 0}$ & $\mathbf{6}$ & $12,09 / 1,20$ & $12,64 / 1,94$ & $11,37 / 1,16$ & $11,38 / 2,08$ & $11,97 / 1,41$ \\
$\mathbf{2 5}$ & $\mathbf{5}$ & $12,13 / 2,35$ & $12,05 / 1,36$ & $12,54 / 2,37$ & $13,00 / 2,60$ & $14,99 / 1,24$ \\
\hline
\end{tabular}

Tabela 2.14 - Tempo de processamento para obtenção das soluções de alinhamentos para operação de HST entre Campinas e Poços de Caldas [(Média / Desvio Padrão) minutos]

\begin{tabular}{ccccccc}
\hline \multirow{2}{*}{$\begin{array}{l}\text { Distância média } \\
\text { entre PIs }(\mathbf{k m})\end{array}$} & $\begin{array}{l}\text { Número } \\
\text { de PIs }\end{array}$ & \multicolumn{5}{c}{ Número de Máquinas Virtuais Disponíveis } \\
\cline { 3 - 7 } & & $\mathbf{1}$ & $\mathbf{5}$ & $\mathbf{1 0}$ & $\mathbf{2 5}$ & $\mathbf{5 0}$ \\
\hline $\mathbf{5}$ & $\mathbf{2 4}$ & $193 / 83$ & $57 / 35$ & $44 / 11$ & $54 / 11$ & $63 / 46$ \\
$\mathbf{1 0}$ & $\mathbf{1 2}$ & $109 / 54$ & $41 / 25$ & $35 / 16$ & $41 / 20$ & $36 / 12$ \\
$\mathbf{1 5}$ & $\mathbf{8}$ & $111 / 40$ & $46 / 21$ & $33 / 17$ & $30 / 12$ & $27 / 17$ \\
$\mathbf{2 0}$ & $\mathbf{6}$ & $112 / 27$ & $41 / 33$ & $21 / 14$ & $19 / 11$ & $22 / 12$ \\
$\mathbf{2 5}$ & $\mathbf{5}$ & $107 / 44$ & $50 / 31$ & $17 / 9$ & $17 / 12$ & $21 / 4$ \\
\hline
\end{tabular}

Tabela 2.15 - Comprimentos dos alinhamentos para operação de HST entre Campinas e Poços de Caldas [(Média / Desvio Padrão) km]

\begin{tabular}{ccccccc}
\hline \multirow{2}{*}{$\begin{array}{c}\text { Distância média } \\
\text { entre PIs }(\mathbf{k m})\end{array}$} & $\begin{array}{l}\text { Número } \\
\text { de PIs }\end{array}$ & \multicolumn{5}{c}{ Número de Máquinas Virtuais Disponíveis } \\
\cline { 3 - 7 } & & $\mathbf{1}$ & $\mathbf{5}$ & $\mathbf{1 0}$ & $\mathbf{2 5}$ & $\mathbf{5 0}$ \\
\hline $\mathbf{5}$ & $\mathbf{2 4}$ & $147,8 / 8,5$ & $149,0 / 11,1$ & $150,3 / 10,0$ & $153,3 / 8,9$ & $148,2 / 7,3$ \\
$\mathbf{1 0}$ & $\mathbf{1 2}$ & $158,2 / 23,1$ & $151,0 / 6,6$ & $150,0 / 4,6$ & $147,7 / 7,7$ & $151,9 / 5,7$ \\
$\mathbf{1 5}$ & $\mathbf{8}$ & $143,9 / 8,7$ & $155,9 / 17,8$ & $160,3 / 13,8$ & $151,7 / 13,7$ & $162,6 / 22,3$ \\
$\mathbf{2 0}$ & $\mathbf{6}$ & $161,9 / 12,1$ & $156,4 / 21,8$ & $152,8 / 17,8$ & $167,6 / 21,3$ & $149,1 / 10,6$ \\
$\mathbf{2 5}$ & $\mathbf{5}$ & $154,9 / 17,6$ & $152,5 / 3,4$ & $163,6 / 22,6$ & $175,2 / 22,8$ & $158,9 / 17,1$ \\
\hline
\end{tabular}

Tabela 2.16 - Custos médios de alinhamentos para operação de HST entre Campinas e Poços de Caldas [(Média / Desvio Padrão) $\cdot 10^{7} \mathrm{R} \$ / \mathrm{km}$ ]

\begin{tabular}{ccccccc}
\hline \multirow{2}{*}{$\begin{array}{l}\text { Distância média } \\
\text { entre PIs }(\mathbf{k m})\end{array}$} & $\begin{array}{l}\text { Número } \\
\text { de PIs }\end{array}$ & \multicolumn{5}{c}{ Número de Máquinas Virtuais Disponíveis } \\
\cline { 3 - 7 } & & $\mathbf{1}$ & $\mathbf{5}$ & $\mathbf{1 0}$ & $\mathbf{2 5}$ & $\mathbf{5 0}$ \\
\hline $\mathbf{5}$ & $\mathbf{2 4}$ & $5,50 / 0,92$ & $5,24 / 0,63$ & $5,43 / 0,76$ & $5,58 / 0,80$ & $5,37 / 0,90$ \\
$\mathbf{1 0}$ & $\mathbf{1 2}$ & $6,62 / 0,53$ & $6,32 / 0,68$ & $7,02 / 0,66$ & $6,65 / 0,89$ & $6,79 / 1,37$ \\
$\mathbf{1 5}$ & $\mathbf{8}$ & $7,35 / 1,03$ & $7,01 / 0,25$ & $7,06 / 0,91$ & $7,31 / 1,30$ & $7,14 / 0,52$ \\
$\mathbf{2 0}$ & $\mathbf{6}$ & $7,49 / 0,89$ & $8,08 / 0,60$ & $7,47 / 0,66$ & $6,77 / 0,67$ & $8,03 / 0,77$ \\
$\mathbf{2 5}$ & $\mathbf{5}$ & $7,82 / 1,09$ & $7,92 / 1,03$ & $7,66 / 0,78$ & $7,40 / 1,06$ & $9,51 / 0,99$ \\
\hline
\end{tabular}



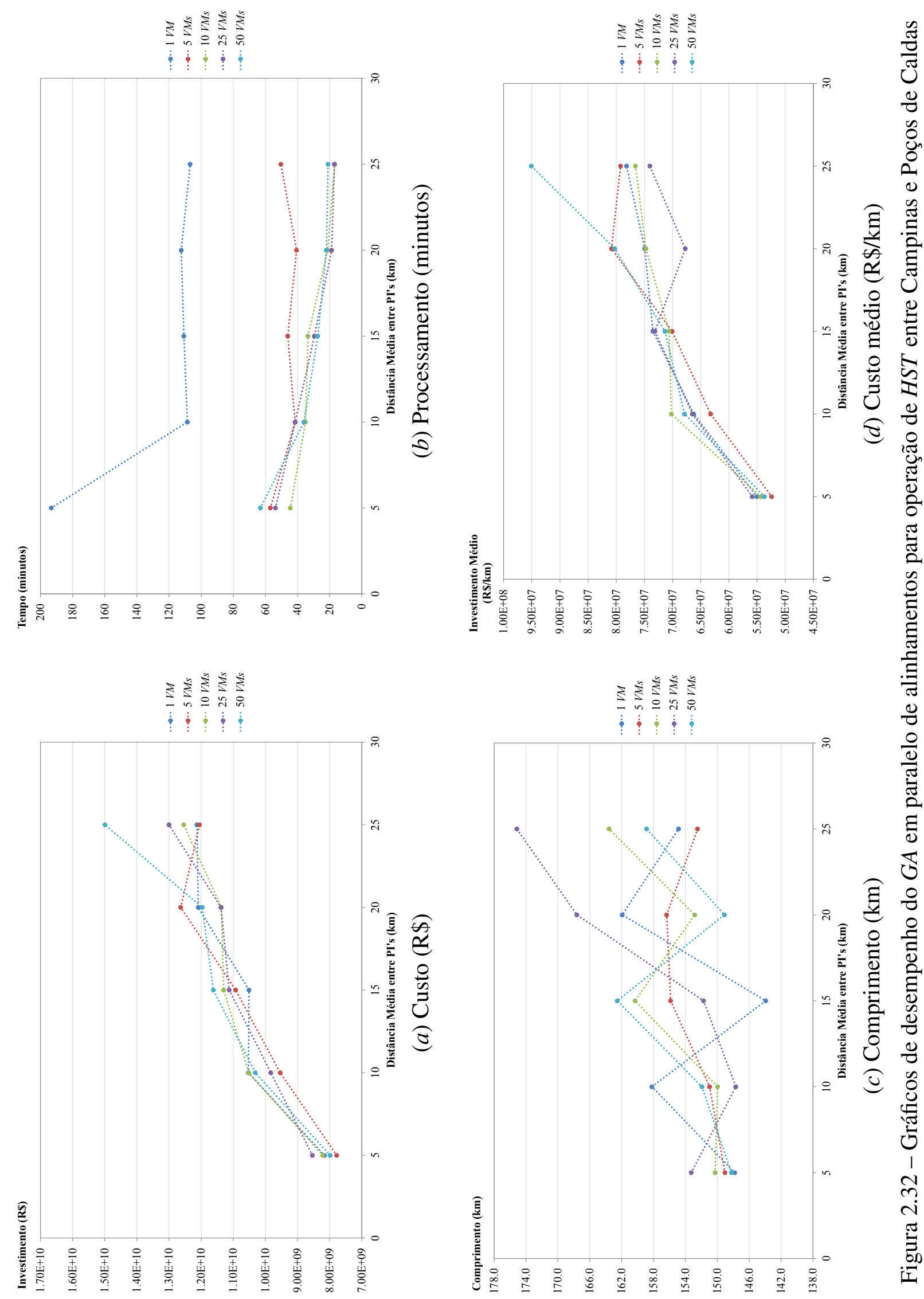
As tendências observadas para obtenção dos traçados entre Rio de Janeiro e Juiz de Fora são semelhantes às identificadas para os alinhamentos que viabilizam a operação de HPTs e HSTs entre Campinas e Poços de Caldas, apesar da diferença em termos da magnitude dos valores obtidos. Para os traçados entre Campinas e Poços de Caldas observa-se uma menor dispersão dos valores médios de custos totais, o que pode ser justificado pela maior uniformidade da topografia dessa região como indicado na Figura 2.31 e Figura 2.32.

Os tempos de processamento também reduzem-se consideravelmente quando o número de $V M s$ varia de uma para cinco, sem redução acentuada até 50 máquinas virtuais. Nesse cenário, os comprimentos médios aumentam gradualmente quando a distância média entre PIs aumenta, com valor médio mínimo de 140,2 km (desvio padrão de 4,7 km) para as replicações com distância de $5 \mathrm{~km}$ entre PIs e uma máquina virtual, e máximo médio de 176,1km (desvio padrão 19,0 km) nas replicações com distância de $25 \mathrm{~km}$ entre PIs e 5 VMs disponíveis para obtenção de traçados de HPT.

Para HSTs o valor médio mínimo dos comprimentos é de 143,9 km (desvio padrão de 8,7 km) para as replicações com distância média de $15 \mathrm{~km}$ entre PIs e uma $V M s$ disponível, e o valor máximo médio é de 175,2 km (desvio padrão de 22,8km) nas replicações com distância média de $25 \mathrm{~km}$ entre PIs e 25 máquinas virtuais disponíveis para processamento.

Em relação ao custo por quilômetro, no caso de novos alinhamentos para operação de HPTs entre Campinas e Poços de Caldas, o valor médio mínimo é de $\mathrm{R} \$ 4,96 \cdot 10^{7} / \mathrm{km}$ (desvio padrão de $\mathrm{R} \$ 0,71 \cdot 10^{7} / \mathrm{km}$ ) para replicações com 24 PIs e $5 \mathrm{VMs}$, com aumento proporcional à distância média entre PIs.

No caso dos $H S T$ s o valor médio mínimo é de $\mathrm{R} \$ 5,24 \cdot 10^{7} / \mathrm{km}$ (desvio padrão de $\mathrm{R} \$ 0,63 \cdot 10^{7} / \mathrm{km}$ ) também para as replicações com 24 PIs e 5 VMs. Novamente, esses valores médios não variam significativamente em relação à tecnologia ferroviária, porém observa-se uma redução dos custos médios entre Campinas e Poços de Caldas em relação ao cenário anterior.

O último cenário analisado foi entre as cidades de Ribeirão Preto e Araraquara (interior de São Paulo), cujos valores das replicações são apresentados entre a Tabela 2.17 e a Tabela 2.24 e nos gráficos da Figura 2.33 e Figura 2.34 para operação de HPTs e HSTs respectivamente. 
Tabela 2.17 - Custos totais de alinhamentos para operação de HPT entre Ribeirão Preto e Araraquara [(Média / Desvio Padrão) $10^{9} \mathrm{R} \$$ ]

\begin{tabular}{ccccccc}
\hline Distância média & \multirow{2}{*}{$\begin{array}{l}\text { Número } \\
\text { entre PIs (km) }\end{array}$} & \multicolumn{5}{c}{ Número de Máquinas Virtuais Disponíveis } \\
\cline { 3 - 7 } & & $\mathbf{1}$ & $\mathbf{5}$ & $\mathbf{1 0}$ & $\mathbf{2 5}$ & $\mathbf{5 0}$ \\
\hline $\mathbf{5}$ & $\mathbf{1 4}$ & $2,49 / 0,48$ & $2,43 / 0,36$ & $2,75 / 1,36$ & $2,42 / 0,58$ & $2,28 / 0,91$ \\
$\mathbf{1 0}$ & $\mathbf{7}$ & $3,76 / 0,94$ & $3,60 / 0,86$ & $3,16 / 0,49$ & $3,6 / 1,08$ & $3,19 / 1,21$ \\
$\mathbf{1 5}$ & $\mathbf{5}$ & $3,54 / 0,38$ & $3,61 / 0,36$ & $3,35 / 0,61$ & $3,91 / 1,68$ & $3,65 / 0,68$ \\
$\mathbf{2 0}$ & $\mathbf{4}$ & $5,36 / 1,87$ & $4,52 / 1,19$ & $4,72 / 1,04$ & $4,25 / 1,03$ & $4,31 / 0,73$ \\
$\mathbf{2 5}$ & $\mathbf{3}$ & $5,42 / 0,59$ & $5,09 / 0,81$ & $4,90 / 0,76$ & $4,39 / 0,37$ & $4,28 / 0,65$ \\
\hline
\end{tabular}

Tabela 2.18 - Tempo de processamento para obtenção das soluções de alinhamentos para operação de HPT entre Ribeirão Preto e Araraquara [(Média / Desvio Padrão) minutos]

\begin{tabular}{ccccccc}
\hline Distância média & \multirow{2}{*}{$\begin{array}{l}\text { Número } \\
\text { entre PIs (km) }\end{array}$} & \multicolumn{5}{c}{ Número de Máquinas Virtuais Disponíveis } \\
\cline { 3 - 7 } & & $\mathbf{1}$ & $\mathbf{5}$ & $\mathbf{1 0}$ & $\mathbf{2 5}$ & $\mathbf{5 0}$ \\
\hline $\mathbf{5}$ & $\mathbf{1 4}$ & $142 / 108$ & $44 / 18$ & $30 / 14$ & $24 / 13$ & $42 / 9$ \\
$\mathbf{1 0}$ & $\mathbf{7}$ & $110 / 69$ & $20 / 8$ & $28 / 4$ & $17 / 5$ & $19 / 9$ \\
$\mathbf{1 5}$ & $\mathbf{5}$ & $137 / 48$ & $33 / 12$ & $20 / 13$ & $15 / 4$ & $18 / 5$ \\
$\mathbf{2 0}$ & $\mathbf{4}$ & $149 / 68$ & $25 / 12$ & $18 / 5$ & $17 / 5$ & $14 / 8$ \\
$\mathbf{2 5}$ & $\mathbf{3}$ & $95 / 52$ & $27 / 2$ & $10 / 2$ & $11 / 2$ & $14 / 3$ \\
\hline
\end{tabular}

Tabela 2.19 - Comprimentos dos alinhamentos para operação de HPT entre Ribeirão Preto e Araraquara [(Média / Desvio Padrão) km]

\begin{tabular}{ccccccc}
\hline Distância média & \multirow{2}{*}{$\begin{array}{l}\text { Número } \\
\text { entre PIs (km) }\end{array}$} & \multicolumn{5}{c}{ Número de Máquinas Virtuais Disponíveis } \\
\cline { 3 - 7 } & & $\mathbf{1}$ & $\mathbf{5}$ & $\mathbf{1 0}$ & $\mathbf{2 5}$ & $\mathbf{5 0}$ \\
\hline $\mathbf{5}$ & $\mathbf{1 4}$ & $95,6 / 11,6$ & $100,0 / 10,2$ & $101,7 / 13,3$ & $98,0 / 14,9$ & $106,8 / 21,9$ \\
$\mathbf{1 0}$ & $\mathbf{7}$ & $104,4 / 16,8$ & $99,9 / 11,1$ & $104,4 / 10,7$ & $113,9 / 30,4$ & $95,9 / 6,9$ \\
$\mathbf{1 5}$ & $\mathbf{5}$ & $99,9 / 5,5$ & $102,4 / 15,5$ & $96,8 / 7,1$ & $100,4 / 16,5$ & $101,8 / 8,1$ \\
$\mathbf{2 0}$ & $\mathbf{4}$ & $107,6 / 25,5$ & $113,4 / 24,7$ & $105,7 / 11,5$ & $98,8 / 8,6$ & $100,5 / 8,2$ \\
$\mathbf{2 5}$ & $\mathbf{3}$ & $100,7 / 5,6$ & $120,1 / 19,4$ & $103,0 / 8,8$ & $104,2 / 12,9$ & $101,5 / 14,6$ \\
\hline
\end{tabular}

Tabela 2.20 - Custos médios de alinhamentos para operação de HPT entre Ribeirão Preto e Araraquara [(Média / Desvio Padrão) $10^{7} \mathrm{R} \$ / \mathrm{km}$ ]

\begin{tabular}{ccccccc}
\hline \multirow{2}{*}{$\begin{array}{l}\text { Distância média } \\
\text { entre PIs }(\mathbf{k m})\end{array}$} & $\begin{array}{l}\text { Número } \\
\text { de PIs }\end{array}$ & \multicolumn{5}{c}{ Número de Máquinas Virtuais Disponíveis } \\
\cline { 3 - 7 } & & $\mathbf{1}$ & $\mathbf{5}$ & $\mathbf{1 0}$ & $\mathbf{2 5}$ & $\mathbf{5 0}$ \\
\hline $\mathbf{5}$ & $\mathbf{1 4}$ & $2,60 / 0,38$ & $2,43 / 0,33$ & $2,61 / 1,01$ & $2,51 / 0,73$ & $2,11 / 0,67$ \\
$\mathbf{1 0}$ & $\mathbf{7}$ & $3,68 / 1,13$ & $3,57 / 0,45$ & $3,01 / 0,17$ & $3,22 / 0,94$ & $3,30 / 1,05$ \\
$\mathbf{1 5}$ & $\mathbf{5}$ & $3,54 / 0,28$ & $3,56 / 0,40$ & $3,46 / 0,53$ & $3,79 / 1,02$ & $3,62 / 0,82$ \\
$\mathbf{2 0}$ & $\mathbf{4}$ & $4,95 / 1,13$ & $3,99 / 0,76$ & $4,44 / 0,61$ & $4,27 / 0,78$ & $4,33 / 0,95$ \\
$\mathbf{2 5}$ & $\mathbf{3}$ & $5,39 / 0,60$ & $4,29 / 0,73$ & $4,73 / 0,37$ & $4,23 / 0,17$ & $4,30 / 0,91$ \\
\hline
\end{tabular}



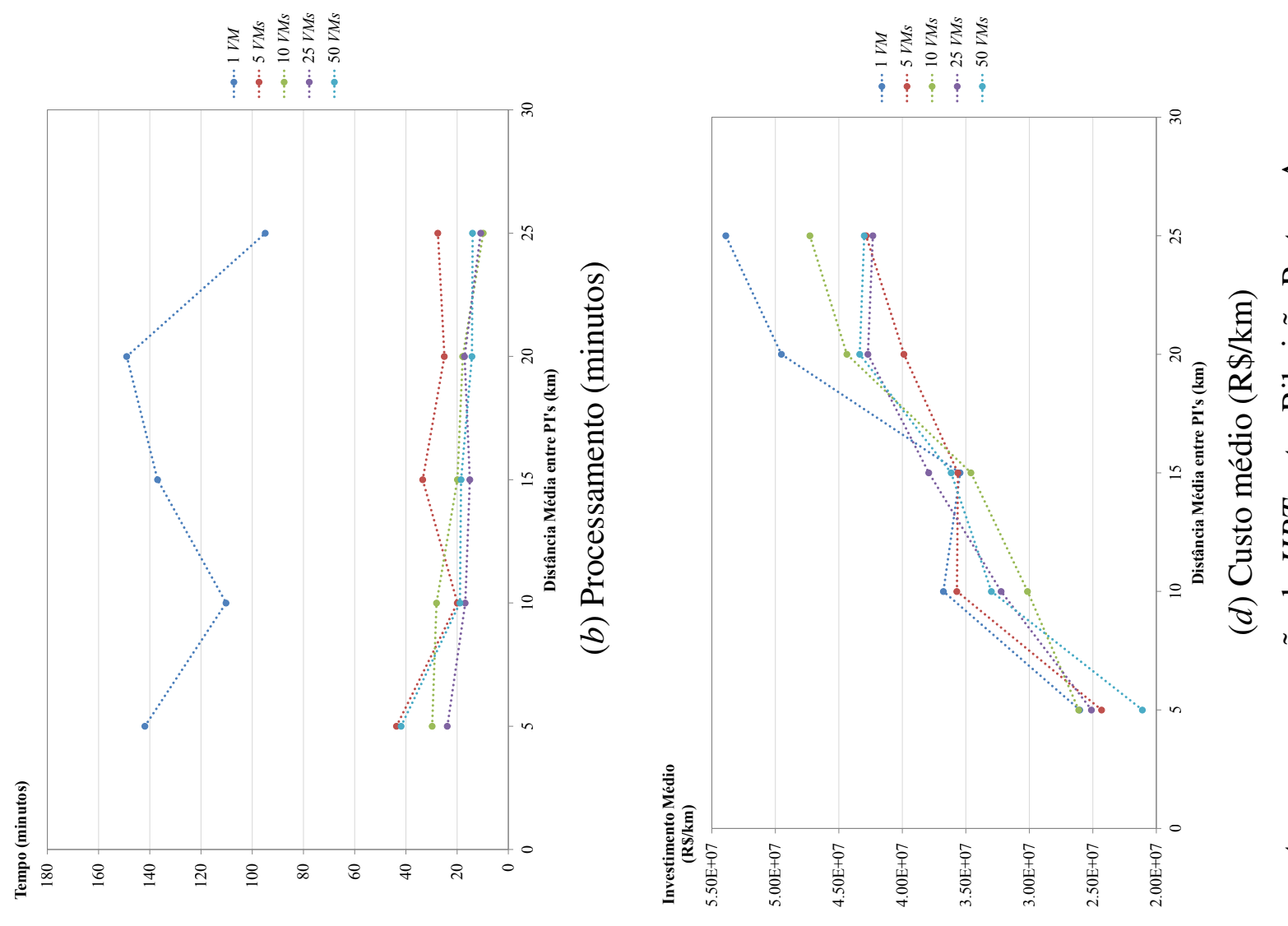

₹

ב

की
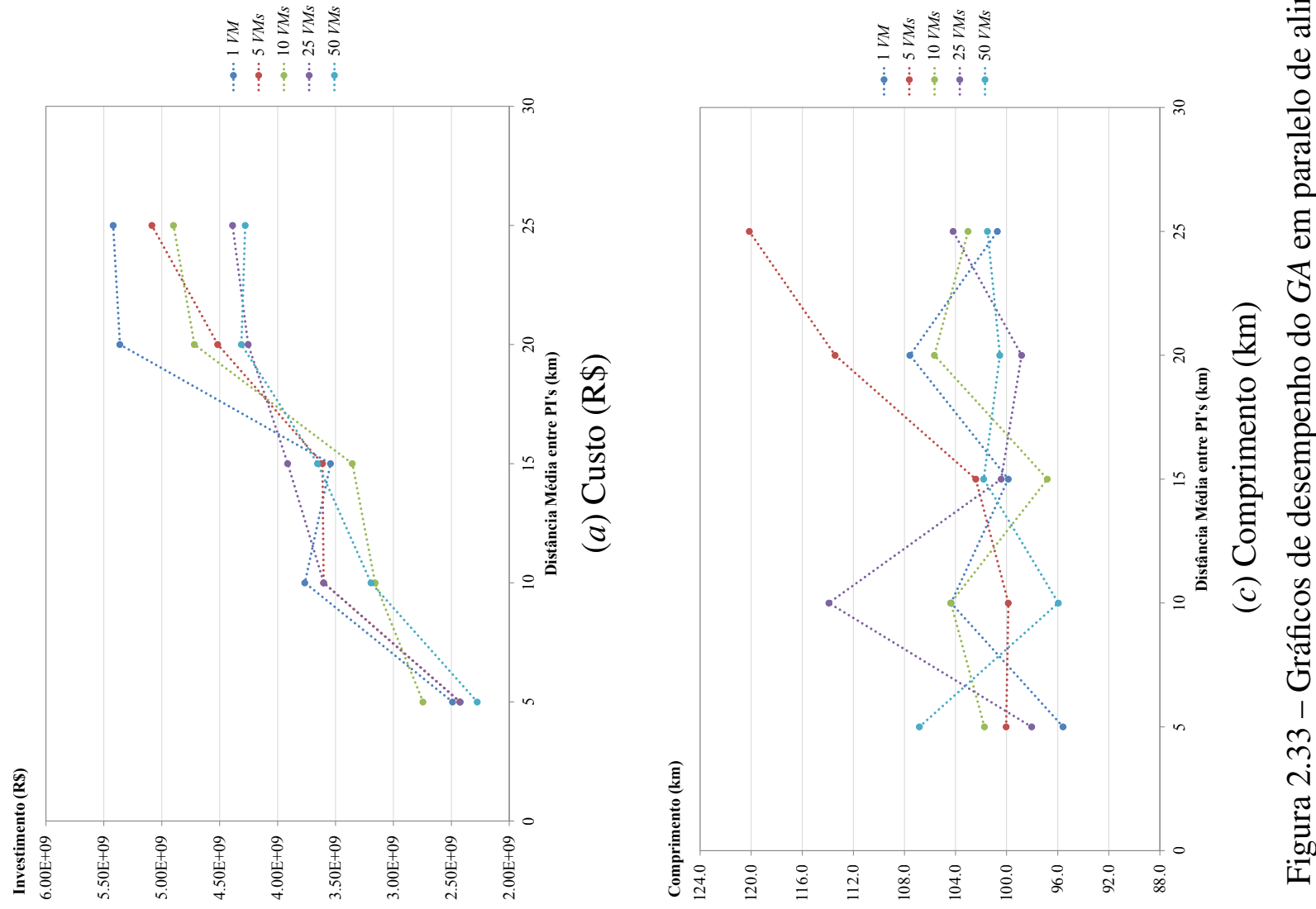
Tabela 2.21 - Custos totais de alinhamentos para operação de HST entre Ribeirão Preto e Araraquara [(Média / Desvio Padrão) $\cdot 10^{9} \mathrm{R} \$$ ]

\begin{tabular}{ccccccc}
\hline Distância média & Número & \multicolumn{5}{c}{ Número de Máquinas Virtuais Disponíveis } \\
\cline { 3 - 7 } entre PIs (km) & de PIs & $\mathbf{1}$ & $\mathbf{5}$ & $\mathbf{1 0}$ & $\mathbf{2 5}$ & $\mathbf{5 0}$ \\
\hline $\mathbf{5}$ & $\mathbf{1 4}$ & $2,38 / 0,31$ & $2,39 / 0,96$ & $2,40 / 0,52$ & $2,59 / 0,41$ & $2,96 / 1,34$ \\
$\mathbf{1 0}$ & $\mathbf{7}$ & $4,03 / 1,12$ & $3,62 / 1,21$ & $3,43 / 1,00$ & $3,44 / 0,72$ & $3,96 / 0,95$ \\
$\mathbf{1 5}$ & $\mathbf{5}$ & $4,86 / 0,69$ & $4,22 / 0,81$ & $4,09 / 0,60$ & $4,59 / 1,80$ & $3,68 / 0,75$ \\
$\mathbf{2 0}$ & $\mathbf{4}$ & $4,26 / 0,68$ & $4,56 / 0,99$ & $4,73 / 0,51$ & $5,38 / 1,13$ & $4,53 / 0,44$ \\
$\mathbf{2 5}$ & $\mathbf{3}$ & $5,48 / 0,60$ & $5,49 / 0,34$ & $5,36 / 1,55$ & $5,24 / 0,58$ & $5,54 / 0,72$ \\
\hline
\end{tabular}

Tabela 2.22 - Tempo de processamento para obtenção das soluções de alinhamentos para operação de $H S T$ entre Ribeirão Preto e Araraquara [(Média / Desvio Padrão) minutos]

\begin{tabular}{ccccccc}
\hline Distância média & \multirow{2}{*}{$\begin{array}{l}\text { Número } \\
\text { entre PIs (km) }\end{array}$} & \multicolumn{5}{c}{ Número de Máquinas Virtuais Disponíveis } \\
\cline { 3 - 7 } & & $\mathbf{1}$ & $\mathbf{5}$ & $\mathbf{1 0}$ & $\mathbf{2 5}$ & $\mathbf{5 0}$ \\
\hline $\mathbf{5}$ & $\mathbf{1 4}$ & $162 / 57$ & $50 / 19$ & $29 / 17$ & $29 / 7$ & $26 / 7$ \\
$\mathbf{1 0}$ & $\mathbf{7}$ & $101 / 38$ & $28 / 8$ & $23 / 5$ & $23 / 5$ & $30 / 21$ \\
$\mathbf{1 5}$ & $\mathbf{5}$ & $85 / 37$ & $20 / 12$ & $18 / 10$ & $14 / 7$ & $18 / 10$ \\
$\mathbf{2 0}$ & $\mathbf{4}$ & $68 / 41$ & $19 / 5$ & $17 / 11$ & $10 / 4$ & $13 / 4$ \\
$\mathbf{2 5}$ & $\mathbf{3}$ & $66 / 13$ & $14 / 6$ & $24 / 3$ & $21 / 8$ & $15 / 4$ \\
\hline
\end{tabular}

Tabela 2.23 - Comprimentos dos alinhamentos para operação de HST entre Ribeirão Preto e Araraquara [(Média / Desvio Padrão) km]

\begin{tabular}{ccccccc}
\hline Distância média & \multirow{2}{*}{$\begin{array}{l}\text { Número } \\
\text { entre PIs (km) }\end{array}$} & \multicolumn{5}{c}{ Número de Máquinas Virtuais Disponíveis } \\
\cline { 3 - 7 } & & $\mathbf{1}$ & $\mathbf{5}$ & $\mathbf{1 0}$ & $\mathbf{2 5}$ & $\mathbf{5 0}$ \\
\hline $\mathbf{5}$ & $\mathbf{1 4}$ & $93,4 / 8,2$ & $94,0 / 7,6$ & $90,3 / 4,8$ & $96,1 / 3,6$ & $96,3 / 9,7$ \\
$\mathbf{1 0}$ & $\mathbf{7}$ & $101,9 / 11,2$ & $100,0 / 15,6$ & $93,1 / 9,6$ & $100,9 / 9,9$ & $103,4 / 14,4$ \\
$\mathbf{1 5}$ & $\mathbf{5}$ & $104,3 / 10,1$ & $97,1 / 4,9$ & $109,5 / 22,2$ & $97,2 / 11,9$ & $92,4 / 2,9$ \\
$\mathbf{2 0}$ & $\mathbf{4}$ & $101,9 / 13,5$ & $97,3 / 8,5$ & $103,2 / 11,6$ & $105,2 / 22,1$ & $100,5 / 9,2$ \\
$\mathbf{2 5}$ & $\mathbf{3}$ & $107,6 / 7,8$ & $113,4 / 11,7$ & $107,4 / 18,4$ & $109,6 / 11,2$ & $107,4 / 18,6$ \\
\hline
\end{tabular}

Tabela 2.24 - Custos médios de alinhamentos para operação de HST entre Ribeirão Preto e Araraquara [(Média / Desvio Padrão) $10^{7} \mathrm{R} \$ / \mathrm{km}$ ]

\begin{tabular}{ccccccc}
\hline \multirow{2}{*}{$\begin{array}{c}\text { Distância média } \\
\text { entre PIs (km) }\end{array}$} & $\begin{array}{l}\text { Número } \\
\text { de PIs }\end{array}$ & \multicolumn{5}{c}{ Número de Máquinas Virtuais Disponíveis } \\
\cline { 3 - 7 } & & $\mathbf{1}$ & $\mathbf{5}$ & $\mathbf{1 0}$ & $\mathbf{2 5}$ & $\mathbf{5 0}$ \\
\hline $\mathbf{5}$ & $\mathbf{1 4}$ & $2,57 / 0,47$ & $2,52 / 0,87$ & $2,66 / 0,54$ & $2,69 / 0,34$ & $3,00 / 1,04$ \\
$\mathbf{1 0}$ & $\mathbf{7}$ & $3,98 / 1,11$ & $3,55 / 0,65$ & $3,64 / 0,79$ & $3,43 / 0,79$ & $3,82 / 0,62$ \\
$\mathbf{1 5}$ & $\mathbf{5}$ & $4,68 / 0,72$ & $4,34 / 0,77$ & $3,77 / 0,34$ & $4,62 / 1,17$ & $3,97 / 0,79$ \\
$\mathbf{2 0}$ & $\mathbf{4}$ & $4,24 / 0,92$ & $4,69 / 0,99$ & $4,63 / 0,74$ & $5,19 / 1,09$ & $4,53 / 0,50$ \\
$\mathbf{2 5}$ & $\mathbf{3}$ & $5,10 / 0,49$ & $4,87 / 0,37$ & $5,05 / 1,53$ & $4,82 / 0,62$ & $5,21 / 0,48$ \\
\hline
\end{tabular}



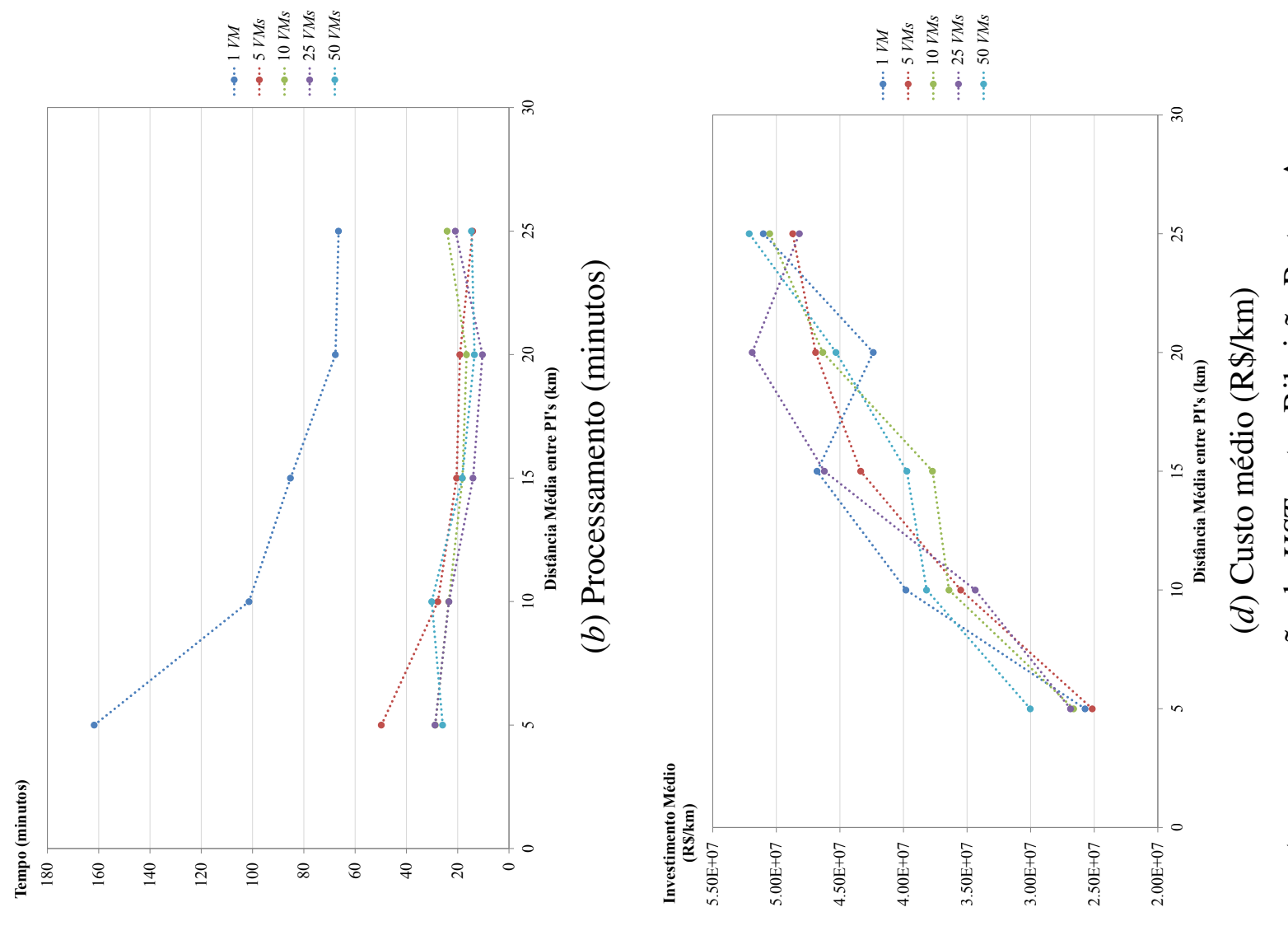

₹

בats

की
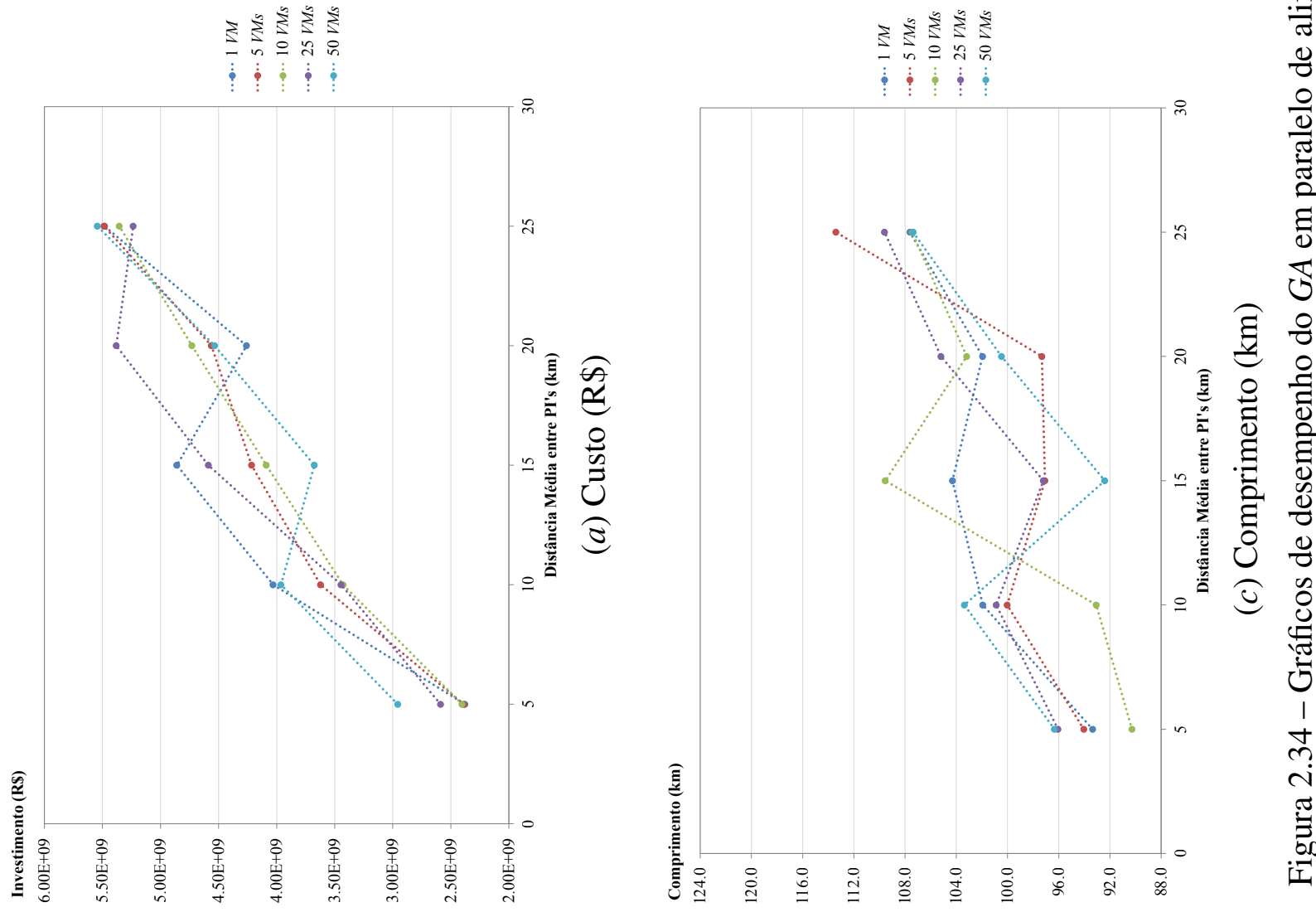
Os resultados referentes às possíveis conexões entre Araraquara e Ribeirão Preto indicam as mesmas tendências em relação aos cenários analisados anteriormente. Apesar dos custos médios aumentarem proporcionalmente com a distância média entre PIs, observa-se uma menor variabilidade desses resultados para ambas as tecnologias entre Campinas e Poços de Caldas em relação às análises do cenário anterior.

Os tempos de processamento são reduzidos consideravelmente quando o número de máquinas virtuais disponíveis para o processamento do $G A$ aumenta de 1 para 5, e esses valores reduzemse menos acentuadamente quando o número de VMs aumenta até 50. Para os traçados de HPTs, esse valor médio mínimo é de 95 minutos (desvio padrão de 52 minutos) para as replicações com $1 V M$ e 14 PIs, em detrimento de média mínima de 20 minutos (desvio padrão de 8 minutos) com 5 VMs e distância média entre PIs de $10 \mathrm{~km}$.

Para os traçados de HSTs, o tempo médio mínimo de processamento com uma máquina virtual é de 66 minutos (desvio parão de 13 minutos) nas replicações com distância média entre PIs de $25 \mathrm{~km}$. Nesse mesmo cenário com 5 VMs disponíveis, o tempo médio médio de processamento é de 14 minutos com desvio padrão de 6 minutos.

Em relação ao comprimento dos alinhamentos observa-se pouca variabilidade para os traçados de HPT, com comprimento médio mínimo de 95,6 km (desvio padrão de 11,6 km) para as replicações com uma máquina virtual e distância média entre PIs de $5 \mathrm{~km}$, e comprimento máximo médio de 120,1 km (desvio padrão de 19,4 km) para as replicações com cinco VMs e distância média de $25 \mathrm{~km}$ entre PIs.

Para os traçados compatíveis com os HSTs há uma tendência de aumento do comprimento do alinhamento com o maior distanciamento entre PIs. Quando esse valor é de $5 \mathrm{~km}$ e o número de máquinas virtuais é igual a dez, o comprimento médio mínimo é de 90,3km com desvio padrão de 4,8 km e, por outro lado, o comprimento máximo médio é de 113,4 km (desvio padrão de 11,7 km) nas replicações com distância média entre PIs de 25 km e cinco máquinas virtuais.

Em relação aos custos por quilômetro de ferrovia construída, observa-se um valor médio mínimo de $\mathrm{R} \$ 2,11 \cdot 10^{7} / \mathrm{km}$ (desvio padrão de $\mathrm{R} \$ 0,67 \cdot 10^{7} / \mathrm{km}$ ) para traçados que viabilizam a operação de HPTs nas replicações com $50 \mathrm{VMs}$ disponíveis e distância média de 5 km entre 
PIs, valor expressivamente menor que os identificados nos cenários anteriores.

Na mesma tendência quanto aos custos por quilômetro, os traçados para operação de $H S T S$ apresentam custos médios mínimos de $\mathrm{R} \$ 2,52 \cdot 10^{7} / \mathrm{km}$ (desvio padrão de $\mathrm{R} \$ 0,87 \cdot 10^{7} / \mathrm{km}$ ) nas replicações com distância média de $5 \mathrm{~km}$. Novamente, os valores médios mínimos por quilômetro mantém-se nos mesmos patamares seja qual for a tecnologia ferroviária escolhida para operação nos traçados, seguindo a tendência dos cenários anteriores.

Os resultados tabelados anteriormente referem-se aos valores médios obtidos pelas replicações dos diferentes cenários propostos para avaliação do desempenho do GA. A Tabela 2.25 a seguir apresenta o resumo das medidas de desempenho das replicações que resultaram nos custos mínimos para cada tecnologia contemplada nesta tese e cenários analisados.

Tabela 2.25 - Resultados relativos aos traçados de menor custo

\begin{tabular}{lrrrrrr}
\hline Cenário & \multicolumn{2}{c}{ Rio de Janeiro-Juiz de Fora } & \multicolumn{2}{c}{ Campinas-Poços de Caldas } & \multicolumn{2}{c}{ Araraquara-Ribeirão Preto } \\
\hline Tecnologia & $\boldsymbol{H P T}$ & $\boldsymbol{H S T}$ & $\boldsymbol{H P T}$ & $\boldsymbol{H S T}$ & $\boldsymbol{H P T}$ & $\boldsymbol{H S T}$ \\
\hline Distância Média entre PIs $(\mathrm{km})$ & 5,0 & 5,0 & 5,0 & 5,0 & 5,0 & 5,0 \\
Número de PIs & 19 & 19 & 24 & 24 & 14 & 14 \\
Gerações $G A$ & 340 & 877 & 645 & 1081 & 755 & 648 \\
Tempo de Processamento (minutos) & 23 & 58 & 67 & 93 & 47 & 35 \\
Custo total $\left(\mathrm{R} \$ \cdot 10^{9}\right)$ & 7,00 & 7,67 & 6,19 & 6,23 & 1,51 & 1,87 \\
Comprimento $(\mathrm{km})$ & 111,1 & 106,7 & 146,3 & 149,1 & 94,5 & 87,9 \\
Custo por quilômetro $\left(\mathrm{R} \$ \cdot 10^{6} / \mathrm{km}\right)$ & 62,98 & 71,87 & 42,33 & 41,75 & 15,94 & 21,22 \\
Superestrutura $\left(\mathrm{R} \$ \cdot 10^{9}\right)$ & $0,17(2,7 \%)$ & $0,45(6,5 \%)$ & $0,23(4,0 \%)$ & $0,63(11,1 \%)$ & $0,15(10,7 \%)$ & $0,37(21,9 \%)$ \\
Terraplenagem $\left(\mathrm{R} \$ \cdot 10^{9}\right)$ & $0,63(9,9 \%)$ & $0,57(8,2 \%)$ & $0,71(12,6 \%)$ & $0,68(12,1 \%)$ & $0,25(18,2 \%)$ & $0,37(21,9 \%)$ \\
Túneis $\left(\mathrm{R} \$ \cdot 10^{9}\right)$ & $4,12(64,7 \%)$ & $4,48(64,3 \%)$ & $2,64(46,9 \%)$ & $3,22(57,0 \%)$ & $0,51(37,2 \%)$ & $0,47(27,6 \%)$ \\
Pontes e Viadutos $\left(\mathrm{R} \$ \cdot 10^{9}\right)$ & $1,42(22,3 \%)$ & $1,44(20,7 \%)$ & $2,02(36,0 \%)$ & $1,10(19,4 \%)$ & $0,45(32,8 \%)$ & $0,47(27,8 \%)$ \\
Desapropriações $\left(\mathrm{R} \$ \cdot 10^{9}\right)$ & $0,02(0,4 \%)$ & $0,02(0,3 \%)$ & $0,03(0,5 \%)$ & $0,03(0,5 \%)$ & $0.02(1,1 \%)$ & $0.01(0,8 \%)$ \\
\hline
\end{tabular}

Os resultados apresentados nessa tabela mostram que os custos totais de traçados compatíveis para operação de HSTs em geral são maiores que os de $H P T$, porém relativamente próximos para todos os cenários analisados. Entretanto, no cenário entre Campinas e Poços de Caldas o custo médio para construção de traçados para operação daquela tecnologia ( $\mathrm{R} \$ 41,75 \cdot 10^{6} / \mathrm{km}$ ) é menor do que para a operação de HPTs $\left(\mathrm{R} \$ 42,33 \cdot 10^{6} / \mathrm{km}\right)$.

Além disso, os itens mais expressivos de custos totais para ambas as tecnologias são: túneis (com máximo de 64,7\% na conexão por HPT entre o Rio de Janeiro e Juiz de Fora); pontes e viadutos (máximo de 36,0\% para HPT entre Campinas e Poços de Caldas); e terraplenagem (máximo de 21,9\% para HST entre Araraquara e Ribeirão Preto). 
A comparação entre os custos de construção dos traçados para operação de HPTs e HSTs indica que os parâmetros geométricos que definem esses alinhamentos não afetam os valores dos custos totais na mesma proporção que as características da topografia onde pretende-se implantar os sistemas. Isso ocorre devido à maior influência dos itens de terraplenagem e custos de obras de arte (túneis, pontes e viadutos).

Sob a premissa de que é inviável a utilização da infraestrutura ferroviária existente - cujas características geométricas são inadequadas à operação das tecnologias consideradas nesta tese -, os valores apresentados nesse capítulo podem ser, portanto, considerados realistas e válidos para aplicação de uma análise custo-benefício como apresentado nesta tese.

Além das considerações anteriores, a Figura 2.35 apresenta os valores mínimos e máximos dos custos de construção de infraestrutura ferroviária para operação de HSTs em diferentes países. Considerando uma cotação média de $\mathrm{R} \$ 3,10$ para 1,00 € no período entre 19/01/2015 e 19/05/2014 (BCB, 2015b), o intervalo dos custos totais é definido entre os valores aproximados mínimo de $\mathrm{R} \$ 14,6 \cdot 10^{6} / \mathrm{km}$ (França) e máximo de $\mathrm{R} \$ 204,3 \cdot 10^{6} / \mathrm{km}$ (Itália).

Esses resultados indicam que, apesar das particularidades da topografia do território brasileiro e das premissas consideradas na execução do $G A$, os valores de custo médio indicados nas tabelas anteriores são, em média, da mesma ordem de grandeza daqueles observados em projetos internacionais.

Esse argumento pode ser confirmado pela análise dos valores de custo médio por quilômetro aplicados mundialmente na construção de infraestrutura para operação de Trens de Alta Velocidade conforme ilustrado na Figura 2.35. Enquanto a média mundial do custo por quilômetro de ferrovia para $H S T$ é da ordem de $\mathrm{R} \$ 78,4 \cdot 10^{6} / \mathrm{km}$, o valor médio obtido pelo $G A$ para essa tecnologia nas conexões estabelecidas anteriormente (Rio de Janeiro-Juiz de Fora, CampinasPoços de Caldas e Araraquara-Ribeirão Preto) é estimado em $\mathrm{R} \$ 65,9 \cdot 10^{6} / \mathrm{km}$, enquanto para a operação de $H P T$ o valor médio de $\mathrm{R} \$ 63,6 \cdot 10^{6} / \mathrm{km}$ é menor em comparação àquela tecnologia. 


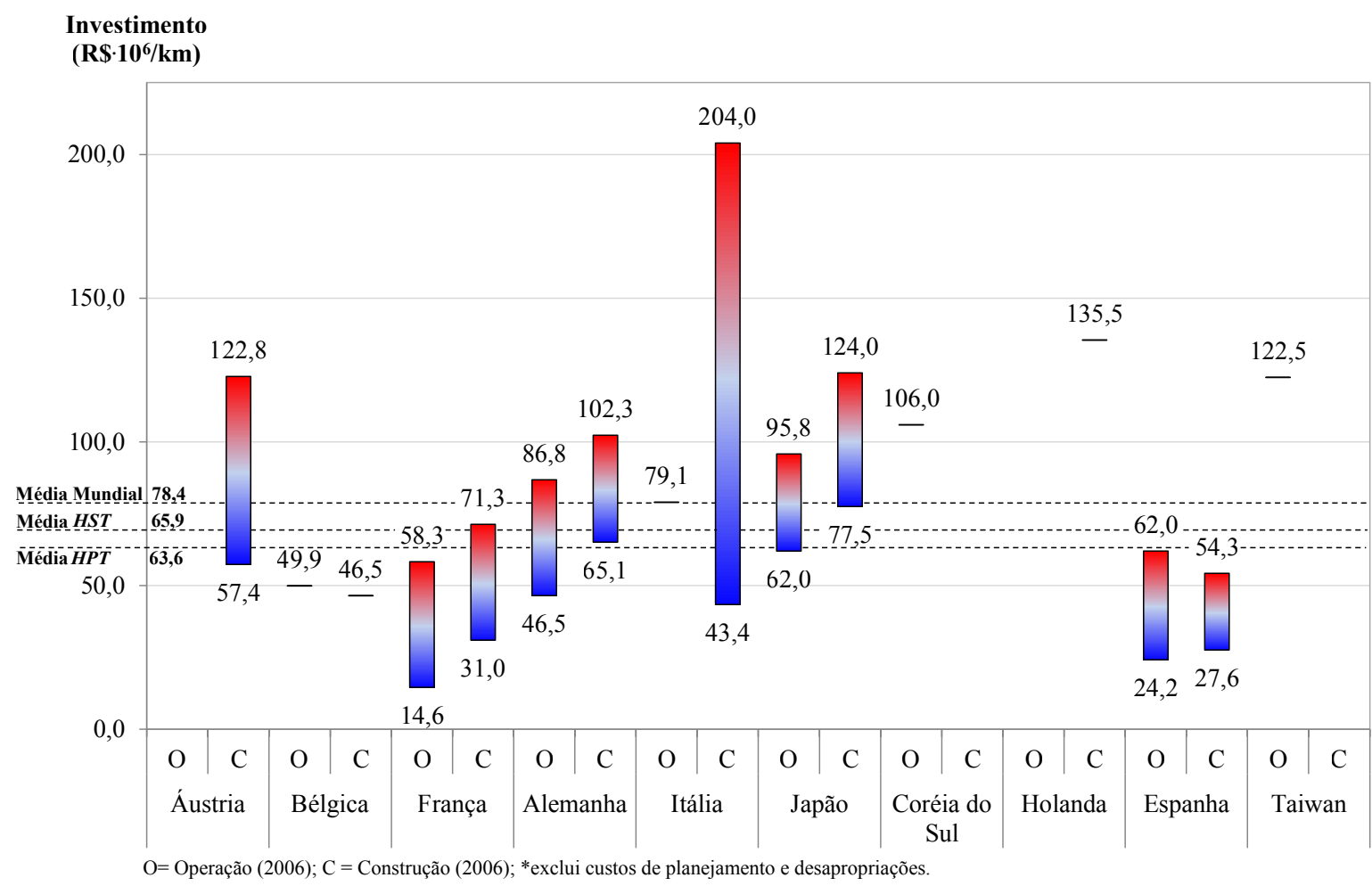

Figura 2.35 - Custos médios por quilômetro para construção de novos alinhamentos ferroviários de HST - Fonte: adaptado de De Rus et al. (2009)

Na comparação dos custos totais para construção de 10 linhas ferroviárias de alta velocidade na Europa, Gleave (2004) indica que os valores variam aproximadamente entre $\mathrm{R} \$ 31 \cdot 10^{6} / \mathrm{km}$ $\left(10 \cdot 10^{6} € / \mathrm{km}\right)$ na Espanha e França e entre $\mathrm{R} \$ 124 \cdot 10^{6} / \mathrm{km}$ e $\mathrm{R} \$ 155 \cdot 10^{6} / \mathrm{km}\left(40 \cdot 10^{6} € / \mathrm{km} \mathrm{e}\right.$ $\left.50 \cdot 10^{6} € / \mathrm{km}\right)$ na Itália. No caso específico da travessia do Canal da Mancha no projeto HS1 entre Londres e Paris, o custo final foi de aproximadamente $\mathrm{R} \$ 217 \cdot 10^{6} / \mathrm{km}\left(70 \cdot 10^{6} € / \mathrm{km}\right)$ devido aos elevados custos de construção dos túneis.

A seguir são apresentados os traçados obtidos pela execução do $G A$ entre as cidades de Rio de Janeiro e Juiz de Fora, Campinas e Poços de Caldas, e Araraquara e Ribeirão Preto adequados à operação de HPTs e HSTs. Para cada par de cidade e tecnologia ferroviária são representados os alinhamentos sobrepostos à projeção das vias existentes e ao raster de elevações do terreno, com indicação das áreas urbanas, e as respectiva seções longitudinais. 

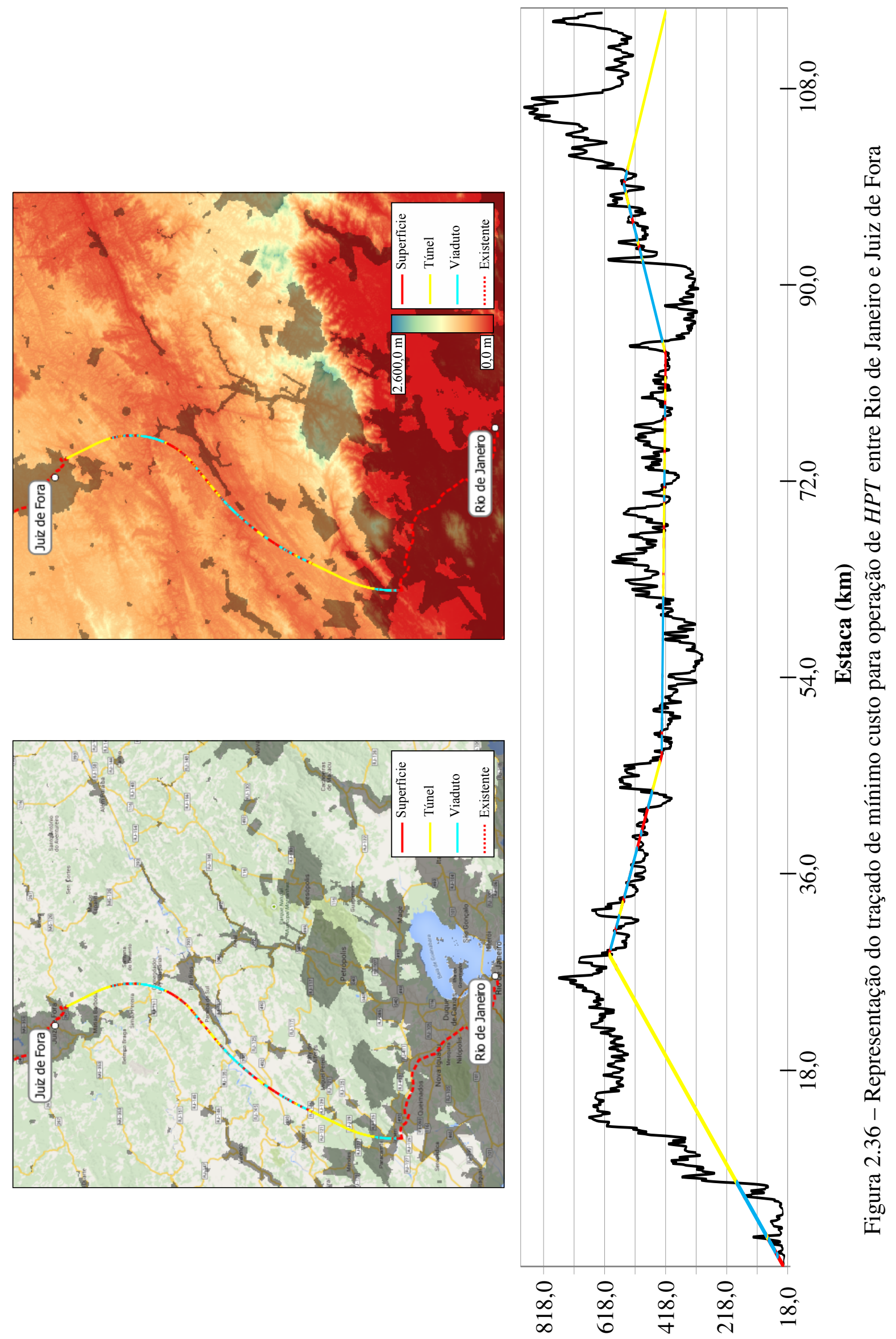

(u) วpm!ฺ 

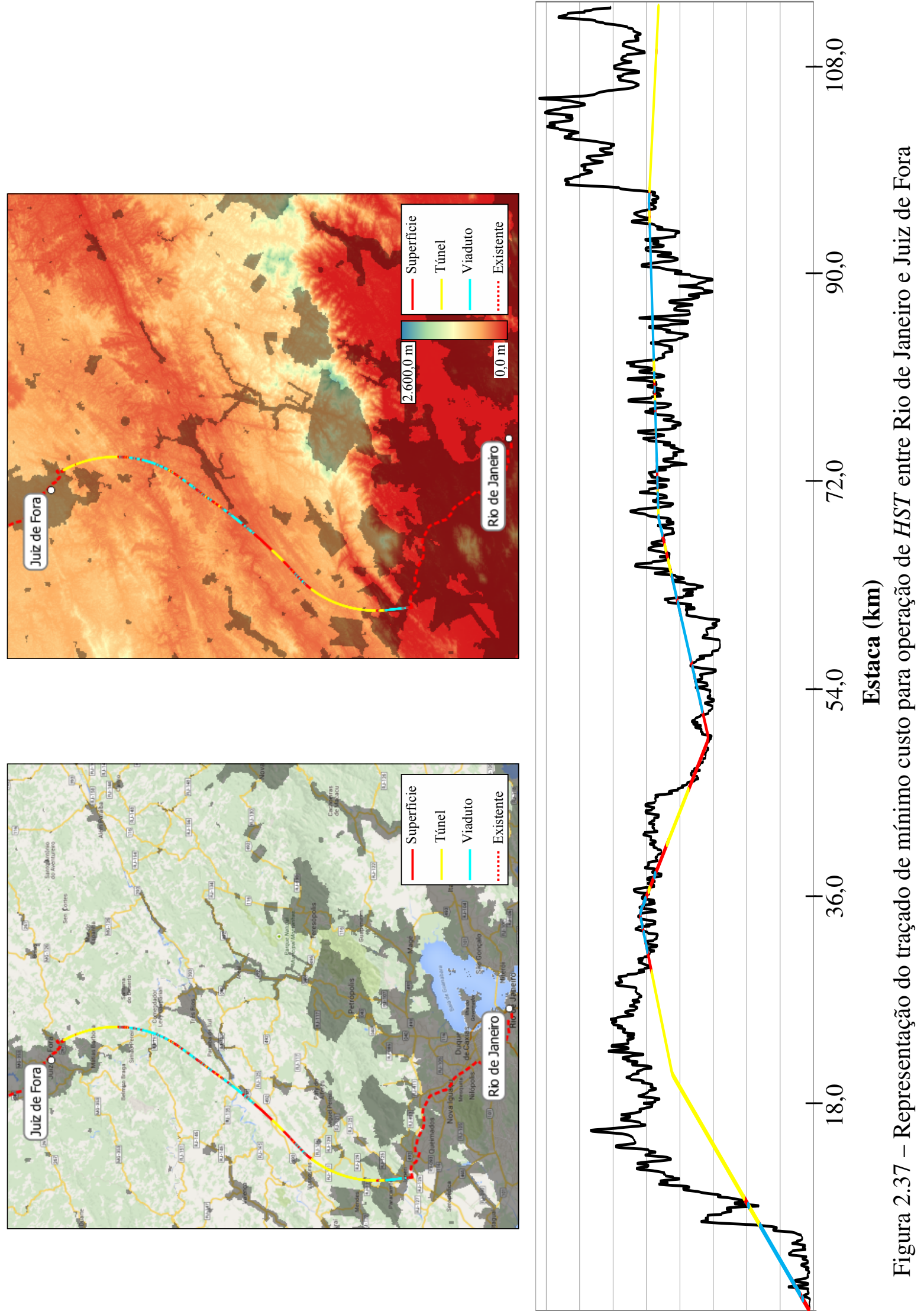

$\begin{array}{ccccc}0 & 0 & 0 & 0 & 0 \\ 0 & 0 & 0 & 0 & 0\end{array}$

(u) әpnџ!ฺIV 

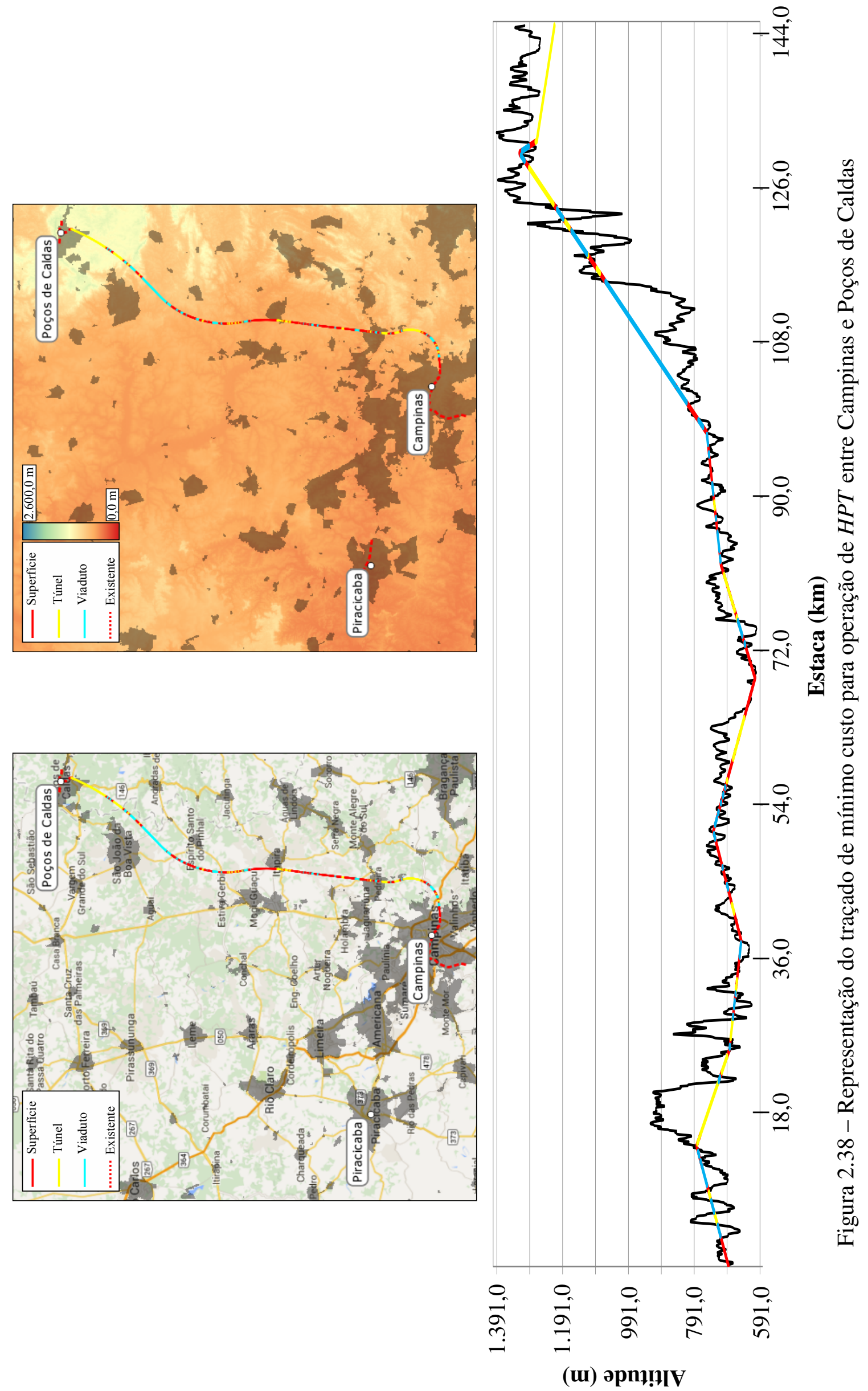

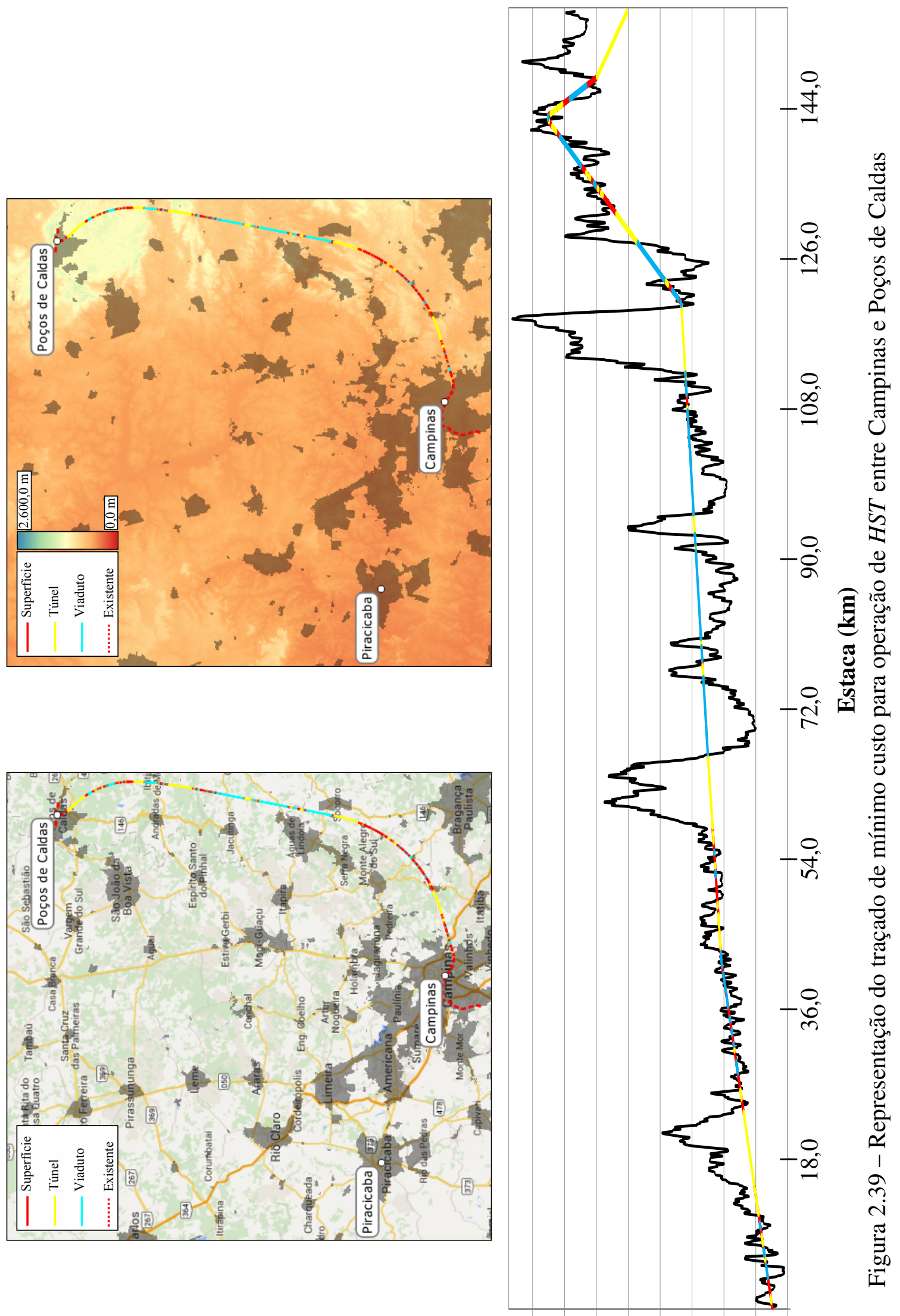

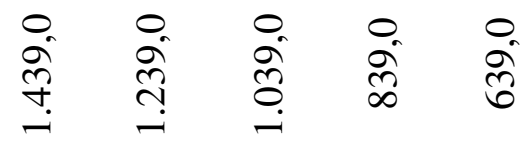

(u) әрnџ!ाV 

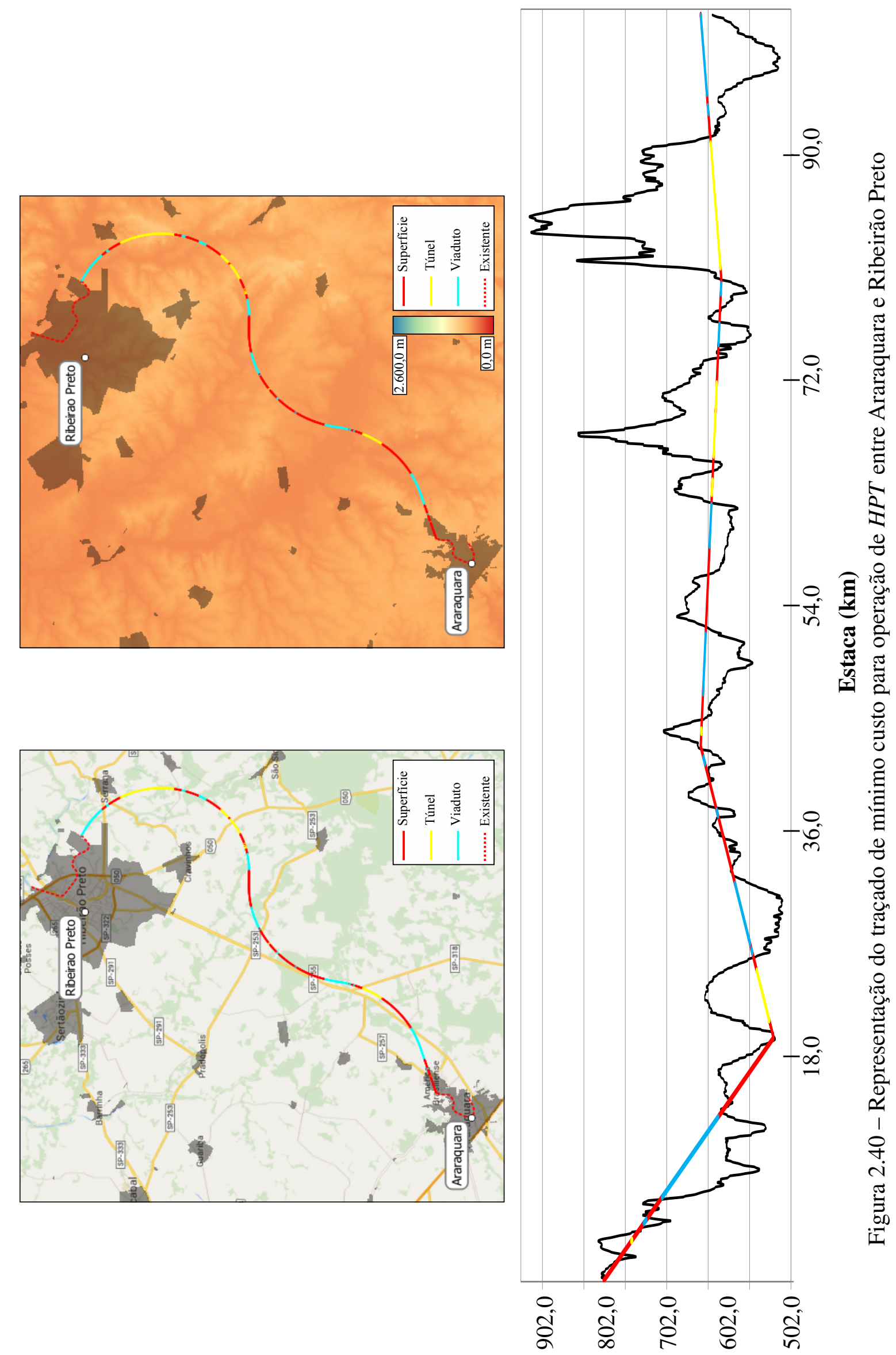

(u) วрм!нІ

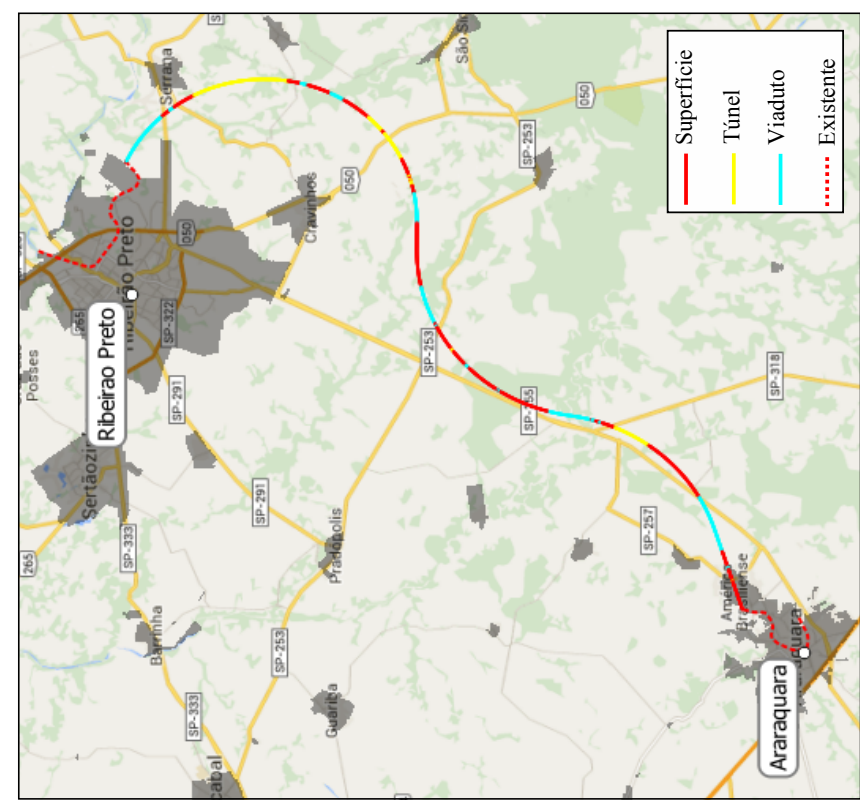



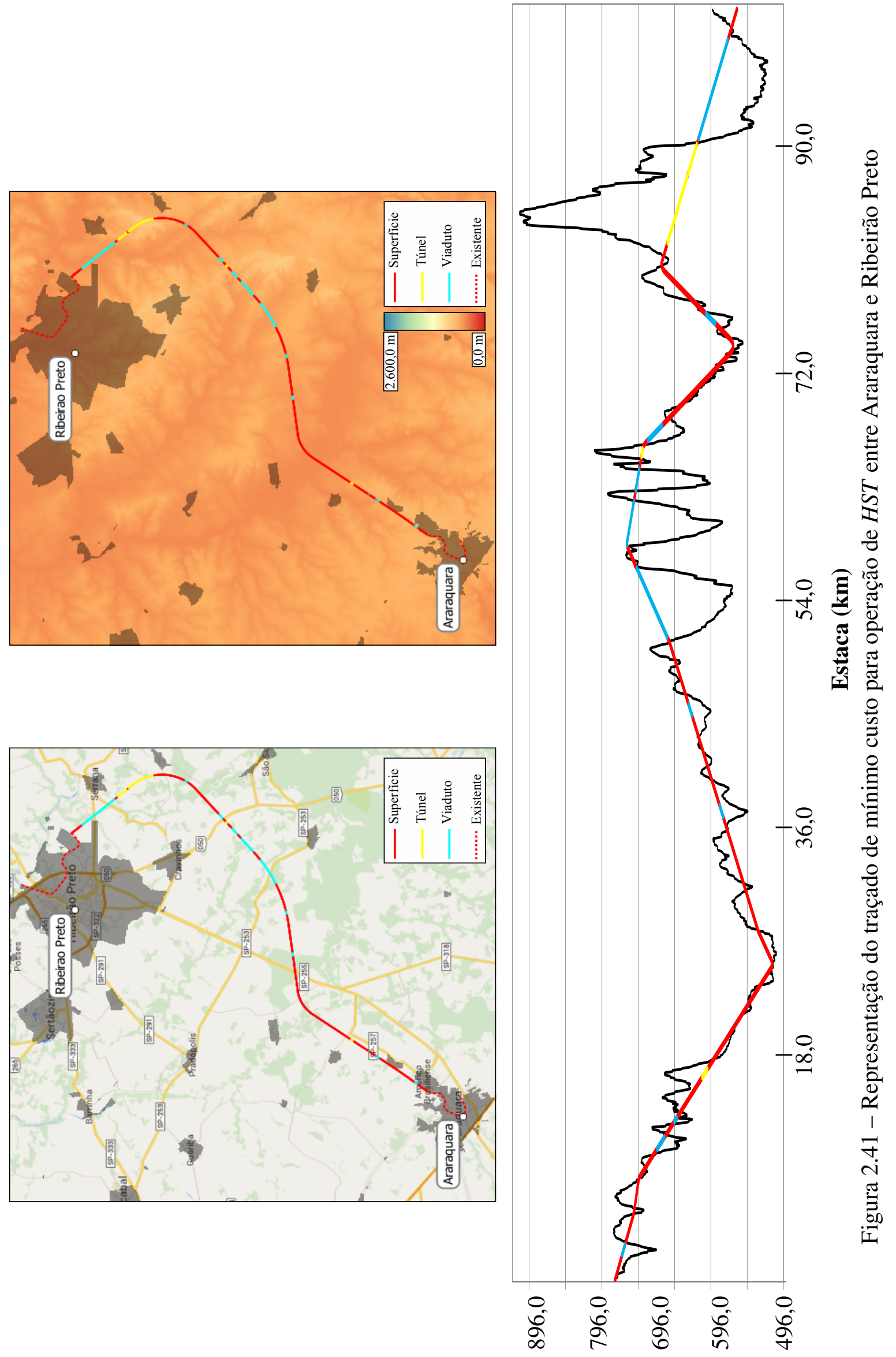

(ui) әpnฺ!ฺIV 
Capítulo

\section{Estimativa de Demanda}

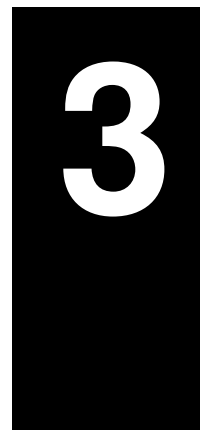

Um dos requisitos para aplicação da formulação de análise custo-benefício para o transporte ferroviário de passageiros proposta nesta tese é a estimativa do número de viagens entre cidades da Região Sudeste do Brasil, bem como a análise da propensão à escolha dos HPTs ou HSTs para realização dessas viagens.

No âmbito do planejamento e modelagem de sistemas de transportes, a abordagem tradicional de quatro etapas caracterizada na Figura 3.1 é a mais recorrente na literatura e aplicação prática. Essa estrutura considera as informações sobre os sistemas de transportes existentes e projeções sobre as regiões (ou zonas de tráfego) em que estão inseridas quanto às características populacionais e socieconômicas.

Na primeira etapa da abordagem (Geração) são calibrados os modelos para estimativa do número de viagens produzidas e atraídas pelas zonas de tráfego para, na segunda etapa (Distribuição), serem estabelecidos os padrões de deslocamentos entre pares de origens e destinos.

A terceira etapa (Divisão Modal) refere-se à segregação da matriz de viagens obtida anteriormente em termos dos modos de transporte utilizados para realização dos deslocamentos interzonais. Finalmente, na quarta etapa (Alocação) os fluxos identificados nas matrizes quanto a cada modo de transporte são atribuídos aos arcos que conectam as zonas de tráfego. 


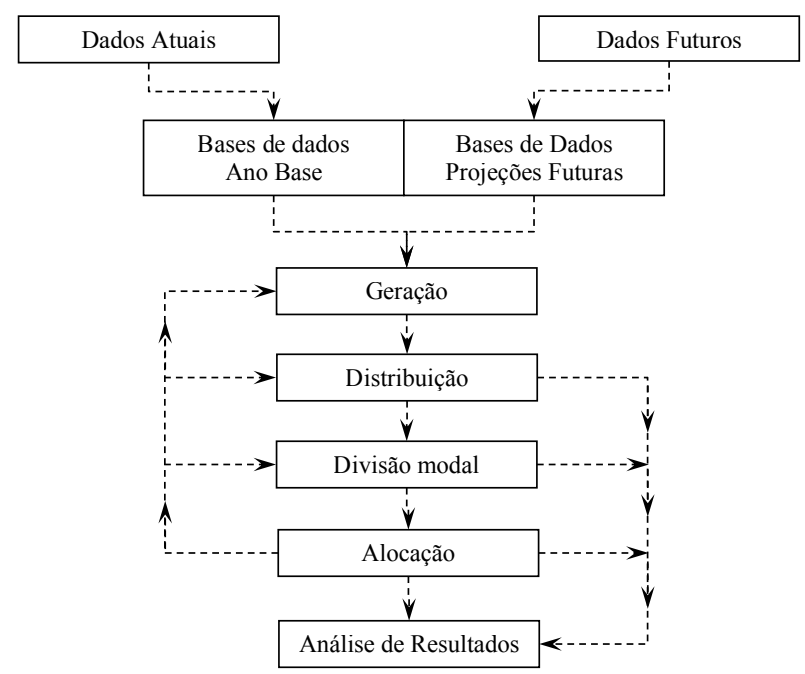

Figura 3.1 - Fluxograma do método de modelagem quatro etapas - Fonte: adaptado de Ortúzar e Willumsen (2011)

Conforme ilustrado na Figura 3.1, a abordagem quatro etapas é um processo iterativo em que os resultados de uma etapa afetam as subsequentes, de modo que a modelagem adequada de um item é fator preponderante para obtenção de resultados consistentes para as etapas posteriores.

Nesta tese são abordadas a distribuição e divisão modal para aplicação da análise custobenefício. Os modelos de geração são suprimidos pois o número de viagens é estimado para cada par de cidades da Região Sudeste mediante a calibração de modelos baseados nos fluxos observados atualmente.

Ainda, a etapa de alocação também não é contemplada pois requer a existência de uma rede de transporte existente (com múltiplos modos disponíveis e as interações entre eles) e os custos vinculados aos seus arcos.

\subsection{Distribuição de viagens}

Segundo Ortúzar e Willumsen (2011) os modelos de distribuição tem como objetivo atribuir as viagens estimadas na etapa de geração, com vistas a identificar os padrões de deslocamentos entre origens e destinos.

Esses padrões são representados como matrizes Origem Destino (OD) quanto ao modo de 
transporte, motivo da viagem ou outras características, e, em geral, são preenchidas a partir da extrapolação dos dados observados através de diferentes métodos.

Uma matriz OD possui os índices que definem as zonas de origem $(i)$ e de destino $(j)$ tal que as viagens $\left(T_{i j}\right)$ entre os pares de zonas preenchem o seu interior. A somas das linhas resultam no total de viagens originadas na zona $i\left(O_{i}\right.$ na Equação 3.1) e a soma das colunas resultam nas viagens destinadas à zona $j\left(D_{j}\right.$ na Equação 3.2).

$$
\begin{aligned}
& \sum_{j} T_{i j}=O_{i} \\
& \sum_{i} T_{i j}=D_{j}
\end{aligned}
$$

Existem diferentes métodos para preenchimento e extrapolação das matrizes OD: Fator de Crescimento, Modelo Gravitacional, Maximização da Entropia e os Modelos Econométricos. A descrição dos três primeiros métodos é realizada com base nas premissas de Ortúzar e Willumsen (2011) e a última apresenta considerações de diferentes autores.

\subsubsection{Método do Fator de Crescimento}

O Growth Factor Method permite extrapolar os valores observados em uma matriz OD para um período futuro em horizonte de planejamento sob a premissa de que os padrões de viagem observados mantêm-se constantes ao longo do tempo (ORTÚZAR; WILLUMSEN, 2011).

Ao considerar um fator de crescimento uniforme (Uniform Growth Factor - $\tau$ ) para toda uma região de estudo, a expansão das viagens entre origens e destinos na matriz pode ser efetuada pela aplicação da Equação 3.3.

$$
T_{i j}=\tau \cdot t_{i j}
$$

onde $t_{i j}$ é o número de viagens entre $i$ e $j$ no ano base de planejamento.

Por outro lado, a partir de um fator de crescimento em relação às origens ou destinos é possível expandir a matriz em relação a essas zonas de tráfego, conforme definido na Equação 3.4 e Equação 3.5 respectivamente. 


$$
\begin{aligned}
& T_{i j}=\tau_{i} \cdot t_{i j} \\
& T_{i j}=\tau_{j} \cdot t_{i j}
\end{aligned}
$$

onde $\tau_{i}$ e $\tau_{j}$ são os fatores de crescimento em relação às origens e destinos respectivamente.

Analogamente, é possível aplicar uma estratégia de expansão quando se tem conhecimento das taxas de crescimento das viagens nas origens e nos destinos simultaneamente. Nesse caso, uma das possibilidades é considerar um fator de crescimento ajustado pela média dos fatores das origens e destinos ou a Equação 3.6 proposta por Furness (1965).

$$
T_{i j}=t_{i j} \cdot \tau_{i} \cdot \tau_{j} \cdot A_{i} \cdot B_{j}
$$

em que $A_{i}$ e $B_{j}$ são denominados fatores de balanceamento quanto às características socioeconômicas da origem e destino.

O método do fator de crescimento é de fácil implementação e aplicação direta às matrizes observadas, preservando as características das informações iniciais. Entretanto, a acurácia na estimativa da matriz inicial influencia fortemente a qualidade das projeções.

A partir disso, a matriz OD é expandida para períodos futuros mediante um procedimento iterativo para equilibrar as projeções das linhas e colunas resultantes da expansão das viagens totais, em um procedimento comumente denominado como "Método de Fratar".

\subsubsection{Modelo Gravitacional}

Esta estratégia de modelagem é uma analogia à lei gravitacional de Newton e também conhecida como modelo sintético de distribuição de viagens. Essa abordagem considera que as viagens entre uma origem e um destino são proporcionais às respectivas populações e inversamente proporcionais à distância entre elas, tal como a Equação 3.7.

$$
T_{i j}=\alpha_{1} \cdot \frac{P_{i}^{\alpha_{2}} \cdot P_{j}^{\alpha_{3}}}{d^{\alpha_{4}}}
$$

em que $P_{i}$ é a população da cidade de origem, $P_{j}$ é a cidade de destino, $d$ é a distância entre elas e $\alpha_{k}(k=1,2,3)$ são coeficientes estimados segundo as viagens observadas. 
O desenvolvimento das técnicas de modelagem substituiu as parcelas de população pelo número total de viagens na origem e destino e uma função de impedância, geralmente definida como um custo generalizado $f\left(c_{i j}\right)$ em função do valor monetário e de tempo da viagem, conforme caracterizado na Equação 3.8.

$$
T_{i j}=\psi \cdot O_{i} \cdot D_{j} \cdot f\left(c_{i j}\right)
$$

As versões recorrentes da função de impedância são a exponencial $f\left(c_{i j}\right)=e^{-\beta \cdot c_{i j}}$, a potência $f\left(c_{i j}\right)=c_{i j}^{-n}$ e a combinada $f\left(c_{i j}\right)=c_{i j}^{n} \cdot e^{-\beta \cdot c_{i j}}$. Uma alternativa a essa função considera valores empíricos baseados no custo generalizado das viagens agrupado em classes como definido na Equação 3.9 .

$$
f\left(c_{i j}\right)=\sum_{m} F^{m} \cdot \delta_{i j}^{m}
$$

em que $F^{m}$ é o valor médio da classe $m$ e $\delta_{i j}^{m}$ é igual a 1 se o custo generalizado de uma viagem está no intervalo da classe $m$, e 0 caso contrário.

\subsubsection{Maximização da Entropia}

Este método consiste na definição de diferentes estados que caracterizam os padrões de viagens modelados na etapa de distribuição (ORTÚZAR; WILLUMSEN, 2011). Um micro estado caracteriza esses padrões detalhadamente, pela especificação de cada viagem em termos da origem, destino, motivo e modo de transporte.

Por outro lado, um meso estado é um nível mais agregado de especificação formado por vários diferentes micro estados, por exemplo, pelo grupo de indivíduos que realizam viagens pelo mesmo modo de transporte. Finalmente, um macro estado apresenta maior agregação, por exemplo, pela estimativa do número total de viagens em um arco de uma rede de transporte. Em geral, as estimativas no planejamento de transportes restringem-se a níveis mais agregados de informação dadas as incertezas em relação àqueles mais desagregados.

No método de maximização da entropia busca-se identificar os micro estados que apresentam maior probabilidade de ocorrência dadas as restrições dos meso estados (ORTÚZAR; WILLUMSEN, 2011). Segundo Wilson (1970), no contexto da distribuição de viagens, o número de possibilidades de ocorrências do micro estado $W\left(T_{i j}\right)$ associado ao meso estado $T_{i j}$ é dado por: 


$$
W\left(T_{i j}\right)=\frac{T !}{\prod_{i j} T_{i j} !}
$$

Assumindo a mesma probabilidade de ocorrência para todos os micro estados, o meso estado mais provável é aquele que maximiza o número de ocorrências daqueles mais desagregados. Assim, a maximização da Equação 3.10 pela sua diferenciação em relação à $T_{i j}$ na forma linear (aplicando-se o operador logaritmo) resulta na função de entropia da Equação 3.11.

$$
\log W^{\prime}\left(T_{i j}\right)=-\sum_{i j}\left(T_{i j} \cdot \log T_{i j}-T_{i j}\right)
$$

A maximização dessa função (sob as restrições da Equação 3.1 e Equação 3.2, além da condição $T_{i j} \geq 0$ ) permite a obtenção dos valores de $T_{i j}$ que representam a matriz OD de viagens mais provável. O desenvolvimento algébrico dessa função entropia e sua maximização pode ser verificado em Ortúzar e Willumsen (2011) (página 185) e outras abordagens para estimação de matrizes OD na etapa de distribuição de viagens (Abordagem Tri-proportional, Técnicas de Matrizes Parciais, Modelo de Oportunidades Intervenientes e Abordagens Desagregadas) também podem ser consultadas naquela referência.

Apesar do desenvolvimento desses modelos, existem algumas considerações práticas acerca da sua aplicação no contexto do planejamento de transportes. Por exemplo, a ocorrência de matrizes esparsas (i.e. muitas células com valor igual a zero) podem resultar em erros de estimativa pelos métodos tradicionais como no "Método de Fratar".

\subsubsection{Modelos Econométricos de Regressão Linear}

Dado que o objetivo desta tese não é explorar os métodos de estimativa de distribuição de viagens e contribuir para avanços relativos ao tema, optou-se pela generalização do modelo gravitacional caracterizado pela Equação 3.7 para estimativa do número de viagens por modo de transporte. Para isso, utiliza-se uma abordagem econométrica para estimativa dos prováveis números de viagens entre cidades da Região Sudeste.

Os modelos econométricos consideram a aplicação de métodos estatísticos de estimação envolvendo variáveis socioeconômicas. Esses modelos estão associados à definição de relações entre variáveis econômicas e sociais e permitem identificar a capacidade explanatória da va- 
riável dependente em relação às independentes e verificação dos resíduos que representam as parcelas do fenômeno não explicadas pelo modelo (TINTNER, 1965; THEIL, 1971).

Nesse contexto, a regressão linear simples e múltipla colaboram para a definição de padrões de comportamento de uma variável dependente mediante, respectivamente, uma ou várias variáveis independentes cujos valores são observáveis.

O padrão de viagens entre cidades pode ser expresso por equações de diferente natureza como exponencial ou multiplicativa. No caso do modelo gravitacional, a Equação 3.7 de distribuição de viagens da matriz OD pode ser expressa na forma linear pela aplicação de um operador de logaritmo neperiano para estimativa dos coeficientes $\alpha_{k}^{\prime}(k=1,2,3)$ conforme a Equação 3.12.

$$
\ln \left(T_{i j}\right)=\alpha_{1}^{\prime}+\alpha_{2}^{\prime} \cdot \ln \left(P_{i}\right)+\alpha_{3}^{\prime} \cdot \ln \left(P_{j}\right)+\alpha_{4}^{\prime} \cdot \ln (d)
$$

No contexto da modelagem econométrica, a Equação 3.12 pode ser reescrita com variáveis independentes relacionadas aos aspectos econômicos e sociais da origem $i$ e destino $j$, para redução dos erros das estimativas em relação aos valores observados da variável $T_{i j}$.

\subsubsection{Estimativa de Viagens no Ano Base}

Nas próximas seções são descritos os procedimentos de análise dos dados observados e de estimação dos parâmetros dos modelos econométricos para cálculo do número de viagens pelo modos Ônibus, Automóvel e Avião. Em seguida, descreve-se a expansão das viagens estimadas para os períodos futuros do horizonte de planejamento no qual se pretende avaliar a operação de serviços ferroviários de passageiros na Região Sudeste do Brasil.

Para estimativa do número de viagens no ano base do horizonte de planejamento pelos modos de transporte cujas infraestruturas estão disponíveis atualmente (Ônibus, Automóvel e Avião) foram selecionadas as cidades de médio e grande porte, incluindo as regiões metropolitanas do Brasil, que correspondem àquelas com população entre 50 mil e 500 mil habitantes e com mais de 500 mil habitantes, respectivamente, segundo classificação do Instituto Brasileiro de Geografia e Estatística (IBGE) .

Para cada modo de transporte foram obtidas informações do número de passageiros transportados a partir de bancos de dados das agências reguladoras do setor de transporte no país 
e de projetos de planejamento nos casos em que essas informações não estavam disponíveis diretamente para consulta.

Apesar das variações temporais do número de viagens observadas entre pares de origens e destinos, os parâmetros estimados para os modelos de distribuição de viagem mantêm-se constantes ao longo do horizonte de planejamento da análise socioeconômica. Entretanto, esses coeficientes podem ser atualizados à medida que as viagens são computadas nos anos desse horizonte a fim de identificar eventuais tendências não identificadas nesta pesquisa.

\subsubsection{Modo Ônibus}

Como um dos meios de transporte de maior uso no Brasil para realização de viagens intermunicipais de longa distância, o modo Ônibus têm atraído a atenção para a definição de modelos de estimativa do números de passageiros transportados em diferentes contextos.

Uma das primeiras propostas de modelagem do número de viagens interestaduais é apresentada por Gomes (1973) apud Aguiar Júnior (2004) pela estimativa dos parâmetros de um modelo gravitacional baseado na Equação 3.12. Com base em dados históricos sobre o número de passageiros transportados em viagens interestaduais, o modelo tem sido submetido a correções periódicas em relação aos parâmetros estimados naquela equação.

O Consórcio STE-ENEFER (STE-ENEFER, 2001 apud AGUIAR JÚNIOR, 2004) propôs valores atualizados para os coeficientes de um modelo gravitacional que contempla variáveis complementares à abordagem tradicional. Além da população e distância entre as origens e destinos, são consideradas variáveis de atratividade entre cidades $(a)$ e um fator de regionalidade $(r)$, de modo que a Equação 3.12 é reescrita pela Equação 3.13.

$$
\ln \left(T_{i j}\right)=\alpha_{2}^{\prime} \cdot \ln \left(P_{i}\right)+\alpha_{3}^{\prime} \cdot \ln \left(P_{j}\right)+\alpha_{4}^{\prime} \cdot \ln (d)+\alpha_{5}^{\prime} \cdot \ln (a)+\alpha_{6}^{\prime} \cdot \ln (r)
$$

A atratividade $a$ é definida por um valor binário ( 0 ou 1) tal que o valor unitário é assumido quando um dos municípios é sede de região metropolitana e a menos de $2.000 \mathrm{~km}$ de outro município, quando um deles é cidade turística a menos de $1.000 \mathrm{~km}$ do outro, quando são centros metropolitanos ou capitais estaduais, ou quando as ligações são especificamente Rio de Janeiro-Juiz de Fora ou Ribeirão Preto-Uberlândia. 
O estudo considera coeficientes binários apresentados na Tabela 3.1 para caracterizar um fator de regionalidade $(r)$ segundo as regiões em que estão localizados os municípios de origem e destino das conexões rodoviárias interestaduais.

Tabela 3.1 - Fatores de regionalidade para o modelo gravitacional do modo Ônibus (STEENEFER, 2001 apud AGUIAR JÚNIOR, 2004)

\begin{tabular}{cccccc}
\hline Origem/Destino & Norte & Nordeste & Sudeste & Sul & Centro-Oeste \\
\hline Norte & 1 & 1 & 0 & 0 & 1 \\
Nordeste & 1 & 0 & 1 & 0 & 0 \\
Sudeste & 0 & 1 & 1 & 0 & 1 \\
Sul & 0 & 0 & 0 & 1 & 1 \\
Centro-Oeste & 1 & 0 & 1 & 1 & 1 \\
\hline
\end{tabular}

Após análise desse modelo, Aguiar Júnior (2004) propõe o treinamento de uma rede neural artificial para aumento do número de acertos na estimativa das viagens interestaduais no Brasil em relação aos modelos tradicionais. Na pesquisa, o autor aumenta a acurácia da previsão do número de viagens em relação ao modelo gravitacional do Consórcio STE-ENEFER (STEENEFER, 2001 apud AGUIAR JÚNIOR, 2004), propondo uma topologia de rede neural com base na população urbana e rural dos municípios, frota de automóveis, Índice de Desenvolvimento Humano (IDH), renda per capita e distâncias rodoviárias.

Mais recentemente, Gonçalves, Bez e Novaes (2007) propuseram uma atualização do modelo gravitacional similar ao do Consórcio STE-ENEFER (STE-ENEFER, 2001 apud AGUIAR JÚNIOR, 2004) para estimativa da demanda por transporte de passageiros interestaduais por Ônibus, considerando variáveis de número de habitantes dos municípios, renda, número de viagens per capita por ano, número de habitantes não naturais dos estados dos municípios de origem e destino, distância rodoviária e características de polo turístico dos municípios.

Os autores apresentam uma estratégia de tratamento do banco de dados da Agência Nacional de Transportes Terrestres (ANTT) e estimativa dos coeficientes de modelos econométricos com base em regressões lineares, bem como testes de robustez das estimativas.

Apesar dos estudos realizados no contexto da estimativa do número de viagens pelo modo Ônibus, nesta tese optou-se pela calibração de modelos gravitacionais específicos em relação ao referido modo de transporte. Foram utilizados dados obtidos pela ANTT em uma pesquisa 
realizada no contexto federal (ANTT, 2011). Para estimar os dados de demanda, a agência realizou o levantamento do número de viagens (intermunicipais e interestaduais) entre municípios para elaboração do modelo de concessão de linhas de transporte coletivo no país.

A pesquisa para os serviços de longa distância (com extensão superior a $75 \mathrm{~km}$ ) foi realizada em âmbito nacional entre Dezembro de 2009 e Abril de 2010 em rodoviárias de 179 cidades. Foram pesquisadas 2.289 linhas nos terminais rodoviários e 1.425 linhas com pesquisador embarcado, com amostragem de 170 mil viagens e mais de 688 mil passageiros entrevistados.

Após análise desse banco de dados foram excluídas as linhas cujo volume é inferior a 45 viagens por semana, conforme executado por Aguiar Júnior (2004) na etapa de análise de verificação do banco de dados do seu procedimento de modelagem de redes neurais.

Um problema da base de dados disponibilizada pela ANTT é a discriminação do número de viagens somente entre pares OD, sem a caracterização dessas observações quanto ao sentido do deslocamento. Assim, como alternativa ao modelo gravitacional, propõe-se a Equação 3.14 para estimativa do número de viagens pelo modo Ônibus contemplando parâmetros socioeconômicos e de características das viagens.

$$
\begin{aligned}
\ln \left(T_{i j}\right)= & \alpha+\alpha_{P O P} \cdot \ln \left(P_{O} P_{i} \cdot P O P_{j}\right)+\alpha_{O C U P} \cdot \ln \left(O C U P_{i} \cdot O C U P_{j}\right) \\
& +\alpha_{d} \cdot \ln (d)+\alpha_{R E N D A} \cdot \ln \left(R E N D A_{i} \cdot R E N D A_{j}\right) \\
& +\alpha_{A U T O} \cdot \ln \left(A U T O_{i} \cdot A U T O_{j}\right)
\end{aligned}
$$

onde $O C U P_{i}=$ população ocupada do município $i ; O C U P_{j}=$ população ocupada do município $j ; R E N D A_{i}=$ renda média per capita do município $i ; R E N D A_{j}=$ renda média per capita do município $j ; A U T O_{i}=$ frota de automóveis do município $i ; A U T O_{j}=$ frota de automóveis do município $j$.

A multiplicação dos valores das variáveis nessa equação permite estimar o número de viagens com base no banco de dados da ANTT sem o efeito da ordem de origem e destino da linha. Para calibração do modelo gravitacional optou-se por considerar apenas as ligações entre cidades da Região Sudeste do Brasil e pela segregação dos dados em três grupos. 
O Grupo A contempla linhas rodoviárias entre capitais dos Estados: São Paulo (SP), Rio de Janeiro (RJ), Belo Horizonte (BH) e Vitória (ES). O Grupo B é composto das linhas interestaduais (excluindo-se as conexões entre capitais) e o Grupo C contempla as linhas intermunicipais entre cidades do mesmo Estado.

Para os três grupos foram estimados modelos com e sem o intercepto $\alpha$ da Equação 3.14. No caso dos grupos B e C os dados também foram segregados nas linhas em que nenhuma das cidades é capital (SEM CAPITAL) e naquelas em que pelo menos uma das cidades é uma capital estadual (COM CAPITAL). Em outro cenário, as estimativas dos coeficientes foram efetuadas com os dados generalizados por grupo (GERAL). Após a aplicação de uma regressão linear pelo método Stepwise para o Grupo A foram obtidos os resultados resumidos na Tabela 3.2.

Tabela 3.2 - Estimativa dos parâmetros do modelo gravitacional para o modo Ônibus em viagens entre capitais (Grupo A)

\begin{tabular}{lccc}
\hline \multicolumn{4}{c}{ SEM INTERCEPTO } \\
\hline$R^{2}$ & \multicolumn{3}{c}{0,999} \\
$R^{2}$ Ajustado & 0,999 & \\
Subestimados & & $83,3 \%$ & \\
Superestimados & & $16,7 \%$ & \\
\hline Coeficiente & Valor & $t$-test & p-value \\
$\alpha$ & - & - & - \\
$\alpha_{P O P}$ & 0,430 & 80,436 & 0,000 \\
$\alpha_{d}$ & - & - & - \\
\hline
\end{tabular}

\begin{tabular}{lccc}
\hline \multicolumn{4}{c}{ COM INTERCEPTO } \\
\hline$R^{2}$ & \multicolumn{3}{c}{0,983} \\
$R^{2}$ Ajustado & 0,971 & \\
Subestimados & & $50,0 \%$ & \\
Superestimados & & $50,0 \%$ & \\
\hline Coeficiente & Valor & $t$-test & $p$-value \\
$\alpha$ & 17,036 & 3,693 & 0,034 \\
$\alpha_{P O P}$ & 0,457 & 10,004 & 0,002 \\
$\alpha_{d}$ & $-1,351$ & $-4,498$ & 0,021 \\
\hline
\end{tabular}

Nessa tabela, apesar de a estatística $R^{2}$ ser mais próxima de 1,000 para o modelo gravitacional linearizado sem intercepto, aquele com intercepto apresentou resultados satisfatórios em relação à estatística $\left(0,983\right.$ e 0,971 para o $R^{2}$ e $R^{2}$ Ajustado respectivamente).

Assim, dado que a porcentagem de valores subestimados e superestimados pelo modelo com intercepto é mais equilibrada (50,0\% e 50,0\%, respectivamente) do que para aquele sem intercepto $(83,3 \%$ e $16,7 \%$, respectivamente), o modelo admitido como representativo das viagens ente capitais da Região Sudeste é aquele que contempla as variáveis independentes população $\left(\alpha_{P O P}\right)$ e distância $\left(\alpha_{d}\right)$, acrescido de um termo constante $(\alpha)$.

Para o Grupo B, os valores dos coeficientes obtidos pela segregação dos dados e regressão linear pelo método Stepwise são apresentados na Tabela 3.3. 
Tabela 3.3 - Estimativa dos parâmetros do modelo gravitacional para o modo Ônibus em viagens interestaduais excluindo-se as capitais (Grupo B)

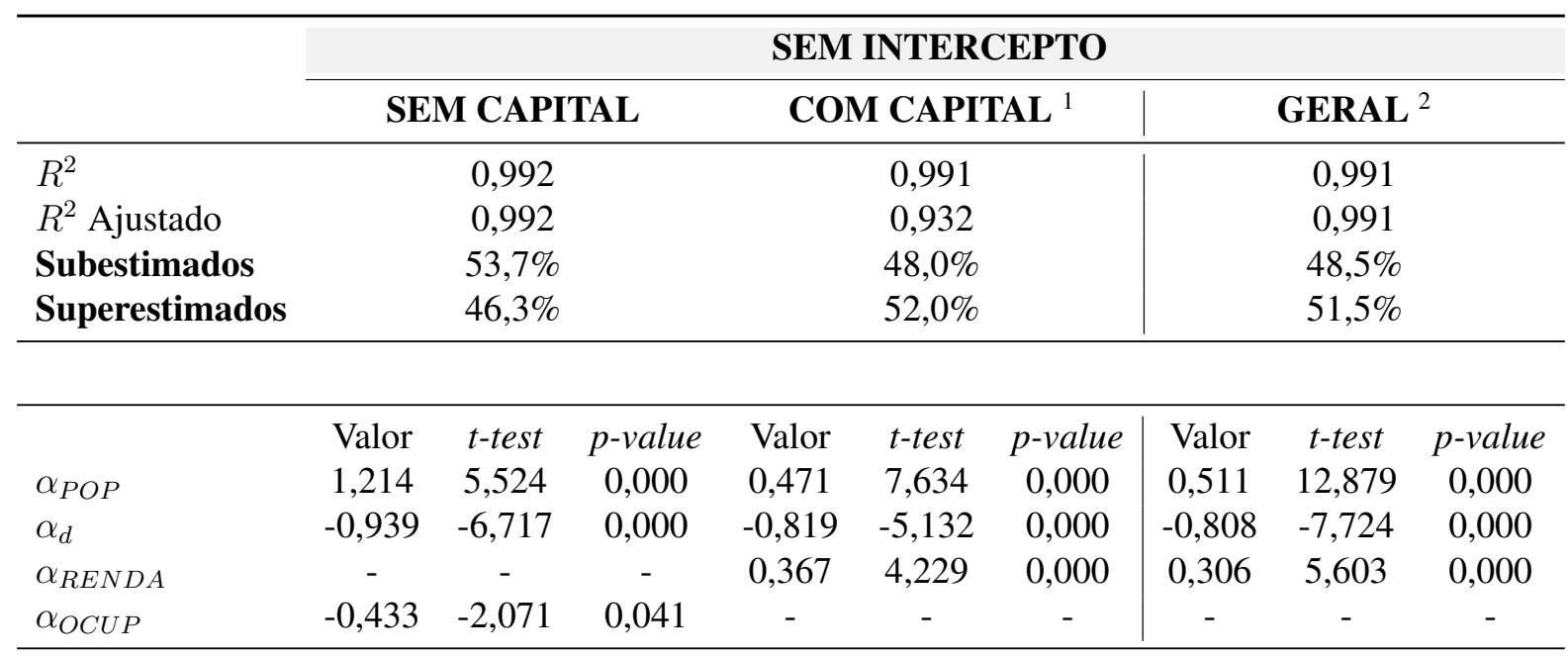

\begin{tabular}{|c|c|c|c|c|c|c|c|c|c|}
\hline & \multicolumn{9}{|c|}{ COM INTERCEPTO } \\
\hline & \multicolumn{3}{|c|}{ SEM CAPITAL } & \multicolumn{3}{|c|}{ COM CAPITAL $^{1}$} & \multicolumn{3}{|c|}{ GERAL $^{2}$} \\
\hline$R^{2}$ & & 0,409 & & & 0,321 & & & 0,432 & \\
\hline$R^{2}$ Ajustado & & 0,396 & & & 0,313 & & & 0,427 & \\
\hline Subestimados & & $49,1 \%$ & & & $48,7 \%$ & & & $48,1 \%$ & \\
\hline Superestimados & & $50,9 \%$ & & & $51,3 \%$ & & & $51,9 \%$ & \\
\hline & Valor & $t$-test & $p$-value & Valor & $t$-test & $p$-value & Valor & t-test & p-value \\
\hline$\alpha$ & 8,877 & 3,538 & 0,000 & 17,267 & 5,599 & 0,000 & 9,904 & 7,187 & 0,000 \\
\hline$\alpha_{P O P}$ & 0,549 & 5,984 & 0,000 & 0,395 & 6,283 & 0,000 & 0,520 & 13,746 & 0,000 \\
\hline$\alpha_{d}$ & $-1,091$ & $-7,510$ & 0,000 & $-6,497$ & 0,000 & - & $-1,106$ & $-9,082$ & 0,000 \\
\hline
\end{tabular}

${ }^{1}$ Pelo menos uma das cidades é uma capital estadual

${ }^{2}$ Entre todos os pares OD

As estatísticas $R^{2}$ e $R^{2}$ Ajustado dos modelos estimados com intercepto são todas abaixo de 0,432, indicando que o intercepto na Equação 3.14 não resulta em valores apropriados para as estimativas. Por outro lado, os modelos sem o termo constante proveram valores elevados para essa estatística, com mínimo de 0,932 para o $R^{2}$ Ajustado no caso da modelagem das viagens interestaduais em que uma das cidades é uma capital estadual.

O modelo calibrado a partir de todos os dados observados (GERAL) foi escolhido para estimativa do número de viagens para o Grupo B uma vez que as porcentagens de valores subestimados e superestimados são próximos daqueles resultantes da segregação dos dados (COM CAPITAL e SEM CAPITAL). Portanto, o modelo considerado é aquele com as variáveis independentes de população $\left(\alpha_{P O P}\right)$, distância $\left(\alpha_{d}\right)$ e renda $\left(\alpha_{R E N D A}\right)$ sem a constante $\alpha$. 
A Tabela 3.4 apresenta os resultados da calibração dos coeficientes da Equação 3.14 a partir dos dados do Grupo C, pela aplicação do método Stepwise à regressão linear múltipla.

Tabela 3.4 - Estimativa dos parâmetros do modelo gravitacional para o modo Ônibus em viagens intermunicipais (Grupo C)

\begin{tabular}{|c|c|c|c|c|c|c|c|c|c|}
\hline & \multicolumn{9}{|c|}{ SEM INTERCEPTO } \\
\hline & \multicolumn{3}{|c|}{ SEM CAPITAL } & \multicolumn{3}{|c|}{ COM CAPITAL $^{1}$} & \multicolumn{3}{|c|}{ GERAL $^{2}$} \\
\hline$R^{2}$ & & 0,993 & & & 0,990 & & & 0,991 & \\
\hline$R^{2}$ Ajustado & & 0,992 & & & 0,990 & & & 0,991 & \\
\hline Subestimados & & $46,9 \%$ & & & $53,3 \%$ & & & $42,6 \%$ & \\
\hline Superestimados & & $53,1 \%$ & & & $46,7 \%$ & & & $57,4 \%$ & \\
\hline Coeficiente & Valor & $t$-test & p-value & Valor & $t$-test & $p$-value & Valor & $t$-test & $p$-value \\
\hline$\alpha_{P O P}$ & - & - & - & 0,349 & 38,036 & 0,000 & 0,353 & 70,870 & 0,000 \\
\hline$\alpha_{d}$ & $-0,580$ & $-2,353$ & 0,025 & - & - & - & - & - & - \\
\hline$\alpha_{R E N D A}$ & 0,789 & 5,287 & 0,000 & - & - & - & - & - & - \\
\hline
\end{tabular}

\begin{tabular}{|c|c|c|c|c|c|c|c|c|c|}
\hline & \multicolumn{9}{|c|}{ COM INTERCEPTO } \\
\hline & \multicolumn{3}{|c|}{ SEM CAPITAL } & \multicolumn{3}{|c|}{ COM CAPITAL $^{1}$} & \multicolumn{3}{|c|}{ GERAL $^{2}$} \\
\hline$R^{2}$ & & 0,444 & & & 0,328 & & & 0,395 & \\
\hline$R^{2}$ Ajustado & & 0,384 & & & 0,276 & & & 0,368 & \\
\hline Subestimados & & $46,9 \%$ & & & $53,3 \%$ & & & $46,8 \%$ & \\
\hline Superestimados & & $53,1 \%$ & & & $46,7 \%$ & & & $53,2 \%$ & \\
\hline Coeficiente & Valor & t-test & p-value & Valor & $t$-test & $p$-value & Valor & $t$-test & p-value \\
\hline$\alpha$ & 22,143 & 4,707 & 0,000 & $-0,844$ & $-0,205$ & 0,841 & 10,448 & 3,976 & 0,000 \\
\hline$\alpha_{P O P}$ & $-0,894$ & $-2,270$ & 0,0311 & 0,380 & 2,519 & 0,026 & - & - & - \\
\hline$\alpha_{d}$ & $-0,900$ & $-4,088$ & 0,000 & - & - & - & $-0,715$ & $-3,403$ & 0,000 \\
\hline$\alpha_{A U T O}$ & 0,875 & 2,897 & 0,007 & - & - & - & 0,314 & 4,897 & 0,000 \\
\hline
\end{tabular}

${ }^{1}$ Pelo menos uma das cidades é uma capital estadual

${ }^{2}$ Entre todos os pares OD

Os comentários a respeito da calibração dos modelos de distribuição do Grupo B podem ser estendidos às viagens intermunicipais, dados os resultados das estatísticas de $R^{2}$ e $R^{2}$ Ajustado. Assim, o modelo representativo das viagens intermunicipais pelo modo Ônibus para o Grupo C contempla a variável independente população $\left(\alpha_{P O P}\right)$ sem o intercepto $\alpha$.

\subsubsection{Modo Automóvel}

Existe uma dificuldade na modelagem do número de viagens intermunicipais e interestaduais pelo modo Automóvel uma vez que, ao contrário do modo Ônibus, não há disponibilidade de 
uma base de dados que informe o número de viagens realizadas por aquele modo. Em geral, esses valores são obtidos através de pesquisas de campo para estudos específicos de melhoria ou implantação de sistemas de transporte.

Dadas as restrições de execução de uma pesquisa dessa natureza no contexto desta tese de doutorado, propõe-se uma alternativa para estimativa desses valores. O Plano Nacional de Logística e Transportes (PNLT, 2014) proposto pelo Governo Federal para implantação e melhoria dos sistemas logísticos do Brasil disponibiliza o Volume Diário Médio Anual (VDMA) dos carregamentos nas principais rodovias do país em relação o número de veículos leves (automóveis) sob a forma de um arquivo vetorial georreferenciado (Figura 3.2).

Os carregamentos nos arcos correspondentes às rodovias estaduais e federais podem ser de utilidade em diferentes projetos de planejamento de infraestrutura de transporte. No contexto de aplicação da presente pesquisa, alguns procedimentos foram executados naquele banco de dados para que pudesse ser utilizado na calibração de modelos de distribuição de viagens pelo modo Automóvel.

Primeiramente, foram eliminados os centroides da rede que correspondem a municípios menores que a classificação de médio e grande porte do IBGE (aqueles com população menor que 100 mil habitantes), e os arcos (rodovias) cujos registros de VDMA não correspondessem a valores numéricos. 


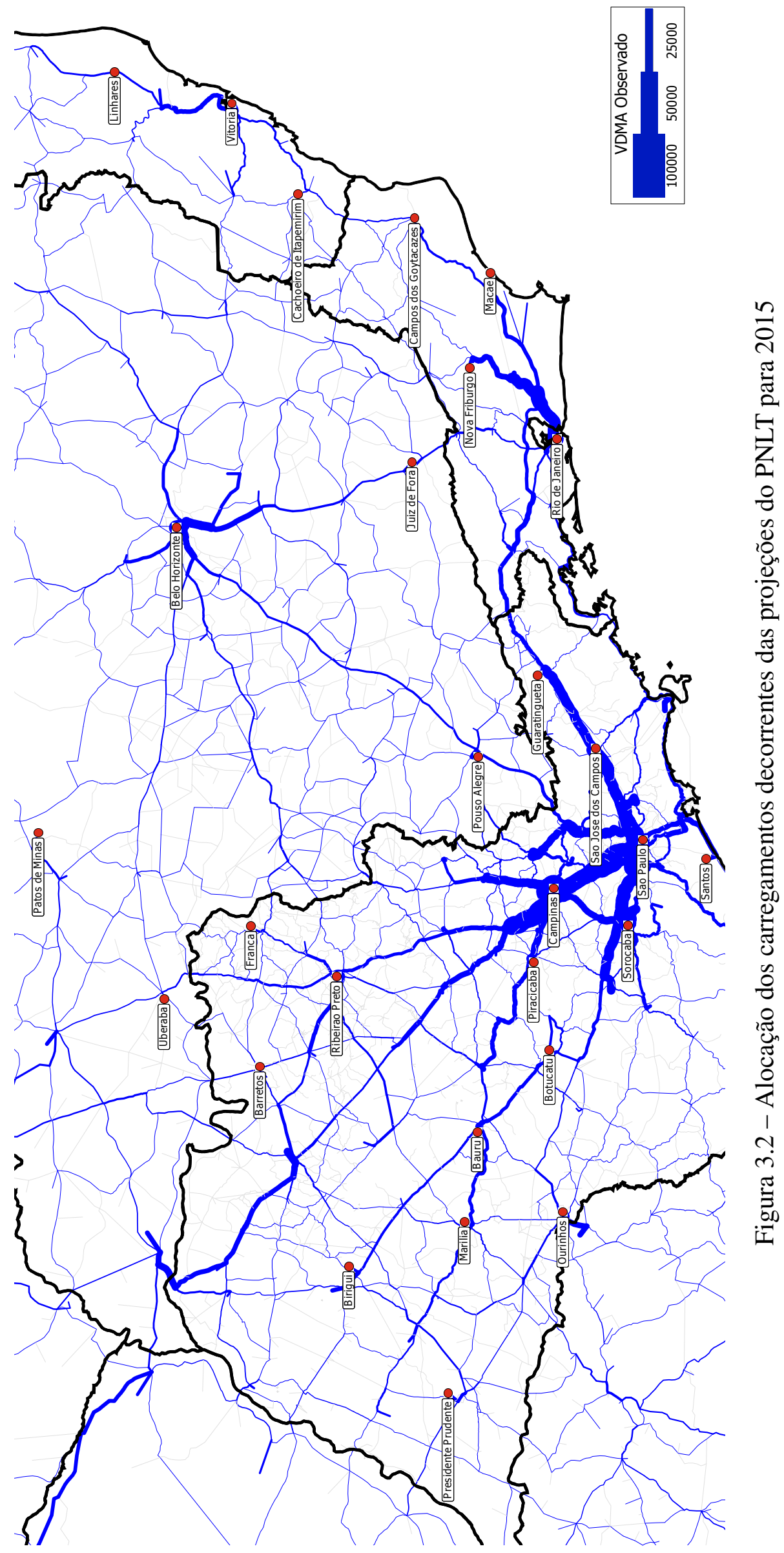


Todas as cidades brasileiras que se enquadram na classificação do IBGE quanto ao porte foram consideradas na estimativa de uma matriz OD pela rede fornecida pelo PNLT. Essa condição foi estabelecida para evitar inconsistências nas demandas estimadas e considerar as viagens entre todas as cidades inclusive fora da Região Sudeste - por exemplo, aquelas efetuadas entre as cidades de São Paulo e Brasília - mesmo que não contabilizadas na análise custo-benefício proposta nesta tese.

Existem métodos de reconstrução de matrizes OD com base nos fluxos observados nos arcos de uma rede (PITOMBEIRA NETO; BERTONCINI; LOUREIRO, 2011; CASCETTA; NGUYEN, 1988). Ainda, Bertoncini e Kawamoto (2012) propõem um método alternativo que permite estimar os valores de uma matriz de viagens com base nos fluxos observados nos nós de uma rede.

O software de planejamento TRANSCAD (CALIPER, 2007) possui uma rotina computacional de estimativa de matrizes sob o comando $O-D$ Estimation do pacote Planning, sob uma rede de transporte vetorial georeferenciada com informações sobre o volume de tráfego nos arcos e uma matriz inicial (matriz semente). Essa matriz semente define as proporções das viagens entre pares de cidades e permite a convergência do método para estimativa da matriz final.

Ocorre que mesmo as proporções das viagens entre municípios são desconhecidas no âmbito da estimativa de uma matriz OD para automóveis, ou seja, a matriz semente nessas condições também é um parâmetro desconhecido do problema. Wei et al. (2007) afirmam que a qualidade dessa matriz interfere significativamente na acurácia das estimativas finais do número de viagens entre zonas de tráfego. Nesse sentido, Yuanqing et al. (2010) utilizam um modelo gravitacional de parâmetros conhecidos para inferência de uma matriz semente, a qual é aplicada na obtenção do número de viagens atraídas e geradas pelas zonas de tráfego através dos métodos de alocação "Tudo-ou-Nada"(All-or-Nothing) e "Equilíbrio do Usuário"(User Equilibrium).

Nesta tese, admite-se a premissa de que os padrões de viagens por Automóvel repetem-se nas mesmas proporções que os do modo Ônibus entre pares de origens e destinos de uma rede. Assim, uma matriz construída a partir do modelo gravitacional de viagens pelo modo Ônibus foi utilizada como semente para o procedimento de alocação das viagens do modo Automóvel e a determinação da matriz OD foi baseada nos carregamentos fornecidos pelo PNLT. 
Essa premissa é justificada pelo fato de que a criação das linhas de Ônibus intermunicipais e interestaduais pode ser considerada uma consequência do tráfego de automóveis e surgimento de demanda para aqueles serviços.

A aplicação dos coeficientes dos modelos econométricos da seção 3.1.5.1 (página 102) resultaram em uma matriz semente para aplicação da rotina computacional do TRANSCAD de estimativa de matrizes Origem-Destino.

Nesse software, a função $O-D$ Estimation requer a definição de um tipo de alocação de tráfego (CALIPER, 2007), sendo escolhido o "Método Tudo-ou-Nada"no qual a rota de menor custo entre duas cidades é identificada e todo o volume de tráfego estimado entre a origem e o destino é alocado nessa rota. O "Método Tudo-ou-Nada" requer, além da definição da rede vetorial de tráfego georreferenciada, um parâmetro de impedância da viagem definido como tempo estimado de deslocamento nos arcos da rede (Figura 3.3).

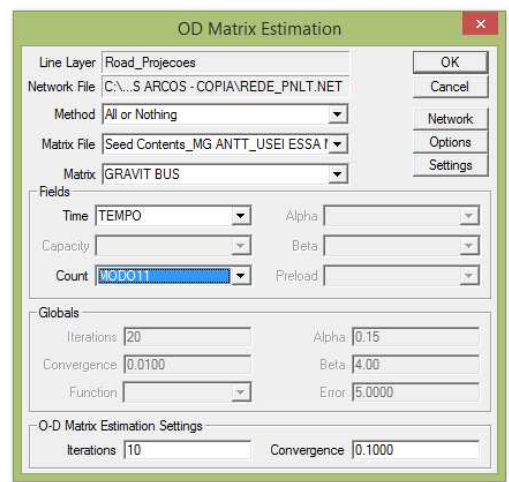

Figura 3.3 - Exemplo de alocação de tráfego para estimativa de matriz OD pelo método "Tudoou-Nada"no TRANSCAD (CALIPER, 2007)

Após a execução da rotina computacional no referido software obtém-se uma matriz de distribuição de viagens para o modo Automóvel. Analogamente ao executado no modo Ônibus, foram removidos os dados com VDMA menores que 2350 viagens por ano (ou seja, 45 viagens por dia) em uma etapa de pré-processamento dos dados. 
Em seguida, os parâmetros da Equação 3.14 foram calibrados por uma regressão linear múltipla pelo método Stepwise. Analogamente ao modo Ônibus, os pares de cidades foram segregados em três grupos para obtenção de estimativas mais acuradas dos parâmetros conforme preconizado por Gonçalves, Bez e Novaes (2007): Grupo A para viagens somente entre capitais dos Estados; Grupo B para viagens interestaduais excluindo-se as conexões entre capitais; e Grupo C com viagens intermunicipais (entre cidades do mesmo Estado).

Novamente, para os três grupos foram estimados modelos com e sem o intercepto $(\alpha)$ da Equação 3.14. No caso dos grupos B e C, além dessas estimativas a respeito da constante, os dados foram segregados pelas viagens em que nenhuma das cidades é capital (SEM CAPITAL) e naquelas em que pelo menos uma das cidades é uma capital estadual (COM CAPITAL). Por fim, os coeficientes também foram estimados com todos os dados agrupados (GERAL).

Assim, os valores da Tabela 3.5 representam os resultados da calibração dos coeficientes para o Grupo A (entre capitais estaduais da Região Sudeste do Brasil).

Tabela 3.5 - Estimativa dos parâmetros do modelo gravitacional para o modo Automóvel em viagens entre capitais (Grupo A)

\begin{tabular}{lccc}
\hline \multicolumn{4}{c}{ SEM INTERCEPTO } \\
\hline$R^{2}$ & \multicolumn{3}{c}{0,992} \\
$R^{2}$ Ajustado & 0,642 & \\
Subestimados & & $45,5 \%$ & \\
Superestimados & & $54,5 \%$ & \\
\hline Coeficiente & Valor & $t$-test & $p$-value \\
$\alpha$ & - & - & - \\
$\alpha_{A U T O}$ & 0,407 & 36,088 & 0,000 \\
$\alpha_{R E N D A}$ & - & - & - \\
\hline
\end{tabular}

\begin{tabular}{lccc}
\hline \multicolumn{4}{c}{ COM INTERCEPTO } \\
\hline$R^{2}$ & 0,991 & \\
$R^{2}$ Ajustado & 0,606 & \\
Subestimados & & $54,5 \%$ & \\
Superestimados & & $45,5 \%$ & \\
\hline Coeficiente & Valor & $t$-test & $p$-value \\
$\alpha$ & 52,739 & 5,377 & 0,000 \\
$\alpha_{A U T O}$ & - & - & - \\
$\alpha_{R E N D A}$ & $-1,954$ & $-4,231$ & 0,002 \\
\hline
\end{tabular}

Nesse Grupo A observa-se que os valores de $R^{2}$ da equação proposta sem o intercepto são maiores (e mais próximos da unidade) do que aquele com a constante na equação. Assim, o modelo admitido para representação das viagens entre capitais pelo modo Automóvel contempla somente a variável independente relativa ao número de automóveis nas capitais $\left(\alpha_{A U T O}\right)$. Na sequência, para o Grupo B, são apresentados os valores estimados para os coeficientes da Equação 3.14 na Tabela 3.6 . 
Tabela 3.6 - Estimativa dos parâmetros do modelo gravitacional para o modo Automóvel em viagens interestaduais excluindo-se as capitais (Grupo B)

\begin{tabular}{|c|c|c|c|c|c|c|c|c|c|}
\hline & \multicolumn{9}{|c|}{ SEM INTERCEPTO } \\
\hline & \multicolumn{3}{|c|}{ SEM CAPITAL } & \multicolumn{3}{|c|}{ COM CAPITAL $^{1}$} & \multicolumn{3}{|c|}{ GERAL $^{2}$} \\
\hline$R^{2}$ & & 0,990 & & & 0,992 & & & 0,990 & \\
\hline$R^{2}$ Ajustado & & 0,990 & & & 0,992 & & & 0,990 & \\
\hline Subestimados & & $42,4 \%$ & & & $44,6 \%$ & & & $43,1 \%$ & \\
\hline Superestimados & & $57,6 \%$ & & & $55,4 \%$ & & & $56,9 \%$ & \\
\hline Coeficientes & Valor & $t$-test & p-value & Valor & $t$-test & $p$-value & Valor & $t$-test & $p$-value \\
\hline$\alpha_{P O P}$ & 0,453 & 13,208 & 0,000 & 0,583 & 7,617 & 0,000 & 0,498 & 16,440 & 0,000 \\
\hline$\alpha_{d}$ & $-0,335$ & $-9,170$ & 0,000 & $-0,991$ & $-11,641$ & 0,000 & $-0,451$ & $-13,630$ & 0,000 \\
\hline$\alpha_{R E N D A}$ & 0,396 & 18,051 & 0,000 & 0,564 & 10,928 & 0,000 & 0,383 & 21,532 & 0,000 \\
\hline$\alpha_{O C U P}$ & $-0,280$ & $-7,959$ & 0,000 & $-0,220$ & $-2,457$ & 0,014 & $-0,252$ & $-9,125$ & 0,000 \\
\hline
\end{tabular}

\begin{tabular}{|c|c|c|c|c|c|c|c|c|c|}
\hline & \multicolumn{9}{|c|}{ COM INTERCEPTO } \\
\hline & \multicolumn{3}{|c|}{ SEM CAPITAL } & \multicolumn{3}{|c|}{ COM CAPITAL $^{1}$} & \multicolumn{3}{|c|}{ GERAL $^{2}$} \\
\hline$R^{2}$ & & 0,140 & & & 0,340 & & & 0,197 & \\
\hline$R^{2}$ Ajustado & & 0,139 & & & 0,337 & & & 0,196 & \\
\hline Subestimados & & $50,5 \%$ & & & $45,5 \%$ & & & $42,5 \%$ & \\
\hline Superestimados & & $49,5 \%$ & & & $54,5 \%$ & & & $57,5 \%$ & \\
\hline Coeficientes & Valor & $t$-test & $p$-value & Valor & $t$-test & $p$-value & Valor & $t$-test & $p$-value \\
\hline$\alpha$ & 17,516 & 31,225 & 0,000 & 9,926 & 4,689 & 0,000 & 16,162 & 30,377 & 0,000 \\
\hline$\alpha_{P O P}$ & - & - & - & 0,310 & 9,546 & 0,000 & 0,114 & 2,873 & 0,004 \\
\hline$\alpha_{d}$ & $-0,799$ & $-20,309$ & 0,000 & $-1,333$ & $-11,539$ & 0,000 & $-0,899$ & $-23,772$ & 0,000 \\
\hline$\alpha_{A U T O}$ & $-0,148$ & $-3,788$ & 0,000 & - & - & - & $-0,201$ & $-4,234$ & 0,000 \\
\hline$\alpha_{O C U P}$ & 0,215 & 5,801 & - & - & - & - & 0,260 & 7,647 & 0,000 \\
\hline
\end{tabular}

${ }^{1}$ Pelo menos uma das cidades é uma capital estadual

${ }^{2}$ Entre todos os pares OD

No caso das viagens interestaduais pelo modo Automóvel excluindo-se aquelas entre capitais estaduais, o modelo mais adequado é o que considera todos os dados observados (GERAL), sem o termo constante $(\alpha)$, e as variáveis independentes relacionadas à população $\left(\alpha_{P O P}\right)$, renda $\left(\alpha_{R E N D A}\right)$ e pessoal ocupado assalariado $\left(\alpha_{O C U P}\right)$ e distância rodoviária $\left(\alpha_{d}\right)$.

Isso decorre do fato de que as estatísticas $R^{2}$ são melhores do que para a equação com intercepto (para todos os casos) e de que as porcentagens de valores subestimados e superestimados são de $43,1 \%$ e $56,9 \%$, respectivamente.

Finalmente, para o GRUPO C de viagens intermunicipais, os resultados da calibração dos parâmetros da Equação 3.14 são apresentados na Tabela 3.7 a seguir. Em relação à modela- 
gem do número de viagens desse último grupo, a equação mais adequada é a "GERAL", sem intercepto e com as variáveis independentes relativas à população $\left(\alpha_{P O P}\right)$, renda $\left(\alpha_{R E N D A}\right)$ e pessoal ocupado assalariado $\left(\alpha_{O C U P}\right)$ e distância rodoviária $\left(\alpha_{d}\right)$ entre cidades, à semelhança das viagens interestaduais excluindo-se entre capitais. Nesse caso, as estatísticas $R^{2}$ são novamente melhores no modelo sem intercepto, cujas proporções entre valores subestimados e superestimados mantêm-se próximas (de 45,0\% e 55,0\%, respectivamente).

É importante salientar que os parâmetros da Equação 3.14 referem-se a estimativas do número de automóveis anuais entre cidades da Região Sudeste, uma vez que foram estabelecidos com base no VDMA dos carregamentos da rede provida pelos estudos do PNLT (PNLT, 2014). Ainda, para definição do número de pessoas que viajam pelo referido modo para aplicação na análise custo-benefício proposta nesta tese considera-se em média dois usuários por veículo conforme indicado pela Empresa Paulista de Planejamento Metropolitana (EMPLASA, 2006).

\subsubsection{Modo Avião}

Como nas viagens pelo modo Ônibus, existem estudos propostos a modelar o número de viagens realizadas pelo modo Avião. No contexto internacional, Grosche, Rothlauf e Heinzl (2007) apresentam uma revisão sobre a estimativa de modelos gravitacionais, indicando as variáveis escolhidas para caracterizar as observações e os respectivos coeficientes explicativos $R^{2}$. Naquele estudo os autores apresentam valores de parâmetros para dois modelos gravitacionais calibrados a partir de dados de fluxos de passageiros entre a Alemanha e 28 países europeus.

Sob a perspectiva nacional, a ANAC (ANAC, 1998) utiliza um modelo gravitacional para estimativa da demanda por viagens pelo modo aéreo considerando três variáveis: o PIB brasileiro, o yeld aéreo (preço médio de passagens por quilômetro - ANAC, 2014a), e uma variável binária para estimativas anteriores e posteriores ao lançamento do Plano Real.

Apesar de útil na estimativa do número de viagens pelo referido modo, o modelo apresenta restrições importantes como a reduzida quantidade de dados para calibração e a defasagem em relação aos atuais volumes de tráfego aéreo, que cresceram a uma taxa de $10 \%$ ao ano entre 2003 e 2008 (MCKINSEY, 2010). 
Tabela 3.7 - Estimativa dos parâmetros do modelo gravitacional para o modo Automóvel em viagens intermunicipais (Grupo C)

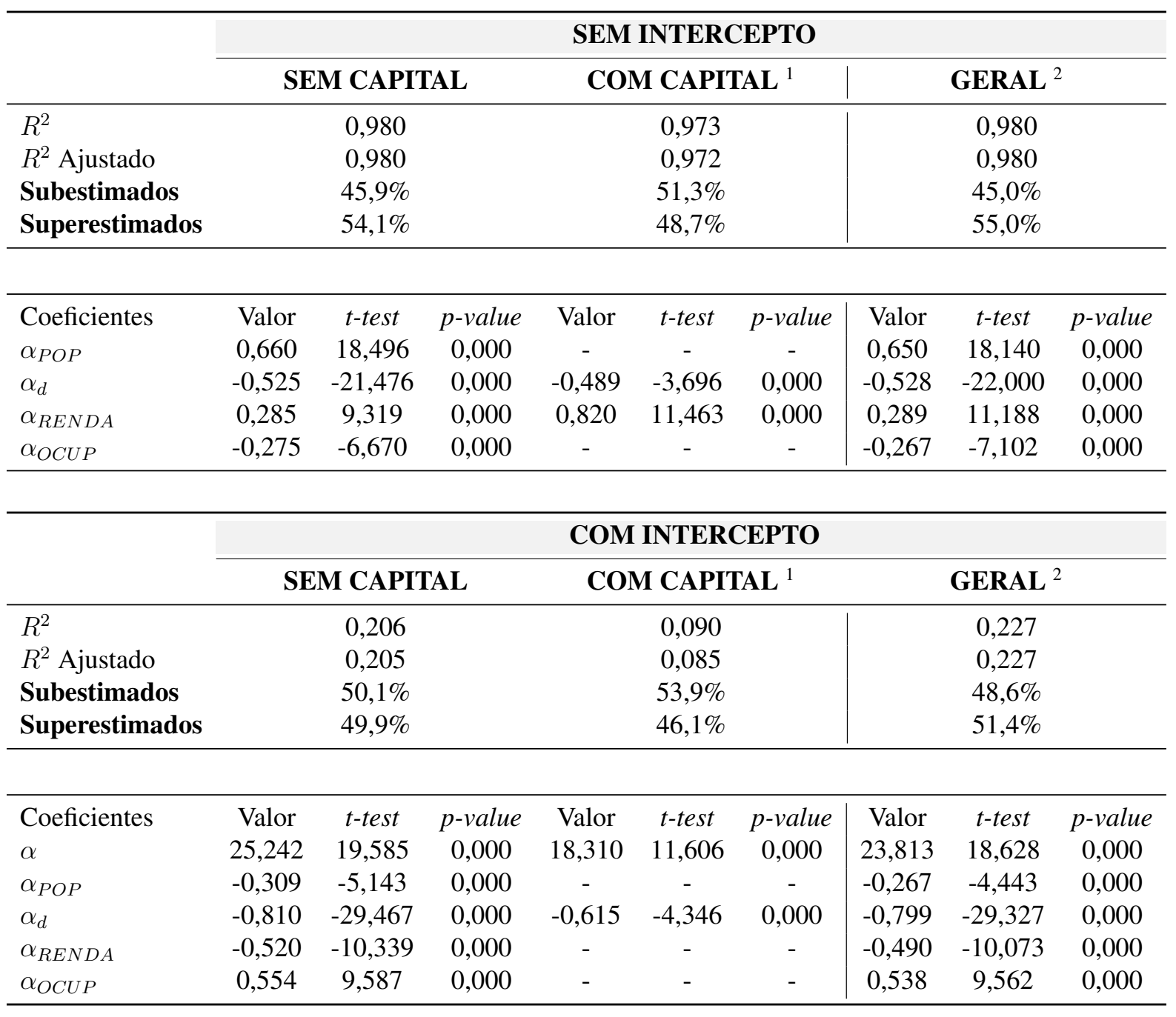

${ }^{1}$ Pelo menos uma das cidades é uma capital estadual

${ }^{2}$ Entre todos os pares OD

Com abordagem de treinamento de redes neurais artificiais, Sun, Brauner e Hormby (1998) propõem um procedimento alternativo à calibração de modelos econométricos tradicionais para representação dos padrões de viagens do setor aéreo. No contexto brasileiro, Alekseev e Seixas (2002) apresentam uma proposta de treinamento de rede neural que resultou no aumento da acurácia dos acertos em relação aos valores observados, reduzindo o erro médio de 4,6\% do modelo gravitacional da Agência Nacional de Aviação Civil (ANAC) (ANAC, 1998) para aproximadamente 1,0\%, comparando-se diferentes variáveis de entrada e funções de ativação.

Nesta tese, a estimativa do número de viagens pelo modo aéreo deu-se de maneira análoga ao modo Ônibus, pela calibração de um modelo gravitacional considerando variáveis socioe- 
conômicas, com algumas simplificações em relação à segregação dos dados e às conexões entre cidades. Inicialmente foram obtidos os números de viagens observados entre aeroportos nas cidades e regiões metropolitanas da Região Sudeste disponibilizados no Relatório Gerencial da Agência Nacional de Aviação Civil (ANAC, 2013).

A base de dados contém os aeroportos de origem e destino e os respectivos números de passageiros transportados no ano de 2012. A partir desses valores procedeu-se à remoção de observações não representativas para adequada modelagem do problema. Foram consideradas apenas as conexões entre aeroportos localizados em cidades da Região Sudeste do Brasil com número de passageiros maior que 2350 por ano (ou seja, mais que 45 passageiros transportados diariamente, analogamente ao realizado por AGUIAR JÚNIOR, 2004).

A Figura 3.4 representa as linhas de desejo (fluxos de passageiros entre aeroportos) obtidas pelo software TRANSCAD (CALIPER, 2007) após a remoção dos valores não representativos para a definição do modelo gravitacional de distribuição de viagens.

No caso da base de dados desse modo de transporte optou-se pela calibração dos coeficientes do modelo considerando-se a multiplicação das variáveis independentes como na Equação 3.14, apesar de os fluxos de passageiros entre aeroportos serem discriminados em cada direção.

Ainda, dado o número restrito de aeroportos considerados nas análises, as observações foram segregadas em dois grupos - em que ambas as cidades conectadas são capitais estaduais (ENTRE CAPITAIS) e aquelas em que pelo menos uma das cidades é capital de Estado - e posteriormente um modelo único foi calibrado contemplando todos os fluxos de passageiros (GERAL). Por outro lado, mantiveram-se as estimativas dos coeficientes para modelos com e sem intercepto da Equação 3.14. 


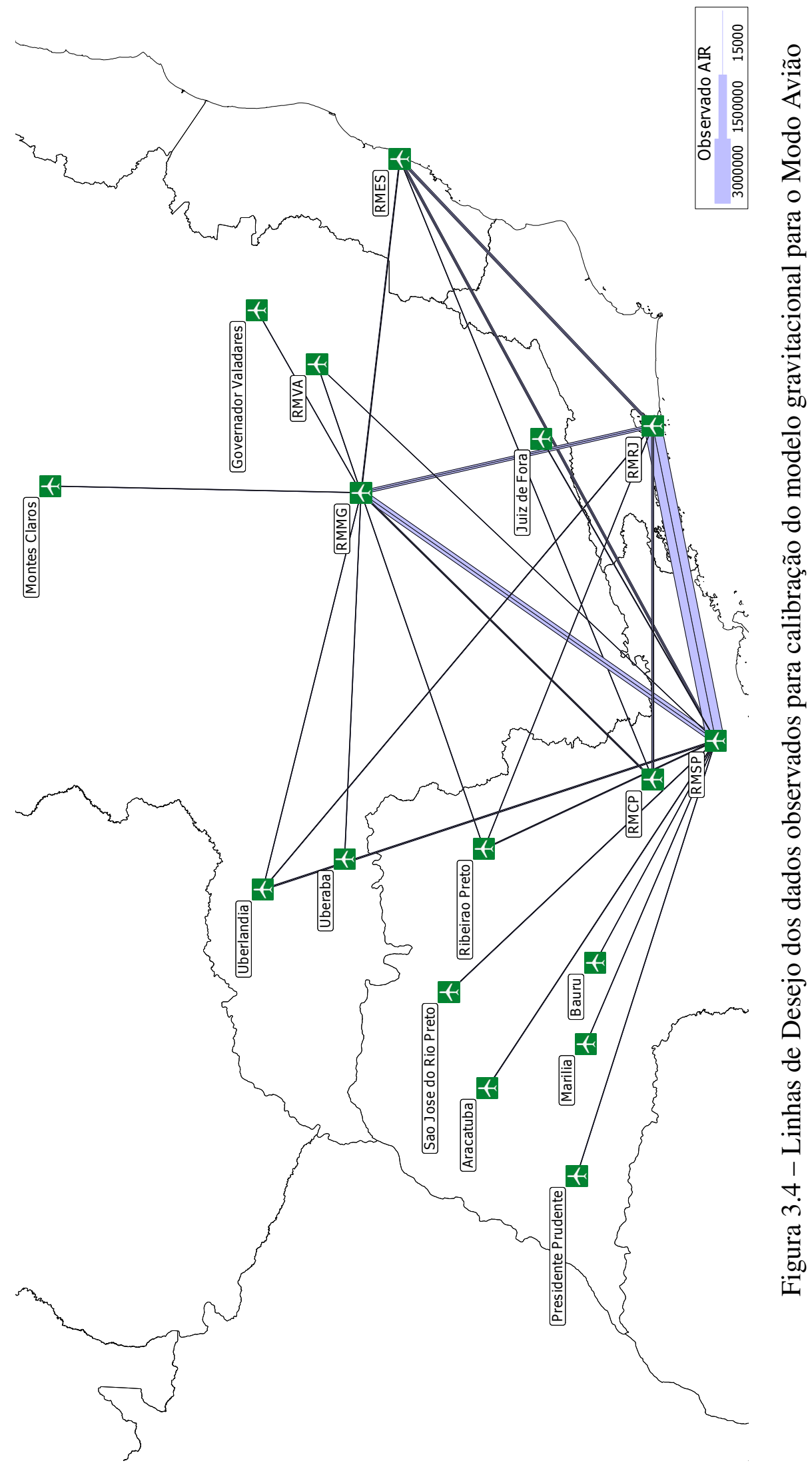


Assim, através do método Stepwise foram identificadas as variáveis independentes que afetam significativamente, do ponto de vista estatístico, a estimativa do número de viagens entre pares de aeroportos na Região Sudeste. A Tabela 3.8 apresenta os coeficientes selecionados e suas respectivas significâncias.

Tabela 3.8 - Estimativa dos parâmetros do modelo gravitacional para o modo Avião

\begin{tabular}{|c|c|c|c|c|c|c|c|c|c|}
\hline & \multicolumn{9}{|c|}{ SEM INTERCEPTO } \\
\hline & \multicolumn{3}{|c|}{ ENTRE CAPITAIS } & \multicolumn{3}{|c|}{ COM CAPITAL $^{1}$} & \multicolumn{3}{|c|}{ GERAL $^{2}$} \\
\hline$R^{2}$ & & 1,000 & & & 0,997 & & & 0,998 & \\
\hline$R^{2}$ Ajustado & & 1,000 & & & 0,994 & & & 0,997 & \\
\hline Superestimados & & $50,0 \%$ & & & $51,3 \%$ & & & $51,0 \%$ & \\
\hline Subestimados & & $50,0 \%$ & & & $48,7 \%$ & & & $49,0 \%$ & \\
\hline Coeficientes & Valor & $t$-test & p-value & Valor & $t$-test & $p$-value & Valor & $t$-test & $p$-value \\
\hline$\alpha_{P O P}$ & 0,450 & 160,497 & 0,000 & - & - & - & $-1,621$ & $-5,792$ & 0,000 \\
\hline$\alpha_{d}$ & - & - & - & - & - & - & $-0,497$ & $-3,116$ & 0,003 \\
\hline$\alpha_{O C U P}$ & - & - & - & 0,413 & 80,761 & 0,000 & 2,391 & 8,416 & 0,000 \\
\hline
\end{tabular}

\begin{tabular}{|c|c|c|c|c|c|c|c|c|c|}
\hline & \multicolumn{9}{|c|}{ COM INTERCEPTO } \\
\hline & \multicolumn{3}{|c|}{ ENTRE CAPITAIS } & \multicolumn{3}{|c|}{ COM CAPITAL $^{1}$} & \multicolumn{3}{|c|}{ GERAL $^{2}$} \\
\hline$R^{2}$ & & 0,996 & & & 0,628 & & & 0,864 & \\
\hline$R^{2}$ Ajustado & & 0,992 & & & 0,395 & & & 0,746 & \\
\hline Superestimados & & $41,7 \%$ & & & $59,0 \%$ & & & $54,9 \%$ & \\
\hline Subestimados & & $58,3 \%$ & & & $41,0 \%$ & & & $45,1 \%$ & \\
\hline Coeficientes & Valor & $t$-test & $p$-value & Valor & t-test & $p$-value & Valor & t-test & $p$-value \\
\hline$\alpha$ & $-10,562$ & $-5,911$ & 0,000 & $-2,433$ & $-0,616$ & 0,542 & $-6,518$ & $-2,680$ & 0,010 \\
\hline$\alpha_{P O P}$ & - & - & - & $-1,618$ & $-2,907$ & 0,006 & $-1,525$ & $-5,011$ & 0,000 \\
\hline$\alpha_{d}$ & $-1,339$ & $-9,114$ & 0,000 & - & - & - & - & - & - \\
\hline$\alpha_{R E N D A}$ & 1,012 & 10,924 & 0,000 & - & - & - & - & - & - \\
\hline$\alpha_{A U T O}$ & 0,713 & 28,147 & 0,000 & - & - & - & - & - & - \\
\hline$\alpha_{O C U P}$ & - & - & - & 2,237 & 3,779 & 0,001 & 2,292 & 7,768 & 0,000 \\
\hline
\end{tabular}

${ }^{1}$ Pelo menos uma das cidades é uma capital estadual

${ }^{2}$ Entre todos os pares OD

Dados os resultados da Tabela 3.8 optou-se pela segregação dos dados (ENTRE CAPITAIS e COM CAPITAL) em detrimento da calibração de um único modelo (GERAL). Para as viagens entre capitais, o modelo escolhido é aquele sem intercepto (com única variável independente referente à população, $\left(\alpha_{P O P}\right)$ uma vez que o $R^{2}$ é igual a 1,000 e a proporção de valores subestimados e superestimados é de $50 \%$. 
Para as demais viagens - em que umas cidades é uma capital estadual - o modelo escolhido também é sem intercepto (com única variável independente $\alpha_{O C U P}$ referente à população ocupada) dado o alto valor da estatística $R^{2}=0,997$ em relação ao modelo com intercepto.

\subsubsection{Projeção das Viagens Estimadas}

Para aplicação da estimativa do número de viagens entre municípios da Região Sudeste à análise custo-benefício de uma rede ferroviária é necessário considerar a expansão dos valores obtidos pelos modelos gravitacionais descritos anteriormente em um horizonte de planejamento.

A expansão do número de viagens entre pares de origem e destino foi realizada pela projeção dos valores das variáveis independentes dos modelos gravitacionais e aplicação aos respectivos coeficientes estimados nas seções anteriores para cálculo de $T_{i j}$ da Equação 3.14.

Essas projeções foram efetuadas da seguinte maneira: para cada variável independente dos modelos escolhidos para representação do número de viagens por modo de transporte, foram obtidos os valores observados no Censo de 2010 reportados pelo IBGE (IBGE, 2014c). A partir desses valores, foram realizadas projeções até o horizonte de 2050 conforme procedimento utilizado pelo instituto e descrito a seguir.

Seja uma variável $X(t)$ representativa de um parâmetro que caracteriza uma determinada região em um período $t$, e $x_{i}(t) \operatorname{com} i=1,2, \cdots, n$, os valores da variável subdividida em $n$ partições relativas às regiões menores que a compõe (Equação 3.15).

$$
X(t)=\sum_{i=1}^{n} x_{i}(t)
$$

A variável $x_{i}(t)$ é admitida como uma parcela de $X(t)$ representada na forma linear pela Equação 3.16, em que $a_{i}$ é denominado "coeficiente de proporcionalidade"do incremento da área menor $i$ em relação à área maior e $b_{i}$ é um coeficiente linear de correção.

$$
x_{i}(t)=a_{i} \cdot X(t)+b_{i}
$$

Para definição dos coeficientes dessa equação utilizam-se valores das variáveis referentes a dois períodos diferentes de observação (e.g. dois Censos Demográficos sucessivos). Assim, seja $t_{0}$ e $t_{1}$ os períodos do primeiro e segundo censos respectivamente, então: 


$$
\left\{\begin{array}{l}
x_{i}\left(t_{0}\right)=a_{i} \cdot X\left(t_{0}\right)+b_{i} \\
x_{i}\left(t_{1}\right)=a_{i} \cdot X\left(t_{1}\right)+b_{i}
\end{array}\right.
$$

Resolvendo-se o sistema de equações é possível calcular os valores dos coeficientes da Equação 3.17 mediante as observações nos períodos de referência. Assim, tem-se que:

$$
\begin{gathered}
a_{i}=\frac{x_{i}\left(t_{1}\right)-x_{i}\left(t_{0}\right)}{X\left(t_{1}\right)-X\left(t_{0}\right)} \\
b_{i}=x_{i}\left(t_{0}\right)-a_{i} \cdot X\left(t_{0}\right)
\end{gathered}
$$

Portanto, projetando-se os valores de $X(t)$ em um horizonte de planejamento é possível calcular os valores dessa variável para as áreas menores conhecendo os respectivos valores de períodos anteriores, considerando-se válida a hipótese de que as tendências de projeção das áreas menores seguem as mesmas observadas para a área maior.

Assim, para a projeção das variáveis independentes relacionadas à população $(P O P)$ e pessoal ocupado assalariado $(O C U P)$ das cidades com mais de 100 mil habitantes na Região Sudeste foram obtidas informações a respeito das estimativas de projeção da população brasileira (IBGE, 2014b), cujos valores são representados na Figura 3.5.

A partir desses valores, os parâmetros da Equação 3.17 para essas variáveis foram calculados e as populações do municípios foram projetadas para o ano de 2050. No caso da variável $O C U P$ preferiu-se a projeção em relação à população uma vez que admite-se válida a hipótese de que os níveis de emprego manter-se-ão estáveis e iguais ao período 2000-2010 até 2050.

Para as variáveis relacionadas à renda per capita da população $(R E N D A)$ e frota de automóveis das cidades $(A U T O)$, optou-se pela expansão no horizonte de planejamento com base em dados de projeção da renda per capita brasileira nas projeções da Previdência Social (MPS, 2013), representados na Figura 3.6. No caso da frota de automóveis optou-se também pela projeção com base nessa variável pela hipótese de que, no caso brasileiro, o aumento da renda reflete na maior aquisição de veículos particulares e aumento de viagens intermunicipais. 


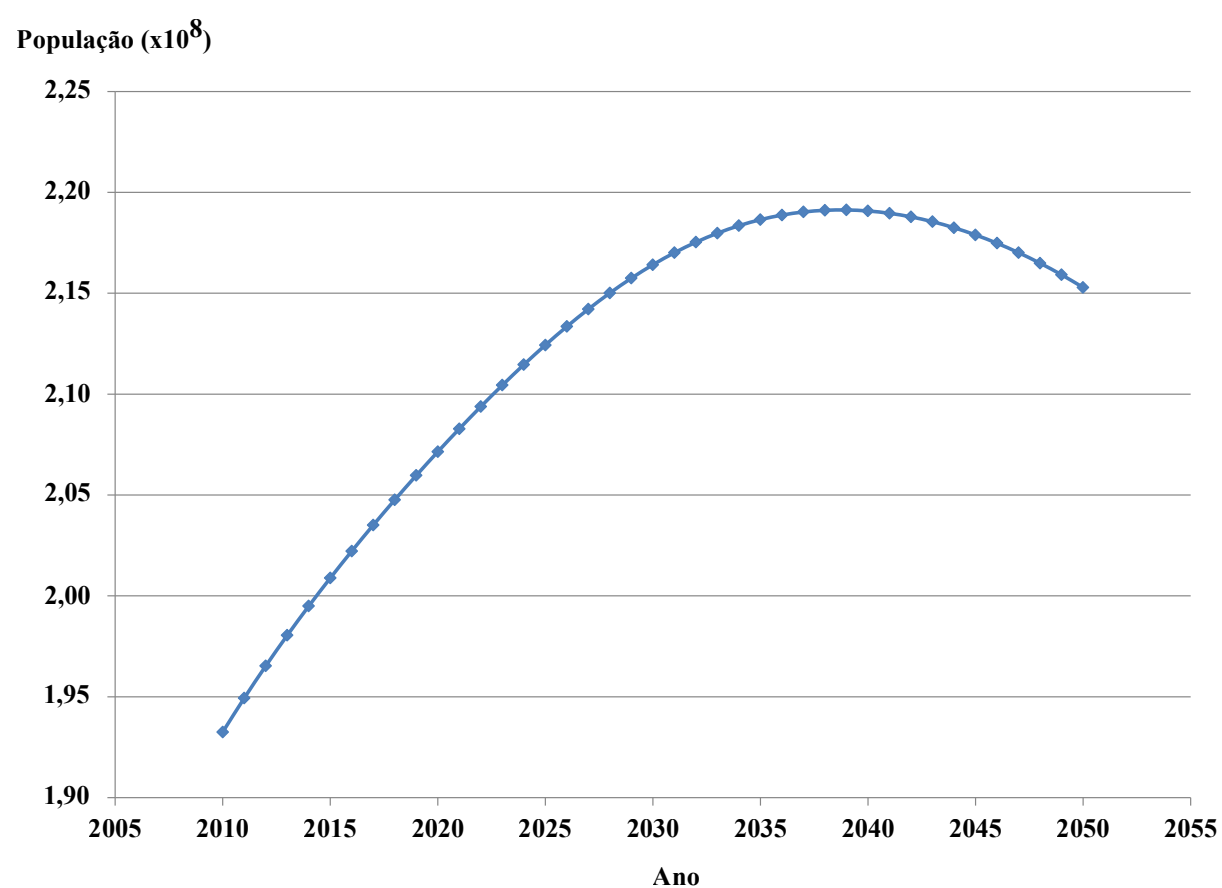

Figura 3.5 - Estimativa de crescimento da população brasileira - Fonte: IBGE (2014b)

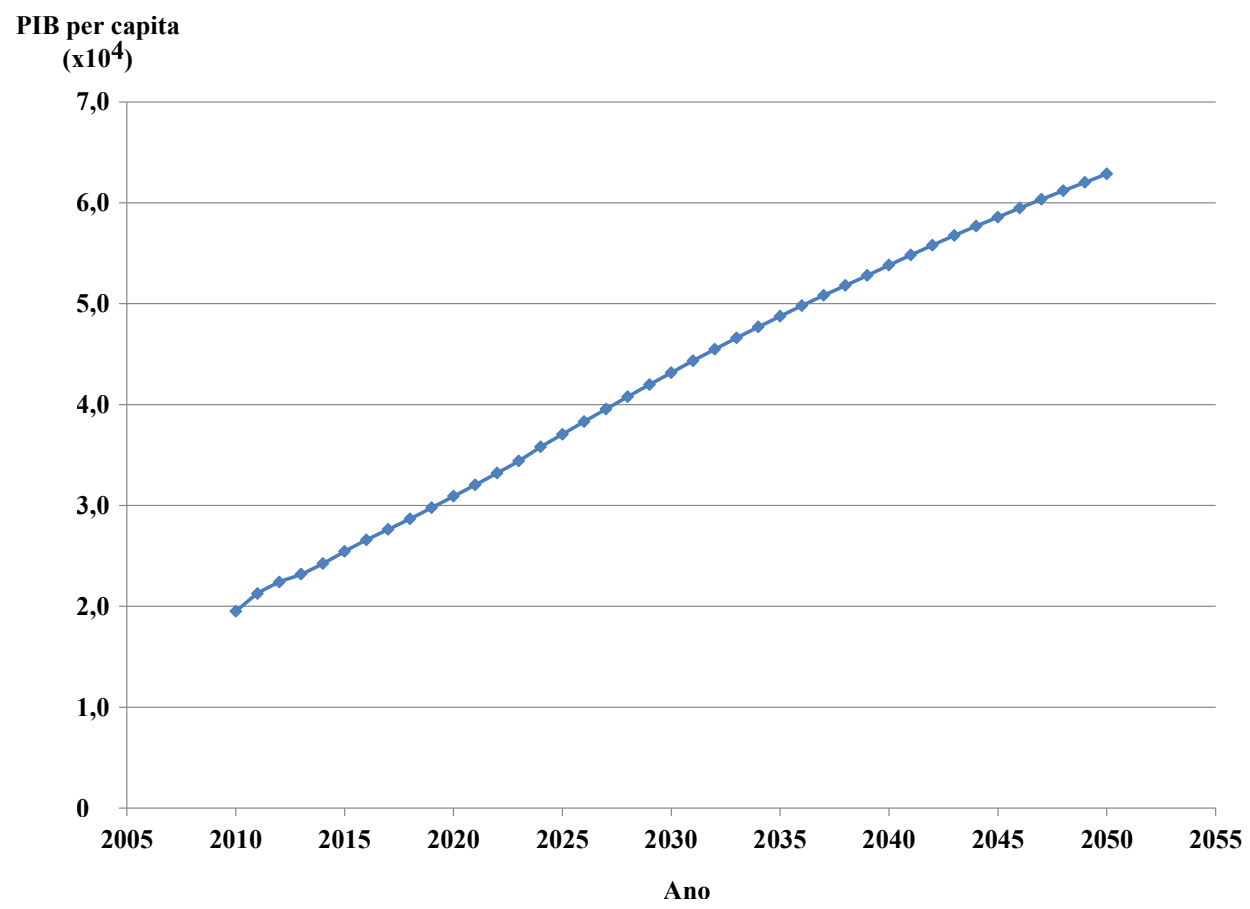

Figura 3.6 - Estimativa de crescimento da renda média per capita brasileira - Fonte: MPS (2013) 


\subsubsection{Modo Ônibus}

A aplicação dos valores de projeção das variáveis independentes até o horizonte de planejamento de 2050 à Equação 3.17 resulta nas estimativas de viagens representadas pela Tabela B.2 e Tabela B.3 do Apêndice B. Observa-se naquela matriz que as projeções não são estimadas entre todos os pares de municípios da Região Sudeste, uma vez que não existem serviços de transporte rodoviário coletivo (diretos) entre todos eles.

Assim, para definição daquelas tabelas foram identificadas as linhas de Ônibus diretas intermunicipais em cada Estado da referida Região e as interestaduais. As primeiras foram obtidas junto aos órgãos competentes pela regulação dos serviços nos respectivos Estados (o Departamento de Estradas de Rodagem, DER, no caso do Espírito Santo, Rio de Janeiro e Minas Gerais, e a Agência Reguladora de Transporte do Estado de São Paulo, ARTESP ) e o segundo com base no plano nacional de rede de transporte rodoviário proposto pela ANTT (PNLT, 2014).

Dadas essas projeções, foram estimadas as quantidades de viagens entre os pares de cidades com linhas regulares de Ônibus na Região Sudeste pela aplicação desses valores na Equação 3.14. Na Figura 3.7 apresenta-se ilustrativamente o padrão de distribuição dessas viagens estimadas, na rede rodoviária da Região Sudeste pelo modo Ônibus em 2015.

Cabe ressaltar que a Figura 3.7 é meramente ilustrativa das estimativas dos fluxos passageiros pelo modo Ônibus na rede rodoviária da Região Sudeste. Em algumas conexões os carregamentos não representam necessariamente a realidade observada nas rodovias, por exemplo, entre São Paulo e Santos, o que ocorre pelo fato de que a alocação dos fluxos pelo software TRANSCAD (CALIPER, 2007) considera os caminhos mínimos entre pares de origem e destino.

Ainda, é necessário considerar que a calibração dos modelos para estimativa do número de viagens entre cidades representa apenas a base de dados da Agência Nacional de Transporte Terrestre para viagens intermunicipais, que não contempla aquelas realizadas pelo modo Ônibus sob condições específicas (e.g. por fretamento). Isso justifica, por exemplo, a baixa densidade relativa entre a Região Metropolitana de Campinas e São Paulo, cujas viagens não são necessariamente realizadas com acesso pelos terminais rodoviários das cidades. 


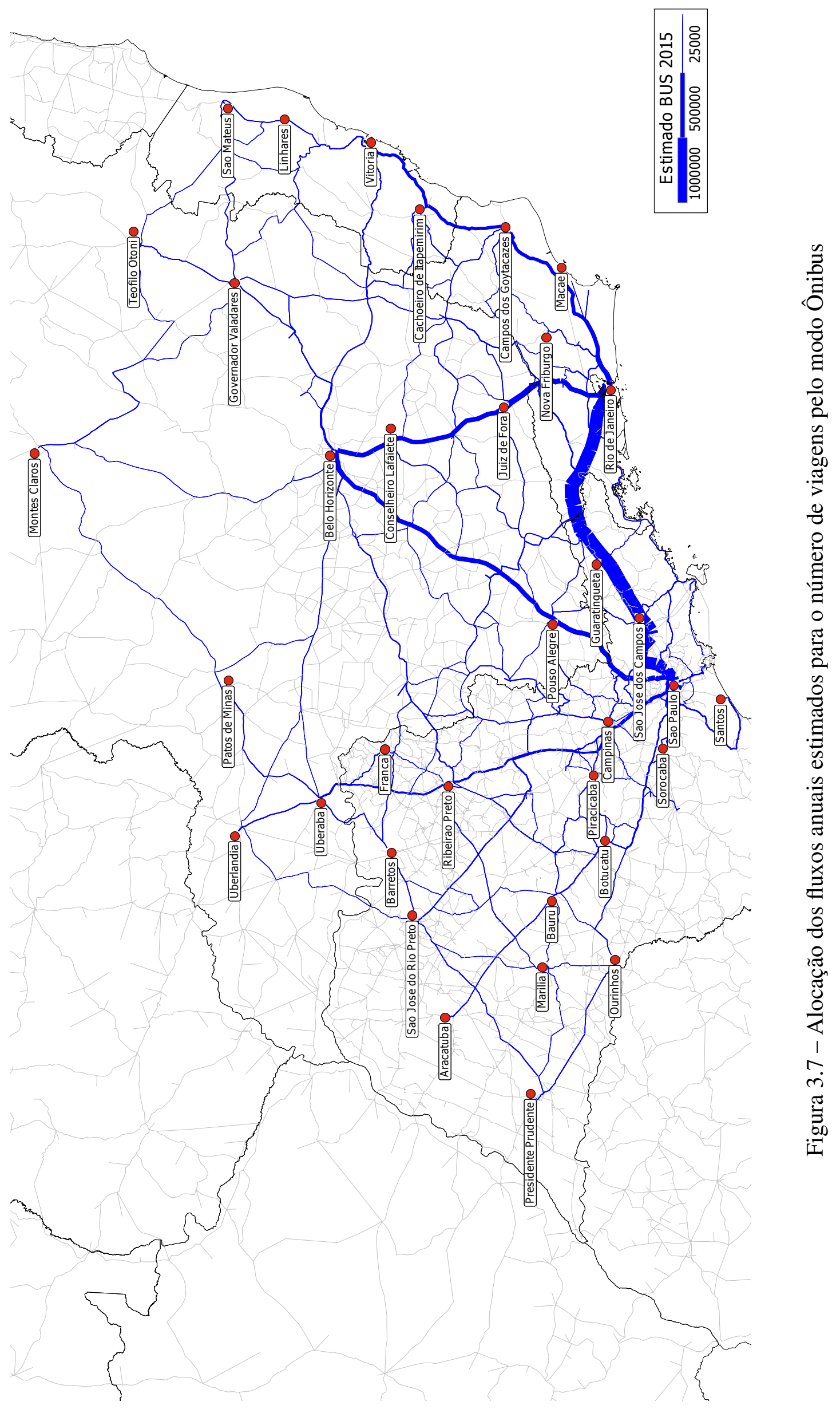




\subsubsection{Modo Automóvel}

O precedimento executado para expansão das viagens pelo modo Automóvel é análogo ao modo Ônibus. Após projeções das variáveis independentes da Equação 3.17, o número de viagens entre municípios da Região Sudeste foi projetado para aquele modo de transporte.

Assim, a Tabela B.4 e Tabela B.5 do Apêndice B contêm a lista de origens e destinos e o número de viagens estimadas entre cada cidade da Região Sudeste para o horizonte de planejamento até o ano de 2050. Na Figura 3.8 é apresentado, para efeito de ilustração, a alocação dos fluxos de passageiros estimados, cujas viagens são realizadas pelo modo Automóvel no ano de 2015 (considerando média de dois passageiros por Automóvel - EMPLASA, 2006).

Como na Figura 3.7 referente à alocação dos fluxos de passageiros pelo modo Ônibus, essa Figura 3.8 tem como motivação a representação da proporcionalidade dos fluxos de automóveis entre cidades na rede rodoviária da Região Sudeste, não representando necessariamente a realidade dos carregamentos nas rodovias. Novamente, verifica-se uma maior concentração de passageiros em Automóveis em viagens entre as capitais dos Estados e, ainda, no eixo rodoviário entre a Região Metropolitana de São Paulo e o interior do Estado. 


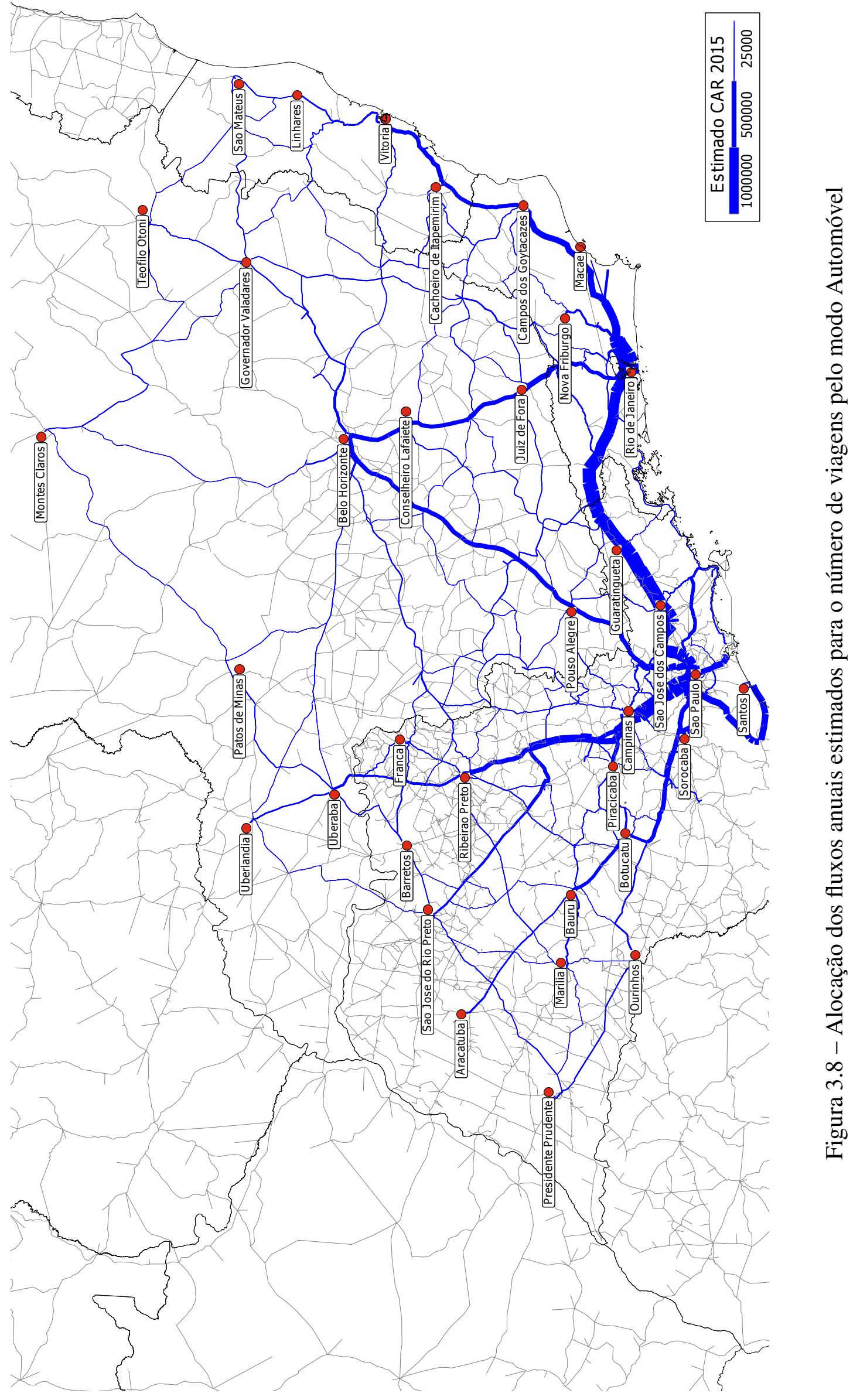




\subsubsection{Modo Avião}

Para definição dos pares de cidades que são contempladas com projeções de passageiros até o horizonte de planejamento de novas linhas ferroviárias foram obtidas os pares de origens e destinos que possuem operação comercial de voos diretos entre pares de cidades da Região Sudeste e infraestrutura aeroportuária para tal propósito, segundo banco de dados da ANAC.

Assim, dada a Equação 3.14 de estimativa do número de viagens entre cidades pelo modo aéreo, e as projeções de suas variáveis independentes, apresenta-se a Tabela B.6 e a Tabela B.7 do Apêndice B sobre o número de viagens entre pares de cidades da Região Sudeste com volume representativo de viagens no ano de 2010.

A partir dessas projeções apresenta-se o gráfico das linhas de desejo do número de passageiros entre as referidas cidades estimados para o ano de 2015. Nesse caso, tem-se maior concentração de viagens entre as capitais São Paulo, Belo Horizonte, Rio de Janeiro e Vitória. É importante ressaltar que na estimativa e projeção das viagens são computados os deslocamentos entre cada origem e destino incluindo aqueles voos com escalas ou conexões, uma vez que a base de dados para a calibração do modelo gravitacional inclui todas as viagens realizadas entre cada OD não importando o percurso realizado. 


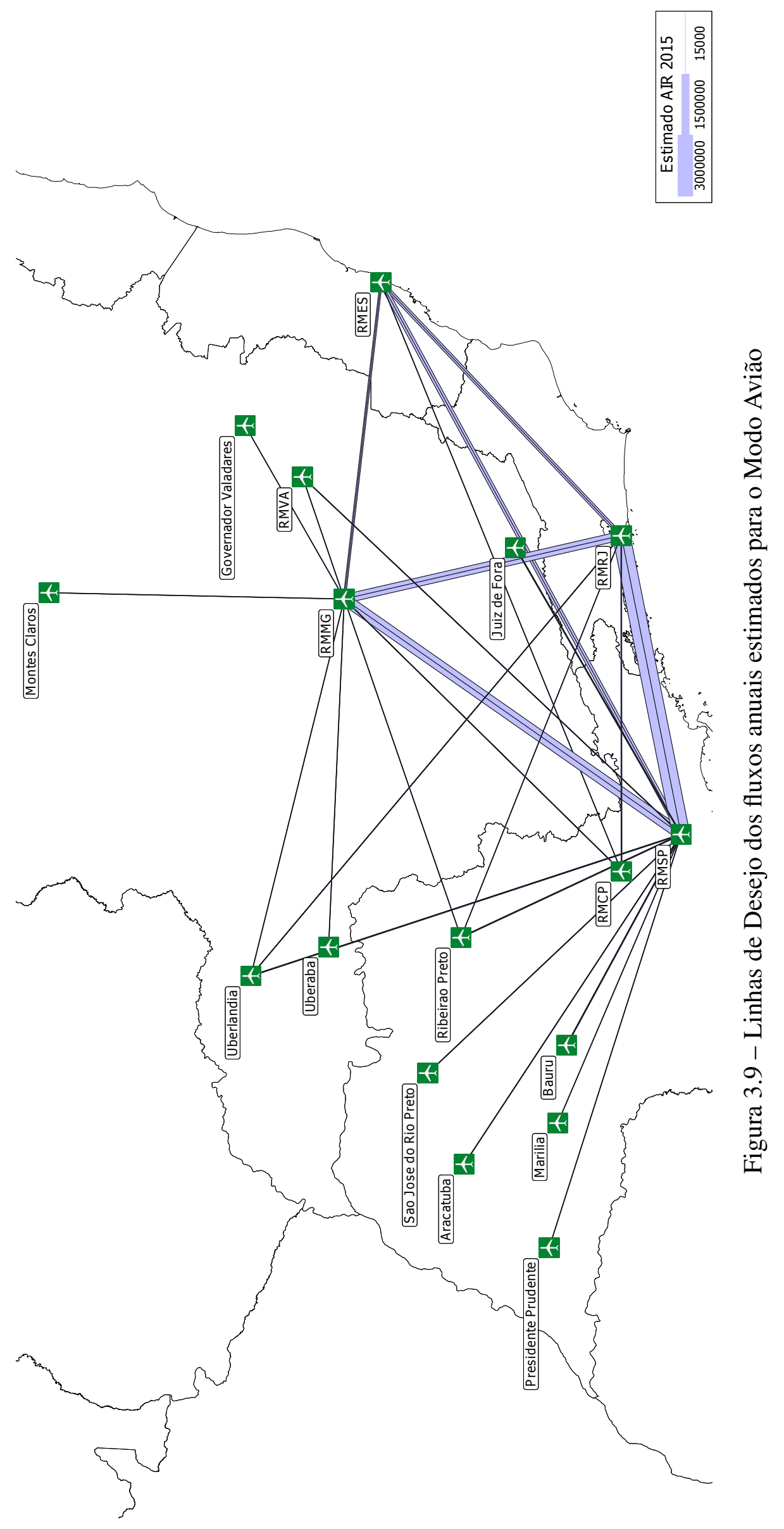




\subsection{Escolha Modal}

Diferentemente de muitos países europeus em que a malha ferroviária de trens convencionais está consolidada e existe uma propensão à instalação e expansão de uma malha de alta velocidade, a inexistência de serviços competitivos dessa natureza no Brasil dificulta a estimativa da divisão modal no caso da implantação de novos serviços.

Assim, no contexto de incertezas a respeito da propensão à escolha modal nos cenários de reativação do transporte ferroviário de passageiros no Brasil, propõe-se uma pesquisa de preferência declarada conduzida na Região Sudeste considerando sistemas de HPTs e HSTs.

No contexto da abordagem quatro etapas, a escolha modal diz respeito à identificação das proporções da população que utilizam os modos de transporte disponíveis para a realização de viagens entre pares de cidades. No caso de novos projetos de sistemas de transporte, essa análise tenta refletir da melhor maneira possível os padrões das novas viagens, cujas tendências são observadas através de pesquisas específicas aplicadas a uma amostra da população.

No âmbito do planejamento de transportes, uma pesquisa de preferência revelada refere-se à aplicação de um questionário em que o participante reporta ao pesquisador as características de uma viagem que já realizou no passado. Por outro lado, uma pesquisa de preferência declarada apresenta diferentes cenários envolvendo modos de transporte e suas respectivas características

- incluindo os existentes e potenciais novos sistemas - e o entrevistado é conduzido à escolha de uma das alternativas mediante suas preferências pessoais.

\subsubsection{Pesquisa de Preferência Declarada}

Ortúzar e Willumsen (2011) definem três classes de métodos de pesquisa de preferência declarada: Contingent Valuation, Conjoint Analysis e Stated Choice. Na Contingent Valuation, os respondentes são questionados sobre o quanto pagariam por um serviço ou produto diferente daquele que já é ofertado (MITCHELL; CARSON, 1989). A Conjoint Analysis pede que os participantes ordenem uma série de alternativas quanto à sua preferência e a Stated Choice propõe seja escolhida uma alternativa de serviço ou produto entre novos e existentes em múltiplas situações. 
Vários autores corroboram a afirmação de que comportamento relativo a viagens, sobretudo a escolha modal, é fortemente relacionado às características dos indivíduos, da viagem e das instalações do sistema de transporte (CERVERO; RADISCH, 1996; KITAMURA; MOKHTARIAN; LAIDET, 1997; ORTÚZAR; WILLUMSEN, 2011).

Nesta seção descreve-se uma pesquisa da classe Stated Choice em que os respondentes escolheram um modo de transporte para viagens na situação hipotética de oferta de serviços de HPTs ou HSTs. A pesquisa teve por objetivo coletar respostas sobre a escolha modal em viagens de longa distância (entre 100 km e 1000 km) na Região Sudeste com alternativas envolvendo os modos Automóvel, Ônibus, Trem (HPT ou HST) e Avião.

Para facilidade de representação algumas denominações são apresentadas no contexto da língua portuguesa e representadas por siglas que remetem à sua tradução em inglês. No caso dos modos de transporte envolvidos são atribuídas as denominações, respectivamente, de $C A R$, $B U S, H P T, H S T$ e AIR . É importante esclarecer que em algumas viagens de longa distância o modo aéreo não está disponível para escolha pela ausência de uma infraestrutura aeroportuária que opere voos comerciais regulares.

Dado que o motivo da viagem é um fator importante na escolha modal e que influencia os resultados de possíveis aplicações da pesquisa de preferência declarada, optou-se pela segmentação dos respondentes cujas viagens são por motivo trabalho (Work, representado por $W$ ) ou lazer, estudos e outros motivos (denominado como Leisure e representado por $L$ ).

Assim, considerando a disponibilidade dos modos e motivos de viagem, são definidos cenários de operação de $H P T$ ou $H S T$ em que o modo aéreo pode ou não ser ofertado, resultando nas seguintes combinações: HPT sem AIR, HPT com AIR, HST sem AIR e HST com AIR pelo motivo $W$ e $H P T$ sem AIR, HPT com AIR, HST sem AIR e HST com AIR pelo motivo $L$.

\subsubsection{Atributos dos Modos de Transporte}

O número máximo de atributos característicos de cada modo foi limitado a três para viabilizar a formulação do questionário em termos de número de perguntas apresentadas aos respondentes e proporcionar um realismo adequado à pouca experiência da população brasileira no uso de transporte ferroviário intermunicipal. 
Para evitar o foco em apenas alguns atributos de cada modo (CARSON et al., 1994) e respostas aleatórias pelo excesso de informações (SAELENSMINDE, 1999), o modo Automóvel foi caracterizado pelo Tempo de Viagem $\left(T T_{C A R}\right)$, Custo de Combustível $\left(P E_{C A R}\right)$ e Custo de Pedágio $\left(T O_{C A R}\right)$ e os modos Ônibus, Trem $(H P T$ e $H S T)$ e Avião foram caracterizados pelo Tempo de Viagem ( $\left.T T_{B U S}, T T_{H P T}, T T_{H S T}, T T_{A I R}\right)$, Frequência em termos de intervalo entre serviços $\left(F R_{B U S}, F R_{H P T}, F R_{H S T}, F R_{A I R}\right)$ e Preço da Passagem $\left(F A_{B U S}, F A_{H P T}, F A_{H S T}, F A_{A I R}\right)$, conforme resumido na Tabela 3.9.

Tabela 3.9 - Atributos considerados nas pesquisa de preferência declarada

\begin{tabular}{cccc}
\hline Automóvel $(\boldsymbol{C A R})$ & $\begin{array}{c}\text { Tempo de Viagem } \\
\left(T T_{C A R}\right)\end{array}$ & $\begin{array}{c}\text { Combustível } \\
\left(P E_{C A R}\right)\end{array}$ & $\begin{array}{c}\text { Pedágio } \\
\left(T O_{C A R}\right)\end{array}$ \\
\hline \multirow{2}{*}{ Onibus $(\boldsymbol{B U S})$} & $\begin{array}{c}\text { Tempo de Viagem } \\
\left(T T_{B U S}\right)\end{array}$ & $\begin{array}{c}\text { Frequência } \\
\left(F R_{B U S}\right)\end{array}$ & $\begin{array}{c}\text { Preço da Passagem } \\
\left(F A_{B U S}\right)\end{array}$ \\
\hline \multirow{2}{*}{ Trem $(\boldsymbol{H P T} / \boldsymbol{H S T})$} & $\begin{array}{c}\text { Tempo de Viagem } \\
\left(T T_{H P T / H S T}\right)\end{array}$ & $\begin{array}{c}\text { Frequência } \\
\left(F R_{H P T / H S T}\right)\end{array}$ & $\begin{array}{c}\text { Preço da Passagem } \\
\left(F A_{H P T / H S T}\right)\end{array}$ \\
\hline \multirow{2}{*}{ Aéreo (AIR) } & $\begin{array}{c}\text { Tempo de Viagem } \\
\left(T T_{A I R}\right)\end{array}$ & $\begin{array}{c}\text { Frequência } \\
\left(F R_{A I R}\right)\end{array}$ & $\begin{array}{c}\text { Preço da Passagem } \\
\left(F A_{A I R}\right)\end{array}$ \\
\hline
\end{tabular}

Apesar de nem todas as rodovias brasileiras serem concessionadas à iniciativa privada e, por isso, não possuírem praças de pedágio em sua extensão, os custos operacionais dos automóveis foram divididos em combustível e pedágio de modo a tornar os cenários mais próximos da realidade atual das rodovias da Região Sudeste e por acreditar-se que o modelo de concessões tende a se expandir em um futuro próximo.

\subsubsection{Níveis dos Atributos}

A cada um dos atributos dos respectivos modos de transporte foram atribuídos três níveis de valores numéricos (Baixo, Médio e Alto) de modo a captar a variabilidade dos valores em função da decisão dos respondentes. O tempo de viagem foi definido com base na velocidade média dos veículos (Tabela 3.10) em função das características dos veículos, dos limites de velocidade e de eventuais atrasos, e a distância média entre cidades caracterizada posteriormente na definição das possíveis conexões entre cidades.

A frequência dos serviços de Ônibus, Trens e Avião também foi definida em três níveis em função do intervalo entre partidas sucessivas, com valores "BAIXO" para saídas a cada 12 horas, "MÉDIO" a cada 6 horas e "ALTO" a cada 3 horas. 
Tabela 3.10 - Níveis de velocidade média para definição dos tempos de viagem

\begin{tabular}{cccccc}
\hline Nível & $\boldsymbol{C A R}$ & $\boldsymbol{B U S}$ & $\boldsymbol{H P T}$ & $\boldsymbol{H S T}$ & $\boldsymbol{A I R}$ \\
\hline BAIXO & 70 & 60 & 100 & 200 & 400 \\
MÉDIO & 90 & 75 & 150 & 250 & 500 \\
ALTO & 110 & 90 & 200 & 300 & 600 \\
\hline
\end{tabular}

Por fim, os custos da viagem foram estabelecidos em função da distância entre origens e destinos, e dos custos médios de cada modo conforme apresentados na Tabela 3.11. Para os automóveis, os níveis de Custo de Combustível $\left(P E_{C A R}\right)$ foram estabelecidos com base em preços regulamentados pela Agência Nacional de Petróleo (ANP) Agência Nacional de Petróleo (ANP) (ANP, 2013) e os níveis de Pedágio $\left(\mathrm{TO}_{C A R}\right)$ foram estabelecidos com base no preço médio das rodovias atualmente concessionadas à iniciativa privada segundo a Associação Brasileira de Concessionárias de Rodovias (ABCR) (ABCR, 2013) .

Os níveis dos preços das passagens de Ônibus $\left(F A_{B U S}\right)$ foram definidos pelas tarifas médias autorizadas pela ANTT (ANTT, 2013) e os das passagens de Avião $\left(F A_{A I R}\right)$ com base nas regulações da ANAC (ANAC, 2014a).

Há uma dificuldade para estabelecer o preço da passagem dos trens no Brasil uma vez que esses serviços são praticamente inexistentes no país. Assim, os níveis desses atributos foram definidos com base em estudos de benchmarking das tarifas praticadas nos sistemas ferroviários dos países europeus (TAYLOR et al., 2013; PRODAN, 2011).

Tabela 3.11 - Formulação para cálculo dos níveis de custo dos modos de transporte em função da distância média de viagem

\begin{tabular}{lccccc}
\hline MODO & $\boldsymbol{C A R}$ & $\boldsymbol{B U S}$ & $\boldsymbol{H P T}$ & $\boldsymbol{H S T}$ & $\boldsymbol{A I R}$ \\
\hline NÍVEL & $\begin{array}{c}\frac{D I^{a}}{D M^{6}}+\text { Combustível }(\mathrm{R} \$ / \mathrm{km}) \\
+D I \cdot \text { Pedágio }(\mathrm{R} \$ \mathrm{~km})\end{array}$ & \multicolumn{2}{c}{$D I \cdot$ Preço da Passagem $(\mathrm{R} \$ / \mathrm{km})$} & \\
\hline \multirow{2}{*}{ BAIXO } & $\frac{D I}{10} \cdot 2,5+D I \cdot 0,125$ & $D I \cdot 0,1814$ & $D I \cdot 0,620$ & $D I \cdot 0,676$ & $D I \cdot 1,084$ \\
MÉDIO & $\frac{D I}{10} \cdot 3,0+D I \cdot 0,166$ & $D I \cdot 0,2002$ & $D I \cdot 0,804$ & $D I \cdot 0,794$ & $D I \cdot 1,285$ \\
ALTO & $\frac{D I}{10} \cdot 3,5+D I \cdot 0,220$ & $D I \cdot 0,2918$ & $D I \cdot 0,919$ & $D I \cdot 0,984$ & $D I \cdot 1,527$
\end{tabular}

${ }^{a} D I=\overline{\text { Distância Média entre cidades }(\mathrm{km}) ;{ }^{b} D M=\text { Desempenho Médio de Automóvel }}(\mathrm{km} / \mathrm{l})$ 


\subsubsection{Planejamento do Experimento}

O planejamento do experimento visa definir a combinação de níveis dos atributos apresentados aos respondentes em cada cenário hipotético (ou linha do experimento) de uma pesquisa. Inicialmente foram definidas as cidades de origem e destino a partir das quais seriam identificados potenciais respondentes para a pesquisa. Como o intuito era identificar a divisão modal em cenários hipotéticos de existência de transporte ferroviário de passageiro com e sem a eventual disponibilidade do modo aéreo, decidiu-se pela definição das cidades em que existe infraestrutura aeroportuária instalada que permite a operação de voos comerciais domésticos regulares.

Assim, foram identificados os dez aeroportos da Região Sudeste com maior movimentação de passageiros no ano de 2011 (Tabela 3.12) segundo uma base de dados da Agência Nacional de Aviação Civil (ANAC, 2013).

Tabela 3.12 - Aeroportos com maior movimentação de passageiros em voos domésticos na Região Sudeste no ano de 2011

\begin{tabular}{cc}
\hline CIDADE & PASSAGEIROS (2011) \\
\hline RIO DE JANEIRO (Santos Dumont) & 7.216 .030 \\
SÃO PAULO (Congonhas) & 6.727 .822 \\
BELO HORIZONTE (Pampulha) & 4.863 .637 \\
ARAÇATUBA & 2.274 .262 \\
IPATINGA & 2.209 .371 \\
GOVERNADOR VALADARES & 1.894 .309 \\
CAMPINAS & 1.183 .575 \\
VITÓRIA & 1.128 .600 \\
RIBEIRÃO PRETO & 968.216 \\
CAMPOS DOS GOYTACAZES & 695.691 \\
\hline
\end{tabular}

Uma vez que os aeroportos de Belo Horizonte (Pampulha), Ipatinga e Governador Valadares são muito próximos, este último foi substituído pelo aeroporto de Campos dos Goytacazes. Entre cada um desses aeroportos foram identificadas as distâncias rodoviárias e estabelecidas aproximações para esses valores, a partir dos quais foram definidos os níveis dos atributos de cada modo de transporte conforme estabelecido na Tabela 3.11 a respeito dos custos de viagem.

Das 58 possíveis combinações entre cidades com aeroportos, foram escolhidas as 38 mais representativas (Tabela 3.13) quanto ao porte das cidades e número de passageiros transportados, de modo a garantir a diversificação das distâncias entre origens e destinos, ou a variabilidade dos níveis de tempo e custos de viagens apresentados aos respondentes. 
Tabela 3.13 - Cidades de origem, destino, distâncias rodoviárias aproximadas e distâncias estabelecidas para definição dos níveis dos atributos

\begin{tabular}{cccc}
\hline Origem & Destino & $\begin{array}{c}\text { Distância } \\
\text { Rodoviária }\end{array}$ & $\begin{array}{c}\text { Distância } \\
\text { Estabelecida }\end{array}$ \\
\hline VCP & CGH & 103 & 100 \\
CGH & VCP & 103 & 100 \\
CAW & MEA & 105 & 100 \\
SDU & JDF & 178 & 235 \\
IPN & PLU & 235 & 235 \\
PLU & IPN & 235 & 235 \\
CAW & VIX & 243 & 235 \\
VCP & BAU & 261 & 235 \\
CAW & SDU & 275 & 320 \\
RAO & CGH & 318 & 320 \\
CGH & RAO & 318 & 320 \\
SDU & CGH & 430 & 440 \\
CGH & SDU & 430 & 440 \\
SDU & PLU & 437 & 440 \\
VCP & SDU & 430 & 440 \\
IPN & VIX & 430 & 440 \\
PLU & SDU & 437 & 440 \\
RAO & PLU & 516 & 520 \\
VIX & SDU & 516 & 520 \\
\hline BAU &
\end{tabular}

\begin{tabular}{cccc}
\hline Origem & Destino & $\begin{array}{c}\text { Distância } \\
\text { Rodoviária }\end{array}$ & $\begin{array}{c}\text { Distância } \\
\text { Estabelecida }\end{array}$ \\
\hline PLU & VIX & 527 & 520 \\
SDU & VIX & 516 & 520 \\
VIX & PLU & 527 & 520 \\
CAW & PLU & 525 & 520 \\
IPN & SDU & 563 & 565 \\
CGH & PLU & 584 & 580 \\
PLU & CGH & 584 & 580 \\
VCP & PLU & 579 & 580 \\
PLU & SJP & 671 & 670 \\
RAO & SDU & 715 & 715 \\
SDU & RAO & 715 & 715 \\
CAW & CGH & 712 & 715 \\
CGH & IPN & 801 & 800 \\
IPN & CGH & 802 & 800 \\
VIX & CGH & 941 & 940 \\
CGH & VIX & 941 & 940 \\
PLU & PPB & 956 & 955 \\
SDU & UDI & 982 & 980 \\
VCP & VIX & 999 & 1000 \\
\hline
\end{tabular}

BAU = Bauru; PLU = Belo Horizonte (Pampulha); VCP = Campinas; CAW = Campos dos Goytacazes; IPN = Ipatinga; JDF = Juiz de Fora; MEA = Macaé; PPB = Presidente Prudente; RAO = Ribeirão Preto; SDU = Rio de Janeiro (Santos Dumont); SJP = São José do Rio Preto; $\mathrm{CGH}=$ São Paulo (Congonhas); UDI = Uberlândia ;VIX = Vitória.

Basicamente, podem ser distinguidas cinco abordagens no âmbito do planejamento de experimentos para pesquisas de preferência declarada: Fatorial Completo (Full Factorial), Fatorial Fracionado (Fractional Factorial), Fatorial Fracionado Ortogonal (Orthogonal Fractional Factorial), Fatorial Fracionado D-Ótimo (D-Optimal Fractional Factorial) e Fatorial Fracionado D-Eficiente (D-Efficient Fractional Factorial).

A abordagem mais simples (Fatorial Completo) contempla todas as possibilidades de combinações de níveis dos atributos e apresenta crescimento exponencial do número de linhas (questões apresentadas aos respondentes) do experimento pela inserção de novos atributos e níveis. Por outro lado, o planejamento Fatorial Fracionado é definido como um subconjunto de todas as combinações do fatorial completo, podendo ser escolhidas aleatoriamente ou pela divisão dessas combinações em conjuntos apresentados aos participantes.

O planejamento Fatorial Fracionado Ortogonal diferencia-se do Fatorial Fracionado pelo balanceamento dos níveis dos atributos na escolha do subconjunto de linhas do experimento e garantia de ortogonalidade na escolha das linhas do subconjunto formado. 
Mais recentemente, os planejamentos Fatorial Fracionado $D$-Ótimo e Fatorial Fracionado $D$-Eficiente têm sido sugeridos como alternativa aos fatoriais fracionados convencionais (ROSE; BLIEMER, 2008). Na definição desses experimentos, os pesquisadores consideram eficiência em termos da minimização da variância (raiz quadrada do erro padrão) dos parâmetros estimados nos modelos de escolha modal (ORTÚZAR; WILLUMSEN, 2011), de modo que existe um valor mínimo global para essa variância que define um planejamento $D$-Ótimo.

Em termos práticos, esse método exige inferências a respeito dos valores iniciais sobre os parâmetros associados aos atributos podendo-se, inclusive, atribuir valores nulos quando as suas tendências são desconhecidas (STREET; BUNCH; MOORE, 2001;STREET; BURGESS, 2004;STREET; BURGESS; LOUVIERE, 2005).

Existem atualmente diferentes softwares para obtenção de experimentos com base nas diferentes abordagens descritas. O CHOICE METRICS (2014) é uma ferramenta computacional difundida por permitir o desenvolvimento de experimentos elaborados, inclusive pela abordagem de planejamento eficiente. Por outro lado, apesar de mais limitado em termos de métodos disponíveis, o SPSS (2008) também é amplamente utilizado no planejamento de experimentos.

Apesar do planejamento eficiente referir-se ao estado-da-arte no planejamento de experimentos, o objetivo é obter um conjunto de combinações dos níveis dos atributos caracterizados anteriormente para aplicação prática viável. Assim, optou-se pela utilização da abordagem fatorial fracionado ortogonal utilizando-se o software SPSS (2008) devido à disponibilidade de licença e da adequação dos seus resultados aos propósitos da pesquisa.

Portanto, para cada par OD com aeroportos em operação (Tabela 3.13), a execução do planejamento ortogonal pelo referido software resultou em 27 linhas (situações hipotéticas para escolha modal) para os cenários HPT sem AIR, HPT com AIR, HST sem AIR e HST com AIR.

Apesar de todas as cidades possuírem aeroportos (não necessariamente com conexões diretas entre as cidades da Tabela 3.13), o primeiro e o terceiro cenários foram estabelecidos sem a disponibilidade do modo aéreo para que fosse possível modelar a escolha modal entre cidades que não possuíssem este modo disponível na eventualidade da operação de serviços ferroviários. 
Considerando que 27 questões apresentadas para um mesmo respondente são excessivas e que os resultados de escolha modal poderiam ser tendenciosos, o experimento resultante entre cada par OD foi dividido em três blocos de nove questões, como exemplificado na Tabela 3.14.

Tabela 3.14 - Exemplo de bloco para um cenário de HST com AIR de 400 km

\begin{tabular}{|c|c|c|c|c|c|c|c|c|c|c|c|}
\hline${ }^{T T_{C A R}}$ & $T T_{B U S}$ & $T T_{H S T}$ & $T T_{A I R}$ & $F R_{B U S}$ & ${ }^{F R_{H S T}}$ & $F R_{A I R}$ & ${ }^{F A_{B U S}}$ & ${ }^{F A}{ }_{H S T}$ & $F A_{A I R}$ & ${ }^{P E_{C A R}}$ & ${ }^{T O}{ }_{C A R}$ \\
\hline $6 \mathrm{~h} 50$ & $8 \mathrm{~h} 15$ & $2 \mathrm{~h} 55$ & 1h10 & 12 & 6 & 6 & 170 & 570 & 750 & 150 & 70 \\
\hline $6 \mathrm{~h} 50$ & $7 \mathrm{~h} 15$ & $2 \mathrm{~h} 20$ & $1 \mathrm{~h}$ & 12 & 12 & 3 & 170 & 460 & 750 & 200 & 100 \\
\hline $6 \mathrm{~h} 30$ & $7 \mathrm{~h} 45$ & $2 \mathrm{~h} 20$ & 1h10 & 3 & 12 & 6 & 110 & 390 & 750 & 150 & 100 \\
\hline $6 \mathrm{~h} 05$ & $7 \mathrm{~h} 15$ & 1h55 & $1 \mathrm{~h} 25$ & 3 & 6 & 3 & 170 & 570 & 890 & 150 & 100 \\
\hline $6 \mathrm{~h} 50$ & $8 \mathrm{~h} 15$ & $2 \mathrm{~h} 55$ & $1 \mathrm{~h} 25$ & 6 & 12 & 3 & 110 & 390 & 890 & 150 & 130 \\
\hline $6 \mathrm{~h} 50$ & $7 \mathrm{~h} 45$ & 1h55 & $1 \mathrm{~h} 10$ & 3 & 12 & 3 & 120 & 570 & 630 & 170 & 70 \\
\hline $6 \mathrm{~h} 05$ & $7 \mathrm{~h} 15$ & 1h55 & $1 \mathrm{~h}$ & 12 & 12 & 12 & 110 & 390 & 630 & 150 & 70 \\
\hline $6 \mathrm{~h} 30$ & $8 \mathrm{~h} 15$ & $1 \mathrm{~h} 55$ & 1h10 & 12 & 6 & 12 & 120 & 390 & 890 & 200 & 100 \\
\hline $6 \mathrm{~h} 50$ & $7 \mathrm{~h} 15$ & $2 \mathrm{~h} 20$ & $1 \mathrm{~h} 25$ & 3 & 6 & 6 & 120 & 390 & 630 & 200 & 130 \\
\hline
\end{tabular}

Tal como explicitado, uma replicação do experimento entre um par OD implica na identificação de 24 respondentes (três blocos para os quatro cenários preestabelecidos, pelos dois motivos de viagem), o que resulta em 216 escolhas escolhas disponíveis para posterior modelagem.

Apesar de existirem diversas plataformas para execução de pesquisas online dessas natureza - como Bristol Online Surveys (BOS, 2013), SurveyMonkey (SURVEYMONKEY, 2013) -, a plataforma Qualtrics (QUALTRICS, 2013) foi utilizada para diagramação do experimento em uma configuração amigável aos participantes. A vasta disponibilidade de recursos visuais da ferramenta, as possibilidades de interação do usuário e o acesso a uma licença comercial foram os fatores que influenciaram nessa escolha.

Nessa configuração, os blocos são escolhidos aleatoriamente no início da pesquisa, a ordem de alternativas dos modos de transporte é mantida constante em cada linha do experimento e o respondente pode participar uma única vez da pesquisa.

Além disso, foi de interesse identificar participantes que tivessem realizado pelo menos uma viagem entre algum dos pares OD pela correlação da acurácia das respostas em relação ao conhecimento do usuário sobre as características das cidades, da infraestrutura de transporte existente e da viagem.

A definição do tamanho da amostra (número de participantes) da pesquisa de preferência declarada é um item importante para as etapas posteriores de modelagem das respostas obtidas. Lemeshow et al. (1990) propõem duas abordagens para definição da amostragem: a prospectiva, 
em que se define o número de respostas necessárias para ajustar um modelo de regressão com significância estatística aceitável; e a retrospectiva, na qual é verificado se os dados obtidos em uma pesquisa são suficientes para calibrar um modelo adequadamente.

No contexto da primeira abordagem, Orme (1998) apresenta a Equação 3.20 como uma regra para a definição da amostra mínima para posterior modelagem de escolha modal.

$$
n \geq 500 \cdot \frac{c}{a \cdot t}
$$

onde $n=$ número estimado de respondentes; $a=$ maior número de níveis dos atributos; $c=$ número de alternativas apresentadas ao participante; $t=$ número de linhas resultantes do planejamento do experimento.

Lemeshow et al. (1990) também apresentam uma formulação para estimação desse parâmetro do ponto de vista de um teste estatístico de hipóteses para calibração de modelos Logit Binomiais e diversos outros autores tratam do tema sob a mesma perspectiva (e.g. WHITTEMORE, 1981; HSIEH, 1989; DESU, 2012; DATTALO, 2008; e MATHEWS, 2010). Hsieh (1989) apresenta uma correção para o modelo de Whittemore (1981) na estimativa de modelos Logit Multinomial.

De maneira mais pragmática, Peduzzi et al. (1996) demonstra que 10 eventos por parâmetro a ser estimado na etapa de modelagem são necessários para minimizar o viés na estimação das variâncias nos teste de significância das variáveis. Rose e Bliemer (2013) apresentam uma formulação para definição do tamanho de uma amostra baseado no valor desejado da estatística $t$ que exige uma estimativa prévia dos valores dos parâmetros associados aos atributos.

A literatura mostra que o tema não está definitivamente esclarecido - e.g. nos argumentos apresentados por Agresti (1996) e nas duas formulações apresentadas por Adedayo e Agunbiade (2013) - e outras pesquisas são necessárias para consolidação de uma regra específica que abranja a maioria das pesquisas de preferência declarada.

No caso da pesquisa conduzida nesta tese, o fator determinante na definição do tamanho da amostra foi o orçamento disponível para identificação dos participantes, coleta das respostas e consolidação dos dados. 
Com o intuito de avaliar a eficácia da pesquisa, uma versão piloto foi lançada entre os dias 2 de Setembro e 20 de Setembro de 2013 através de mídias eletrônicas (redes sociais, envio de e-mails) e apoio de uma agência de comunicação universitária. Nesse período, 184 pessoas acessaram a pesquisa (a maioria concentrada nos Estados de São Paulo e Rio de Janeiro) e apenas 37 participantes $(20,1 \%)$ a finalizaram.

A execução dessa versão preliminar permitiu o aprimoramento da formatação da pesquisa para o lançamento da versão final, apesar da baixa adesão e impossibilidade do uso das respostas na calibração de um modelo de escolha modal.

\subsubsection{Aplicação do Questionário}

O questionário resultante da diagramação das linhas do planejamento ortogonal do experimento é descrito a seguir. Ao acessar o link da pesquisa online o respondente depara-se com uma primeira página com explicação do propósito da pesquisa. Em seguida, o participante segue para uma tela (Figura 3.10) representativa da Região Sudeste na qual pode escolher a cidade de onde está respondendo a pesquisa (no caso, a origem de uma viagem) e, caso não esteja em nenhuma das localidades existe uma alternativa que encerra a pesquisa.

Caso uma, e somente uma, das localidades seja escolhida, o respondente é conduzido para uma segunda página (Figura 3.11) em que deve escolher uma cidade para onde já tenha realizado pelo menos uma viagem no passado dentre as alternativas de destino apresentadas na Tabela 3.13. Caso nunca tenha viajado para nenhum desses destinos uma opção também é disponibilizada para encerramento do questionário.

No caso de prosseguimento da pesquisa, uma tela surge para escolha do modo de transporte que foi utilizado em uma viagem anterior entre a origem e o destino definidos (Figura 3.12), sendo orientado que essa viagem seja tomada como referência para as demais respostas às perguntas subsequentes. Nas telas seguintes, o participante é questionado sobre as características dessa viagem quanto ao motivo (Figura 3.13) e tempos de acesso e egresso (se existentes como exemplificado na Figura 3.14) e uma estimativa desses tempos aos terminais dos modos alternativos àquele escolhido (inclusive para as estações ferroviárias uma vez que todas as cidades escolhidas possuem essa infraestrutura, mesmo que fora de operação). 


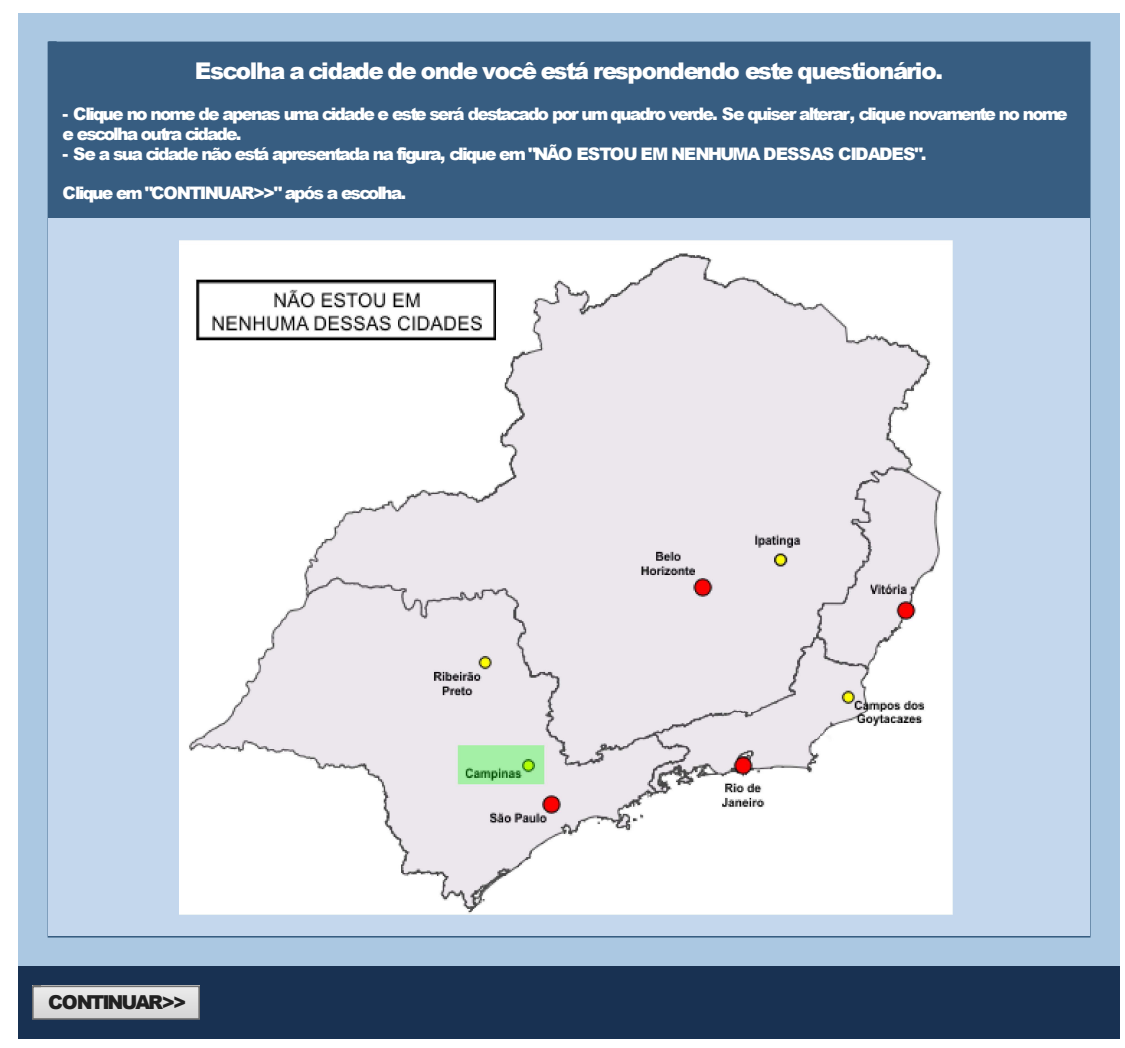

Figura 3.10 - Escolha da cidade de origem de onde o participante respondeu a pesquisa

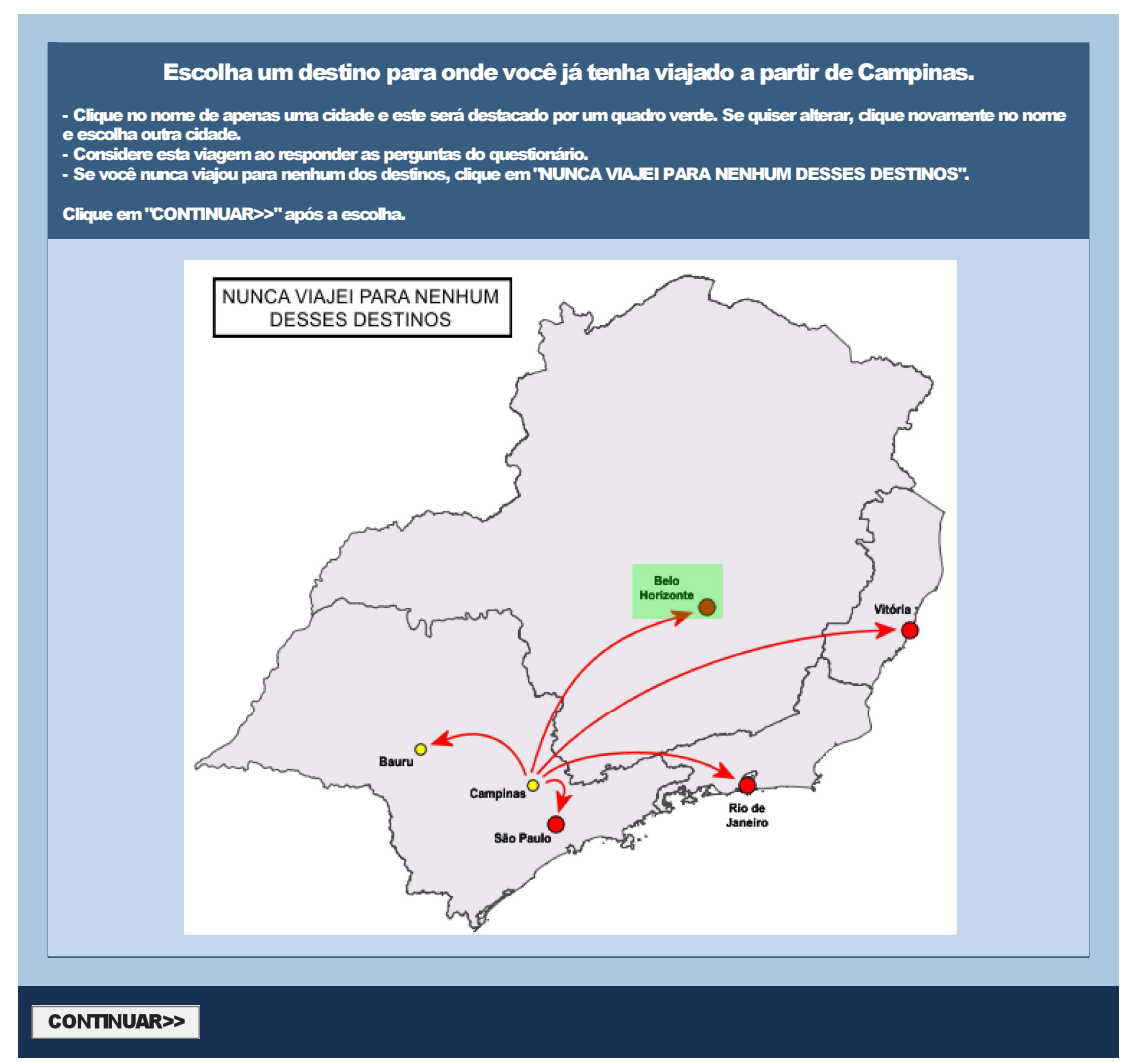

Figura 3.11 - Escolha de um destino para onde o participante já tenha viajado 


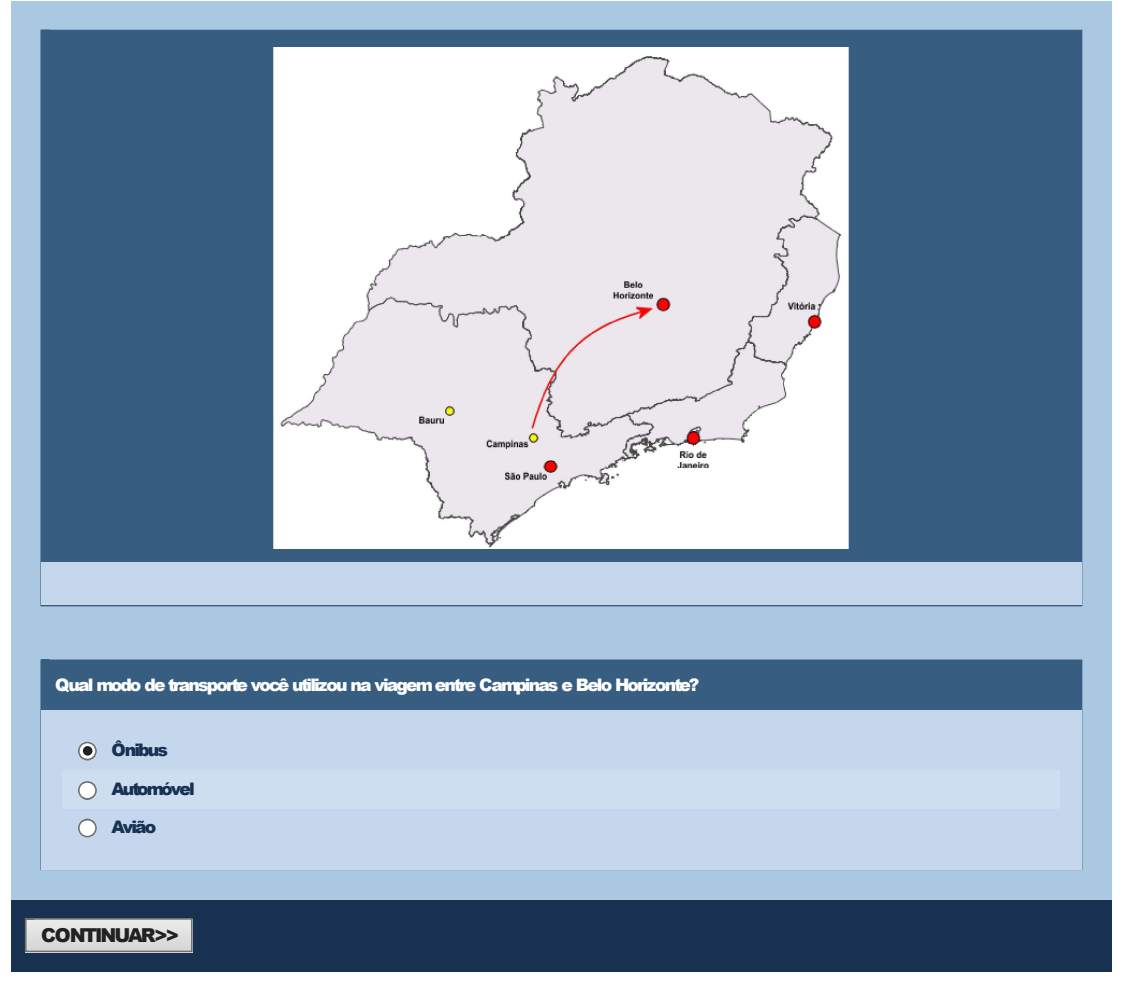

Figura 3.12 - Escolha do modo da viagem realizada pelo participante

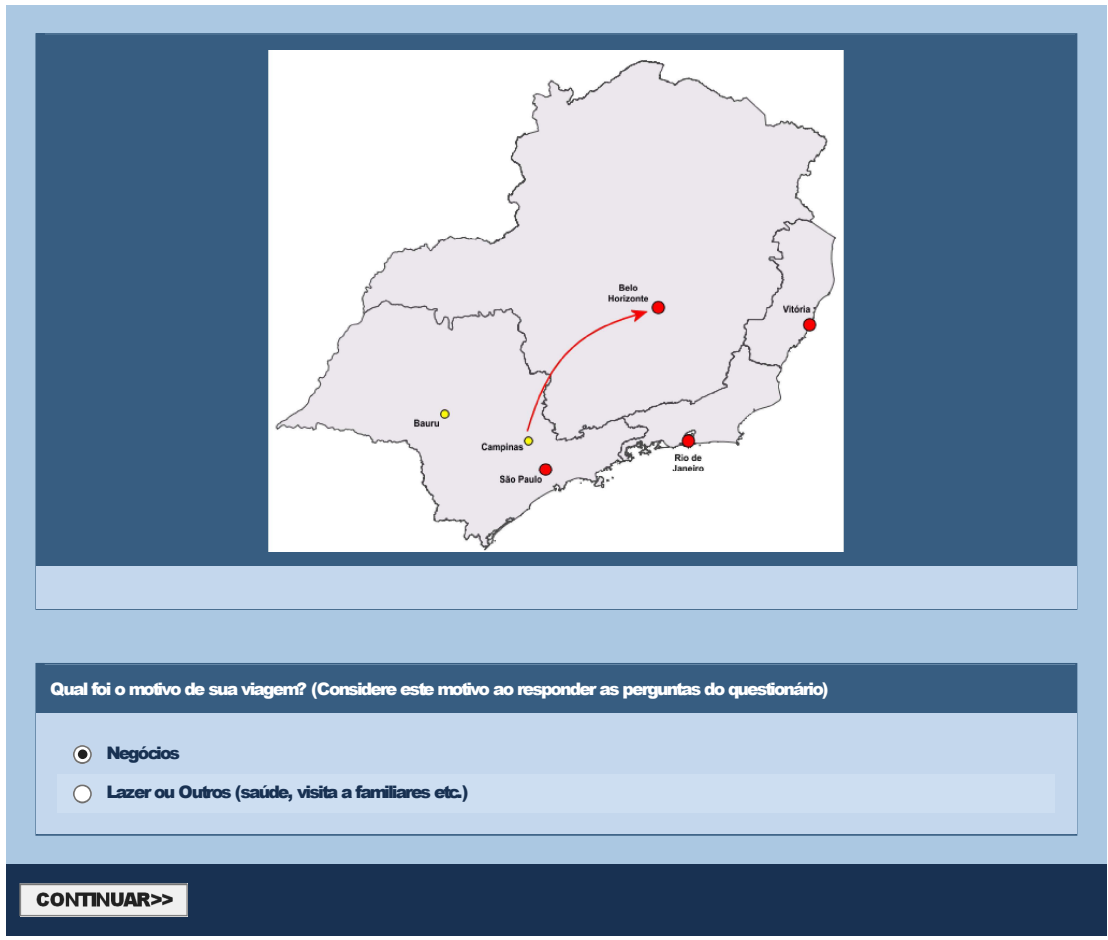

Figura 3.13 - Escolha do motivo da viagem realizada pelo participante 


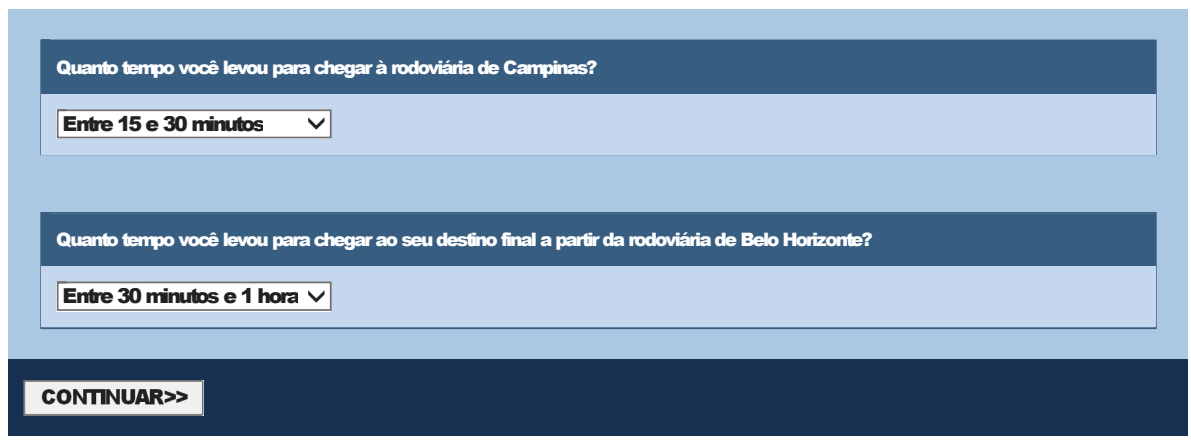

Figura 3.14 - Obtenção de informações a respeito da viagem realizada

Ao final dessa etapa, uma tela é apresentada ao usuário com a caracterização dos modos de transporte disponíveis para escolha (Figura 3.15). Os modos apresentados para cada participante são escolhidos aleatoriamente e mantêm-se os mesmos durante toda a pesquisa, alterandose apenas os níveis dos respectivos atributos.

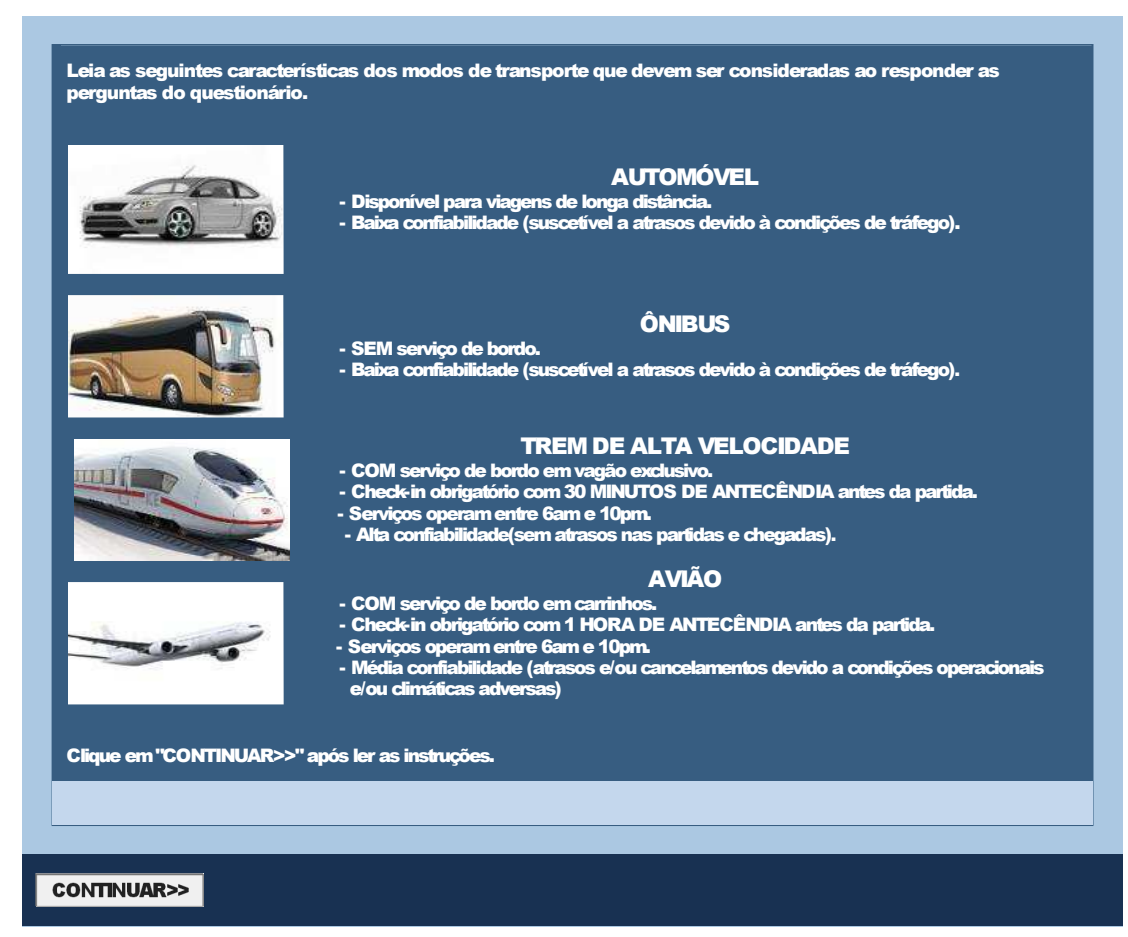

Figura 3.15 - Caracterização dos modos de transporte considerados na pesquisa

As nove telas subsequentes dizem respeito à escolha modal sujeita aos valores dos níveis dos atributos de cada modo disponibilizado conforme ilustrado na Figura 3.16. 


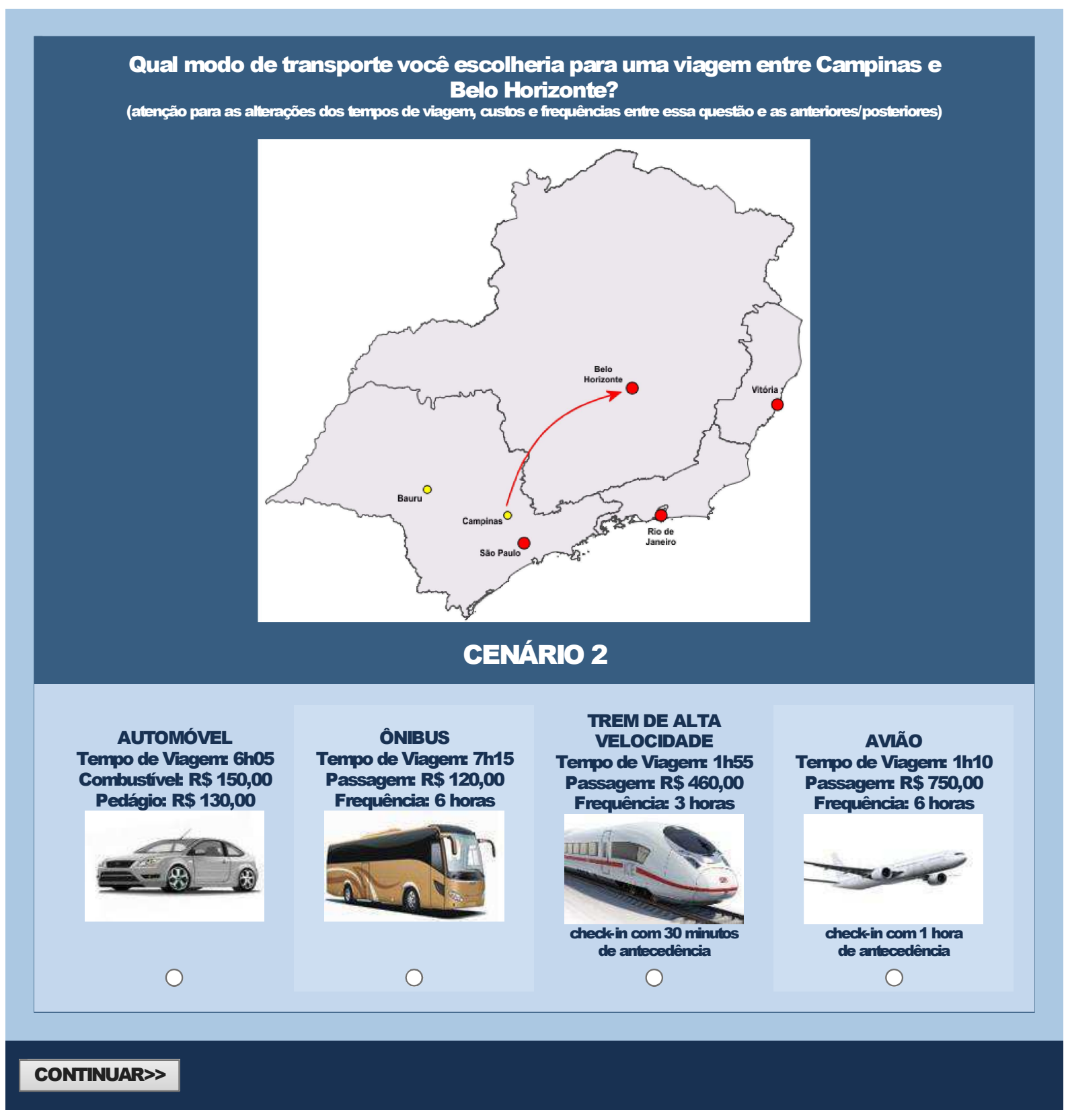

Figura 3.16 - Cenário de escolha modal mediante diferentes níveis de atributos (equivalente a uma linha do planejamento ortogonal)

Na sequência, uma tela é apresentada para obtenção a opinião do respondente a respeito do realismo dos valores dos atributos e disponibilização de um espaço para comentários abertos. Finalmente, a última tela apresenta questões de caráter socioeconômico como idade, se o respondente possui emprego formal, a sua renda média familiar, o número de pessoas que vivem na residência e sobre a posse de carteira nacional de habilitação (Figura 3.17) 


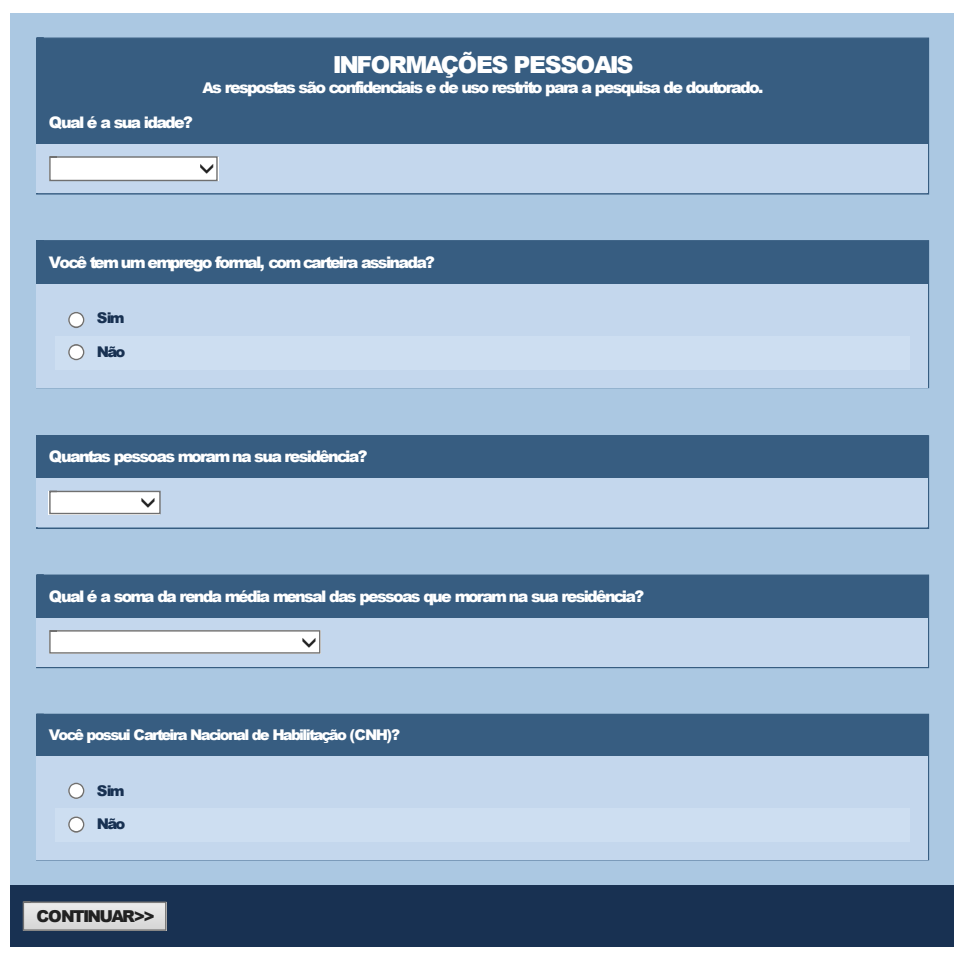

Figura 3.17 - Obtenção de informações socioeconômicas

Uma empresa especializada na realização de pesquisas online foi contratada para execução da versão final da pesquisa de preferência declarada, realizada entre os dias 24 de Outubro e 5 de Novembro de 2013, com garantia de sigilo dos dados do participante mediante a política de privacidade da empresa, que pode ser acessada no hyperlink Política de Privacidade - Livra.

A pesquisa com duração média de 10 minutos teve a participação de 580 respondentes virtuais, dos quais 279 (48\%) declararam ter viajado pelo menos uma vez entre um dos pares de cidades propostos por motivo de trabalho, e 301 (52\%) por motivo lazer ou outros. Como cada participante respondeu a nove cenários hipotéticos de escolha modal, a Tabela 3.15 apresenta o total de respostas obtidas segundo a tecnologia ferroviária disponibilizada para escolha e a eventual oferta do modo Aéreo entre as cidades.

Tabela 3.15 - Número de repostas obtidas na pesquisa de preferência declarada

\begin{tabular}{lcccccccccccc}
\hline Cenário & \multicolumn{1}{c}{ HPT sem $\boldsymbol{A I R}$} & \multicolumn{1}{c}{ HPT com $\boldsymbol{A I R}$} & \multicolumn{1}{c}{ HST sem $\boldsymbol{A I R}$} & \multicolumn{3}{c}{ HST com $\boldsymbol{A I R}$} \\
\hline Motivo & $\boldsymbol{W}$ & $\boldsymbol{L}$ & Total & $\boldsymbol{W}$ & $\boldsymbol{L}$ & Total & $\boldsymbol{W}$ & $\boldsymbol{L}$ & Total & $\boldsymbol{W}$ & $\boldsymbol{L}$ & Total \\
Número de respostas & 729 & 549 & 1278 & 639 & 603 & 1242 & 612 & 648 & 1260 & 711 & 729 & 1440 \\
\hline
\end{tabular}


A Figura 3.18 apresenta uma análise preliminar das respostas obtidas na pesquisa em relação à distribuição da escolha dos modos em cada cenário estabelecido, demonstrando que a combinação dos atributos e seus respectivos níveis permitiu captar o comportamento dos usuários em relação à escolha modal, sem a predominância de um modo de transporte.

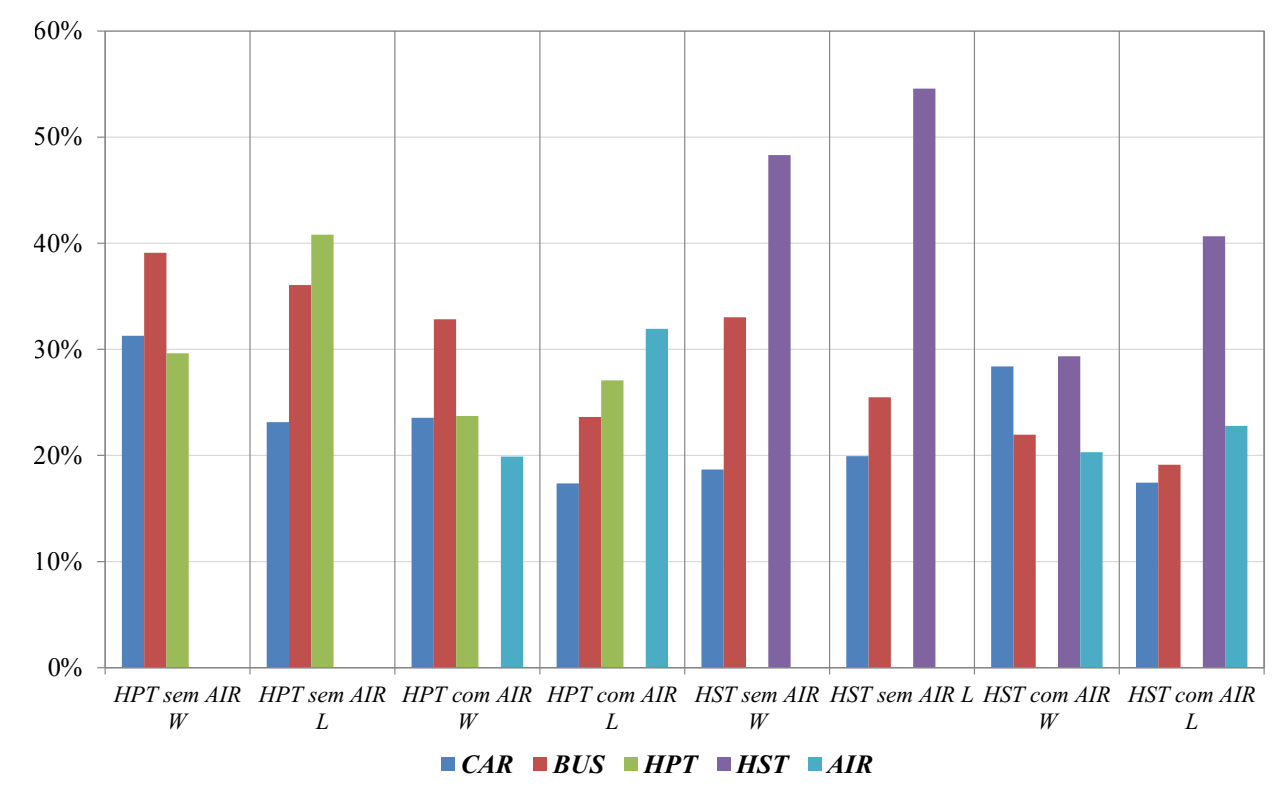

Figura 3.18 - Distribuição da escolha dos modos de transporte na pesquisa online

Nos cenários com oferta de HPT observa-se uma proporcionalidade nas escolhas dos modos de transporte sem a predominância de uma alternativa específica ou padrão de escolha modal em função do motivo de viagem e disponibilidade do modo Aéreo. Por outro lado, nos cenários com oferta de serviços de HST há uma tendência de escolha desse modo em detrimento dos demais, sobretudo na ausência da oferta de transporte aéreo.

\subsubsection{Análise dos Dados Coletados na Pesquisa}

Nesta seção são apresentadas considerações sobre as informações coletadas na pesquisa. Inicialmente apresenta-se um histograma (Figura 3.19) do número de respondentes obtidos em cada par de origem e destino indicado na Tabela 3.13. Apesar de ser desejável uma uniformidade de respostas entre pares OD, observa-se uma concentração nas principais cidades e regiões metropolitanas (São Paulo, Rio de Janeiro, Belo Horizonte, Campinas e Ribeirão Preto). 


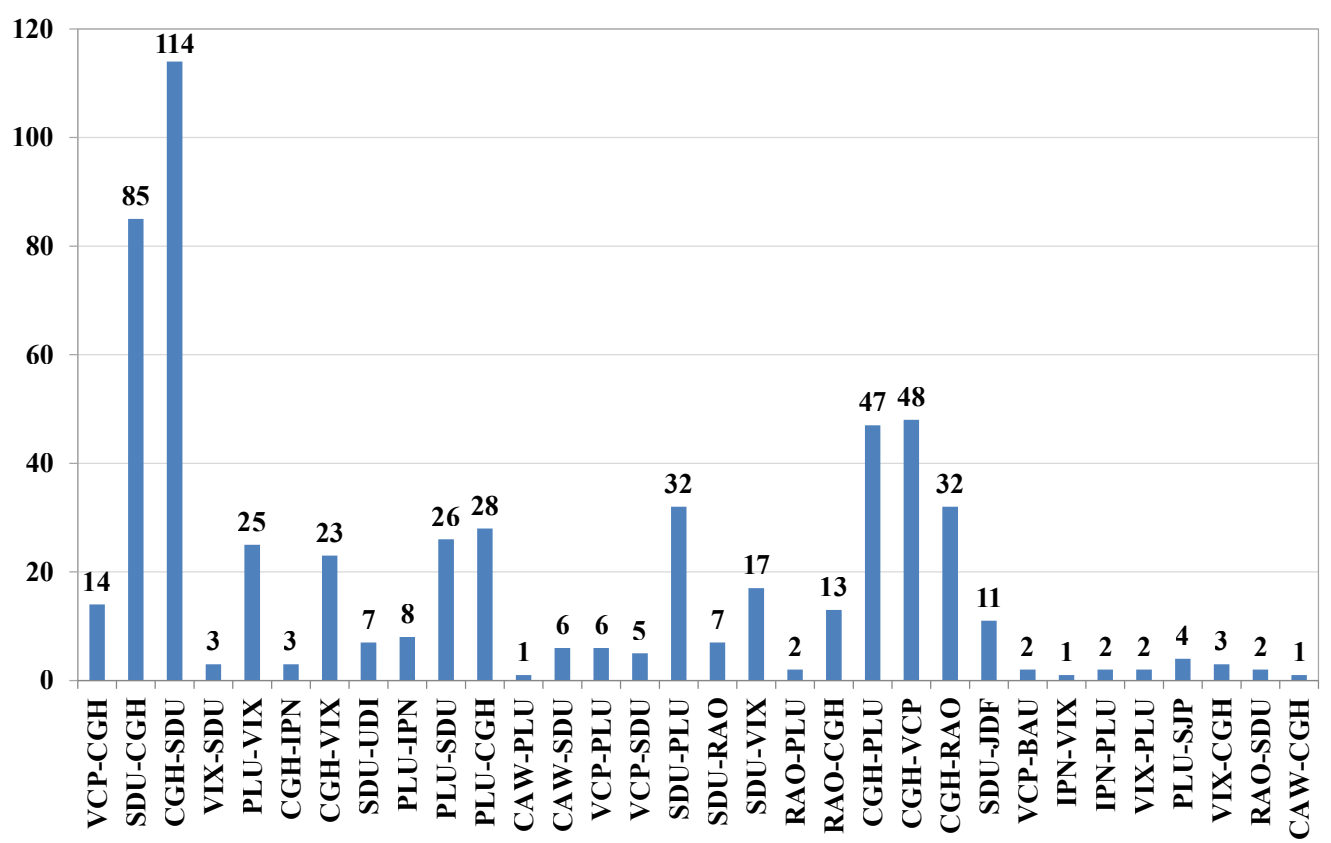

Figura 3.19 - Número de respostas entre pares Origem-Destino (siglas na Tabela 3.13)

Foram coletados dados quanto às características das viagens realizadas como referência para responder ao questionário. Nesse grupo enquadra-se primeiramente o meio de transporte utilizado nessas viagens (Figura 3.20), com uma distribuição homogênea entre os modos existentes.

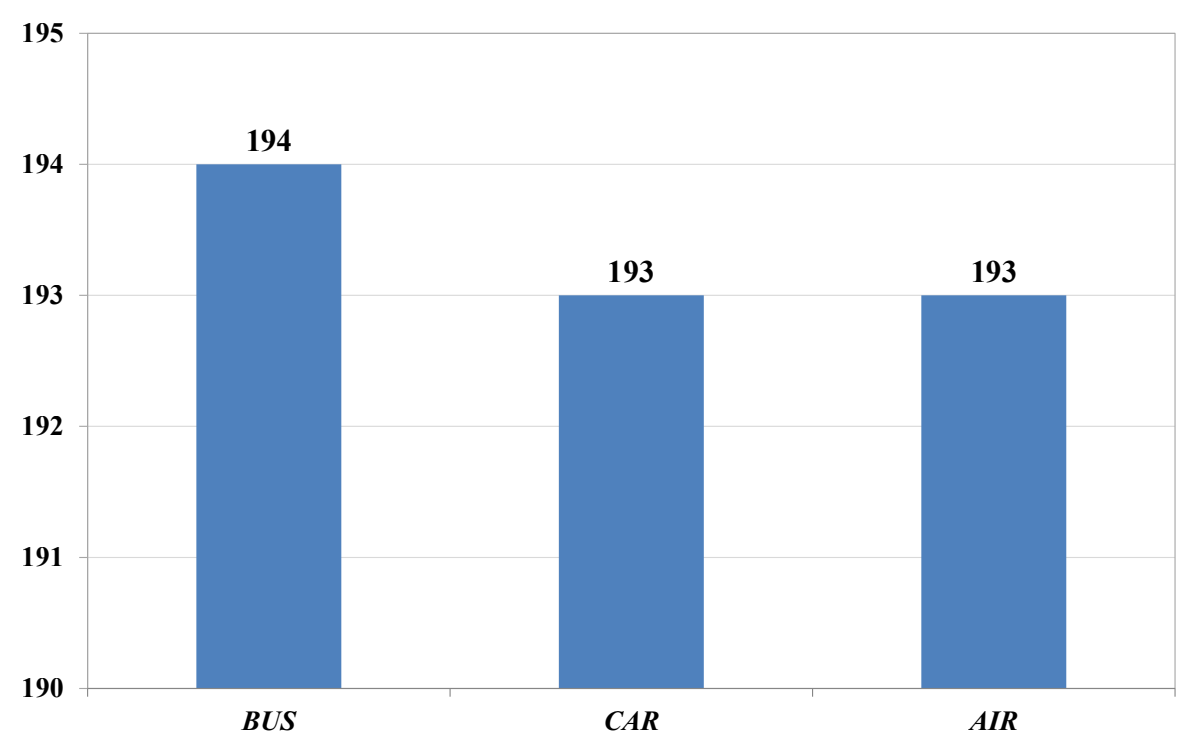

Figura 3.20 - Modos de transporte utilizados nas viagens realizadas pelos participantes

A seguir, a Figura 3.21 e Figura 3.22 resumem os tempos para o acesso e o egresso, respectivamente, aos terminais de transporte para as viagens realizadas pelo modo Ônibus ou Avião. 


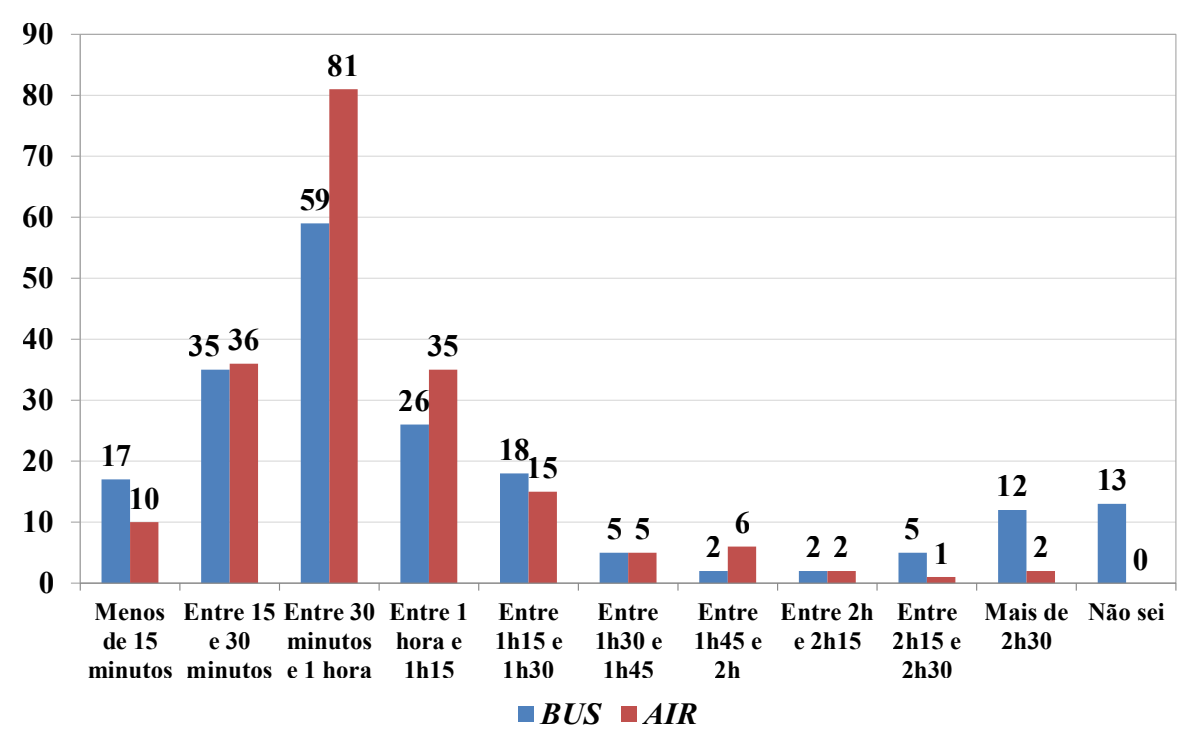

Figura 3.21 - Histograma dos tempos de acesso nas viagens realizadas

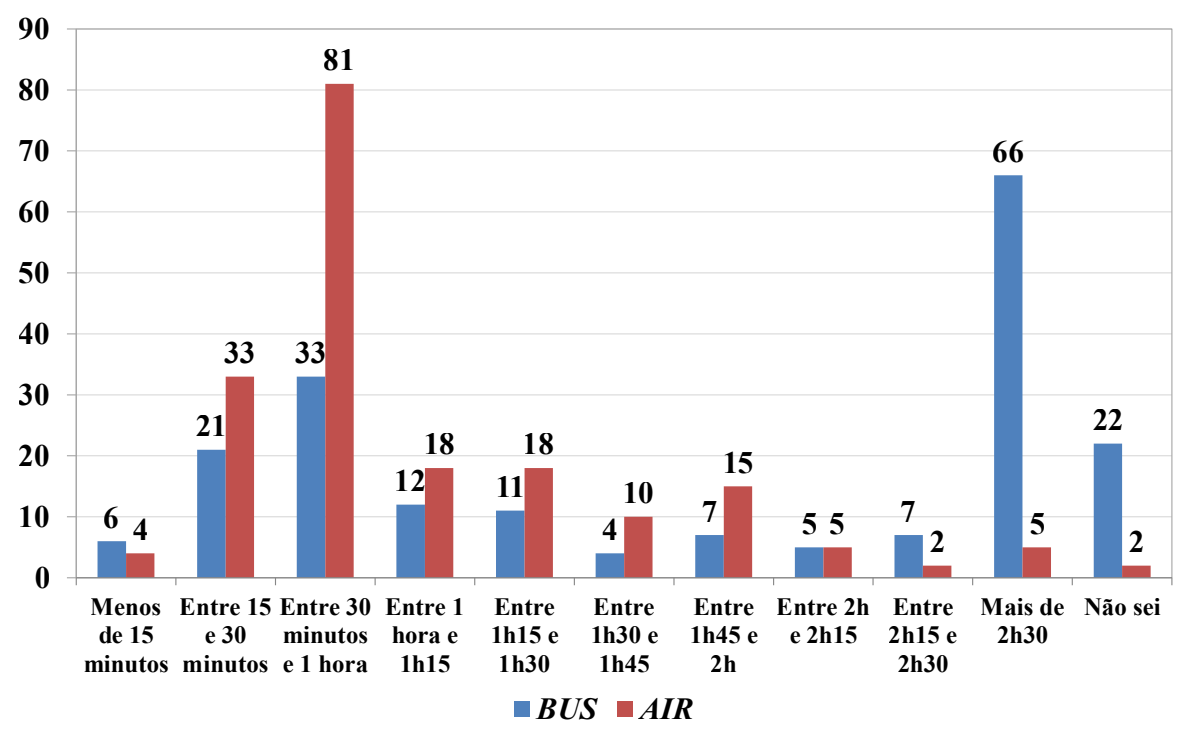

Figura 3.22 - Histograma dos tempos de egresso dispendidos nas viagens realizadas

Ainda em relação aos tempos de acesso e egresso, a Figura 3.23 e Figura 3.24 indicam respectivamente os valores estimados pelos participantes para os modos de transporte que não foram utilizados nas viagens realizadas.

Nesse caso, observa-se que ambos os tempos de acesso e egresso apresentam concentração no intervalo entre 30 minutos e 1 hora (na mesma tendência que as respostas dos tempos efetivamente utilizados para acessar as rodoviárias e aeroportos na Figura 3.21 e Figura 3.22), com 
elevada taxa de respostas "Não sei" às estações ferroviárias (modo Trem), as quais podem ser justificadas pela inexistência de serviços ferroviários na maioria das cidades consultadas.

Quanto às características socioeconômicas dos respondentes, a Figura 3.25 apresenta um histograma de idade, das características de empregabilidade formal, número de pessoas residentes no mesmo domicílio, renda total familiar e posse de carteira nacional de habilitação $(\mathrm{CNH})$.

Quanto à idade observa-se uma distribuição uniforme e ligeira concentração na faixa de 30 a 45 anos (interpretada como uma amostra da população economicamente ativa). Ainda, a maioria dos respondentes declarou que possui emprego formal $(55,2 \%)$ e $\mathrm{CNH}(70,6 \%)$ no momento da pesquisa. Finalmente, observa-se o tamanho médio da família em domicílios com 3 pessoas, seguidas de 2 e 4 pessoas, e renda média familiar entre $R \$ 2.500,00$ e $R \$ 3.500,00$, seguida do intervalo entre $\mathrm{R} \$ 1.500,00$ e $\mathrm{R} \$ 2.500,00$.

O último conjunto de dados obtidos caracteriza as opiniões dos respondentes acerca do realismo dos atributos e respectivos níveis apresentados para escolha dos modos de transporte. Quanto a este item, os gráficos da Figura 3.26 à Figura 3.28 são apresentados em relação às escolhas sobre realismo dos níveis dos atributos com diferentes possibilidades de escolha: muito irrealista, irrealista, não sabe, realista e muito realista.

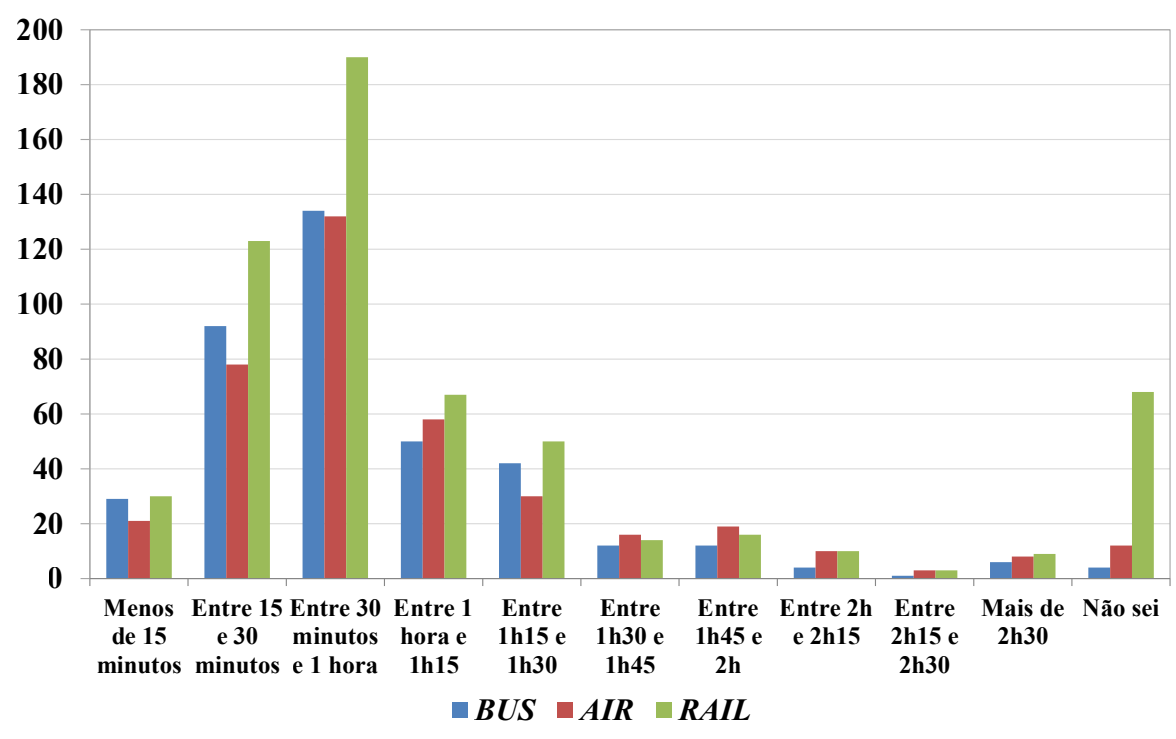

Figura 3.23 - Histograma dos tempos de acesso estimados para os modos de transporte não utilizados nas viagens realizadas 


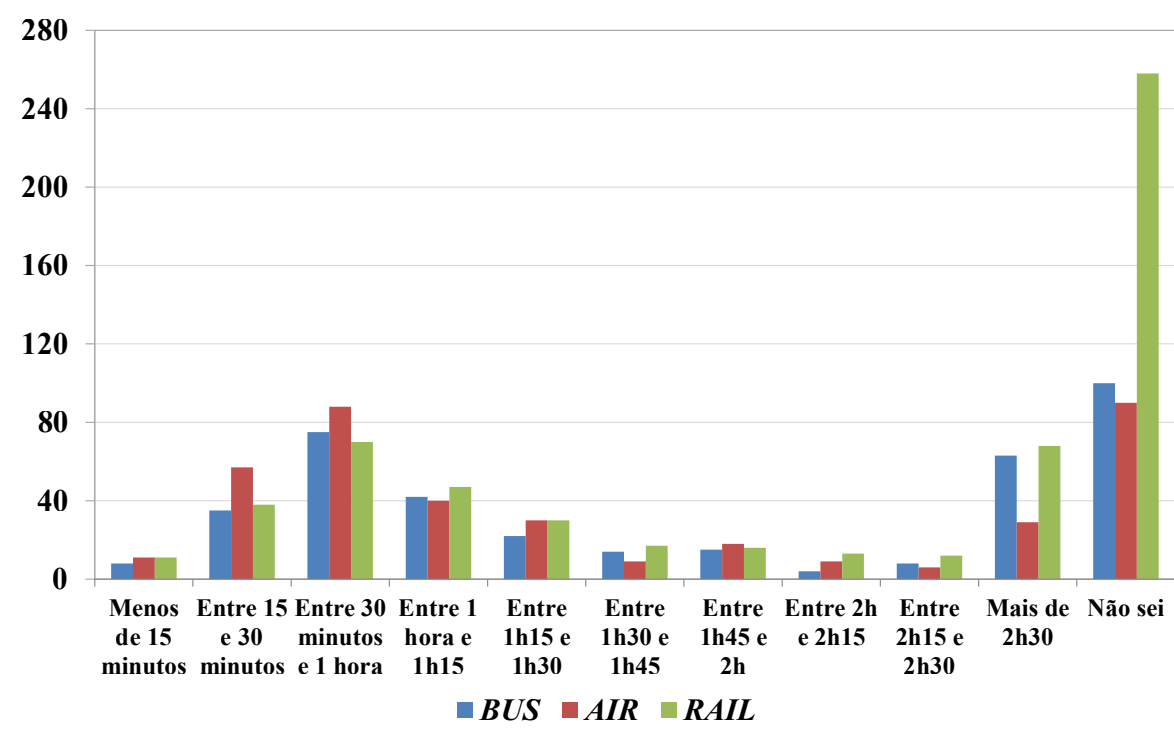

Figura 3.24 - Histograma dos tempos de egresso estimados para os modos de transporte não utilizados nas viagens realizadas 


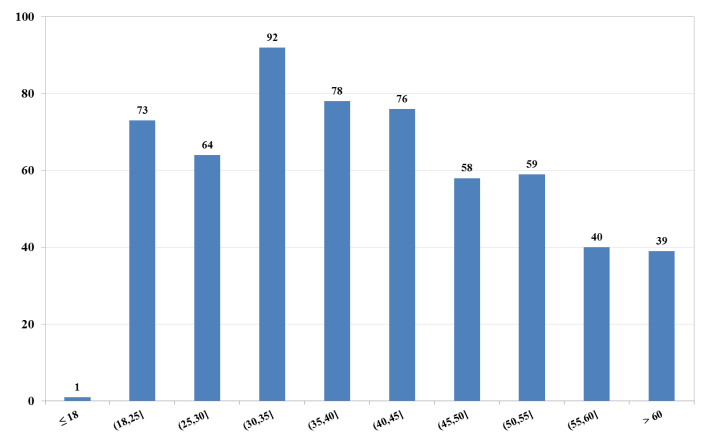

(a) Idade

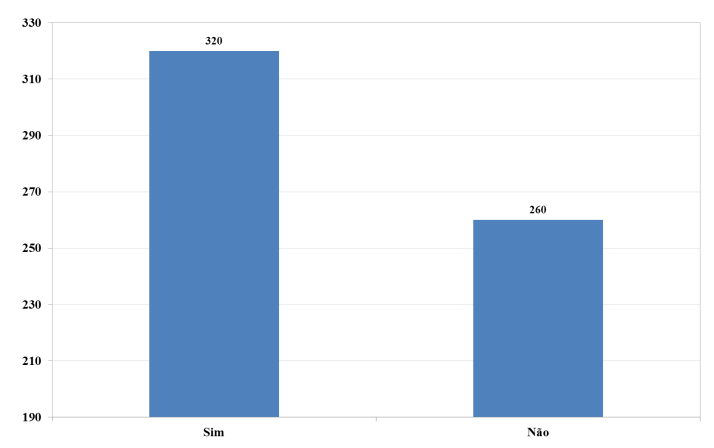

(b) Vínculo Empregatício

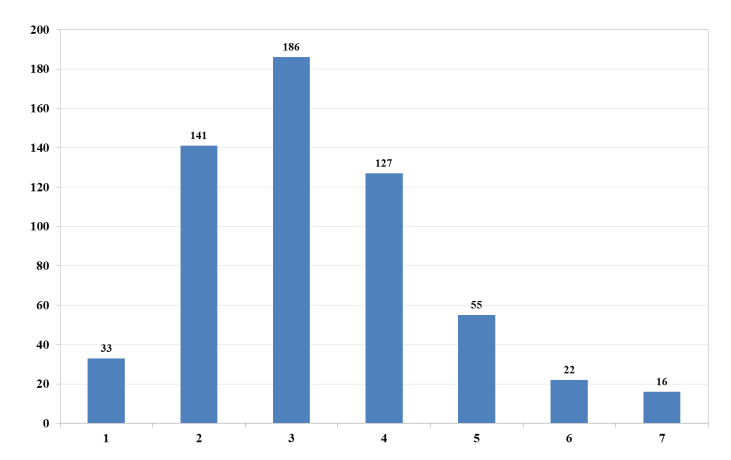

(c) Residentes no Domicílio

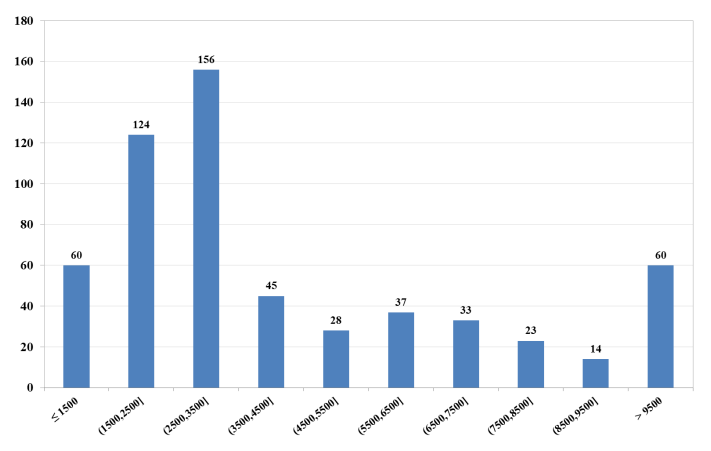

(d) Renda Média Familiar

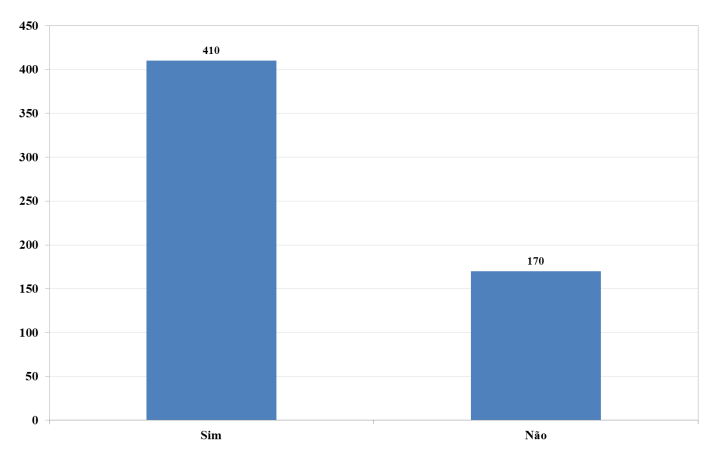

(e) Posse de CNH

Figura 3.25 - Distribuição dos valores observados dos atributos socioeconômicos

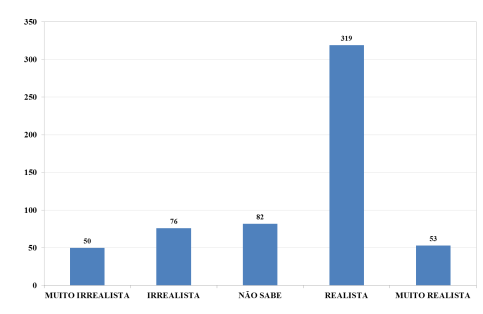

$T T_{C A R}$

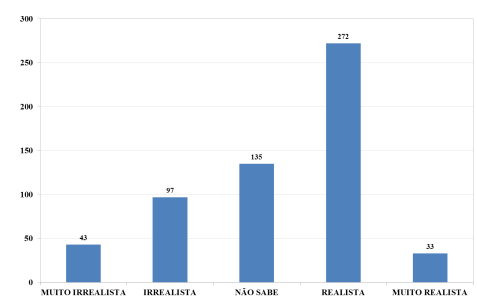

$P E_{C A R}$

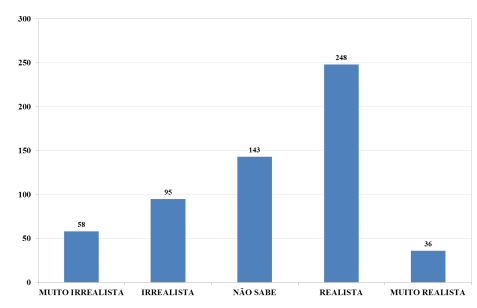

TO $O_{C A R}$

Figura 3.26 - Opinião dos respondentes a respeito do realismo dos níveis dos atributos de caracterização das viagens pelo modo Automóvel (CAR) 




Figura 3.27 - Opinião dos respondentes a respeito do realismo dos níveis dos atributos de caracterização das viagens pelo modo Ônibus (BUS)

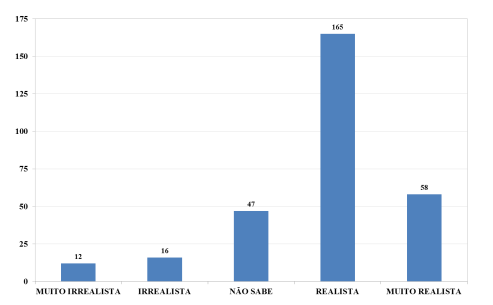

(a) $\boldsymbol{T} \boldsymbol{T}_{A I R}$

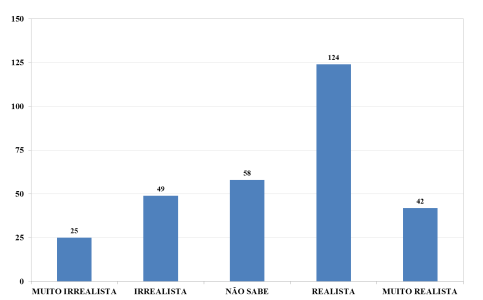

(b) $\boldsymbol{F A}$

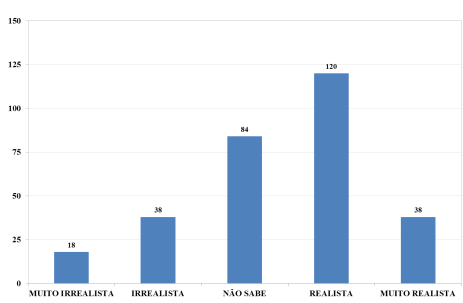

(c) $\boldsymbol{F} \boldsymbol{R}_{A I R}$

Figura 3.28 - Opinião dos respondentes a respeito do realismo dos níveis dos atributos de caracterização das viagens pelo modo Avião $(A I R)$

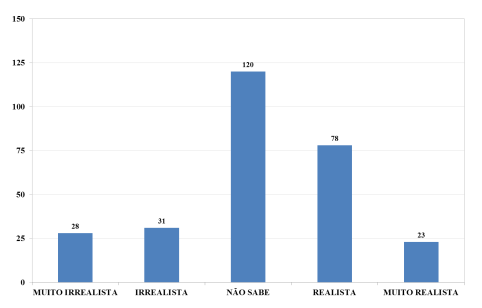

(a) $\boldsymbol{T} \boldsymbol{T}_{\mathrm{HPT}}$

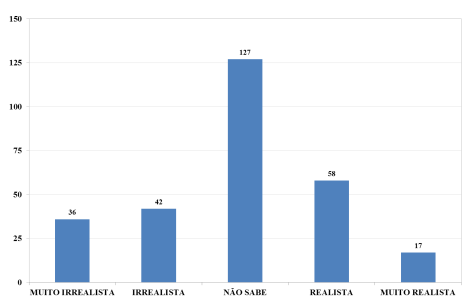

(b) $\boldsymbol{F A} \boldsymbol{A}_{\boldsymbol{H P T}}$

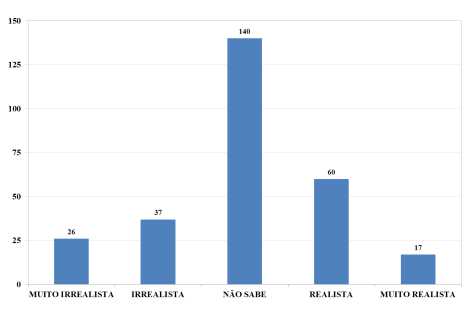

(c) $\boldsymbol{F} \boldsymbol{R}_{H P T}$

Figura 3.29 - Opinião dos respondentes a respeito do realismo dos níveis dos atributos de caracterização das viagens pelo modo $H P T$

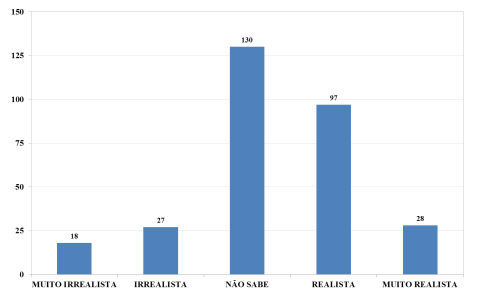

(a) $\boldsymbol{T} \boldsymbol{T}_{\boldsymbol{H S T}}$

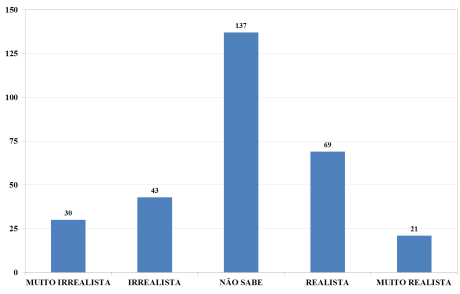

(b) $\boldsymbol{F} \boldsymbol{A}_{\boldsymbol{H S T}}$

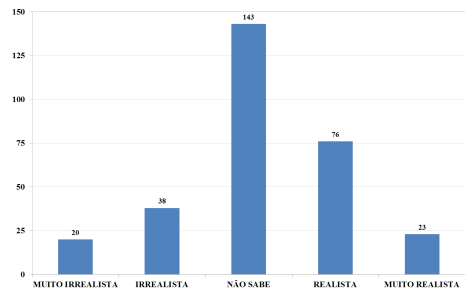

(c) $\boldsymbol{F} \boldsymbol{R}_{\boldsymbol{H S T}}$

Figura 3.30 - Opinião dos respondentes a respeito do realismo dos níveis dos atributos de caracterização das viagens pelo modo $H S T$ 
A análise dos gráficos da Figura 3.26, Figura 3.27 e Figura 3.28 indica que os respondentes consideraram, em sua maioria, os níveis dos atributos que caracterizam o tempo de viagem $(T T)$, custo de combustível (PE), custo de pedágio (TO) dos automóveis como realistas, bem como o custo da passagem $(F A)$ e frequência $(F R)$ dos modos Ônibus e Avião, todos com maioria de reposta secundária igual a "Não sabe".

Em relação ao modo ferroviário, tanto para o HPT (Figura 3.29) quanto para o HST (Figura 3.30) observa-se uma predominância da resposta "Não sei" seguida de "Realista" para todos os atributos que os caracterizam, dado que a primeira pode refleti a inexperiência da população sobre a realidade operacional do transporte ferroviário de passageiros. Porém, as opiniões dos participantes indicam que a formulação da pesquisa atendeu satisfatoriamente os requisitos de investigação da propensão à escolha modal desta tese.

Finalmente, são apresentadas as transcrições diretas e algumas opiniões gerais dos participantes a respeito da pesquisa em espaço disponibilizado para digitação de um texto limitado a 160 caracteres. Essas opiniões permitem inferir que a aplicação do questionário corrobora a afirmação de que um padrão comportamental no âmbito de planejamento de novas infraestruturas de transporte é um processo iterativo e em constante amadurecimento.

"Muito Bom! Gostei de ver a comparação de todos os transportes juntos. Ainda prefiro o carro, pois teria que gastar com táxi ida e volta até chegar ao destino."

"Levo mais em consideração o ônibus pois em relação ao trem é mais barato e em relação ao carro é mais barato e confortável."

"No início não havia entendido, porém estão baseadas em informações concretas nas quais já tive experiências."

"Prefiro viajar de avião, mas procuro a opção mais em conta. A escolha pelo ônibus foi devido ao custo e por ser confortável."

"Dependendo da emergência da viagem, o valor da passagem de avião não influencia, mas, por gosto mesmo e pra aproveitar melhor a viagem, prefiro veículo próprio."

"O questionário é interessante embora eu não tenha conhecimento dos parâmetros para trens, o que trouxe uma certa dificuldade para opinar." 


\subsubsection{Modelagem de Escolha Modal}

A modelagem da escolha modal pode ser definida como um problema de reconhecimento de padrões comportamentais explicados por múltiplas variáveis que caracterizam as escolhas de alternativas (XIE; LU; PARKANY, 2003). Esse reconhecimento pode ser através de técnicas de mineração de dados para investigar o comportamento individual em relação à escolha modal, ou pela aplicação da modelagem como a baseada nos princípios da teoria da utilidade.

Em geral, as respostas de uma pesquisa são avaliadas por métodos de segregação de dados como árvores de decisão (AD) (XIE; LU; PARKANY, 2003; SHMUELI; SALOMON; SHEFER, 1996; PITOMBO; KAWAMOTO; SOUSA, 2011) ou pela calibração de modelos baseados de maximização da utilidade (WILLIAMS, 1978; AHERN; TAPLEY, 2008; GRANGE et al., 2013).

A AD é uma técnica de simples classificação das relações entre atributos de um conjunto de dados e permite segregar as informações coletadas em um número finito de classes através de regras hierárquicas, organizando-as de maneira compacta e permitindo uma visão geral da natureza do fenômeno estudado (QUINLAN, 1983).

Isler e Pitombo (2014) apresentam os resultados da aplicação dessa técnica aos dados da pesquisa de preferência declarada descrita na seção anterior como método alternativo à modelagem proposta nesta tese, cujas comparações são apresentadas ao final deste capítulo.

Ortúzar e Willumsen (2011) descrevem um modelo agregado da propensão à escolha modal, cujo custo generalizado das viagens em cada modo de transporte viabiliza o cálculo da probabilidade de escolha conforme exemplificado na Equação 3.21. Os autores apresentam também alternativas de modelos sintéticos como o de distribuição e escolha modal simultânea (fundamentado pela teoria de maximização da entropia) e o baseado na teoria comportamental de escolha racional Williams e Senior (1977).

$$
P_{i j}^{k}=\frac{\left(C_{i j}^{k}\right)^{-n}}{\sum_{1}^{k}\left(C_{i j}^{k}\right)^{-n}}
$$

onde $C_{i j}^{k}=$ custo generalizado da viagem entre a origem $i$ e o destino $j$ pelo modo $k ; n=$ parâmetro de calibração. 
Por outro lado, os modelos de demanda direta permitem estimar as viagens entre origens e destinos agregando as etapas de geração, distribuição e escolha modal simultaneamente. Esses modelos diretos relacionam-se às variáveis econométricas a exemplo de Kraft (1968), que estabelece uma equação multiplicativa de variáveis socioeconômicas e os atributos dos modos de transporte (Equação 3.22).

$$
T_{i j}^{k}=\phi \cdot\left(P_{i} \cdot P_{j}\right)^{\theta_{k 1}} \cdot\left(I_{i} \cdot I_{j}\right)^{\theta_{k 2}} \cdot \prod_{m}\left[\left(t_{i j}^{m}\right)^{\alpha_{k m}^{1}} \cdot\left(c_{i j}^{m}\right)^{\alpha_{k m}^{2}}\right]
$$

em que $P_{i}$ e $P_{j}$ são as populações das zonas $i$ e $j$; e $I_{i}$ e $I_{j}$ são as renda per capita das zonas $i$ e $j ; t=$ tempo de viagem pelo modo de transporte $m ; c=$ custo monetário pelo modo de transporte $m ; \phi, \theta$ e $\alpha$ são coeficientes de calibração.

Apesar de atraentes do ponto de vista de aplicação, por permitirem relacionar simultaneamente a geração, distribuição e divisão modal, esses modelos podem ser problemáticos na tentativa de representação da realidade devido ao elevado número de parâmetros a serem estimados (ORTÚZAR; WILLUMSEN, 2011). Uma abordagem alternativa para o equacionamento também pode ser verificada em Domencich, Kraft e Valette (1968), que propõem termos lineares e exponenciais em complemento à equação sob forma multiplicativa exemplificada.

Porém, a partir da década de 1980 os modelos de escolha discreta passaram a ser uma alternativa prática (WILLIAMS, 1981), cuja definição é formalizada por Ortúzar e Willumsen (2011) como "a probabilidade dos indivíduos escolherem uma opção entre um conjunto de alternativas preestabelecidos como função das suas características socioeconômicas e da atratividade relativa da opção escolhida".

Assim, em detrimento das abordagens apresentadas anteriormente, surgiram os modelos desagregados de escolha discreta que consideram informações sobre as escolhas individuais mediante um conjunto de alternativas apresentadas a potenciais usuários no caso de operação futura de um novo sistema de transporte. Essa abordagem permite retratar convenientemente as respostas de uma pesquisa de preferência declarada tal como aquela descrita neste capítulo. 


\subsubsection{Modelagem de Escolha Discreta}

A abordagem teórica mais comum para definição de modelos de escolha discreta baseia-se na teoria de utilidade (DOMENCICH; MCFADDEN, 1975; WILLIAMS; SENIOR, 1977), mediante as seguintes premissas (ORTÚZAR; WILLUMSEN, 2011):

- Os indivíduos pertencem a uma população homogênea $Q$, agem racionalmente em um ambiente com assimetria de informações e buscam maximizar sua utilidade pessoal segundo restrições legais, sociais, físicas e de orçamento;

- Existe um conjunto de alternativas a serem escolhidas $\boldsymbol{A}=\left\{A_{1}, \ldots, A_{j}, \ldots, A_{N}\right\}$ e um conjunto $\boldsymbol{X}$ de vetores de atributos relacionados aos indivíduos e às respectivas alternativas por eles escolhidas. Um indivíduo $q$ possui os atributos $x \in X$ e sua escolha é caracterizada por $A(q) \in \boldsymbol{A}$.

- Cada alternativa $A_{j} \in \boldsymbol{A}$ possui uma utilidade $U_{i j q}$ correspondente ao indivíduo $q$. Dado que o planejador não possui todas as informações a respeito dos elementos que remetem à escolha do indivíduo, a sua utilidade é definida por duas componentes: uma parcela mensurável $V_{i j q}$ descrita como uma função dos atributos $x$ da escolha do indivíduo; e uma parcela aleatória que representa as particularidades do indivíduo e possíveis erros inerentes à modelagem. Assim, a utilidade de uma escolha pode ser especificada por:

$$
U_{j q}=V_{j q}+\varepsilon_{j q}
$$

A parcela determinística dessa equação mais recorrente na literatura é definida como uma função linear de atributos $\left(x_{j k q}\right)$ e seus respectivos pesos $\left(\theta_{k j}\right)$, tal como exemplificado na Equação 3.24 a seguir.

$$
V_{j q}=\sum_{k} \theta_{k j} \cdot x_{j k q}
$$

Sob a premissa de homogeneidade da população, a parcela aleatória $\varepsilon_{j q}$ da Equação 3.23 pode ser representada por uma variável aleatória com média 0 (zero) e distribuição de probabilidade específica. 
- O indivíduo seleciona a alternativa que maximiza a sua utilidade, ou seja, a alternativa $A_{j}$ é escolhida somente se

$$
U_{j q} \geq U_{i q} \quad \forall A_{i} \in A(q)
$$

ou seja

$$
V_{j q}-V_{i q} \geq \varepsilon_{i q}-\varepsilon_{j q}
$$

Uma vez que o analista desconhece os valores de $\varepsilon_{i q}$ e $\varepsilon_{j q}$, é impossível garantir essa desigualdade. Assim, a probabilidade de escolha da alternativa $A_{j}$ é caracterizada como:

$$
\begin{aligned}
\operatorname{Prob}_{j q} & =\operatorname{Prob}\left(V_{j q}-V_{i q} \geq \varepsilon_{i q}-\varepsilon_{j q}\right) \\
& =\operatorname{Prob}\left(\varepsilon_{i q} \leq \varepsilon_{j q}+V_{j q}-V_{i q}\right) \quad \forall A_{i} \in A(q)
\end{aligned}
$$

Dado que a parcela aleatória da escolha de um indivíduo é desconhecida, os resíduos $\varepsilon_{i q}$ e $\varepsilon_{j q}$ podem ser caracterizados por uma função de distribuição de probabilidade $f(\varepsilon)$, em geral definida como uma função com resíduos independentes e igualmente distribuídos (Independent and Identically Distributed - IID) .

Em geral, os resíduos caracterizados por $f(\varepsilon)$ são representados por uma função IID de Gumbell (Equação 3.28) e a probabilidade de escolha do modo $j$ pelo indivíduo $q$ é definida como um modelo Logit Multinomial - MNL (DOMENCICH; MCFADDEN, 1975)

$$
f(\varepsilon)=\frac{1}{\sigma} \exp \left[\frac{\varepsilon-\mu}{\sigma}-\exp \left(\frac{\varepsilon-\mu}{\sigma}\right)\right] \quad \varepsilon \in(-\infty, \infty)
$$

Assim, dada a função $f(\varepsilon)$ de Gumbell, a probabilidade de escolha da alternativa $j$ pelo indivíduo $q$ é caracterizada pela Equação 3.29 considerando a desigualdade da Equação 3.27.

$$
\operatorname{Prob}_{j q}=\frac{e^{\left(V_{j q}\right)}}{\sum_{A_{i} \in A(q)} e^{V_{i q}}}
$$

Para estimativa dos coeficientes da função utilidade $V_{i q}$ no âmbito da escolha modal, suponha que uma amostra $Q$ de indivíduos provê valores da variáveis $\gamma_{j k q}$ a respeito da escolha do modo de transporte $k$ tal que: $\gamma_{j q}=1$, se a alternativa $A_{j}$ é escolhida por $q$; e $\gamma_{j q}=0$, caso contrário. 
Uma vez que essas observações a respeito do comportamento dos usuários são independentes, uma função de verosimilhança pode ser definida pelo produto das probabilidades de escolha de cada indivíduo tal como caracterizado na Equação 3.30.

$$
L(\theta)=\prod_{A_{j} \in A(q)} \prod_{q=1}^{Q}\left(\operatorname{Prob}_{j q}\right)^{\gamma_{j q}}
$$

onde $\operatorname{Prob}_{j q}=$ probabilidade de escolha da alternativa $j$ pelo indivíduo $q$.

Assim, os parâmetros $\theta$ da parcela determinística da função utilidade representada sob a forma linear da Equação 3.24 podem ser estimados derivando-se a função logarítmica de $L(\theta)$ parcialmente em relação àqueles parâmetros e igualando-a a zero (ORTUZAR, 1982). Assim, a maximização da verosimilhança para estimativa de $\theta_{k j}$ é dada por :

$$
l(\theta)=\log L(\theta)=\sum_{q=1}^{Q} \sum_{A_{J} \in A(q)} \gamma_{j q} \cdot \log P_{j q}=0
$$

Nessas condições, a maximização da verossimilhança resulta em valores médios para os coeficientes das funções utilidade e as respectivas covariâncias são calculadas a partir das derivadas de segunda ordem de $\log L(\theta)$, tal como caracterizado na Equação 3.32, que resulta em uma matriz de covariância dos coeficientes.

$$
S^{2}=-\left(E\left(\frac{\partial^{2} l(\theta)}{\partial \theta^{2}}\right)\right)^{-1}
$$

Apesar dessas expressões explícitas para obtenção dos parâmetros $\theta_{k j}$ e cálculo de uma matriz de covariância $S^{2}$, a resolução da igualdade $\log L(\theta)=0$ envolve um processo iterativo quando se trata de uma função de verossimilhança com mais de um estimador.

Os modelos Probit Multinomial e Mixed Logit consideram diferentes equações de estimativa da probabilidade de escolha modal em detrimento daquela especificada na Equação 3.29. Por outro lado, os modelos Nested Logit integram as propriedades do Multinomial Logit considerando a utilidade conjunta de escolha de um modo. Maiores informações a respeito desses modelos podem ser obtidas em Ortúzar e Willumsen (2011). 


\subsubsection{Avaliação de Modelos Logit Multinomial}

Existem testes estatísticos de hipótese para análise da significância dos coeficientes estimados na função utilidade de caracterização dos modos de transporte e para comparação de desempenho entre modelos especificados.

\section{- Teste $t$ de Significância dos Atributos}

A Equação 3.33 considera que os estimadores $\theta_{k j}$ possuem variância $s_{k k}$ tal que se a média $\theta_{k}=0$ em $f\left(\theta, S^{2}\right)$ tem distribuição normal padrão $[N(0,1)]$, então a estatística $t$ é:

$$
t=\frac{\theta_{k}^{*}}{s_{k k}}
$$

Nesse caso, é possível verificar se $\theta_{k j}$ é estatisticamente diferente de zero a um nível de significância preestabelecido. Valores suficientemente grandes de $t$ (em geral maiores que 1,96 para níveis de confiança de 95\%) permitem não rejeitar hipótese nula de que $\theta_{k j}=0$ e, portanto, o $k$-ésimo estimador da função utilidade afeta significativamente a probabilidade de escolha do modo de transporte $j$.

\section{- Teste de Razão de Verossimilhança}

É possível avaliar se um modelo definido por coeficientes genéricos (denominado modelo restrito) é mais adequado do que aquele com valores específicos para cada atributo do ponto de vista estatístico. Para isso, a verossimilhança do modelo restrito $l\left(\theta_{r}\right)$ e os seus respectivos parâmetros são estimados e, em seguida, o mesmo procedimento é executado considerando-se atributos específicos para obtenção de uma verossimilhança $l(\theta)$. Assim, a estatística (Likelihood Ratio - LR) é calculada segundo a Equação 3.34.

$$
L R=-2 \cdot\left\{l\left(\theta_{r}\right)-l(\theta)\right\}
$$

Nesse caso, a hipótese nula de que o modelo restrito (genérico) é adequado é rejeitada se o valor $t$ calculado é menor que um valor crítico de uma distribuição $\chi^{2} \operatorname{com} n_{\theta_{r}}-n_{\theta}$ graus de liberdade, em que $r$ é o número de equações (ou funções utilidade). 


\section{- Índice $\rho^{2}$}

O índice $\rho^{2}$ definido pela Equação 3.35 permite comparar a qualidade do modelo (aderência) em relação às respostas observadas na pesquisa de preferência declarada tal que $\rho^{2}=0$ caracteriza um modelo sem aderência e $\rho^{2}=1,0$ indica representação total das respostas pelo modelo. Ortúzar e Willumsen (2011) indicam que valores próximos de 0,4 para esse parâmetro correspondem a aderência satisfatória.

$$
\rho^{2}=1-\frac{l(\theta)}{l(0)}
$$

Uma vez que $\rho^{2}$ pode ser computado em relação a qualquer hipótese nula, ou seja, um modelo pode ser comparado a qualquer outro que não necessariamente sob o valor de $l(0)$, Tardiff (1976) propôs um ajuste à equação anterior tal que o referido índice é calculado em relação ao modelo de divisão de mercado

$$
\bar{\rho}^{2}=1-\frac{l(\theta)}{l(C)}
$$

onde $l(C)=\sum_{j} Q_{j} \cdot \log \left(Q_{j} / Q\right)$ e $Q_{j}$ é o número de indivíduos que escolhem $A_{j}$.

\subsubsection{Procedimento para Especificação dos Modelos Logit Multinomial}

A decisão sobre a combinação dos coeficientes que devem fazer parte de um modelo de escolha discreta é feita por um procedimento iterativo. Em geral, as análises iniciam-se com um modelo simples e progridem para versões mais elaboradas pelo aumento do poder explanatório.

Primeiramente, define-se uma constante ASC (Alternative Specific Constant) que representa a utilidade inerente a uma alternativa $A_{j}$ ( $j$-ésimo modo de transporte), ou seja, o valor do atributo associado à $A S C$ é constante e igual 1 na representação da função utilidade.

Entretanto, por questões associadas ao método de estimação dos coeficientes (maximização da verossimilhança), a definição de uma ASC para cada equação é inviável (ORTÚZAR; WILLUMSEN, 2011). Desse modo, uma alternativa é definida como referência - fixando-se o valor de $A S C$ igual a zero - e os coeficientes associados às respectivas funções utilidade são estimados e comparados com essa referência. 
Após a caracterização dos modelos de função utilidade e calibração dos coeficientes, procedese à análise dos seus respectivos sinais (positivo ou negativo), tal que valores negativos indicam que a utilidade de um modo de transporte decresce com o aumento do valor numérico do atributo associado. Por outro lado, valores de sinal positivo indicam que a utilidade do modo aumenta quando o valor do respectivo atributo também aumenta.

Assim, do ponto de vista de análise do sinal dos coeficientes, a verificação de uma calibração está relacionada à compatibilidade dos sinais do ponto de vista lógico e em relação à literatura precedente. Por exemplo, espera-se que o sinal de um coeficiente associado ao tempo de viagem seja negativo, dado que a utilidade desse modo decresce com o aumento do tempo de percurso sob a percepção do usuário.

Em seguida, a representatividade de um coeficiente é avaliado segundo o seu nível de significância dado pelo teste estatístico da Equação 3.33. Na prática, se um coeficiente é considerado relevante para caracterização da escolha modal, a sua inclusão no modelo é limitada a um nível de significância mínimo de $80 \%$.

Eventualmente, a inclusão de uma variável relevante com o sinal correto pode ser admitida mesmo que esta falhe no teste de significância, justificado pelo fato de que o valor estimado pode representar de maneira mais adequada as condições reais, e por esses resultados poderem ser consequência de insuficiência de dados para calibração (ORTÚZAR; WILLUMSEN, 2011).

Quanto à admissão de variáveis socioeconômicas (como gênero, idade, renda e ocupação), a maneira convencional de considerá-las nas funções utilidade é através de coeficientes estimados em apenas uma das equações - como exemplificado a seguir - dado que os atributos associados aos usuários não variam em relação ao modo de transporte utilizado.

$$
\left\{\begin{array}{l}
V_{1 q}=\beta_{T T} \cdot T T_{1 q}+\beta_{F A} \cdot F A_{1 q}+\beta_{F R} \cdot F R_{1 q}+\cdots+\sum_{i} \beta_{i} \cdot s_{i q} \\
V_{2 q}=\beta_{T T} \cdot T T_{2 q}+\beta_{F A} \cdot F A_{2 q}+\beta_{F R} \cdot F R_{2 q}
\end{array}\right.
$$

onde $T T$ é o tempo de viagem, $F A$ é o custo, $F R$ é frequência e as variáveis binárias $s_{l q}$ representam as características socioeconômicas do indivíduo $q$.

A prática mostra que na maioria dos casos a inclusão dessas variáveis melhora muito pouco o poder explanatório do modelo a ponto de serem incluídas (ORTÚZAR; WILLUMSEN, 2011). 
Entretanto, uma alternativa de modelagem proposta por Fowkes e Wardman (1988) indica um conjunto de funções (Equação 3.38) para estimativa de coeficientes considerando o perfil dos usuários, onde a variável binária $s_{l q}$ refere-se à característica socioeconômica $l$ do indivíduo $q$.

$$
\begin{aligned}
& V_{i q}=\left(\alpha+\sum_{l} \alpha_{T T_{l}} \cdot s_{l q}\right) \cdot T T_{i q} \\
& \quad+\left(\theta+\sum_{l} \theta_{F A_{l}} \cdot s_{l q}\right) \cdot c_{i q}+\left(\lambda+\sum_{l} \lambda_{F R_{l}} \cdot s_{l q}\right) \cdot f_{i q} \quad(i=1,2)
\end{aligned}
$$

\subsubsection{Estimativa dos modelos}

Além da extensa literatura a respeito de modelagem de escolha discreta, existem atualmente softwares que permitem estimar os coeficientes das funções utilidade pela maximização da verossimilhança e valores de alguns dos testes estatísticos descritos anteriormente.

O software SPSS (2008) utilizado para o delineamento do experimento ortogonal também possui método para estimativa dos coeficientes de um modelo Logit Multinomial. Entretanto, a ferramenta limita-se à definição de funções utilidade lineares, impedindo investigações mais aprofundadas como a inclusão de variáveis socioeconômicas nos modelos.

Por outro lado, o Biogeme (BIERLAIRE; FETIARISON, 2009) é uma ferramenta computacional mais robusta na resolução do problema, uma vez que permite a caracterização de qualquer tipo de função e apresenta resultados mais elaborados a respeito dos testes de hipóteses. Esse software requer um arquivo do tipo texto para definição do modelo ilustrado pela Figura 3.31.

Naquela figura os termos entre colchetes são: [Choice], define o nome da coluna do arquivo de dados de entrada que contém informações sobre as respostas dos participantes da pesquisa de preferência declarada; [Beta], estabelece os nomes dos coeficientes associados aos atributos das funções utilidade; [Utilities] permite a caracterização das funções utilidade; [Expressions] permite a inserção de restrições na estimação dos modelos (como exclusão de conjuntos de dados, por exemplo); e [Model] define a abordagem utilizada para maximização da verossimilhança.

O arquivo de entrada de dados (também do tipo texto) contém as respostas da pesquisa, os respectivos níveis dos atributos apresentados aos respondentes e informações sobre as características socioeconômicas dos participantes. 


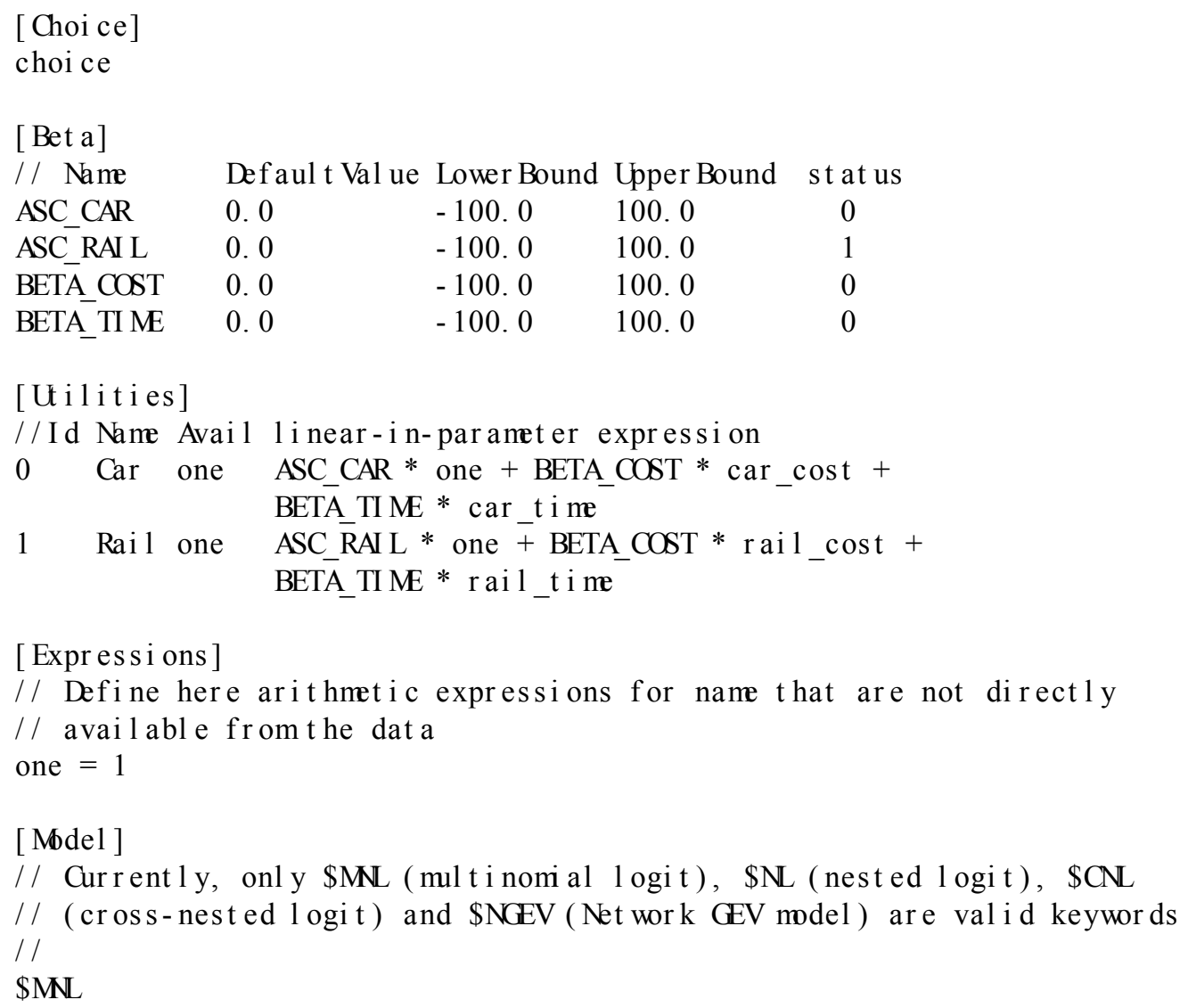

Figura 3.31 - Exemplo de arquivo de um $M N L$ no Biogeme - Fonte: Bierlaire e Fetiarison (2009)

Após as calibrações obtém-se um arquivo do tipo HTML contendo valores de verossimilhança, os coeficientes estimados e as respectivas significâncias. Ademais, o Biogeme provê arquivos auxiliares para posterior cálculo das probabilidades de escolha modal mediante os níveis dos atributos apresentados aos respondentes através de um outro software (Biosim).

Os itens subsequentes desta seção contêm os modelos calibrados no Biogeme para representação das respostas da pesquisa de preferência declarada. A base de dados foi segregada em amostras por motivo de viagem ( $W$ ou $L$ ), sendo a de calibração correspondente a $75 \%$ das observações da Tabela 3.15 e a de validação correspondente a $25 \%$ daquelas respostas, resultando nos valores representados na Tabela 3.16 .

A primeira amostra foi utilizada para estimativa dos valores dos coeficientes associados aos atributos da função utilidade para cada modelo proposto e a segunda parcela foi utilizada para validação, comparando-se a porcentagem de acertos entre as escolhas dos modelos e as dos participantes da pesquisa. 
Tabela 3.16 - Número de respostas das amostras para calibração e validação dos modelos de escolha discreta relativos à pesquisa de preferência declarada

\begin{tabular}{|c|c|c|c|c|c|c|c|c|c|c|c|c|}
\hline \multirow{2}{*}{$\begin{array}{l}\text { Cenário } \\
\text { Motivo }\end{array}$} & \multicolumn{3}{|c|}{$H P T \operatorname{sem} A I R$} & \multicolumn{3}{|c|}{$H P T \operatorname{com} A I R$} & \multicolumn{3}{|c|}{$H S T$ sem $A I R$} & \multicolumn{3}{|c|}{$H S T \operatorname{com} A I R$} \\
\hline & $W$ & $L$ & Total & $\boldsymbol{W}$ & $L$ & Total & $\boldsymbol{W}$ & $L$ & Total & $\boldsymbol{W}$ & $L$ & Total \\
\hline Amostra de Calibração & 441 & 588 & 1029 & 509 & 474 & 984 & 502 & 550 & 1053 & 557 & 589 & 1146 \\
\hline Amostra de Validação & 147 & 196 & 343 & 170 & 159 & 328 & 168 & 184 & 351 & 186 & 197 & 383 \\
\hline
\end{tabular}

\subsubsection{Modelo A}

O Biogeme permite que todas as funções sejam declaradas no mesmo arquivo paramétrico de definição do modelo (Figura 3.31), dado que a presença ou ausência de um modo é declarado no arquivo de dados de entrada mediante a definição de uma variável binária ("AVAIL") que assume o valor "1"caso o modo tenha sido disponibilizado para escolha do respondente e "0"caso contrário. Para o modo Automóvel $(C A R)$, essa variável é igual a "1"se o respondente da pesquisa declarou que possui Carteira Nacional de Habilitação e igual a "0"caso contrário.

No caso do modo Avião (AIR), a variável "AVAIL"assume valor "1"se o cenário apresentado ao participante contém essa alternativa para escolha, e para o modo ferroviário assume esse valor unitário se o cenário apresentado corresponde à oferta de HPT ou HST de maneira complementar (ou seja, se é igual a 1 para HPT então assume valor 0 para o $H S T$ ). Finalmente, no modo Ônibus (BUS) essa variável sempre assume valor "1"uma vez que está sempre disponível para viagens intermunicipais e interestaduais na Região Sudeste.

O primeiro modelo proposto para representação das escolhas da pesquisa de preferência declarada considera funções utilidade para cada modo de transporte (CAR, BUS, HPT, HST e AIR) com coeficientes específicos (não genéricos) para cada atributo. A constante $A S C$ relacionada à função utilidade do modo $C A R$ é igual a zero e o mesmo conjunto de equações foi definido para os dois motivos de viagem ( $W$ e $L$ ) conforme representado a seguir.

$$
\left\{\begin{array}{l}
V_{C A R}=\beta_{T T_{C A R}} \cdot T T_{C A R}+\beta_{P E} \cdot P E_{C A R}+\beta_{T O} \cdot T O_{C A R} \\
V_{B U S}=A S C_{B U S}+\beta_{T T_{B U S}} \cdot T T_{B U S}+\beta_{F R_{B U S}} \cdot F R_{B U S}+\beta_{F A_{B U S}} \cdot F A_{B U S} \\
V_{H P T}=A S C_{H P T}+\beta_{T T_{H P T}} \cdot T T_{H P T}+\beta_{F R_{H P T}} \cdot F R_{H P T}+\beta_{F A_{H P T}} \cdot F A_{H P T} \\
V_{H S T}=A S C_{H S T}+\beta_{T T_{H S T}} \cdot T T_{H S T}+\beta_{F R_{H S T}} \cdot F R_{H S T}+\beta_{F A_{H S T}} \cdot F A_{H S T} \\
V_{A I R}=A S C_{A I R}+\beta_{T T_{A I R}} \cdot T T_{A I R}+\beta_{F R_{A I R}} \cdot F R_{A I R}+\beta_{F A_{A I R}} \cdot F A_{A I R}
\end{array}\right.
$$


A Tabela C.1 e a Tabela C.2 do Apêndice C contêm os valores dos coeficientes das funções utilidade e respectivas significâncias para os motivos de viagem $W$ e $L$ desse modelo, respectivamente. A Tabela 3.17 resume as medidas de desempenho da calibração por motivo de viagem.

Tabela 3.17 - Medidas de desempenho para estimativa dos parâmetros do Modelo A

\begin{tabular}{lrr}
\hline Motivo & $\boldsymbol{W}$ & $\boldsymbol{L}$ \\
Coeficientes estimados & 19 & 19 \\
Observações & 1714 & 1744 \\
$l(0)$ & $-2043,927$ & $-1965,484$ \\
$l(\theta)$ & $-1877,46$ & $-1862,198$ \\
$\rho^{2}$ & 0,081 & 0,053 \\
$\bar{\rho}^{2}$ & 0,072 & 0,043 \\
\hline
\end{tabular}

\subsubsection{Modelo B}

Haja vista que os testes de significância estatística de alguns coeficientes do Modelo A indicam que alguns deles não afetam estatisticamente as decisões representadas pelas funções utilidade, propõe-se uma modelagem alternativa correspondente às equações de (3.39).

Nessa proposta, os coeficientes associados ao tempo de viagem $\left(\beta_{T T}\right)$ dos modos Automóvel, Ônibus, Trens (HPT e HST) e Avião são generalizados para um mesmo valor, bem como os coeficientes relativos à frequência $\left(\beta_{F R}\right)$ e preço da passagem $\left(\beta_{F A}\right)$ dos três últimos modos de transporte. Novamente, as funções representam a utilidade dos modos de transporte para os motivos de viagem trabalho $(W)$ e lazer $(L)$.

$$
\left\{\begin{array}{l}
V_{C A R}=\beta_{T T} \cdot T T_{C A R}+\beta_{P E} \cdot P E_{C A R}+\beta_{T O} \cdot T O_{C A R} \\
V_{B U S}=A S C_{B U S}+\beta_{T T} \cdot T T_{B U S}+\beta_{F R} \cdot F R_{B U S}+\beta_{F A} \cdot F A_{B U S} \\
V_{H P T}=A S C_{H P T}+\beta_{T T} \cdot T T_{H P T}+\beta_{F R} \cdot F R_{H P T}+\beta_{F A} \cdot F A_{H P T} \\
V_{H S T}=A S C_{H S T}+\beta_{T T} \cdot T T_{H S T}+\beta_{F R} \cdot F R_{H S T}+\beta_{F A} \cdot F A_{H S T} \\
V_{A I R}=A S C_{A I R}+\beta_{T T} \cdot T T_{A I R}+\beta_{F R} \cdot F R_{A I R}+\beta_{F A} \cdot F A_{A I R}
\end{array}\right.
$$

Nesse caso, a maximização da verossimilhança resulta nos valores de parâmetros indicados na Tabela C.3 e na Tabela C.4 do Apêndice C e, em resumo, o desempenho das estimativas pode ser verificado na Tabela 3.18. 
Tabela 3.18 - Medidas de desempenho para estimativa dos parâmetros do Modelo B

\begin{tabular}{lrr}
\hline Motivo & $\boldsymbol{W}$ & $\boldsymbol{L}$ \\
Coeficientes estimados & 9 & 9 \\
Observações & 1714 & 1744 \\
$l(0)$ & $-2043,927$ & $-1965,484$ \\
$l(\theta)$ & $-1902,922$ & $-1878,197$ \\
$\rho^{2}$ & 0,069 & 0,044 \\
$\bar{\rho}^{2}$ & 0,065 & 0,040 \\
\hline
\end{tabular}

A aplicação do teste de hipótese descrito pela Equação 3.34 para avaliação da hipótese de generalização dos parâmetros associados aos atributos dos modos de transporte, cujo resultado pode ser verificado na Tabela 3.19 .

Tabela 3.19 - Testes de razão de verossimilhança entre o Modelo A e o Modelo B

\begin{tabular}{|c|c|c|c|c|c|c|c|}
\hline Motivo & Modelo & $l(\theta)$ & Parâmetros $(n)$ & $L R$ & Graus de Liberdade $(g l)$ & $\chi_{(g l ; 95 \%)}^{2}$ & Teste de Hipótese \\
\hline \multirow{2}{*}{$W$} & A & $-1877,460$ & 19 & \multirow{2}{*}{50,92} & \multirow{2}{*}{10} & \multirow{2}{*}{18,31} & \multirow{2}{*}{ Não Rejeitar $H_{0}$} \\
\hline & B & $-1902,922$ & 9 & & & & \\
\hline \multirow{2}{*}{$L$} & A & $-1862,198$ & 19 & \multirow{2}{*}{32,00} & \multirow{2}{*}{10} & \multirow{2}{*}{18,31} & \multirow{2}{*}{ Não Rejeitar $H_{0}$} \\
\hline & B & $-1878,197$ & 9 & & & & \\
\hline
\end{tabular}

O valor obtido do Teste de Razão de Verossimilhança $(L R)$ indica que, a um nível de confiança de $95 \%$, o modelo de representação da utilidade dos modos de transporte pode ser generalizado por valores idênticos de parâmetros para os modelos de ambos os motivos de viagem. Isso pode ser justificado pelo fato de que $\chi_{(10 ; 95 \%)}^{2}=18,31<L R=50,92$ para o motivo de viagem trabalho $(W)$ e $\chi_{(10 ; 95 \%)}^{2}=18,31<L R=32,00$ para o motivo lazer ou outros $(L)$.

Portanto, na comparação entre o Modelo A (parâmetros não genéricos, ou seja, irrestritos) e o Modelo B (parâmetros genéricos, ou seja, restritos), a hipótese nula de que o segundo é estatisticamente correto para representação da escolha modal não é rejeitada para os dois motivos de viagem, indicando que a generalização dos coeficientes pode ser considerada viável.

\subsubsection{Modelo C}

Como consequência dos resultados do Modelo A e do Modelo B, propõe-se um terceiro modelo pela eliminação ou generalização dos coeficientes não significativos estimados anteriormente. Nesse caso, optou-se pela calibração de diferentes conjuntos de funções utilidade por motivo de viagem, conforme apresentado em (3.41) e (3.42). 


$$
\left\{\begin{array}{l}
V_{C A R}=\beta_{T T} \cdot T T_{C A R}+\beta_{F A_{C A R}} \cdot P E_{C A R}+\beta_{F A_{C A R}} \cdot T O_{C A R} \\
V_{B U S}=A S C_{B U S}+\beta_{T T} \cdot T T_{B U S}+\beta_{F R} \cdot F R_{B U S}+\beta_{F A} \cdot F A_{B U S} \\
V_{H P T}=A S C_{H P T}+\beta_{T T} \cdot T T_{H P T}+\beta_{F R} \cdot F R_{H P T}+\beta_{F A} \cdot F A_{H P T} \\
V_{H S T}=\beta_{T T} \cdot T T_{H S T}+\beta_{F R} \cdot F R_{H S T}+\beta_{F A} \cdot F A_{H S T} \\
V_{A I R}=A S C_{H S T}+\beta_{T T} \cdot T T_{A I R}+\beta_{F R} \cdot F R_{A I R}+\beta_{F A} \cdot F A_{A I R}
\end{array}\right.
$$

$$
\left\{\begin{array}{l}
V_{C A R}=\beta_{T T} \cdot T T_{C A R}+\beta_{F A_{C} A R} \cdot P E_{C A R}+\beta_{F A_{C} A R} \cdot T O_{C A R} \\
V_{B U S}=\beta_{T T} \cdot T T_{B U S}+\beta_{F A} \cdot F A_{B U S} \\
V_{H P T}=A S C_{H P T}+\beta_{T T} \cdot T T_{H P T}+\beta_{F A} \cdot F A_{H P T} \\
V_{H S T}=A S C_{H S T}+\beta_{T T} \cdot T T_{H S T}+\beta_{F A} \cdot F A_{H S T} \\
V_{A I R}=A S C_{A I R}+\beta_{T T} \cdot T T_{A I R}+\beta_{F A} \cdot F A_{A I R}
\end{array}\right.
$$

A calibração dos coeficientes dessas equações resultou nas medidas de desempenho resumidas na Tabela 3.20, cujos valores numéricos e significâncias estatísticas são apresentados na Tabela C.5 e Tabela C.6 do Apêndice C.

Tabela 3.20 - Medidas de desempenho para estimativa dos parâmetros do Modelo C

\begin{tabular}{lrr}
\hline Motivo & $\boldsymbol{W}$ & $\boldsymbol{L}$ \\
Coeficientes estimados & 7 & 6 \\
Observações & 1714 & 1744 \\
$l(0)$ & $-2043,927$ & $-1965,484$ \\
$l(\theta)$ & $-1905,033$ & $-1881,372$ \\
$\rho^{2}$ & 0,068 & 0,043 \\
$\bar{\rho}^{2}$ & 0,065 & 0,040 \\
\hline
\end{tabular}

\subsubsection{Modelo D}

Após avaliação do sinal e da significância dos resultados do Modelo C, propõe-se a alteração do conjunto de funções utilidade dos modos de transporte pelo motivo de viagem trabalho $(W)$, dado que apenas a constante $A S C_{B U S}$ resultou em significância menor do que $95 \%$. Ainda, a proposta de alteração do modelo anterior tem por objetivo verificar a possibilidade de aumento do valor da verossimilhança calculada na calibração dos modelos. 


$$
\begin{aligned}
& \left\{\begin{array}{l}
V_{C A R}=\beta_{T T} \cdot T T_{C A R}+\beta_{F A_{C A R}} \cdot P E_{C A R}+\beta_{F A_{C A R}} \cdot T O_{C A R} \\
V_{B U S}=A S C+\beta_{T T} \cdot T T_{B U S}+\beta_{F R} \cdot F R_{B U S}+\beta_{F A} \cdot F A_{B U S} \\
V_{H P T}=A S C+\beta_{T T} \cdot T T_{H P T}+\beta_{F R} \cdot F R_{H P T}+\beta_{F A} \cdot F A_{H P T} \\
V_{H S T}=A S C+\beta_{T T} \cdot T T_{H S T}+\beta_{F R} \cdot F R_{H S T}+\beta_{F A} \cdot F A_{H S T} \\
V_{A I R}=A S C+\beta_{T T} \cdot T T_{A I R}+\beta_{F R} \cdot F R_{A I R}+\beta_{F A} \cdot F A_{A I R}
\end{array}\right. \\
& \left\{\begin{array}{l}
V_{C A R}=\beta_{T T} \cdot T T_{C A R}+\beta_{F A_{C A R}} \cdot P E_{C A R}+\beta_{F A_{C A R}} \cdot T O_{C A R} \\
V_{B U S}=\beta_{T T} \cdot T T_{B U S}+\beta_{F A} \cdot F A_{B U S} \\
V_{H P T}=A S C_{R A I L}+\beta_{T T} \cdot T T_{H P T}+\beta_{F A} \cdot F A_{H P T} \\
V_{H S T}=A S C_{R A I L}+\beta_{T T} \cdot T T_{H S T}+\beta_{F A} \cdot F A_{H S T} \\
V_{A I R}=A S C_{A I R}+\beta_{T T} \cdot T T_{A I R}+\beta_{F A} \cdot F A_{A I R}
\end{array}\right.
\end{aligned}
$$

Os resultados da calibração desses modelos no Biogeme são indicados na Tabela C.7 e na Tabela C.8 do Apêndice C. Os valores indicados naquelas tabelas mostram que os coeficientes estimados são todos significativos do ponto de vista estatístico (tanto para o motivo de viagem trabalho quanto para lazer ou outros).

O resumo das medidas de desempenho da Tabela 3.21 indicam que as alterações de verossimilhança $(l(\theta))$ e dos índices $\rho^{2}$ e $\bar{\rho}^{2}$ em relação aos modelos anteriores não são expressivas em termos numéricos. Assim, esse Modelo D é um potencial candidato a representar as utilidades dos modos de transporte envolvidos na caracterização da divisão modal mediante novos serviços ferroviários na Região Sudeste do Brasil.

Tabela 3.21 - Medidas de desempenho para estimativa dos parâmetros do Modelo D

\begin{tabular}{lrr}
\hline Motivo & $\boldsymbol{W}$ & $\boldsymbol{L}$ \\
Coeficientes estimados & 5 & 5 \\
Observações & 1714 & 1744 \\
$l(0)$ & $-2043,927$ & $-1965,484$ \\
$l(\theta)$ & $-1910,560$ & $-1881,378$ \\
$\rho^{2}$ & 0,065 & 0,043 \\
$\bar{\rho}^{2}$ & 0,063 & 0,040 \\
\hline
\end{tabular}

\subsubsection{Modelo E}

Este Modelo E contempla a inserção dos atributos socioeconômicos da pesquisa de preferência declarada nas funções utilidade por motivo de viagem. Uma vez que a comparação do Mo- 
delo A e do Modelo B indicou a possibilidade de generalização dos coeficientes dos atributos comuns às funções utilidade, propõe-se modelos baseados em (3.37) da página 158 com a inclusão de coeficientes genéricos associados às variáveis de Idade, Renda Média per Capita, Empregabilidade e posse de $\mathrm{CNH}$.

Assim, as amostras foram segregadas na tentativa de representar as escolhas modais segundo grupos da população com características socioeconômicas semelhantes. Os atributos Idade $(A G E)$ e Renda Média per Capita (INC) foram divididos nas três classes da Tabela 3.22 (com valor "1"quando o atributo pertencer à respectiva classe e "0"caso contrário), e os atributos Empregabilidade $(E M P)$ e Posse de $\mathrm{CNH}\left(D R I V_{-} L I C\right)$ foram definidos por variáveis binárias com valor "1"em caso afirmativo e "0"caso contrário.

Tabela 3.22 - Intervalos das classes de atributos socioeconômicos para inserção nos modelos de escolha modal

\begin{tabular}{ccc}
\hline Classe & Idade $(A G E)$ & Renda $(I N C)$ \\
\hline 1 & $18<A G E_{1} \leq 33$ & $215<I N C_{1} \leq 830$ \\
2 & $33<A G E_{2} \leq 48$ & $830<I N C_{2} \leq 1900$ \\
3 & $A G E_{3}>48$ & $I N C_{3}>1900$ \\
\hline
\end{tabular}

Assim, (3.45) representa as funções utilidade a serem calibradas considerando as variáveis socioeconômicas no formato aditivo, igualmente para ambos os motivos de viagem ( $W$ e $L$ ). Notase que os atributos socioeconômicos estão associados a apenas uma função utilidade $(C A R)$ escolhida arbitrariamente - conforme sugerido por (ORTÚZAR; WILLUMSEN, 2011).

$$
\left\{\begin{aligned}
V_{C A R}= & \beta_{T T} \cdot T T_{C A R}+\beta_{P E} \cdot P E_{C A R}+\beta_{T O} \cdot T O_{C A R}+\beta_{E M P} \cdot E M P \\
& +\beta_{D R I V_{-} L I C} \cdot D R I V_{-} L I C+\beta_{A G E_{1}} \cdot A G E_{1}+\beta_{A G E_{2}} \cdot A G E_{2} \\
& +\beta_{A G E_{3}} \cdot A G E_{3}+\beta_{I N C_{1}} \cdot I N C_{1}+\beta_{I N C_{2}} \cdot I N C_{2}+\beta_{I N C_{3}} \cdot I N C_{3} \\
V_{B U S}= & A S C_{B U S}+\beta_{T T} \cdot T T_{B U S}+\beta_{F R} \cdot F R_{B U S}+\beta_{F A} \cdot F A_{B U S} \\
V_{H P T}= & A S C_{H P T}+\beta_{T T} \cdot T T_{H P T}+\beta_{F R} \cdot F R_{H P T}+\beta_{F A} \cdot F A_{H P T} \\
V_{H S T}= & A S C_{H S T}+\beta_{T T} \cdot T T_{H S T}+\beta_{F R} \cdot F R_{H S T}+\beta_{F A} \cdot F A_{H S T} \\
V_{A I R}= & A S C_{A I R}+\beta_{T T} \cdot T T_{A I R}+\beta_{F R} \cdot F R_{A I R}+\beta_{F A} \cdot F A_{A I R}
\end{aligned}\right.
$$


Os resultados da calibração desses modelos são representados na Tabela C.9 e Tabela C.10 do Apêndice C, cujas medidas de desempenho são resumidos na Tabela 3.23. Os testes de significância estatística dos coeficientes indicam que a inserção dos atributos socioeconômicos não influencia no valor de caracterização da utilidade dos modos e, pelo contrário, torna outros atributos estimados nos modelos anteriores também não significativos estatisticamente.

Tabela 3.23 - Medidas de desempenho para estimativa dos parâmetros do Modelo E

\begin{tabular}{lrr}
\hline Motivo & $\boldsymbol{W}$ & $\boldsymbol{L}$ \\
Coeficientes estimados & 27 & 27 \\
Observações & 1714 & 1744 \\
$l(0)$ & $-2043,927$ & $-1965,484$ \\
$l(\theta)$ & $-1866,843$ & $-1845,596$ \\
$\rho^{2}$ & 0,087 & 0,061 \\
$\bar{\rho}^{2}$ & 0,073 & 0,047 \\
\hline
\end{tabular}

Apesar da obtenção de valores melhores das estatísticas de verossimilhança maximizada $(l(\theta))$ e de $\rho^{2}$ e $\bar{\rho}^{2}$ em relação aos modelos anteriores - para os motivos de viagem $W$ e $L-$ este Modelo E não necessariamente é melhor que o Modelo D (considerado até o momento o mais adequado para representação das escolhas modais).

Isso decorre do fato de que vários coeficientes estimados não são estatisticamente significativos e a melhora percentual das medidas de desempenho não necessariamente justifica o aumento do número de variáveis a serem consideradas nos modelos.

\subsubsection{Modelo F}

Conforme descrito em (3.38) na página 159, Fowkes e Wardman (1988) propõem uma alternativa para representação da utilidade pela inserção de variáveis socioeconômicas dos usuários. O conjunto de funções aplicados à pesquisa de preferência declarada são representados em (3.46) onde os coeficientes são generalizados, inclusive para os atributos socioeconômicos. 


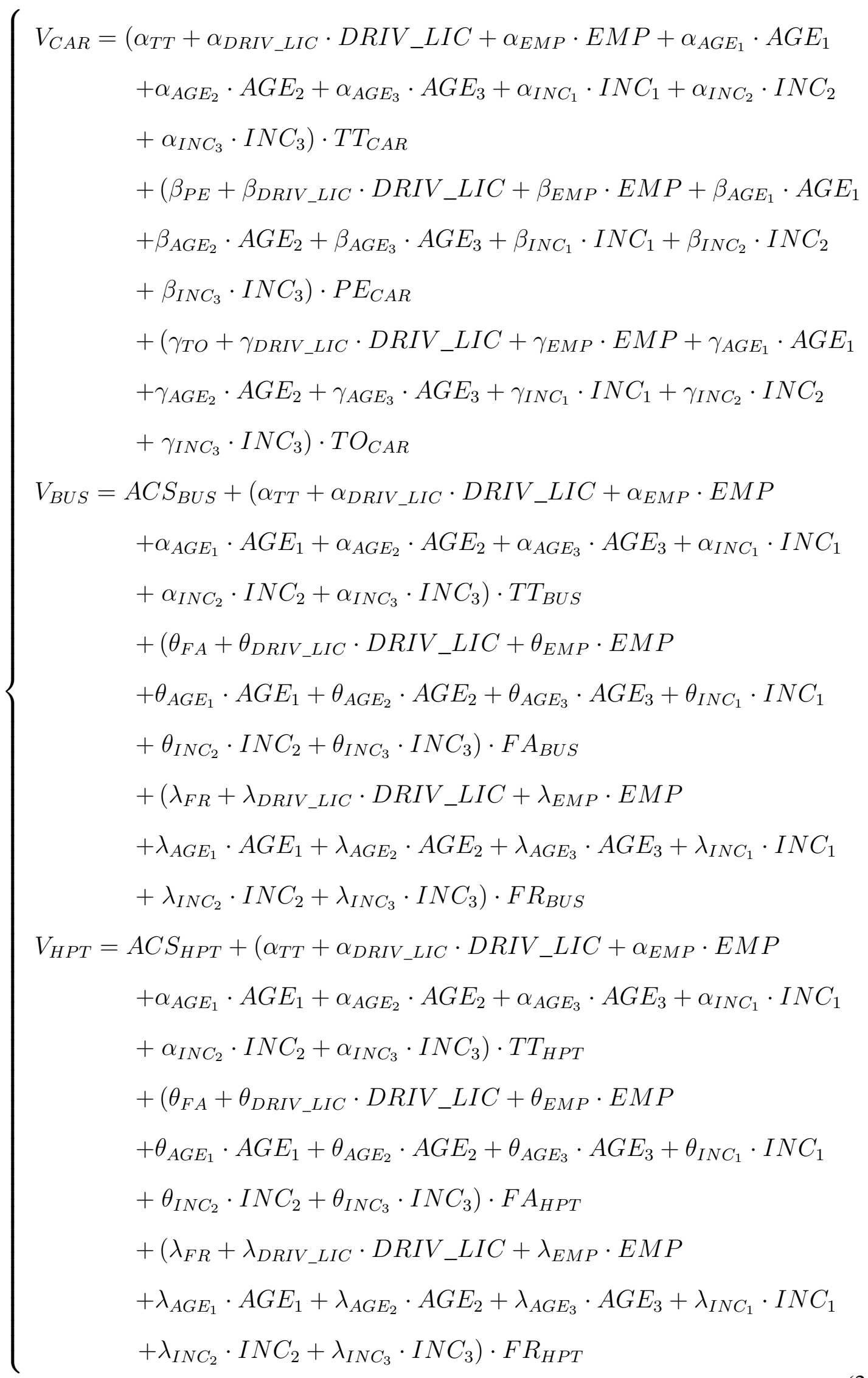




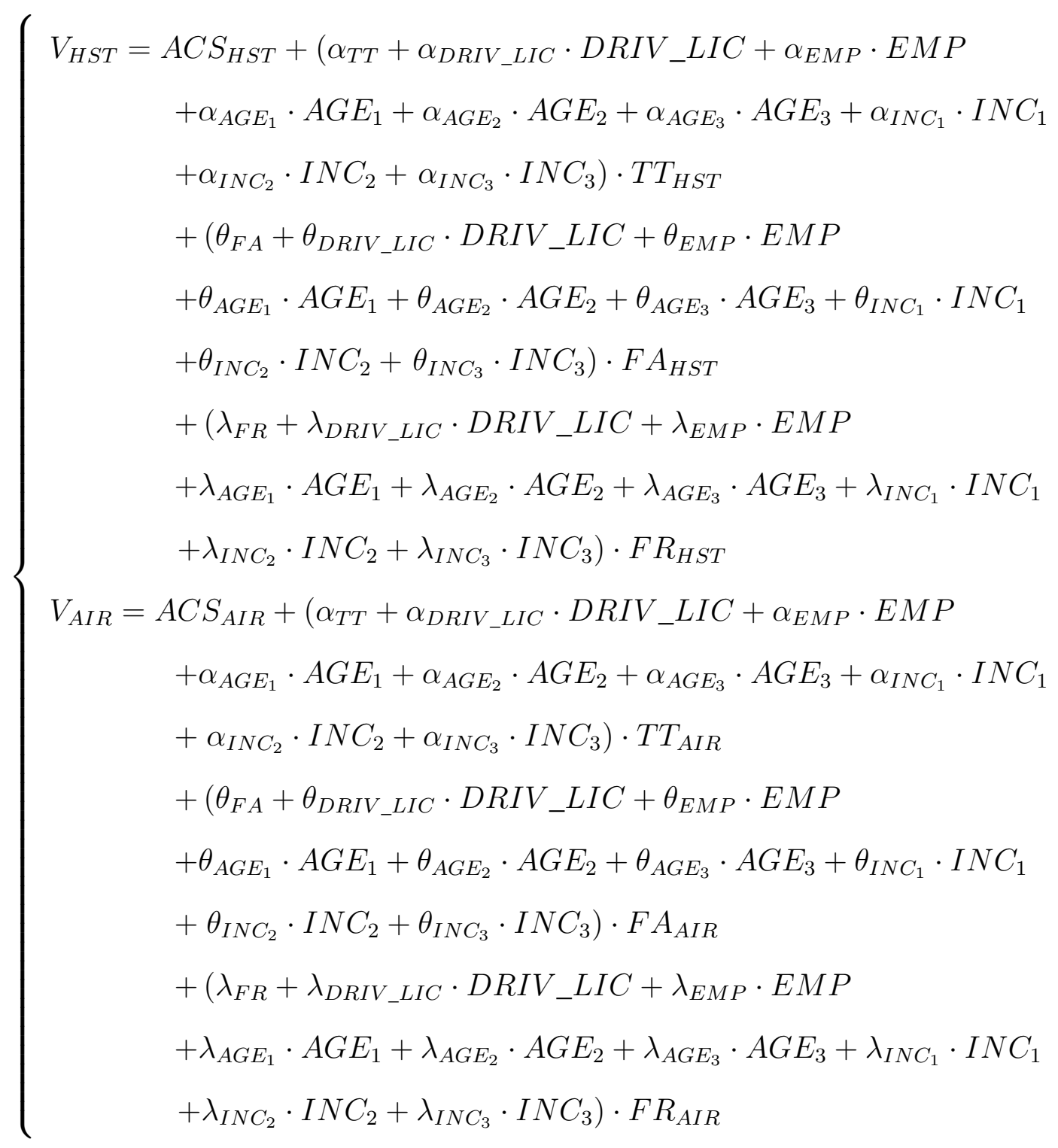

Os coeficientes estimados segundo esse padrão de definição das funções utilidade são descritos na Tabela C.11 e na Tabela C.12 do Apêndice C, com o resumo das medidas de desempenho apresentado na Tabela 3.24. Novamente, as significâncias estatísticas dos parâmetros socioeconômicos são menores do que $95 \%$ e, também, interferem nos resultados de significância de coeficientes que outrora eram representativos na estimativa numérica da utilidade dos modos.

Novamente, tem-se uma melhora dos valores das medidas de desempenho para ambos os motivos de viagem, em relação aos modelos sem inclusão de variáveis socioeconômicas (Modelo A ao Modelo D) e àquele que considera essas variáveis sob a forma aditiva (Modelo E). Entretanto, a modelagem alternativa das utilidades e melhora percentual das estatísticas de verossimilhança, $\rho^{2}$ e $\bar{\rho}^{2}$ eventualmente não justifica o aumento do número de variáveis do modelo, agravado pelo 
fato de que muitos dos parâmetros estimados não são significativos estatisticamente conforme indicado nas tabelas do Apêndice C.

Tabela 3.24 - Medidas de desempenho para estimativa dos parâmetros do Modelo F

\begin{tabular}{lrr}
\hline Motivo & $\boldsymbol{W}$ & $\boldsymbol{L}$ \\
Coeficientes estimados & 49 & 49 \\
Observações & 1714 & 1744 \\
$l(0)$ & $-2043,927$ & $-1965,484$ \\
$l(\theta)$ & $-1841,428$ & $-1834,984$ \\
$\rho^{2}$ & 0,099 & 0,066 \\
$\bar{\rho}^{2}$ & 0,075 & 0,041 \\
\hline
\end{tabular}

\subsubsection{Considerações sobre a Modelagem de Escolha Modal}

Primeiramente, os gráficos da Figura 3.32 representam os valores de verossimilhança calculados no procedimento de calibração dos coeficientes dos modelos descritos nas subseções anteriores. Observa-se que tanto para as viagens por motivo trabalho quanto para lazer, o Modelo E e o Modelo F que contêm as variáveis socioeconômicas da pesquisa de preferência declarada apresentam melhor desempenho quanto a essa medida de desempenho.

Ainda, é possível afirmar que a generalização dos parâmetros dos atributos das funções utilidade (do Modelo A para o Modelo B) incorrem em redução da verossimilhança calculada e que a eliminação de alguns atributos entre o Modelo B e o Modelo D também têm o mesmo efeito.

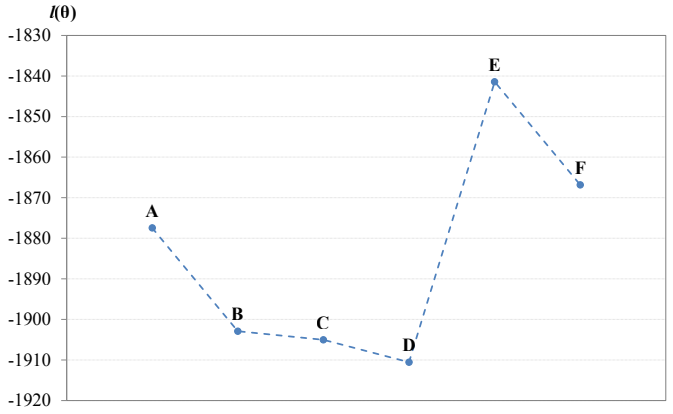

(a) Motivo Trabalho $(W)$

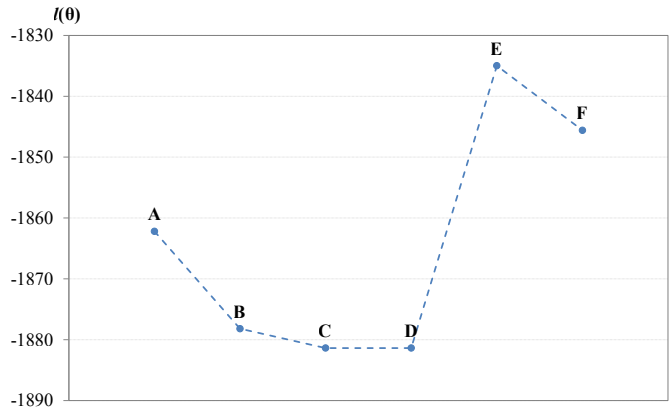

(b) Motivo Lazer $(L)$

Figura 3.32 - Gráfico da verossimilhança dos modelos estimados para o motivo trabalho $(a)$ e lazer $(b)$

Entretanto, as alterações percentuais de verossimilhança entre modelos apresentadas na Tabela 3.25 e a Tabela 3.26 indicam que a maior variação positiva desse valor ocorre entre o Modelo D e o Modelo E, igual a 3,62\% para as viagens a trabalho e 2,47\% para as de motivo 
lazer. Apesar do aumento, as pequenas variações percentuais de verossimilhança não justificam a inclusão das variáveis socioeconômicas do ponto de vista de aplicação prática dos modelos, inclusive para as análises socioeconômicas desta tese.

Tabela 3.25 - Diferenças percentuais de verossimilhanças entre modelos pelo motivo $W$

\begin{tabular}{cccccc}
\hline Modelo Anterior/Modelo Posterior & B & C & D & E & F \\
\hline A & $-1,36 \%$ & $-1,47 \%$ & $-1,76 \%$ & $1,92 \%$ & $0,57 \%$ \\
B & - & $-0,11 \%$ & $-0,40 \%$ & $3,23 \%$ & $1,90 \%$ \\
C & - & - & $-0,29 \%$ & $3,34 \%$ & $2,00 \%$ \\
D & - & - & - & $3,62 \%$ & $2,29 \%$ \\
E & - & - & - & - & $-1,38 \%$ \\
\hline
\end{tabular}

Tabela 3.26 - Diferenças percentuais de verossimilhanças entre modelos pelo motivo $L$

\begin{tabular}{cccccc}
\hline Modelo Anterior/Modelo Posterior & B & C & D & E & F \\
\hline A & $-0,86 \%$ & $-1,03 \%$ & $-1,03 \%$ & $1,46 \%$ & $0,89 \%$ \\
B & - & $-0,17 \%$ & $-0,17 \%$ & $2,30 \%$ & $1,74 \%$ \\
C & - & - & $0,00 \%$ & $2,47 \%$ & $1,90 \%$ \\
D & - & - & - & $2,47 \%$ & $1,90 \%$ \\
E & - & - & - & - & $-0,58 \%$ \\
\hline
\end{tabular}

Portanto, nas análises posteriores propostas nesta pesquisa, considerar-se-á o Modelo D como representativo das escolhas modais na oferta de serviços ferroviários de transporte de passageiros na Região Sudeste do Brasil. Nesse modelo, para o motivo de viagem trabalho $(W)$ observa-se que a estimação das funções utilidade resultaram em coeficientes iguais para os modos ferroviário (HPT e $H S T)$ e aéreo $(A I R)$.

O mesmo valor dos coeficientes entre modos de transporte indica que os usuários têm a mesma percepção da viagem em relação aos Trens - seja qual for a tecnologia - e Avião. Entretanto, os valores numéricos finais da utilidade para cálculo das respectivas probabilidade de escolha não são idênticos, dado que os níveis dos atributos são distintos em relação a cada modo de transporte.

Por outro lado, para o motivo de viagem lazer $(L)$ no Modelo D, os coeficientes das funções que caracterizam o modo ferroviário (HPT ou HST) são iguais, ao passo que os termos constantes das equações para aquele modo de transporte são maiores que o aéreo.

Quanto às estatísticas $\rho^{2}$ e $\bar{\rho}^{2}$, a Tabela 3.27 mostra que, apesar do aumento dos valores estimados para os modelos que contemplam os atributos socioeconômicos dos usuários, os 
resultados não apresentam variações significativas que justifiquem a adoção de um daqueles modelos em detrimento do Modelo D.

Tabela 3.27 - Resumo das estatísticas $\rho^{2}$ e $\bar{\rho}^{2}$ da calibração dos modelos de escolha modal

\begin{tabular}{cccccccc}
\hline \multirow{2}{*}{ Estatística } & \multirow{2}{*}{ Motivo } & \multicolumn{7}{c}{ Modelo } \\
\cline { 3 - 8 } & & $\mathbf{A}$ & $\mathbf{B}$ & $\mathbf{C}$ & $\mathbf{D}$ & $\mathbf{E}$ & $\mathbf{F}$ \\
\hline \multirow{2}{*}{$\rho^{2}$} & $\boldsymbol{W}$ & 0,081 & 0,069 & 0,068 & 0,065 & 0,087 & 0,099 \\
& $\boldsymbol{L}$ & 0,053 & 0,044 & 0,043 & 0,043 & 0,061 & 0,066 \\
\hline \multirow{2}{*}{$\bar{\rho}^{2}$} & $\boldsymbol{W}$ & 0,072 & 0,065 & 0,065 & 0,063 & 0,073 & 0,075 \\
& $\boldsymbol{L}$ & 0,043 & 0,040 & 0,040 & 0,040 & 0,047 & 0,041 \\
\hline
\end{tabular}

Conforme explicado anteriormente, uma amostra de $75 \%$ das respostas da pesquisa de preferência declarada foi utilizada para calibração dos coeficientes das funções utilidade. A amostra complementar foi utilizada para avaliação do desempenho dos modelos segundo os acertos das escolhas previstas em relação às respostas dos participantes.

Assim, a partir da obtenção das probabilidades de escolhas modais e identificação daquelas que apresentam maiores valores - e que correspondem ao modo de transporte escolhido pelos respectivos modelos - os desvios percentuais dos acertos em relação às respostas efetivamente apresentadas pelos participantes da pesquisa são apresentados nos gráficos da Figura 3.33 para o motivo trabalho $(W)$ e na Figura 3.34 para o motivo lazer ou outros $(L)$.

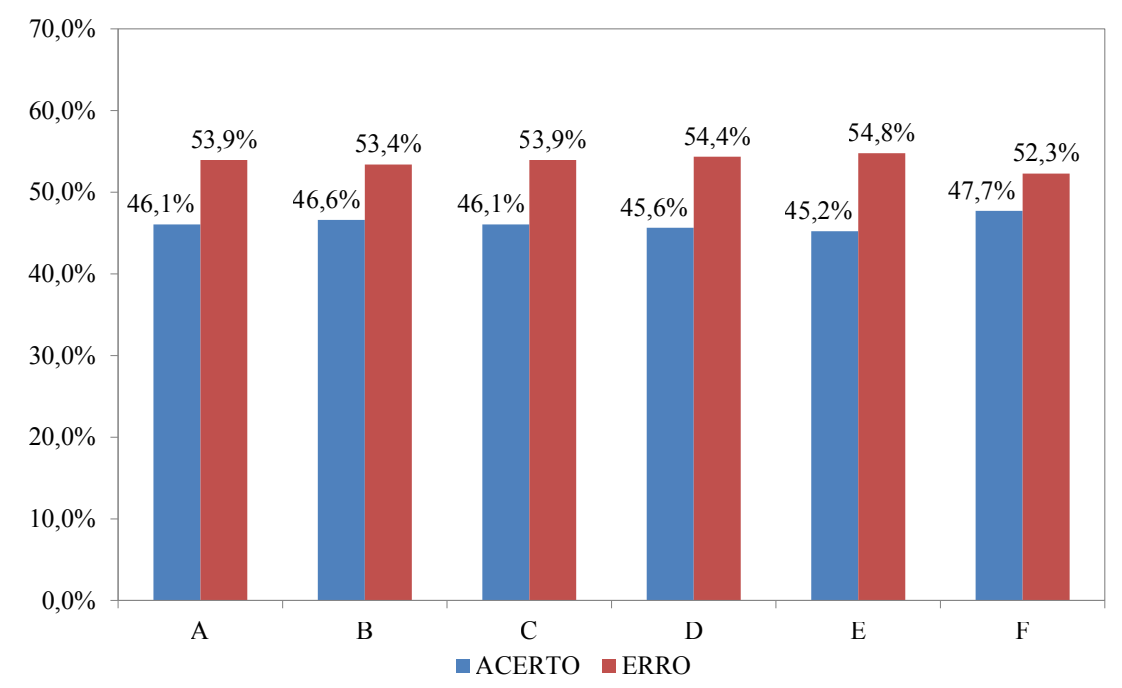

Figura 3.33 - Gráfico de acertos dos modelos estimados em relação às respostas da pesquisa para o motivo trabalho $W$ 


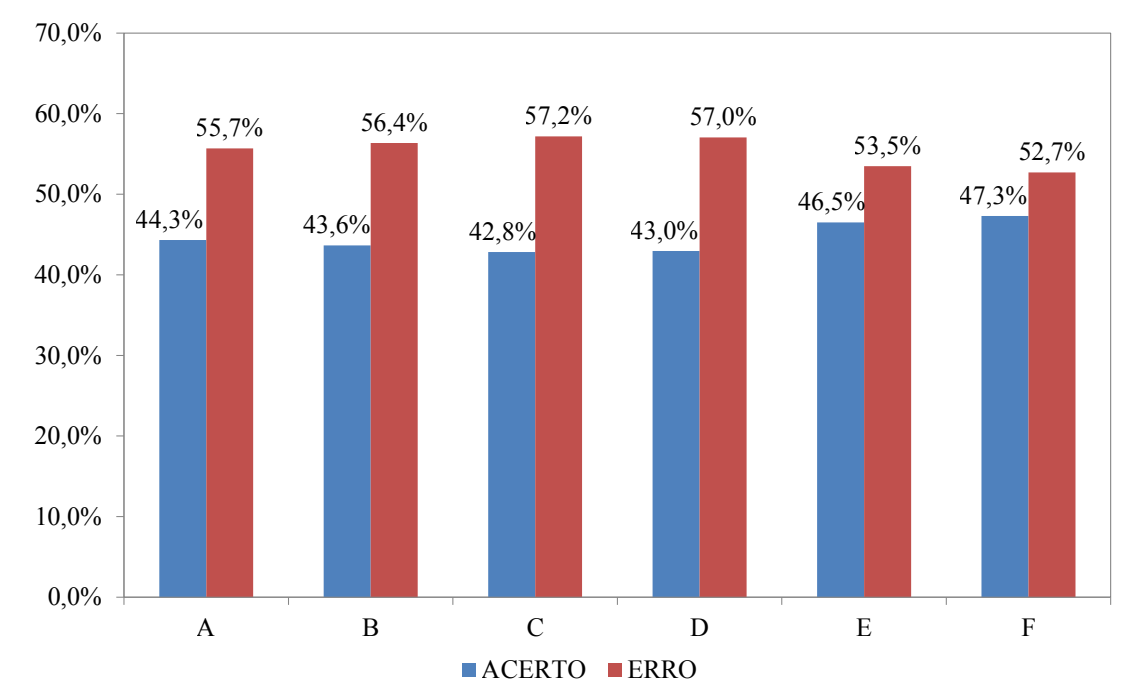

Figura 3.34 - Gráfico de acertos dos modelos estimados em relação às respostas da pesquisa para o motivo lazer $L$

Os resultados representados na Figura 3.33 e Figura 3.34 indicam que nenhum dos modelos propostos consegue superar o número de acertos em relação aos erros (i.e. os modelos apresentam índice de acerto sempre inferior a 50\%), apesar do esforço em identificar aquele mais adequado à representação dos dados coletados.

Ademais, apesar de o modelo F (que contempla as variáveis socioeconômicas mediante a formulação proposta por FOWKES; WARDMAN, 1988) apresentar a maior porcentagem de acertos para ambos os motivos de viagem, o Modelo D apresenta $0,4 \%$ acertos superior ao Modelo E e apenas 2,1\% em relação ao Modelo E para o motivo de viagem trabalho. Em relação ao motivo de viagem lazer, essa tendência apresenta pequena alteração, porém sem diferenças representativas com aumento de 3,5\% dos acertos entre o Modelo D e o Modelo E e de 4,3\% entre aquele e o Modelo F.

As investigações propostas por Isler e Pitombo (2014) pela geração de árvores de decisão com os dados da pesquisa de preferência declarada indicam que, provavelmente, as variáveis socioeconômicas exercem pouca influência na escolha modal no formato da pesquisa proposta nesta tese. Naquele estudo, pode-se verificar pela Tabela 3.28 que os índices médios de acertos dos modelos de segregação em relação às respostas dos participantes foram de 46,0\% para a modelagem incluindo as variáveis socioeconômicas e 43,2\% sem considerá-las nas análises. 
Tabela 3.28 - Porcentagem de acertos das Árvores de Decisão na modelagem da pesquisa de preferência declarada - Fonte: Isler e Pitombo (2014)

\begin{tabular}{lrrr}
\hline CENÁRIO/MÉTODO & CHAID $^{1}$ & CART $^{1}$ & QUEST $^{1}$ \\
\hline $\boldsymbol{H P T} \operatorname{com} \boldsymbol{A I R}(\boldsymbol{L})$ & $44,4 / 39,0[-12,2 \%]$ & $37,7 / 37,7[0 \%]$ & $41,6 / 29,4[-29,3 \%]$ \\
$\boldsymbol{H P T} \operatorname{com} \boldsymbol{A I R}(\boldsymbol{W})$ & $35,2 / 35,2[0 \%]$ & $43,5 / 41,1[-5,5 \%]$ & $38,4 / 38,4[0 \%]$ \\
$\boldsymbol{H P T} \operatorname{sem} \boldsymbol{A I R}(\boldsymbol{L})$ & $47,6 / 43,8[-8 \%]$ & $56,8 / 47,5[-16,4 \%]$ & $44,3 / 44,3[0 \%]$ \\
$\boldsymbol{H P T} \operatorname{sem} \boldsymbol{A I R}(\boldsymbol{W})$ & $43,7 / 40,8[-6,6 \%]$ & $42,5 / 41,6[-2,1 \%]$ & $37,1 / 37,1[0 \%]$ \\
$\boldsymbol{H S T} \boldsymbol{c o m} \boldsymbol{A I R}(\boldsymbol{L})$ & $35,3 / 45,1[27,8 \%]$ & $43,5 / 43,5[0 \%]$ & $44,7 / 44,7[0 \%]$ \\
$\boldsymbol{H S T} \boldsymbol{\operatorname { c o m }} \boldsymbol{A I R}(\boldsymbol{W})$ & $33,8 / 36,7[8,6 \%]$ & $42,0 / 38,1[-9,3 \%]$ & $36,3 / 32,6[-10,2 \%]$ \\
$\boldsymbol{H S T} \operatorname{sem} \boldsymbol{A I R}(\boldsymbol{L})$ & $53,2 / 55,5[4,3 \%]$ & $59,4 / 53,6[-9,8 \%]$ & $51,1 / 51,1[0 \%]$ \\
$\boldsymbol{H S T} \boldsymbol{s e m} \boldsymbol{A I R}(\boldsymbol{W})$ & $42,6 / 43,6[2,3 \%]$ & $42,6 / 42,6[0 \%]$ & $47,1 / 47,1[0 \%]$ \\
MÉDIA & $42,0 / 42,5[1,2 \%]$ & $46,0 / 43,2[-6,1 \%]$ & $42,6 / 40,6[-4,7 \%]$ \\
\hline
\end{tabular}

${ }^{1}$ Com variáveis socioeconômicas $(\%) /$ Sem variáveis socioeconômicas $(\%)$ [Diferença percentual $=(\%$ acertos sem variáveis socioeconômicas - \% acertos com variáveis socioeconômicas)/(\% acertos com variáveis socioeconômicas)].

Portanto, existem indícios significativos de que as variáveis socioeconômicas não exercem influência na caracterização da escolha modal, pois as maioria das árvores geradas não incluem tais variáveis, como demonstrado naquele artigo.

Os resultados a respeito das estatísticas $\rho^{2}$ e $\bar{\rho}^{2}-$ aquém do valor $\rho^{2}=0,4$ recomendado por Ortúzar e Willumsen (2011) - e o índice de acertos dos modelos corroboram a afirmação daqueles autores que a inclusão de variáveis socioeconômicas nos modelos de utilidade não necessariamente melhoram o seu desempenho de maneira expressiva no formato em que pesquisa de preferência foi executado, o que não implica que esses atributos nunca influenciam a escolha modal de uma viagem.

Diante das análises e argumentos apresentados, e para efeito de aplicação nesta tese, optou-se pelo Modelo D para representação da escolha modal dos usuários mediante novos serviços de transporte ferroviário para ambos os motivos de viagem investigados, dado o seu desempenho tão satisfatório quanto os demais modelos. 


\section{Capítulo \\ Análise Socioeconômica de Projetos Ferroviários}

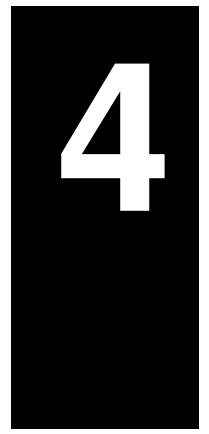

Os objetivos da análise socioeconômica de uma nova infraestrutura de transporte são quantificar os seus efeitos sociais e econômicos atuais e futuros, estimar o bem estar social proporcionado pela sua implementação e definir a alocação de recursos para esse fim da melhor maneira possível (DREYER, 2010). Atualmente, a Análise Multi-Critério (Multi-criteria Analysis - MCA) e a Análise Custo-Benefício ( $C B A)$ são os métodos mais utilizados para atingir esses objetivos (THOMOPOULOS; GRANT-MULLER; TIGHT, 2009; HAYASHI; MORISUGI, 2000).

De acordo com Florio et al. (2004), a $M C A$ consiste em uma sequência de escolhas para selecionar a alternativa mais adequada entre um conjunto de soluções disponíveis com base em um lista de critérios e seus respectivos pesos (ou importâncias). Esse método é uma ferramenta que permite a análise de diferentes propriedades qualitativas e quantitativas simultaneamente, as quais não precisam ser mensuradas em uma mesma unidade representativa.

A $M C A$ também permite que os planejadores identifiquem as interferências e o equilíbrio entre diferentes objetivos a serem atingidos pelo projeto (e.g. a mitigação de externalidades, o aumento da eficiência de uma medida de desempenho) de modo a racionalizar o processo decisório e permitir a sistematização da escolha entre alternativas (BERECHMAN, 2010).

Apesar de existirem diferentes definições das etapas de uma MCA (TSAMBOULAS, 2007; BERECHMAN, 2010; THOMOPOULOS; GRANT-MULLER; TIGHT, 2009; MUNASINGHE, 2007; STEVENS, 2004; GAMPER; TURCANU, 2007), os itens comuns ao método são a identificação dos critérios e preferências, avaliação desses critérios e definição dos respectivos pesos, atribuição de valores às alternativas de projetos, priorização das alternativas com base nesses valores e 
pesos, e, finalmente, análise de sensibilidade considerando os objetivos do investimento.

Em contrapartida a esse método, a $C B A$ é uma abordagem quantitativa para o problema de escolha de investimentos e tem sido extensivamente explorada na literatura (e.g. YEH et al., 1999; BOARDMAN, 2010; TUDELA; AKIKI; CISTERNAS, 2006; BERECHMAN, 2010), sendo definida por Dreyer (2010) como um método que visa quantificar os custos e benefícios econômicos e sociais de investimentos em termos monetários, e compará-los com o objetivo de identificação daquele que provê maiores benefícios totais à sociedade e ao investidor.

Nesta tese a $C B A$ é priorizada em detrimento da $M C A$ por ser considerada uma abordagem mais simples e suficiente no contexto desta pesquisa para uma primeira quantificação da atratividade de serviços ferroviários para o transporte de passageiros na Região Sudeste sob a perspectiva social e econômica.

\subsection{Análise Custo-Benefício de Projetos de Transporte Ferroviário}

Dreyer (2010) apresenta uma extensa revisão da literatura a respeito das práticas relativas à análise de novos projetos de trens de alta velocidade para o transporte de passageiros na Europa, além de uma comparação detalhada dos métodos de $C B A$ e $M C A$ no qual argumenta que o primeiro método é utilizado mais amplamente no âmbito do continente europeu.

As condições favoráveis à implantação de linhas ferroviárias de alta velocidade são os mercados com elevado índice de crescimento econômico e em corredores de transporte congestionados, tal que o crescimento expressivo de novas linhas de HST no mundo (Figura 4.1) deve-se aos benefícios desse modo de transporte como confiabilidade, conforto, segurança e redução de impactos ambientais (AMOS; BULLOCK; SONDHI, 2010).

A China é um exemplo característico desse cenário, cujos investimentos na criação de uma rede ferroviária permitirão o aumento da acessibilidade em regiões remotas do país e, portanto, de sua competitividade econômica. Entretanto, no caso específico chinês, existem indícios de que a política de construção acelerada desse sistema vem aumentando o déficit financeiro do 
país (RONG; WU, 2013).

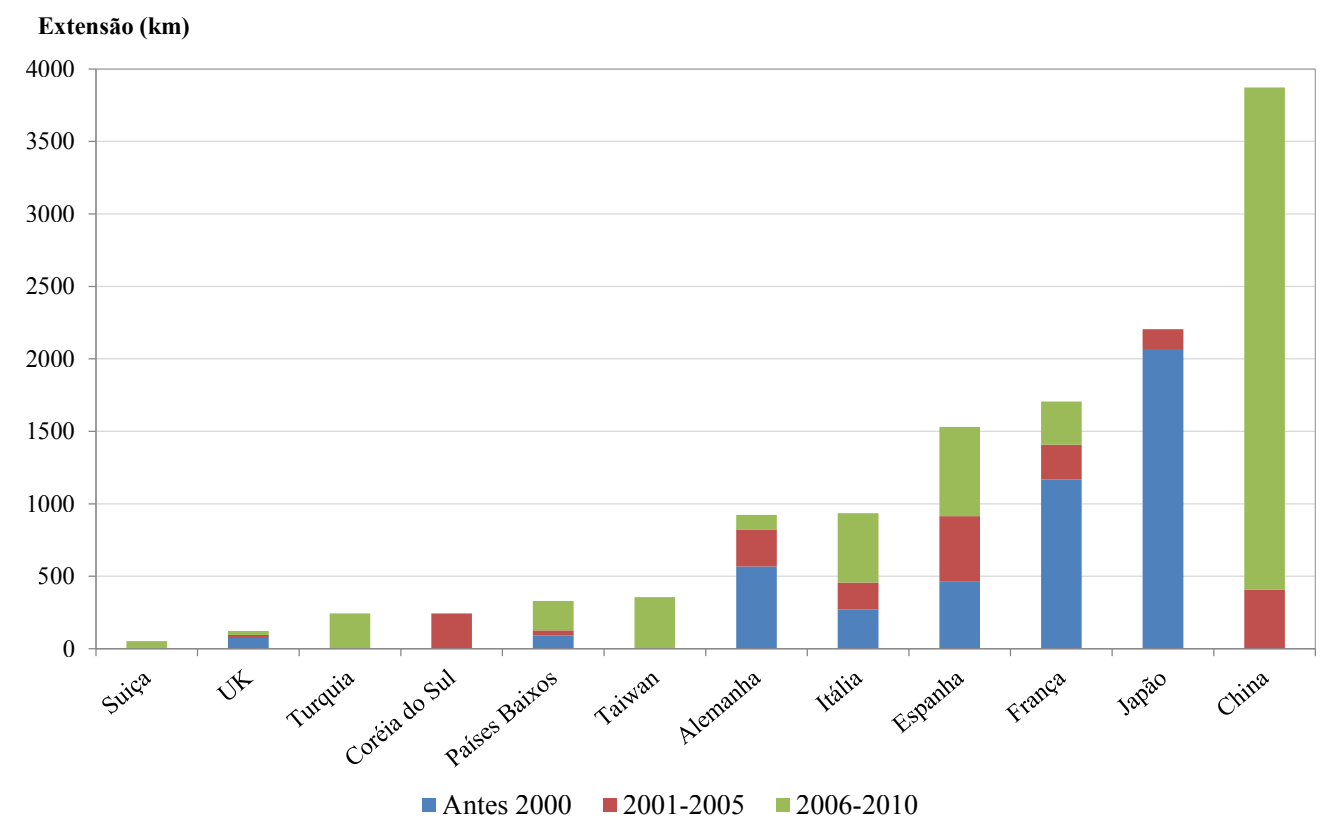

Figura 4.1 - Extensão dos sistemas ferroviários que operam trens com velocidade maior que 200 km/h no mundo - Fonte: Amos, Bullock e Sondhi (2010)

Gleave (2004) provê uma descrição das linhas de Trens de Alta Velocidade existentes e métodos de avaliação socioeconômica no Reino Unido, França, Alemanha, Itália, Japão e Austrália. O relatório contém um panorama dos potenciais mercados a serem atendidos nesses países, as estimativas de investimentos requeridos para implantação dos projetos e um conjuntos de recomendações para a prática de análises dessa natureza.

De Rus e Nombela (2007) e De Rus (2008) apresentam comparações dos benefícios sociais de novas linhas de trens de alta velocidade em relação ao excedente dos usuários e operadores, e quanto aos investimentos na sua construção e operação. As investigações concluem que, apesar de mostrarem-se eficientes do ponto de vista de redução dos tempos de viagem e dos impactos ambientais em relação aos demais modos, o sucesso de projetos de HSTs dependem da capacidade de geração de benefícios econômicos para pagamento dos investimentos.

Esses autores indicam que uma demanda entre oito e 10 milhões de viagens no primeiro ano de operação do sistema é necessária para viabilizar a operação de um HST com extensão de $500 \mathrm{~km}$ na Europa a uma taxa mínima de atratividade de 5\% ao ano. Ainda, o envolvimento da inciativa privada na execução e operação é apontada como fator de minimização dos riscos de 
perdas dos benefícios econômicos ao longo do tempo, uma vez que essa conjuntura proporciona maior competitividade dos serviços.

De Rus et al. (2009) apresentam uma análise detalhada dos investimentos em linhas de trens de alta velocidade do ponto de vista social e econômico sob a forma de um compêndio de diversos estudos com diferentes enfoques. Um dos artigos descreve um exercício numérico de estimativa preliminar dos custos e benefícios da implantação de uma nova linha de $H S T$.

Ao apresentar uma revisão da literatura sobre os métodos de $C B A$ e $M C A$, Dreyer (2010) compara estudos sobre o tema realizados na Europa, incluindo a Noruega, Suécia, Alemanha, Reino Unido e Espanha. Uma das dificuldades dessas comparações, segundo os autores, decorre das diferentes estratégias de atribuição de valor aos itens da avaliação socioeconômica. As principais discrepâncias que caracterizam os métodos de análise são: a estrutura das instituições do sistema ferroviário nos países; o objetivo principal dos serviços (por exemplo, minimizar as restrições de capacidade ou reduzir as emissões de poluentes); a qualidade das linhas ferroviárias existentes; a densidade populacional; e as características topográficas dos países.

\subsection{Formulação para Análise Custo-Benefício}

\section{de Projetos Ferroviários}

Existem diversos manuais que formalizam os itens mais relevantes necessários à análise de viabilidade de projetos do ponto de vista socioeconômico. O Transport Infrastrucutre Needs Assessment - TINA (MACKIE et al., 1999) é um conjunto de instruções publicados pela Comissão Europeia para avaliação econômica e social de projetos de infraestrutura de transporte no continente. O documento concentra-se na descrição dos principais aspectos de uma análise econômica no âmbito social e suas implicações financeiras, bem como dos itens mais relevantes como os investimentos, despesas operacionais, estimativa de receitas, benefícios aos usuários e as medidas de desempenho consideradas na avaliação do projeto.

O Guide to Cost Benefit Analysis of Investment Projects (FLORIO et al., 2004) é um compêndio de exemplos numéricos baseados nas recomendações do TINA (MACKIE et al., 1999) para a CBA de projetos de infraestrutura de transporte com ênfase na estimativa das externalidades. 
No caso específico de investimentos em infraestrutura de transporte ferroviário, o Railway Project Appraisal Guidelines - RAILPAG (TURRÓ; INVERSIONES, 2005) também provê exemplos numéricos sob as recomendações de Mackie et al. (1999), considerando diferentes cenários de construção e operação de novas linhas e recuperação das existentes.

No Brasil não existem evidências de um método oficial para análise socioeconômica de novos projetos de infraestrutura de transportes, de modo que a maioria é avaliada sob premissas específicas e não padronizadas. Moreira (2000) compara os resultados de uma $C B A$ em relação à aplicação de um método de análise hierárquica ao cenário de avaliação das alternativas de rede para o transporte coletivo da cidade de Porto Alegre.

Neste capítulo é apresentada uma formulação explícita para Análise Custo-Benefício de projetos para o transporte ferroviário de passageiros no Brasil sob influência de dois principais manuais internacionais, o Toolkit for the Economic Evaluation of World Bank Transport Projects (MACKIE et al., 2003) e o Transport Analysis Guidance - WebTAG (DFT, 2014).

\subsubsection{Recomendações do Banco Mundial}

Nas economias emergentes (por exemplo China, Índia, Brasil, Rússia e África do Sul) existem diretrizes específicas para análise de projetos candidatos a financiamento pelo Banco Mundial (MACKIE et al., 2003), com abordagem para estimativa dos itens de uma $C B A$ com base nas premissas de Mackie et al. (1999) à semelhança de Florio et al. (2004) para os projetos europeus.

Segundo o Banco Mundial (MACKIE et al., 2003), uma CBA deve representar os impactos econômicos para os usuários, investidores e operadores, e os benefícios de um projeto devem contemplar o seus efeitos sobre os níveis de emprego e preços dos bens de consumo. Entretanto, na prática, os requisitos para cômputo de todos os itens que influenciam as análises podem representar um impedimento para sua execução, de modo que hipóteses simplificadoras devem ser admitidas no processo.

De acordo com as recomendações desse órgão, os seguintes elementos devem ser estabelecidos em uma $C B A$ : definição do escopo da avaliação socioeconômica (modo de transporte, área de estudo etc.) e de parâmetros como vida útil do projeto, taxa de desconto e unidade de 
contabilização; cálculo dos benefícios aos usuários; valoração monetária do tempo; tratamento dos impactos ambientais e acidentes; e caracterização de medidas de desempenho. Esses itens estão relacionados na Figura 4.2 e são detalhados nas seções subsequentes deste capítulo.

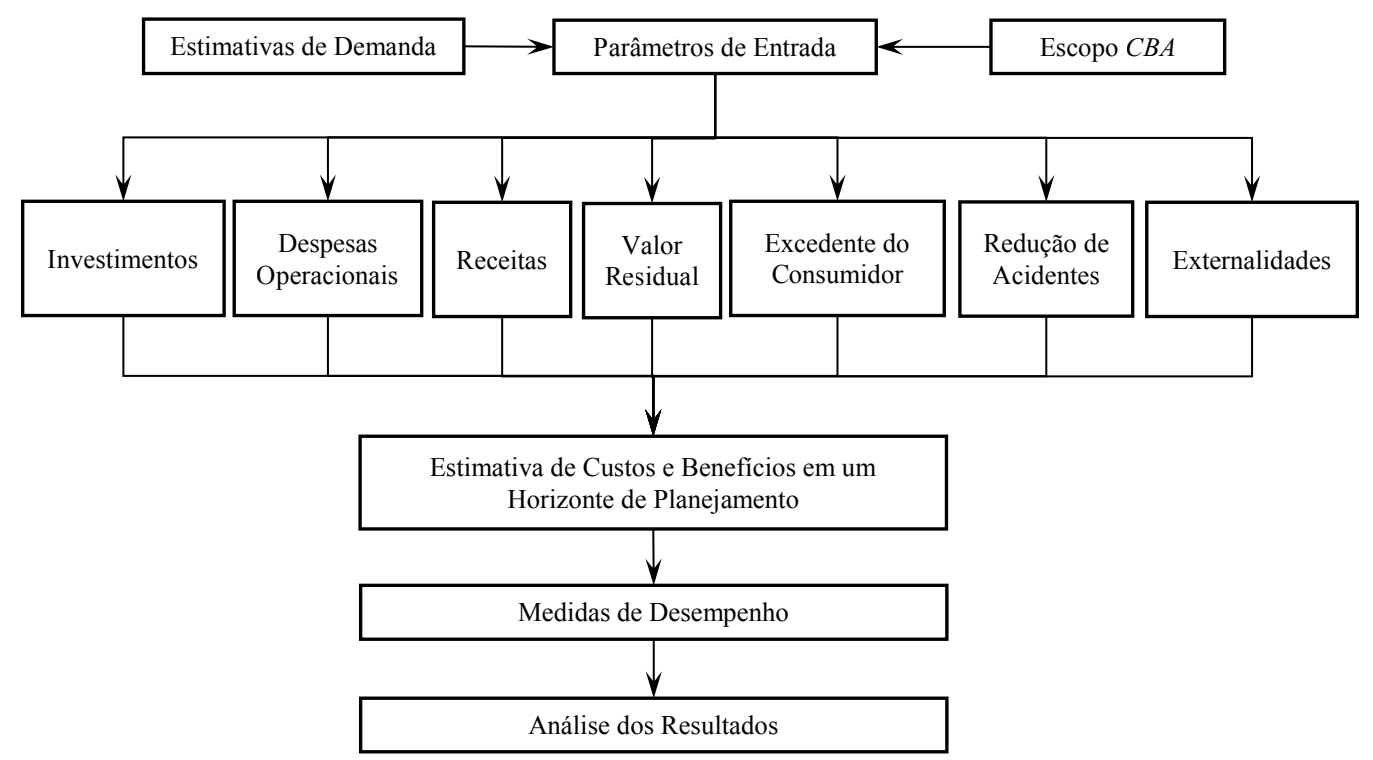

Figura 4.2 - Relação entre os elementos de uma Análise Custo-Benefício - Fonte: adaptado de Mackie et al. (2003)

Os principais parâmetros de entrada da Análise Custo-Benefício para um projeto de transporte segundo o Banco Mundial são as matrizes de custos e tempos de percurso entre pares de origens e destinos, além das estimativas dos valores monetários requeridos à implantação do projeto e da potencial demanda de utilização do sistema.

Do ponto de vista de análise temporal da avaliação socioeconômica, é necessário estabelecer o ano de início da execução projeto, o ano de início da operação e o período de apreciação econômica (ciclo de vida útil). Ademais, é importante definir o ano base para o qual os custos e benefícios do projeto são descontados para cálculo das medidas de desempenho. Nesse contexto considera-se a substituição dos ativos adquiridos ao longo do horizonte de planejamento e os respectivos valores residuais ao final da vida útil.

Para cálculo do desconto dos custos e benefícios do projeto no ano base utiliza-se uma "Taxa de Desconto"que reflete o custo de oportunidade do capital investido no projeto em detrimento da sua aplicação para outros propósitos. 


\subsubsection{Recomendações do WebTAG}

O Reino Unido, sob representação do Department for Transport - DfT, possui uma documentação específica para avaliação socioeconômica de projetos de infraestrutura de transporte através de um conjunto de documentos sob a denominação de WebTAG (DFT, 2014).

O WebTAG é dividido em três partes principais: Overview, Guidance for the Project Manager e Guidance for the Expert. A última parte contém uma extensa documentação sobre os objetivos de uma análise socioeconômica e alternativas de modelagem - por exemplo, quanto à estimativa de demanda - para projetos rodoviários, ferroviários, cicloviários etc.

Especificamente em relação a projetos ferroviários, a seção TAG Unit 3.13: Guidance on Rail Appraisal contém dois módulos. O primeiro (Module 3.13.1: Guidance on Rail Appraisal) apresenta os princípios para avaliação econômica de projetos dessa natureza (unidade de contabilização, impactos à sociedade, premissas de financiamento etc.) e o segundo contém as abordagens para modelagem de diferentes itens como demanda e avaliação das externalidades.

Baseados nas recomendações do WebTAG, Worsley (2011) apresenta uma análise socioeconômica do London CrossRail Scheme - um novo projeto ferroviário para conexão dos extremos leste e oeste da cidade de Londres com o intuito de reduzir os tempos de viagem - e provê reflexões acerca dos métodos de avaliação socioeconômica propostas pelo $D f T$.

Em relação aos parâmetros da análise socioeconômica, o WebTAG contém recomendações equivalentes ao Banco Mundial, porém com especificações mais detalhadas. Do ponto de vista dos parâmetros de entrada dos modelos, as avaliações devem incluir: os valores de tempos de viagem dos modos de transporte existentes e daqueles em análise; as despesas operacionais dos veículos; as tarifas cobradas dos usuários; os impactos econômicos nos provedores dos serviços; as alterações da quantidade de acidentes; e os impactos ambientais dos projetos.

Além dos períodos de contabilização da $C B A$ discriminados pelo Banco Mundial, o WebTAG também considera a separação dos projetos naqueles com vida útil finita ou infinita. No primeiro caso, o projeto é considerado operante até o limite da vida útil de seus ativos, em geral estabelecido até o máximo de 60 anos no casos de projetos de transporte. Nessas condições a $C B A$ deve computar o valor residual dos ativos envolvidos e estimá-los com base em preços de 
revenda do material utilizado ou pelos valores de disposição (como sucata, por exemplo).

Por outro lado, nos projetos com vida útil infinita é esperado que sejam efetuados reparos e substituições dos equipamentos e instalações que permitam a sua utilização por um período de tempo indefinido, de modo que a avaliação socioeconômica pode ser executada para períodos maiores que 60 anos.

O DfT também considera a aplicação da taxa de desconto como uma forma de comparação dos custos e benefícios em um horizonte de planejamento, pela conversão desses itens econômicos em valores presentes no ano base de avaliação sem considerar os efeitos inflacionários.

\subsubsection{Parâmetros de Entrada}

Na aplicação do método de análise custo-benefício proposto nesta tese, os bens adquiridos na construção e operação da infraestrutura são calculados em termos monetários a preços de mercado da moeda corrente brasileira (Real - R\$). O ano base é considerado como o de aplicação da análise (2015), bem como o de início da construção da infraestrutura, sobre a qual incide uma taxa de produtividade da construção (km/ano).

Em relação à demanda, os valores assumidos para o fluxo de tráfego são aqueles resultantes dos modelos de distribuição e de projeção de viagens detalhados no Capítulo 3, bem como os modelos de divisão modal derivados da pesquisa de preferência declarada descrita nesta tese.

Uma vez que a taxa mínima de atratividade é reflexo das condições econômicas do país onde se pretende implantar uma nova infraestrutura de transporte, o valor utilizado nas análises apresentadas nesta tese é aquele indicado para as condições brasileiras segundo as recomendações do Banco Mundial, equivalente a 5,1\% (LOPEZ, 2008).

Quanto ao horizonte de avaliação socioeconômica, considera-se um período de 35 anos incluindo aquele necessário para construção da infraestrutura ferroviária para operação dos trens. Portanto, a $C B A$ apresentada restringe-se ao horizonte operacional até o ano de 2050, compatível com as projeções de demanda indicadas no Capítulo 3. 


\subsubsection{Custos}

\subsubsection{Investimentos em Infraestrutura}

Os valores monetários de investimentos são aqueles relacionados à construção de uma nova infraestrutura de transporte. Os investimentos na construção de túneis e instalação da via em áreas urbanas geralmente são os mais expressivos em relação ao valor total de um novo traçado (NASH, 2010) e também variam expressivamente em função da topografia do terreno nas áreas onde serão implantadas conforme relatado no Capítulo 2.

Os elevados investimentos no acesso dos trens às áreas urbanas podem ser mitigados pela utilização da infraestrutura ferroviária existente nessas regiões, o que incorre na redução dos investimentos totais dos projetos sob a penalidade de aumento dos tempos de acesso às cidades. No Brasil, sobretudo na Região Sudeste, é possível aproveitar-se dessa estratégia (conforme exemplificado na seção 2.3.2, página 68) uma vez que as principais cidades e regiões metropolitanas desenvolveram-se nos eixos ferroviários.

Apesar de a formulação de $C B A$ proposta por De Rus et al. (2009) considerar investimentos médios de construção de uma nova infraestrutura ferroviária para operação de trens de alta velocidade, as particularidades da configuração topográfica da Região Sudeste do Brasil justificam a aplicação do método de estimativa de investimentos baseado no $G A$ descrito no Capítulo 2.

Nesta tese apresenta-se a formulação de $C B A$ de um novo traçado ferroviário para operação de trens de passageiros tendo-se como principal referência a metodologia proposta por De Rus et al. (2009). Essa formulação é apresentada neste capítulo considerando-se uma nova conexão entre duas cidades genéricas, cujas equações podem se estendidas a uma rede ferroviária conforme descrito no Capítulo 5.

Inicialmente, considera-se $T_{0}$ o ano de início da operação dos trens após o término da construção da via, tal que:

$$
T_{0}=\frac{L_{R}}{\omega}
$$

onde $L_{R}=$ comprimento do alinhamento ferroviário entre estações; e $\omega=$ produtividade média da construção do alinhamento (km/ano). 
Apesar das possibilidades atuais de maior acurácia na estimativa dos investimentos de implantação dos novos traçados ferroviários, existem outras fontes de incertezas que podem afetar os valores finais dos projetos, representadas por uma constante de majoração denominada "Viés do Otimismo" (Optimism Bias).

Nesse contexto, Chevroulet e Reynaud (2011) avaliaram seis projetos de HST na Europa e concluíram que o aumento dos investimentos totais em infraestrutura são, em geral, motivados pelos atrasos no início da construção, alterações nas especificações do projeto, mudanças nos requisitos de proteção ambiental, alteração da quantidade e preços dos materiais, e subestimativa dos valores de desapropriações.

TRT (2008) apresenta valores dos investimentos estimados e efetivamente realizados em diferentes projetos de novas linhas ferroviárias de alta velocidade na Europa (Tabela 4.1), indicando que a maioria dos métodos apresentam resultados aquém dos valores efetivamente praticados.

Tabela 4.1 - Investimentos estimados e realizados para construção de novos alinhamentos ferroviários para Trens de Alta Velocidade em países europeus

\begin{tabular}{lccc}
\hline Projeto & $\begin{array}{c}\text { Estimado } \\
\text { (milhões Euros) }\end{array}$ & $\begin{array}{c}\text { Realizado } \\
\text { (milhões Euros) }\end{array}$ & $\begin{array}{c}\text { Subestimativa } \\
(\boldsymbol{\%})\end{array}$ \\
\hline ICE Frankfurt - Cologne & 2.784 & 6.015 & 116 \\
Eurotunnel & 2.702 & 4.568 & 69 \\
Oeresund Fixed Link & 1.795 & 2.924 & 63 \\
Paris - Lille TGV & 2.666 & 3.334 & 25 \\
Madrid - Seville & 3.263 & 4.029 & 23 \\
Lyon - Marseille TGV & 4.015 & 4.338 & 8 \\
\hline
\end{tabular}

Dessas considerações, o valor presente líquido dos investimentos totais para construção de um novo alinhamento ferroviário pode ser calculado conforme a Equação (4.2).

$$
I C^{C}=\sum_{t=0}^{T_{0}-1} \frac{(1+\varphi) \cdot(1+\rho) \cdot C C}{T_{0} \cdot(1+M A R R)^{t}}
$$

onde $I C^{C}=$ valor presente líquido dos investimentos para construção da infraestrutura ; $C C=$ estimativa do custo de construção do novo alinhamento ferroviário, resultante da aplicação do Algoritmo Genético descrito no Capítulo 2; $\varphi=$ fator de correção devido ao viés do otimismo; $\rho=$ custo de planejamento (porcentagem do investimento total); $M A R R=$ taxa mínima de atratividade . 


\subsubsection{Investimentos de aquisição de material rodante}

Anteriormente à estimativa dos investimentos em aquisição do material rodante para operação de uma conexão ferroviária é necessário estabelecer uma formulação para o cálculo da frota que atenda uma demanda específica em um horizonte operacional. Assumindo que um trem jamais operará em sua capacidade total, seja $\delta$ a ocupação média (em porcentagem) e $\bar{q}$ a sua capacidade total em número de assentos, então a sua ocupação efetiva $\left(\bar{q}_{e}\right)$ é dada por:

$$
\overline{q_{e}}=\delta \cdot \bar{q}
$$

Ainda, considera-se que a demanda diária total pelos serviços ferroviários no ano $t$ do horizonte de operação é calculada conforme a Equação (4.4).

$$
q_{t}=\frac{D^{t} \cdot(1+G T) \cdot\left(P_{R w}+P_{R l}\right)}{N D}
$$

onde $D^{t}=$ número total de viagens estimadas entre uma origem e um destino no ano $t$ (em ambos os sentidos); $P_{R w}=$ percentual de usuários que escolhem o modo trem para viagens por motivo de trabalho no ano $t$ após o início da operação do sistema mediante uma tarifa ferroviária preestabelecida; $P_{R l}=$ percentual de usuários que escolhem o modo trem para viagens por lazer ou outros motivos no ano $t ; G T=$ percentual de tráfego gerado pela operação dos novos serviços ferroviários; $N D=$ número de dias por ano de operação do sistema.

Considerando que a frota ferroviária é calculada para atender a demanda do horário de pico, tal que $\psi$ é a porcentagem da demanda diária total nesse período e $H$ é o intervalo de operação do sistema (e.g. de 16 horas entre 6 horas e 22 horas), a frequência mínima para os serviços em cada direção no ano $t$ é dada por:

$$
F_{t}=\frac{\psi \cdot\left(q_{t} / \bar{q}_{e}\right)}{H}=\frac{\psi \cdot q_{t}}{\bar{q}_{e} \cdot H}
$$

Ainda, seja $\tau$ a duração da viagem redonda entre as cidades de origem e destino (i.e. tempo sair da cidade de origem, chegar ao destino e retornar àquela localidade incluindo as paradas nas estações). Então, a quantidade mínima de trens diários necessários para operar o serviço de transporte de passageiros é dada pela Equação 4.6. 


$$
M R S^{t}=\frac{\tau}{1 / F_{t}}=\tau \cdot \frac{q_{t}}{\bar{q}_{e} \cdot H}
$$

onde $\tau=2 \cdot\left(L_{R} / S_{R}+W T\right)($ em horas $) ; S_{R}=$ velocidade média dos trens $(\mathrm{km} / \mathrm{h}) ; W T=$ tempo de espera nas estações (horas).

Entretanto, considerando que fatores exógenos podem afetar a operação do sistema (e.g. manutenções programadas ou falhas imprevistas), um fator de contingência $(C F)$ é aplicado à equação anterior, de modo que o número total de trens a serem adquiridos anualmente pelo operador é dado por:

$$
R S^{t}=(1+C F) \cdot M R S^{t}=\frac{(1+C F) \cdot \tau \cdot q_{t}}{\bar{q}_{e} \cdot H}
$$

Portanto, dessa estimativa final da frota de veículos, o investimento total de aquisição do material rodante $\left(R S C^{A}\right)$ ao longo do horizonte de operação do sistema é dado por:

$$
R S C^{A}=\sum_{t=0}^{T} \frac{\left(R S^{t}-R S^{t-1}\right) \cdot a \cdot \bar{q}}{(1+M A R R)^{t}}
$$

onde $R S^{t}-R S^{t-1}=$ número de trens adquiridos entre o ano $(t-1)$ e o ano $(t) ; a=$ custo unitário por assento de um trem; $\bar{q}=$ número de assentos de um trem; $T$ = último ano do horizonte de avaliação socioeconômica; e $M A R R=$ taxa mínima de atratividade.

Assume-se na formulação proposta que os primeiros trens são adquiridos no ano em que a construção da infraestrutura é iniciada $(t=0)$ pela adoção de uma abordagem conservadora em relação aos custos totais do projeto. Quanto mais cedo for a aquisição do material rodante, maior é o seu valor presente líquido pois o resultado do denominador da Equação (4.8) reduz-se com o aumento do valor de $t$ no horizonte de planejamento.

\subsubsection{Despesas Operacionais}

Além dos investimentos para construção da infraestrutura e aquisição de material rodante, a avaliação socioeconômica deve contemplar as despesas decorrentes da oferta dos serviços. Os principais itens relativos a essas despesas são devido à operação dos trens (sinalização e controle de tráfego) e manutenção do sistema (reparos na via e limpeza de instalações). 
O TRN-14: Sources of Operating Costs das referências do Banco Mundial (MACKIE et al., 2003) apresenta os principais itens de despesas operacionais de rodovias, ferrovias e infraestruturas portuárias. No caso dos projetos ferroviários, essas despesas incidem sobre os operadores e variam entre serviços de transporte de cargas e passageiros em função das distâncias percorridas, das características das vias e da política operacional do sistema.

$\mathrm{Na}$ formulação apresentada nesta tese, as despesas totais operacionais são calculadas com base em coeficientes médios incidentes sobre os agentes responsáveis pela oferta dos serviços. A partir do número de trens adquiridos anualmente segundo a Equação (4.7) as despesas de operação da frota de trens no horizonte de planejamento é calculado pela Equação (4.9).

$$
R S C^{O}=\sum_{t=T_{0}}^{T} \frac{r_{o} \cdot \bar{q} \cdot R S^{t} \cdot 2 \cdot L_{R} \cdot T D}{(1+M A R R)^{t}}
$$

onde $R S C^{O}=$ valor presente líquido das despesas operacionais dos trens; $T=$ último ano do horizonte de avaliação socioeconômica; $r_{o}=$ custo médio de consumo de energia (ou combustível) e com a tripulação (R\$/assento-km); $R S^{t}=$ número de trens operados no ano $(t)$; $L_{R}=$ comprimento do alinhamento ferroviário entre estações; $\bar{q}=$ capacidade total de um trem (número de assentos); $T D=N D \cdot \tau / H=$ número de viagens (ida e volta) executadas por um trem anualmente; e $M A R R=$ taxa mínima de atratividade.

\subsubsection{Despesas de Manutenção da Via Permanente}

As referências para avaliação socioeconômica do Banco Mundial (MACKIE et al., 2003) proveem um relatório (TRN-13: Treatment of Maintenance) dedicado exclusivamente ao tratamento das despesas de manutenção sob a perspectiva do operador da infraestrutura de transporte instalada.

Segundo a referência, a estratégia de manutenção é uma questão chave na redução dos custos repassados aos usuários, uma vez que a política de manutenção eficaz pode reduzir as despesas totais finais e, portanto, aquelas transferidas aos passageiros.

Mackie et al. (2003) classificam as despesas de manutenção da via permanente em quatro categorias principais: a Manutenção de Rotina diz respeito aos itens básicos de conservação, como corte de grama e iluminação; a Manutenção Recorrente refere-se às atividades executadas em pequenos períodos de tempo (e.g um ano ou menos), tal como a manutenção do lastro; 
e a Manutenção Periódica é aquela realizada em grandes intervalos tempo, como a troca de dormentes. Finalmente, a Manutenção Urgente ou Especial está relacionada a imprevistos ou eventos cujas ocorrências são de difícil previsão.

No contexto da proposta de formulação de $C B A$, as despesas relativas à manutenção da via permanente são calculadas em função de um coeficiente médio e da extensão dos alinhamentos ferroviários conforme indicado na Equação (4.10). Essa equação considera que a manutenção da via só começa a ocorrer nos períodos posteriores ao início da operação efetiva dos trens.

$$
I C^{M}=\sum_{t=T_{0}}^{T} \frac{m \cdot \bar{q} \cdot R S^{t} \cdot 2 \cdot L_{R} \cdot T D}{(1+M A R R)^{t}}
$$

onde $I C^{M}=$ valor presente líquido das despesas de manutenção da infraestrutura; $T$ = último ano do horizonte de avaliação socioeconômica; $m$ = custo médio de manutenção da via permanente $\left(\mathrm{R} \$\right.$ /assento-km); $R S^{t}=$ número de trens operados no ano $(t) ; L_{R}=$ comprimento do alinhamento ferroviário entre estações; $\bar{q}=$ capacidade total de um trem (número de assentos); $T D=N D \cdot \tau / H=$ número de viagens (ida e volta) executadas por um trem anualmente; e $M A R R=$ taxa mínima de atratividade.

\subsubsection{Despesas de Manutenção do Material Rodante}

Para esse item, o valor presente líquido é calculado conforme a Equação (4.11), que considera um custo médio anual em função da distância total percorrida pela frota operante no ano $t$.

$$
R S C^{M}=\sum_{t=T_{0}}^{T} \frac{r_{m} \cdot \bar{q} \cdot R S^{t} \cdot 2 \cdot L_{R} \cdot T D}{(1+M A R R)^{t}}
$$

onde $R S C^{M}=$ valor presente líquido das despesas de manutenção do material rodante; $T=$ último ano do horizonte de avaliação socioeconômica; $r_{m}=$ custo médio de manutenção do material rodante $\left(\mathrm{R} \$\right.$ /assento-km); $R S^{t}=$ número de trens operados no ano $(t) ; L_{R}=$ comprimento do alinhamento ferroviário entre estações; $\bar{q}=$ capacidade total de um trem (número de assentos); $T D=N D \cdot \tau / H=$ número de viagens (ida e volta) executadas por um trem anualmente; e $M A R R=$ taxa mínima de atratividade. 
Analogamente às despesas de manutenção da infraestrutura, aquelas relativas ao material rodante são computadas apenas nos períodos posteriores ao final da construção da infraestrutura, ou seja, a partir do início da operação comercial dos trens.

\subsubsection{Benefícios}

\subsubsection{Receitas}

Ambos os documentos do Banco Mundial e do WebTAG esclarecem que as receitas operacionais são um dos itens mais importantes de benefícios econômicos de uma $C B A$. A demanda que potencialmente utilizará um novo modo de transporte é uma questão a ser equacionada pelos planejadores e depende dos objetivos do projeto do ponto de vista socioeconômico e das condições de modelagem (fontes de dados, orçamento disponível para pesquisas etc.).

O Banco Mundial apresenta instruções a respeito do cálculo dos benefícios econômicos advindos dos usuários induzidos a escolher o novo modo de transporte (TRN-11: Treatment of Induced Traffic) e as principais fontes de erros na previsão da demanda (TRN-12: Demand Forecasting Errors). O Reino Unido possui, em concomitância com o WebTAG, um manual específico para o tratamento da modelagem de demanda - o PHDF (Passenger Demand Forecasting Handbook) - a qual está sujeita às condições específicas de tráfego daquele país e que dificilmente podem ser equiparadas àquelas observadas na realidade brasileira.

O Banco Mundial apresenta princípios gerais em relação à definição do valor das passagens de um novo serviço de transporte, entretanto, os comentários limitam-se a informações generalizadas que dificultam o estabelecimento de uma estrutura tarifária. Maiores informações podem ser obtidas no TRN-23: Evaluation Implications of Sub-optimum Pricing, que trata dos efeitos da definição de subpreços como a superlotação do sistema e déficit financeiro.

O WebTAG apresenta um método específico para precificação de novos investimentos em rodovias no Reino Unido - sob as recomendações contidas no TAG Unit 2.12C: Introduction to Modelling and Appraisal for Road Pricing e no TAG Unit 3.12: Road Pricing - e para a aplicação na avaliação socioeconômica em projetos ferroviários de transporte de passageiros (TAG Unit 3.13: Guidance on Rail Appraisal). 
Dadas as especificidades do WebTAG e a generalização do tema nas recomendações do Banco Mundial, a estimativa da demanda para utilização de novos sistemas ferroviários na Região Sudeste do Brasil foram estabelecidos especificamente para os propósitos desta pesquisa conforme descrito no Capítulo 3.

Na formulação de $C B A$ proposta, a principal fonte de recursos econômicos para o operador é a receita do serviço ferroviário, dada pelo número total de passageiros que utilizam os serviços nos anos do horizonte de planejamento e a tarifa média cobrada por cada bilhete emitido.

Para uma dada tarifa específica, o valor presente líquido da receita anual para o operador considerando a demanda total que utiliza o sistema (equivalente à mudança modal e ao tráfego gerado pela operação de um novo modo de transporte) é dado pela Equação (4.12).

$$
T R=\sum_{t=T_{0}}^{T} \frac{D^{t} \cdot(1+G T) \cdot\left(P_{R w}+P_{R l}\right) \cdot F A_{R} \cdot L_{R}}{(1+M A R R)^{t}}
$$

onde $T R=$ valor presente líquido da receita total $; T=$ último ano do horizonte de avaliação socioeconômica; $D^{t}=$ número total de viagens estimadas entre uma origem e um destino no ano $t$ (em ambos os sentidos); $P_{R w}=$ percentual de usuários que escolhem o modo trem para viagens por motivo de trabalho no ano $t$ após o início da operação do sistema mediante uma tarifa ferroviária preestabelecida; $P_{R l}=$ percentual de usuários que escolhem o modo trem para viagens por lazer ou outros motivos no ano $t ; F A_{R}=$ tarifa ferroviária média $(\mathrm{R} \$ / \mathrm{km}) ; L_{R}=$ comprimento do alinhamento ferroviário entre estações; e $M A R R=$ taxa mínima de atratividade.

Nesta tese a definição da tarifa ferroviária é estabelecida com base na abordagem de maximização dos benefícios totais do projeto, que tem como objetivo identificar o preço médio das passagens que maximiza os benefícios econômicos e/ou sociais advindos da operação dos trens na nova infraestrutura ferroviária. As análises socioeconômicas de uma rede ferroviária hipotética indicadas no Capítulo 5 abordam essa estratégia com maior detalhamento.

\subsubsection{Valor Residual}

Do ponto de vista econômico, após a construção da infraestrutura ferroviária e operação dos ativos adquiridos durante o horizonte de planejamento de um projeto é possível considerar que 
existe um valor residual ao final do período de avaliação socioeconômica que representa uma parcela do valor total aplicado no investimento.

Esse valor depende dos níveis de utilização e manutenção da infraestrutura e dos demais ativos adquiridos ao longo do tempo. Entretanto, no caso de projetos de grande porte como uma nova infraestrutura ferroviária, o valor residual pode resultar valores expressivos ao final do horizonte de análise socioeconômica.

Nesta tese o valor residual total é calculado como uma porcentagem dos investimentos na construção da infraestrutura, desconsiderando-se um valor residual relacionado à aquisição dos demais ativos de tal modo que, por hipótese, esses itens depreciam-se totalmente durante o horizonte de planejamento de 35 anos.

Assim, o valor presente líquido do valor residual total $(T R V)$ decorrente da depreciação é calculado como uma proporção dos investimentos em infraestrutura conforme a Equação 4.13.

$$
T R V=\frac{\xi \cdot C C}{(1+M A R R)^{T}}
$$

onde $\xi=$ porcentagem de valor residual estimado da infraestrutura após utilização no horizonte de planejamento; $C C$ = estimativa de custo de construção do novo traçado ferroviário, resultante da aplicação do Algoritmo Genético descrito no Capítulo 2; $M A R R=$ taxa mínima de atratividade; e $T$ = último ano do horizonte de avaliação socioeconômica.

Nesse sentido, do ponto de vista social, o valor residual (TVR) também pode ser considerado como um benefício que se estende à sociedade quando a entidade investidora na construção de uma infraestrutura é um órgão público. Portanto, além de um benefício econômico, o resultado da depreciação dos ativos relacionados à infraestrutura também é computado nesta tese como um benefício social na comparação entre os custos e benefícios da análise socioeconômica.

\subsubsection{Excedente do Consumidor}

A mensuração dos benefícios do excedente do consumidor baseia-se no conceito da disponibilidade do usuário em arcar com os custos de uma viagem diferente daquela que realiza. Esses benefícios são calculados com base na variação do custo generalizado de uma viagem e, con- 
sequentemente, na possibilidade de redução do valor de um ou mais itens de custo da viagem pela melhoria do sistema de transporte existente ou implantação de uma nova tecnologia.

Apesar do usuário perceber diretamente apenas os custos econômicos de uma viagem, existem outros itens que perfazem o seu custo generalizado total (em geral, em termos de moeda corrente), tais como o equivalente monetário ao tempo dispendido no acesso ao equipamento de transporte e na viagem, desconfortos passíveis de mensuração, segurança etc.

O TAG Unit 3.5.3: Transport User Benefit Calculation do WebTAG introduz um procedimento de cálculo do excedente do consumidor em um cenário de demanda inelástica às alterações de custo generalizado da viagem. A Figura 4.3 representa graficamente esse excedente do consumidor $\left(C S_{i j}\right)$ quando há uma alteração das condições de transporte entre uma origem $i$ e um destino $j$.

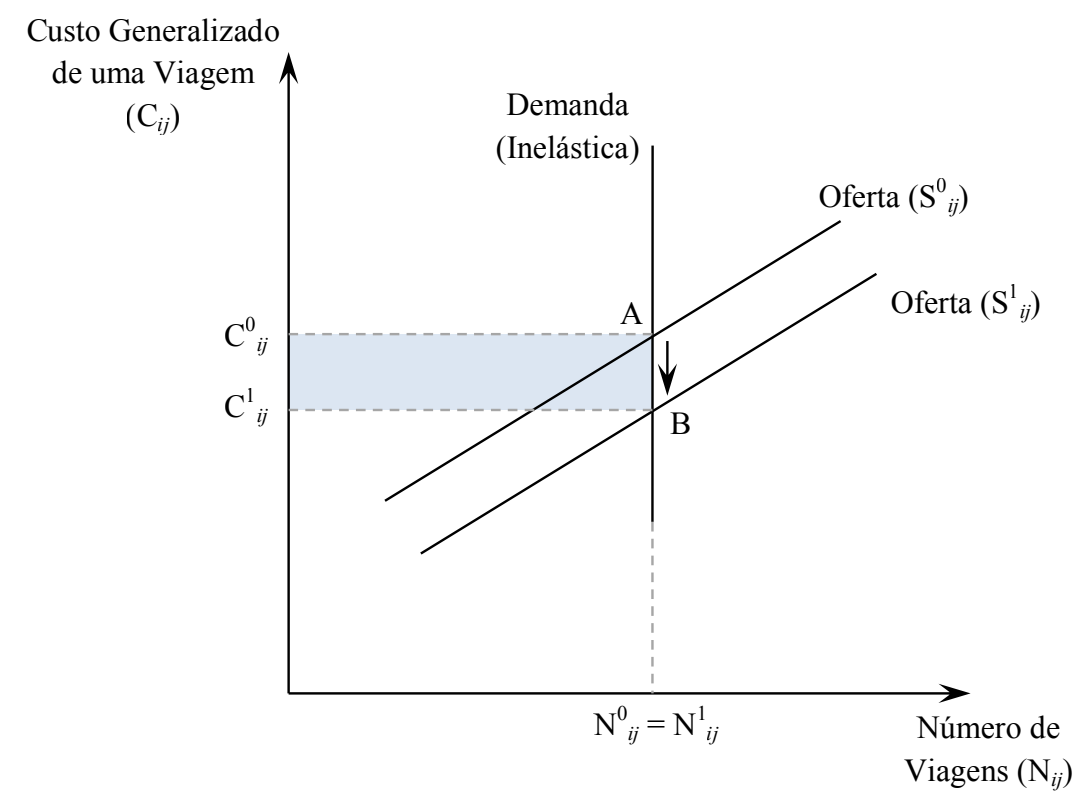

Figura 4.3 - Estimativa do excedente do consumidor considerando demanda inelástica Fonte: DfT (2014)

$$
\begin{aligned}
C S_{i j}= & \text { (Número Inicial de Viagens + Variação do Número de Viagens }) \\
& \cdot \text { Variação do Custo Generalizado } \\
= & \text { Área do Retângulo } \mathrm{C}_{i j}^{0} A B \mathrm{C}_{i j}^{1}=\left(\mathrm{C}_{i j}^{0}-\mathrm{C}_{i j}^{1}\right) \cdot \mathrm{N}_{i j}^{0}=\left(\mathrm{C}_{i j}^{0}-\mathrm{C}_{i j}^{1}\right) \cdot \mathrm{N}_{i j}^{1}
\end{aligned}
$$


onde $\mathrm{C}_{i j}^{0}=$ custo generalizado de uma viagem antes da modificação do sistema de transporte; $\mathrm{C}_{i j}^{1}=$ custo generalizado de uma viagem após a modificação do sistema de transporte; $\mathrm{N}_{i j}^{0}=$ número de viagens antes da modificação do sistema de transporte; $\mathrm{N}_{i j}^{1}=$ número de viagens após a modificação do sistema de transporte.

Entretanto, no âmbito da Engenharia de Transportes, a demanda geralmente decresce assintoticamente em função do custo generalizado de uma viagem e, portanto, ela é elástica e pode ser representada pela Figura 4.4. Nesse caso, analogamente à Equação (4.14), o excedente do consumidor é calculado em relação aos usuários que utilizam um modo de transporte (retângulo $\mathrm{C}_{i j}^{0} A B \mathrm{C}_{i j}^{1}$ ) e àqueles que migram para o sistema (triângulos $A B D$ ).

Para efeito de simplificação a curva de demanda pode ser aproximada para um segmento reto $(A D)$. Nesse caso, o excedente do consumidor pode ser formulado conforme a Equação (4.15) conforme recomendado pelo Banco Mundial (MACKIE et al., 2003).

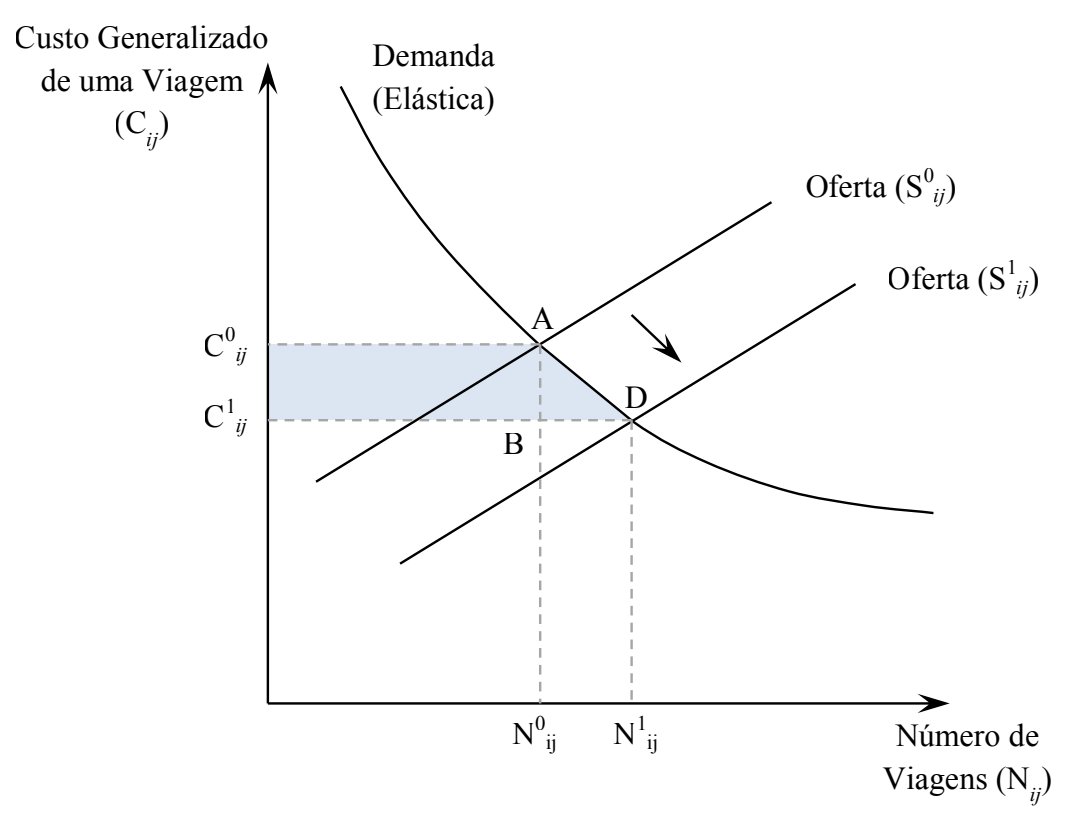

Figura 4.4 - Rule of Half para estimativa do excedente do consumidor considerando demanda elástica

$$
\begin{aligned}
C S_{i j} & =\text { Área do Retângulo } \mathrm{C}_{i j}^{0} A B \mathrm{C}_{i j}^{1}+\text { Área do Triângulo } A B D \\
& =\left(\mathrm{C}_{i j}^{0}-\mathrm{C}_{i j}^{1}\right) \cdot \mathrm{N}_{i j}^{1}+\frac{1}{2} \cdot\left(\mathrm{C}_{i j}^{0}-\mathrm{C}_{i j}^{1}\right) \cdot\left(\mathrm{N}_{i j}^{1}+\mathrm{N}_{i j}^{0}\right)
\end{aligned}
$$


Apesar dessa definição ser contemplada pelo TAG Unit 3.5.3 (DFT, 2014) para o cálculo do excedente do consumidor, as diretrizes estabelecidas esclarecem que essa abordagem geralmente não permite estimativas acuradas em relação ao modo de transporte que os usuários deixaram de usar. Assim, Williams e Sugden (1988) propõem a aplicação da Equação (4.15) ao $k$-ésimo modo de transporte resultando na Equação (4.16).

$$
T C S_{i j}=\sum_{M} C S_{i j M}=\sum_{M} \frac{1}{2} \cdot\left(\mathrm{C}_{i j M}^{0}-\mathrm{C}_{i j M}^{1}\right) \cdot\left(\mathrm{N}_{i j M}^{1}-\mathrm{N}_{i j M}^{0}\right)
$$

onde $T C S_{i j}=$ excedente do consumidor total considerando todos os modos de transporte; $\mathrm{C}_{i j M}^{0}=$ custo generalizado de uma viagem pelo modo $M$ antes da modificação do sistema de transporte; $\mathrm{C}_{i j M}^{1}=$ custo generalizado de uma viagem pelo modo $M$ após a modificação do sistema de transporte; $\mathrm{N}_{i j M}^{0}=$ número de viagens pelo modo $M$ antes da modificação do sistema de transporte; $\mathrm{N}_{i j M}^{1}=$ número de viagens pelo modo $M$ após a modificação do sistema de transporte.

Nellthorp e Hyman (2001) esclarecem que, apesar dessa abordagem ser amplamente difundida para o cálculo do excedente do consumidor na análise de projetos de transporte, o método é falho em três situações: quando há uma grande diferença nos custos generalizados antes e depois da melhoria do sistema (i.e. quando a curva de demanda entre $\mathrm{C}_{i j M}^{0}$ e $\mathrm{C}_{i j M}^{1}$ não pode ser aproximada para uma reta); quando um novo modo de transporte é introduzido; ou quando novos polos geradores ou atratores de viagens são criados após a implantação da infraestrutura.

No âmbito da formulação de análise custo-benefício desta tese o cálculo do excedente do consumidor enquadra-se na segunda falha ao aplicar-se a Equação (4.16). Nesse sentido, Nellthorp e Hyman (2001) apresentam uma abordagem alternativa considerando a demanda pelos serviços como uma função contínua dependente do custo generalizado de uma viagem.

Os autores estabelecem que o excedente do consumidor pela oferta de um novo modo de transporte pode ser representado graficamente pela Figura 4.5 e calculado pela Equação (4.17). 


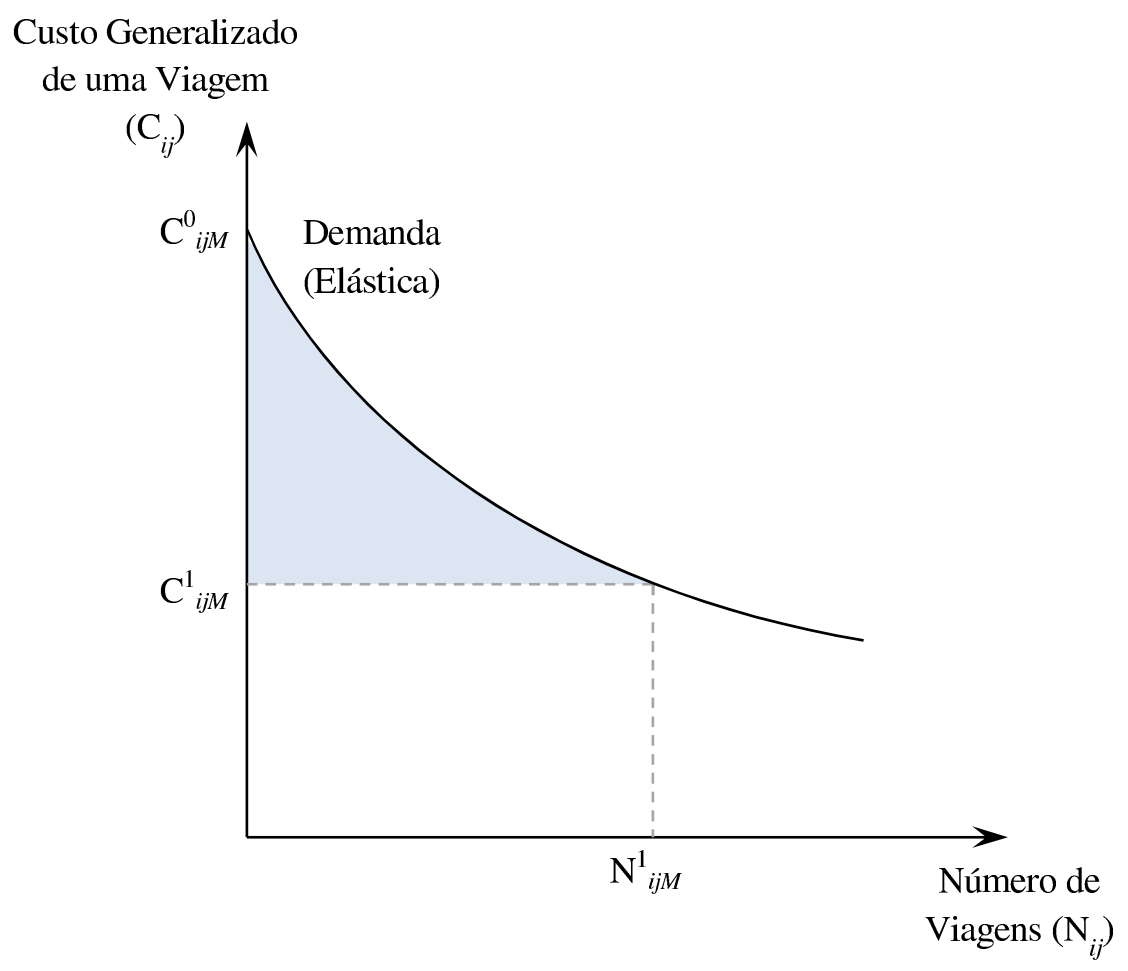

Figura 4.5 - Modelo teórico para estimativa do excedente do consumidor - Fonte: Nellthorp e Hyman (2001)

$$
C S_{i j M}=\int_{\mathbf{C}_{i j M}^{0}}^{\mathbf{C}_{i j M}^{1}} D_{i j M}\left(\mathbf{C}_{i j M}\right) d \mathbf{C}_{i j M}
$$

onde $N_{i j M}\left(\mathrm{C}_{i j M}\right)=$ número de passageiros pelo modo de transporte $M$ entre $i$ e $j$ representado como uma função contínua do custo generalizado $\mathrm{C}_{i j M} ; \mathrm{C}_{i j M}^{0}=$ custo generalizado da viagem para o qual nenhum usuário escolheria o modo de transporte $M$ entre $i$ e $j ; \mathrm{C}_{i j M}^{1}=$ custo generalizado entre $i$ e $j$ após a implementação do sistema.

Um problema prático de aplicação dessa formulação decorre do fato de que a função de demanda nem sempre é diferenciável e, portanto, o cálculo da integral da Equação (4.17) pode ser inviabilizado, como no caso de modelos de escolha hierárquica (e.g. árvores de decisão) ou de funções descontínuas que representam a escolha modal. Para resolver esse problema, Nellthorp e Hyman (2001) consideram a integração numérica da curva de demanda em intervalos igualmente espaçados conforme indicado na Figura 4.6. 


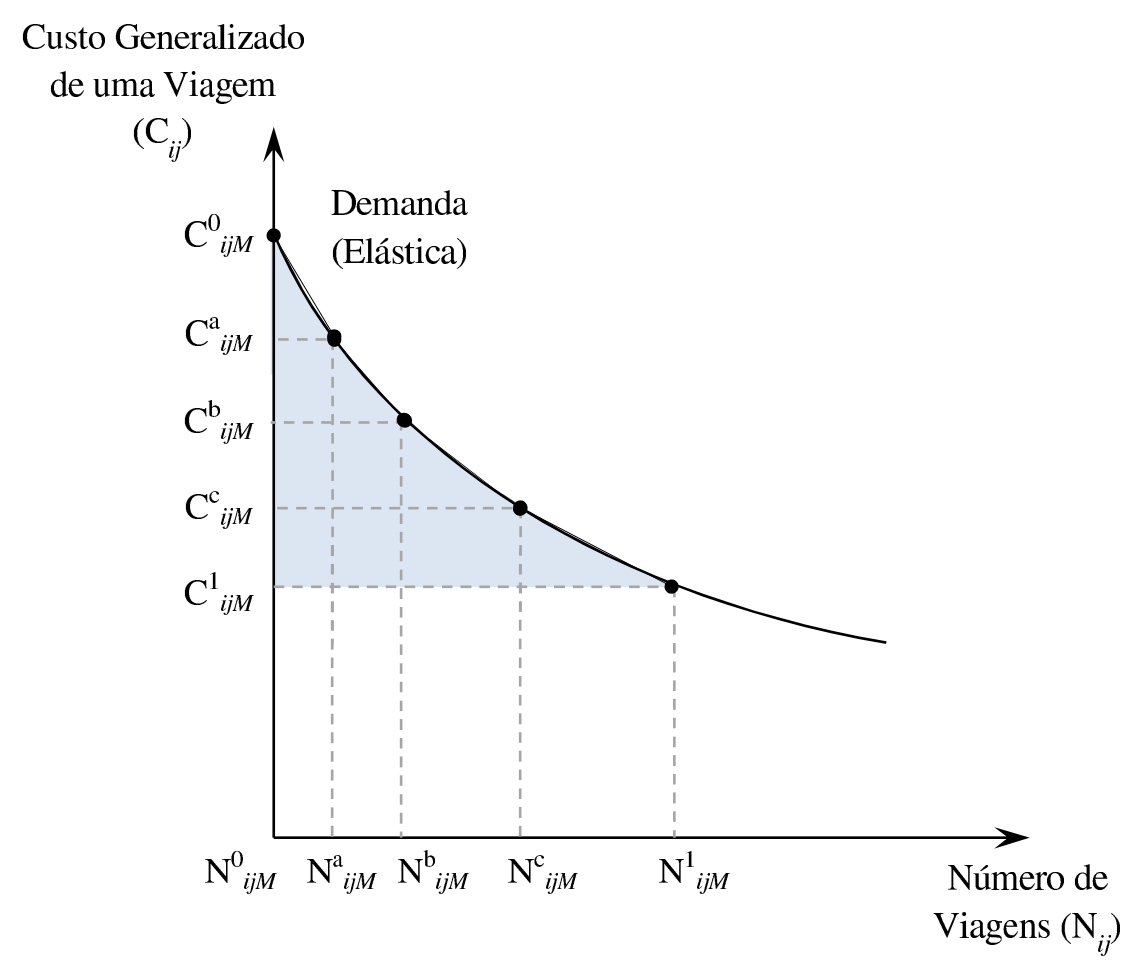

Figura 4.6 - Aproximação numérica do Rule of Half para estimativa do excedente do consumidor segundo Nellthorp e Hyman (2001)

A recomendação dos autores é considerar intervalos iguais entre $C_{i j M}^{0}$ e $C_{i j M}^{1}$, de modo que o custo generalizado nos pontos intermediários esses valores destacados na Figura 4.6 são calculados pelas equações a seguir.

$$
\begin{aligned}
& \mathrm{C}^{\mathrm{a}}{ }_{i j M}=\mathrm{C}_{i j M}^{1}+0,75 \cdot\left(\mathrm{C}_{i j M}^{0}-\mathrm{C}_{i j M}^{1}\right)=0,75 \cdot \mathrm{C}_{i j M}^{0}+0,25 \cdot \mathrm{C}_{i j M}^{1} \\
& \mathrm{C}^{\mathrm{b}}{ }_{i j M}=\mathrm{C}_{i j M}^{1}+0,50 \cdot\left(\mathrm{C}_{i j M}^{0}-\mathrm{C}_{i j M}^{1}\right)=0,50 \cdot \mathrm{C}_{i j M}^{0}+0,50 \cdot \mathrm{C}_{i j M}^{1} \\
& \mathrm{C}^{\mathrm{c}}{ }_{i j M}=\mathrm{C}_{i j M}^{1}+0,25 \cdot\left(\mathrm{C}_{i j M}^{0}-\mathrm{C}_{i j M}^{1}\right)=0,25 \cdot \mathrm{C}_{i j M}^{0}+0,75 \cdot \mathrm{C}_{i j M}^{1}
\end{aligned}
$$

Portanto, o excedente do consumidor decorrente da implantação de um novo sistema de transporte ferroviário de passageiro mediante um custo generalizado de viagem poder ser calculado conforme a Equação (4.21).

$$
\begin{aligned}
& C S_{i j M}=\frac{1}{2} \cdot\left\{\mathrm{N}^{\mathrm{a}}{ }_{i j M} \cdot\left(\mathrm{C}_{i j M}^{0}-\mathrm{C}^{\mathrm{a}}{ }_{i j M}\right)+\left(\mathrm{N}^{\mathrm{a}}{ }_{i j M}+\mathrm{N}^{\mathrm{b}}{ }_{i j M}\right) \cdot\left(\mathrm{C}^{\mathrm{a}}{ }_{i j M}-\mathrm{C}^{\mathrm{b}}{ }_{i j M}\right)\right. \\
& +\left(\mathrm{N}^{\mathrm{b}}{ }_{i j M}+\mathrm{N}^{\mathrm{c}}{ }_{i j M}\right) \cdot\left(\mathrm{C}^{\mathrm{b}}{ }_{i j M}-\mathrm{C}^{\mathrm{c}}{ }_{i j M}\right) \\
& \left.+\left(\mathrm{N}^{\mathrm{c}}{ }_{i j M}+\mathrm{N}_{i j M}^{1}\right) \cdot\left(\mathrm{C}^{\mathrm{c}}{ }_{i j M}-\mathrm{C}_{i j M}^{1}\right)\right\} \\
& =\frac{1}{2} \cdot\left(0,25 \cdot \mathrm{C}_{i j M}^{0}-0,25 \cdot \mathrm{C}_{i j M}^{1}\right) \cdot\left(2 \cdot \mathrm{N}^{\mathrm{a}}{ }_{i j M}+2 \cdot \mathrm{N}^{\mathrm{b}}{ }_{i j M}+2 \cdot \mathrm{N}^{\mathrm{c}}{ }_{i j M}+\mathrm{N}_{i j M}^{1}\right)
\end{aligned}
$$


Nellthorp e Hyman (2001) apontam que a integração numérica satisfaz o cálculo do excedente do consumidor apesar de dificuldades práticas para definição de alguns parâmetros no procedimento. O primeiro problema paramétrico é estabelecer o valor de $C_{i j M}^{0}$ da Figura 4.5 que resulta em um número de viagens $N_{i j M}$ próximo de zero. Nesse caso, os autores recomendam um valor aproximado de $C_{i j M}^{0}=3 \cdot C_{i j M}^{1}$, o qual pode ser ajustado para valores mais realísticos dependendo das condições da função de demanda.

Outro fator de ordem prática diz respeito à quantidade de intervalos entre os extremos $C_{i j M}^{0}$ e $C_{i j M}^{1}$ que resulte em uma aproximação adequada da integração numérica da função de demanda. Novamente, Nellthorp e Hyman (2001) indicam que três pontos intermediários (conforme ilustrado na Figura 4.6) são suficientes para uma estimativa adequada e que a adição de mais intervalos não contribui para um aumento significativo da acurácia.

Para efeito das análises socioeconômicas propostas nesta tese, o custo generalizado da viagem é dividido em dois elementos: custos econômicos referentes ao preço das passagens dos novos serviços ferroviários; e custos de tempo de viagem resultantes da relação entre o tempo de percurso (incluindo acesso e egresso) e o valor do tempo mediante o motivo da viagem.

\section{a. Excedente do Consumidor devido às Tarifas}

Primeiramente, considera-se que os custos médios de viagem dos modos de transporte diferentes do ferroviário não sofrerão alterações significativas ao longo do horizonte de planejamento da análise socioeconômica, mesmo aquelas decorrentes de efeitos inflacionários uma vez que incidiriam também no preço das passagens de trem.

Portanto, é válida a premissa de que o excedente do consumidor para os modos de transporte diferentes do ferroviário é nula - ou seja, os custos $C_{i j M}^{0}$ e $C_{i j M}^{1}$ permanecem constantes na Equação (4.16) -, sobretudo pelo fato de que a previsão de alterações nos demais sistemas de transporte e a estimativa de seus efeitos econômicos são inviáveis para aplicação nesta tese.

Para efeito de cálculo numérico, considera-se a substituição do número de viagens $N_{i j}$ entre o par de cidades $(i, j)$ na Equação (4.21) pelos percentuais de usuários que escolhem o modo ferroviário para viagens a trabalho $\left(P_{R w}\right)$ ou lazer $\left(P_{R l}\right)$. Disto, considere $C_{R}^{1}$ o custo monetário dessa viagem ao passageiro (i.e. o preço da passagem) e $C_{R}^{0}$ o valor da passagem em que a 
escolha do modo ferroviário (HPT ou HST) é igual a zero, ou seja, na situação hipotética de que nenhum usuário está disposto a pagar esse valor pela viagem.

Assim, considerando os percentuais de escolha modal a partir das tarifas ferroviárias nos pontos intermediários entre $C_{R}^{0}$ e $C_{R}^{1}$, o excedente do consumidor decorrente da cobrança de tarifa pelos serviços pode ser calculado conforme a Equação (4.22).

$$
\begin{aligned}
& \text { TCSUC }= \sum_{t=T_{0}}^{T} \frac{1}{2} \cdot \frac{D^{t}}{(1+M A R R)^{t}} \\
& \cdot\left\{\left[0,25 \cdot \mathrm{C}_{R}^{0}-0,25 \cdot \mathrm{C}_{R}^{1}\right]\right. \\
& \cdot\left[2 \cdot\left(P^{\mathrm{a}}{ }_{R w}+P^{\mathrm{a}}{ }_{L w}\right)+2 \cdot\left(P^{\mathrm{b}}{ }_{R w}+P^{\mathrm{b}}{ }_{L w}\right)\right. \\
&\left.\left.+2 \cdot\left(P^{\mathrm{c}}{ }_{R w}+P^{\mathrm{c}}{ }_{L w}\right)+\left(P^{1}{ }_{R w}+P^{1}{ }_{L w}\right)\right]\right\}
\end{aligned}
$$

onde $P_{R w}^{1}=$ percentual de usuários que escolhem o modo ferroviário para viagens por motivo de trabalho quando a tarifa é igual a $C_{R}^{1}$;

$P_{R w}^{a}=$ percentual de usuários que escolhem o modo ferroviário para viagens por motivo de trabalho quando a tarifa é igual a $C_{R}^{1}+0,25 \cdot\left(C_{R}^{0}-C_{R}^{1}\right)$;

$P_{R w}^{b}=$ percentual de usuários que escolhem o modo ferroviário para viagens por motivo de trabalho quando a tarifa é igual a $C_{R}^{1}+0,50 \cdot\left(C_{R}^{0}-C_{R}^{1}\right)$;

$P_{R w}^{c}=$ percentual de usuários que escolhem o modo ferroviário para viagens por motivo de trabalho quando a tarifa é igual a $C_{R}^{1}+0,75 \cdot\left(C_{R}^{0}-C_{R}^{1}\right)$;

$P_{R w}^{0}=$ percentual de usuários que escolhem o modo ferroviário para viagens por motivo de trabalho quando a tarifa é igual a $C_{R}^{0}$;

$P_{R l}^{1}=$ percentual de usuários que escolhem o modo ferroviário para viagens por motivo de lazer ou outros quando a tarifa é igual a $C_{R}^{1}$;

$P_{R l}^{a}=$ percentual de usuários que escolhem o modo ferroviário para viagens por motivo de lazer ou outros quando a tarifa é igual a $C_{R}^{1}+0,25 \cdot\left(C_{R}^{0}-C_{R}^{1}\right)$;

$P_{R l}^{b}=$ percentual de usuários que escolhem o modo ferroviário para viagens por motivo de lazer ou outros quando a tarifa é igual a $C_{R}^{1}+0,50 \cdot\left(C_{R}^{0}-C_{R}^{1}\right)$; 
$P_{R l}^{c}=$ percentual de usuários que escolhem o modo ferroviário para viagens por motivo de lazer ou outros quando a tarifa é igual a $C_{R}^{1}+0,75 \cdot\left(C_{R}^{0}-C_{R}^{1}\right)$;

$P_{R l}^{0}=$ percentual de usuários que escolhem o modo ferroviário para viagens por motivo de lazer ou outros quando a tarifa é igual a $C_{R}^{0}$.

\section{b. Excedente do Consumidor devido ao Tempo de Viagem}

Assim como no caso das tarifas para o cálculo do excedente dos consumidor, considera-se válida a premissa de que os tempos de viagem dos modos de transporte diferentes do ferroviário (Automóvel, Ônibus e Avião) permanecerão praticamente constantes ao longo do horizonte de planejamento da $C B A$. Portanto, novamente, o excedente do consumidor daqueles modos é considerado nulo uma vez que $\mathrm{C}_{i j}^{0}=\mathrm{C}_{i j}^{1}$ na Equação (4.16).

De acordo com o documento TRN-15: Valuation of Time Saving das recomendações do Banco Mundial, a redução dos tempos de viagem pela implementação ou melhoria das condições de um modo de transporte pode ser contabilizado em até $80 \%$ dos benefícios totais do projeto em países desenvolvidos.

Seja $V O T_{w}$ o valor monetário do tempo de viagem por motivo de trabalho (R $\$ /$ hora), $V O T_{l}$ o valor monetário do tempo de viagem por lazer ou outros motivos ( $\$$ /hora), $T T_{R}^{0}$ o tempo de viagem pelo modo ferroviário (HPT ou $H S T)$ no qual a sua escolha é praticamente nula (i.e. o número de passageiros nessas condições de viagens não é significativo) e $T T_{R}^{1}$ o tempo de viagem efetivo dependendo da velocidade média da tecnologia ferroviária.

Assim, o excedente do consumidor total decorrente da redução do tempo de viagem para os motivos de viagem (TCSTS) pode ser calculado conforme a Equação (4.23).

$$
\begin{aligned}
& \text { TCSTS }=\sum_{t=T_{0}}^{T} \frac{1}{2} \cdot \frac{D^{t}}{(1+M A R R)^{t}} \\
& \cdot\left\{\left[0,25 \cdot V O T_{W} \cdot T T_{R}^{0}-0,25 \cdot V O T_{W} \cdot T T_{R}^{1}\right]\right. \\
& \cdot\left[2 \cdot P^{\mathrm{a}}{ }_{R w}+2 \cdot P^{\mathrm{b}}{ }_{R w}+2 \cdot P_{R w}^{\mathrm{c}}+P_{R w}^{1}\right] \\
& +\left[0,25 \cdot V O T_{L} \cdot T T_{R}^{0}-0,25 \cdot V O T_{L} \cdot T T_{R}^{1}\right] \\
& \left.\cdot\left[2 \cdot P_{R l}^{\mathrm{a}}+2 \cdot P^{\mathrm{b}}{ }_{R l}+2 \cdot P^{\mathrm{c}}{ }_{R l}+P^{1}{ }_{R l}\right]\right\}
\end{aligned}
$$


onde $P_{R w}^{1}=$ percentual de usuários que escolhem o modo ferroviário para viagens por motivo de trabalho quando o equivalente monetário do tempo de viagem é igual a $V O T_{w} \cdot T T_{R}^{1}$;

$P_{R w}^{\mathrm{a}}=$ percentual de usuários que escolhem o modo ferroviário para viagens por motivo de trabalho quando o equivalente monetário do tempo de viagem é igual a $V O T_{w} \cdot\left[T T_{R}^{1}+0,75\right.$. $\left.\left(T T_{R}^{0}-T T_{R}^{1}\right)\right]$

$P^{\mathrm{b}}{ }_{R w}=$ percentual de usuários que escolhem o modo ferroviário para viagens por motivo de trabalho quando o equivalente monetário do tempo de viagem é igual a $V O T_{w} \cdot\left[T T_{R}^{1}+0,50\right.$. $\left.\left(T T_{R}^{0}-T T_{R}^{1}\right)\right]$

$P_{R w}^{\mathrm{c}}=$ percentual de usuários que escolhem o modo ferroviário para viagens por motivo de trabalho quando o equivalente monetário do tempo de viagem é igual a $V O T_{w} \cdot\left[T T_{R}^{1}+0,25\right.$. $\left.\left(T T_{R}^{0}-T T_{R}^{1}\right)\right]$

$P_{R w}^{0}=$ percentual de usuários que escolhem o modo ferroviário para viagens por motivo de trabalho quando o equivalente monetário do tempo de viagem é igual a $V O T_{w} \cdot T T_{R}^{0}$;

$P_{R l}^{1}=$ percentual de usuários que escolhem o modo ferroviário para viagens por motivo de lazer ou outros quando o equivalente monetário do tempo de viagem é igual a $V O T_{l} \cdot T T_{R}^{1}$;

$P^{\mathrm{a}}{ }_{R l}=$ percentual de usuários que escolhem o modo ferroviário para viagens por motivo de lazer ou outros quando o equivalente monetário do tempo de viagem é igual a $V O T_{l} \cdot\left[T T_{R}^{1}+\right.$ $\left.0,75 \cdot\left(T T_{R}^{0}-T T_{R}^{1}\right)\right]$

$P^{\mathrm{b}}{ }_{R l}=$ percentual de usuários que escolhem o modo ferroviário para viagens por motivo de lazer ou outros quando o equivalente monetário do tempo de viagem é igual a $V O T_{l} \cdot\left[T T_{R}^{1}+\right.$ $\left.0,50 \cdot\left(T T_{R}^{0}-T T_{R}^{1}\right)\right]$

$P_{R l}^{\mathrm{c}}=$ percentual de usuários que escolhem o modo ferroviário para viagens por motivo de lazer ou outros quando o equivalente monetário do tempo de viagem é igual a $V O T_{l} \cdot\left[T T_{R}^{1}+\right.$ $\left.0,25 \cdot\left(T T_{R}^{0}-T T_{R}^{1}\right)\right]$

$P_{R l}^{0}=$ percentual de usuários que escolhem o modo ferroviário para viagens por motivo de lazer ou outros quando o equivalente monetário do tempo de viagem é igual a $V O T_{l} \cdot T T_{R}^{0}$. 
Do ponto de vista de análise do valor do tempo de viagem por motivo de trabalho, existem duas abordagens apresentadas pelo Banco Mundial para aplicações em projetos de países em desenvolvimento: a comparação em relação ao salário médio e a abordagem de Hensher.

A primeira estratégia sugere que a economia em relação à redução do tempo de viagem é equivalente a uma proporção do salário médio somado aos custos de uma unidade extra de trabalho. Por outro lado, o segundo método sugere uma alteração do valor do salário médio considerando diferentes fatores, como a proporção do tempo utilizado para lazer ao invés de trabalho adicional, ou a proporção do tempo da viagem utilizado para execução de uma atividade relacionada ao trabalho.

Apesar de mais acurada, a abordagem de Hensher mostra-se mais difícil de aplicação prática e requer um banco de dados confiável para sua estimativa, de modo que o TRN-15: Valuation of Time Saving recomenda aquela baseada no salário médio para avaliação preliminar de viabilidade socioeconômica de projetos de transporte. A Tabela 4.2 a seguir representa os três principais métodos de estimativa do valor do tempo de viagem por motivo de viagem a trabalho segundo essa abordagem proposta pelo Banco Mundial.

Tabela 4.2 - Alternativas para estimativa do tempo médio de viagem por motivo trabalho adaptado de Mackie et al. (2003)

\begin{tabular}{lll}
\hline ABORDAGEM & TIPO & \multicolumn{1}{c}{ MÉTODO } \\
\hline Caso Base & Valor Simples & $\begin{array}{l}\text { Opção 1: Salário médio modificado por fatores } \\
\text { exógenos de ajuste } \\
\text { Opção 2: 1,33·Salário Médio }\end{array}$ \\
\hline $\begin{array}{l}\text { Segunda melhor } \\
\text { alternativa }\end{array}$ & Por modo de transporte & $\begin{array}{l}\text { Ajustado pelo salário médio observado } \\
\text { utilizando fatores de ajuste }\end{array}$ \\
\hline Ideal & Por setor da economia & $\begin{array}{l}\text { Ajustado pelo salário médio a partir de fatores } \\
\text { em função do setor da economia (serviços, } \\
\text { indústria, comércio etc.) }\end{array}$ \\
\hline
\end{tabular}

Por outro lado, a estimativa do valor do tempo de viagem por motivo lazer depende de outros fatores como a renda do indivíduo, status social, tempos de espera e acesso/egresso ao modo de transporte e condições da viagem (MACKIE et al., 2003). Assim, no âmbito econômico, a sua definição está associada à diferença entre o valor marginal do tempo dispendido na viagem e no tempo efetivo de lazer. 
Analogamente à estimativa do valor do tempo de viagem a trabalho, o Banco Mundial sugere alternativas para esse parâmetro em viagens pelo motivo lazer conforme a Tabela 4.3.

Tabela 4.3 - Alternativas para estimativa do tempo médio de viagem por motivo lazer - adaptado de Mackie et al. (2003)

\begin{tabular}{lll}
\hline ABORDAGEM & TIPO & \multicolumn{1}{c}{ MÉTODO } \\
\hline \multirow{2}{*}{ Base } & Adultos: 0,3·Renda Média Familiar \\
& Calor Simples & $\begin{array}{l}\text { Ajuste para tempo de acesso/egresso e } \\
\text { espera:1,5·Valor do Tempo de Viagem no } \\
\text { Veículo }(I V T \text { - In-vehicle Time })\end{array}$ \\
\hline Segunda Melhor & Por modo de transporte & $\begin{array}{l}\text { Valoração por métodos de pesquisa de } \\
\text { preferência declarada e revelada }\end{array}$ \\
& Ajustado pelo preço base da tarifa \\
\hline \multirow{2}{*}{ Ideal } & $\begin{array}{l}\text { Por grupos de renda, } \\
\text { socioeconômicos ou motivos } \\
\text { específicos de viagem }\end{array}$ & $\begin{array}{l}\text { Valoração por métodos de pesquisa de } \\
\text { preferencia declarada e revelada }\end{array}$ \\
& Ajustado pelo preço base da tarifa \\
\hline
\end{tabular}

$\mathrm{Na}$ avaliação de novos projetos ferroviários apresentado nesta tese, o valor monetário do tempo de viagem pelo motivo trabalho $\left(V O T_{w}\right)$ é definido como "1,33·Salário Médio"na Região Sudeste (Tabela 4.2) e pelo motivo lazer $\left(V O T_{l}\right)$ é definido como "0,3·Renda média familiar per capita" na mesma região (Tabela 4.3).

\subsubsection{Redução de Acidentes}

Ao invés de considerar os custos com acidentes como uma componente do custo generalizado da viagem, o Banco Mundial infere que esses itens são eventos aleatórios que podem ser computados pelo total de acidentes ocorridos e as suas respectivas severidades por modo de transporte. Nellthorp, Mackie e Bristow (1998) apresentam uma classificação da severidade na tentativa de mensurar os benefícios econômicos decorrentes da redução de acidentes, os quais são discriminados nos itens a seguir.

- Fatal: com pelo menos uma morte no intervalo máximo de 30 dias em consequência do acidente;

- Grave: não há mortes porém os danos requerem tratamento hospitalar intenso e resulta em lesões permanentes; 
- Moderado: ocorrências que não necessitam de atendimento hospitalar mas, se o requererem, os efeitos das lesões não são duradouros;

- Danos menores: apenas danos materiais sem vítimas.

Jacobs (1995) apresenta cinco possíveis métodos de estimativa dos custos de acidentes em sistemas de transporte.

- Gross Output ou Human Capital: o custo de uma fatalidade é equivalente aos ganhos futuros da vítima;

- Net Output: o custo da fatalidade é igual ao Gross Output subtraído do consumo da vítima após o sinistro;

- Life Insurance: o custo do acidente é equivalente à quantia monetária que a vítima está disposta a pagar pelo seguro de sua própria vida;

- Court Award: o custo de um acidente está vinculado à soma das recompensas dadas pelos tribunais aos dependentes das vítimas;

- Implicit Public Sector Valuation: o custo dos acidentes é dado por uma estimativa dos custos necessários à sua prevenção;

- Value of Risk Change ou Willingness-to-Pay: o custo dos acidentes é definido pelo valor que os usuários estão dispostos a pagar pela melhoria da segurança do sistema de transporte (i.e. pela redução dos riscos).

Sob essas definições, Nellthorp, Mackie e Bristow (1998) consideram os componentes de custo dos acidentes como a soma daqueles relativos à severidade (e.g. custos médicos e administrativos, tratamento psicológico às vítimas etc.) e aos danos materiais ocorridos (e.g. serviços de emergência como bombeiros e polícia, custos legais etc.).

Do ponto de vista do Banco Mundial a abordagem Gross Output é o método mais apropriado para definição do valor dos acidentes para estimativa dos benefícios decorrentes da implementação de sistemas de transporte mais seguros. Por outro lado, o WebTAG recomenda Willingnessto-Pay como alternativa mais adequada para estimativa desses benefícios. Nesta tese, a primeira abordagem (Gross Output) será considerada para desenvolvimento da formulação de CBA em detrimento da recomendação do WebTAG.

Segundo Mackie et al. (2003), é necessário estabelecer um modelo de estimativa do número de acidentes para cada modo de transporte, dadas as respectivas demandas e suas características operacionais, em geral, em termos do número de acidentes em um período de tempo. 
Dado que a ocorrência de um acidente envolve mais de uma perda, é comum que o número médio de perdas por acidente seja definido em termos de valores médios (e.g. danos materiais severos e mortes). Portanto, os custos econômicos decorrentes dos acidentes devem refletir um número médio de danos por severidade (fatal, grave, moderado ou de danos menores).

Uma vez que a formulação de $C B A$ apresentada nesta tese é para estimar os valores mais representativos da análise socioeconômica de novas conexões ferroviárias, a formulação apresentada considera um coeficiente que representa o número médio de acidentes por modo de transporte e os respectivos custos médios considerando a severidade. Assim, o custo total dos acidentes é dado pela soma do produto entre o número de acidentes por severidade e seus respectivos custos por modo de transporte e, portanto, os benefícios estão relacionados à redução dos custos totais após a implementação do projeto.

Os padrões de viagens intermunicipais da Região Sudeste indicam que o número de passageiros transportados pelos modos Automóvel e Ônibus são maiores que por Avião (conforme relatado no Capítulo 3). Considerando válidas as premissas de que o risco de acidentes por aqueles dois modos é maior do que pelo último, e de que o número de passageiros transferidos daqueles para modo ferroviário é maior que a transferência do modo aéreo, espera-se uma redução do custo total de acidentes pela implementação de serviços ferroviários pois o número de viagens transferidas é maior dos modos com maior índice de acidentalidade.

Sejam $A A C_{C}, A A C_{B}, A A C_{R}$ e $A A C_{A}$ os custos médios de acidentes para Automóveis, Ônibus, Trens e Avião, receptivamente, expressos em passageiros-km e que incorporam uma taxa de acidentalidade em função de cada modo de transporte.

A formulação proposta para estimativa da redução dos valores monetários decorrentes de acidentes é dada pela diferença entre o custo total de acidentes por modo de transporte na ausência de uma infraestrutura ferroviária e esse custo total no cenário com a operação das ferrovias. Assim, a formulação para cômputo dos valores monetários totais de acidentes pelo modo Automóvel no ano $t$ sem a existência de uma infraestrutura ferroviária (i.e. $P_{R}^{t}=0$ ) é dada pela Equação (4.24).

$$
A C N R_{C}^{t}=A A C_{C} \cdot D^{t} \cdot P N R_{C}^{t} \cdot L_{C}
$$


onde $A C N R_{C}^{t}=$ custo de acidentes pelo modo Automóvel no ano $t$ no cenário sem infraestrutura ferroviária; $P N R_{C}^{t}=$ percentual de usuários que escolhem o modo Automóvel no ano $t$ por motivo de viagem trabalho e lazer na ausência do modo ferroviário.

De maneira análoga, o valor monetário total dos acidentes por Ônibus e Avião na ausência do modo ferroviário no ano $t$ do horizonte de planejamento é dado por, respectivamente:

$$
\begin{aligned}
& A C N R_{B}^{t}=A A C_{B} \cdot D^{t} \cdot P N R_{B}^{t} \cdot L_{B} \\
& A C N R_{A}^{t}=A A C_{A} \cdot D^{t} \cdot P N R_{A}^{t} \cdot L_{A}
\end{aligned}
$$

onde $A C N R_{B}^{t}=$ custo de acidentes pelo modo Ônibus no ano $t$ no cenário sem infraestrutura ferroviária; $A C N R_{A}^{t}=$ custo de acidentes pelo modo Avião no ano $t$ no cenário sem infraestrutura ferroviária; $P N R_{B}^{t}=$ percentual de usuários que escolhem o modo Ônibus no ano $t$ por motivo de viagem trabalho e lazer na ausência do modo ferroviário; $P N R_{A}^{t}=$ percentual de usuários que escolhem o modo Avião no ano $t$ por motivo de viagem trabalho e lazer na ausência do modo ferroviário.

Por outro lado, no ano $t$ do horizonte de planejamento em que supõe-se a existência de uma infraestrutura ferroviária e operação dos trens, o valor monetário total de acidentes para os modos Automóvel, Ônibus, Trens e Avião são dados, respectivamente, pela Equação 4.27 à Equação 4.30. O índice referente ao ano na proporção de usuários $\left(P_{C}^{t}, P_{B}^{t}, P_{R}^{t}\right.$ e $\left.P_{A}^{t}\right)$ fazse necessário para distinguir a utilização dos sistemas antes e depois da finalização das linhas ferroviárias e início da operação dos serviços.

$$
\begin{gathered}
A C_{C}^{t}=A A C_{C} \cdot D^{t} \cdot P_{C}^{t} \cdot L_{C} \\
A C_{B}^{t}=A A C_{B} \cdot D^{t} \cdot P_{B}^{t} \cdot L_{B} \\
A C_{R}^{t}=A A C_{R} \cdot D^{t} \cdot(1+G T) \cdot P_{R}^{t} \cdot L_{R} \\
A C_{A}^{t}=A A C_{A} \cdot D^{t} \cdot P_{A}^{t} \cdot L_{A}
\end{gathered}
$$

onde $D^{t}=$ número total de viagens estimadas entre uma origem e um destino no ano $t$ (em ambos os sentidos); $P_{C}^{t}=$ percentual de usuários que escolhem o modo Automóvel no ano $t$ 
por motivo de viagem trabalho e lazer após implantação do modo ferroviário; $P_{B}^{t}=$ percentual de usuários que escolhem o modo Ônibus no ano $t$ por motivo de viagem trabalho e lazer após implantação do modo ferroviário; $P_{R}^{t}=$ percentual de usuários que escolhem o modo Trem no ano $t$ por motivo de viagem trabalho e lazer; $P_{A}^{t}=$ percentual de usuários que escolhem o modo Avião no ano $t$ por motivo de viagem trabalho e lazer após implantação do modo ferroviário.

Portanto, das equações apresentadas anteriormente o valor monetário esperado pela redução de acidentes para os modos Automóvel, Ônibus, Trens e Avião são, respectivamente:

$$
\begin{aligned}
M A R_{C}^{t} & =A C N R_{C}^{t}-A C_{C}^{t} \\
& =A A C_{C} \cdot D^{t} \cdot\left(P N R_{C}^{t}-P_{C}^{t}\right) \cdot L_{C} \\
M A R_{B}^{t} & =A C N R_{B}^{t}-A C_{B}^{t} \\
& =A A C_{B} \cdot D^{t} \cdot\left(P N R_{B}^{t}-P_{B}^{t}\right) \cdot L_{B} \\
M A R_{R}^{t} & =A C_{R}^{t} \\
& =A A C_{R} \cdot D^{t} \cdot(1+G T) \cdot P_{R}^{t} \cdot L_{R} \\
& \\
M A R_{A}^{t} & =A C N R_{A}^{t}-A C_{A}^{t} \\
& =A A C_{A} \cdot D^{t} \cdot\left(P N R_{A}^{t}-P_{A}^{t}\right) \cdot L_{A}
\end{aligned}
$$

Portanto, o valor presente líquido total estimado dos benefícios de redução de acidentes decorrentes da operação de novos serviços ferroviários é calculado segundo a Equação (4.35).

$$
\begin{aligned}
T A R= & \sum_{t=0}^{T} \frac{M A R_{C}^{t}+M A R_{B}^{t}+M A R_{R}^{t}+M A R_{A}^{t}}{(1+M A R R)^{t}} \\
= & \sum_{t=0}^{T} \frac{D^{t}}{(1+M A R R)^{t}} \cdot\left[A A C_{C} \cdot\left(P N R_{C}^{t}-P_{C}^{t}\right) \cdot L_{C}\right. \\
& +A A C_{B} \cdot\left(P N R_{B}^{t}-P_{B}^{t}\right) \cdot L_{B} \\
& -A A C_{R} \cdot(1+G T) \cdot P_{R}^{t} \cdot L_{R} \\
& \left.+A A C_{A} \cdot\left(P N R_{A}^{t}-P_{A}^{t}\right) \cdot L_{A}\right]
\end{aligned}
$$


É importante esclarecer que os benefícios monetários da redução de acidentes pela operação de Trens de Alto Desempenho (HPT) são calculados conforme a Equação (4.35). Entretanto, dadas as especificidades operacionais dos Trens de Alta Velocidade pela automatização do controle dos trens, nenhum acidente com veículos acima de $300 \mathrm{~km} / \mathrm{h}$ foi registrado até o momento (NASH, 2010) e, portanto, o valor da Equação 4.33 é nulo (i.e. $A R R_{R}=0$ para $H S T s$ ) resultando em maiores benefícios quanto a esse item da $C B A$ para essa tecnologia.

\subsubsection{Externalidades}

As externalidades em uma análise socioeconômica estão relacionadas às alterações dos impactos ambientais decorrentes da modificação do sistema de transporte de uma região. Segundo as recomendações do Banco Mundial contidas no TRN 17: Treatment of Environmental Impacts esses impactos são "distúrbios no ambiente natural e incluem as alterações no solo, recursos hídricos, vida animal e flora".

Mackie et al. (2003) sugerem um procedimento de Avaliação Ambiental (Environmental Assessment) para identificar e evitar (ou mitigar) os potenciais efeitos negativos decorrentes da implementação do investimento. Entretanto, dado o seu alto grau de especificidade e a grande quantidade de dados necessários para sua elaboração, considera-se nesta tese apenas a estimativa dos prováveis valores econômicos decorrentes das alterações das externalidades provocadas pela implantação de novos sistemas ferroviários para o transporte de passageiros.

Os valores médios decorrentes das externalidades de cada modo de transporte são obtidos de estudos prévios acerca dos seus efeitos sobre a biodiversidade e o meio urbano, e quanto à poluição do solo, ar e água, e de alterações da paisagem natural.

Sejam $A E C_{C}, A E C_{B}, A E C_{R}$ e $A E C_{A}$ os custos médios das externalidades (poluição ambiental, alteração do ambiente e efeitos sobre a biodiversidade) devido à operação dos Automóveis, Ônibus, Trens e Aviões, respectivamente. Assim, o valor econômico das externalidades para cada modo de transporte existente antes da implantação de uma infraestrutura ferroviária é dado pelo conjunto de equações a seguir. 


$$
\begin{aligned}
& E C N R_{C}^{t}=A E C_{C} \cdot D^{t} \cdot P N R_{C}^{t} \cdot L_{C} \\
& E C N R_{B}^{t}=A E C_{B} \cdot D^{t} \cdot P N R_{B}^{t} \cdot L_{B} \\
& E C N R_{A}^{t}=A E C_{A} \cdot D^{t} \cdot P N R_{A}^{t} \cdot L_{A}
\end{aligned}
$$

onde $E C N R_{C}^{t}=$ custo de externalidades pelo modo Automóvel no ano $t$ no cenário sem infraestrutura ferroviária; $E C N R_{B}^{t}=$ custo de externalidades pelo modo Ônibus no ano $t$ no cenário sem infraestrutura ferroviária; $E C N R_{A}^{t}=$ custo de externalidades pelo modo aéreo no ano $t$ no cenário sem infraestrutura ferroviária; $D^{t}=$ número total de viagens estimadas entre uma origem e um destino no ano $t$ (em ambos os sentidos); $P N R_{C}^{t}=$ percentual de usuários que escolhem o modo Automóvel no ano $t$ por motivo de viagem trabalho e lazer na ausência do modo ferroviário; $P N R_{B}^{t}=$ percentual de usuários que escolhem o modo Ônibus no ano $t$ por motivo de viagem trabalho e lazer na ausência do modo ferroviário; $P N R_{A}^{t}=$ percentual de usuários que escolhem o modo Avião no ano $t$ por motivo de viagem trabalho e lazer na ausência do modo ferroviário.

No caso da operação ferroviária os valores monetários das externalidades dos Automóveis, Ônibus, Trens e Aviões são calculados pelas respectivas Equação (4.39) à Equação (4.42). Novamente, o índice referente ao ano na proporção de usuários $\left(P_{C}^{t}, P_{B}^{t}, P_{R}^{t}\right.$ e $\left.P_{A}^{t}\right)$ distingue a utilização dos sistemas antes e depois do início da operação dos serviços.

$$
\begin{gathered}
E C_{C}^{t}=A E C_{C} \cdot D^{t} \cdot P_{C}^{t} \cdot L_{C} \\
E C_{B}^{t}=A E C_{B} \cdot D^{t} \cdot P_{B}^{t} \cdot L_{B} \\
E C_{R}^{t}=A E C_{R} \cdot D^{t} \cdot(1+G T) \cdot P_{R}^{t} \cdot L_{R} \\
E C_{A}^{t}=A E C_{A} \cdot D^{t} \cdot P_{A}^{t} \cdot L_{A}
\end{gathered}
$$

onde $E C_{C}^{t}=$ custo de externalidades pelo modo Automóvel no ano $t$ no cenário de operação ferroviária; $E C_{B}^{t}=$ custo de externalidades pelo modo Ônibus no ano $t$ no cenário de operação 
ferroviária; $E C_{R}^{t}=$ custo de externalidades dos trens no ano $t$ no cenário de operação ferroviária; $E C_{A}^{t}=$ custo de externalidades pelo modo aéreo no ano $t$ no cenário de operação ferroviária; $D^{t}=$ número total de viagens estimadas entre uma origem e um destino no ano $t$ (em ambos os sentidos); $P_{C}^{t}=$ percentual de usuários que escolhem o modo Automóvel no ano $t$ por motivo de viagem trabalho e lazer após implantação do modo ferroviário; $P_{B}^{t}=$ percentual de usuários que escolhem o modo Ônibus no ano $t$ por motivo de viagem trabalho e lazer após implantação do modo ferroviário; $P_{R}^{t}=$ percentual de usuários que escolhem o modo Trem no ano $t$ por motivo de viagem trabalho e lazer; $P_{A}^{t}=$ percentual de usuários que escolhem o modo Avião no ano $t$ por motivo de viagem trabalho e lazer após implantação do modo ferroviário.

Do exposto, a variação dos valores monetários devido às alterações de externalidade no ano $t$ para cada modo de transporte após o início da operação dos trens são calculados como se segue.

$$
\begin{aligned}
E R_{C}^{t} & =E C N R_{C}^{t}-E C_{C}^{t} \\
& =A E C_{C} \cdot D^{t} \cdot\left(P N R_{C}^{t}-P_{C}^{t}\right) \cdot L_{C} \\
E R_{B}^{t} & =E C N R_{B}^{t}-E C_{B}^{t} \\
& =A E C_{B} \cdot D^{t} \cdot\left(P N R_{B}^{t}-P_{B}^{t}\right) \cdot L_{B} \\
E R_{R}^{t} & =E C_{R}^{t} \\
& =A E C_{R} \cdot D^{t} \cdot(1+G T) \cdot P_{R}^{t} \cdot L_{R} \\
E R_{A}^{t} & =E C N R_{A}^{t}-E C_{A}^{t} \\
& =A E C_{A} \cdot D^{t} \cdot\left(P N R_{A}^{t}-P_{A}^{t}\right) \cdot L_{A}
\end{aligned}
$$

Portanto, o valor presente líquido total da variação dos valores econômicos das externalidades pela construção e operação de uma conexão ferroviária é calculado pela Equação 4.47. 


$$
\begin{aligned}
T E R= & \sum_{t=0}^{T} \frac{E R_{C}^{t}+E R_{B}^{t}+E R_{R}^{t}+E R_{A}^{t}}{(1+M A R R)^{t}} \\
= & \sum_{t=0}^{T} \frac{D^{t}}{(1+M A R R)^{t}} \cdot\left[A E C_{C} \cdot\left(P N R_{C}^{t}-P_{C}^{t}\right) \cdot L_{C}\right. \\
& +A E C_{B} \cdot\left(P N R_{B}^{t}-P_{B}^{t}\right) \cdot L_{B} \\
& -A E C_{R} \cdot(1+G T) \cdot P_{R}^{t} \cdot L_{R} \\
& \left.+A E C_{A} \cdot\left(P N R_{A}^{t}-P_{A}^{t}\right) \cdot L_{A}\right]
\end{aligned}
$$

\subsubsection{Medidas de Desempenho}

O Valor Presente Líquido Total $(T N P V)$ e a Taxa Interna de Retorno $(I R R)$ são as medidas de desempenho mais comuns para avaliação e comparação de projetos. Enquanto o foco do $T N P V$ é a relação entre os benefícios e custos totais ao longo da vida útil do projeto, a $I R R$ está relacionada à taxa decorrente do fluxo financeiro no horizonte de planejamento.

O TNPV é a soma dos valor presente líquido dos benefícios do projeto subtraído do valor presente líquido dos seus custos totais ao longo da vida útil descontados a uma taxa específica de atratividade. Algebricamente, essa medida de desempenho é definida pela Equação (4.48).

$$
\begin{aligned}
T N P V= & B^{0}+\frac{B^{1}}{(1+M A R R)}+\ldots+\frac{B^{t}}{(1+M A R R)^{t}} \\
& -C^{0}-\frac{C^{1}}{(1+M A R R)}-\ldots-\frac{C^{t}}{(1+M A R R)^{t}} \\
= & B^{0}-C^{0}+\frac{B^{1}-C^{1}}{(1+M A R R)}+\ldots+\frac{B^{t}-C^{t}}{(1+M A R R)^{t}} \\
= & \sum_{t=0}^{T} \frac{B^{t}-C^{t}}{(1+M A R R)^{t}} \\
= & (T R+T R V+T C S U C+T C S T S+T A R+T E R) \\
& -\left(I C^{C}+R S C^{A}+R S C^{O}+I C^{M}+R S C^{M}\right)
\end{aligned}
$$

onde $B^{t}=$ Benefícios Totais no ano $t$; $C^{t}=$ Custos Totais no ano $t$; onde $T R=$ valor presente líquido da receita total; $T R V=$ valor presente líquido do valor residual da infraestrutura; $T C S U C=$ valor presente líquido do excedente do consumidor devido à tarifa; $T C S T S=$ valor 
presente líquido do excedente do consumidor devido ao tempo de viagem ;TAR = valor presente líquido devido à redução de acidentes ; TER = valor presente líquido devido à redução de externalidades; $I C^{C}=$ valor presente líquido dos investimentos para construção da infraestrutura; $R S C^{A}$ = valor presente líquido dos investimentos para aquisição de material rodante; $R S C^{O}=$ valor presente líquido das despesas de operação do material rodante; $I C^{M}=$ valor presente líquido das despesas de manutenção da infraestrutura; $R S C^{M}=$ valor presente líquido das despesas de manutenção do material rodante.

Nesta tese, o termo "Valor Presente Líquido Econômico" ( $E N P V$ ) é utilizado para representar somente a diferença entre o valor presente líquido dos benefícios econômicos do projetos e os seus respectivos custos econômicos segundo a Equação 4.49 .

$$
E N P V=(T R+T R V)-\left(I C^{C}+R S C^{A}+R S C^{O}+I C^{M}+R S C^{M}\right)
$$

Por outro lado, a $I R R$ é estimada como a taxa de desconto que anula os custos e benefícios econômicos totais do projeto no ano base de cálculo da avaliação socioeconômica, tal como caracterizado na Equação (4.50)

$$
\begin{aligned}
& I R R=\text { Taxa de Desconto }(M A R R) \text { quando } \\
& \quad(T R+T R V)-\left(I C^{C}+R S C^{A}+R S C^{O}+I C^{M}+R S C^{M}\right)=0
\end{aligned}
$$

Do ponto de vista estritamente econômico, um projeto é considerado viável se $E N P V>0$ e se o $I R R$ calculado é maior que um valor predefinido, em geral maior que uma taxa de oportunidade oficializada pelo governo, tal como a taxa SELIC (Sistema Especial de Liquidação e de Custódia) no caso brasileiro. Para esta pesquisa de doutorado, um cenário é considerado economicamente viável se $E N P V>0$ e a condição da $I R R$ maior que o valor médio da taxa SELIC de 10,9\% equivalente à media diária entre Janeiro/2014 e Janeiro/2015 (BCB, 2015a).

O WebTAG (TAG Unit 3.5.4 - Cost Benefit Analysis) apresenta a Razão Benefício-Custo (Benefit Cost Ratio - BCR) como uma medida de desempenho para análise de projetos de transporte por refletir a proporção dos benefícios sociais obtidos para cada unidade de investimento dispendido no projeto como apresentado na Equação (4.51).

$$
B C R=\frac{T R V+T C S U C+T C S T S+T A R+T E R}{I C^{C}+R S C^{A}+R S C^{O}+I C^{M}+R S C^{M}}
$$


Em um aspecto mais abrangente, um projeto é considerado viável do ponto de vista dos custos e benefícios totais quando o valor presente líquido total é positivo $(T N P V>0)$ e o resultado da razão entre os benefícios sociais e os custos ao investidor e operador $B C R$ é maior ou igual a 1,50 (DE RUS et al., 2009).

Cabe ressaltar novamente que no cômputo das medidas de desempenho socieconômicas o valor residual ao final do horizonte de planejamento $(T V R)$ é considerado como um benefício econômico e social simultaneamente, pelo fato de que os investimentos representam um bem material com valor econômico ao final do horizonte de planejamento e que pode ser considerado um bem intangível pertencente à sociedade. Assim, além de benefício econômico esse valor residual também é considerado um benefício social por representar uma infraestrutura revertida à sociedade após sua construção e utilização, de modo que os valores estimados são considerados tanto no cálculo do $E N P V$ quanto do $B C R$. 


\section{Cenários para 0 Transporte Ferroviário Regional de Passageiros}

\section{Capítulo}

5

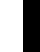

A avaliação socioeconômica de uma rede ferroviária hipotética na Região Sudeste do Brasil é apresentada neste capítulo mediante a operação exclusiva de HPTs ou de HSTs para verificação da hipótese de tese proposta. Ao considerar a formulação de análise custo-benefício do Capítulo 4, os investimentos requeridos para construção da infraestrutura são obtidos pela execução do GA em paralelo em diferentes conexões ferroviárias conforme discutido no Capítulo 2, e a distribuição de viagens e divisão modal são consideradas segundo as análises do Capítulo 3.

Para caracterização da rede ferroviária hipotética foram consideradas as cidades da Região Sudeste conforme a estruturação hierárquica dos centros urbanos brasileiros definido pelo IBGE no estudo denominado "Regiões de influência das cidades 2007" (HENDERSON, 2008). Nessa publicação, a Região Metropolitana de São Paulo é denominada "Grande Metrópole Nacional", a do Rio de Janeiro é "Metrópole Nacional"e a de Belo Horizonte é simplesmente "Metrópole".

Em uma subdivisão dessa classificação, as regiões metropolitanas de Vitória e Campinas são denominadas "Capitais Regionais A", as cidades de Uberlândia, Juiz de Fora, Montes Claros, Uberaba, Ribeirão Preto e São José do Rio Preto são denominadas "Capitais Regionais B"e outras 21 cidades na Região Sudeste são denominadas "Capitais Regionais C". Nessa hierarquia, outras cidades de menor porte são classificadas como "Centros Sub-Regionais A ou B".

Nesta tese a Região Metropolitana de São Paulo, do Rio de Janeiro e de Belo Horizonte, e as "Capitais Regionais A" e "Capitais Regionais B" foram consideradas como os 11 centros urbanos a serem conectados por uma rede ferroviária hipotética de trens de passageiros, cujas respectivas siglas podem se consultadas no Apêndice B. 
Assim, uma análise da posição relativa desses centros urbanos e avaliação dos fluxos de passageiros resultantes das considerações do Capítulo 3 resultaram na definição da rede ferroviária hipotética ilustrada na Figura 5.1.

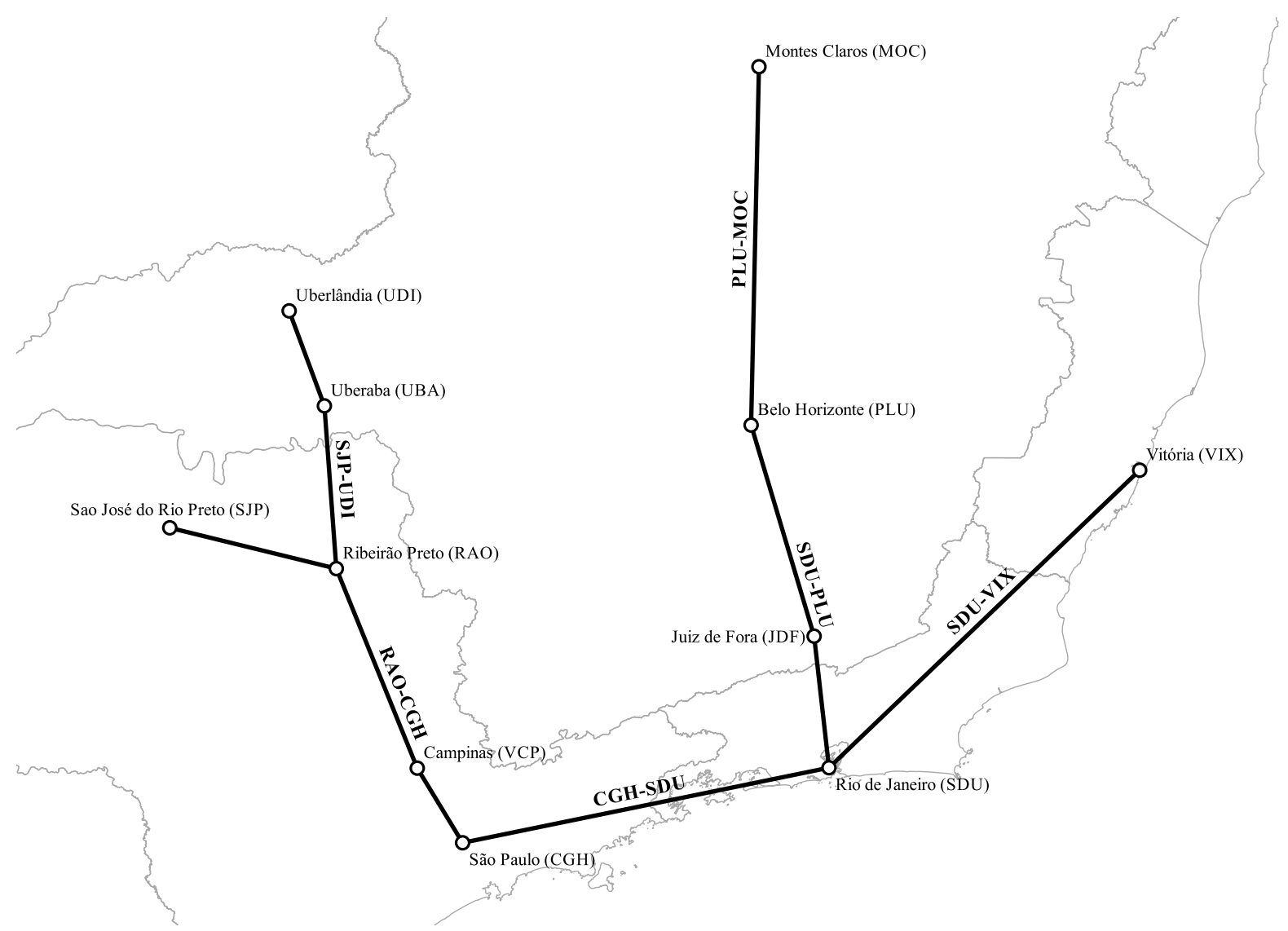

Figura 5.1 - Proposta de rede ferroviária hipotética conectando os principais centros urbanos da Região Sudeste

Dado que a proposta de formulação de análise custo-benefício do Capítulo 4 requer a definição de estações iniciais e finais para os serviços ofertados (para cálculo do tempo total de viagem, frequência de operação etc.) e que a rede da Figura 5.1 é ramificada (impedindo a operação de um único serviço que atenda a todas as cidades), as suas conexões foram agrupadas regionalmente para satisfazer aquelas restrições e na tentativa de estabelecer serviços com distâncias de mesma ordem de grandeza e atendimento adequado da demanda estimada. Esse agrupamento resultou na segregação de serviços em 6 eixos ferroviários ilustrados na Figura 5.2. 


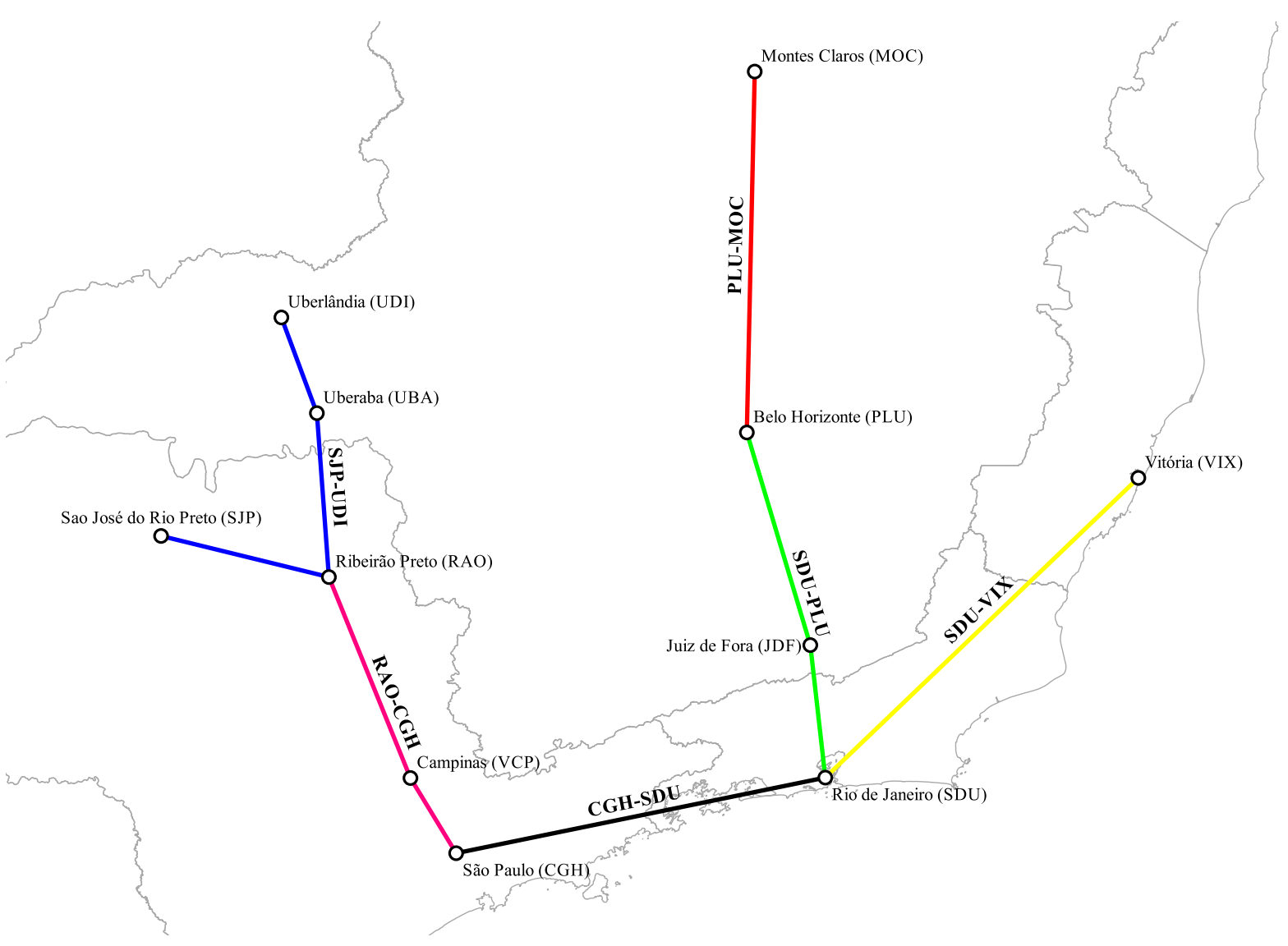

Figura 5.2 - Segregação dos serviços da rede hipotética em eixos ferroviários para avaliação socioeconômica

Assim, os serviços segregados nos eixos ferroviários da Figura 5.2 foram distinguidos conforme as seguintes denominações e respectivas cidades atendidas: SJP-UDI: São José do Rio Preto - Ribeirão Preto - Uberaba - Uberlândia; RAO-CGH: Ribeirão Preto - Campinas - São Paulo; CGH-SDU: São Paulo - Rio de Janeiro; SDU-VIX: Rio de Janeiro - Vitória; SDU-PLU: Rio de Janeiro - Juiz de Fora - Belo Horizonte; PLU-MOC: Belo Horizonte - Montes Claros.

No contexto dessa rede ferroviária foram admitidas as premissas a seguir para aplicação da formulação de análise custo-benefício proposta.

1. Somente um tipo de tecnologia ferroviária (HPT ou HST) circula em todos os arcos da rede em um cenário da análise socioeconômica;

2. O início da operação de um eixo ferroviário independe do término da construção da rede; 
3. Todos os trens são paradores nas cidades (estações) que pertencem a um eixo ferroviário, não havendo oferta de serviços expressos;

4. Os arcos da rede são construídos em função de uma produtividade média e todos têm construção iniciada no primeiro ano do horizonte de análise socioeconômica (2015);

5. As cidades de um eixo ferroviário começam a ser atendidas somente quando todos os seus respectivos arcos estiverem finalizados;

6. As características dos sistemas de transporte para os modos Automóvel, Ônibus e Avião mantêm-se inalteradas após início da operação dos serviços ferroviários e em todo o horizonte de análise socioeconômica;

7. Os usuários podem acessar qualquer cidade da rede pela troca de trens em estações que possuem conexão entre os eixos ferroviários da rede (Ribeirão Preto, São Paulo, Rio de Janeiro e Belo Horizonte);

8. Os tempos de parada dos trens são fixos e iguais em todas as estações, mesmo naquelas em que há transbordo entre eixos ferroviários;

9. Os investimentos estimados pelo AG para construção de novos alinhamentos ferroviários contemplam somente as regiões rurais, de modo que as faixas de domínio em áreas urbanas são definidas para circulação dos trens com velocidade reduzida. Nesse caso, os investimentos nos trechos urbanos são estimados com base em um comprimento médio de via na área urbana e um custo médio de superestrutura;

10. Os benefícios de receita são computados entre todos os pares de cidades, cujos números de viagens são representados no Apêndice B entre os anos de 2015 e 2050.

\subsection{Definição de Traçados e Estimativa de Investimentos}

Os traçados que conectam as cidades da rede ferroviária ilustrada na Figura 5.2 foram definidos com base na aplicação do $G A$ executado com múltiplas máquinas virtuais em paralelo conforme caracterizado no Capítulo 2. 
As máquinas virtuais acessadas remotamente pelo ambiente de infraestrutura computacional em nuvem da USP (NUVEMUSP, 2013) são equipamentos idênticos com oito processadores de memória RAM total de 32.768 MB e disco rígido com capacidade de 500 GB.

A apresentação dos resultados relativos à análise de desempenho do AG no Capítulo 2 demonstrou que a condição de distância média de 5 km entre Pontos de Interseção (PIs) e disponibilidade de 50 máquinas virtuais simultâneas é aquela que propicia resultados de maior acurácia para estimativa de investimentos na construção de novas ferrovias em áreas rurais - uma vez que permite o melhor detalhamento do traçado na projeção horizontal e longitudinal - e em menor tempo de processamento computacional.

Quanto aos investimentos na infraestrutura das áreas urbanas, infere-se um custo médio por quilômetro como parte de um processo de revitalização das vias outrora implantadas nessas regiões. Esse valor é equivalente ao custo médio por quilômetro de ferrovia indicado no Apêndice A ("Custo Médio da Via"em $\mathrm{R} \$ / \mathrm{km}$ ) dependendo da tecnologia ferroviária implantada.

Além disso, o Apêndice A contém os valores relativos aos demais parâmetros considerados na execução do $\mathrm{AG}$, aos custos unitários para estimativa do investimento total e às características geométricas dos traçados para cada tecnologia de trens.

Do ponto de vista dos raios mínimos das curvas horizontais circulares, são consideradas as análises indicadas na seção 2.3.1 (página 66) segundo os critérios de segurança e conforto em função da tecnologia ferroviária a ser operada na rede.

Assim, após executar cinco replicações do $G A$ entre as cidades da Figura 5.2 (em pontos específicos nas interfaces entre as zonas urbana e rural) foram obtidos os valores indicados na Tabela 5.1 e na Tabela 5.2 referentes às replicações que resultaram no menor valor de investimento total estimado para traçados apropriados à operação de $H P T$ e $H S T$, respectivamente. Nas tabelas também são apresentadas as estimativas para recuperação das linhas em áreas urbanas segundo o valor de custo médio indicado no Apêndice A. 

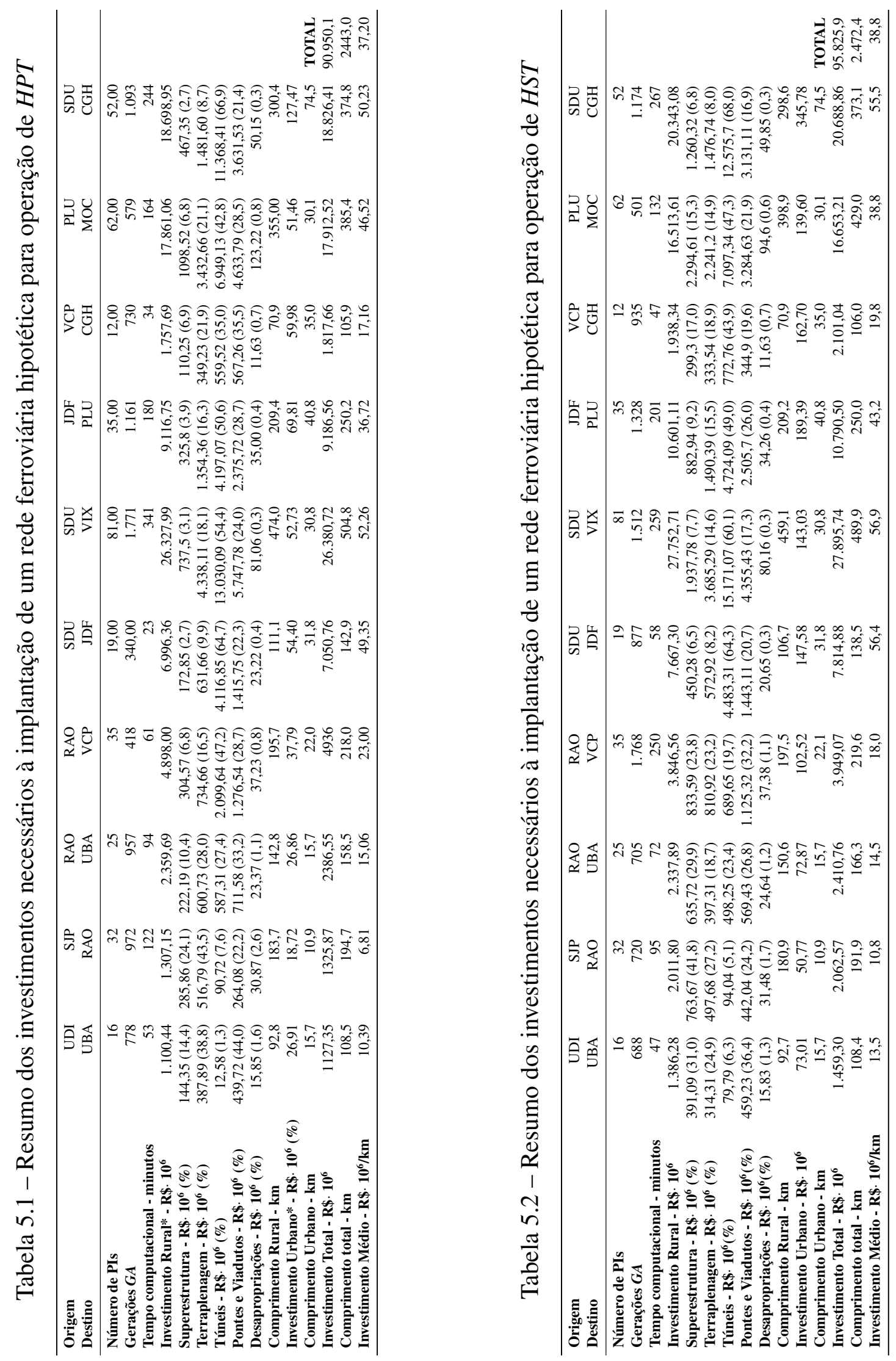
Primeiramente, há uma variação substancial das proporções entre os itens que compõem os investimentos totais (superestrutura, terraplenagem, túneis, pontes e desapropriações), tanto para construção da infraestrutura para operação de HPTs quanto para de HSTs.

Nas regiões com declividades do terreno mais acentuadas (SDU-JDF, SDU-VIX, JDF-PLU, VCP-CGH, PLU-MOC, SDU-CGH) os valores referentes à construção de túneis são os mais representativos entre os itens da composição de investimentos do $\mathrm{AG}$, com valores máximos de 64,7\% e 64,3\% na conexão entre o Rio de Janeiro (SDU) e Juiz de Fora (JDF) para traçados de HPT e HST respectivamente. Por outro lado, nas regiões mais planas (UDI-UBA, SJP-RAO, RAO-UBA, RAO-VCP) essas respectivas proporções reduzem-se expressivamente, com valores mínimos de 1,3\% e 5,1\% entre Ribeirão Preto (RAO) e São José do Rio Preto (SJP).

Cabe ressaltar que as proporções dos investimentos em desapropriação de áreas rurais são pequenas em comparação aos totais para ambas as tecnologias ferroviárias, com valores menores que $3,0 \%$ nas regiões mais planas e $1,0 \%$ naquelas de topografia acentuada.

Quando os investimentos totais são analisados em função da tecnologia ferroviária (HPT ou $H S T$ ), a diferença entre valores necessários para a construção da rede proposta na Figura 5.2 é relativamente pequena. No caso da operação de HPTs é necessário um investimento total de $\mathrm{R} \$ 90.950,11 \cdot 10^{6}$ para a construção de uma rede de $2.443,03 \mathrm{~km}$, perfazendo um investimento médio de $\mathrm{R} \$ 37,2 \cdot 10^{6} / \mathrm{km}$.

Por outro lado, a construção da rede para operação de $H S T s$ com comprimento total de $2.472,41 \mathrm{~km}$ requer um investimento total de $\mathrm{R} \$ 95.825,94 \cdot 10^{6}$, ou seja, um valor médio de $\mathrm{R} \$ 38,8 \cdot 10^{6} / \mathrm{km}$. Assim, em termos absolutos, a diferença de investimento total entre tecnologias ferroviárias é de $\mathrm{R} \$ 4.875,83 \cdot 10^{6}$, ou um aumento de 5,36\% do investimento para construção da rede de $H S T$ em detrimento de $H P T$. Em valores médios essa alteração de tecnologia representa um aumento de investimento de $\mathrm{R} \$ 1,6 \cdot 10^{6} / \mathrm{km}$, que pode ser considerado uma diferença pequena pelas perspectivas de redução dos tempo de viagem pela operação de HSTs.

A análise dos investimentos médios nos arcos da rede em relação às características do terreno também indica uma pequena diferença entre tecnologias. No caso de $H P T$, observa-se o investimento médio na conexão entre São José do Rio Preto e Ribeirão Preto (SJP-RAO), cuja 
topografia regional pode ser considerada plana, é de de $\mathrm{R} \$ 6,5 \cdot 10^{6} / \mathrm{km}$, em detrimento de um valor máximo de $\mathrm{R} \$ 52,3 \cdot 10^{6} / \mathrm{km}$ entre Rio de Janeiro e Vitória (SDU-VIX), em uma região com topografia montanhosa sobretudo nas proximidades daquela cidade.

Essas avaliações indicam que, a partir da premissa que a atual infraestrutura ferroviária da Região Sudeste não é compatível para a oferta competitiva de serviços ferroviários para o transporte de passageiros, o aumento relativo do investimento em uma rede para operação de $H S T$ é pequeno quando comparado à uma rede de HPT. Ou seja, nas condições analisadas, as características geométricas dos traçados para operação de uma determinada tecnologia ferroviária não exercem influencia significativa sobre os investimentos totais em uma nova infraestrutura.

A Figura 5.3 e Figura 5.4 a seguir representam os traçados da rede de menor investimento para operação de $H P T$ sobre a projeção de declividade do terreno e ocupação do solo respectivamente, e a Figura 5.5 e Figura 5.6 representam os alinhamentos de menor investimento total das conexões entre cidades para operação de $H S T$.

Além desses investimentos em novos alinhamentos ferroviários, aqueles referentes à construção das estações para acesso aos trens também podem afetar os resultados de uma avaliação socioeconômica. No caso das cidades contempladas na análise custo benefício apresentada nesta tese, todas possuem instalações que já foram utilizadas para oferta de serviços dessa natureza, algumas das quais ainda em operação, como nas regiões metropolitanas de São Paulo, Rio de Janeiro e Belo Horizonte.

Entretanto, existe uma dificuldade na estimativa dos investimentos requeridos na recuperação dessas instalações devido às suas particularidades arquitetônicas e atual estado de conservação. A literatura sobre análises socioeconômicas de novos investimentos em infraestruturas de transporte em geral desconsidera esse item de investimento nas investigações justamente devido às dificuldades de estimativas acuradas desses valores (e.g. DE RUS et al., 2009).

Desse modo, nas avaliações apresentadas nesta tese, também são desconsiderados valores específicos de investimentos nas estações para aplicação da formulação de análise custo-benefício. Entretanto, são apresentados alguns exemplos de pesquisas que sugerem valores para esse item na tentativa de avaliar os possíveis efeitos sobre as análises socioeconômicas. 


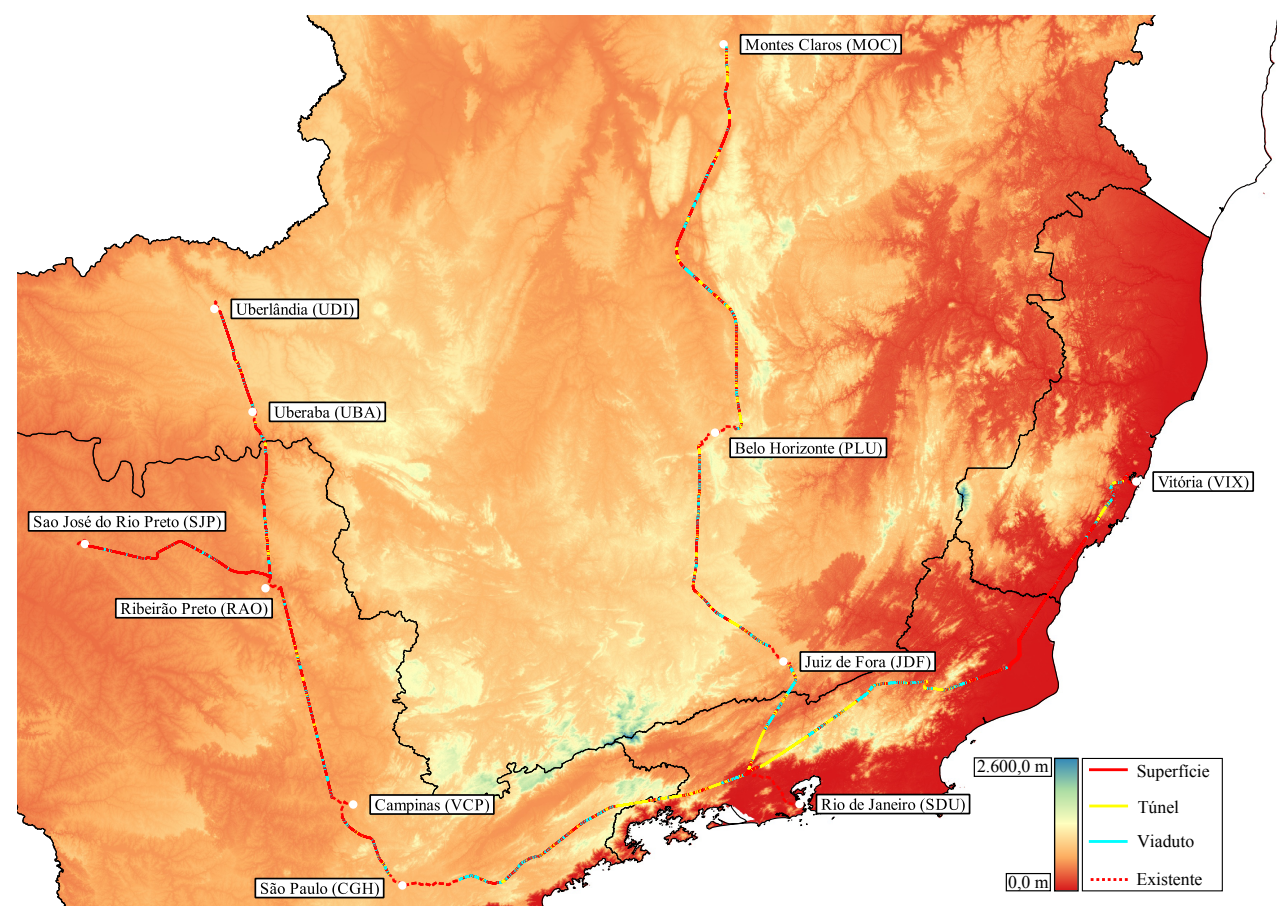

Figura 5.3 - Rede ferroviária estimada para o transporte de passageiros por HPT sobre a projeção de declividade do terreno

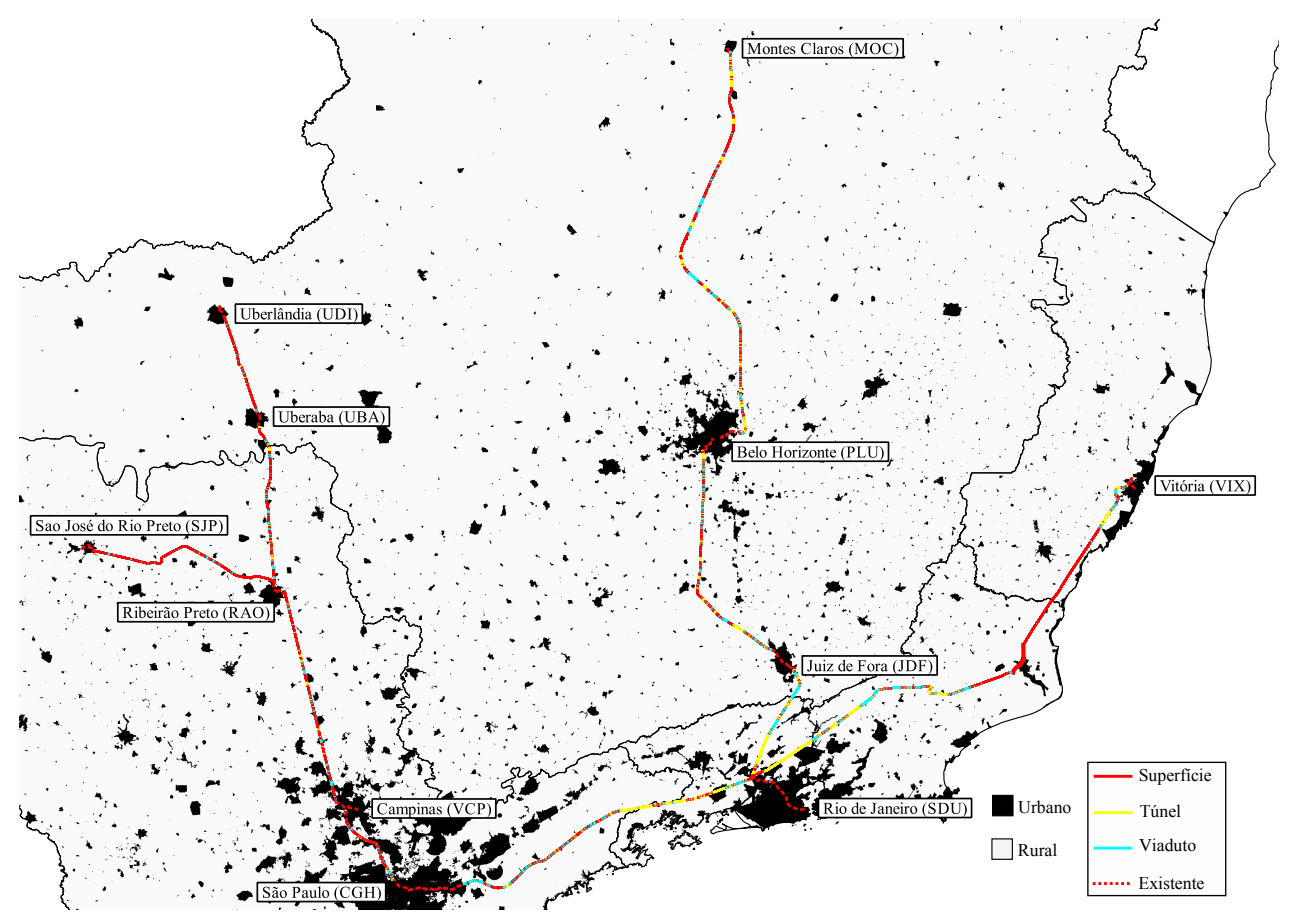

Figura 5.4 - Rede ferroviária estimada para o transporte de passageiros por HPT sobre a projeção de uso do solo 


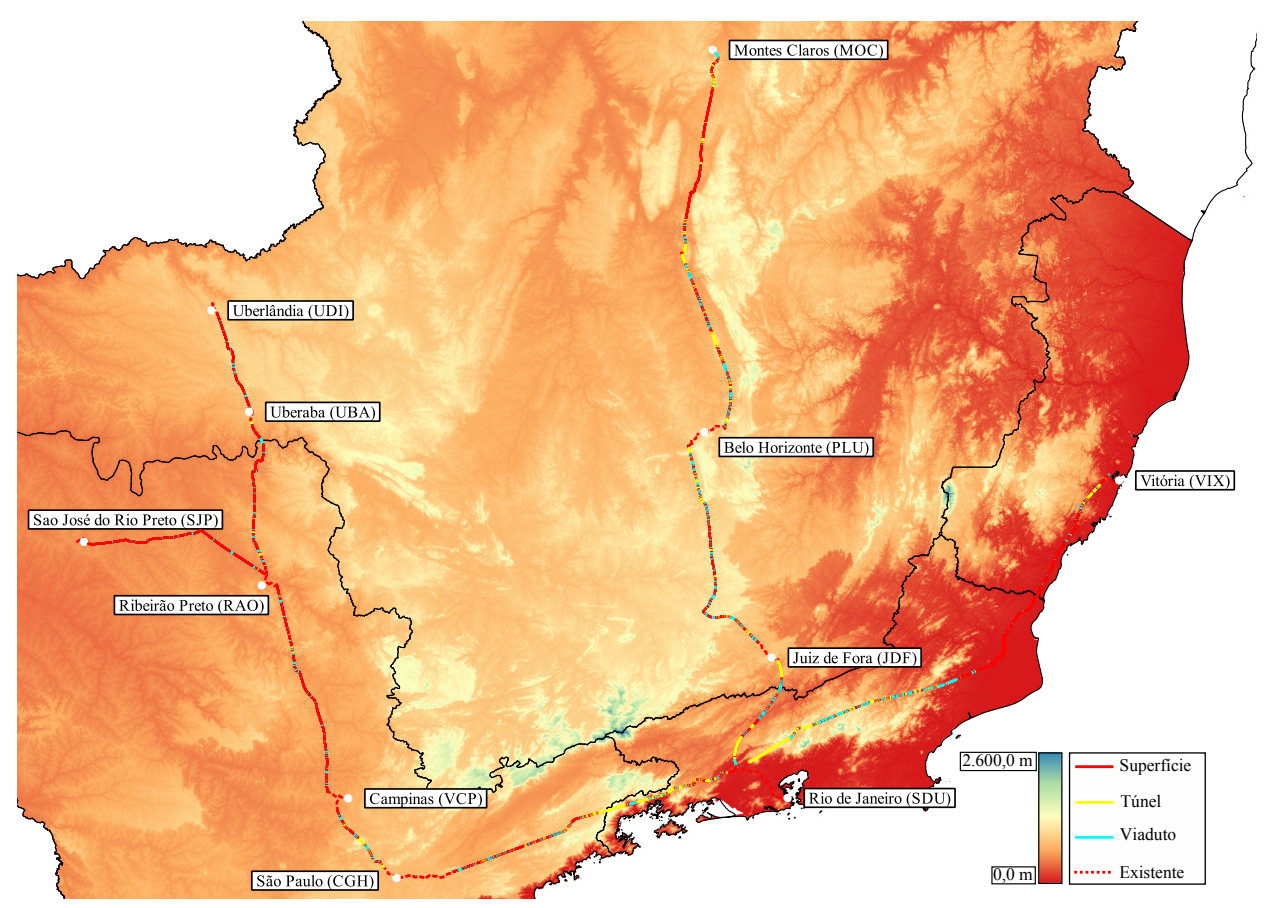

Figura 5.5 - Rede ferroviária estimada para o transporte de passageiros por HST sobre a projeção de declividade do terreno

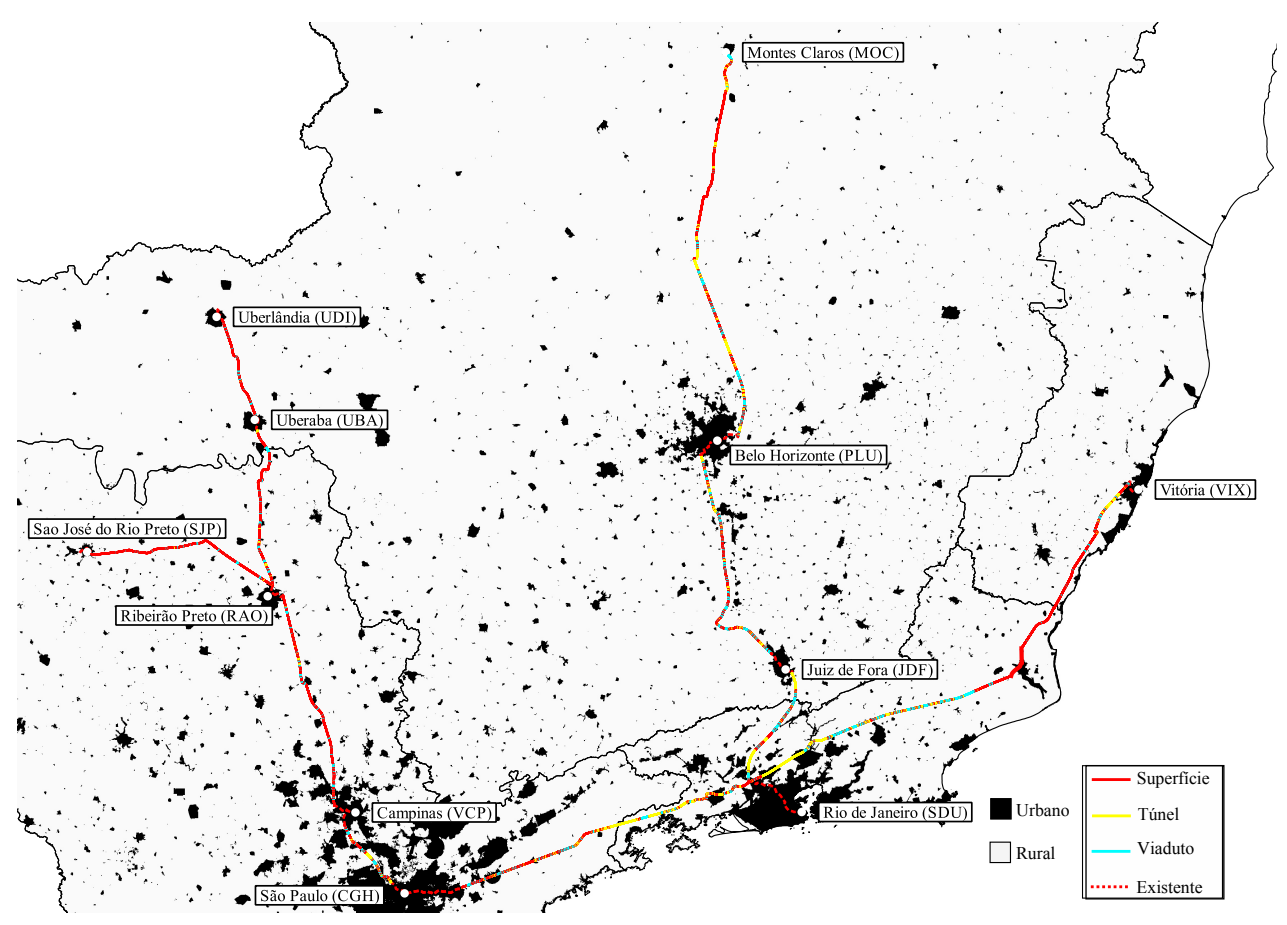

Figura 5.6 - Rede ferroviária estimada para o transporte de passageiros por HST sobre a projeção de uso do solo 
Ao analisar os efeitos da implantação de HSTs sobre a reestruturação do espaço urbano Bellet (2009) apresenta um valor estimado de $180 €$ milhões (ou aproximadamente $\mathrm{R} \$ 558$ milhões) para construção de uma nova estação na cidade de Logroño (Espanha). Em um relatório técnico sobre os efeitos da reestruturação de estações ferroviárias na Inglaterra, Gleave (2011) apresenta os seguintes investimentos nas respectivas localidades: $£ 62 \cdot 10^{6}$ em Machester Pic-

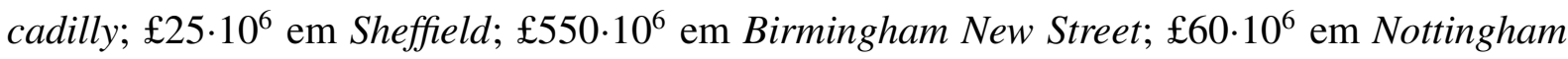
Hub; $£ 35 \cdot 10^{6}$ em Reading; $£ 6 \cdot 10^{6}$ em St. Helens; $£ 5 \cdot 10^{6}$ em St. Albans; e £4,5·10 6 em Epsom.

É importante salientar que, além da variação significativa, esses valores referem-se à investimentos em infraestruturas já existentes e com oferta regular de serviços ferroviários em contraposição à atual situação da maioria estações nas cidades contempladas na rede hipotética desta tese, o que incorre em maior dificuldade para estimativa acurada desse item da $C B A$.

Assim, em um exercício de avaliação da influência dos investimentos em estações sobre as estimativas totais para a rede proposta, se esses valores forem superestimados em relação àquele apresentado por Bellet (2009) e equivalentes a $\mathrm{R} \$ 1$ bilhão por estação, o valor total dos recursos aplicados em estações para a rede ferroviária proposta seria estimado em $\mathrm{R} \$ 11$ bilhões, ou aproximadamente $12,0 \%$ do investimento total para a construção dos traçados da rede de $H P T$ e de $11,5 \%$ para a rede de $H S T$.

Portanto, o valor equivalente à reestruturação das estações ferroviárias para a operação de trens de passageiros pode ser considerado como uma porcentagem dos investimentos totais na rede. Nesse caso, ao analisar a operação ferroviária sob a perspectiva de diferentes cenários dos investimentos totais da rede, é possível captar os efeitos da reestruturação de estações sobre as medidas de desempenho da $C B A$.

Sob a hipótese de que a construção de todos os arcos da rede hipotética proposta têm início no primeiro ano do horizonte de planejamento da avaliação socioeconômica é possível analisar o tempo total de finalização da rede - e, portanto, o período de obtenção de receita - em função da produtividade média de construção dos alinhamentos ferroviários. Nesse sentido, os comprimentos dos traçados estimados pelo GA (Tabela 5.1 e Tabela 5.2) e os respectivos períodos para finalização da rede são apresentados na Tabela 5.3 para ambas as tecnologias ferroviárias. 
Tabela 5.3 - Estimativa de tempo necessário para construção da rede ferroviária em cada cenário mediante a tecnologia ferroviária

\begin{tabular}{|c|c|c|c|c|c|c|c|c|c|}
\hline Origem & Destino & $\begin{array}{c}\text { Comprimento } \\
\text { HPT (km) }\end{array}$ & Conservador & $\begin{array}{l}\text { Cenário } \\
\text { Intermediário }\end{array}$ & Otimista & $\begin{array}{l}\text { Comprimento } \\
\text { HST }(\mathbf{k m})\end{array}$ & Conservador & $\begin{array}{l}\text { Cenário } \\
\text { Intermediário }\end{array}$ & Otimista \\
\hline UDI & UBA & 108,5 & 5 & 3 & 2 & 108,4 & 5 & 3 & 2 \\
\hline SJP & RAO & 194,7 & 8 & 4 & 2 & 191,9 & 8 & 4 & 2 \\
\hline RAO & UBA & 158,5 & 7 & 4 & 2 & 166,3 & 7 & 4 & 2 \\
\hline RAO & $\mathrm{VCP}$ & 217,8 & 9 & 5 & 3 & 219,6 & 9 & 5 & 3 \\
\hline SDU & JDF & 142,9 & 6 & 3 & 2 & 138,5 & 6 & 3 & 2 \\
\hline SDU & VIX & 504,8 & 21 & 11 & 6 & 489,9 & 20 & 10 & 5 \\
\hline JDF & PLU & 250,2 & 11 & 6 & 3 & 250,0 & 10 & 5 & 3 \\
\hline VCP & $\mathrm{CGH}$ & 105,9 & 5 & 3 & 2 & 106,0 & 5 & 3 & 2 \\
\hline PLU & MOC & 385,0 & 16 & 8 & 4 & 429,0 & 18 & 9 & 5 \\
\hline SDU & $\mathrm{CGH}$ & 374,8 & 15 & 8 & 4 & 373,1 & 15 & 8 & 4 \\
\hline
\end{tabular}

No cenário Conservador, em um horizonte de 35 anos (entre 2015 e 2050) a rede proposta na Figura 5.2 para a operação de HPT estaria totalmente conectada somente no ano de 2036 quando da finalização do trecho mais extenso entre o Rio de Janeiro e Vitória, resultando em apenas 14 anos de benefícios econômicos e sociais plenos.

Por outro lado, em um cenário Otimista com produtividade de construção de $100 \mathrm{~km} / \mathrm{ano}$, a finalização da rede dar-se-ia apenas seis anos após o primeiro período do horizonte de planejamento (em 2021), resultando em 29 anos de rendimento de benefícios.

Para uma rede com operação de $H S T$ no cenário Conservador, o tempo necessário para conexão total da rede seria de 20 anos, com conclusão em 2035 e, portanto, com 15 anos de retorno econômico e social do investimento. No cenário Otimista esse período seria de 5 anos, com finalização da rede em 2020 pela conclusão do trecho entre o Rio de Janeiro e Vitória.

A produtividade da construção afeta significativamente o período disponível para obtenção de receita e cômputo dos benefícios sociais advindos do uso do sistema ferroviário implantado. Portanto, o tempo de finalização dos arcos da rede ferroviária é um fator importante para garantia de retorno do investimento, sobretudo em termos de benefícios econômicos.

\subsection{Estimativa de Número de Passageiros e Divisão Modal}

Quanto à estimativa do número de viagens pelos modos de transporte atualmente disponíveis na Região Sudeste do Brasil (Automóvel, Ônibus e, eventualmente, Avião) foram consideradas as projeções dos modelos indicados na seção 3.1.6 (página 119) para os anos do horizonte de avaliação socioeconômica, cujos valores estão representados nas tabelas do Apêndice B. 
Quanto à divisão modal, apesar dos modelos de utilidade referirem-se à escolha dos modos de transporte em termos desagregados - ou seja, representativos das probabilidades de escolha em função do perfil do usuário e da viagem-, na aplicação da formulação de $C B A$ considera-se que essas escolhas representam as características médias da população extrapolando-se, assim, a decisão individual para um nível agregado de divisão modal.

Segundo o Modelo D escolhido para cálculo das probabilidades de escolha modal (seção 3.2.4.4, página 164), as funções utilidade dos modos de transporte podem ser representadas por (5.1) e (5.2) para os motivos trabalho e lazer, respectivamente, conforme os coeficientes da Tabela C.7 e Tabela C.8 do Apêndice B.

$$
\left\{\begin{array}{l}
V_{C A R}=-0,00497 \cdot T T_{C A R}-0,00841 \cdot P E_{C A R}-0,00841 \cdot T O_{C A R} \\
V_{B U S}=-0,51200-0,00497 \cdot T T_{B U S}-0,00511 \cdot F R_{B U S}-0,00240 \cdot F A_{B U S} \\
V_{H P T}=-0,51200-0,00497 \cdot T T_{H P T}-0,00511 \cdot F R_{H P T}-0,00240 \cdot F A_{H P T} \\
V_{H S T}=-0,51200-0,00497 \cdot T T_{H S T}-0,00511 \cdot F R_{H S T}-0,00240 \cdot F A_{H S T} \\
V_{A I R}=-0,51200-0,00497 \cdot T T_{A I R}-0,00511 \cdot F R_{A I R}-0,00240 \cdot F A_{A I R}
\end{array}\right.
$$

$$
\left\{\begin{array}{l}
V_{C A R}=-0,00788 \cdot T T_{C A R}-0,00261 \cdot P E_{C A R}-0,00261 \cdot T O_{C A R} \\
V_{B U S}=-0,00788 \cdot T T_{B U S}-0,00354 \cdot F A_{B U S} \\
V_{H P T}=-1,06000-0,00788 \cdot T T_{H P T}-0,00261 \cdot F A_{H P T} \\
V_{H S T}=-1,06000-0,00788 \cdot T T_{H S T}-0,00261 \cdot F A_{H S T} \\
V_{A I R}=-1,43000-0,00788 \cdot T T_{A I R}-0,00261 \cdot F A_{A I R}
\end{array}\right.
$$

Essas funções utilidade que caracterizam as tecnologias ferroviárias apresentam os mesmos valores de coeficientes estimados pela maximização da função de verossimilhança. Isso indica que, sob a premissa de que as estimativas desses coeficientes são válidas para representação da escolha modal, os usuários têm idêntica percepção dos serviços de HPT e HST dependendo do motivo de viagem. Entretanto, isso não significa que a utilidade final para essas tecnologias também é idêntica, uma vez que os níveis dos seus respectivos atributos variam mediante o desempenho operacional (tempo de viagem e frequência dos serviços) e da política tarifária. 
Logo, para calcular o número de usuários potencialmente dispostos a utilizar o modo de transporte ferroviário - na eventualidade de implantação da rede proposta na Figura 5.2 - considerase a multiplicação do número total de viagens projetadas nos anos do horizonte de planejamento da análise socioeconômica pela proporção da escolha pelos trens mediante o motivo de viagem conforme especificado na Equação 4.12 (página 190).

Por sua vez, essas proporções de usuários que escolhem o modo ferroviário (HPT ou HST) são calculadas pelo produto das probabilidades de escolha modal segundo níveis específicos dos seus atributos (Equação 3.29 na página 154) e a proporção de usuários que viajam pelo motivo trabalho $(W)$ ou lazer $(L)$.

Pela dificuldade de estimativa da parcela de usuários em função do motivo de viagem, esses valores são inferidos como equivalentes à porcentagem de respondentes que acessaram a pesquisa de preferência declarada descrita no Capítulo 3 e que escolheram um dos motivos de viagem que já tivessem realizado anteriormente para condução do questionário proposto. Isso foi calculado para todos os acessos à pesquisa, mesmo para os questionários que foram iniciados mas não finalizados tal que, de 651 acessos, 52,2\% revelaram ter viajado pelo menos uma vez entre uma origem e um destino especificado pelo motivo trabalho e $47,8 \%$ revelaram ter viajado entre cidades por motivo lazer ou outros.

Portanto, a proporção de usuários que eventualmente viajariam pelo modo ferroviário a trabalho nas equações do Capítulo 4 é calculada como $P_{R w}=0,522 \cdot \operatorname{Pro} b_{R w}$ e a proporção daqueles que viajariam por motivo lazer ou outros é calculada por $P_{L w}=0,478 \cdot \operatorname{Prob}_{R l}$.

\subsection{Definição dos Tempos de Viagem e Tarifas}

Os custos aos usuários e os respectivos tempos de viagem (incluindo eventuais acesso e egresso) pelos diferentes modos de transporte referem-se aos níveis dos atributos representados nas funções utilidade para cálculo das probabilidades de divisão modal.

Para definição dos tempos totais de viagem pelos diferentes modos de transporte propõe-se uma abordagem que considera os tempos de acesso e egresso, e aqueles efetivamente dispendidos nos veículos conforme a representação esquemática da Figura 5.7. 


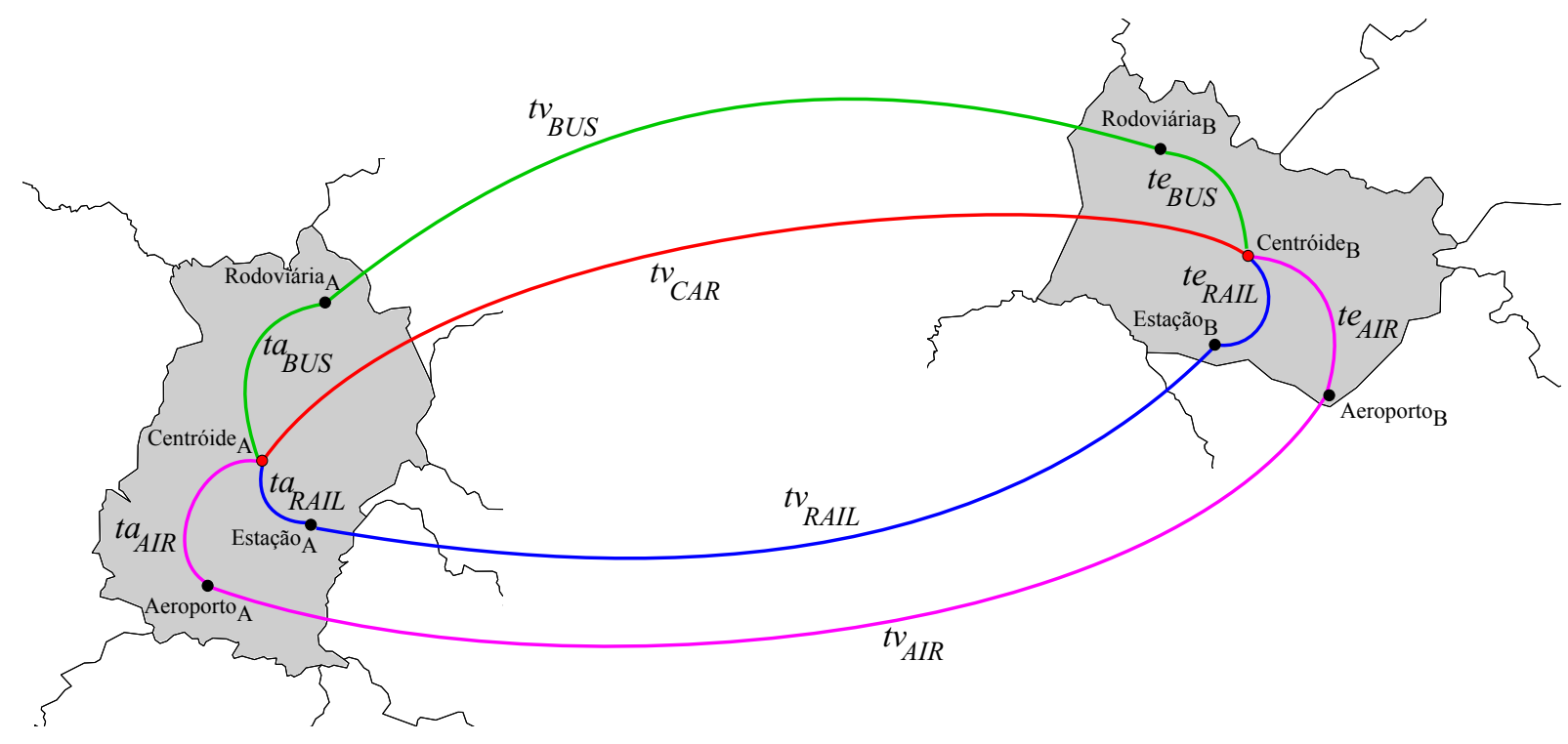

Figura 5.7 - Representação esquemática para estimativa dos tempos de viagem entre uma origem (A) e um destino (B) pelos diferentes modos de transporte

Segundo essa representação, os tempos de viagem para cada modo de transporte podem ser calculados conforme (5.3).

$$
\left\{\begin{array}{l}
T T_{C A R}=t v_{C A R} \\
T T_{B U S}=t a_{B U S}+t v_{B U S}+t e_{B U S} \\
T T_{R A I L}=t a_{R A I L}+t v_{R A I L}+t e_{R A I L} \\
T T_{A I R}=t a_{A I R}+t v_{A I R}+t e_{A I R}
\end{array}\right.
$$

onde $t v_{C A R}=$ tempo de viagem por Automóvel; $t a_{B U S}=$ tempo de acesso ao modo Ônibus; $t v_{B U S}=$ tempo de viagem pelo modo Ônibus; $t e_{B U S}=$ tempo de egresso do modo Ônibus; $t a_{R A I L}=$ tempo de acesso ao modo Trem $(H P T$ ou $H S T) ; t v_{R A I L}=$ tempo de viagem pelo modo Trem $(H P T$ ou $H S T) ; t e_{R A I L}=$ tempo de egresso do modo Trem $(H P T$ ou $H S T) ; t a_{A I R}=$ tempo de acesso ao modo Avião; $t v_{A I R}=$ tempo de viagem pelo modo Avião; $t e_{A I R}=$ tempo de egresso pelo modo Avião.

Os tempos de acesso e egresso às infraestruturas para Ônibus, Avião e Trem (mesmo essas últimas não sejam utilizadas atualmente) são estimados por uma regressão linear multivariada em relação às respostas obtidas na pesquisa de preferência declarada. 
Os valores indicados nos histogramas da Figura 3.21 e Figura 3.22 no caso de Ônibus e Avião quanto aos tempos de acesso e egresso de fato dispendidos pelos modos de transporte utilizados foram agrupados, respectivamente, àqueles da Figura 3.23 e Figura 3.24 para Ônibus, Trem e Avião, referentes aos tempos estimados pelos participantes para os modos de transporte que não utilizaram nas viagens. Esse agrupamento deu-se pelo fato de que as distribuições das respostas em ambos os casos (para as viagens efetivamente realizadas e para os tempos estimados) são semelhantes com valores no intervalo entre 30 minutos e 1 hora.

As variáveis independentes utilizadas na regressão foram a densidade populacional e a distância entre as estações (rodoviária e ferroviária) e aeroportos ao centroide das respectivas cidades de origem (no caso dos tempos de acesso) e destino (para os tempo de egresso), cujos valores resultantes das calibrações são os coeficientes indicados na Tabela 5.4.

Tabela 5.4 - Regressão dos tempos de acesso e egresso segundo a pesquisa de preferência declarada e as características das cidades

\begin{tabular}{|c|c|c|c|c|c|c|c|c|c|}
\hline \multirow[t]{2}{*}{ Modo } & \multirow[t]{2}{*}{ Tempo } & \multirow[t]{2}{*}{$R^{2}$} & \multirow{2}{*}{$\begin{array}{c}R^{2} \\
\text { ajustado }\end{array}$} & \multicolumn{3}{|c|}{$\begin{array}{c}\text { Densidade populacional } \\
\left(\mathbf{h a b} / \mathbf{k m}^{2}\right)\end{array}$} & \multicolumn{3}{|c|}{$\begin{array}{c}\text { Distância } \\
\text { ao centroide }(\mathrm{km})\end{array}$} \\
\hline & & & & Coef. & t-test & p-value & Coef. & t-test & $p$-value \\
\hline \multirow{2}{*}{ Ônibus } & Acesso & 0,715 & 0,714 & 0,021 & 22,173 & 0,000 & 2,552 & 6,425 & 0,000 \\
\hline & Egresso & 0,624 & 0,623 & 0,026 & 9,387 & 0,000 & 7,621 & 7,901 & 0,000 \\
\hline \multirow{2}{*}{ Trem } & Acesso & 0,715 & 0,714 & 0,019 & 12,745 & 0,000 & 3,953 & 3,985 & 0,000 \\
\hline & Egresso & 0,642 & 0,640 & 0,027 & 11,258 & 0,000 & 8,571 & 9,436 & 0,000 \\
\hline \multirow{2}{*}{ Avião } & Acesso & 0,732 & 0,731 & 0,016 & 13,050 & 0,000 & 2,367 & 8,816 & 0,000 \\
\hline & Egresso & 0,637 & 0,636 & 0,014 & 8,124 & 0,000 & 4,168 & 12,449 & 0,000 \\
\hline
\end{tabular}

Os tempos efetivamente em viagem pelos modos Ônibus e Trem foram estimados com base na velocidade média dos veículos, de $80 \mathrm{~km} / \mathrm{h}$ para o primeiro, e $150 \mathrm{~km} / \mathrm{h}$ e $300 \mathrm{~km} / \mathrm{h}$ para os HPT e HST respectivamente, e a distância média entre estações. No caso do Automóvel foi considerada uma velocidade média de $90 \mathrm{~km} / \mathrm{h}$ (menor do que a velocidade regulamentada das rodovias, em geral de $110 \mathrm{~km} / \mathrm{h}$ ) na tentativa de representar os tempos requeridos para entrada e saída das zonas urbanas das cidades.

Para o modo Avião foram considerados os tempos médios de bloco (Tabela 5.5) provenientes dos relatórios da ANAC (ANAC, 2014b) entre os pares de origem e destinos da rede da Figura 5.2 que possuem conexões aéreas operantes comercialmente no ano de 2015. 
Tabela 5.5 - Tempo médio de bloco pelo modo Aéreo (minutos) - Fonte: ANAC (2014b)

\begin{tabular}{ccccccccccc}
\hline \multirow{2}{*}{ ORIGEM } & \multicolumn{10}{c}{ DESTINO } \\
\cline { 2 - 11 } & SDU & PLU & VIX & VCP & UDI & JDF & MOC & UBA & RAO & SJP \\
\hline CGH & 66 & 86 & 93 & 48 & 84 & - & 89 & 84 & 63 & 65 \\
SDU & - & 79 & 71 & 68 & 127 & - & - & - & 94 & - \\
PLU & - & - & 69 & 84 & 74 & 57 & 62 & 81 & 83 & 83 \\
VIX & - & - & - & 99 & - & - & - & - & 146 & - \\
VCP & - & - & - & - & 86 & 93 & - & 78 & 59 & 73 \\
UDI & - & - & - & - & - & - & - & 28 & 48 & 47 \\
JDF & - & - & - & - & - & - & - & - & - & - \\
MOC & - & - & - & - & - & - & - & - & - & - \\
UBA & - & - & - & - & - & - & - & - & 32 & - \\
RAO & - & - & - & - & - & - & - & - & - & 39 \\
\hline
\end{tabular}

Quanto à estimativa do valor monetário desembolsado pelos usuários para os modos Automóvel, Ônibus e Avião foram consideradas as formulações da Tabela 3.11 (página 131) equivalentes aos níveis dos atributos da pesquisa de preferência declarada em função da distância de viagem. No caso de um novo modo ferroviário (HPT ou HST) foram considerados diferentes valores de tarifa média por quilômetro e calculados os respectivos itens da análise custo-benefício de modo a identificar aquele valor médio que maximizasse uma medida de desempenho da rede ferroviária conforme procedimento descrito na seção a seguir.

\subsection{Análise Socioeconômica de Cenários}

A partir das estimativas de investimentos, do número de viagens no ano de 2015 e projetadas até 2050, e a modelagem de propensão à escolha modal proposta, um conjunto de planilhas eletrônicas foi elaborado para cálculo das medidas de desempenho da análise socioeconômica.

Dadas as incertezas inerentes à aplicação do método de $C B A$, propõe-se três cenários distintos pela variação dos investimentos estimados pelo $G A$, da produtividade de construção da infraestrutura e do tráfego gerado pela demanda reprimida após início da operação dos sistemas.

Assim, os valores indicados na Tabela 5.6 caracterizam os cenários "Otimista", "Intermediário" e "Conservador", sendo o viés do otimismo caracterizado pelo coeficiente $\varphi$ da Equação 4.2 (página 184), a produtividade da construção definida pelo coeficiente $\omega$ da Equação 4.1 (página 183) e a porcentagem de tráfego gerado estabelecida pelo parâmetro GT conforme a Equação 4.4 na página 185. 
Tabela 5.6 - Definição dos parâmetros dos cenários para avaliação socioeconômica

\begin{tabular}{lccc}
\hline Cenário & $\begin{array}{c}\text { Viés do } \\
\text { Otimismo }(\varphi-\%)\end{array}$ & $\begin{array}{c}\text { Produtividade de } \\
\text { Construção }(\omega-\mathbf{k m} / \mathbf{a n o})\end{array}$ & $\begin{array}{c}\text { Tráfego } \\
\text { Gerado }(G T-\boldsymbol{\%})\end{array}$ \\
\hline Otimista & 10 & 100 & 40 \\
Intermediário & 50 & 50 & 25 \\
Conservador & 100 & 25 & 10 \\
\hline
\end{tabular}

Uma vez que a porcentagem de usuários do modo ferroviário depende da frequência dos serviços para viagens por motivo trabalho $(W)$, e que esse intervalo entre trens é função do número de passageiros que utilizariam o sistema, é necessário que uma dessas variáveis seja estabelecida para que a outra possa ser calculada.

Assim, em uma abordagem iterativa, para todos os anos do horizonte de planejamento, o valor inicial de intervalo horário entre trens é definido a priori como igual a 6 horas e a divisão modal calculada com base nesse valor e nos demais níveis dos atributos dos modos de transporte, sendo a frequência de serviços calculada conforme a Equação 4.5 (página 185).

Se a diferença entre a frequência calculada e o valor inferido inicialmente for menor do que $5 \%$, então aquela é admitida como correta e os itens da análise socioeconômica são estimados. Caso a condição não seja satisfeita, os valores iniciais de frequência são substituídos pelos calculados e novas iterações são executadas até que a diferença entre a frequência inferida e a calculada seja menor do que aquela porcentagem mínima.

Esse procedimento foi executado nos cenários mediante os parâmetros indicados no Apêndice D para valores de tarifa ferroviária por quilômetro $\left(F A_{R}\right.$ da Equação 4.12 na página 190) aplicados igualmente a todos os serviços operados nos eixos ferroviários da Figura 5.2. Os resultados indicados nesta seção foram obtidos considerando a taxa mínima de atratividade $(M A R R)$ de $5,1 \%$ (LOPEZ, 2008) e porcentagem do valor residual dos investimentos em infraestrutura igual a 60\%, sendo apresentadas algumas considerações sobre o efeito da variação desses dois parâmetros na última seção deste capítulo.

O Apêndice E contém as estimativas dos itens da avaliação socioeconômica nos cenários descritos, cujos valores presente líquido econômico $(E N P V)$ calculados pela Equação 4.49 (página 211) são representados na Figura 5.8 e na Figura 5.9 para HPTs e HSTs respectivamente. 


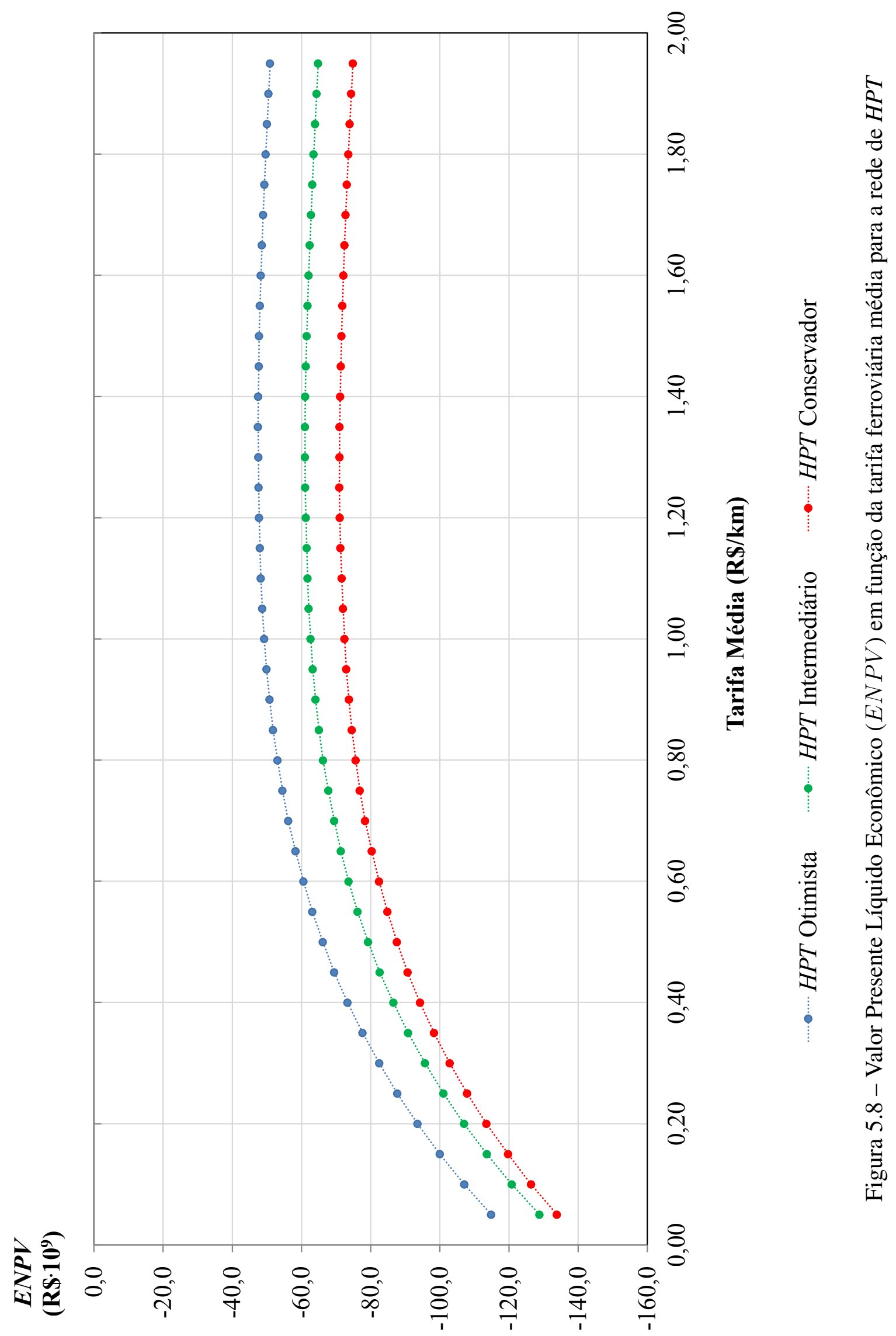




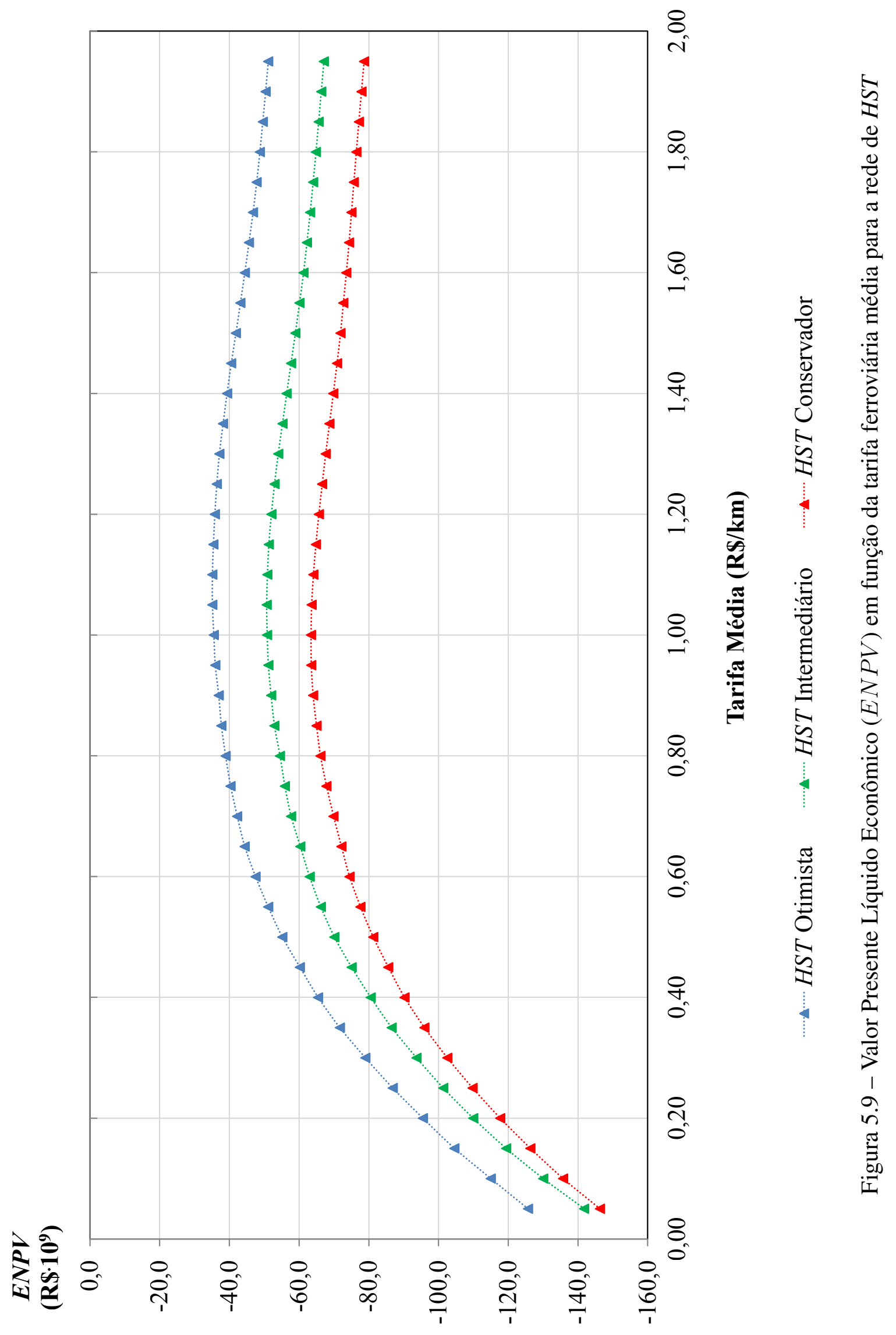


Os resultados desses gráficos indicam que o valor presente líquido econômico $(E N P V)$ devido à construção de uma infraestrutura e operação de $H S T$ é sempre maior que aquele para $H P T$ na comparação entre cenários equivalentes. Entretanto, mesmo para as tarifas médias que maximizam essa medida de desempenho, todos os cenários analisados resultam em $E N P V$ negativo sendo o melhor resultado um déficit de $\mathrm{R} \$-35,14 \cdot 10^{9}$ para tarifa média de $\mathrm{R} \$ 1,10 / \mathrm{km}$ no cenário Otimista para a operação da HSTs.

Uma vez que os resultados dessa medida de desempenho são negativos para todos os cenários, não há uma taxa interna de retorno $(I R R)$ que satisfaça a condição de equilíbrio do valor presente líquido dos custos e benefícios econômicos da rede e, portanto, o valor daquela medida de retorno do investimento é nula para os cenários analisados.

Cabe ressaltar que, mesmo resultando em valores totais negativos para o valor presente líquido econômico, as tarifas médias que maximizam o $E N P V$ são sempre menores para a operação de $H S T$ do que para os HPT na comparação entre cenários respectivos. Para os HPTs, as tarifas consideradas ótimas são de $\mathrm{R} \$ 1,25 / \mathrm{km}, \mathrm{R} \$ 1,35 / \mathrm{km}$ e $\mathrm{R} \$ 1,35 / \mathrm{km}$ para os cenários Conservador, Intermediário e Otimista, respectivamente, enquanto que para os HSTs esses respectivos valores são $\mathrm{R} \$ 1,00 / \mathrm{km}, \mathrm{R} \$ 1,05 / \mathrm{km}$ e $\mathrm{R} \$ 1,10 / \mathrm{km}$.

Essa diferença da tarifa ótima entre tecnologias nos respectivos cenários ocorre pelo fato de que, apesar de os investimentos totais na construção da rede de HST serem maiores do que a de $H P T$, os elementos que compõem a análise socioeconômico não variam linearmente com a tarifa média, sobretudo a demanda atendida pelos trens, a qual varia em função dos resultados das funções utilidade dos modos de transporte dependendo da tecnologia ferroviária estabelecida.

Conforme apresentado ao final da seção 5.1, os investimentos em estações ferroviárias podem ser considerados como uma parcela da majoração dos investimentos estimados para construção dos traçados da rede ferroviária dada a dificuldade de estimativa acurada daqueles valores.

Se, como no cenário Otimista, os valores obtidos pelo GA para construção da infraestrutura forem majorados em $10 \%$ e esse viés for devido à construção ou reestruturação de estações, o déficit referente ao valor presente líquido econômico seria de $\mathrm{R} \$-47,46 \cdot 10^{9}$ para $H P T$ e de $\mathrm{R} \$-35,14 \cdot 10^{9}$ para $H S T$ nas respectivas condições de tarifa que maximizam o $E N P V$. 
Por outro lado, se for considerado um acréscimo de $25 \%$ dos investimentos devido às estações (acima da proporção exemplificada na seção 5.1, página 216) e 35\% em acréscimo de investimento estimados na construção dos traçados, o acréscimo total de investimento seria de $50 \%$ equivalente àquele aplicado no cenário Intermediário. Nesse cenário, reduzindo-se ainda as perspectivas de produtividade da construção da rede e de geração de demanda reprimida em relação ao cenário Otimista, o $E N P V$ nas respectivas tarifas ótimas para aquelas condições seriam de $\mathrm{R} \$-61,05 \cdot 10^{9}$ para $H P T$ e $\mathrm{R} \$-50,70 \cdot 10^{9}$ para $H S T$.

Ainda, se o sobrepreço dos investimentos em estações for equivalente a $50 \%$ do valor total para construção dos traçados e for considerado um acréscimo de $50 \%$ sobre os investimentos estimados pelo $G A$, além da baixa perspectiva de rendimento da construção da rede e captação da demanda reprimida resultando no cenário Conservador, o déficit do ENPV seria de R\$$70,97 \cdot 10^{9}$ e de $\mathrm{R} \$-63,43 \cdot 10^{9}$ respectivamente para $H P T$ e $H S T$.

As estimativas de valor presente líquido total $(T N P V)$ indicadas no Apêndice E quando os investimentos e despesas operacionais são comparados com os benefícios econômicos e sociais resultam na Figura 5.10 e Figura 5.11 para operação de HPT e HST respectivamente. 


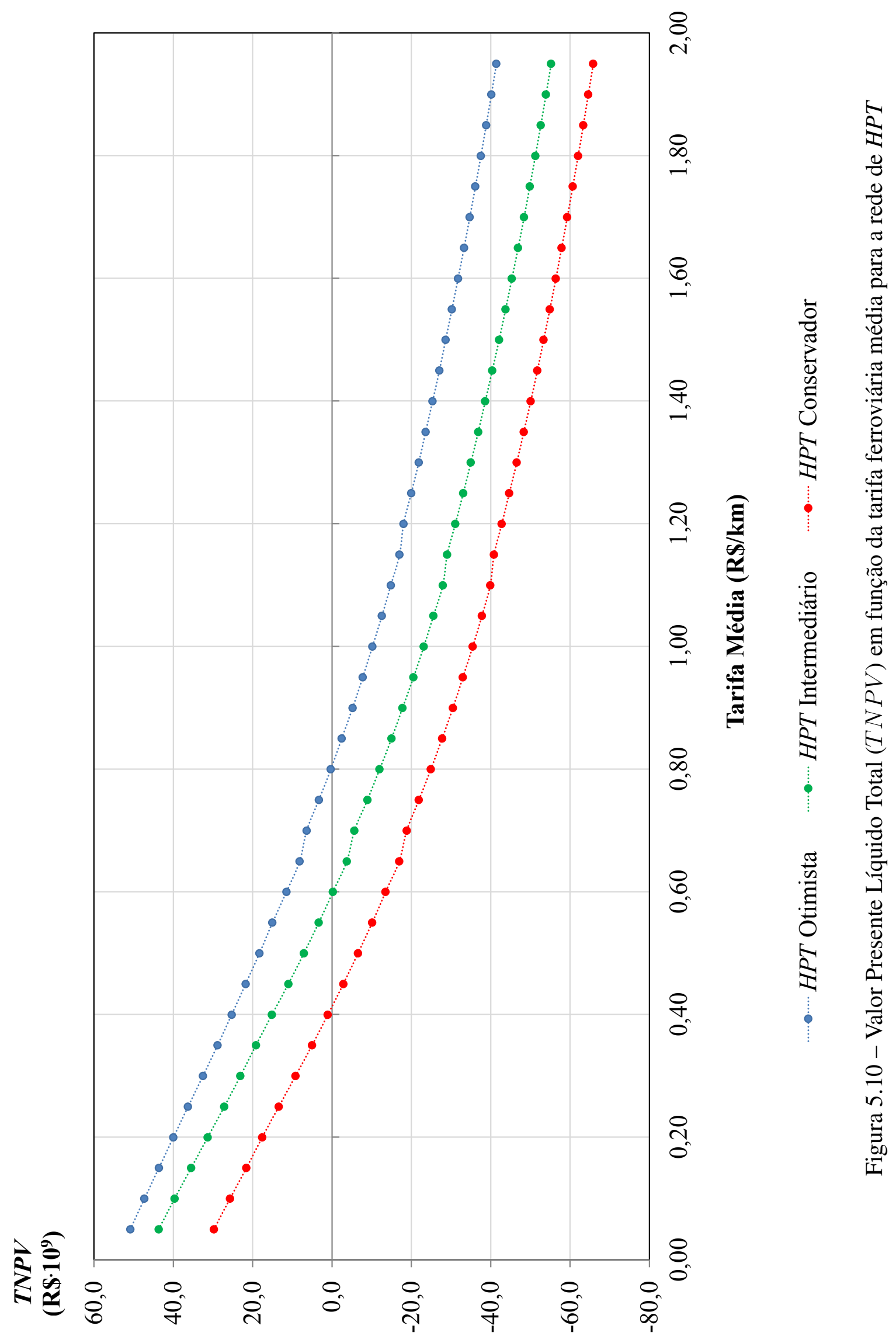




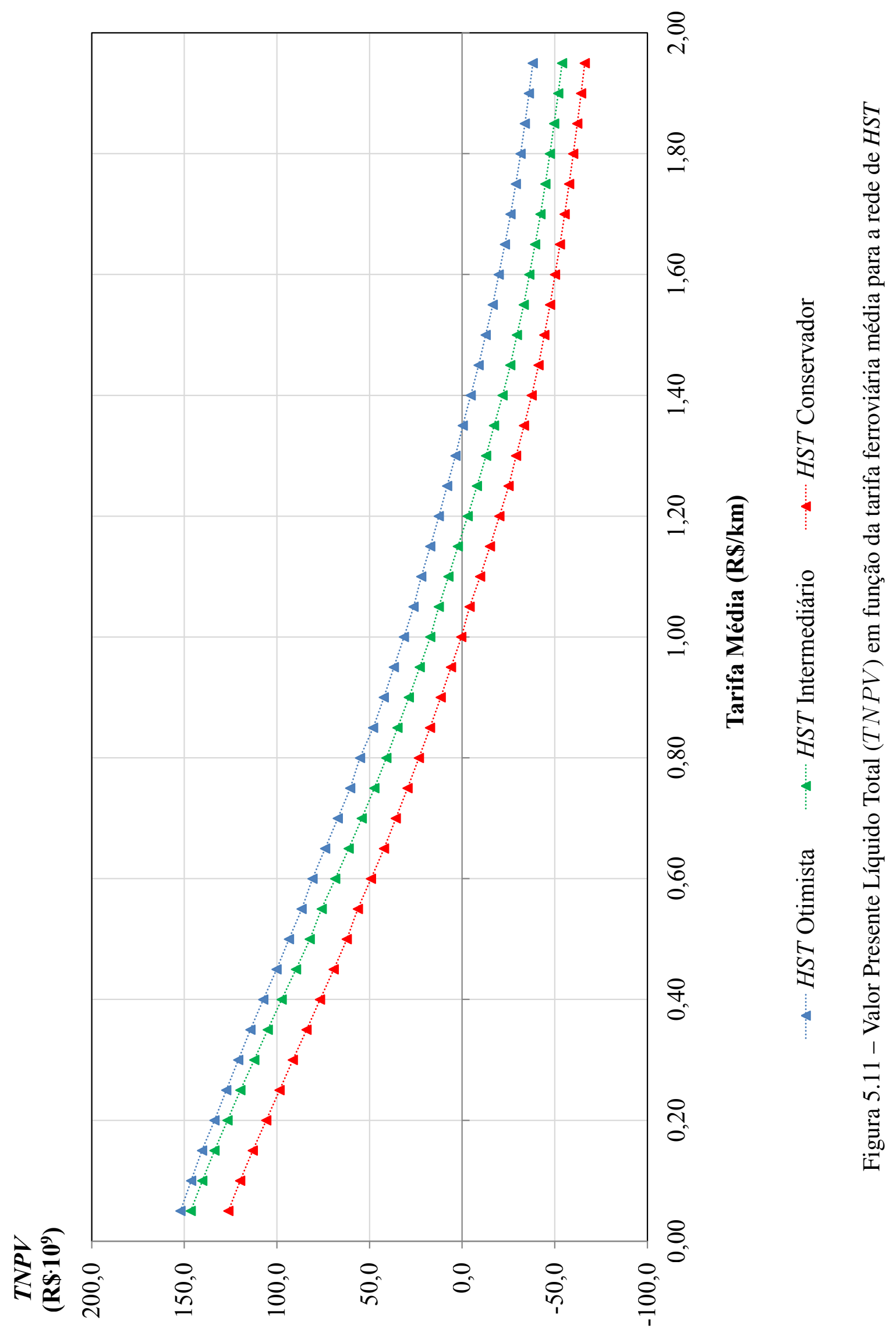


Para a medida de desempenho $T N P V$, os valores estimados no caso da operação de $H S T$ são expressivamente maiores do que para $H P T$ sobretudo nas situações de valores baixos de tarifa média. Segundo os gráficos anteriores, essa medida de desempenho torna-se negativa para os valores de tarifa média maiores que $\mathrm{R} \$ 0,40 / \mathrm{km}, \mathrm{R} \$ 0,60 / \mathrm{km}$ e $\mathrm{R} \$ 0,80 / \mathrm{km}$ nos respectivos cenários Conservador, Intermediário e Otimista para a operação de HPTs, enquanto para a operação de $H S T$ s resulta em valores negativos de $T N P V$ para tarifa média acima de $\mathrm{R} \$ 1,00 / \mathrm{km}$, $\mathrm{R} \$ 1,15 / \mathrm{km}$ e $\mathrm{R} \$ 1,30 / \mathrm{km}$ naqueles respectivos cenários.

Os valores de $T N P V$ representados nos gráficos da Figura 5.10 e Figura 5.11 decrescem assintoticamente em função da tarifa média, pois para ambas as tecnologias ferroviárias, quando o valor desse parâmetro é próximo de zero, o excedente do consumidor devido ao custo da viagem é elevado e, quando a tarifa média aumenta, o valor desse item da análise socioeconômica reduz sua proporção em relação aos demais itens de benefícios econômicos e sociais.

Nas condições das tarifas que maximizam o $E N P V$ descritas anteriormente, o $T N P V$ para a rede de HPTs corresponde a $\mathrm{R} \$-44,70 \cdot 10^{9}, \mathrm{R} \$-36,88 \cdot 10^{9}$ e $\mathrm{R} \$-23,62 \cdot 10^{9}$ para respectivas tarifas de $\mathrm{R} \$ 1,25 / \mathrm{km}$ no cenário Conservador e de $\mathrm{R} \$ 1,35 / \mathrm{km}$ no Intermediário e Otimista. Por outro lado, para a rede de HSTs os valores de $T N P V$ dos cenários são positivos e equivalentes a $\mathrm{R} \$ 0,44 \cdot 10^{9}, \mathrm{R} \$ 12,56 \cdot 10^{9}$ e $\mathrm{R} \$ 22,01 \cdot 10^{9}$ para tarifas de $\mathrm{R} \$ 1,00 / \mathrm{km}, \mathrm{R} \$ 1,05 / \mathrm{km}$ e $\mathrm{R} \$ 1,10 / \mathrm{km}$.

Assim, nas situações de tarifa que maximiza o $E N P V$ (mesmo que com valores negativos), nenhum cenário de rede de $H P T s$ apresenta $T N P V$ positivo, ou seja, a estimativa dos benefícios sociais devido à oferta de serviços com essa tecnologia indicam um valor menor do que os custos totais necessários à sua implantação. Em contrapartida, a operação de HSTs resulta em valores positivos para o $T N P V$ naquelas condições tarifárias apesar de resultados também negativos para essa tecnologia quanto ao $E N P V$.

A Figura 5.12 e Figura 5.13 a seguir representam os valores da Razão Benefício-Custo $(B C R)$ para a operação da rede de HPT e $H S T$, respectivamente, conforme os valores indicados nas tabelas do Apêndice E quando os valores de benefícios sociais são comparados com os investimentos e despesas operacionais dos sistemas. 


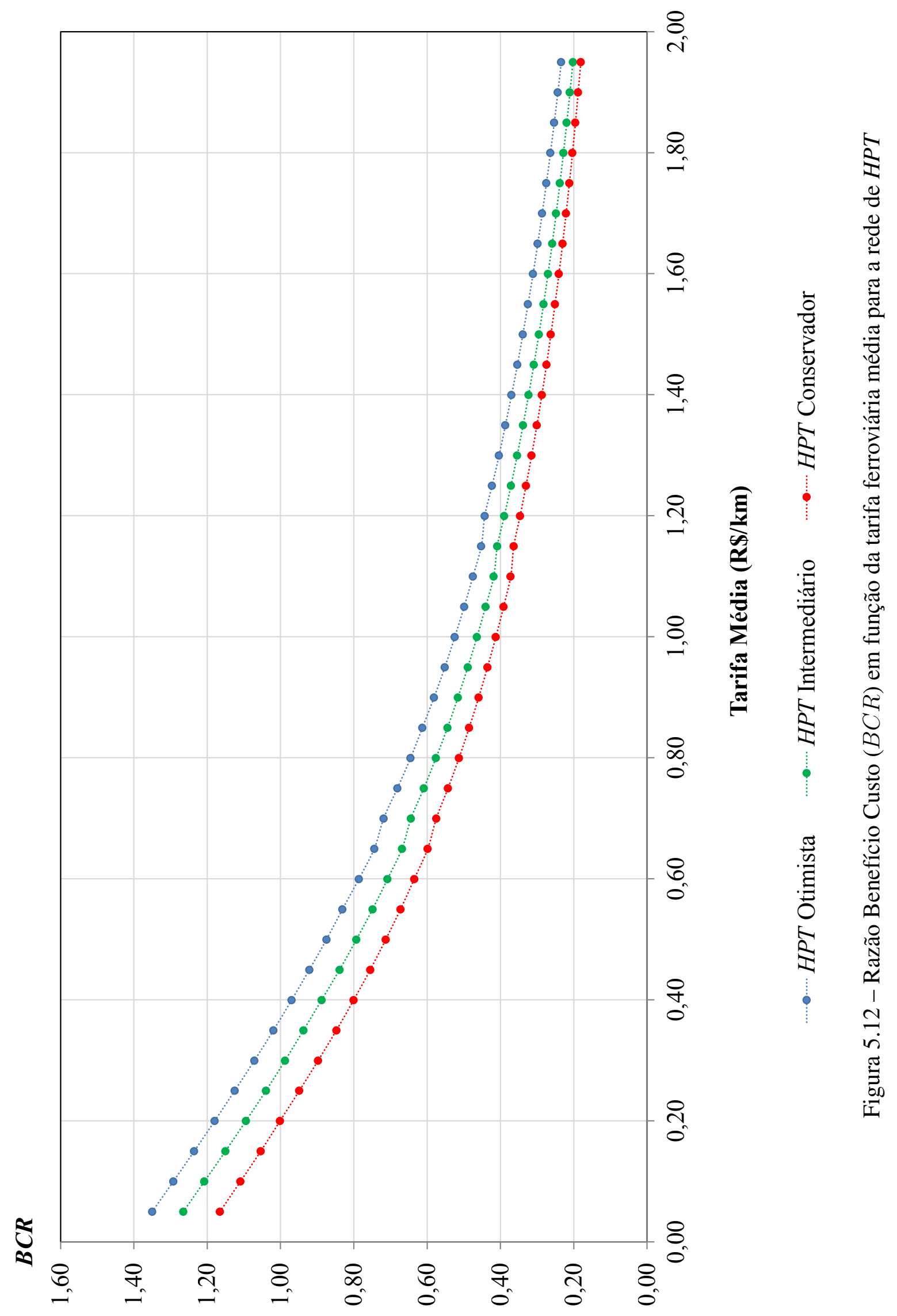




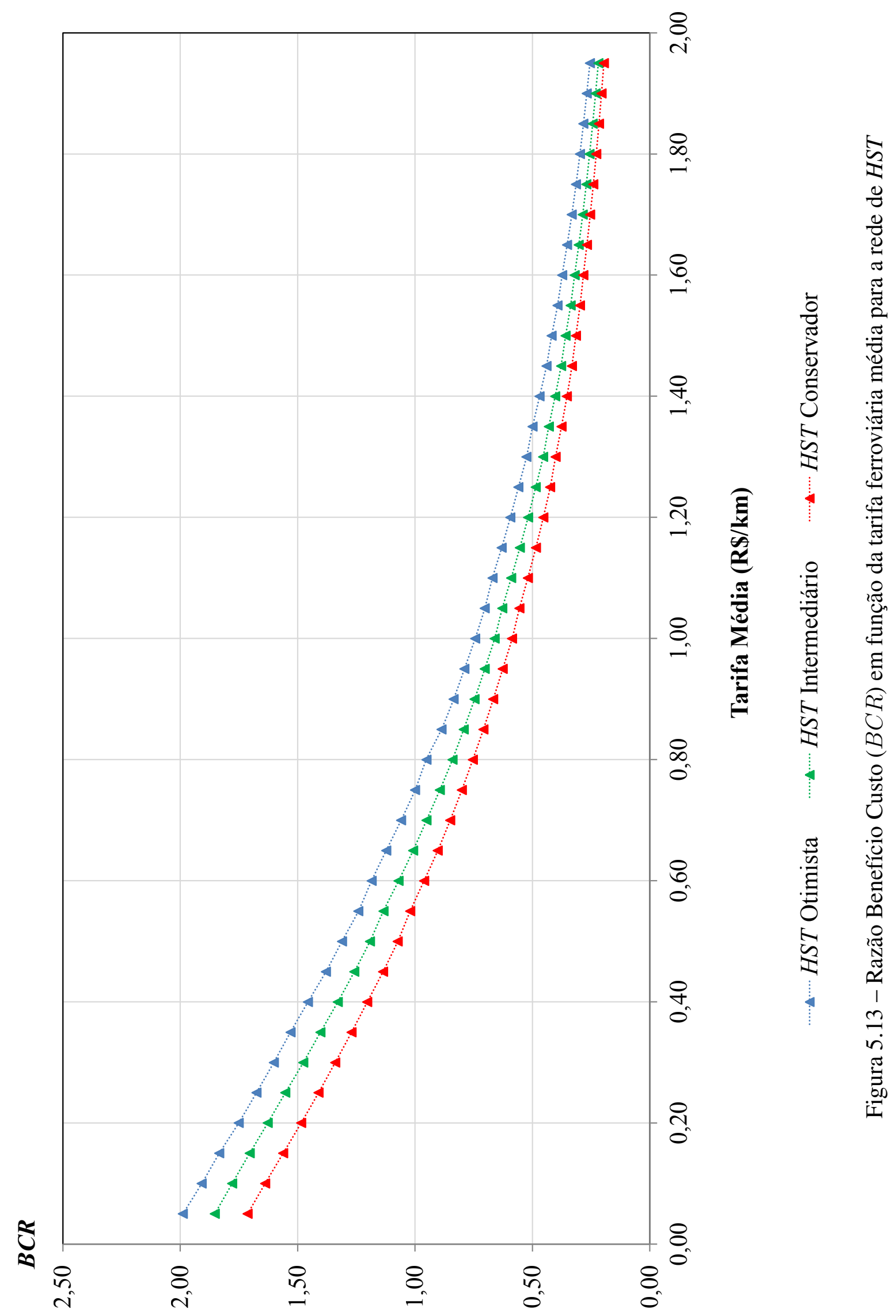


As tendências do $B C R$ são semelhantes às do valor presente líquido total (TNPV). No cenário Conservador para a operação de $H P T$ a razão benefício-custo é maior que 1,00 para tarifa média abaixo de $\mathrm{R} \$ 0,20 / \mathrm{km}$, no Intermediário quando a tarifa é menor que $\mathrm{R} \$ 0,30 / \mathrm{km}$ e no cenário Otimista quando a tarifa é menor que $\mathrm{R} \$ 0,40 / \mathrm{km}$.

Em relação à rede de $H S T$, o $B C R$ é maior do que 1,00 quando a tarifa média ferroviária é menor que $\mathrm{R} \$ 0,55 / \mathrm{km}$ para o cenário Conservador, menor que $\mathrm{R} \$ 0,65 / \mathrm{km}$ no Intermediário e $\mathrm{R} \$ 0,75 / \mathrm{km}$ no cenário Otimista.

Os resultados da razão benefício-custo são maiores para baixas tarifas médias, pois o excedente do consumidor devido aos custos das viagens para os usuários são expressivamente maiores que os demais itens de benefícios nessas condições de política tarifária.

Quando as tecnologias ferroviárias são comparadas, os valores de tarifa média que resultam em $B C R$ acima de 1,00 para operação de $H S T$ são maiores do que para $H P T$ pois, mesmo com tarifas mais altas, aquela tecnologia ferroviária é capaz de captar uma demanda maior que os HPTs, o que resulta em benefícios econômicos e sociais maiores que os custos totais.

Ainda, apenas para a rede de $H S T$ o $B C R$ atinge valores maiores do que 1,50 utilizado na literatura como parâmetro de aceitação da viabilidade do projeto. Entretanto, para essa tecnologia esse resultado é obtido para tarifas relativamente baixas, de $\mathrm{R} \$ 0,20 / \mathrm{km}, \mathrm{R} \$ 0,30 / \mathrm{km}$ e R\$0,40/km para os cenários Conservador, Intermediário e Otimista, respectivamente.

Apesar de o valor presente líquido total $(T N P V)$ serem os máximos possíveis nessas condições de política tarifária, os resultados do valor presente líquido econômico ( $E N P V)$ correspondem aos maiores déficits estimados para a operação de $H S T$, com valores de R $\$-117,68 \cdot 10^{9}$, $\mathrm{R} \$-93,70 \cdot 10^{9}$ e R\$-65,46 $10^{9}$ nos respectivos cenários Conservador, Intermediário e Otimista.

Segundo os gráficos anteriores, o $B C R$ não é necessariamente maior que 1,00 quando o $T N P V$ torna-se positivo (ou seja, quando os benefícios sobrepõem-se aos custos totais) pois o cômputo daquela medida de desempenho não considera o valor presente líquido da receita operacional, que refere-se a um benefício econômico não revertido à sociedade. 
Mesmo que as medidas de desempenho da avaliação socioeconômica tenham resultado em valores negativos para todos os cenários de ambas as tecnologias ferroviárias, são apresentadas a seguir as proporções de custos e benefícios totais para as tarifas que maximizam o ENPV.

Assim, os gráficos da Figura 5.14, Figura 5.15 e Figura 5.16 resumem as porcentagens dos itens de custos e benefícios sociais e econômicos para os cenários Conservador, Intermediário e Otimista na hipótese de operação de uma rede de $H P T$ com tarifa ótima de $\mathrm{R} \$ 1,25 / \mathrm{km}$, $\mathrm{R} \$ 1,35 / \mathrm{km}$ e $\mathrm{R} \$ 1,35 / \mathrm{km}$ respectivamente, cujos valores referem-se às respectivas Tabela E.1, Tabela E.2 e Tabela E.3 do Apêndice E.

No caso da operação de $H P T$ os investimentos para construção da infraestrutura ferroviária predominam sobre as despesas de manutenção dessa infraestrutura e aquisição, operação e manutenção do material rodante nos três cenários analisados. A proporção dos investimentos sobre os custos totais mantém-se constante em 77,7\% nos cenários Conservador e Intermediário e reduzem-se para $76,8 \%$ no Otimista.

Os custos de aquisição de material rodante são pequenos em relação às despesas de manutenção da infraestrutura e dos trens, e da operação dos veículos no horizonte de planejamento. Em todos os cenários a compra do material rodante equivale a apenas $0,3 \%$ dos custos totais, enquanto que os três últimos itens equivalem a 22,1\% no cenário Conservador, 22,0\% no Intermediário, e $22,8 \%$ no Otimista.

Em relação aos benefícios, observa-se um aumento da proporção da receita entre o cenário Conservador, Intermediário e Otimista, com respectivos valores de 43,9\%, 46,4\% e 46,9\% resultante do aumento da demanda reprimida por viagens após a implantação do sistema de $H P T$. Em contrapartida, há redução da proporção dos benefícios sociais do cenário Conservador para o Otimista, sobretudo em relação ao excedente do consumidor devido à tarifa, cujos valores correspondem a 21,3\% no primeiro cenário e $18,7 \%$ nos dois últimos. 


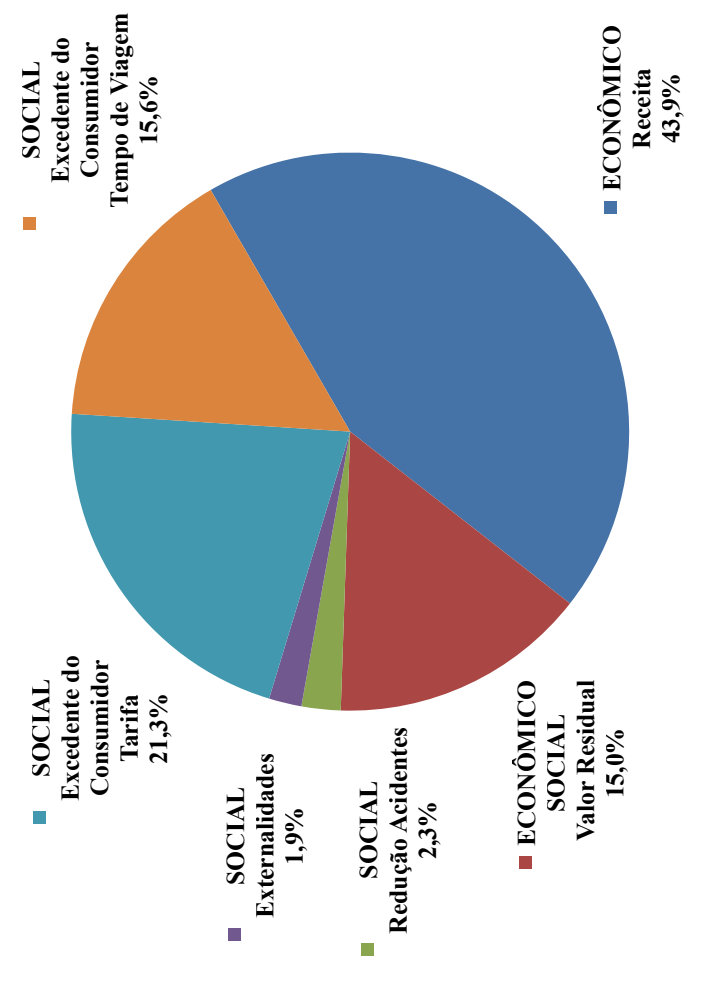

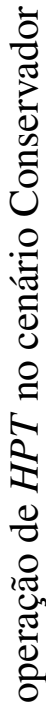

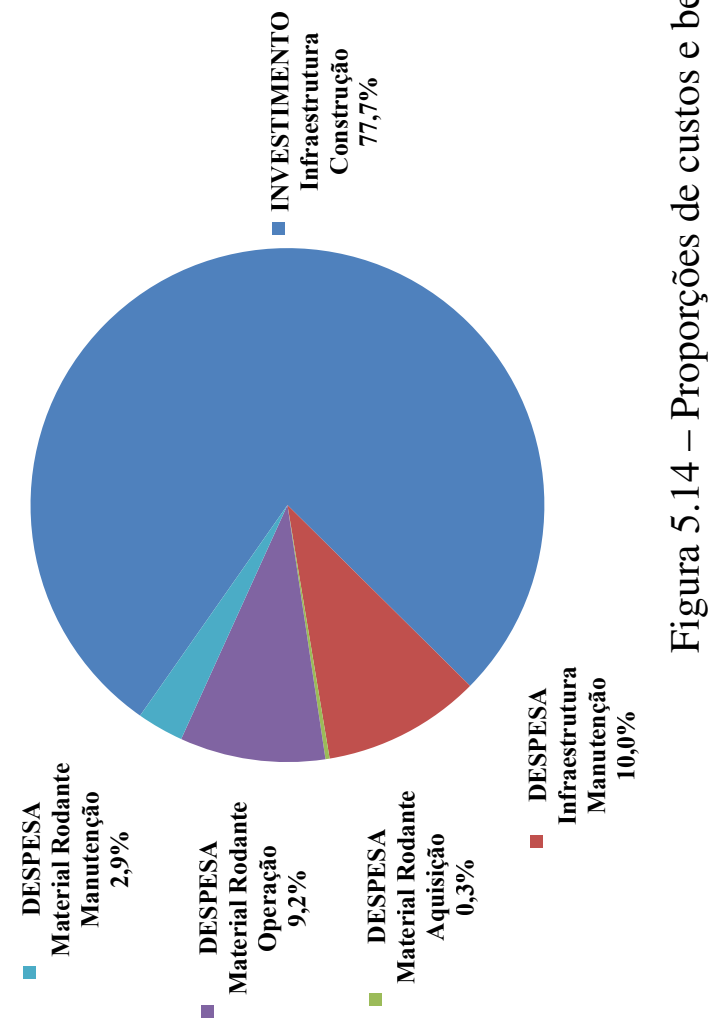




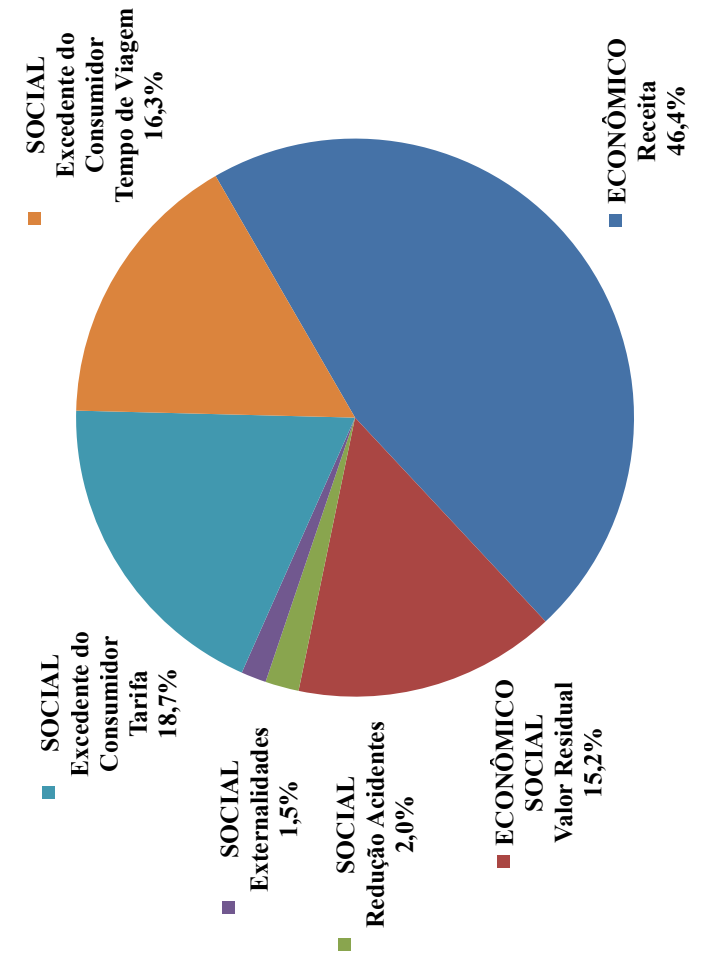

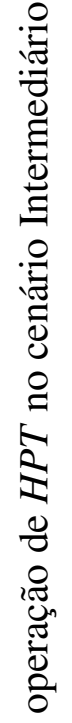
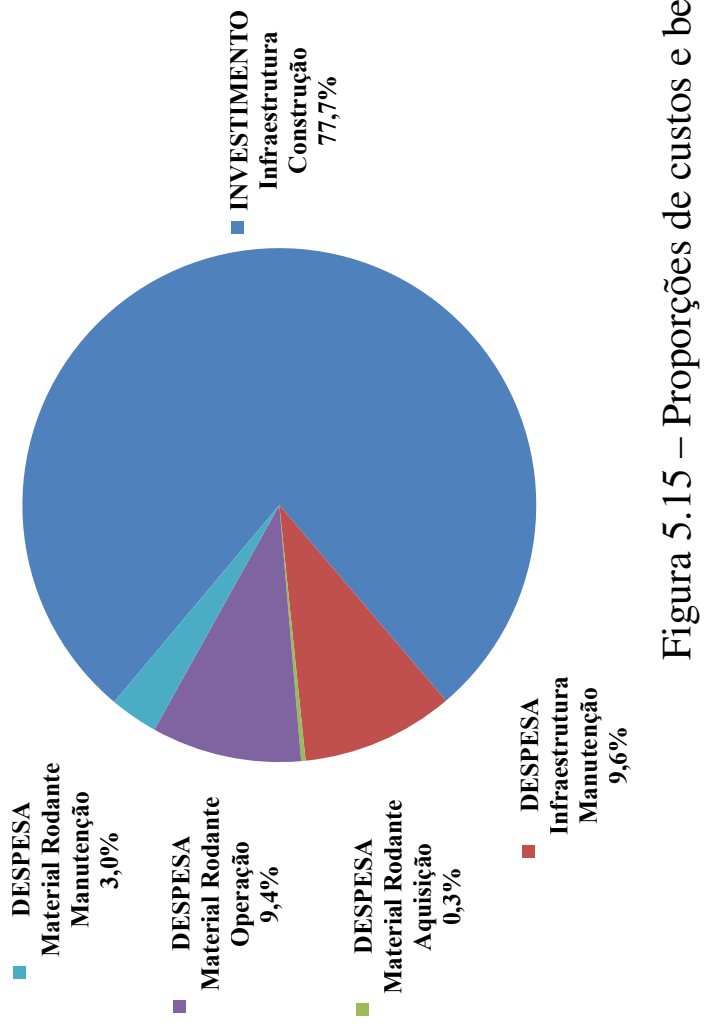


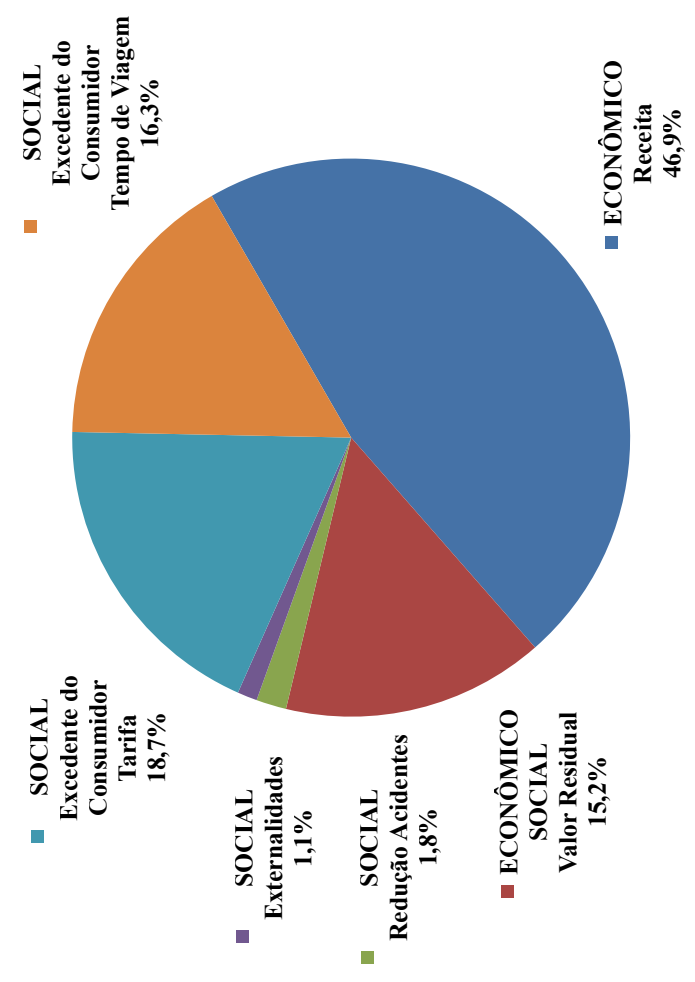

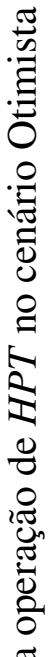

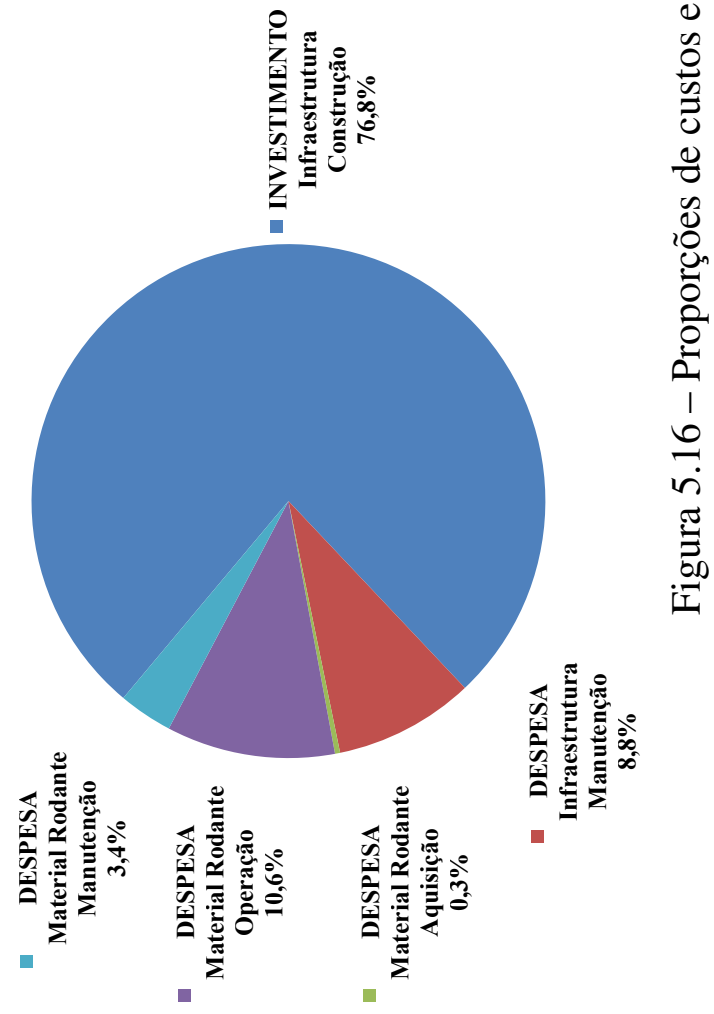


A redução de acidentes e externalidades apresentam pequena representatividade em relação aos valores totais, com proporções de 4,2\%,3,5\% e 2,9\% para os respectivos cenários Conservador, Intermediário e Otimista, indicando que não exercem influência significativa sobre os resultados do valor presente líquido total $(T N P V)$ e da razão benefício-custo $(B C R)$.

Na sequência, a Figura 5.17, Figura 5.18 e Figura 5.19 caracterizam as proporções dos custos e benefícios totais para a rede ferroviária de HST calculados nos cenários Conservador, Intermediário e Otimista para as tarifas que maximizam o valor presente líquido econômico ( $E N P V)$ conforme apresentado nas respectivas Tabela E.4, Tabela E.5 e Tabela E.6 do Apêndice E.

As conclusões sobre as proporções dos itens das análises socioeconômicas para a operação de HPT podem ser estendidas ao desempenho econômico e social dos HST. No caso dos custos totais há predominância das proporções dos investimentos em infraestrutura de 70,7\% para 70,3\% e 70,1\% entre o cenário Conservador, Intermediário e Otimista respectivamente. Essas proporções são menores que para a rede de $H P T$, pois apesar dos maiores investimentos em infraestrutura para aquela tecnologia, as despesas operacionais de HST são maiores resultando na redução dos valores percentuais estimados.

No contexto dessas despesas, há novamente predominância daquelas de manutenção da infraestrutura e dos trens, bem como da operação dos veículos em detrimento da aquisição do trens. As proporções daqueles itens de despesas em relação aos custos totais aumentam de $28,8 \%$ para 29,1\% e 29,3\% respectivamente aos cenários Conservador, Intermediário e Otimista, com ênfase novamente para as baixas proporções das despesas com aquisição do material rodante menores ou iguais a $0,6 \%$.

As proporções das despesas operacionais dos trens aumentam em relação à rede de $H P T$ devido aos maiores valores unitários das despesas de manutenção (infraestrutura e material rodante) e operação dos HSTs, à maior demanda absorvida na operação dessa tecnologia ferroviária e à necessidade de maior número de trens e frequência dos serviços. 


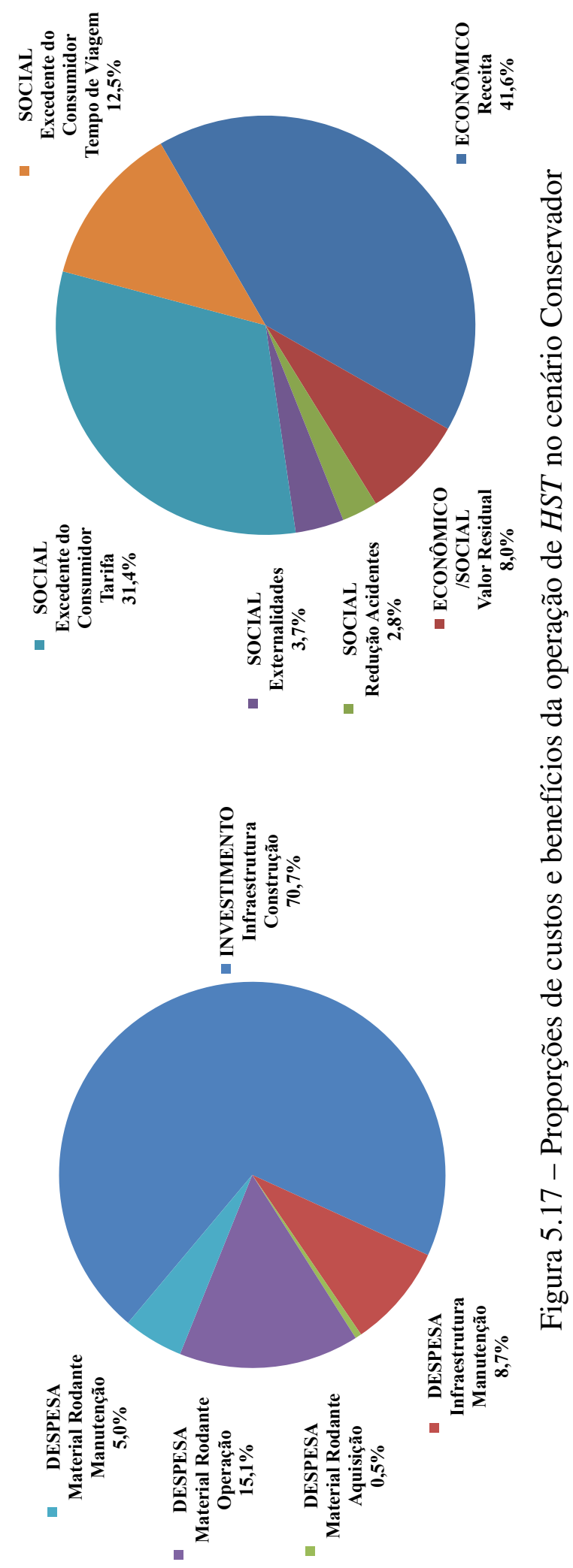




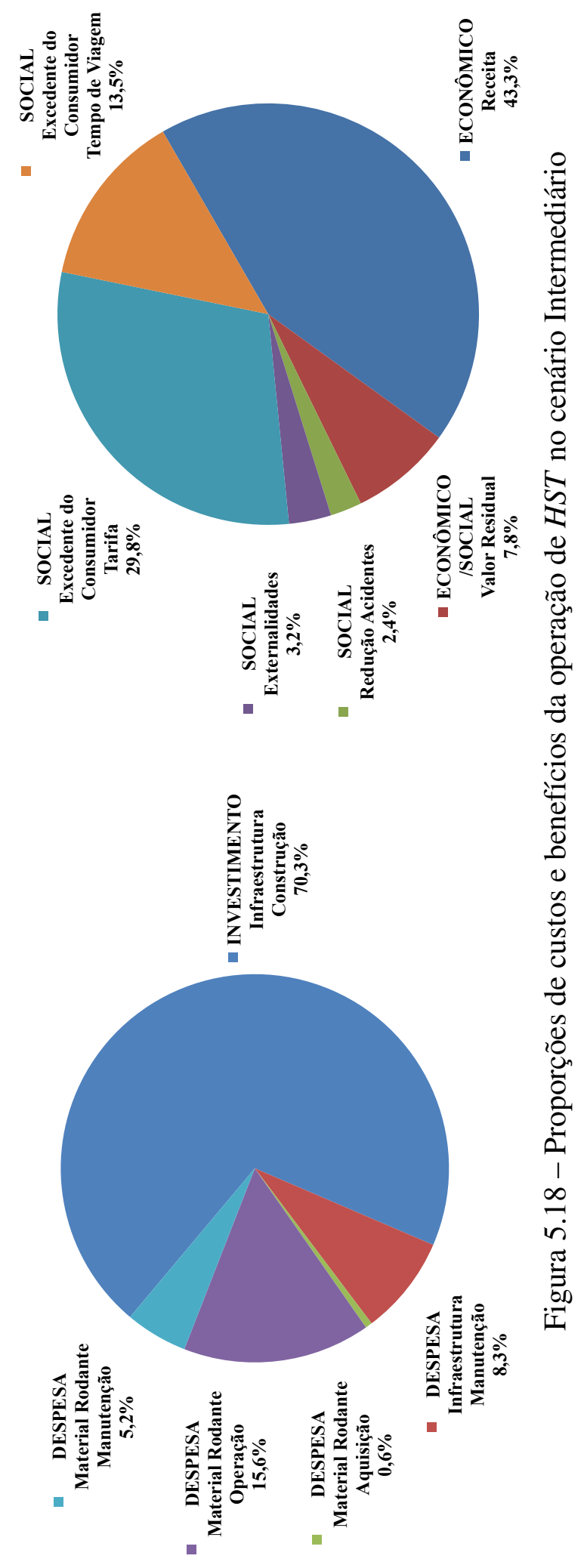




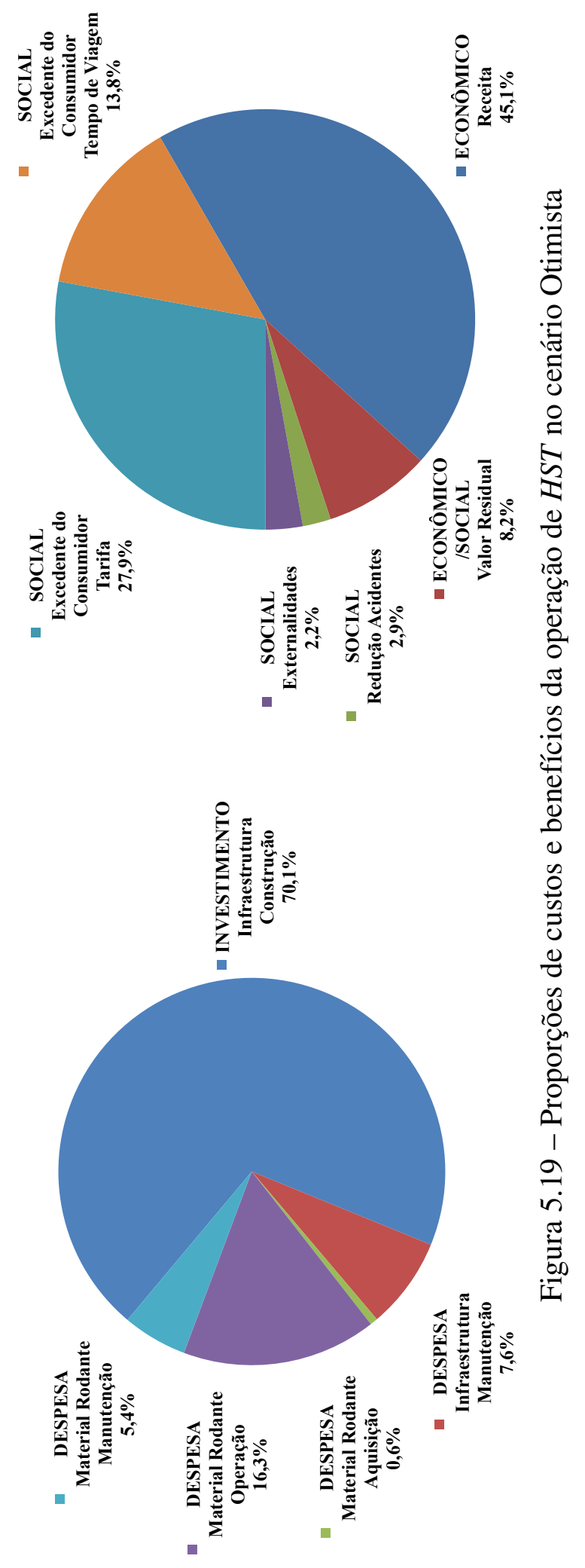


Quanto às receitas, há novamente uma tendência de aumento dos valores em relação aos benefícios totais entre os cenários Conservador, Intermediário e Otimista, com respectivas proporções de $41,6 \%, 43,3 \%$ e $45,1 \%$. No aspecto dos benefícios sociais, as maiores proporções também referem-se ao excedente do consumidor devido à tarifa com respectivos valores de $31,4 \%, 29,8 \%$ e 27,9\%, enquanto que aqueles relativos à redução de acidentes e externalidades mantém-se baixos, com respectivas proporções totais de $6,5 \%$ e $5,6 \%$ e $5,1 \%$.

Apesar de serem observadas tarifas ótimas menores para $H S T$ em relação aos $H P T$ nos cenários correspondentes, a proporção de receita mantém-se alta para aquela tecnologia pois a demanda atendida é elevada devido ao maior valor final da função utilidade pela oferta de HSTs, haja vista que o tempo de viagem é menor para essa tecnologia, incorrendo em maior proporção de divisão modal em detrimento da operação de HPTs.

\subsection{Considerações sobre a Análise Socioeconômica}

Dado que o investimento em infraestrutura é o principal item de custo da $C B A$, cabe investigá-lo sob diferentes enfoques socioeconômicos. Se for considerado um modelo alternativo de construção da infraestrutura em que os investimentos na rede forem aplicados por órgãos públicos sem expectativa de retorno dos investimentos (a fundo perdido), os resultados estimados para o valor presente líquido econômico ( $E N P V)$ seriam alterados pois os itens de investimentos em infraestrutura são os mais significativos entre os custos totais.

Nesse caso, excluindo-se o valor presente líquido dos investimentos para a construção da rede de $H P T$, o $E N P V$ na tarifa ótima do cenário Conservador alterar-se-ia para um valor presente líquido positivo de $\mathrm{R} \$ 13,38 \cdot 10^{9}$ no horizonte de 35 anos, tornando o investimento atraente do ponto de vista de um operador privado mesmo nas condições mais desfavoráveis de produtividade de construção da rede, absorção de demanda e majoração dos investimentos. Sob essas mesmas premissas, o ENPV resultante da operação de HSTs no cenário Conservador aumentaria para um valor positivo de $\mathrm{R} \$ 25,73 \cdot 10^{9}$.

Nas condições do cenário Otimista investigado os resultados dessa medida de desempenho econômico seriam também positivos com valores de $\mathrm{R} \$ 19,02 \cdot 10^{9}$ para a operação de $H P T$ e de 
$\mathrm{R} \$ 35,16 \cdot 10^{9}$ para $H S T$ em um horizonte de planejamento 35 anos, tornando ambos os investimentos atraentes economicamente com destaque para a tecnologia de alta velocidade.

Outra linha de argumentação relativa às avaliações socioeconômicas refere-se à variação da porcentagem de valor residual dos investimentos em infraestrutura e da taxa mínima de atratividade para o cálculo do valor presente líquido dos itens da $C B A$.

Variando-se a porcentagem do valor residual dos investimentos em infraestrutura - ou seja, o parâmetro $\xi$ da Equação 4.13 (página 191) - entre 0\% e 100\% em intervalos de 20\%, e mantendo-se fixos os demais parâmetros para o cenário Intermediário com tarifa ótima de $\mathrm{R} \$ 1,35 / \mathrm{km}$ e $\mathrm{R} \$ 1,05 / \mathrm{km}$ que maximizam o $E N P V$ da operação de $H P T$ e $H S T$ respectivamente, o valor presente líquido econômico $(E N P V)$ e a razão benefício-custo $(B C R)$ sob essas condições são representados na Figura 5.20 e Figura 5.21.

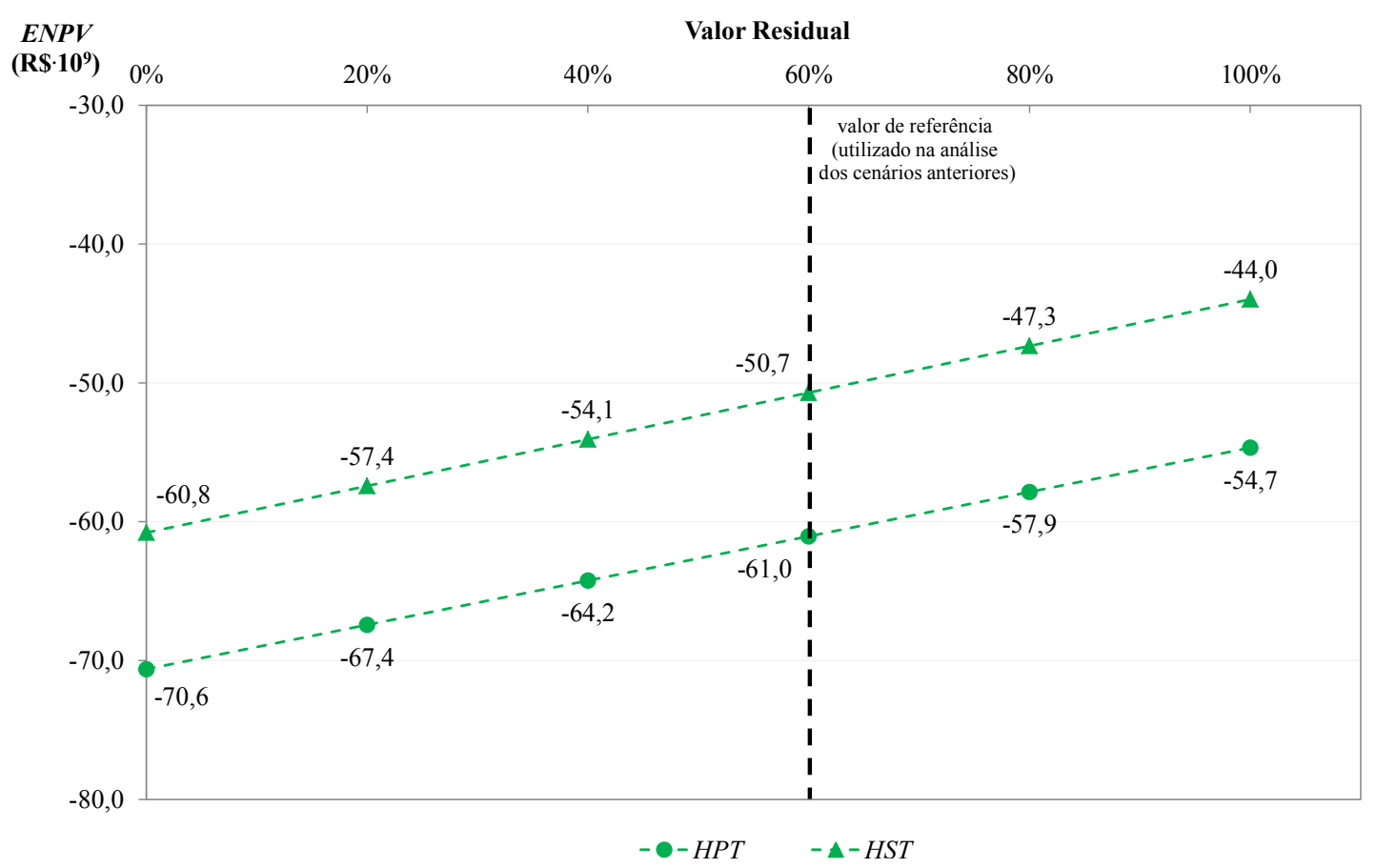

Figura 5.20 - Valor Presente Líquido Econômico ( $E N P V)$ mediante a variação do valor residual dos investimentos em infraestrutura para o cenário Intermediário

Conforme indicado na seção 5.4, nas condições de tarifa ótima para o cenário Intermediário, quando o valor residual dos investimentos em infraestrutura é nulo, o valor presente líquido econômico $(E N P V)$ resulta em déficit da operação de $H P T s$ de $\mathrm{R} \$-70,62 \cdot 10^{9}$ enquanto a ope- 
ração de HSTs resulta também em déficit de $\mathrm{R} \$-60,78 \cdot 10^{9}$.

Por outo lado, na situação em que a depreciação é nula, ou seja, quando o valor residual corresponde a $100 \%$ do investimentos em infraestrutura, o valor presente líquido econômico resultante no cenário Intermediário para a rede de $H P T$ é de $\mathrm{R} \$-54,67 \cdot 10^{9}$ e para $H S T$ é de $\mathrm{R} \$-43,98 \cdot 10^{9}$, os quais mantém-se negativos, porém com valores absolutos de déficit menores em relação à situação anterior de depreciação total da infraestrutura.

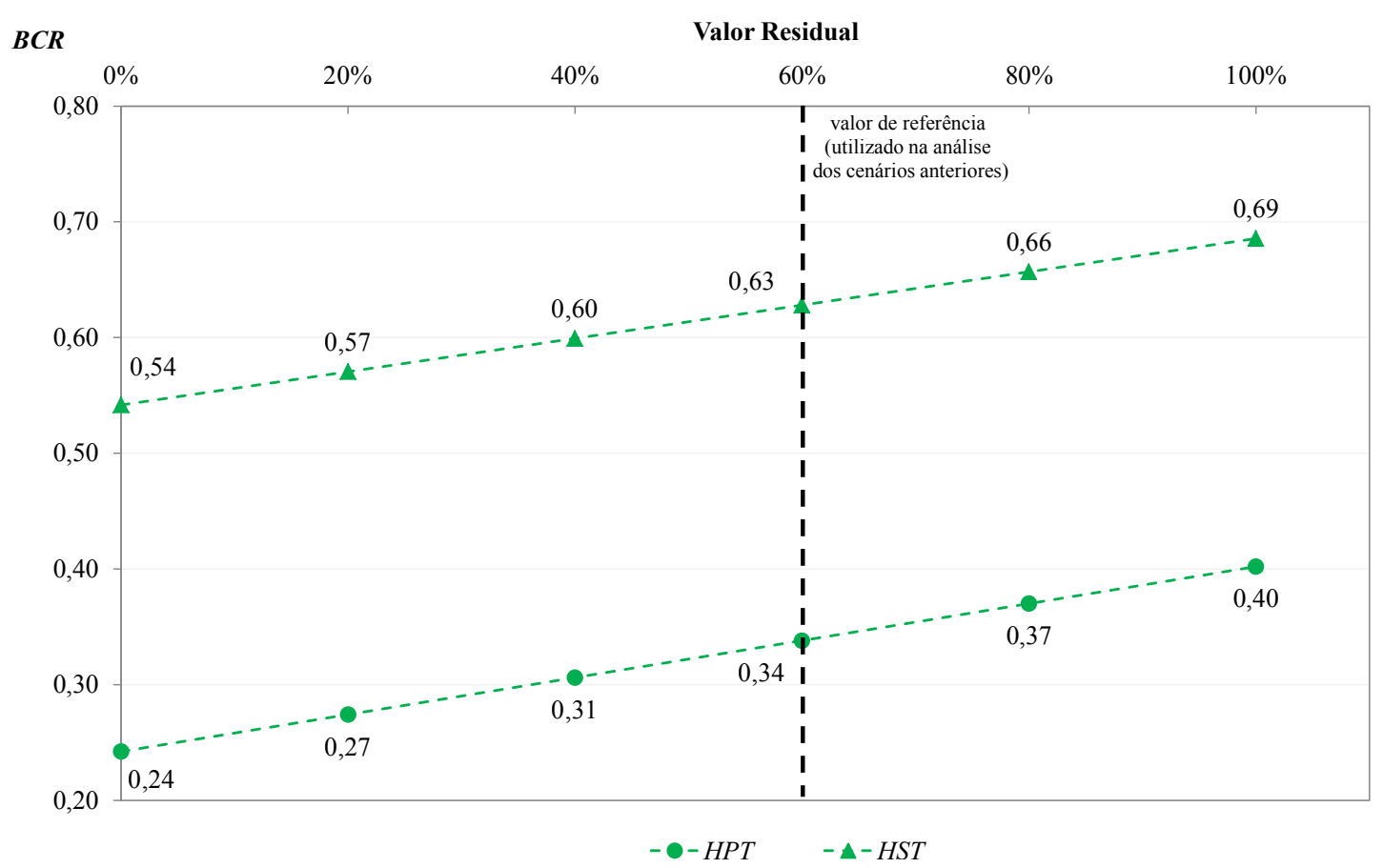

Figura 5.21 - Razão Benefício-Custo $(B C R)$ mediante a variação do valor residual dos investimentos em infraestrutura para o cenário Intermediário

Do ponto de vista social, quando o valor residual dos ativos da infraestrutura são considerados nulos, o valor do $B C R$ estimado é de 0,24 para a operação de $H P T$ e de 0,54 para $H S T$, muito aquém do valor de referência de 1,50 considerado para viabilização de projetos (DE RUS et al., 2009), indicando que o investimento na construção e operação da infraestrutura ferroviária não é vantajoso do ponto de vista dos benefícios para a sociedade nessas circunstâncias.

Quando o valor residual dos ativos de infraestrutura são computados como equivalentes a $100 \%$ do investimento na implantação da infraestrutura e esse valor é caracterizado como um bem de interesse social, os valores do $B C R$ alteram-se para 0,40 e 0,69 no caso da operação 
de $H P T$ e de $H S T$, respectivamente. Novamente, o benefício social que os investimentos em infraestrutura representam continua a indicar custos totais maiores que os benefícios sociais da operação dos sistemas ferroviários para as tarifas que maximizam o $E N P V$.

Finalmente, ao analisar a variação da taxa mínima de atratividade do investimento ( $M A R R)$ com valores de $0,0 \%, 1,0 \%, 3,0 \%$ e 5,1\% (este último aplicado nas análises dos cenários detalhados na seção 5.4) considerando valor residual fixo de $60 \%$ dos investimentos na construção da infraestrutura e as tarifas ótimas do cenário Intermediário, tem-se os resultados dos gráficos da Figura 5.22 e Figura 5.23 respectivamente para o valor presente líquido econômico (ENPV) e a razão benefício-custo $(B C R)$ estimados para a operação de $H P T$ e $H S T$.

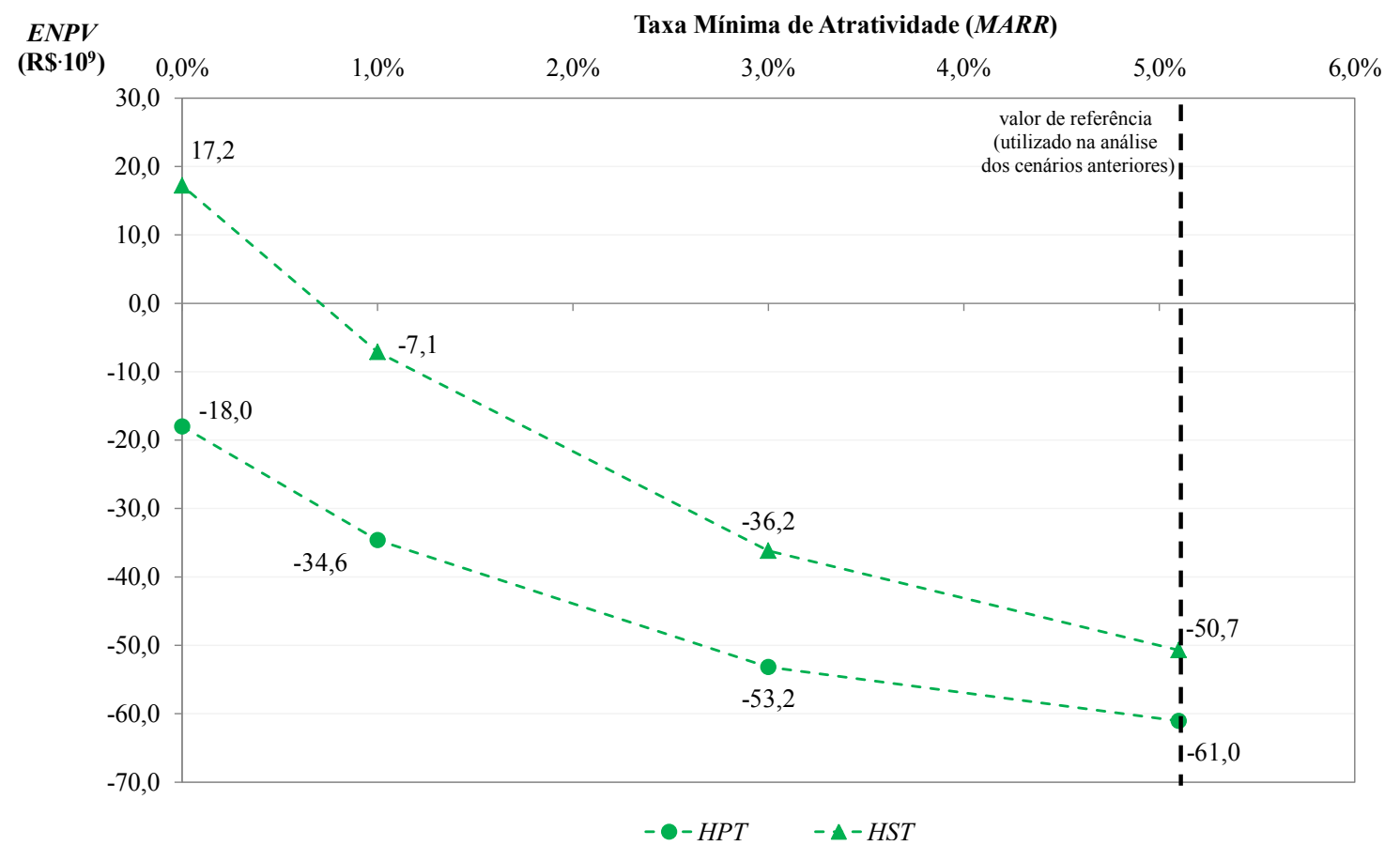

Figura 5.22 - Valor Presente Líquido Econômico (ENPV) mediante a variação da taxa mínima de atratividade para o cenário Intermediário

Os resultados indicam que, se a taxa mínima de atratividade for nula para o cálculo do valor presente líquido dos itens da $C B A$ - por exemplo, se a construção e operação do sistema for de competência do poder público e este não tiver expectativas de retorno do investimento devido aos interesses sociais do projeto - o valor presente líquido econômico $(E N P V)$ devido à operação de $H P T$ é equivalente a um déficit R $\$-17,99 \cdot 10^{9}$ e para a operação de $H S T$ é equivalente a 
um superávit de $\mathrm{R} \$ 17,22 \cdot 10^{9}$. Nesse caso, o valor final positivo para a medida de desempenho na operação de HSTs indica que a implantação dessa tecnologia poderia, eventualmente, ser viável sob o aspecto econômico nas condições estabelecidas.

Nessa mesma tendência, em relação aos benefícios sociais, uma rede de HPTs resultaria em $B C R$ menor que $1,00(0,79)$ mesmo que a taxa de atratividade fosse de $0,0 \%$. Por outro lado no caso da operação de HSTs, para o cenário Intermediário na tarifa ótima e taxa de atratividade nula, a razão benefício-custo resultaria no valor estimado de 1,20 , porém ainda menor do que a recomendação mínima de 1,50 .

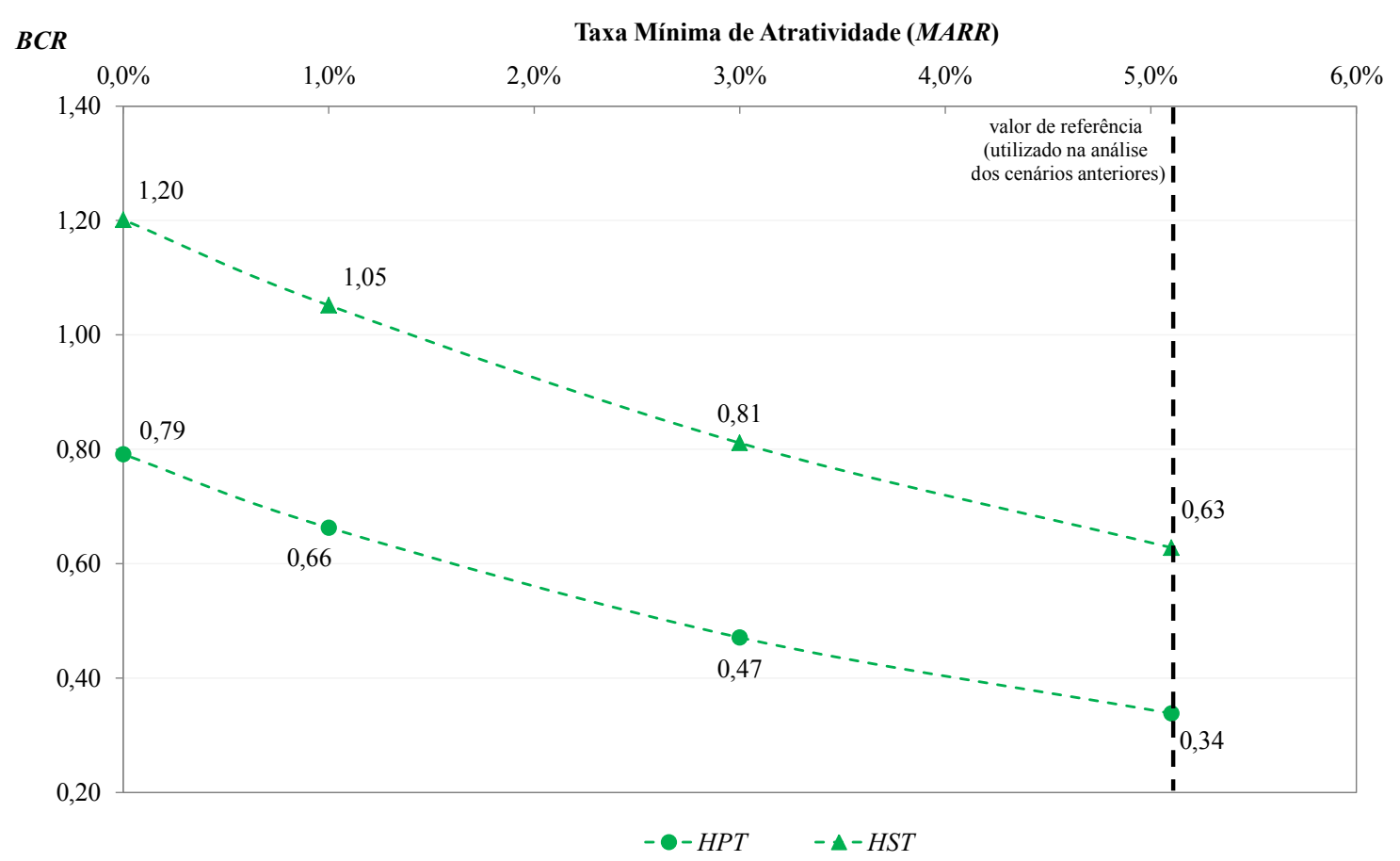

Figura 5.23 - Razão Benefício-Custo $(B C R)$ mediante a variação da taxa mínima de atratividade para o cenário Intermediário

Nas condições do cenário Intermediário, se for considerado um valor residual equivalente a $60 \%$ dos investimentos em infraestrutura, a implantação do sistema de HST poderia viabilizarse do ponto de vista econômico a uma taxa de atratividade $(M A R R)$ menor do que aproximadamente $0,7 \%$ dado que o $E N P V$ torna-se positivo nessas condições. Por outro lado, sob a perspectiva socioeconômica, o $B C R$ é maior que 1,00 somente na operação dos HSTs quando essa taxa de atratividade é menor do que aproximadamente $1,4 \%$. 


\section{Capítulo \\ Considerações Finais e Recomendações

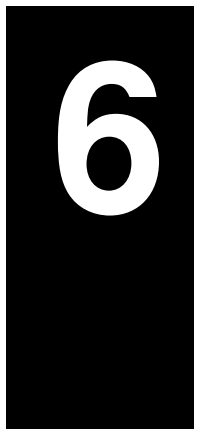

Esta tese visou contribuir para o amadurecimento das ideias sobre alternativas de transporte intermunicipal de passageiros na Região Sudeste do Brasil em um horizonte de planejamento estratégico. Porém, não existe a pretensão de encerrar as discussões a respeito das possibilidades de implantação de um sistema de transporte dessa natureza, haja vista as restrições de tempo e de recursos humanos e econômicos para realização de um trabalho desse porte.

A formulação para análise socioeconômica contida nesta tese abre perspectivas para análises mais aprofundadas sobre os investimentos necessários para a construção de uma infraestrutura ferroviária e sobre uma possível estrutura de pesquisa de preferência que permita captar as escolhas dos usuários pelo transporte ferroviário em um ambiente de pouca experiência do público-alvo com o uso desse tipo de infraestrutura.

Nesse sentido, o objetivo principal de estimar e comparar as perspectivas de implantação de diferentes serviços ferroviários para o transporte de passageiros na Região Sudeste do Brasil sob a perspectiva de desempenho socioeconômico dos projetos foi atingido. Isso foi possível pela estimativa dos investimentos necessários à construção de nova infraestrutura ferroviária compatível com as exigências das tecnologias propostas, da potencial demanda para utilização do modo de transporte e aplicação de uma formulação de $C B A$ em uma rede hipotética.

Mediante os resultados do Capítulo 5 uma reflexão sobre a hipótese de tese proposta no Capítulo 1 indica que, sob a perspectiva estritamente econômica, a implantação de uma rede ferroviária para o transporte de passageiros na Região Sudeste não parece ser promissora independentemente da tecnologia ferroviária a ser operada. 
Sob a premissa de construção de uma nova infraestrutura segregada das atuais linhas ferroviárias para o transporte de cargas, o desempenho econômico da operação de HSTs parece mais atraente que para HPTs, haja vista que as estimativas de investimentos na construção da via permanente são praticamente equivalentes para ambas as tecnologias ferroviárias.

De fato, existia uma ideia de que um projeto de rede de $H S T$ incorresse em elevados investimentos e despesas operacionais que pudessem inviabilizar a sua implementação. Porém, a importante conclusão de que os investimentos são elevados seja qual for a tecnologia ferroviária leva a crer que a operação de HSTs é uma alternativa mais conveniente em relação aos HPTs como proposto pela hipótese de tese, dado que os benefícios marginais pela redução do tempo de viagem para aquela tecnologia são mais expressivos.

Quando o desempenho dos sistemas é avaliado no âmbito dos benefícios e custos totais, os resultados da avaliação socioeconômica são positivos em situações específicas de política tarifária. Assim, sob a hipótese de tese investigada, a diferença entre benefícios e custos socioeconômicos totais pela oferta serviços de $H S T$ s pode resultar em valores positivos para tarifas específicas, sendo essa diferença, em geral, maior do que para a operação de HPTs.

Apesar da necessidade de análises mais aprofundadas ou mais específicas em termos de conexões entre cidades - explorando-se por exemplo alternativas de ofertas de serviços expressos e paradores - esses resultados permitem afirmar que, na atual conjuntura brasileira, eventualmente existem outras áreas prioritárias no setor de transportes que necessitem de maiores investimentos ou que conduzam a benefícios econômicos e sociais mais significativos que um sistema de trens de passageiros conforme investigado nesta pesquisa.

É importante ressaltar que uma configuração de rede distinta daquela proposta nesta tese pode incorrer em resultados mais promissores uma vez que a exclusão de arcos com elevado investimento de construção e pequena contribuição marginal sobre a receita total do sistema eventualmente proveria resultados positivos para a medida de desempenho representativa do valor presente líquido econômico $(E N P V)$. 
Algumas considerações podem ser apresentadas sobre as contribuições da tese do ponto de vista metodológico. A aplicação de um Algoritmo Genético utilizando uma abordagem de computação paralela foi eficaz para estimativa dos investimentos em infraestrutura e obtenção de traçados ferroviários em reduzido tempo de processamento computacional.

A utilização desse método permitiu a exploração de uma infraestrutura computacional robusta e de alta confiabilidade provida pela Universidade de São Paulo e abre perspectivas promissoras para resolução de problemas de otimização combinatória de grande porte ou até mesmo de modelos matemáticos exatos no âmbito da programação paralela e concorrente.

Em relação à modelagem da demanda, a estimativa de modelos de distribuição de viagens e projeção dessas em um horizonte de planejamento mostrou-se pertinente para aplicação nesta tese, tanto para os modos de transporte cuja modelagem é explorada na literatura (no caso de Ônibus e Avião), quanto para o modo Automóvel, em que não há registros na literatura.

Ainda no contexto da demanda, a proposta de uma pesquisa de preferência declarada para estimativa da propensão à escolha modal é uma contribuição para análises da percepção dos usuários em relação à escolha de alternativas de modos de viagem. Os resultados das calibrações dos modelos de divisão modal com base na teoria de maximização da utilidade indicam que, até o momento, essa percepção é igual para serviços de (HPTs e HSTs).

Quanto à formulação de análise custo-benefício, apesar de ser um método extensivamente explorado na literatura, as propostas permitiram a aplicação de uma abordagem quantitativa contextualizada ao problema de uma rede ferroviária regional para o transporte de passageiros.

Cabe ressaltar, entretanto, que as medidas de desempenho apresentadas no Capítulo 5 indicam tendências de resultados socioeconômicos de uma nova rede ferroviária para o transporte de passageiros na Região Sudeste, as quais estão sujeitas às variações decorrentes de múltiplos fatores, como aplicação de diferentes métodos de estimativa e projeção de demanda, oscilações dos valores de investimentos estimados (inclusive pela inclusão daqueles referentes à construção ou estimativas acuradas para readequação de estações) e dos valores unitários considerados na aplicação da formulação de análise socioeconômica. 


\subsection{Recomendações para Pesquisas Futuras}

As considerações apresentadas nesta tese de doutorado possuem diversos desdobramentos possíveis quanto ao melhoramento e aplicação dos modelos propostos. A implementação do Algoritmo Genético em paralelo para resolução do problema de obtenção de traçados ferroviários permite estimar e avaliar os investimentos necessários à duplicação de ferrovias existentes fora das faixas de domínio atuais em que estão instaladas, alternativa que pode ser promissora dada a pequena proporção dos custos de desapropriações em relação aos demais itens.

Do ponto de vista de avaliação da demanda, existem possibilidades de abordagens alternativas aos modelos analíticos para estimativa do número de viagens pelos modos de transporte existentes - tais como redes neurais artificiais e simulação multiagente -, os quais podem apresentar maior acurácia para as estimativas de viagens de longa distância.

Quanto à avaliação da propensão à escolha modal é possível considerar a aplicação de uma abordagem metodológica alternativa à apresentada nesta tese - por exemplo, pela utilização de um modelo do tipo Nested Logit Multinomial ou pelo treinamento de uma rede neural artificial - com vistas ao aumento da porcentagem de acertos em relação às respostas dos respondentes da pesquisa de preferência declarada descrita no Capítulo 3.

Em relação à formulação de análise custo-benefício, além da contribuição direta de proposição de uma formulação específica para as condições brasileiras e explícita para avaliação de novos projetos ferroviários para o transporte de passageiros, pesquisas futuras podem ser realizadas ao considerar diferentes configurações de rede ferroviária em detrimento daquela proposta no Capítulo 5. Investigações dessa natureza podem resultar em valores distintos dos identificados nesta tese como, por exemplo, na restrição da rede a conexões com elevada demanda, em que o investimento marginal na construção da infraestrutura é compensado pelo aumento da demanda entre cidades atendidas.

A avaliação socioeconômica de diferentes configurações de rede ferroviária permite investigações acerca de combinações de arcos que otimizem uma medida de desempenho específica, remetendo à resolução de problemas de planejamento de redes de transporte do ponto de vista da aplicação de métodos de otimização. 
Além disso, a avaliação de diferentes combinações de arcos para composição de uma nova rede ferroviária pode ser associada a investigações mais aprofundadas sobre os efeitos da variação dos diferentes parâmetros considerados na formulação de análise custo-benefício tal como considerado no Capítulo 5 em relação à produtividade média da construção da infraestrutura, majoração dos investimentos requeridos pelos traçados e potencial de absorção de demanda. 


\section{Referências}

ABCR (2013). Associação Brasileira de Concessionárias de Rodovias - Tarifas de Pedágio. http://www.abcr.org.br/TarifasPedagio/TarifaPedagio.aspx. Acessado em $25 / 08 / 2013$.

ADEDAYO, A. K.; AGUNBIADE, D. A. (2013). Parameter estimation and determination of sample size in logistic regression. Journal of Mathematics and Statistics, Science Publications, v. 8, n. 4 , p. 481 .

AGRESTI, A. (1996). An introduction to categorical data analysis. New York, NY, USA: Wiley.

AGUIAR JÚNIOR, S. R. (2004). Modelo RAPIDE: uma aplicação de mineração de dados e redes neurais artificiais para a estimativa da demanda por transporte rodoviário interestadual de passageiros no Brasil. Dissertação (Mestrado) — Universidade Católica de Brasília, Brasília, DF.

AHERN, A. A.; TAPLEY, N. (2008). The use of stated preference techniques to model modal choices on interurban trips in ireland. Transportation Research Part A: Policy and Practice, Elsevier, v. 42, n. 1, p. 15-27.

ALEKSEEV, K. P. G.; SEIXAS, J. M. (2002). Forecasting the air transport demand for passengers with neural modelling. In: IEEE. Proceedings of VII Brazilian Symposium on Neural Networks, 2002. Recife, Brazil, p. 86-91.

AMOS, P.; BULLOCK, D.; SONDHI, J. (2010). High-speed rail: the fast track to economic development? Washington, DC, USA: World Bank.

ANAC (1998). Agência Nacional de Aviação Civil - Demanda Global do Transporte Aéreo Brasileiro. http: / /www2.anac.gov.br/arquivos/pdf/ demandaGlobaltranspAer1998.pdf. Acessado em 17/04/2014.

ANAC (2013). Anuário do Transporte Aéreo: Dados Estatísticos e Econômicos de 2012. http: //www2.anac.gov.br/arquivos/zip/Anuario2012.zip. Acessado em $12 / 11 / 2013$.

ANAC (2014a). Agência Nacional de Aviação Civil - Relatório de Tarifas Aéreas. http: //www. anac.gov.br/. Acessado em 12/08/2014. 
ANAC (2014b). Série Histórica Voo Regular Ativo - VRA. http: / / www2 . anac • gov . br / vra/. Acessado em 12/12/2014.

ANP (2013). Agência Nacional de Petróleo - Boletim Anual de Preços de Combustível. http: / / www . anp . gov . br / ?pg=65870\&m=\&t $1=\& t 2=\& t 3=\& t 4=\& a r=\& p s=$ $\&$ cachebust $=1369405304193$. Acessado em 17/08/2013.

ANTT (2011). Agência Nacional de Transportes Terrestres - Pesquisa Operacional: serviços interestaduais com extensão superior a $75 \mathrm{~km}$. http: //propass. antt.gov.br/ index.php/content/view/105717/Pesquisa_Operacional__servicos_ interestaduais_com_extensao_superior_a_75_km.html. Acessado em $18 / 05 / 2014$.

ANTT (2013). Agência Nacional de Transportes Terrestres - Coeficientes Tarifários de Serviços de Ônibus Intermunicipais. https: / / www . antt.gov.br/sgp/src.br. gov. antt/apresentacao/consultas. Acessado em 15/08/2013.

AREMA (2003). Railway track design. In: Practical Guide to Railway Engineering. Maryland, USA: American Railway Engineering and Maintenance-of-Way Association. cap. 6.

AVDAGIC, Z.; SMAJEVIC, A.; BOSKOVIC, D. (2008). Track layout design using modified genetic algorithm. In: IEEE International Symposium on Industrial Electronics, 2008. Cambridge, UK: [s.n.], p. 803-808.

BATISTA, C. N. O. (2006). Contribuição à Análise da Capacidade de Processamento de Trens Cargueiros em Linhas Ferroviárias Singelas no Brasil. Dissertação (Mestrado) Departamento de Engenharia de Transportes, Escola de Engenharia de São Carlos, USP, São Carlos, SP.

BCB (2015a). Banco Central do Brasil - Taxa SELIC (Sistema Especial de Liquidação e de Custódia). http: / / www . bcb. gov . br/ ? SELICDIARIOS. Acessado em 27/01/2015.

BCB (2015b). Banco Central do Brasil - Taxas de Câmbio. http : / / www 4 . bcb.gov . br / pec/taxas/port/ptaxnpesq.asp?id=txcotacao. Acessado em 19/01/2015.

BELLET, C. (2009). The introduction of the high speed rail and urban restructuring: the case of spain. City Futures, v. 9, p. 4-6.

BERECHMAN, J. (2010). The evaluation of transportation investment projects. [S.1.]: Routledge.

BERTONCINI, B. V.; KAWAMOTO, E. (2012). Modelagem da matriz OD sintética a partir dos volumes observados nas interseções da rede de transportes. Transportes (Rio de Janeiro), v. 20 , n. 2 , p. $75-83$.

BIERLAIRE, M.; FETIARISON, M. (2009). Estimation of discrete choice models: extending biogeme. In: Swiss Transport Research Conference (STRC). [S.1.: s.n.].

BOARDMAN, A. E. (2010). Cost-benefit analysis. [S.1.]: Pearson Education.

BOS (2013). Bristol Online Surveys. www. survey.bris.ac.uk/. Acessado em $15 / 09 / 2013$. 
CALIPER (2007). TransCAD: Transportation GIS Software. Newton, MA, USA: Caliper Corporation.

CARSON, R. T. et al. (1994). Experimental analysis of choice. Marketing letters, Springer, v. 5, n. 4, p. 351-367.

CASCETTA, E.; NGUYEN, S. (1988). A unified framework for estimating or updating origin/destination matrices from traffic counts. Transportation Research Part B: Methodological, Elsevier, v. 22, n. 6, p. 437-455.

CERVERO, R.; RADISCH, C. (1996). Travel choices in pedestrian versus automobile oriented neighborhoods. Transport Policy, Elsevier, v. 3, n. 3, p. 127-141.

CHEN, J. X.; GUO, Y. Y.; LV, M. X. (2011). An adaptive genetic algorithm based on multi-population parallel evolutionary for highway alignment optimization model. Applied Mechanics and Materials, Trans Tech Publications, v. 58, p. 1499-1503.

CHEVROULET, T.; REYNAUD, C. (2011). Assessment of high speed rail projects: Selection of european cases and recommendations from eva-tren research. In: Proceedings of the 11th World Conference on Transportation Research. Lisbon, Portugal: WCTR Society.

CHEW, E. P.; GOH, C. J.; FWA, T. F. (1989). Simultaneous optimization of horizontal and vertical alignments for highways. Transportation Research Part B: Methodological, Elsevier, v. 23 , n. 5 , p. 315-329.

CHOICE METRICS (2014). Ngene. Version 1.1.2., Choice Metrics Pty Ltd.

CPTM (2014a). Companhia Paulista de Trens Metropolitanos. http: / /www . cptm. sp. gov.br. Acesso em: 20/09/2014.

CPTM (2014b). Programa de Invesimentos em Trens Regionais - CPTM. http: //www.cptm.sp.gov.br/Obras/trens-regionais.asp. Acesso em: 21/08/2014.

CRAINIC, T. G.; DAVIDOVIĆ, T.; RAMLJAK, D. (2012). Designing parallel meta-heuristic methods. In: DESPOTOVIC-ZRAKIC, M.; MILUTINOVIC, V.; BELIC, A. (Ed.). Handbook of Research on High Performance and Cloud Computing in Scientific Research and Education. Québec, Canada: IGI Global. cap. 11.

DATTALO, P. (2008). Determining sample size: Balancing power, precision, and practicality. ew York, NY, USA: Oxford University Press.

DE RUS, G. (2008). The economic effects of high speed rail investment. Spain.

DE RUS, G. et al. (2009). Economic analysis of high speed rail in Europe. Spain: Fundación BBVA.

De Rus, G.; NOMBELA, G. (2007). Is investment in high speed rail socially profitable? Journal of transport economics and policy, JSTOR, v. 41, n. 1, p. 3-23.

DESU, M. M. (2012). Sample size methodology. Waltham, MA, USA: Elsevier.

DFT (2014). Transport Analysis Guidance - WebTAG. https: / /www.gov.uk/ transport-analysis-guidance-webtag. UK Department for Transport's website for guidance on the conduct of transport studies. 
DOMENCICH, T.; MCFADDEN, D. (1975). Urban Travel Demand: A Behavioral Approach. Amsterdam, Netherlands: North-Holland Publishing Co.

DOMENCICH, T. A.; KRAFT, G.; VALETTE, J. (1968). Estimation of urban passenger travel behavior: An economic demand model. Highway Research Record.

DREYER, S. B. (2010). Comparative Analysis of the Quality of Appraisal Practices for High Speed Rail Investments Projects in Europe. Dissertação (Mestrado) - Molde University College, Molde, Norway.

EMPLASA (2006). Pesquisa de Origem e Destino do Transporte Rodoviário e Aéreo do Estado de São Paulo- Empresa Paulista de Planejamento Metropolitano. http: //www.emplasa.sp.gov.br/emplasa/conselhos/rmsp/arquivos/ Pesquisa_OD_Rodoviaria_-_Executivo.swf.

FLORIO, M. et al. (2004). Guide to cost-benefit analysis of investment projects. Brussels, Belgium: European Commission, DG Regional Policy.

FOWKES, T.; WARDMAN, M. (1988). The design of stated preference travel choice experiments: with special reference to interpersonal taste variations. Journal of Transport Economics and Policy, JSTOR, p. 27-44.

FURNESS, K. P. (1965). Time function iteration. Traffic Engineering and Control, v. 7, n. 7, p. $458-460$.

GAMPER, C. D.; TURCANU, C. (2007). On the governmental use of multi-criteria analysis. Ecological economics, Elsevier, v. 62, n. 2, p. 298-307.

GIVONI, M. (2006). Development and impact of the modern high-speed train: A review. Transport reviews, Taylor \& Francis, v. 26, n. 5, p. 593-611.

GLEAVE, S. D. (2004). High Speed Rail: International Comparisons: Final Report. [S.1.].

GLEAVE, S. D. (2011). The value of station investment-research on regenerative impacts. Network Rail, London.

GOH, C. J.; CHEW, E. P.; FWA, T. F. (1988). Discrete and continuous models for computation of optimal vertical highway alignment. Transportation Research Part B: Methodological, Elsevier, v. 22, n. 6, p. 399-409.

GOKTEPE, A.; LAV, A.; ALTUN, S. (2009). Method for optimal vertical alignment of highways. In: Proceedings of the ICE - Transport. [S.1.: s.n.], v. 162, n. 4, p. 177-188.

GOMES, L. E. D. (1973). Transporte Rodoviário de Passageiros.

GONÇALVES, M. B.; BEZ, E. T.; NOVAES, A. G. (2007). Modelos econométricos aplicados à previsão de demanda por transporte interestadual de passageiros de ônibus no brasil. Transportes (Rio de Janeiro), v. 15, n. 1, p. 24-33.

GRANGE, L. et al. (2013). A polarized logit model. Transportation research part A: policy and practice, Elsevier, v. 53, p. 1-9.

GROSCHE, T.; ROTHLAUF, F.; HEINZL, A. (2007). Gravity models for airline passenger volume estimation. Journal of Air Transport Management, Elsevier, v. 13, n. 4, p. 175-183. 
GUPTA, M.; DEEP, K. (2009). A state-of-the-art review of population-based parallel meta-heuristics. In: IEEE. World Congress on Nature \& Biologically Inspired Computing, 2009. Coimbatore, India, p. 1604-1607.

HASHEM, I. A. T. et al. (2015). The rise of "big data"on cloud computing: Review and open research issues. Information Systems, Elsevier, v. 47, p. 98 - 115.

HAYASHI, Y.; MORISUGI, H. (2000). International comparison of background concept and methodology of transportation project appraisal. Transport policy, Pergamon, v. 7, n. 1, p. 73-88.

HENDERSON, J. V. (2008). Regiões de influência das cidades 2007. Rio de Janeiro: IBGE.

HOGAN, J. D. (1973). Experience with optloc optimum location of highways by computer. In: Proceedings on Cost Model and Optimization in Highway. London, UK: [s.n.]. Session L10.

HSIEH, F. Y. (1989). Sample size tables for logistic regression. Statistics in medicine, Wiley Online Library, v. 8, n. 7, p. 795-802.

HUANG, S.; CHEN, C.; DZENG, R. (2011). Design of track alignment using building information modeling. Journal of Transportation Engineering, American Society of Civil Engineers, v. 137, n. 11, p. 823-830.

IBGE (1990). Instituto Brasileiro de Geografia e Estatística: Séries Econômicas, Demográficas e Sociais de 1550 a 1990. http://biblioteca.ibge.gov.br/visualizacao/ monografias/GEBIS $\div 20-\% 20 \mathrm{RJ} /$ seriesestatisticasrestrospectivas/ Volume $\% 203 \_E s t a t i s t i c a s \% 20 h i s t o r i c a s \% 20$ do\%20Brasil_series\% 20 economicas_demograficas 20 e2 0 sociais 20 de $201550 \% 20 a \% 201988$. pdf. Acesso em: 12/08/2013.

IBGE (2010). Instituto Brasileiro de Geografia e Estatística: Censo Populacional 2010. http: // censo2010.ibge.gov.br/. Acesso em: 10/04/2013.

IBGE (2014a). Instituto Brasileiro de Geografia e Estatística - Mapa Mural de Cobertura e Uso da Terra. http: / / www. metadados.geo.ibge.gov.br/geonetwork_ibge / srv/por/metadata. show?id=11079\& currTab=simple. Acessado em 25/01/2014.

IBGE (2014b). Instituto Brasilero de Geografia e Estatística - Projeção de Crescimento da População Brasileira. http: //servicodados.ibge.gov.br/Download/ Download.ashx?u=ftp.ibge.gov.br/Projecao_da_Populacao/Revisao_ 2008_Projecoes_1980_2050/Estimativas_1980_2050.zip. Acessado em 20/03/2014.

IBGE (2014c). Instituto Brasilero de Geografia e Estatística - WebCart. http: //www.ibge.gov.br/webcart/. Acessado em 23/02/2014.

ISLER, C. A. (2010). Proposta de um Modelo de Capacidade de Processamento de Trens Cargueiros em Redes Ferroviárias de Linha Singela. Dissertação (Mestrado) - Departamento de Engenharia de Transportes, Escola de Engenharia de São Carlos, USP, São Carlos, SP.

ISLER, C. A.; PITOMBO, C. S. (2014). Avaliação da escolha modal para o transporte ferroviário de passageiros na região sudeste através de árvores de decisão. In: Anais do XXVIII Congresso da ANPET - Associação Nacional de Pesquisa e Ensino em Transportes. Curitiba, PR: ANPET. 
ISLER, C. A.; WIDMER, J. A. (2012). Considerações sobre a via permanente ferroviária brasileira para o transporte de carga em contêineres. In: Anais do XXVI Congresso da ANPET - Associação Nacional de Pesquisa e Ensino em Transportes. Joinvile, SC: ANPET, v. 1, p. 2075-2078.

JACOBS, G. D. (1995). Costing Road Accidents in Developing Countries. London, UK.

JHA, M. K. (2003). Criteria-based decision support system for selecting highway alignments. Journal of Transportation Engineering, American Society of Civil Engineers, v. 129, n. 1, p. 33-41.

JHA, M. K.; MCCALL, C.; SCHONFELD, P. (2001). Using gis, genetic algorithms, and visualization in highway development. Computer-Aided Civil and Infrastructure Engineering, Wiley Online Library, v. 16, n. 6, p. 399-414.

JHA, M. K.; SCHONFELD, P. (2000). Integrating genetic algorithms and geographic information system to optimize highway alignments. Transportation Research Record: Journal of the Transportation Research Board, Transportation Research Board, v. 1719, n. 1, p. 233-240.

JHA, M. K. et al. (2006). Intelligent Road Design. Boston, MA, USA: [s.n.].

JHA, M. K.; SCHONFELD, P.; SAMANTA, S. (2007). Optimizing rail transit routes with genetic algorithms and geographic information system. Journal of Urban Planning and Development, American Society of Civil Engineers, v. 133, n. 3, p. 161-171.

JONG, J. C.; SCHONFELD, P. (2003). An evolutionary model for simultaneously optimizing three-dimensional highway alignments. Transportation Research Part B: Methodological, Elsevier, v. 37, n. 2, p. 107-128.

JPPF (2014). Java Parallel Programming Framework - JPPF. http: / / www . jppf . org/. Acessado em 18/04/2014.

KANG, M.; JHA, M. K.; SCHONFELD, P. (2012). Applicability of highway alignment optimization models. Transportation Research Part C: Emerging Technologies, Elsevier, v. 21, n. 1, p. 257-286.

KAZEMI, S. F.; SHAFAHI, Y. (2013). An integrated model of parallel processing and PSO algorithm for solving optimum highway alignment problem. In: Proceedings of the 27th European Conference on Modelling and Simulation. Aalesund, Norway: European Council for Modeling and Simulation, p. 551-557.

KIM, E. et al. (2004). Intersection modeling for highway alignment optimization. Computer-Aided Civil and Infrastructure Engineering, Wiley Online Library, v. 19, n. 2, p. 119-129.

KIM, E.; JHA, M. K.; SON, B. (2005). Improving the computational efficiency of highway alignment optimization models through a stepwise genetic algorithms approach. Transportation Research Part B: Methodological, Elsevier, v. 39, n. 4, p. 339-360.

KITAMURA, R.; MOKHTARIAN, P. L.; LAIDET, L. (1997). A micro-analysis of land use and travel in five neighborhoods in the san francisco bay area. Transportation, Springer, v. 24, n. 2 , p. $125-158$. 
KOC, W.; PALIKOWSKA, K. (2001). Evolution programming applied to the railway line design in the presence of terrain obstacles. In: 2001 IEEE Intelligent Transportation Systems Proceedings. Oakland, CA, USA: IEEE, p. 1084-1089.

KRAFT, G. (1968). Demand for intercity passenger travel in the Washington-Boston corridor. Boston, MA, USA.

LACERDA, S. M. (2008). Trens de alta velocidade: experiência internacional. Revista do BNDES, v. 14, n. 29 , p. 61-80.

LEE, Y.; CHENG, J.-F. (2001). Optimizing highway grades to minimize cost and maintain traffic speed. Journal of transportation engineering, American Society of Civil Engineers, v. 127 , n. 4 , p. 303-310.

LEMESHOW, S. et al. (1990). Adequacy of sample size in health studies. Chichester: Wiley.

LOPEZ, H. (2008). The social discount rate: Estimates for nine Latin American countries. Washington, DC, USA.

MACKIE, P. et al. (1999). Socio-economic Cost Benefit Analysis: Transport Infrastructure Needs Assessment - TINA. Geneva, Switzerland.

MACKIE, P. et al. (2003). Toolkit for the Economic Evaluation of World Bank Transport Projects. Leeds, UK.

MATHEWS, P. (2010). Sample size calculations: practical methods for engineers and scientists. Fairport Harbor, OH, USA: Mathews Malnar and Bailey, Inc.

MCKINSEY (2010). Estudo do Setor de Transporte Aéreo do Brasil: Relatório Consolidado. Brasil, Rio de Janeiro.

MITCHELL, R. C.; CARSON, R. T. (1989). Using surveys to value public goods: the contingent valuation method. Washington, DC, USA: Resources for the Future.

MOREIRA, R. (2000). Avaliação de projetos de transportes utilizando análise benefício custo e método de análise hierárquica. Dissertação (Mestrado) — Faculdade de Engenharia Civil, Arquitetura e Urbanismo, Universidade Estadual de Campinas - UNICAMP, Campinas, SP.

MPS (2013). Ministério da Previdência Social - Projeções Atuariais para o Regime Geral de Previdência Social. http: //www12. senado.gov.br/orcamento/ documentos/ldo/2014/elaboracao/projeto-de-lei/2014/anexo-iv. 5-2013-projecoes-atuariais-para-o-regime-geral-de-previdencia-social-2

MUNASINGHE, M. (2007). Multi-criteria analysis in environmental decision-making. Washington, DC, USA: Environmental Information Coalition, National Council for Science and the Environment.

MYSQL (2014). Open Source Database - MySQL. http: / / www . mysql . com/. Acessado em 10/07/2014.

NASA (2014). National Aeronautics and Space Administration - NASA. http: //www.nasa.gov/. Acessado em 10/08/2014.

NASH, C. (2010). Enhancing the Cost Benefit Analysis of High Speed Rail. [S.1.]. 
NELLTHORP, J.; HYMAN, G. (2001). Alternatives to the rule of a half in matrix-based appraisal. In: Proceedings of the AET European Transport Conference. Cambridge, UK: Association for European Transport.

NELLTHORP, J.; MACKIE, P. J.; BRISTOW, A. L. (1998). Measurement and valuation of the impacts of transport initiatives. [S.1.].

NICHOLSON, A. J.; ELMS, D. G.; WILLIMAN, A. (1976). A variational approach to optimal route location. Highway Engineer, American Society of Civil Engineers, v. 23, n. 3, p. 22-25.

NUVEMUSP (2013). Ambiente de infraestrutura em nuvem da Universidade de São Paulo NuvemUSP. https: / / nuvem. uspdigital. usp.br/. Acessado em 15/10/2013.

OECD (1973). Optimisation of road alignment by the use of computers. Paris, France: Organisation for Economic Co-operation and Development, $117 \mathrm{p}$.

ORACLE (2012). Java Software. https: / /www. oracle.com/ java/index.html. Acessado em 21/02/2012.

ORME, B. (1998). Sample size issues for conjoint analysis studies. Sawthooth Software Research paper Series. Squim, WA, USA: Sawthooth Software Inc.

ORTUZAR, J. D. (1982). Fundamentals of discrete multimodal choice modelling. Transport Reviews, Taylor and Francis Ltd, v. 2, n. 1, p. 47-78.

ORTÚZAR, J. D.; WILLUMSEN, L. G. (2011). Modelling transport. 4. ed. [S.1.]: John Wiley \& Sons Ltd.

PARKER, N. A. (1977). Rural highway route corridor selection. Transportation Planning and Technology, Taylor \& Francis, v. 3, n. 4, p. 247-256.

PEDUZZI, P. et al. (1996). A simulation study of the number of events per variable in logistic regression analysis. Journal of clinical epidemiology, Elsevier, v. 49, n. 12, p. 1373-1379.

PITOMBEIRA NETO, A. R.; BERTONCINI, B. V.; LOUREIRO, C. F. G. (2011). Abordagem bayesiana na estimação de matrizes origem-destino sintéticas em redes de transportes. In: Anais do XXV Congresso da ANPET - AssociaÃßÃ£o Nacional de Pesquisa e Ensino em Transportes. [S.1.]: ANPET.

PITOMBO, C. S.; KAWAMOTO, E.; SOUSA, A. J. (2011). An exploratory analysis of relationships between socioeconomic, land use, activity participation variables and travel patterns. Transport Policy, Elsevier, v. 18, n. 2, p. 347-357.

PNLT (2014). Plano Nacional de Logística e Transporte. http: / / www2. transportes . gov.br/bit/01-inicial/pnlt.html. Acessado em 10/03/2014.

PRODAN, A. (2011). Infrastructure Pricing Models for New High-Speed Railway Corridors in Europe: Pricing Model Development for the Lisbon-Madrid High-Speed Line. Dissertação (Mestrado) — Technical University of Lisbon, Lisbon, Portugal.

QUALTRICS (2013). Qualtrics Online Surveys. www . qualtrics.com/. Acessado em 20/09/2013. 
QUINLAN, J. R. (1983). Learning efficient classification procedures and their application to chess end games. In: MICHALSKI, R. S.; CARBONELL, J. G.; MITCHELL, T. M. (Ed.). Machine learning. [S.1.]: Springer, (Symbolic Computation). p. 463-482.

RONG, C.; WU, J. (2013). Railways debt crisis intervention and its relevance for railways reform in china. In: Proceedings of the 13th World Conference on Transportation Research. Rio de Janeiro, Brazil: WCTR Society.

ROSE, J. M.; BLIEMER, M. C. J. (2008). Stated preference experimental design strategies. 2. ed. Oxford, UK: Elsevier Science.

ROSE, J. M.; BLIEMER, M. C. J. (2013). Sample size requirements for stated choice experiments. Transportation, Springer, v. 40, n. 5, p. 1021-1041.

SAELENSMINDE, K. (1999). Valuation of Non-Market Goods for Use in Cost-Benefit Analyses: Methodological Issues. Tese (Doutorado) - Department of Economics and Social Sciences, Agricultural University of Norway.

SAMANTA, S.; JHA, M. K. (2011). Modeling a rail transit alignment considering different objectives. Transportation Research Part A: Policy and Practice, Elsevier, v. 45, n. 1, p. 31-45.

SCHONFELD, P. et al. (2007). Improved Alignment Optimization and Evaluation. Maryland, USA.

SCHOPPA, R. F. (2004). 150 anos do trem no Brasil. Rio de Janeiro: Vianapole Design e Comunicação Ltda.

SHMUELI, D.; SALOMON, I.; SHEFER, D. (1996). Neural network analysis of travel behavior: evaluating tools for prediction. Transportation Research Part C: Emerging Technologies, Elsevier, v. 4, n. 3, p. 151-166.

SPSS (2008). SPSS Statistics for Windows. Version 17.0. Chicago: SPSS Inc.

STE-ENEFER (2001). Estudo de reavalização do modelo de estimativa da demanda de passageiros em ligações de transporte. Brasília, DF: Secretaria Nacional de Transportes Terrestres. Não paginado.

STEVENS, A. (2004). The application and limitations of cost-benefit assessment (cba) for intelligent transport systems. Research in Transportation Economics, Elsevier, v. 8, p. 91-111.

STREET, D. J.; BUNCH, D. S.; MOORE, B. J. (2001). Optimal designs for $2 \mathrm{k}$ paired comparison experiments. Communications in Statistics-Theory and Methods, Taylor \& Francis, v. 30, n. 10, p. 2149-2171.

STREET, D. J.; BURGESS, L. (2004). Optimal and near-optimal pairs for the estimation of effects in 2-level choice experiments. Journal of Statistical Planning and Inference, Elsevier, v. 118, n. 1 , p. $185-199$.

STREET, D. J.; BURGESS, L.; LOUVIERE, J. J. (2005). Quick and easy choice sets: constructing optimal and nearly optimal stated choice experiments. International Journal of Research in Marketing, Elsevier, v. 22, n. 4, p. 459-470.

SUN, X. S.; BRAUNER, E.; HORMBY, S. (1998). A large-scale neural network for airline forecasting in revenue management. In: Operations Research in the Airline Industry. [S.1.]: Springer. p. 46-67. 
SURVEYMONKEY (2013). Survey Monkey Surveys. https : / pt . surveymonkey • com. Acessado em 29/08/2013.

TARDIFF, T. J. (1976). A note on goodness-of-fit statistics for probit and logit models. Transportation, Springer, v. 5, n. 4, p. 377-388.

TAV (2014). Trem de Alta Velocidade no Brasil. http: / / www . antt. gov . br/index . php/content/view/5448/Trem_de_Alta_Velocidade. TAV.html. Acesso em: 20/09/2014.

TAYLOR, J. et al. (2013). Comparison of International Rail Fares and Ticketing. [S.1.].

THEIL, H. (1971). Principles of econometrics. New York: Wiley.

THOMOPOULOS, N.; GRANT-MULLER, S.; TIGHT, M. R. (2009). Incorporating equity considerations in transport infrastructure evaluation: Current practice and a proposed methodology. Evaluation and program planning, Elsevier, v. 32, n. 4, p. 351-359.

TINTNER, G. (1965). Elementos de econometria. São Paulo: Pioneira.

TRIETSCH, D. (1987). A family of methods for preliminary highway alignment.

Transportation Science, INFORMS, v. 21, n. 1, p. 17-25.

TRT (2008). High Speed Rail: International Comparisons: Final Report. [S.1.].

TSAMBOULAS, D. A. (2007). A tool for prioritizing multinational transport infrastructure investments. Transport Policy, Elsevier, v. 14, n. 1, p. 11-26.

TUDELA, A.; AKIKI, N.; CISTERNAS, R. (2006). Comparing the output of cost benefit and multi-criteria analysis: An application to urban transport investments. Transportation Research Part A: Policy and Practice, Elsevier, v. 40, n. 5, p. 414-423.

TUNALIOĞLU, N.; SOYCAN, M. (2011). An approach with distance-angle based search algorithm in route design for minimizing earthwork. International Journal of Physical Sciences, Academic Journals, v. 6, n. 23, p. 5442-5453.

TURRÓ, M.; INVERSIONES, B. E. de (2005). Railpag: Railway Project Appraisal Guidelines. [S.1.]: Office for Official Publications of the European Communities.

UIC (2010). Relationship between rail service operating direct costs and speed. http: //errac.uic.org/download.php/publication/527E.pdf. Acesso em: $10 / 01 / 2015$.

UIC (2011). Freight transport growing across all regions of the world and passenger transport also records sustained growth due to growth in Asia. http: / / www . uic. org/com/ IMG / pdf/cp18_uic_stats_2010_en.pdf. Acesso em: 20/02/2013.

USGS (2014). Earth Explorer. http: / / earthexplorer.usgs.gov/. Acessado em 25/08/2014.

VAN ESSEN, H. et al. (2011). External Costs of Transport in Europe. Delft, Netherlands.

WANG, J. J. et al. (2012). The funding of hierarchical railway development in china. Research in Transportation Economics, Elsevier, v. 35, n. 1, p. 26-33. 
WEI, X. L. et al. (2007). Contrast research on od matrix estimation result with transcad software. Highway, v. 6, p. 122-128.

WHITTEMORE, A. S. (1981). Sample size for logistic regression with small response probability. Journal of the American Statistical Association, Taylor \& Francis Group, v. 76, n. 373 , p. 27-32.

WILLIAMS, A.; SUGDEN, R. (1988). The principles of pratical cost-benefit analysis. [S.1.]: University Press.

WILLIAMS, H. C. W. L. (1981). Travel demand forecasting: an overview of theoretical developments. Leeds, UK: School of Geography, University of Leeds.

WILLIAMS, H. C. W. L.; SENIOR, M. L. (1977). Model-based transport policy assessment: 2. removing fundamental inconsistencies from models. Traffic Engineering \& Control, v. 18, n. 10, p. $464-469$.

WILLIAMS, M. (1978). Factors affecting modal choice decisions in urban travel: some further evidence. Transportation Research, Elsevier, v. 12, n. 2, p. 91-96.

WILSON, A. G. (1970). Entropy in urban and regional modelling. [S.1.]: Pion Ltd.

WORSLEY, T. (2011). The evolution of london's crossrail scheme and the development of the department for transport's economic appraisal methods. In: International Transport Forum. [S.l.]: OECD Publishing.

XIE, C.; LU, J.; PARKANY, E. (2003). Work travel mode choice modeling with data mining: decision trees and neural networks. Transportation Research Record: Journal of the Transportation Research Board, Transportation Research Board, v. 1854, n. 1, p. 50-61.

YEH, C. et al. (1999). Task oriented weighting in multi-criteria analysis. European Journal of Operational Research, Elsevier, v. 119, n. 1, p. 130-146.

YUANQING, W. et al. (2010). Od matrix estimation for urban expressway. Journal of Transportation Systems Engineering and Information Technology, Elsevier, v. 10, n. 2, p. 83-87. 


\section{Apêndices}


APÊNDICE

\section{Parâmetros para Estimativa de Investimentos em Traçados}

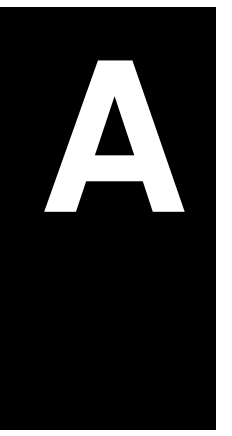




\begin{tabular}{|c|c|c|c|}
\hline PARÂMETRO DO ALGORITMO GENÉTICO & & & FONTE \\
\hline Grau de Não Uniformidade $(k)$ & \multicolumn{2}{|c|}{6,00} & Jha et al. (2006) \\
\hline Parâmetro de Troca $(q)$ & \multicolumn{2}{|c|}{0,25} & Jha et al. (2006) \\
\hline PARÂMETROS GEOMÉTRICOS & $H P T$ & HST & \\
\hline Bitola (m) & 1,435 & 1,435 & - \\
\hline Largura da plataforma com as 2 vias (m) & 8,00 & 8,00 & - \\
\hline Largura da faixa de domínio $(\mathrm{m})$ & 24,00 & 24,00 & - \\
\hline Aceleração Vertical $\left(\mathrm{m} / \mathrm{s}^{2}\right)$ & 0,1829 & 0,1829 & AREMA (2003) \\
\hline Distância entre Estacas (m) & 90,00 & 90,00 & - \\
\hline Coeficiente de Rolamento & 0,29 & 0,29 & AREMA (2003) \\
\hline Rampa Mínima (\%) & $-2,00$ & $-2,00$ & - \\
\hline Rampa Máxima (\%) & 2,00 & 2,00 & - \\
\hline Adendos sobre valor total (\%) & 10,0 & 10,0 & - \\
\hline Velocidade de Projeto $(\mathrm{km} / \mathrm{h})$ & 150 & 300 & - \\
\hline Raio Mínimo Curvas Horizontais (m) & $2.000,0$ & $7.000,0$ & - \\
\hline PARÂMETROS DE TERRAPLENAGEM & $H P T$ & HST & \\
\hline Ângulo de Aterro (graus) & 45 & 45 & - \\
\hline Ângulo de Corte (graus) & 45 & 45 & - \\
\hline PARÂMETROS DE VIADUTOS E TÚNEIS & $H P T$ & HST & \\
\hline Profundidade Máxima de Túneis (m) & 40,0 & 40,0 & - \\
\hline Altura Máxima de Corte (m) & 30,0 & 30,0 & - \\
\hline Altura Máxima de Pontes (m) & 20,0 & 20,0 & - \\
\hline Altura Máxima de Aterro (m) & 20,0 & 20,0 & - \\
\hline Comprimento Mínimo de Túneis e Pontes/Viadutos (m) & 50,0 & 50,0 & - \\
\hline Comprimento Máximo de Túneis e Pontes/Viadutos (m) & 200,0 & 200,0 & - \\
\hline Largura de Pontes (m) & 8,00 & 8,00 & - \\
\hline Área da Seção do Túnel $\left(\mathrm{m}^{2}\right)$ & 90,00 & 90,00 & - \\
\hline CUSTO UNITÁRIO DE SUPERESTRUTURA & $H P T$ & HST & \\
\hline Custo médio da Via $(\mathrm{R} \$ / \mathrm{m})$ & $1.556,0$ & $4.221,0$ & TAV (2014) \\
\hline CUSTOS DE TERRAPLENAGEM & $H P T$ & HST & \\
\hline Custo de Aterro $\left(\mathrm{R} \$ / \mathrm{m}^{3}\right)$ & 2,71 & 2,71 & TAV (2014) \\
\hline Custo de Corte $\left(\mathrm{R} \$ / \mathrm{m}^{3}\right)$ & 15,40 & 15,40 & TAV (2014) \\
\hline Fator de Empolamento & 0,15 & 0,15 & - \\
\hline Custo de Transporte Bota-fora $\left(\mathrm{R} \$ / \mathrm{m}^{3} \cdot \mathrm{km}\right)$ & 1,78 & 1,78 & TAV (2014) \\
\hline Custo de Transporte Empréstimo $\left(\mathrm{R} \$ / \mathrm{m}^{3} \cdot \mathrm{km}\right)$ & 6,70 & 6,70 & TAV (2014) \\
\hline CUSTOS DE VIADUTOS E TÚNEIS & $H P T$ & HST & \\
\hline Custo de Abertura de Túneis (R\$/unid) & $1.660 .000,0$ & $1.660 .000,0$ & TAV (2014) \\
\hline Custo de Construção de Túneis (R\$/m) & $120.000,0$ & $120.000,0$ & TAV (2014) \\
\hline Custo de construção de Pontes/Viadutos $\left(\mathrm{R} \$ / \mathrm{m}^{2}\right)$ & $4.745,0$ & $4.745,0$ & TAV (2014) \\
\hline CUSTOS DE DESAPROPRIAÇÃO & $H P T$ & $H S T$ & \\
\hline Custo de Desapropriação Área Urbana $\left(\mathrm{R} \$ / \mathrm{m}^{2}\right)$ & 23,60 & 23,60 & TAV (2014) \\
\hline Custo de Desapropriação Área Rural (R $\left.\$ / \mathrm{m}^{2}\right)$ & 6,90 & 6,90 & TAV (2014) \\
\hline
\end{tabular}

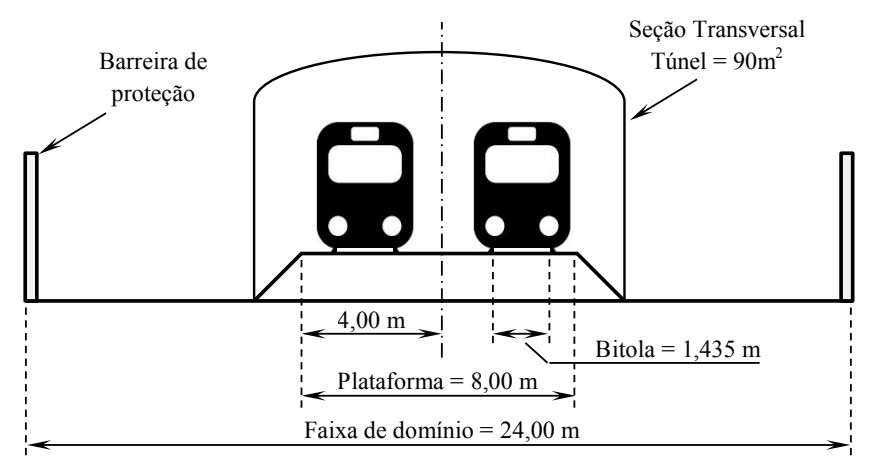

Figura A.1 - Representação esquemática da seção transversal dos traçados ferroviários 


\section{APÊNDICE \\ Projeções do Número de Viagens

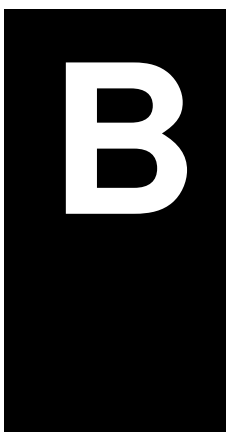

Tabela B.1 - Siglas e respectivos municípios sob influencia das estações consideradas na análise socioeconômica

\begin{tabular}{|c|c|}
\hline Sigla & Municípios \\
\hline PLU & $\begin{array}{l}\text { Baldim, Barão de Cocais, Belo Horizonte, Belo Vale, Betim, Bonfim, Brumadinho, } \\
\text { Caeté, Capim Branco, Confins, Contagem, Esmeraldas, Florestal, Fortuna de Minas, } \\
\text { Funilândia, Ibirité, Igarapé, Inhaúma, Itabirito, Itaguara, Itatiaiuçu, Itaúna, } \\
\text { Jaboticatubas, Juatuba, Lagoa Santa, Mário Campos, Mateus Leme, Matozinhos, } \\
\text { Moeda, Nova Lima, Nova União, Pará de Minas, Pedro Leopoldo, Prudente de } \\
\text { Morais, Raposos, Ribeirão das Neves, Rio Acima, Rio Manso, Sabará, Santa } \\
\text { Bárbara, Santa Luzia, São Joaquim de Bicas, São José da Lapa, São José da } \\
\text { Varginha, Sarzedo, Sete Lagoas, Taquaraçu de Minas, Vespasiano }\end{array}$ \\
\hline VCP & $\begin{array}{l}\text { Americana, Artur Nogueira, Campinas, Cosmópolis, Engenheiro Coelho, Holambra, } \\
\text { Hortolândia, Indaiatuba, Itatiba, Jaguariúna, Monte Mor, Nova Odessa, Paulínia, } \\
\text { Pedreira, Santa Bárbara d'Oeste, Santo Antônio de Posse, Sumaré, Valinhos, } \\
\text { Vinhedo }\end{array}$ \\
\hline SDU & $\begin{array}{l}\text { Belford Roxo, Duque de Caxias, Guapimirim, Itaboraí, Itaguaí, Japeri, Magé, } \\
\text { Maricá, Mesquita, Nilópolis, Niterói, Nova Iguaçu, Paracambi, Queimados, Rio de } \\
\text { Janeiro, São Gonçalo, São João de Meriti, Seropédica, Tanguá, }\end{array}$ \\
\hline CGH & $\begin{array}{l}\text { Arujá, Barueri, Biritiba-Mirim, Caieiras, Cajamar, Carapicuíba, Cotia, Diadema, } \\
\text { Embu, Embu-Guaçu, Ferraz de Vasconcelos, Francisco Morato, Franco da Rocha, } \\
\text { Guararema, Guarulhos, Itapecerica da Serra, Itapevi, Itaquaquecetuba, Jandira, } \\
\text { Juquitiba, Mairiporã, Mauá, Mogi das Cruzes, Osasco, Pirapora do Bom Jesus, Poá, } \\
\text { Ribeirão Pires, Rio Grande da Serra, Salesópolis, Santa Isabel, Santana de Parnaíba, } \\
\text { Santo André, São Bernardo do Campo, São Caetano do Sul, São Lourenço da Serra, } \\
\text { São Paulo, Suzano, Taboão da Serra, Vargem Grande Paulista }\end{array}$ \\
\hline VIX & Cariacica, Fundão, Guarapari, Serra, Viana, Vila Velha, Vitória \\
\hline UDI & Uberlândia \\
\hline UBA & Uberaba \\
\hline RAO & Ribeirão Preto \\
\hline SJP & São José do Rio Preto \\
\hline JDF & Juiz de Fora \\
\hline MOC & Montes Claros \\
\hline
\end{tabular}




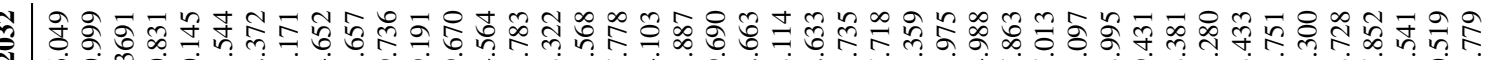

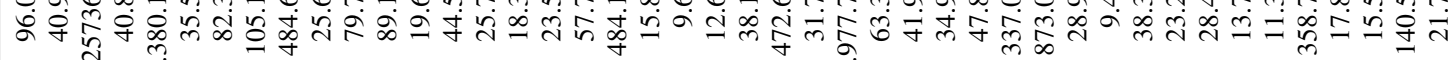

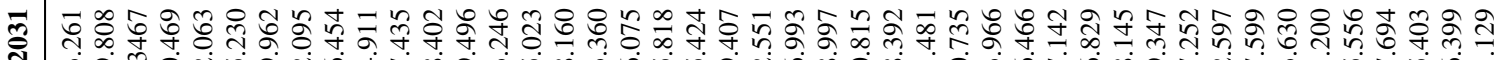

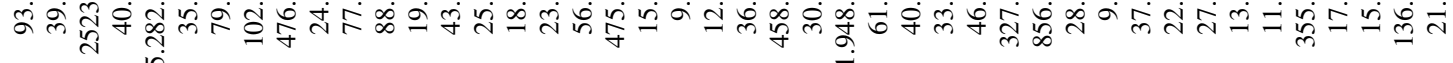

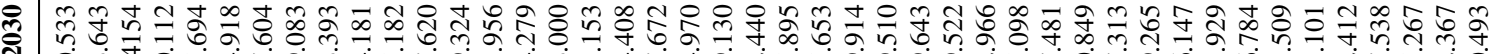

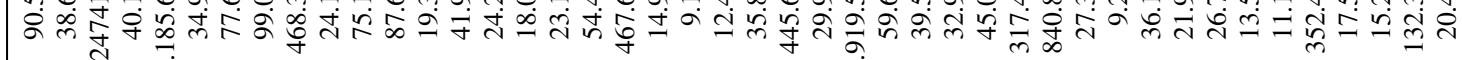

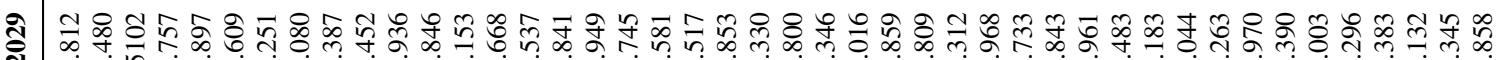

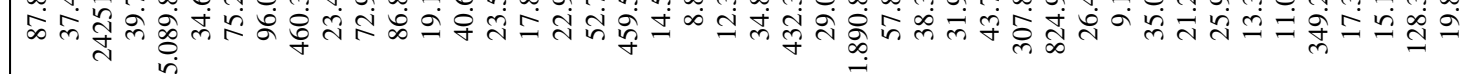

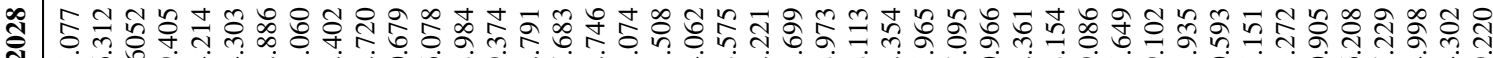

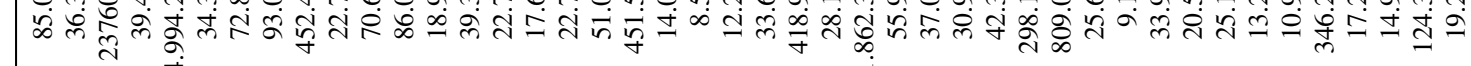

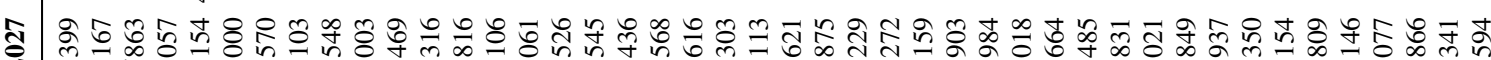
సิ

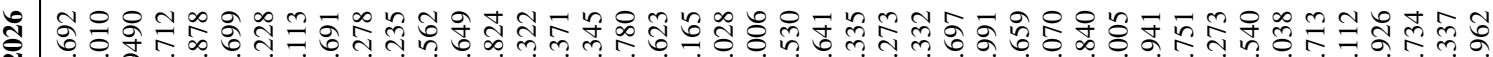

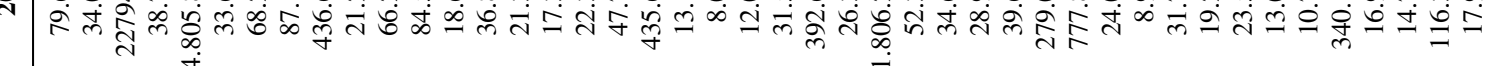

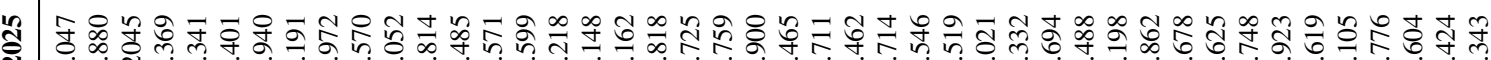

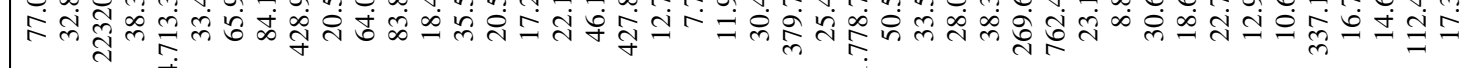

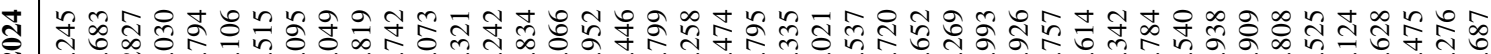

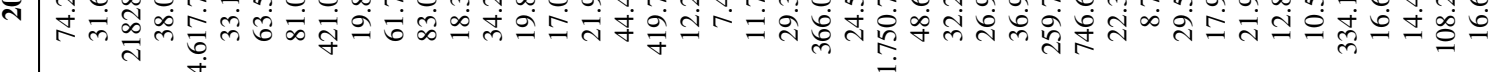

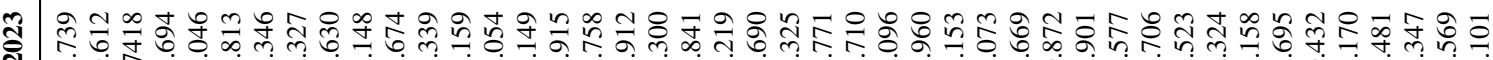
ने

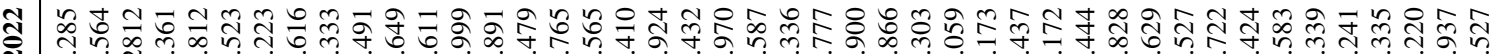

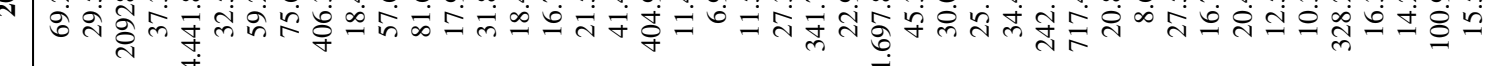

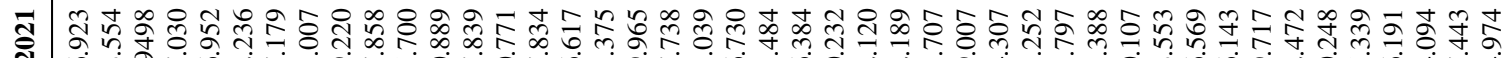

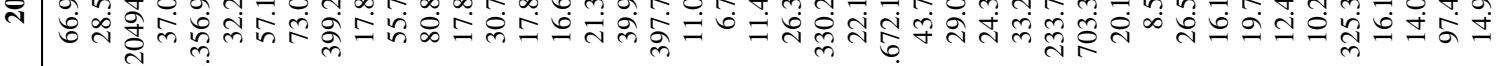

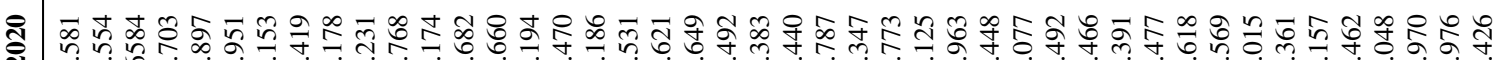

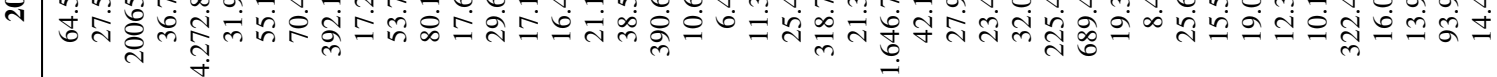

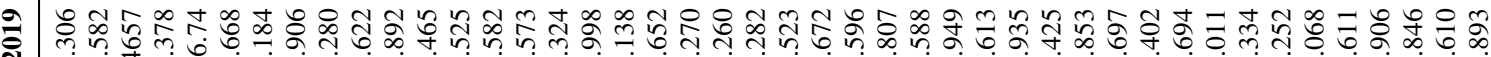
彳

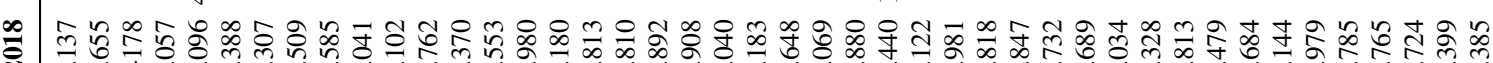
๙

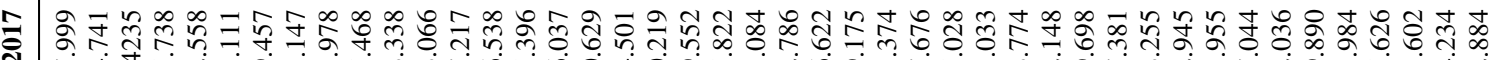

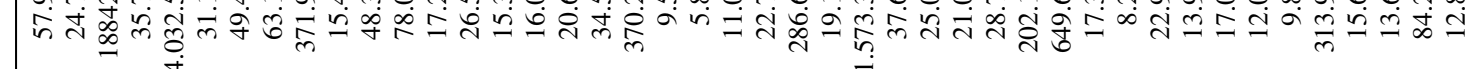

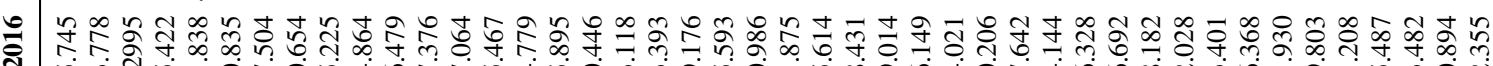

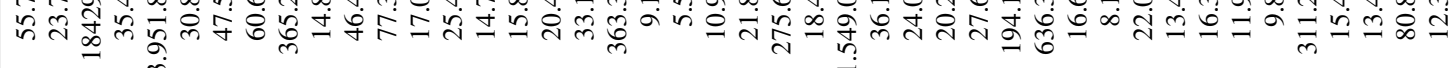

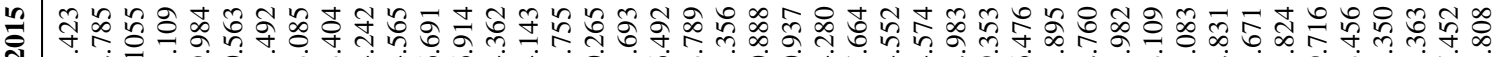

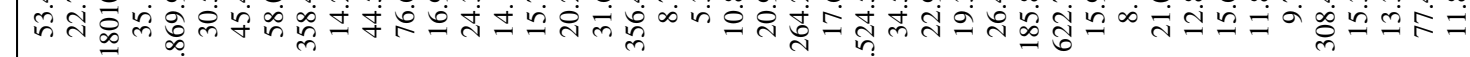

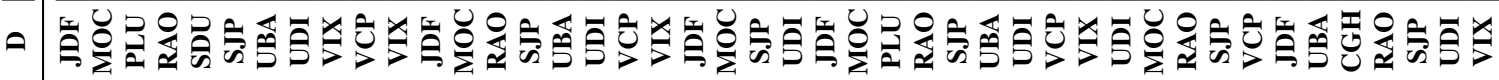

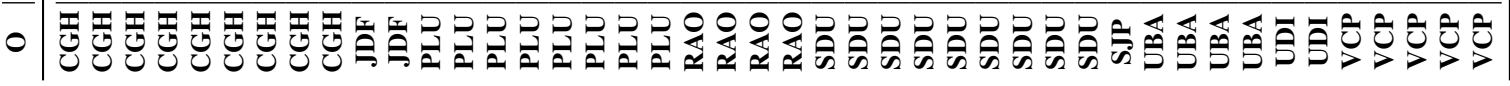




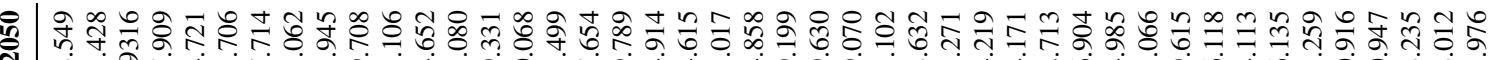

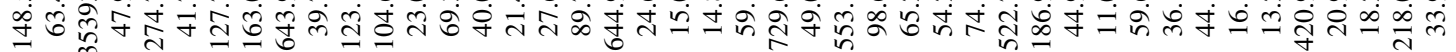

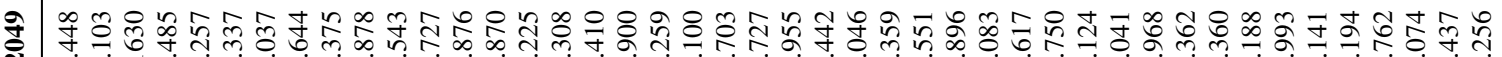

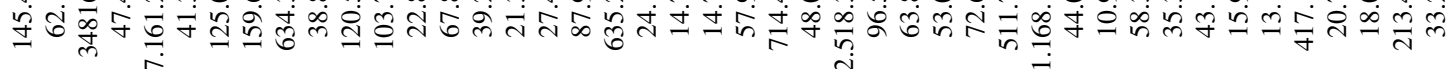

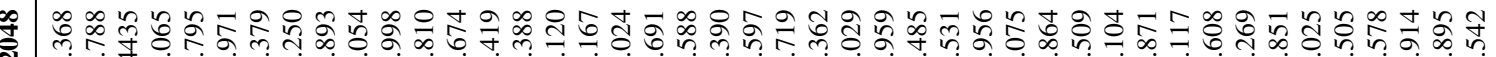

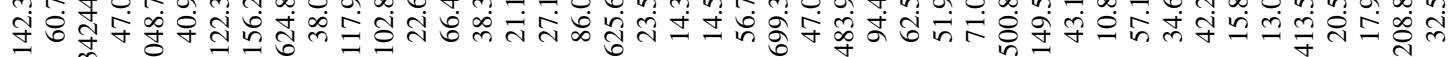

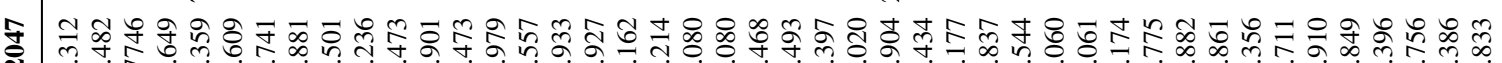



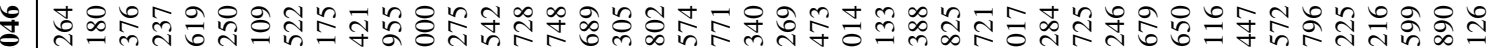

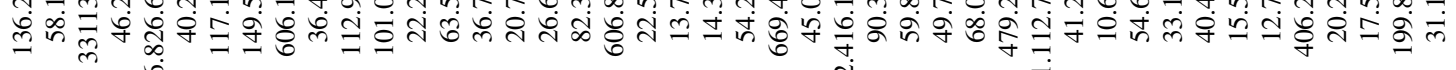

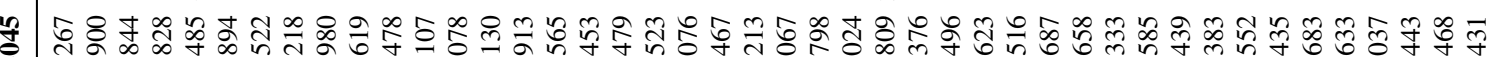

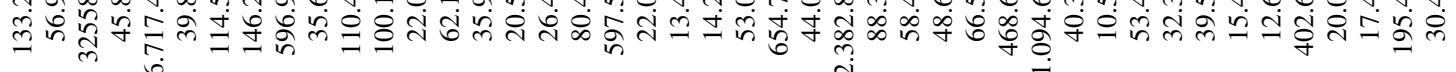

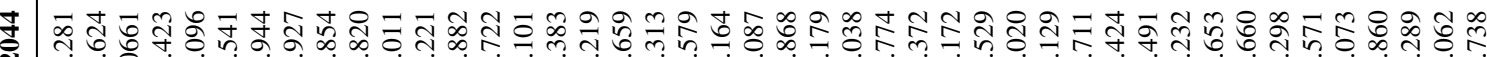

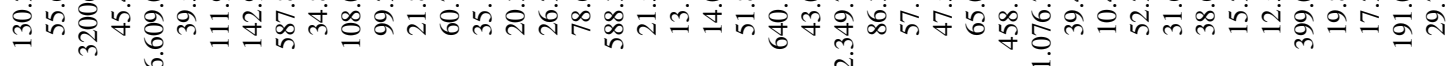

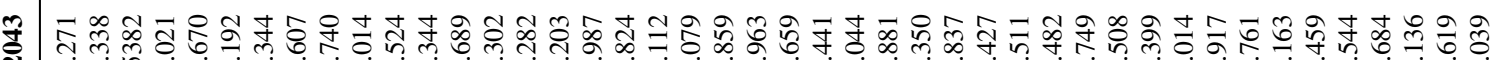

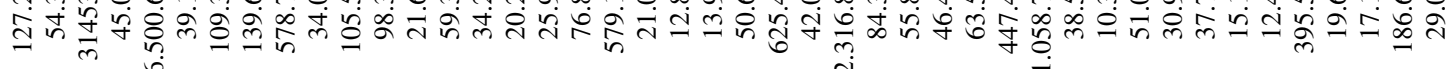

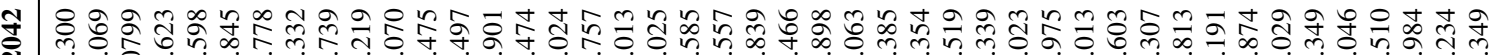

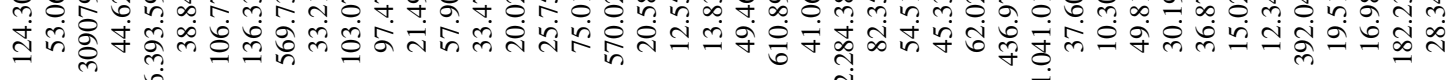

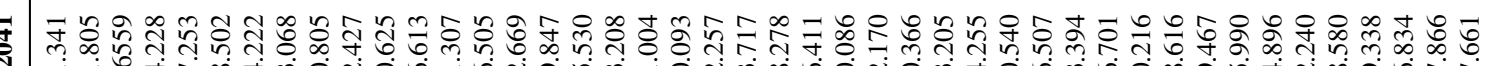

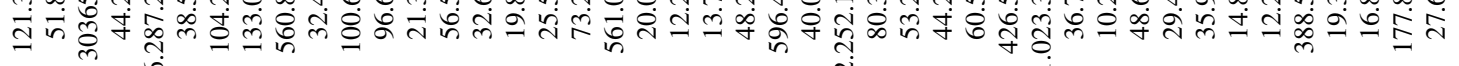

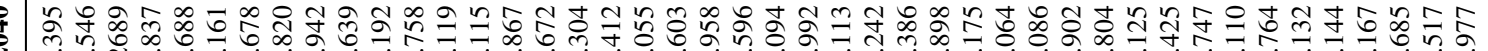

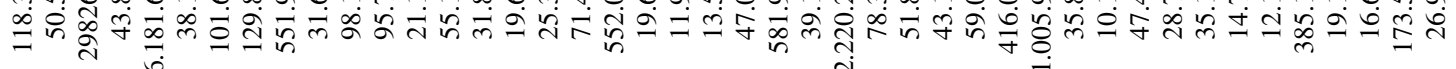

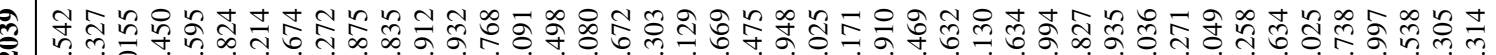

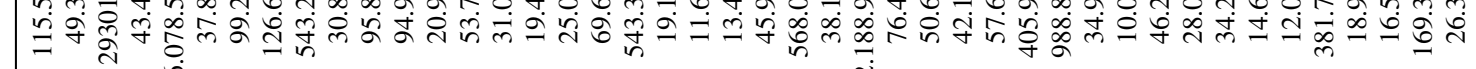

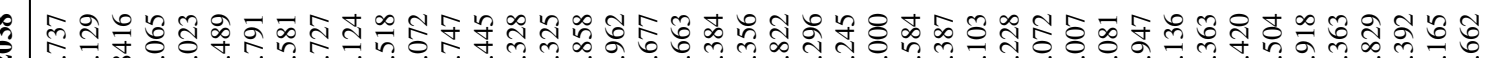

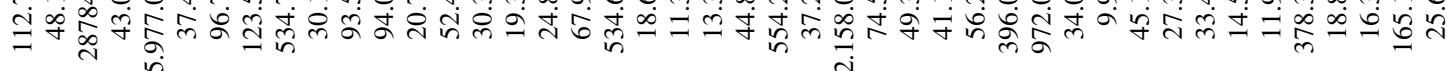

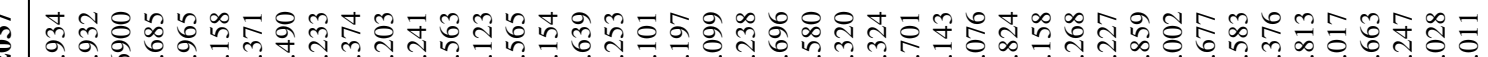

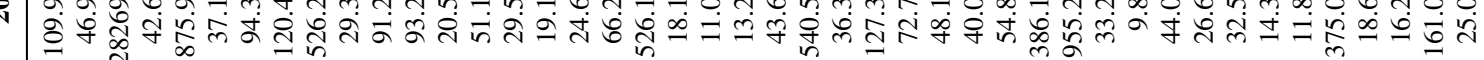

ตํ.

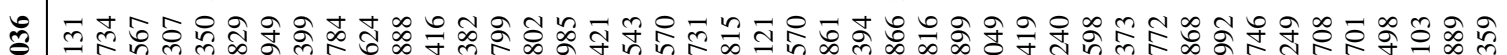

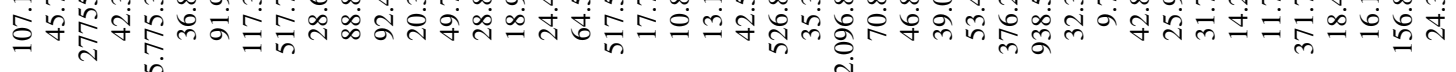

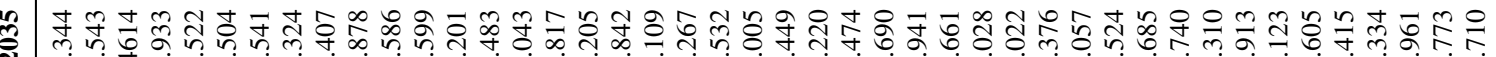

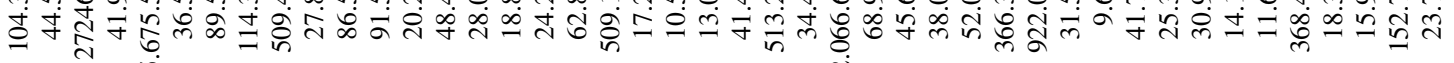

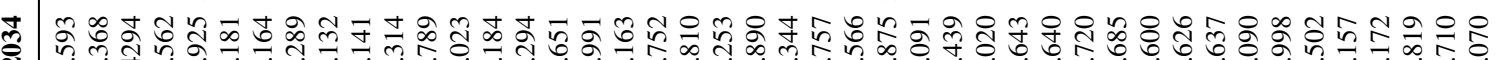

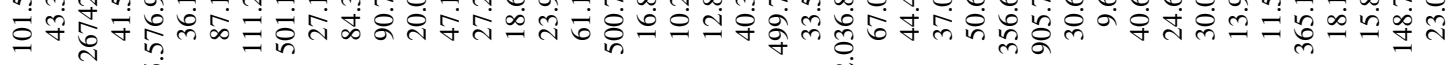



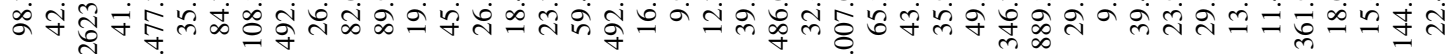

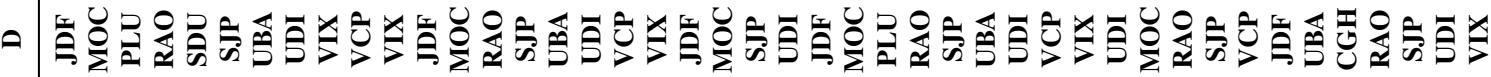

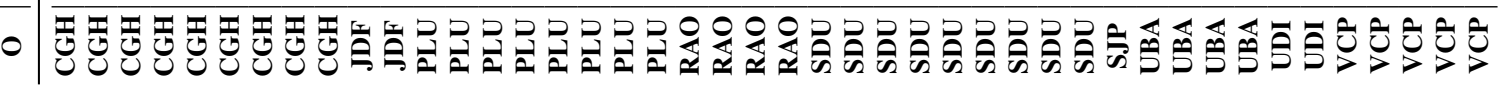




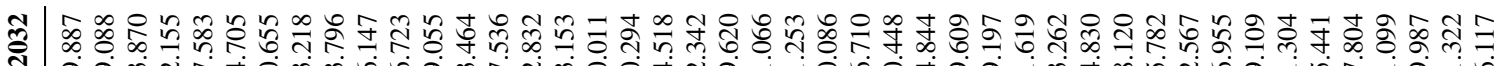

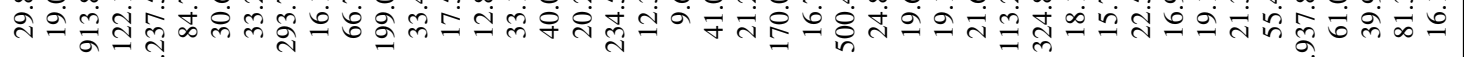

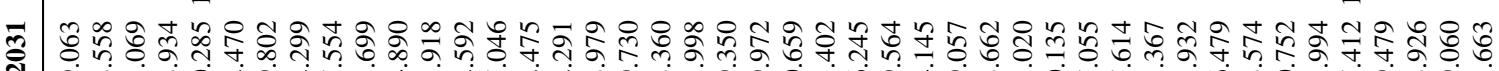

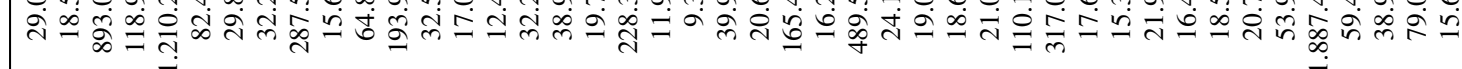

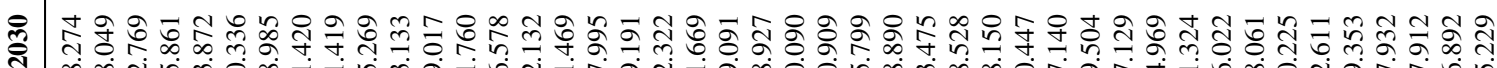

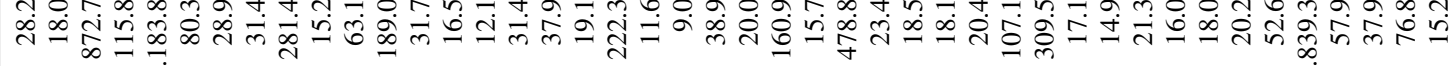

สิે तٓ

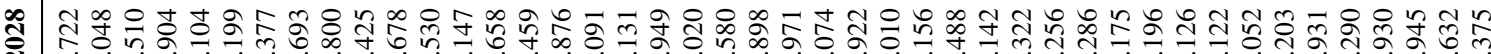

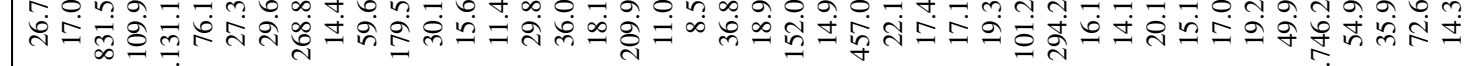

ิิ่ तें

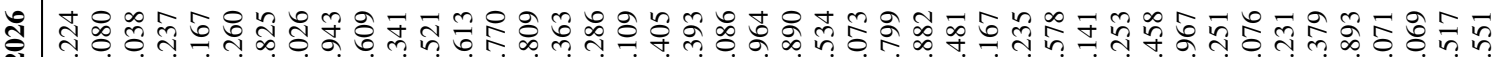

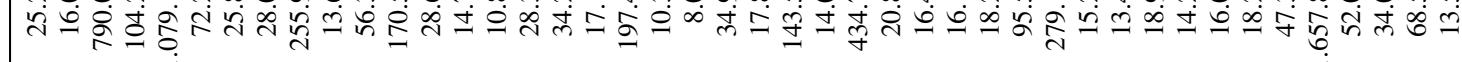

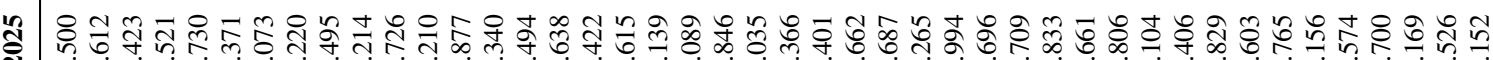

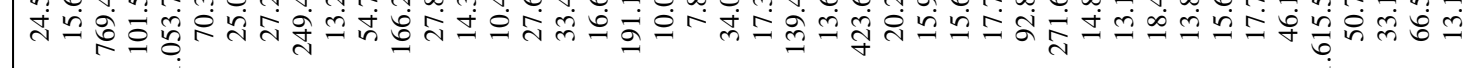

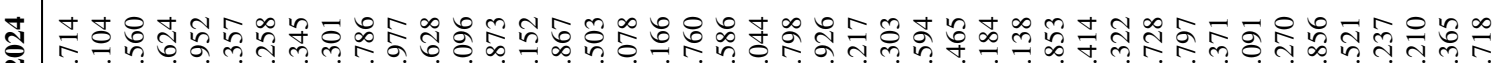

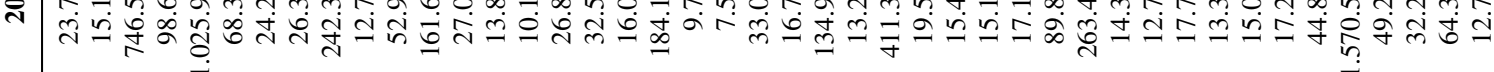

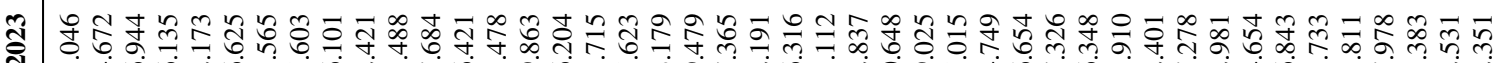
ते

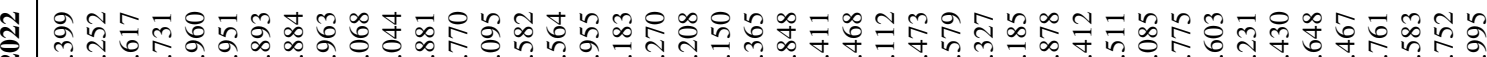

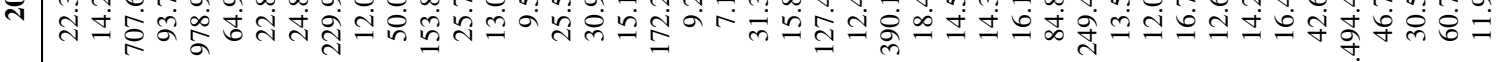
ปิ่

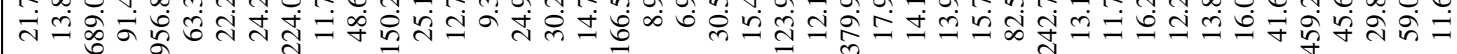

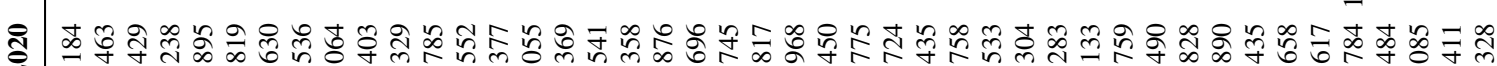
ฟ

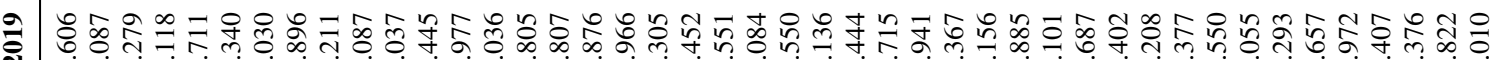

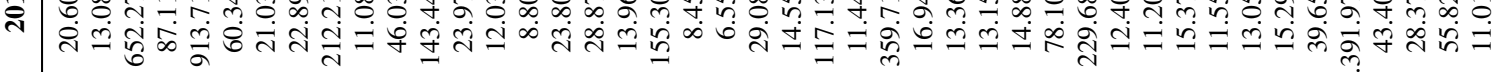



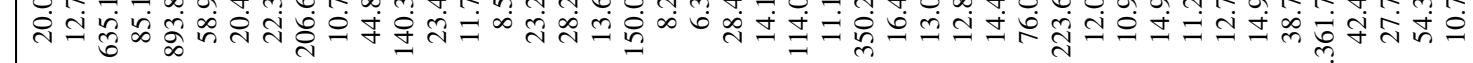

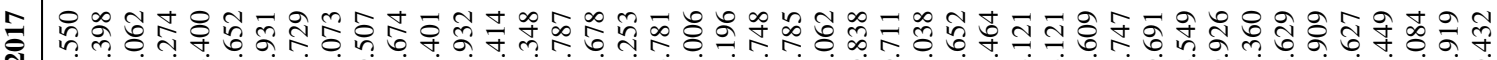

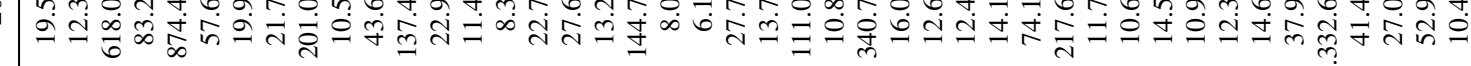

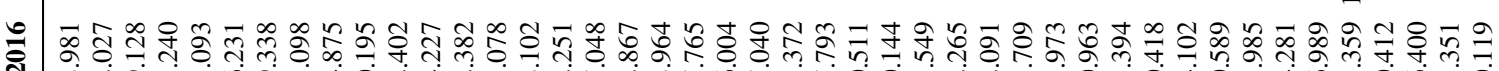

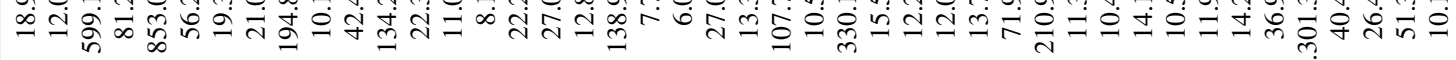

뉵

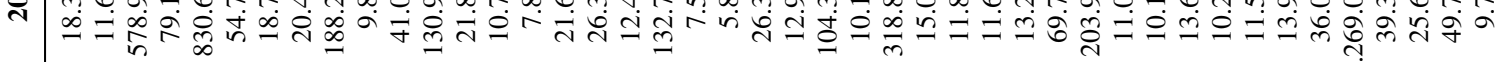




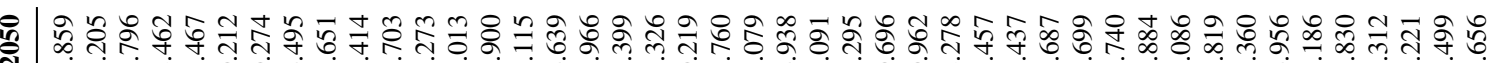

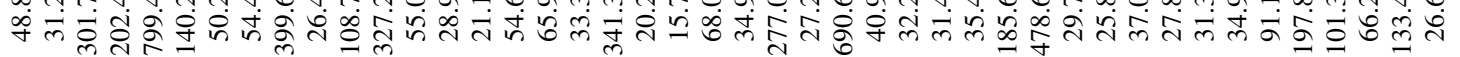

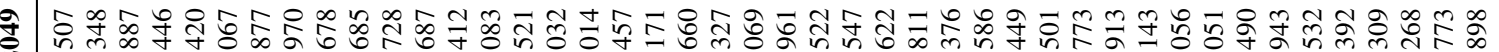

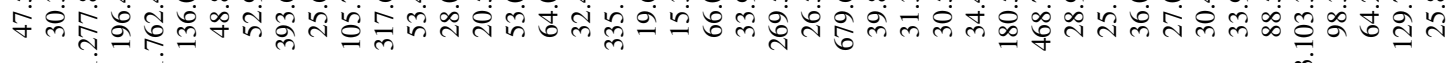

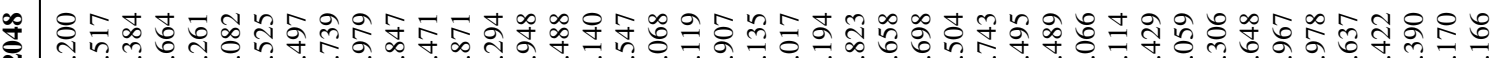

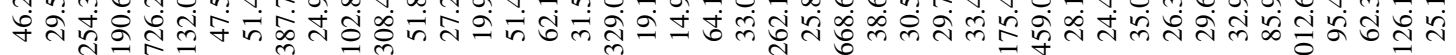

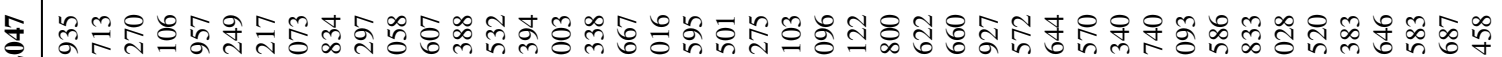

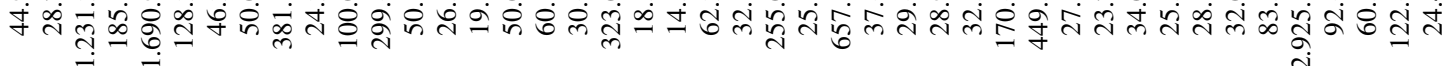

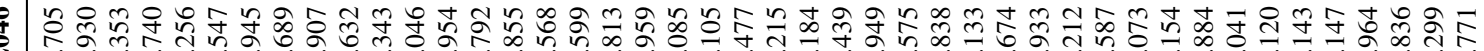

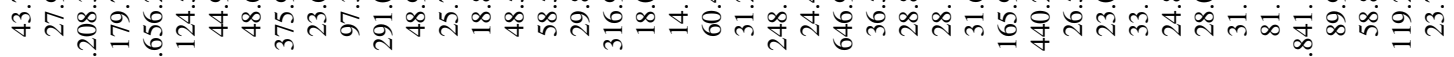

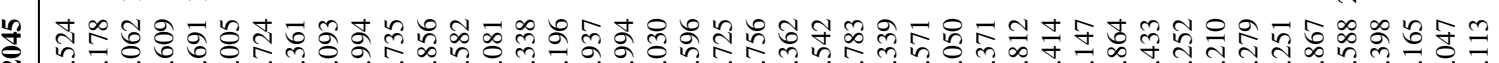

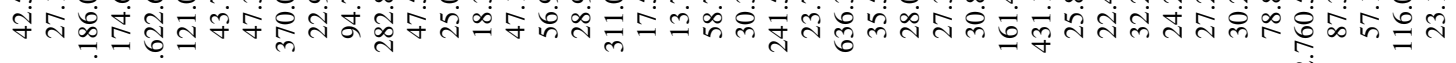

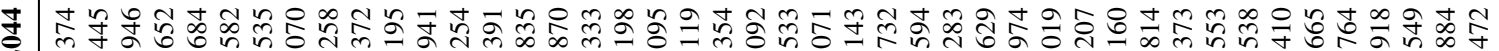

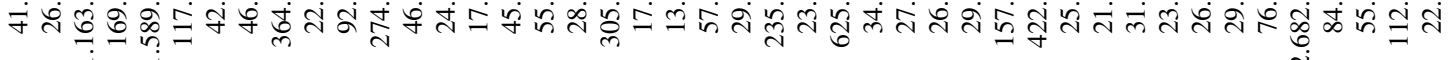

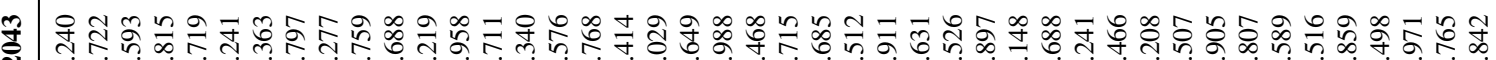

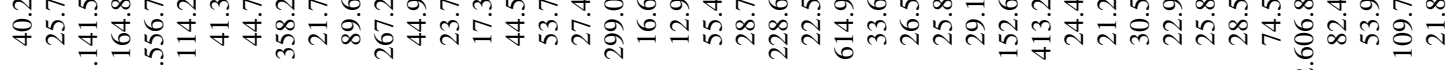

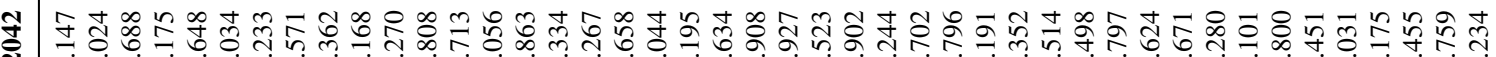

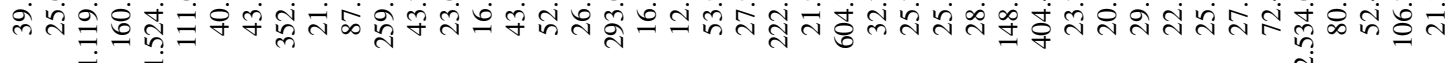

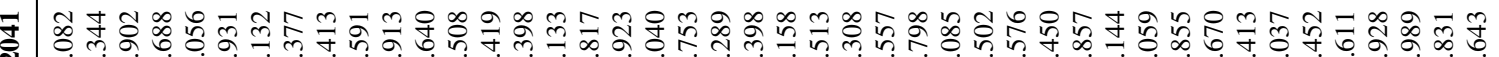

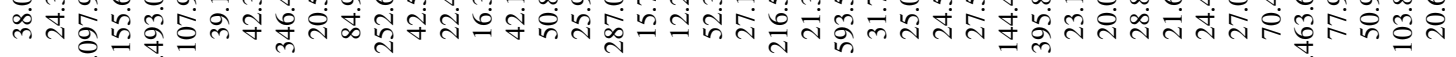

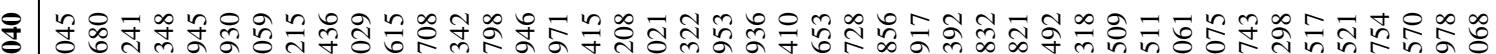

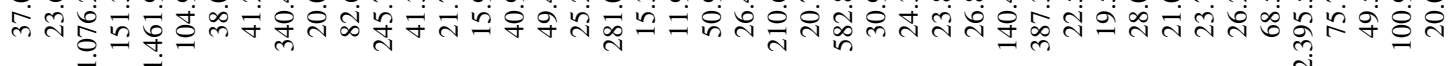

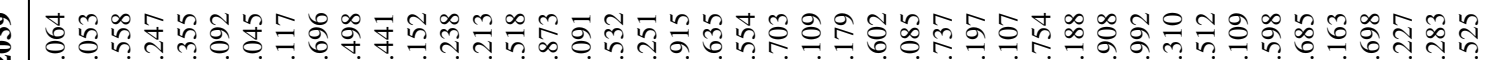

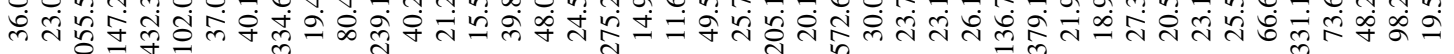

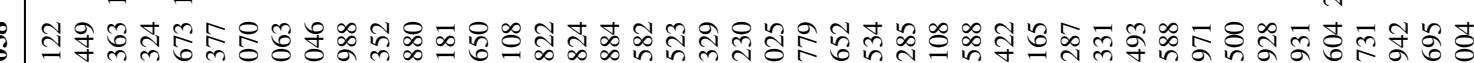

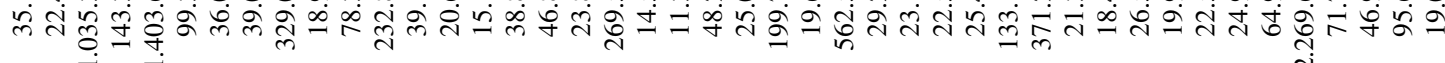

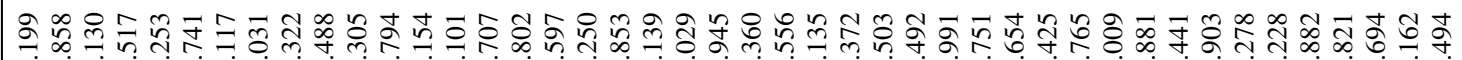
में

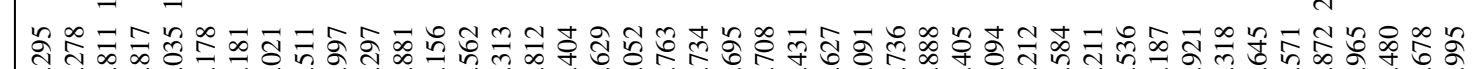

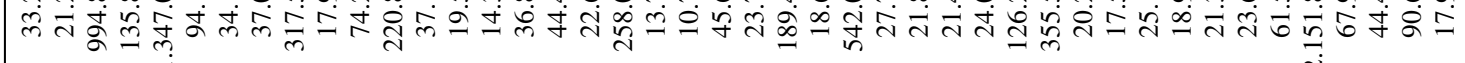

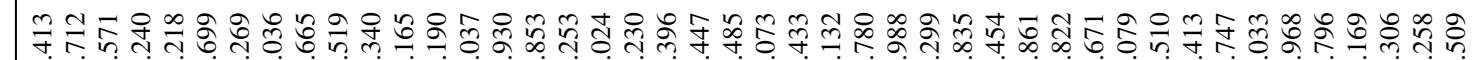

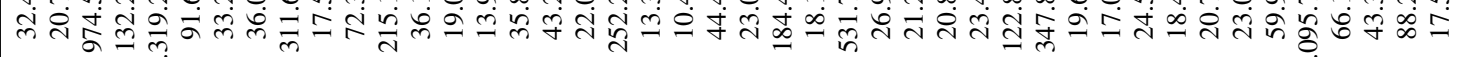

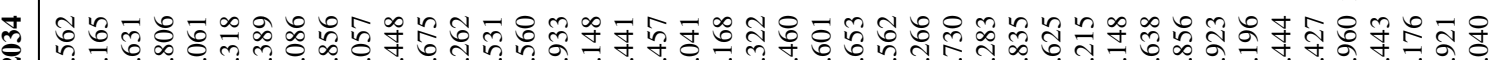

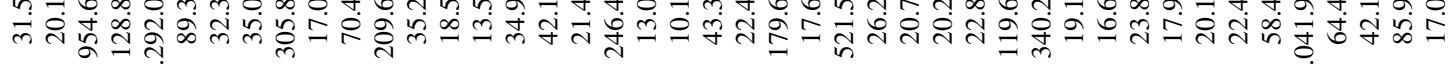

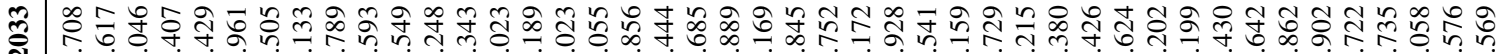

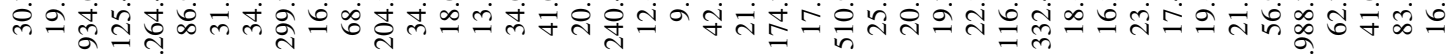

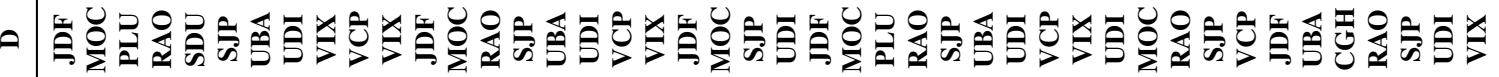

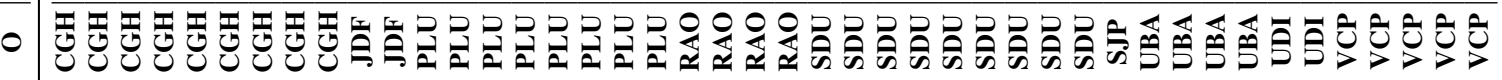




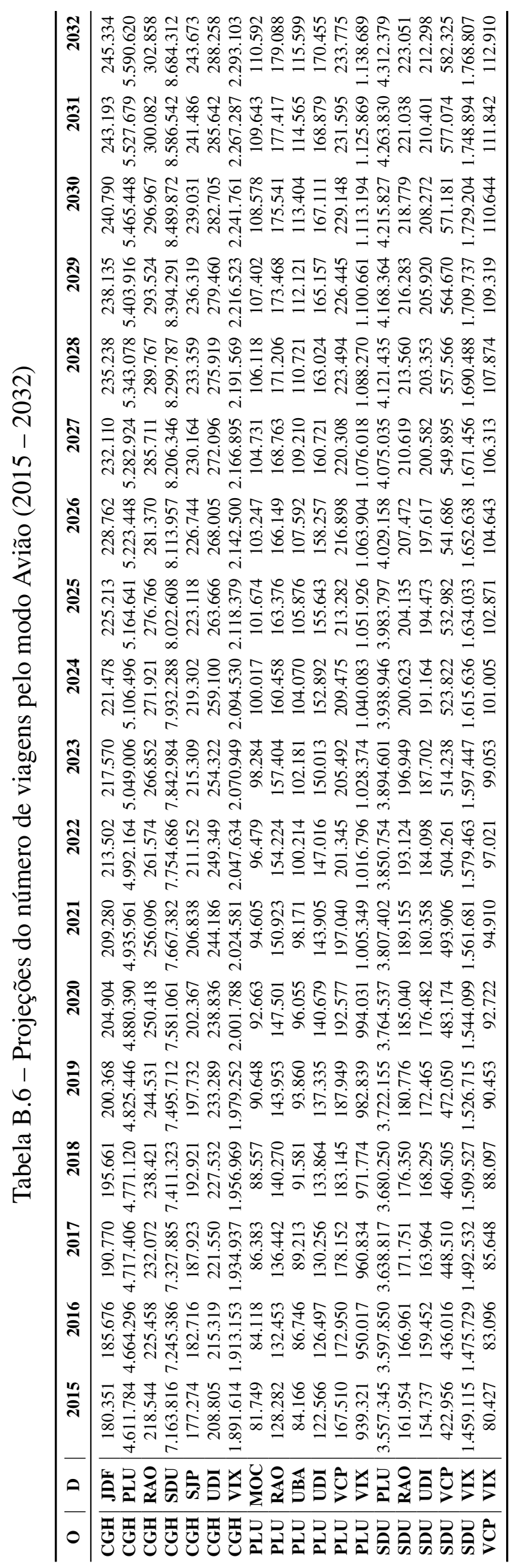




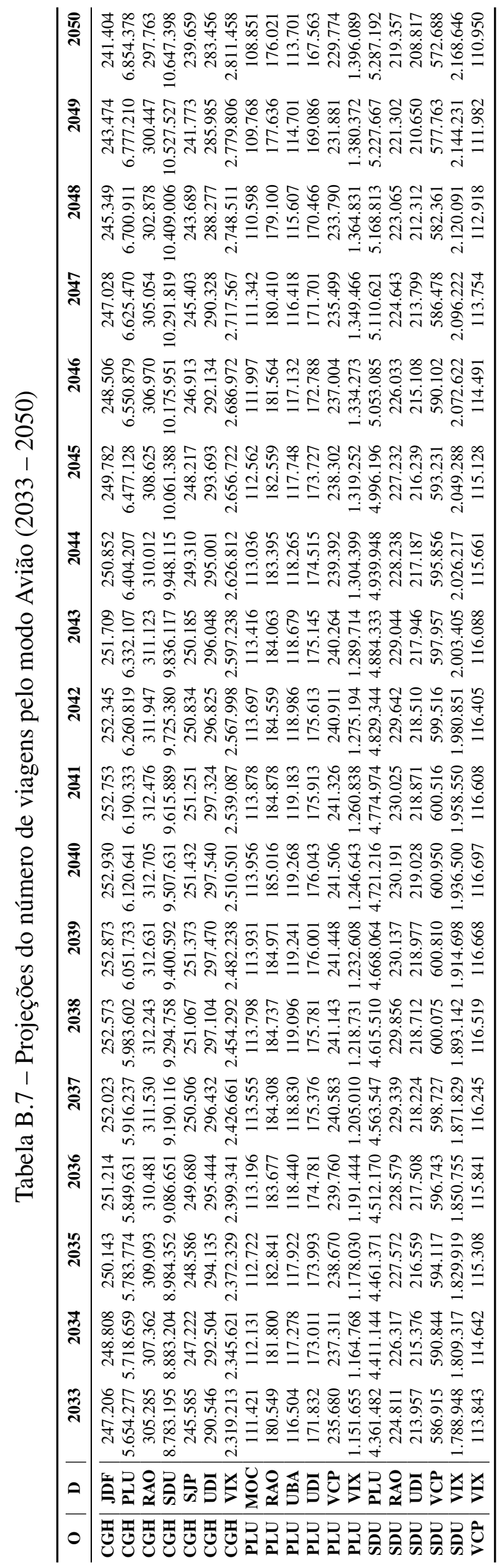


Resultados dos Modelos de Escolha Modal APÊNDICE

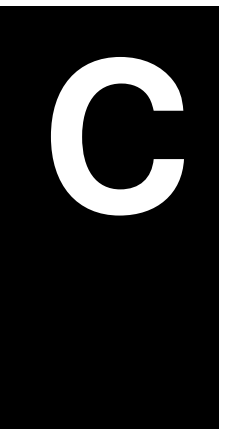



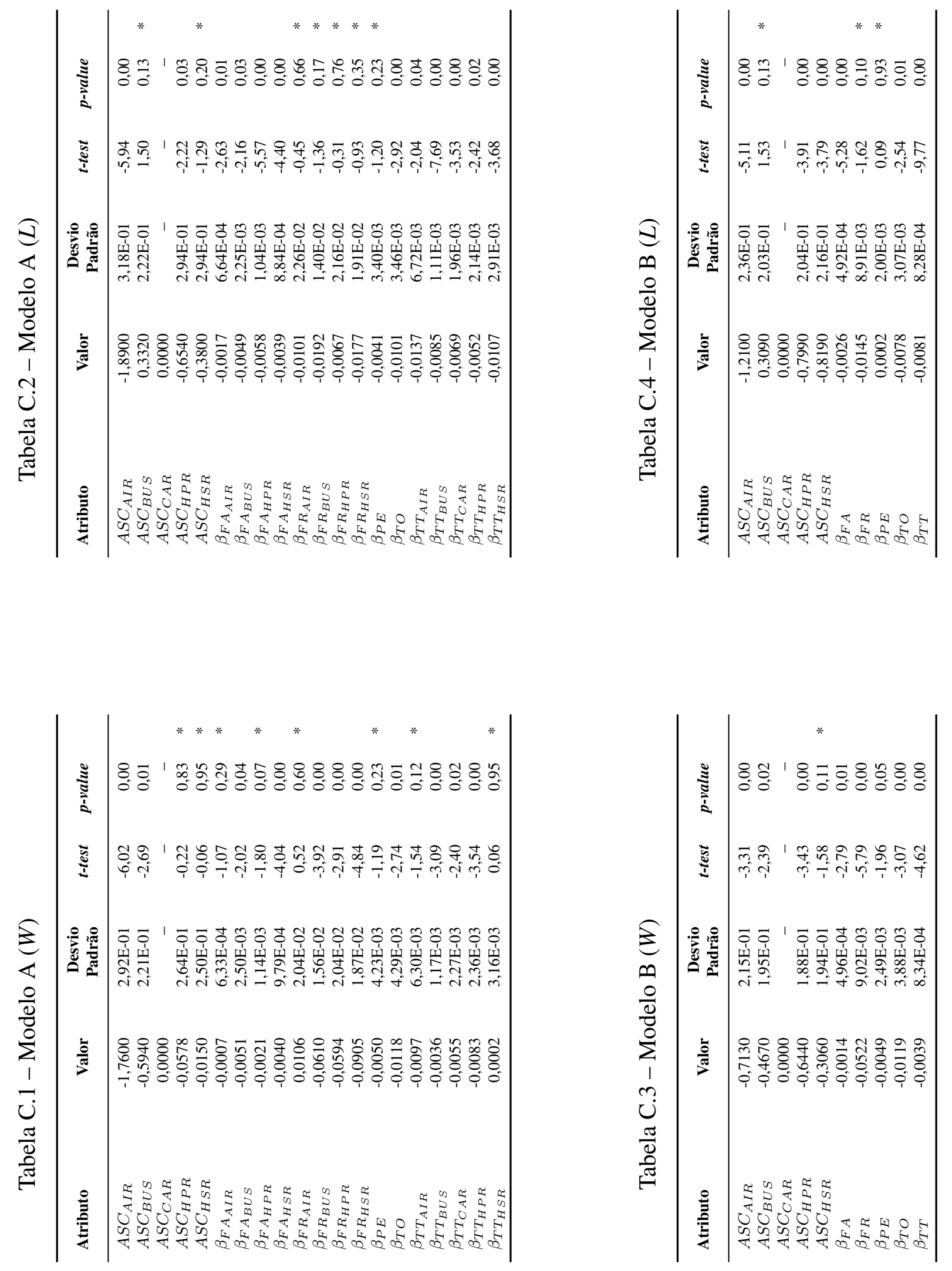

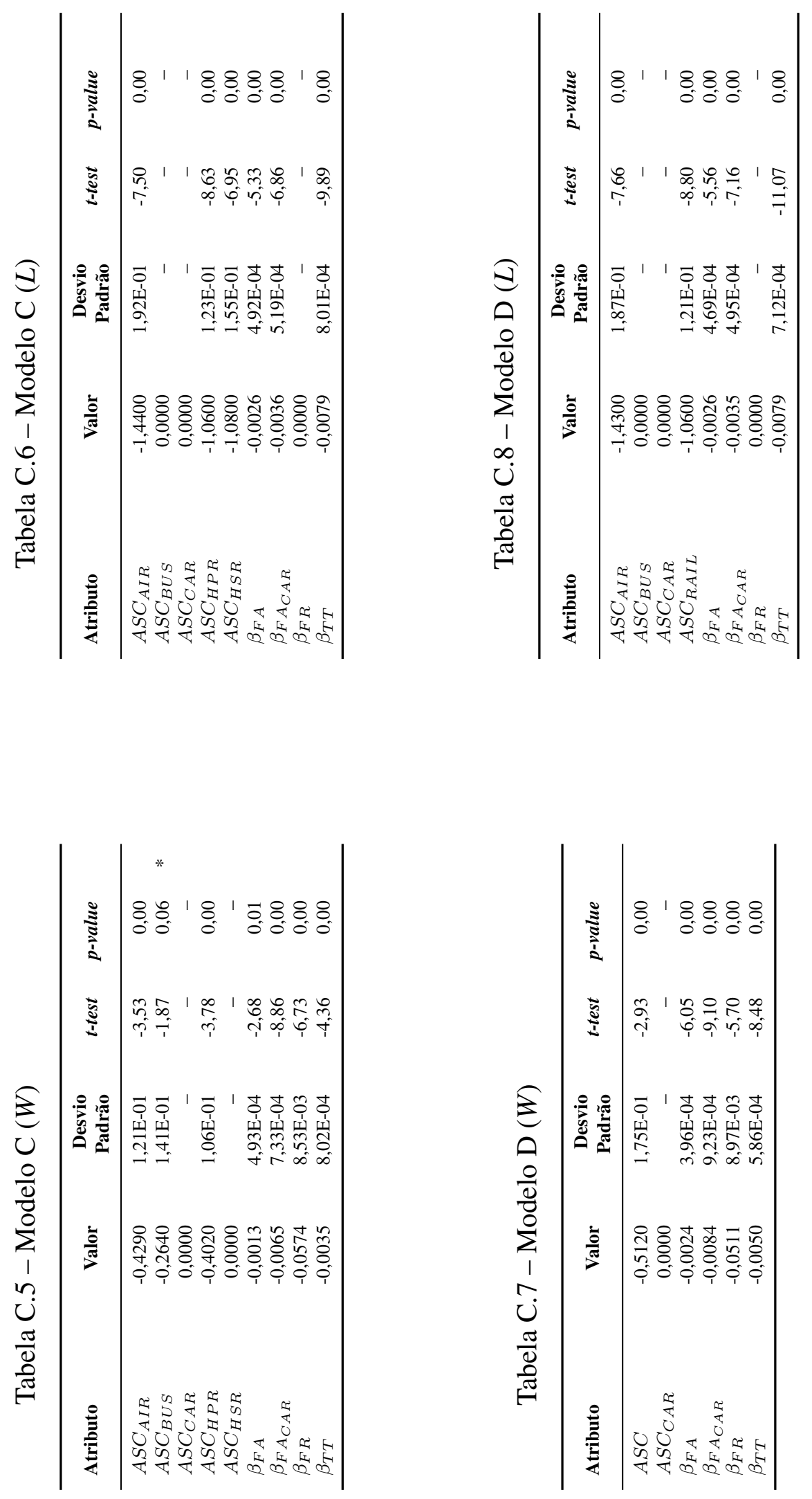
Tabela C.9 - Modelo E (W)

\begin{tabular}{|c|c|c|c|c|c|}
\hline Atributo & Valor & $\begin{array}{l}\text { Desvio } \\
\text { Padrão }\end{array}$ & t-test & p-value & \\
\hline$A S C_{A I R}$ & $-1,2600$ & $6,14 \mathrm{E}+02$ & 0,00 & 1,00 & $*$ \\
\hline$A S C_{B U S}$ & $-0,0782$ & $6,14 \mathrm{E}+02$ & 0,00 & 1,00 & $*$ \\
\hline$A S C_{C A R}$ & 0,0000 & - & - & - & \\
\hline$A S C_{H P R}$ & 0,4330 & $6,14 \mathrm{E}+02$ & 0,00 & 1,00 & $*$ \\
\hline$A S C_{H S R}$ & 0,5150 & $6,14 \mathrm{E}+02$ & 0,00 & 1,00 & $*$ \\
\hline$\alpha_{A G E_{1 C A R}}$ & 0,3160 & $8,29 \mathrm{E}+02$ & 0,00 & 1,00 & $*$ \\
\hline$\alpha_{A G E_{2}}$ & 0,0358 & $8,29 \mathrm{E}+02$ & 0,00 & 1,00 & * \\
\hline$\alpha_{A G E_{3 C A R}}$ & 0,0399 & $8,29 \mathrm{E}+02$ & 0,00 & 1,00 & $*$ \\
\hline$\alpha_{D R I V \_L I C}$ & 0,3910 & $1,80 \mathrm{e}+308$ & 0,00 & 1,00 & * \\
\hline$\alpha_{E M P}$ & $-0,2160$ & $1,50 \mathrm{E}-01$ & $-1,44$ & 0,15 & $*$ \\
\hline$\beta_{F A_{A I R}}$ & $-0,0006$ & $6,33 \mathrm{E}-04$ & $-1,00$ & 0,32 & $*$ \\
\hline$\beta_{F A_{B U S}}$ & $-0,0051$ & $2,50 \mathrm{E}-03$ & $-2,02$ & 0,04 & \\
\hline$\beta_{F A_{H P R}}$ & $-0,0020$ & $1,14 \mathrm{E}-03$ & $-1,79$ & 0,07 & $*$ \\
\hline$\beta_{F A_{H S R}}$ & $-0,0040$ & $9,80 \mathrm{E}-04$ & $-4,05$ & 0,00 & \\
\hline$\beta_{F R_{A I R}}$ & 0,0107 & $2,04 \mathrm{E}-02$ & 0,53 & 0,60 & $*$ \\
\hline$\beta_{F R_{B U S}}$ & $-0,0616$ & $1,56 \mathrm{E}-02$ & $-3,96$ & 0,00 & \\
\hline$\beta_{F R_{H P R}}$ & $-0,0610$ & $2,04 \mathrm{E}-02$ & $-2,98$ & 0,00 & \\
\hline$\beta_{F R_{H S R}}$ & $-0,0899$ & $1,87 \mathrm{E}-02$ & $-4,80$ & 0,00 & \\
\hline$\alpha_{I N C_{1_{C A R}}}$ & 0,5040 & $1,80 \mathrm{e}+308$ & 0,00 & 1,00 & $*$ \\
\hline$\alpha_{I N C_{2}}$ & 0,0367 & $1,80 \mathrm{e}+308$ & 0,00 & 1,00 & $*$ \\
\hline$\alpha_{I N C_{3 A R}}$ & $-0,1500$ & $1,80 \mathrm{e}+308$ & 0,00 & 1,00 & * \\
\hline$\beta_{P E}$ & $-0,0062$ & $4,27 \mathrm{E}-03$ & $-1,44$ & 0,15 & $*$ \\
\hline$\beta_{T O}$ & $-0,0114$ & $4,31 \mathrm{E}-03$ & $-2,66$ & 0,01 & \\
\hline$\beta_{T T_{A I R}}$ & $-0,0096$ & $6,31 \mathrm{E}-03$ & $-1,52$ & 0,13 & $*$ \\
\hline$\beta_{T T_{B U S}}$ & $-0,0036$ & $1,17 \mathrm{E}-03$ & $-3,04$ & 0,00 & \\
\hline$\beta_{T T_{C A R}}$ & $-0,0050$ & $2,30 \mathrm{E}-03$ & $-2,15$ & 0,03 & \\
\hline$\beta_{T T_{H P R}}$ & $-0,0081$ & $2,35 \mathrm{E}-03$ & $-3,43$ & 0,00 & \\
\hline$\beta_{T T_{H S R}}$ & 0,0002 & $3,16 \mathrm{E}-03$ & 0,07 & 0,95 & * \\
\hline
\end{tabular}

Tabela C.10 - Modelo E (L)

\begin{tabular}{|c|c|c|c|c|c|}
\hline Atributo & Valor & $\begin{array}{r}\text { Desvio } \\
\text { Padrão }\end{array}$ & t-test & p-value & \\
\hline$A S C_{A I R}$ & $-1,3200$ & $1,80 \mathrm{e}+308$ & 0,00 & 1,00 & $*$ \\
\hline$A S C_{B U S}$ & 0,8910 & $1,80 \mathrm{e}+308$ & 0,00 & 1,00 & $*$ \\
\hline$A S C_{C A R}$ & 0,0000 & - & - & - & \\
\hline$A S C_{H P R}$ & $-0,1020$ & $1,80 \mathrm{e}+308$ & 0,00 & 1,00 & $*$ \\
\hline$A S C_{H S R}$ & 0,2200 & $1,80 \mathrm{e}+308$ & 0,00 & 1,00 & $*$ \\
\hline$\alpha_{A G E_{1}}{ }_{C A R}$ & 0,5490 & $1,80 \mathrm{e}+308$ & 0,00 & 1,00 & $*$ \\
\hline$\alpha_{A G E_{2}{ }_{C A R}}$ & $-0,3240$ & $1,80 \mathrm{e}+308$ & 0,00 & 1,00 & $*$ \\
\hline$\alpha_{A G E_{3}{ }_{C A R}}$ & 0,0835 & $1,80 \mathrm{e}+308$ & 0,00 & 1,00 & $*$ \\
\hline$\alpha_{D R I V \_L I C}$ & 0,3090 & $1,80 \mathrm{e}+308$ & 0,00 & 1,00 & $*$ \\
\hline$\alpha_{E M P}$ & 0,0178 & 1,39E-01 & 0,13 & 0,90 & $*$ \\
\hline$\beta_{F A_{A I R}}$ & $-0,0018$ & $6,65 \mathrm{E}-04$ & $-2,65$ & 0,01 & \\
\hline$\beta_{F A_{B U S}}$ & $-0,0049$ & $2,25 \mathrm{E}-03$ & $-2,19$ & 0,03 & \\
\hline$\beta_{F A_{H P R}}$ & $-0,0058$ & $1,04 \mathrm{E}-03$ & $-5,60$ & 0,00 & \\
\hline$\beta_{F A_{H S R}}$ & $-0,0039$ & $8,85 \mathrm{E}-04$ & $-4,44$ & 0,00 & \\
\hline$\beta_{F R_{A I R}}$ & $-0,0105$ & $2,27 \mathrm{E}-02$ & $-0,47$ & 0,64 & $*$ \\
\hline$\beta_{F R_{B U S}}$ & $-0,0191$ & $1,41 \mathrm{E}-02$ & $-1,36$ & 0,18 & $*$ \\
\hline$\beta_{F R_{H P R}}$ & $-0,0061$ & $2,16 \mathrm{E}-02$ & $-0,28$ & 0,78 & $*$ \\
\hline$\beta_{F R_{H S R}}$ & $-0,0182$ & 1,91E-02 & $-0,95$ & 0,34 & $*$ \\
\hline$\alpha_{I N C_{1}{ }_{C A R}}$ & 0,3030 & $7,65 \mathrm{E}+02$ & 0,00 & 1,00 & $*$ \\
\hline$\alpha_{I N C_{2}}$ & 0,0230 & $7,65 \mathrm{E}+02$ & 0,00 & 1,00 & $*$ \\
\hline$\alpha_{I N C_{3} C A R}$ & $-0,0167$ & $7,65 \mathrm{E}+02$ & 0,00 & 1,00 & $*$ \\
\hline$\beta_{P E}$ & $-0,0041$ & $3,47 \mathrm{E}-03$ & $-1,19$ & 0,23 & $*$ \\
\hline$\beta_{T O}$ & $-0,0102$ & $3,53 \mathrm{E}-03$ & $-2,89$ & 0,00 & \\
\hline$\beta_{T T_{A I R}}$ & $-0,0139$ & $6,73 \mathrm{E}-03$ & $-2,07$ & 0,04 & \\
\hline$\beta_{T T_{B U S}}$ & $-0,0085$ & $1,11 \mathrm{E}-03$ & $-7,66$ & 0,00 & \\
\hline$\beta_{T T_{C A R}}$ & $-0,0068$ & $2,00 \mathrm{E}-03$ & $-3,41$ & 0,00 & \\
\hline$\beta_{T T_{H P R}}$ & $-0,0051$ & $2,14 \mathrm{E}-03$ & $-2,40$ & 0,02 & \\
\hline$\beta_{T T_{H S R}}$ & $-0,0108$ & 2,91E-03 & $-3,73$ & 0,00 & \\
\hline
\end{tabular}


Tabela C.11 - Modelo F $(W)$

\begin{tabular}{|c|c|c|c|c|c|}
\hline Atributo & Valor & $\begin{array}{l}\text { Desvio } \\
\text { Padrão }\end{array}$ & t-test & p-value & \\
\hline$\alpha$ & $-0,0019$ & $1,80 \mathrm{e}+308$ & 0,00 & 1,00 & * \\
\hline$\alpha_{A G E_{1}}$ & $-0,0005$ & $1,80 \mathrm{e}+308$ & 0,00 & 1,00 & $*$ \\
\hline$\alpha_{A G E_{2}}$ & 0,0012 & $1,80 \mathrm{e}+308$ & 0,00 & 1,00 & * \\
\hline$\alpha_{A G E_{3}}$ & $-0,0025$ & $1,80 \mathrm{e}+308$ & 0,00 & 1,00 & * \\
\hline$\alpha_{D R I V \_L I C}$ & $-0,0033$ & 1,64E-03 & $-2,01$ & 0,04 & \\
\hline$\alpha_{E M P}$ & 0,0030 & $1,29 \mathrm{E}-03$ & 2,29 & 0,02 & \\
\hline$\alpha_{I N C_{1}}$ & 0,0021 & $1,80 \mathrm{e}+308$ & 0,00 & 1,00 & $*$ \\
\hline$\alpha_{I N C_{2}}$ & $-0,0024$ & $1,80 \mathrm{e}+308$ & 0,00 & 1,00 & $*$ \\
\hline$\alpha_{I N C_{3}}$ & $-0,0016$ & $1,80 \mathrm{e}+308$ & 0,00 & 1,00 & $*$ \\
\hline$A S C_{A I R}$ & $-0,8030$ & 1,80E-01 & $-4,45$ & 0,00 & \\
\hline$A S C_{B U S}$ & $-0,5420$ & $2,07 \mathrm{E}-01$ & $-2,63$ & 0,01 & \\
\hline$A S C_{C A R}$ & 0,0000 & - & - & - & \\
\hline$A S C_{H P R}$ & $-0,7150$ & $1,75 \mathrm{E}-01$ & $-4,08$ & 0,00 & \\
\hline$A S C_{H S R}$ & $-0,3380$ & $1,80 \mathrm{E}-01$ & $-1,87$ & 0,06 & $*$ \\
\hline$\beta$ & $-0,0028$ & $2,53 \mathrm{E}+04$ & 0,00 & 1,00 & * \\
\hline$\beta_{A G E_{1}}$ & $-0,0025$ & $3,41 \mathrm{E}+01$ & 0,00 & 1,00 & $*$ \\
\hline$\beta_{A G E_{2}}$ & 0,0036 & $3,41 \mathrm{E}+01$ & 0,00 & 1,00 & * \\
\hline$\beta_{A G E_{3}}$ & $-0,0040$ & $3,41 \mathrm{E}+01$ & 0,00 & 1,00 & * \\
\hline$\beta_{D R I V \_L I C}$ & $-0,0028$ & $2,53 \mathrm{E}+04$ & 0,00 & 1,00 & * \\
\hline$\beta_{E M P}$ & 0,0020 & $5,00 \mathrm{E}-03$ & 0,40 & 0,69 & * \\
\hline$\beta_{I N C_{1}}$ & 0,0018 & $8,94 \mathrm{E}+00$ & 0,00 & 1,00 & * \\
\hline$\beta_{I N C_{2}}$ & $-0,0084$ & $8,94 \mathrm{E}+00$ & 0,00 & 1,00 & $*$ \\
\hline$\beta_{I N C_{3}}$ & 0,0037 & $8,94 \mathrm{E}+00$ & 0,00 & 1,00 & * \\
\hline$\gamma$ & $-0,0058$ & $9,01 \mathrm{E}+05$ & 0,00 & 1,00 & * \\
\hline$\gamma_{A G E_{1}}$ & $-0,0045$ & $6,63 \mathrm{E}+01$ & 0,00 & 1,00 & * \\
\hline$\gamma_{A G E_{2}}$ & $-0,0074$ & $6,63 \mathrm{E}+01$ & 0,00 & 1,00 & * \\
\hline$\gamma_{A G E_{3}}$ & 0,0061 & $6,63 \mathrm{E}+01$ & 0,00 & 1,00 & * \\
\hline$\gamma_{D R I V \_L I C}$ & $-0,0058$ & $9,01 \mathrm{E}+05$ & 0,00 & 1,00 & * \\
\hline$\gamma_{E M P}$ & 0,0066 & $8,58 \mathrm{E}-03$ & 0,77 & 0,44 & * \\
\hline$\gamma_{I N C_{1}}$ & $-0,0010$ & $1,80 \mathrm{e}+308$ & 0,00 & 1,00 & * \\
\hline$\gamma_{I N C_{2}}$ & 0,0034 & $1,80 \mathrm{e}+308$ & 0,00 & 1,00 & * \\
\hline$\gamma_{I N C_{3}}$ & $-0,0081$ & $1,80 \mathrm{e}+308$ & 0,00 & 1,00 & * \\
\hline$\lambda$ & $-0,0370$ & $1,55 \mathrm{E}+02$ & 0,00 & 1,00 & * \\
\hline$\lambda_{A G E_{1}}$ & $-0,0347$ & $9,85 \mathrm{E}+01$ & 0,00 & 1,00 & * \\
\hline$\lambda_{A G E_{2}}$ & $-0,0123$ & $9,85 \mathrm{E}+01$ & 0,00 & 1,00 & $*$ \\
\hline$\lambda_{A G E_{3}}$ & 0,0100 & $9,85 \mathrm{E}+01$ & 0,00 & 1,00 & $*$ \\
\hline$\lambda_{D R I V \_L I C}$ & $-0,0081$ & $2,49 \mathrm{E}-02$ & $-0,33$ & 0,74 & * \\
\hline$\lambda_{E M P}$ & 0,0263 & $1,85 \mathrm{E}-02$ & 1,42 & 0,16 & $*$ \\
\hline$\lambda_{I N C_{1}}$ & $-0,0286$ & $5,05 \mathrm{E}+01$ & 0,00 & 1,00 & * \\
\hline$\lambda_{I N C_{2}}$ & $-0,0137$ & $5,05 \mathrm{E}+01$ & 0,00 & 1,00 & * \\
\hline$\lambda_{I N C_{3}}$ & 0,0053 & $5,05 \mathrm{E}+01$ & 0,00 & 1,00 & * \\
\hline$\theta$ & $-0,0008$ & $1,80 \mathrm{E}+01$ & 0,00 & 1,00 & $*$ \\
\hline$\theta_{A G E_{1}}$ & $-0,0015$ & $1,80 \mathrm{e}+308$ & 0,00 & 1,00 & $*$ \\
\hline$\theta_{A G E_{2}}$ & 0,0017 & $1,80 \mathrm{e}+308$ & 0,00 & 1,00 & $*$ \\
\hline$\theta_{A G E_{3}}$ & $-0,0010$ & $1,80 \mathrm{e}+308$ & 0,00 & 1,00 & $*$ \\
\hline$\theta_{D R I V \_L I C}$ & $-0,0024$ & $1,12 \mathrm{E}-03$ & $-2,14$ & 0,03 & \\
\hline$\theta_{E M P}$ & 0,0028 & $8,81 \mathrm{E}-04$ & 3,22 & 0,00 & \\
\hline$\theta_{I N C_{1}}$ & 0,0008 & $6,13 \mathrm{E}+00$ & 0,00 & 1,00 & $*$ \\
\hline$\theta_{I N C_{2}}$ & $-0,0015$ & $6,13 \mathrm{E}+00$ & 0,00 & 1,00 & $*$ \\
\hline$\theta_{I N C_{3}}$ & $-0,0001$ & $6,13 \mathrm{E}+00$ & 0,00 & 1,00 & $*$ \\
\hline
\end{tabular}


Tabela C.12 - Modelo F $(L)$

\begin{tabular}{|c|c|c|c|c|c|}
\hline Atributo & Valor & $\begin{array}{l}\text { Desvio } \\
\text { Padrão }\end{array}$ & $t$-test & p-value & \\
\hline$\alpha_{T T}$ & $-0,0057$ & $1,80 \mathrm{e}+308$ & 0,00 & 1,00 & $*$ \\
\hline$\alpha_{A G E_{1}}$ & $-0,0029$ & $1,80 \mathrm{e}+308$ & 0,00 & 1,00 & $*$ \\
\hline$\alpha_{A G E_{2}}$ & $-0,0009$ & $1,80 \mathrm{e}+308$ & 0,00 & 1,00 & * \\
\hline$\alpha_{A G E_{3}}$ & $-0,0019$ & $1,80 \mathrm{e}+308$ & 0,00 & 1,00 & $*$ \\
\hline$\alpha_{D R I V \_L I C}$ & 0,0009 & $1,52 \mathrm{E}-03$ & 0,61 & 0,54 & $*$ \\
\hline$\alpha_{E M P}$ & 0,0005 & $1,14 \mathrm{E}-03$ & 0,46 & 0,65 & $*$ \\
\hline$\alpha_{I N C_{1}}$ & 0,0018 & $1,80 \mathrm{e}+308$ & 0,00 & 1,00 & $*$ \\
\hline$\alpha_{I N C_{2}}$ & $-0,0024$ & $1,80 \mathrm{e}+308$ & 0,00 & 1,00 & $*$ \\
\hline$\alpha_{I N C_{3}}$ & $-0,0051$ & $1,80 \mathrm{e}+308$ & 0,00 & 1,00 & $*$ \\
\hline$A S C_{A I R}$ & $-1,0200$ & $1,80 \mathrm{e}+308$ & 0,00 & 1,00 & $*$ \\
\hline$A S C_{B U S}$ & 0,5070 & $1,80 \mathrm{e}+308$ & 0,00 & 1,00 & $*$ \\
\hline$A S C_{C A R}$ & 0,0000 & - & - & - & \\
\hline$A S C_{H P R}$ & $-0,6160$ & $1,80 \mathrm{e}+308$ & 0,00 & 1,00 & $*$ \\
\hline$A S C_{H S R}$ & $-0,5790$ & $1,80 \mathrm{e}+308$ & 0,00 & 1,00 & $*$ \\
\hline$\beta_{P E}$ & 0,0004 & $1,80 \mathrm{e}+308$ & 0,00 & 1,00 & $*$ \\
\hline$\beta_{A G E_{1}}$ & 0,0054 & $1,80 \mathrm{e}+308$ & 0,00 & 1,00 & $*$ \\
\hline$\beta_{A G E_{2}}$ & $-0,0051$ & $1,80 \mathrm{e}+308$ & 0,00 & 1,00 & $*$ \\
\hline$\beta_{A G E_{3}}$ & 0,0001 & $1,80 \mathrm{e}+308$ & 0,00 & 1,00 & $*$ \\
\hline$\beta_{D R I V \_L I C}$ & 0,0004 & $1,80 \mathrm{e}+308$ & 0,00 & 1,00 & $*$ \\
\hline$\beta_{E M P}$ & $-0,0012$ & $3,82 \mathrm{E}-03$ & $-0,31$ & 0,75 & $*$ \\
\hline$\beta_{I N C_{1}}$ & 0,0009 & $1,80 \mathrm{e}+308$ & 0,00 & 1,00 & $*$ \\
\hline$\beta_{I N C_{2}}$ & 0,0040 & $1,80 \mathrm{e}+308$ & 0,00 & 1,00 & $*$ \\
\hline$\beta_{I N C_{3}}$ & $-0,0046$ & $1,80 \mathrm{e}+308$ & 0,00 & 1,00 & * \\
\hline$\gamma_{T O}$ & $-0,0022$ & $1,80 \mathrm{e}+308$ & 0,00 & 1,00 & $*$ \\
\hline$\gamma_{A G E_{1}}$ & $-0,0069$ & $1,80 \mathrm{e}+308$ & 0,00 & 1,00 & $*$ \\
\hline$\gamma_{A G E_{2}}$ & 0,0049 & $1,80 \mathrm{e}+308$ & 0,00 & 1,00 & $*$ \\
\hline$\gamma_{A G E_{3}}$ & $-0,0002$ & $1,80 \mathrm{e}+308$ & 0,00 & 1,00 & $*$ \\
\hline$\gamma_{D R I V \_L I C}$ & $-0,0022$ & $1,80 \mathrm{e}+308$ & 0,00 & 1,00 & $*$ \\
\hline$\gamma_{E M P}$ & $-0,0015$ & $6,40 \mathrm{E}-03$ & $-0,23$ & 0,82 & $*$ \\
\hline$\gamma_{I N C_{1}}$ & 0,0056 & $1,80 \mathrm{e}+308$ & 0,00 & 1,00 & $*$ \\
\hline$\gamma_{I N C_{2}}$ & $-0,0061$ & $1,80 \mathrm{e}+308$ & 0,00 & 1,00 & * \\
\hline$\gamma_{I N C_{3}}$ & $-0,0017$ & $1,80 \mathrm{e}+308$ & 0,00 & 1,00 & $*$ \\
\hline$\lambda_{F R}$ & 0,0050 & $1,80 \mathrm{e}+308$ & 0,00 & 1,00 & $*$ \\
\hline$\lambda_{A G E_{1}}$ & $-0,0036$ & $1,80 \mathrm{e}+308$ & 0,00 & 1,00 & $*$ \\
\hline$\lambda_{A G E_{2}}$ & $-0,0031$ & $1,80 \mathrm{e}+308$ & 0,00 & 1,00 & $*$ \\
\hline$\lambda_{A G E_{3}}$ & 0,0116 & $1,80 \mathrm{e}+308$ & 0,00 & 1,00 & $*$ \\
\hline$\lambda_{D R I V \_L I C}$ & $-0,0192$ & 1,96E-02 & $-0,98$ & 0,33 & * \\
\hline$\lambda_{E M P}$ & $-0,0242$ & $1,74 \mathrm{E}-02$ & $-1,39$ & 0,16 & $*$ \\
\hline$\lambda_{I N C_{1}}$ & 0,0184 & $1,80 \mathrm{e}+308$ & 0,00 & 1,00 & $*$ \\
\hline$\lambda_{I N C_{2}}$ & 0,0038 & $1,80 \mathrm{e}+308$ & 0,00 & 1,00 & $*$ \\
\hline$\lambda_{I N C_{3}}$ & $-0,0172$ & $1,80 \mathrm{e}+308$ & 0,00 & 1,00 & $*$ \\
\hline$\theta_{F A}$ & $-0,0020$ & $1,80 \mathrm{e}+308$ & 0,00 & 1,00 & * \\
\hline$\theta_{A G E_{1}}$ & $-0,0012$ & $1,80 \mathrm{e}+308$ & 0,00 & 1,00 & $*$ \\
\hline$\theta_{A G E_{2}}$ & 0,0001 & $1,80 \mathrm{e}+308$ & 0,00 & 1,00 & $*$ \\
\hline$\theta_{A G E_{3}}$ & $-0,0010$ & $1,80 \mathrm{e}+308$ & 0,00 & 1,00 & $*$ \\
\hline$\theta_{D R I V \_L I C}$ & 0,0007 & 9,92E-04 & 0,75 & 0,46 & $*$ \\
\hline$\theta_{E M P}$ & $-0,0001$ & $8,06 \mathrm{E}-04$ & $-0,16$ & 0,87 & $*$ \\
\hline$\theta_{I N C_{1}}$ & 0,0010 & $1,80 \mathrm{e}+308$ & 0,00 & 1,00 & $*$ \\
\hline$\theta_{I N C_{2}}$ & $-0,0005$ & $1,80 \mathrm{e}+308$ & 0,00 & 1,00 & $*$ \\
\hline$\theta_{I N C_{3}}$ & $-0,0025$ & $1,80 \mathrm{e}+308$ & 0,00 & 1,00 & $*$ \\
\hline
\end{tabular}


APÊNDICE

\section{Parâmetros para Análise Custo-Benefício}

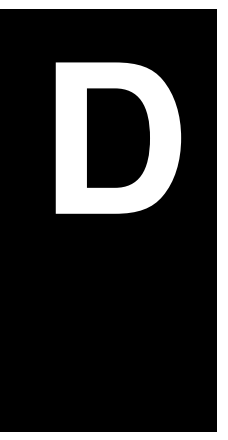




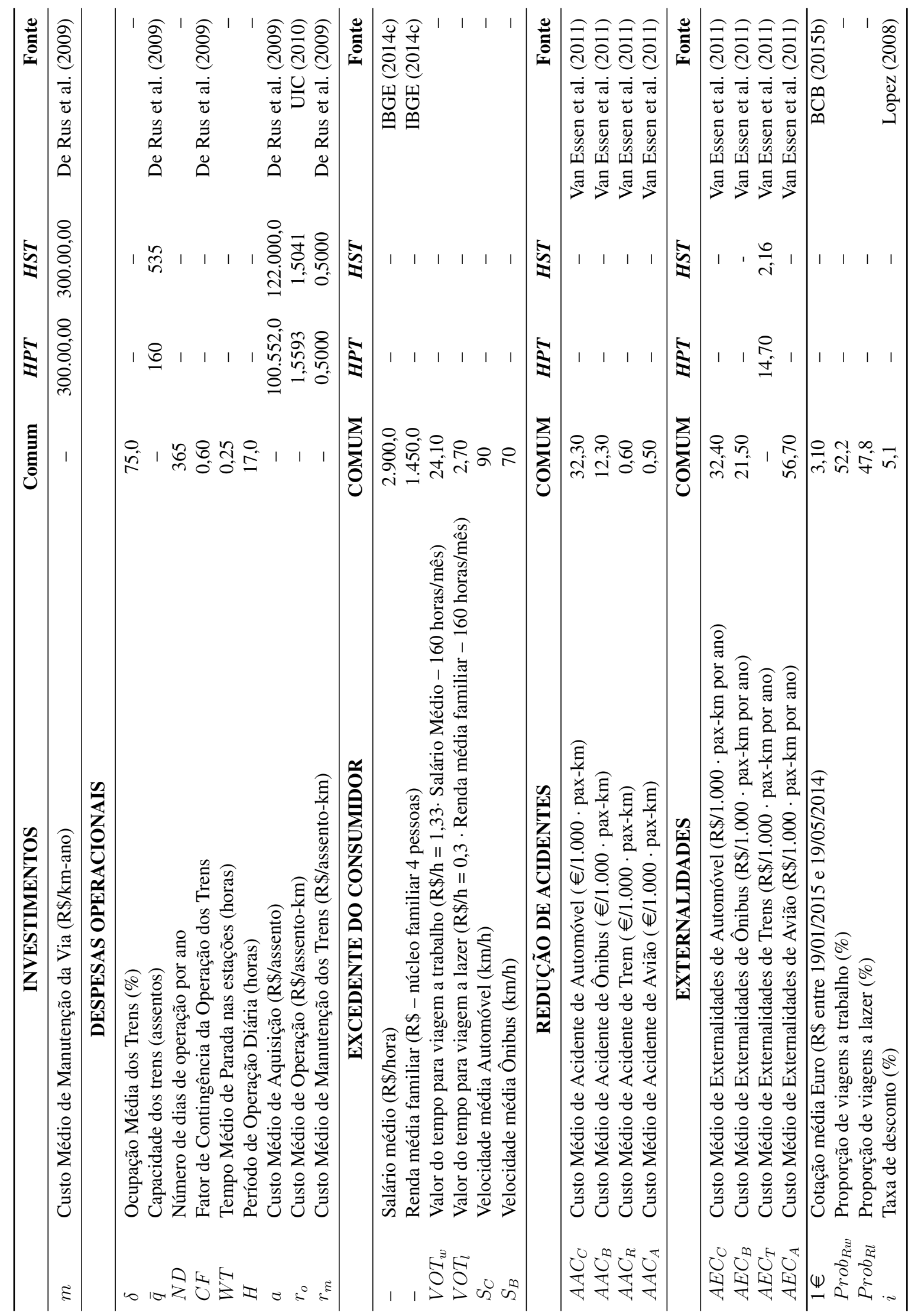


APÊNDICE

\section{Resultados dos Cenários de Análise Socioeconômica}




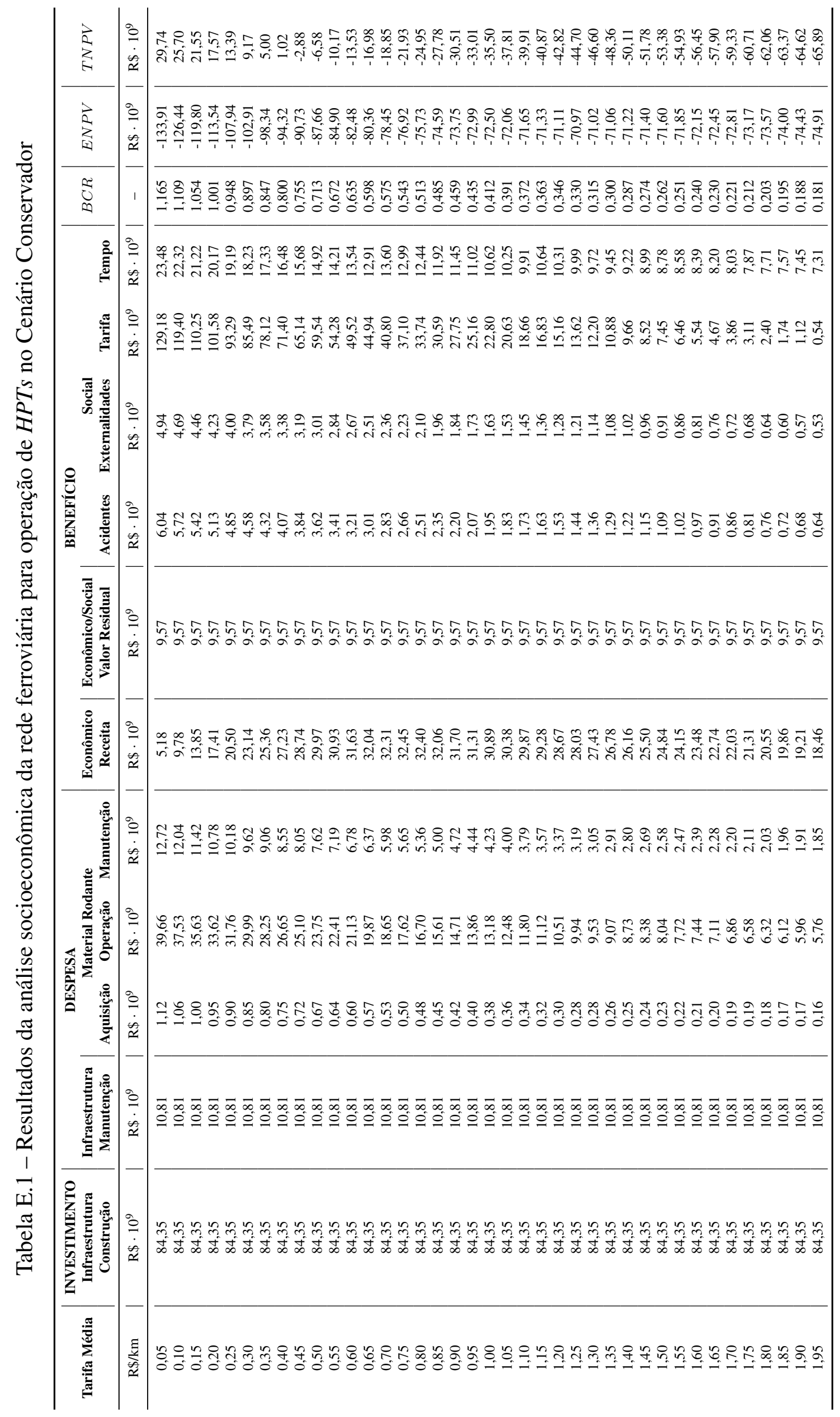




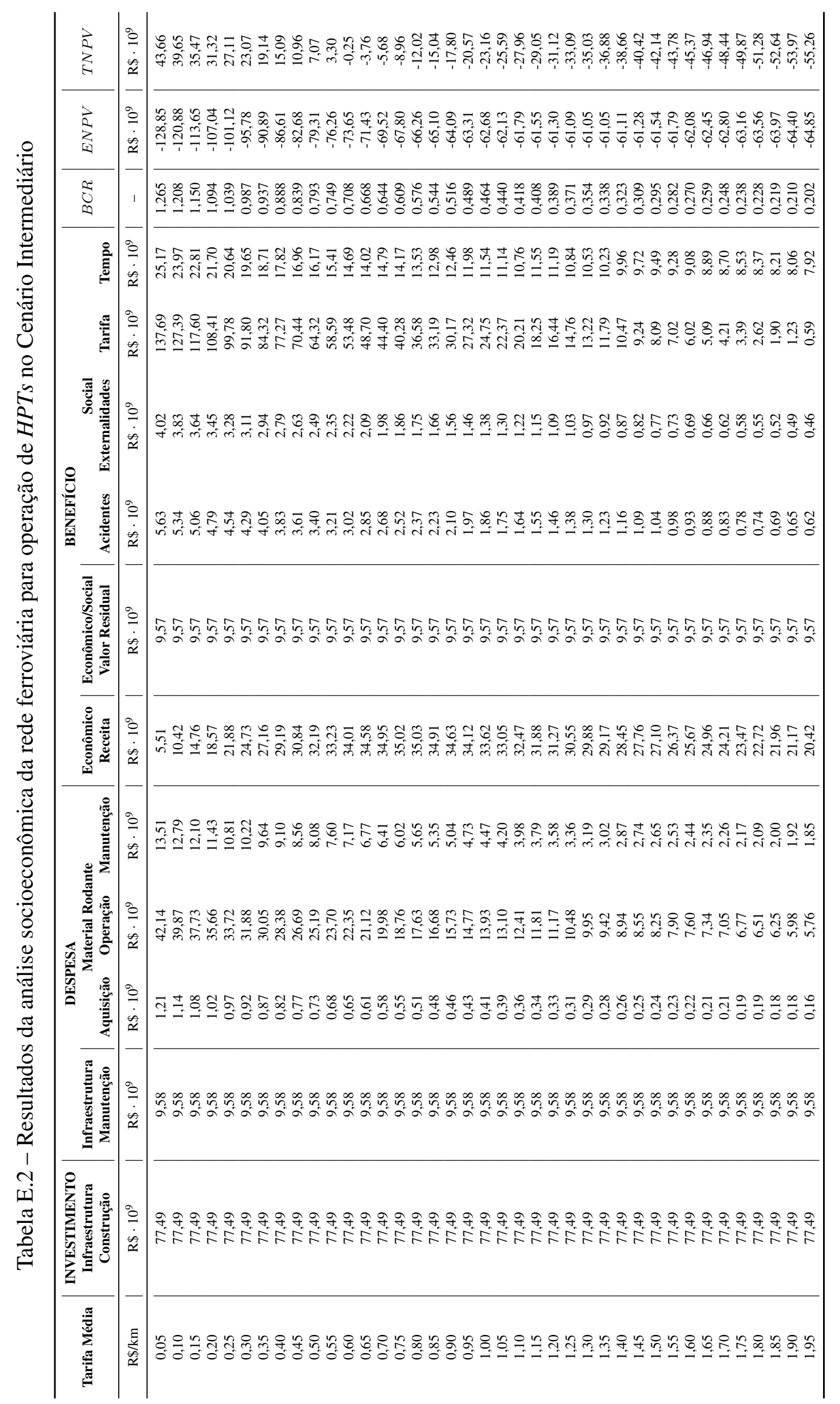




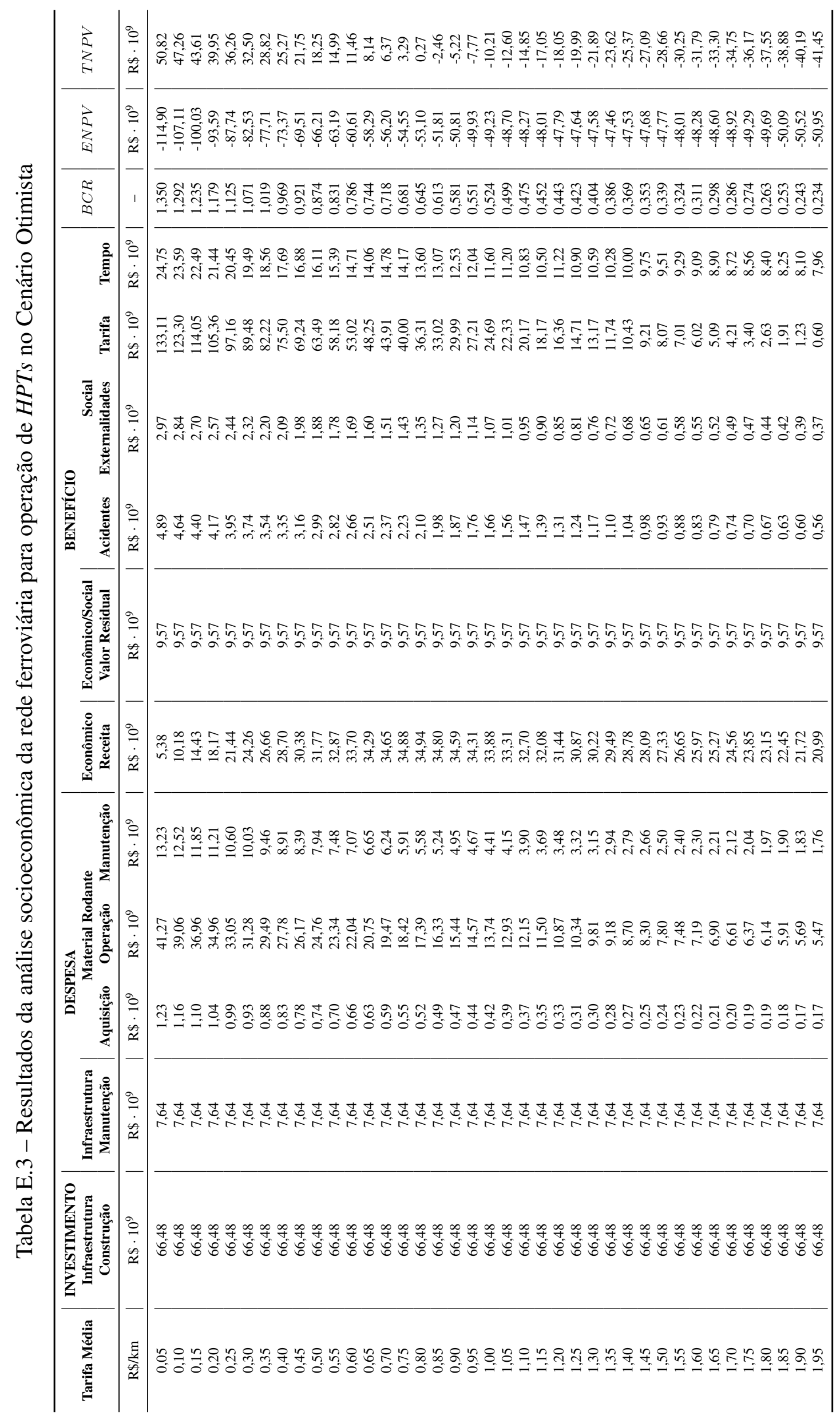




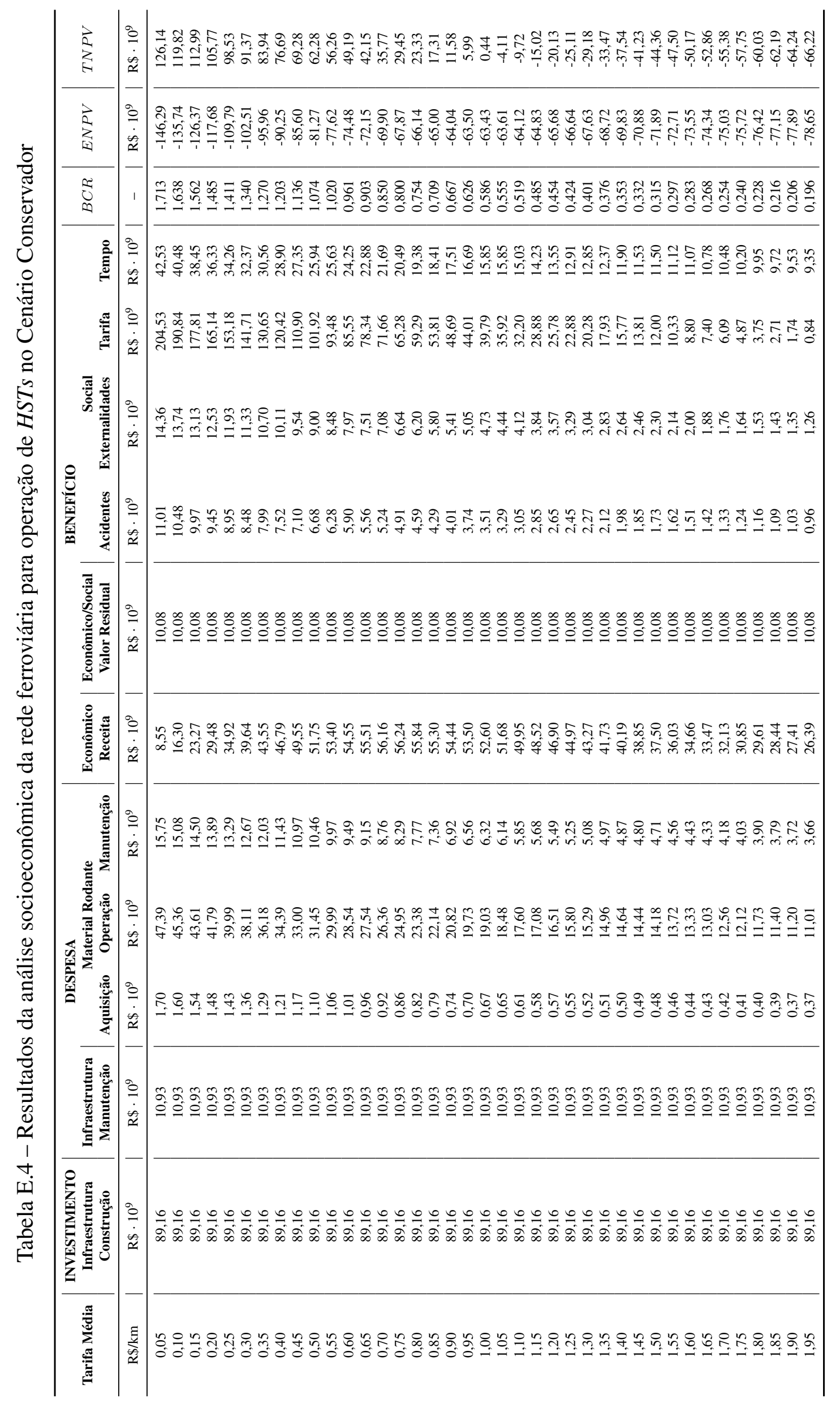




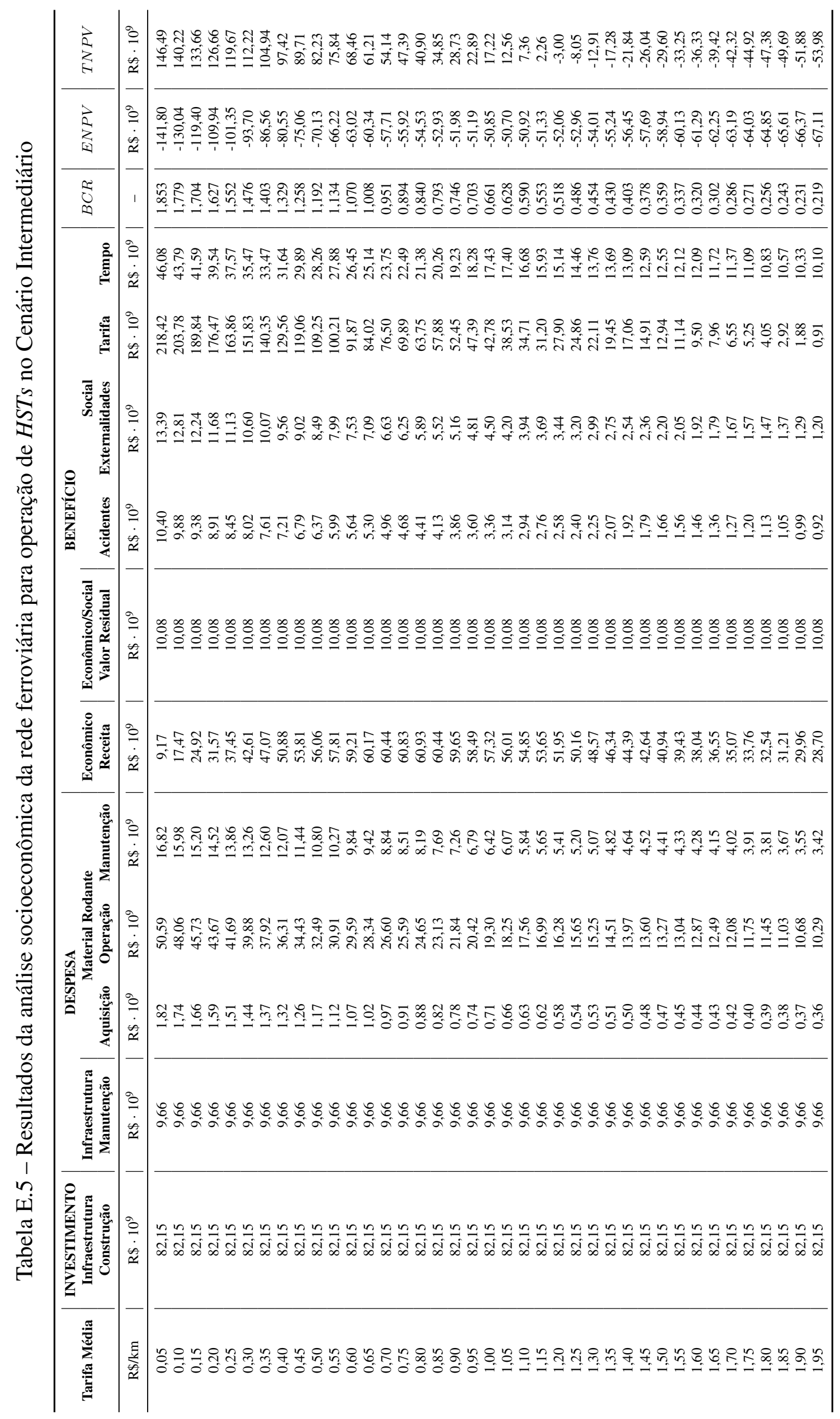




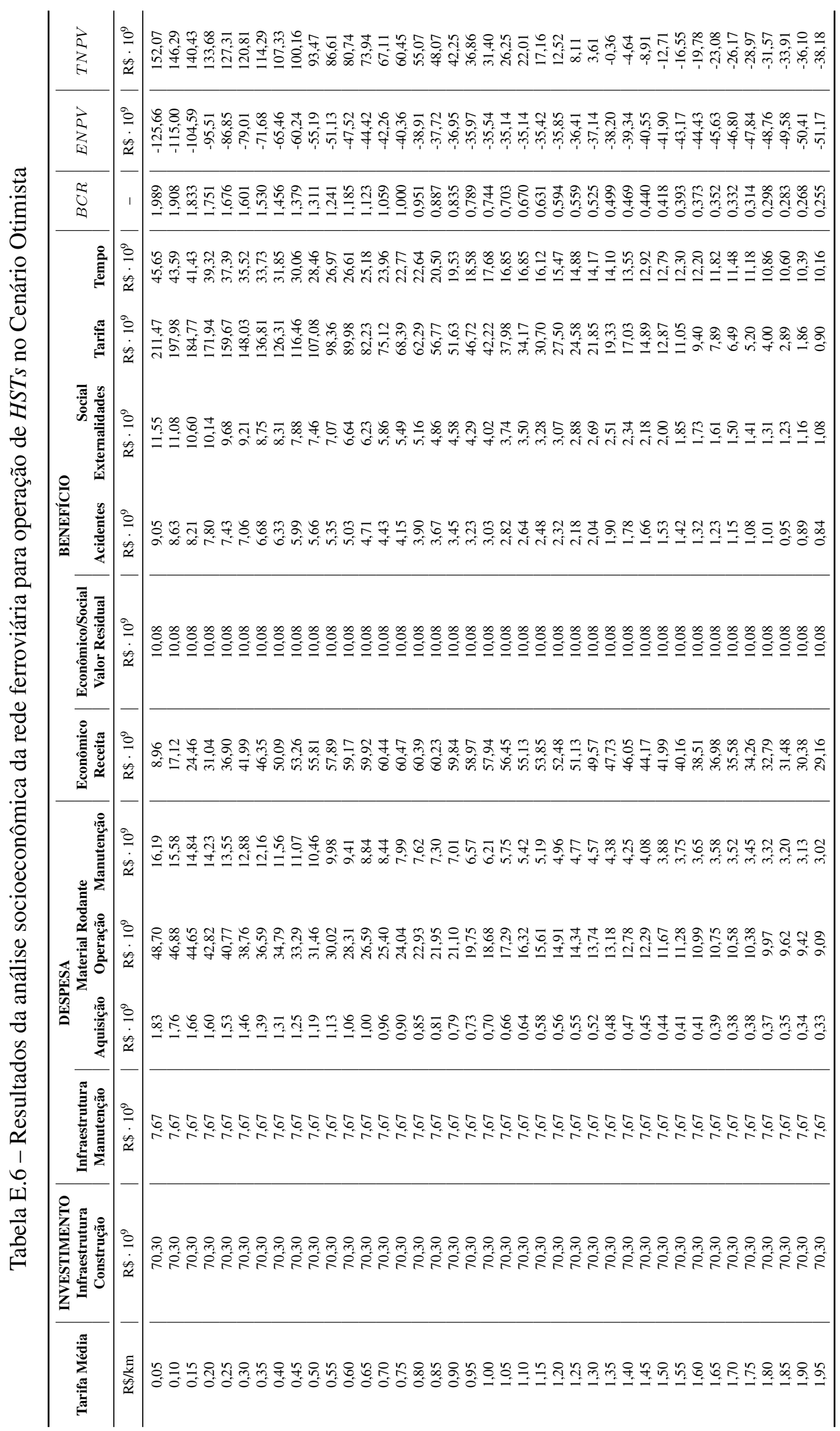

